\title{
Carboxylate-Assisted Ruthenium-Catalyzed C-H Bond meta-Alkylations and Oxidative Annulations
}

\author{
Dissertation \\ zur Erlangung des mathematisch-naturwissenschaftlichen Doktorgrades \\ "Doctor rerum naturalium"
}

der Georg-August-Universität Göttingen

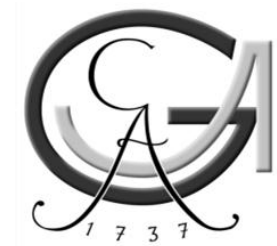

im Promotionsprogramm

Catalysis for Sustainable Synthesis

\section{c)sus}

der Georg-August University School of Science (GAUSS)

vorgelegt von

Nora Hofmann

aus Berlin

Göttingen, 2013 



\section{Betreuungsausschuss}

Prof. Dr. L. Ackermann, Institut für Organische und Biomolekulare Chemie

Prof. Dr. D. Stalke, Institut für Anorganische Chemie

Prof. Dr. M. Buback, Institut für Physikalische Chemie

\section{Mitglieder der Prüfungskommission}

Referent: Prof. Dr. L. Ackermann, Institut für Organische und Biomolekulare Chemie Korreferent: Prof. Dr. D. Stalke, Institut für Anorganische Chemie

Weitere Mitglieder der Prüfungskommission:

Prof. Dr. M. Buback, Institut für Physikalische Chemie

Prof. Dr. H. Laatsch, Institut für Organische und Biomolekulare Chemie

Prof. Dr. U. Diederichsen, Institut für Organische und Biomolekulare Chemie

Prof. Dr. C. Steinem, Institut für Organische und Biomolekulare Chemie 

Für meine Eltern 
Der Mensch hat dreierlei Wege Klug zu handeln:

Erstens durch $\mathcal{N}$ achdenken, das ist der edelste, zweitens durch $\mathcal{N a c h a h m e n , ~}$ das ist der leichteste, und drittens durch Erfahrung, das ist der bitterste. 


\section{Contents}

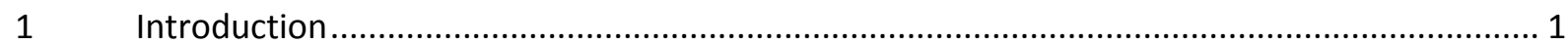

1.1 Transition Metal-Catalyzed C-H Bond Functionalization ..................................................... 1

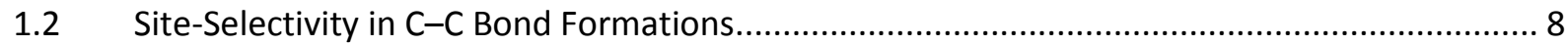

$1.3 \quad$ Transition Metal-Catalyzed Alkylation Reactions .............................................................. 13

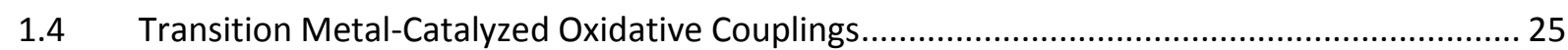

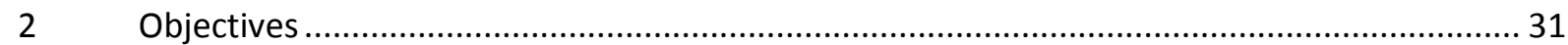

3 Results and Discussion - Ruthenium-Catalyzed Direct Alkylation Reactions.......................... 33

3.1 Ruthenium-Catalyzed Direct ortho-Alkylation .................................................................. 33

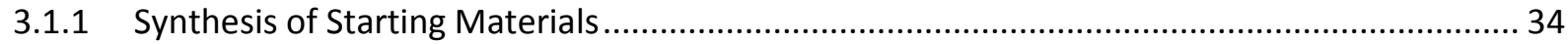

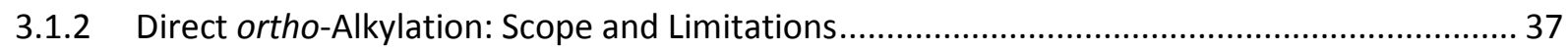

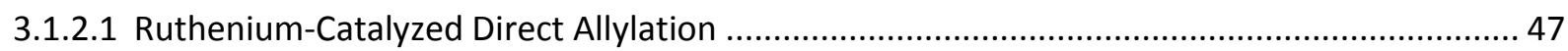

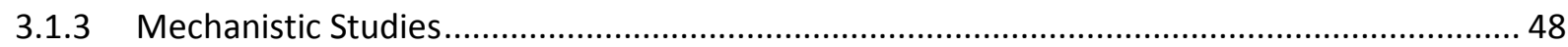

3.1.3.1 Intramolecular Competition Experiments ............................................................................. 49

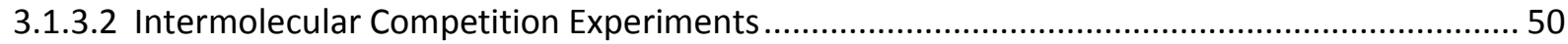

3.1.3.3 Experiments with Deuterium-Labeled Substrates.............................................................. 54

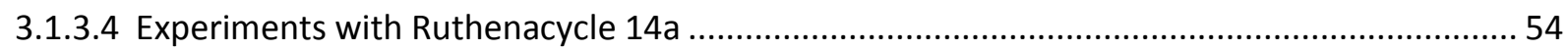

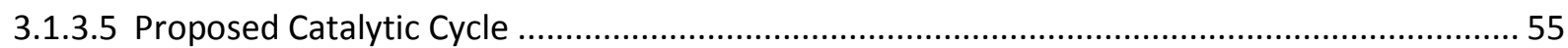

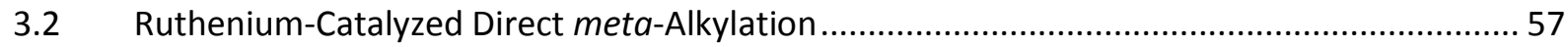

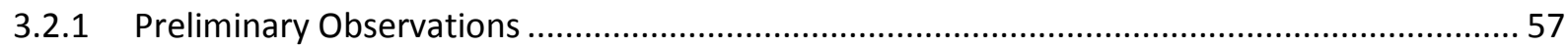

3.2.2 Optimization Studies for the Direct meta-Alkylation ............................................................ 58

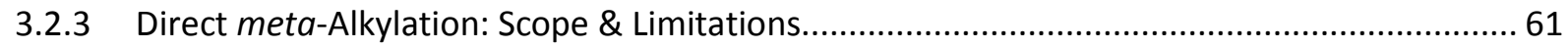

3.2.4 Experiments towards Enantioselective Direct meta-Alkylation ............................................. 76

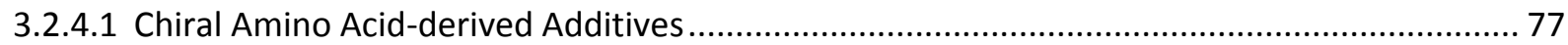

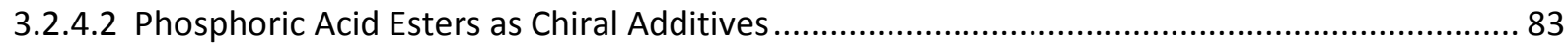

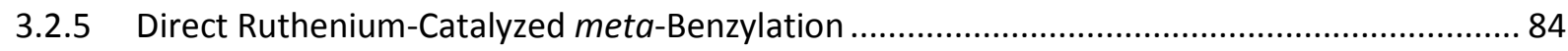

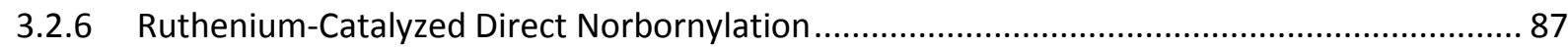




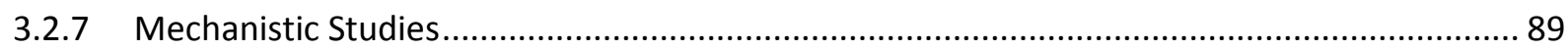

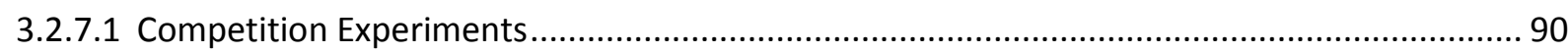

3.2.7.2 Experiments with Isotopically Labeled Substrates ...................................................... 91

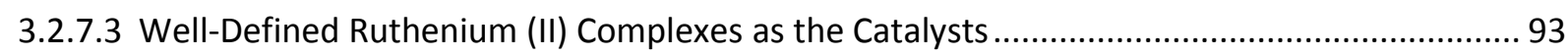

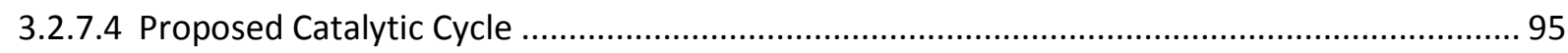

$4 \quad$ Ruthenium-Catalyzed Oxidative Transformations via $\mathrm{C}-\mathrm{H} / \mathrm{N}-\mathrm{H}$ bond Cleavage ..................97

4.1 Ruthenium-Catalyzed Oxidative Annulations........................................................ 97

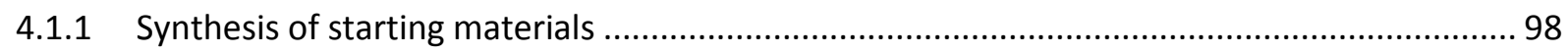

4.1.2 Ruthenium-Catalyzed Synthesis of Isoquinolin-2-ones: Scope and Limitations ....................98

4.1.3 Ruthenium-Catalyzed Synthesis of 2-Pyridones........................................................ 101

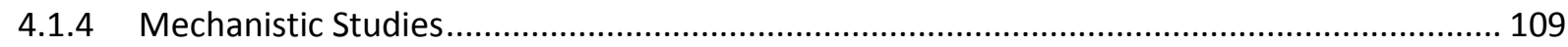

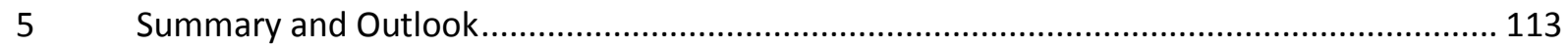

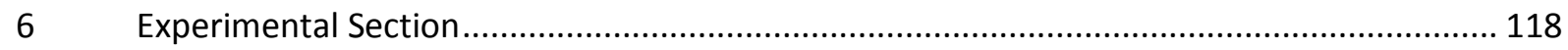

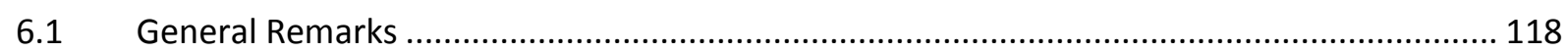

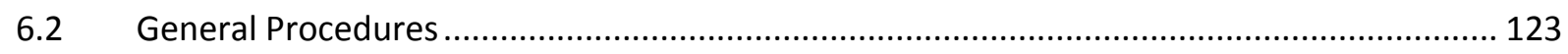

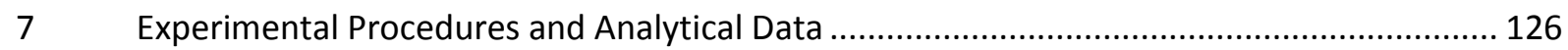

7.1 The Analytical Data for Starting Materials ............................................................ 126

7.2 The Analytical Data for the Products of the Ruthenium-Catalyzed ortho-Alkylation ........... 142

7.3 Analytical Data for the Ruthenium-Catalyzed meta-Alkylation ..................................... 167

7.4 The Analytical Data for the Ruthenium-Catalyzed Oxidative Annulations......................... 223

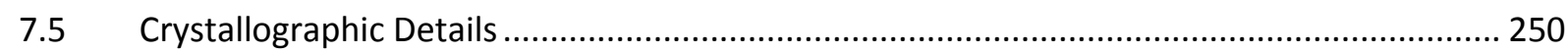

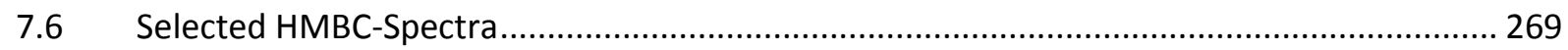

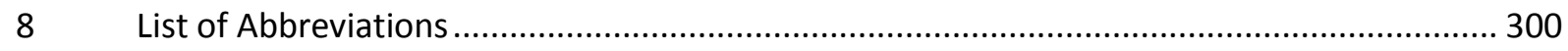

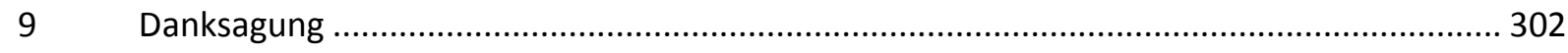

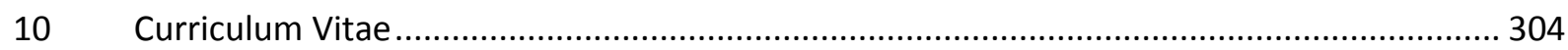






\section{Introduction}

\subsection{Transition Metal-Catalyzed C-H Bond Functionalization}

Sustainability was declared as one of the major goals within synthetic chemistry. ${ }^{1}$ The design of environmentally benign synthetic methods is guided by the '12 Principles of Green Chemistry'. Besides safe and non-toxic processes, waste-prevention, as well as atom- and step-economy in combination with catalysis, are all essential requirements for sustainable organic synthesis. From this point of view, transition metal catalysis is an essential step into the desired direction. Thereby, the efficiency of carbon-carbon ( $\mathrm{C}-\mathrm{C}$ ) or carbon-heteroatom (C-Het) bond formation can be considerably improved.

For almost half a century, selective transition metal-catalyzed $\mathrm{C}-\mathrm{C}$ bond formation reactions have attracted significant attention among various research groups around the world. Even in the field of industrial synthesis of pharmaceuticals, these transformations gain more and more attention over classical reaction routes. ${ }^{3}$ Certainly, one of the most famous transformations in this research area is the transition metal-catalyzed cross-coupling reaction. ${ }^{4}$

Today, traditional cross-coupling chemistry is a powerful synthetic tool in preparative organic chemistry. This is, for instance, illustrated by the fact that Heck, Negishi and Suzuki have been awarded the Nobel Prize of Chemistry in $\mathbf{2 0 1 0}$ for the palladium-catalyzed formation of $\mathrm{C}-\mathrm{C}$ single bonds via cross-coupling chemistry. The major features of these reactions are presented in Scheme 1.1. In general (for the cross-coupling), a (pseudo)halide as an electrophile and an organometallic species as a nucleophile are coupled via a Palladium (0)-Palladium (II)-catalytic cycle. The key steps include an oxidative addition, a transmetalation and a reductive elimination (Scheme 1.1, a). For Mizoroki-Heck-type couplings (Scheme 1.1, b) a mechanism consisting of a syn-insertion followed by $\sigma$-bond-rotation and final $\beta$-H elimination is generally accepted. ${ }^{5}$

\footnotetext{
${ }^{1}$ Essen, M.; Metzger, J. O.; Schmidt, E.; Schneidewind, U. Angew. Chem. Int. Ed. 2002, 41, 414-436.

${ }^{2}$ (a) Anastas, P. T.; Kirchhoff, M. M. Acc. Chem. Res. 2000, 35, 686-694. (b) Anastas, P. T.; Warner, J. C. Green Chemistry: Theory and Practice, Oxford University Press: Oxford, 1998, p. 30.

${ }^{3}$ Busacca, C. A.; Fandrick, D. R.; Song, J. J.; Senanayake, C. H. Adv. Synth. Cat. 2011, 353, 1825-1864.

${ }^{4}$ (a) Johansson Seechurn, C. C. C.; Kitching, M. O.; Colacot, T. J.; Snieckus, V. Angew. Chem. Int. Ed. 2012, 51, 5062-5086. (b) Metal-Catalyzed Cross-Coupling Reactions (Eds. de Meijere, A.; Diederich, F.), $2^{\text {nd }}$ ed., WileyVICHY: Weinheim, 2004. (c) Transition Metals for Organic Synthesis (Eds. Beller, M.; Bolm, C.), $2^{\text {nd }}$ ed., Wiley$\mathrm{VCH}$ : Weinheim, 2004.

${ }^{5}$ Corbet, J.-P.; Mignani, G. Chem. Rev. 2006, 106, 2651-2710.
} 


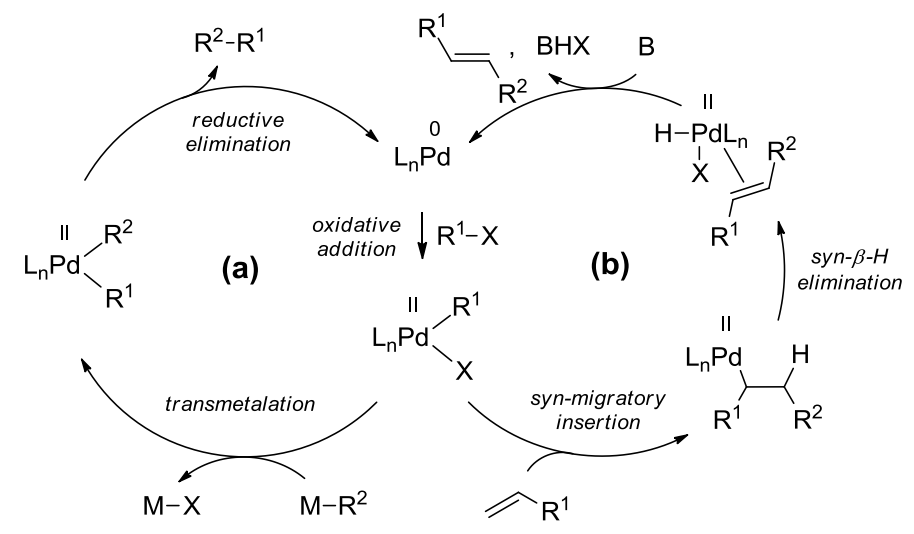

Scheme 1.1: General catalytic cycles for the cross-coupling (a) and the Mizoroki-Heck (b) reaction.

The formation of stoichiometric amounts of potentially harmful metal salts as by-products and the necessity to use prefunctionalized substrates proves to be disadvantageous for the transition metalcatalyzed cross-coupling reaction. To avoid the expensive prefunctionalization steps, transition metalcatalyzed direct functionalizations of $\mathrm{C}-\mathrm{H}$ bonds represent an excellent alternative (Scheme 1.2).

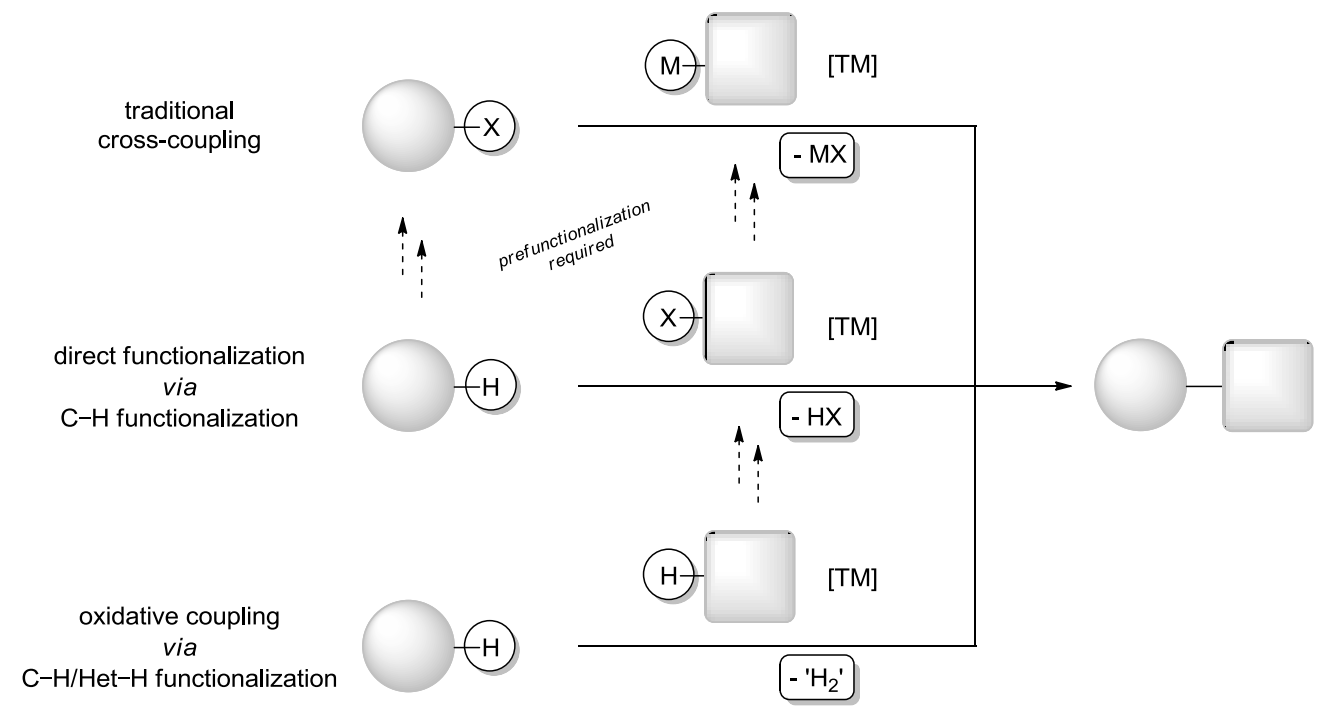

Scheme 1.2: General comparison of transition metal-catalyzed transformations.

During the last 20 years, direct $\mathrm{C}-\mathrm{H}$ bond functionalization has become a complementary synthetic tool in organic chemistry, even in the field of the total synthesis of complex natural products and pharmaceuticals. $^{6}$

The classical synthetic routes towards the derivatization of arene would for example include electrophilic aromatic substitution $\left(\mathrm{S}_{\mathrm{E}}^{\mathrm{Ar}}\right.$ ) or directed ortho-metalation (DoM) ${ }^{7}$ (see below: Chapter

\footnotetext{
${ }^{6}$ (a) Chen, D. Y.-K.; Youn, S. W. Chem. Eur. J. 2012, 18, 9452-9474. (b) Engle, K. M.; Mei, T.-S.; Wasa, M.; Yu, J.Q. Acc. Chem. Res. 2012, 45, 788-802. (c) Yamaguchi, J.; Yamaguchi, A. D.; Itami, K. Angew. Chem. Int. Ed. 2012, 5, 8960-9009. (d) Tran, L. D.; Daugulis, O. Angew. Chem. Int. Ed. 2012, 51, 5188-5191. (e) McMurray, L.; O'Hara, F.; Gaunt, M. J. Chem. Soc. Rev. 2011, 40, 1885-1898.

${ }^{7}$ Snieckus, V. Chem. Rev. 1990, 90, 879-933.
} 
1.2). These reactions are often complicated by harsh reaction conditions and/or side-product formation.

The site-selectivity of catalytic $\mathrm{C}-\mathrm{H}$ bond functionalizations can be controlled by employing either the enhanced acidity of a specific heteroaromatic $\mathrm{C}-\mathrm{H}$ bond in substrates of the type $\mathbf{1}$ or by the directing group (DG) approach for the conversion of substrates $\mathbf{4}$ into their ortho-functionalized derivatives $\mathbf{3}$ or 5, respectively (Scheme 1.3, see also Chapter: 1.2$).{ }^{8}$ Stoichiometric amounts of bases are necessary in both cases.

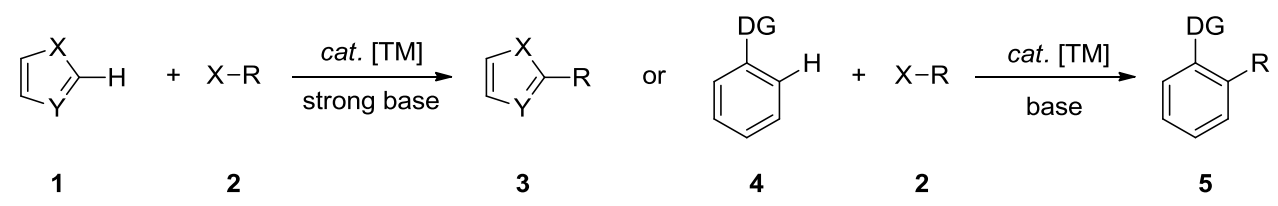

Scheme 1.3: Two variants for $\mathrm{C}-\mathrm{H}$ bond functionalizations.

The $\mathrm{C}-\mathrm{H}$ bond metalation step can be accomplished by the active metal species $L_{n} \mathrm{M}$, according to four generally accepted mechanisms (Scheme 1.4). The results of computational studies of these mechanisms on different theoretical levels have been summarized by Eisenstein and co-workers. ${ }^{9}$

(a) oxidative addition

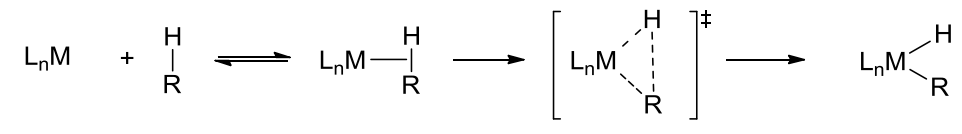

(b) $\sigma$-bond metathesis

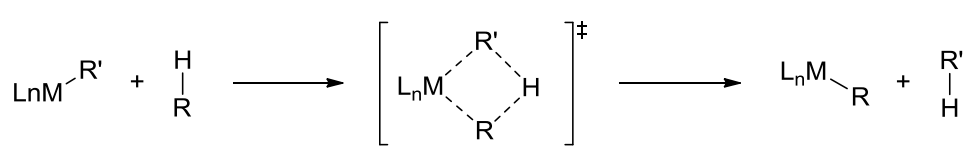

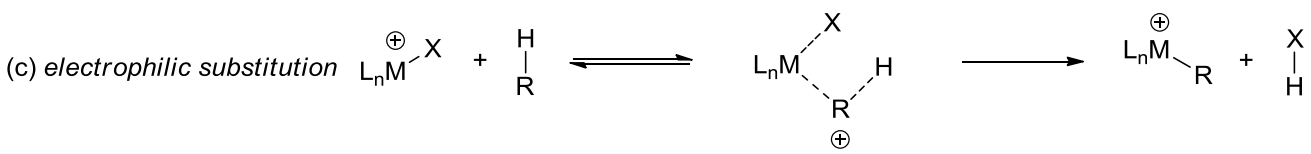

(d) 1,2 addition

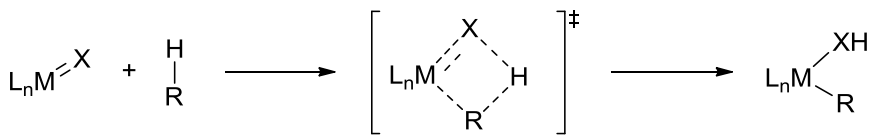

$$
\begin{aligned}
& \mathrm{R}, \mathrm{R}^{\prime}=\text { aryl, alky }
\end{aligned}
$$

Scheme 1.4: Possible mechanisms for $\mathrm{C}-\mathrm{H}$ bond metalation by transition metal complexes.

Oxidative addition (a) is a common process that can mainly be performed by electron-rich, low-valent complexes of late transition metals ( $\mathrm{Fe}, \mathrm{Ru}, \mathrm{Os}, \mathrm{Ir}, \mathrm{Pt}, \mathrm{Re})$. Due to the impossibility of such oxidative transformations for early transition metals with $d^{0}$-configuration, $\sigma$-bond metathesis (b) appears to be the predominant activation pathway for these metals. In a highly polar reaction medium, late transition metals (e.g. Pd, $\mathrm{Pt}$ ) might metalate the $\mathrm{C}-\mathrm{H}$ bond through an electrophilic substitution (c)

\footnotetext{
${ }^{8}$ (a) Colby, D. A.; Bergman, R. G.; Ellman, J. A. Chem. Rev. 2010, 110, 624-655. (b) For a review on removable DG's see: Wang, C.; Huang, Y. Synlett 2013, 24, 145-149.

${ }^{9}$ Balcells, D.; Clot, E.; Eisenstein, O. Chem. Rev. 2010, 110, 749-823.
} 
replacing a former ligand on a metal atom with the organic substituent. Alkylidene or amido complexes of early transition metals further possess the possibility to perform the $\mathrm{C}-\mathrm{H}$ bond activation via 1,2 -additions (d).9,10

Since the aromatic $\mathrm{C}-\mathrm{H}$ bonds feature enhanced thermodynamic stabilities $\left[D_{\mathrm{H} 289}\right.$ (benzene) $=$ $\left.112.9 \pm 0.5 \mathrm{kcal} \cdot \mathrm{mol}^{-1}\right)^{11}$ and low acidities $\left[\mathrm{pK}_{\mathrm{A}}(\mathrm{DMSO})=44.7\right],{ }^{12}$ marginal differences in reactivity were observed for the different $\mathrm{C}-\mathrm{H}$ bonds within the same aromatic molecule. Therefore, different strategies have been probed in order to improve the selectivity of transition metal-catalyzed $\mathrm{C}-\mathrm{H}$ functionalization reactions. Thus, site-selectivity can be achieved via chelation, employing Lewis basic directing groups (DG). Alternatively, this effect can be accomplished by the addition of a supplementary reaction partner, for example a base. Pioneering work in the field of stoichiometric base-assisted metalations has been accomplished by the groups of Shaw ${ }^{13}$ and Reutov ${ }^{14}$ in the 1970s. Concerning catalytic base-assisted metalations, it has been proposed that a bidentate base is operating by the concerted-metalation-deprotonation pathway (CMD, Fagnou) ${ }^{15}$ or by the ambiphilic metal-ligand activation (AMLA, Davies \& Macgregor) mechanism. ${ }^{10}$ Both principles favor a sixmembered transition state including very little charge on the aromatic ring. Theoretical calculations on palladium- and iridium- catalyzed ${ }^{10,16}$ metalation mechanisms disclose that the metal-acetate complexes have an ambiphilic character due to an intramolecular electrophilic activation of a $\mathrm{C}-\mathrm{H}$ bond followed by deprotonation with an internal base (Figure 1.1). Furthermore, the function of the transition metal center was also speculated about, ${ }^{15}$ as several irida-, rhoda- and ruthenacycles were isolated by Davies and co-workers in 2009 upon acetate-assisted C-H-activation reaction of 2phenylpyridine. ${ }^{17}$

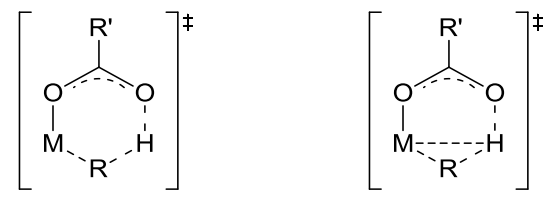

$$
\begin{aligned}
& \text { CMD TS } R, R^{\prime}=\text { alkyl, aryl AMLA (6) TS }
\end{aligned}
$$

Figure 1.1: Possible transition states during concerted metalation-deprotonation (CMD) or ambiphilic metal-ligand activation (AMLA) pathways.

\footnotetext{
${ }^{10}$ Boutadla, Y.; Davies, D. L.; Macgregor, S. A.; Poblador-Bahamonde, A. I. Dalton Trans. 2009, 5820-5831.

${ }^{11}$ Blanksby, S. J.; Ellison, G. B. Acc. Chem. Res. 2003, 36, 255-263.

12 Shen, K.; Fu, Y.; Li, J.-N.; Liu, L.; Guo, Q.-X. Tetrahedron 2007, 63, 1568-1576.

${ }^{13}$ (a) Duff, J. M.; Shaw, B. L. J. Chem. Soc., Dalton Trans. 1972, 2219-2225. (b) Duff, J. M.; Mann, B. E.; Shaw, B. L.; Turtle, B. J. Chem. Soc., Dalton Trans. 1974, 139-145. (c) Gaunt, J. C.; Shaw, B. L. J. Organomet. Chem. 1975, 102, 511-516.

${ }^{14}$ Sokolov, V. I.; Troitskaya, L. L.; Reutov, O. A. J. Organomet. Chem. 1979, 182, 537-546.

${ }^{15}$ Lapointe, D.; Fagnou, K. Chem. Lett. 2010, 39, 1118-1126.

${ }^{16}$ Ess, D. H.; Bischof, S. M.; Oxgaard, J.; Periana, R. A.; Goddard, W. A., III Organometallics 2008, 27, 6440-6445.

${ }^{17}$ Boutadla, Y.; Al-Duaij, O.; Davies, D. L.; Griffith, G. A.; Singh, K. Organometallics 2009, 28, 433-440.
} 
The mode of action of monodentate anionic ligands has been explored by the research groups of Goddard as well as Gunnoe. ${ }^{18}$ DFT-studies favor an internal electrophilic substitution (IES) prior to traditional $\sigma$-bond metathesis (Figure 1.2).

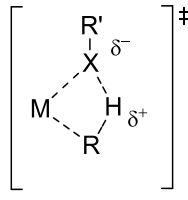

IES TS

$(X \neq$ alkyl, aryl)

Figure 1.2: Proposed transition state during the internal electrophilic substitution (IES).

During the last decades, the research interest in transition metal-catalyzed $\mathrm{C}-\mathrm{H}$ bond functionalization as a tool for a variety of $\mathrm{C}-\mathrm{C}$ bond forming reactions has increased rapidly, especially in the field of biaryl-synthesis. ${ }^{19}$

Among other metals, ruthenium (II) catalysts not only include the remarkably broad substrate scope and the extraordinarily high chemo- and site-selectivity, as reflected by the outstanding functional group tolerance and excellent catalytic activity with water as the reaction medium, ${ }^{20}$ but also are significantly less expensive than other transition metal sources. Thus, in 2012, the prices of gold, platinum, rhodium, iridium, palladium and ruthenium were 1730, 1600, 1100, 1050, 669 and 110 US\$ per troy oz, respectively. ${ }^{21}$

The Ackermann group and others have focused on the application of ruthenium complexes for chelation-assisted direct arylations. ${ }^{19,22,23}$ Starting from easily available aryl chlorides as electrophiles and a ruthenium-complex derived from a (hetero-atom-substituted) secondary phosphine oxide [(HA)SPO], they have elaborated the preparative methods for ortho-selective direct mono- and bis-

${ }^{18}$ (a) Oxgaard, J.; Trenn, W. J., III; Nielsen R. J.; Periana, R. A.; Goddard, W. A., III Organometallics 2007, 26, 1565-1567. (b) Conner, D.; Jayaprakash, K. N.; Cundari, T. R.; Gunnoe, T. B. Organometallics 2004, 23, 27242733. (c) for a review, see: Webb, J. R.; BolaÇo, T.; Gunnoe, T. B. Chem. Sus. Chem. 2011, 4, 37-49.

${ }^{19}$ Selected reviews: (a) Ackermann, L.; Kapdi, A. R.; Potukuchi, H. K.; Kozhushkov, S. I. In Handbook of Green Chemistry (Ed. Li, C.-J.), Wiley-VCH: Weinheim, 2012, 259-305. (b) Kulkarni, A. A.; Daugulis, O. Synthesis 2009, 4087-4109; (c) Modern Arylation Methods (Ed.: Ackermann, L.), $1^{\text {st }}$ ed., Wiley-VCH: Weinheim, 2009. (d) Daugulis, O.; Do, H.-Q.; Shabashov, D. Acc. Chem. Res. 2009, 42, 1074-1086. (e) Alberico, D.; Scott, M. E.; Lautens, M. Chem. Rev. 2007, 107, 174-238. (f) Bellina, F.; Rossi R. Chem. Rev. 2010, 110, 1082-1146. (g) Seregin, I. V.; Gevorgyan, V. Chem. Soc. Rev. 2007, 36, 1173-1193. (h) Brückl, T.; Baxter, R. D.; Ishihara, Y.; Baran, P. S. Acc. Chem. Res. 2012, 45, 826-839. (i) Cho, S. H.; Kim, J. Y.; Kwak, J.; Chang, S. Chem. Soc. Rev. 2011, 40, 5068-5083.

${ }^{20}$ (a) Ackermann, L. Org. Lett. 2005, 7, 3123-3125. (b) Arockiam, P. B.; Bruneau, C.; Dixneuf, P. H. Chem. Rev. 2012, 112, 5879-5918.

${ }^{21}$ http://www.platinumgroupmetals.org/

22 (a) Ackermann, L.; Vicente, R. Top. Curr. Chem. 2010, 292, 211-229. (b) Ackermann, L.; Althammer, A.; Born, R. Angew. Chem. Int. Ed. 2006, 45, 2619-2622.

23 (a) Oi, S.; Funayama, R.; Hattori, T.; Inoue, Y. Tetrahedron 2008, 64, 6051-6059; (b) Oi, S.; Ogino, Y.; Fukita, S.; Inoue, Y. Org. Lett. 2002, 4, 1783-1785; (c) Oi, S.; Fukita, S.; Hirata, N.; Watanuki, N.; Miyano, S.; Inoue, Y. Org Lett. 2001, 3, 2579-2581. 
arylation of 2-arylsubstituted pyridines, pyrazoles and ketimines. Even unprecedented direct arylation using tosylates as electrophiles appeared to be successful with a mono-selective outcome (Scheme $1.5)^{22}$<smiles>c1ccc(-c2ccccn2)cc1</smiles>

6aa<smiles>CC(=O)c1ccc([Se-])cc1</smiles>

$7 a$

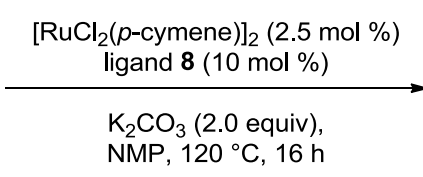

$65 \%$

Scheme 1.5: Ruthenium-catalyzed direct arylation with tosylate $7 a$ as the electrophiles.

The direct arylation could also be performed via initial one-pot in-situ tosylation of inexpensive phenol derivatives. $^{24}$

Intensive screening in less polar solvents revealed that sterically demanding carboxylic acids can act in a fashion comparable to the HASPO preligands (Scheme 1.6). ${ }^{25}$

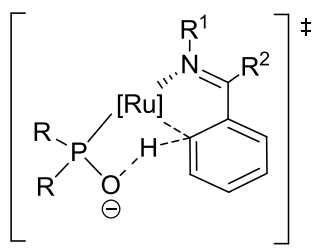

10

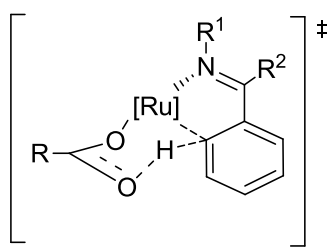

11

Scheme 1.6: Comparison of $\mathrm{C}-\mathrm{H}$ metalation transition states between HASPO-preligands and carboxylates.

Mechanistic studies could demonstrate that the direct arylation using carboxylic acids as additives proceeds via the in-situ formation of a ruthenium-carboxylate complex 12 , which can perform reversible $\mathrm{C}-\mathrm{H}$ bond functionalization with the substrate. An isolated cycloruthenated complex 14 proved to be catalytically active and is thus expected to participate in the proposed catalytic cycle (Scheme 1.7). ${ }^{25,26}$

\footnotetext{
${ }^{24}$ (a) Ackermann, L.; Mulzer, M. Org. Lett. 2008, 10, 5043-5045; (b) Review: Kozhushkov, S. I.; Potukuchi, H. K.; Ackermann, L. Catal. Sci. Technol. 2013, in press. DOI: 10.1039/C2CY20505.

${ }^{25}$ Ackermann, L.; Vicente, R.; Althammer, A. Org. Lett. 2008, 10, 2299-2302.

26 (a) Ackermann, L.; Vicente, R.; Potukuchi, H. K.; Pirovano, V. Org. Lett. 2010, 12, 5032-5035. For recent reports highlighting the participation of similar ruthenacycles $\mathbf{1 4}$ in ruthenium-catalyzed $\mathrm{C}-\mathrm{H}$ bond functionalizations, see: (b) Li, B.; Feng, H.; Wang, N.; Ma, J.; Song, H.; Xu, S.; Wang, B. Chem. Eur. J. 2012, 18, 12873-12879. (c) Li, B.; Roisnel, T.; Darcel, C.; Dixneuf, P. H. Dalton Trans. 2012, 41, 10934-10937.
} 


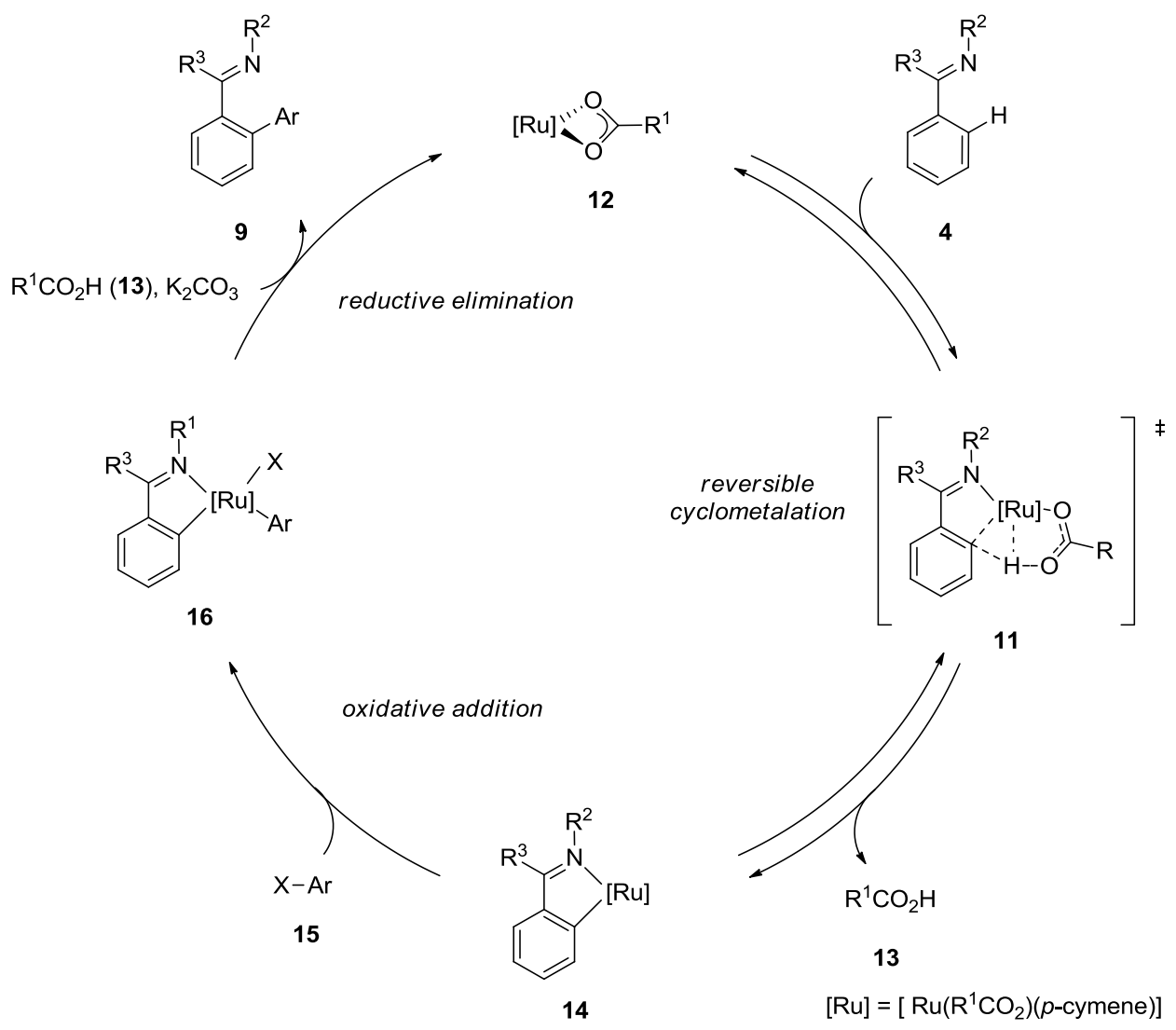

Scheme 1.7: Proposed mechanism for carboxylate-assisted ruthenium-catalyzed direct arylation.

In 2011, Seki reported an alternative catalytic system for the ruthenium-catalyzed direct arylation reactions. The use of inexpensive $\mathrm{RuCl}_{3} \cdot \mathrm{xH}_{2} \mathrm{O} / \mathrm{PPh}_{3}$ catalyst resulted in elaborated efficient protocols towards the synthesis of the biaryl unit 18 in angiotensin II receptor blockers like valsartan. ${ }^{27}$ Very recently, the group of Ackermann showed a carboxylate-assisted complementary rutheniumcatalyzed procedure using mono-protected aryl-tetrazoles as substrate (Scheme 1.8). ${ }^{28}$

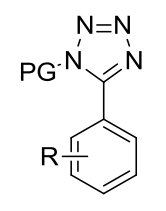

17<smiles>[X]c1ccccc1</smiles>

15

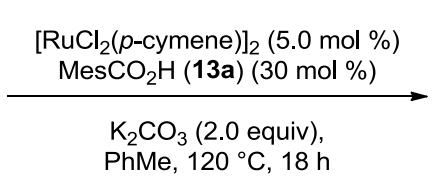

up to $70 \%$

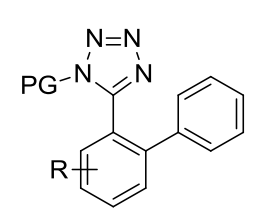

18

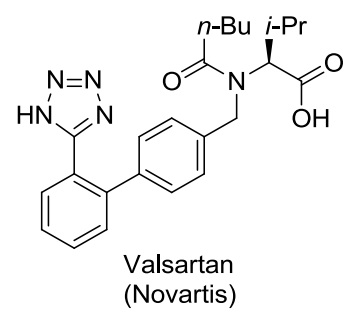

Scheme 1.8: Ruthenium-catalyzed direct arylation towards the synthesis of pharmaceutically important biaryl-structures 18.

\footnotetext{
27 (a) Seki, M. ACS Catal. 2011, 1, 607-610. For $\mathrm{RuCl}_{3} \cdot \mathrm{xH}_{2} \mathrm{O}$ as catalyst, see also: (b) Ackermann, L.; Althammer, A.; Born, R. Synlett 2007, 2833-2836. (c) Ackermann, L.; Althammer, A.; Born, R. Tetrahedron 2008, 64, 6115-6124.

28 Diers, E.; Kumar, N. Y. P.; Mejuch, T.; Marek, I.; Ackermann, L. Tetrahedron 2013, in press, DOI:10.1016/ j.tet.2013.01.006.
} 


\subsection{Site-Selectivity in C-C Bond Formations}

When employing classical synthetic methods, such as electrophilic aromatic substitution, the siteselectivity of aromatic $\mathrm{C}-\mathrm{H}$ bond functionalizations strongly relies on the substitution pattern of the substrate 19. Depending on the electronic and steric properties of these substituents, the substrate can get para- (21), ortho- (22) or meta-substituted (20)(Scheme 1.9).

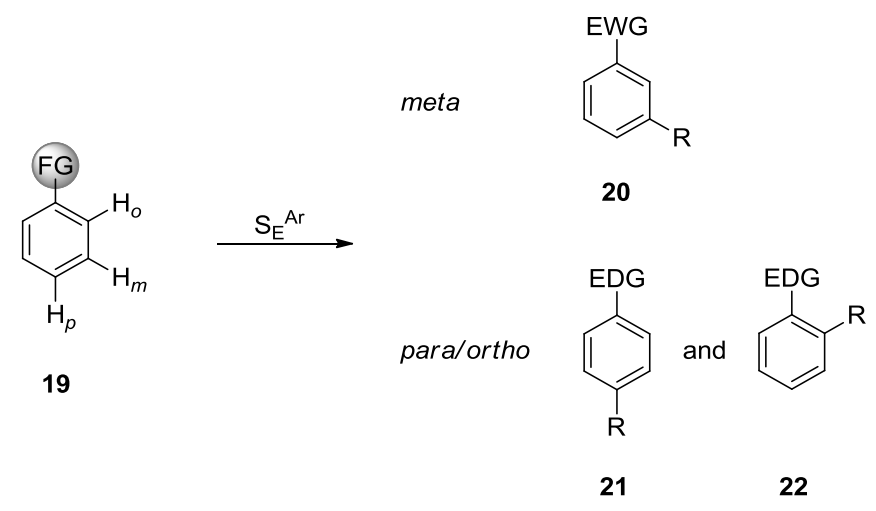

Scheme 1.9: Usual site-selectivity of the electrophilic aromatic substitution.

The research aim of discovering reaction conditions that provide pathways which do not depend on the substitution pattern of the substrate, or in which one can directly functionalize a specific $\mathrm{C}-\mathrm{H}$ bond remains to be of prime importance. ${ }^{29}$ One approach for such a site-selective insertion of a substituent is the use of main group metals in combination with directing groups. This so called 'Directed ortho Metalation' (DoM) approach has been independently developed in the 1940ies by Gilman $^{30}$ and Wittig ${ }^{31}$, and furnished usually ortho-functionalized products. Recently, Knochel could demonstrate that the use of DoM with organomagnesium compounds in combination with a variety of removable directed-metalation groups (DMG) could be employed for the functionalization of meta and para $\mathrm{C}-\mathrm{H}$ bonds as well (Scheme 1.10). ${ }^{32,33}$

Simultaneously, the group of Brown reported the site-selective meta-substitution using DoM applying organolithiums, and a removable sulfoxide group as DMG. ${ }^{34}$ Two simplified examples are shown in Scheme 1.10.

\footnotetext{
${ }^{29}$ Mahatthananchai, J.; Dumas, A. M.; Bode, J. W. Angew. Chem. Int. Ed. 2012, 51, 10954-10990.

${ }^{30}$ Gilman, H.; Bebb, R.L. J. Am. Chem. Soc. 1939, 61, 109-112.

${ }^{31}$ Wittig, G.; Fuhrmann, G. Chem. Ber. 1940, 73, 1197-1218.

32 Rohbogner, C. J.; Clososki, G. C.; Knochel, P. Angew. Chem. Int. Ed. 2008, 47, 1503-1507.

${ }^{33}$ Monzón, G.; Tirotta, I.; Knochel, P. Angew. Chem. Int. Ed. 2012, 51, 10624-10627.

${ }^{34}$ Flemming, J. P.; Berry, M. B.; Brown, J. M. Org. Biomol. Chem. 2008, 6, 1215-1221.
} 


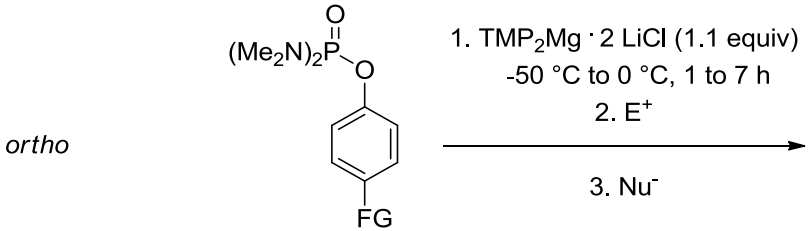

23

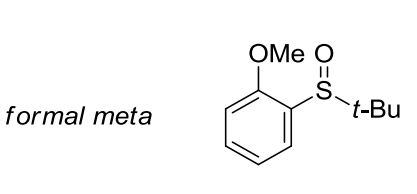

26

3. Reduction
EtOH/Raney-Ni

1. $n$-BuLi (1.2 equiv)

THF, $-78{ }^{\circ} \mathrm{C}, 2 \mathrm{~h}$

2. $\mathrm{E}^{+}$<smiles>Nc1ccc(O)cc1F</smiles>

24<smiles>COc1cccc(F)c1</smiles>

27<smiles>CN(C)OP(=O)(O)Oc1ccc(F)cc1N=O</smiles>

25

Scheme 1.10: Examples for site-selective $\mathrm{C}-\mathrm{H}$ deprotonations via DoM.

In spite of the generally high selectivities and efficiency of this DoM strategy, the necessity to use stoichiometric amounts of highly reactive main group metal compounds, such as $n$-BuLi, the low reaction temperatures and the need for the removal of the DMG group certainly restricts this approach from the viewpoint of step- and atom-economy. ${ }^{35}$

As an opportunity to avoid disadvantageous stoichiometric amounts of main group metal sources as reactants, transition metal-catalyzed $\mathrm{C}-\mathrm{H}$ bond functionalization could give access to site-selective incorporations of substituents into arenes.

Due to its high ability for selective $\mathrm{C}-\mathrm{C}$ bond formations, palladium, one of the most often applied transition metals in catalysis, has been studied intensively by the Sanford group. Thus, recently this group has published an overview on the predictive control of site-selectivities in oxidative palladiumcatalyzed transformations. ${ }^{36}$ The authors differentiate between three the types of control possibilities (Scheme 1.11): Substrate-based through directing groups (a), substrate-based through electronic properties (b), and catalyst-controlled (c).

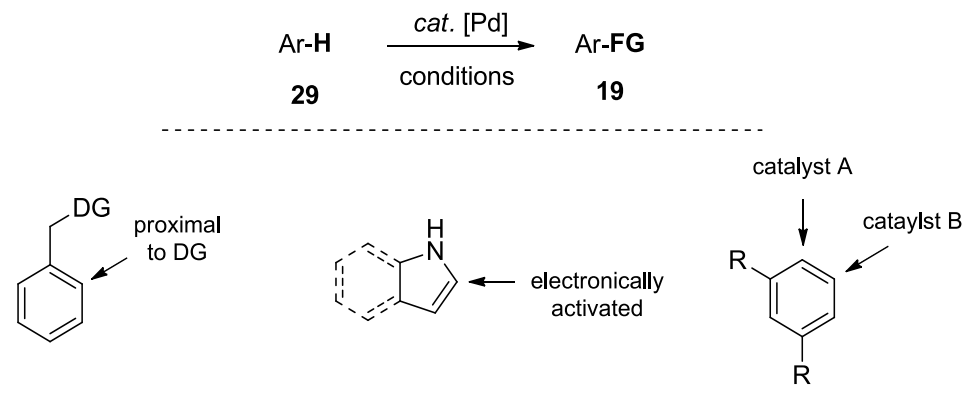

(a)

(b)

(c)

Scheme 1.11: Three possible ways to influence the regioselectivity of palladium-catalyzed C-H bond functionalization according to Sanford.

\footnotetext{
35 Atom economy: (a) Trost, B. M. Science 1991, 254, 1471-1477. (b) Trost, B. M. Acc. Chem. Res. 2002, 35, 695-705.

${ }^{36}$ Neufeldt, S. R.; Sanford, M. S. Acc. Chem. Res. 2012, 45, 936-946.
} 
These three presented possibilities have been used not only in oxidative couplings, but also in plenty of other transformations. The directing group approach thus usually leads to an orthofunctionalization of the substrate. An innovative approach, using carboxylic acids (13) as traceless directing groups for formal meta-arylation, has been published in 2011 by Larossa (Scheme 1.12). ${ }^{37}$

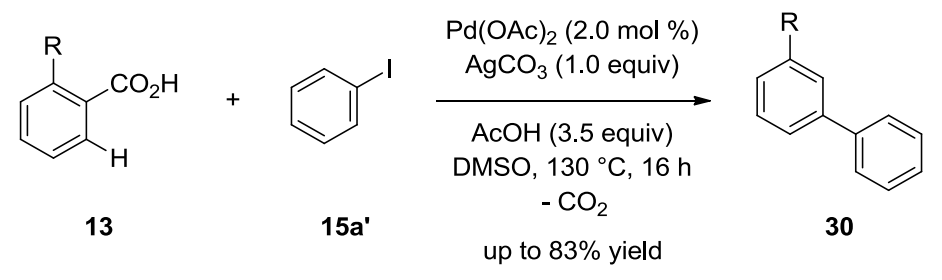

Scheme 1.12: Larossa's formal meta-arylation.

An important example of ortho-selective palladium-catalyzed transformation is the so called Catellani reaction, in which one can replace both hydrogen atoms in ortho-positions to an iodine substituent with diverse nucleophiles followed by Mizoroki-Heck-type reaction at the iodine location itself (Scheme 1.13). ${ }^{38}$

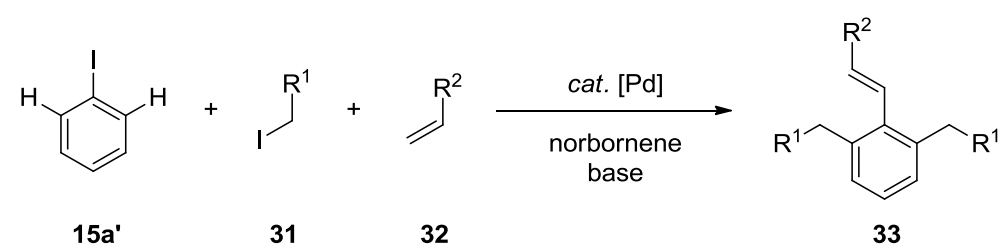

Scheme 1.13: The Catellani-reaction in general.

The corresponding cascade mechanism will not be discussed herein. ${ }^{38}$ However, it has to be mentioned that a catalytic or stoichiometric amount of norbornene is necessary and that the substrate scope is rather limited, since only iodo arenes (15a'), or recently published heteroarenes, can be used exclusively. ${ }^{39,40}$

Besides these approaches for site-selective transition metal-catalyzed functionalization reactions, a recent example for direct meta-selective palladium-catalyzed alkenylations using an end-on template have been reported by $Y u$ and co-workers in 2012 (Scheme 1.14). ${ }^{41}$<smiles>CC(C)(C)C(C)(C)C(C)(C)C</smiles>

34<smiles>C=COCC</smiles>

32a

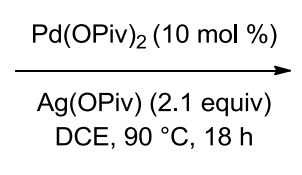

$63 \%(95 \%$ meta-product)

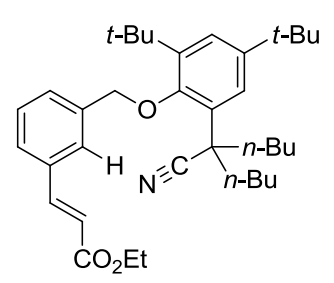

35

\footnotetext{
${ }^{37}$ Cornella, J.; Righi, M.; Larossa, I. Angew. Chem. Int. Ed. 2011, 50, 9429-9432.

38 Martins, A.; Mariampillai, B.; Lautens, M. Top. Curr. Chem. 2010, 292, 1-34.

${ }^{39}$ Catellani, M.; Frignani, F.; Rangoni, A. Angrew. Chem. Int. Ed. 1997, 36, 119-122.

40 Jiao, L.; Bach, T. J. Am. Chem. Soc. 2011, 133, 12990-12993.
}

41 (a) Leow, D.; Li, G.; Mei, T.-S.; Yu, J.-Q. Nature 2012, 486, 518-522; (b) Highlighted in: Truong, T.; Daugulis, O. Angew. Chem. Int. Ed. 2012, 51, 11677-11679. 


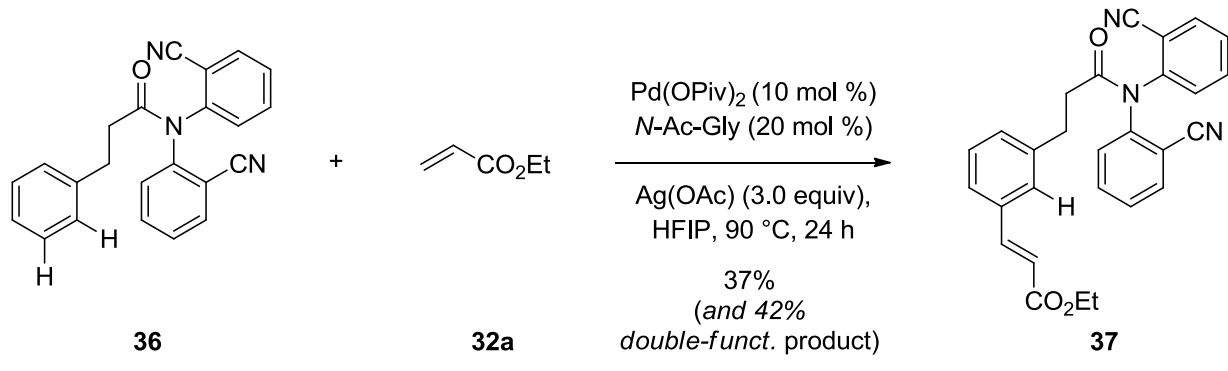

(b)

Scheme 1.14: First example of direct meta-alkenylation as reported by $Y u$.

This Fujiwara-Moritani-type reaction involves the formation of rigid six- or seven-membered cyclic transition states and the use of easily removable nitrile-containing directing groups. In 2009 Yu et al. have also reported an approach for meta-alkenylation of electron-deficient arenes, wherein the meta-selectivity was achieved not due to the meta-directing group-effect, but by applying sterically demanding pyridine ligands. ${ }^{42,43}$

Nevertheless, only several meta-selective reactions catalyzed by other transition metals, than palladium, have been reported until now. In 2009, the Gaunt group has published their findings in the field of copper-catalyzed meta-arylations of anilides $\mathbf{3 8}$ (Scheme 1.15). ${ }^{44,45}$

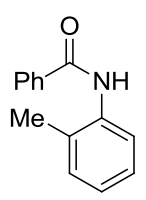

$38 a$

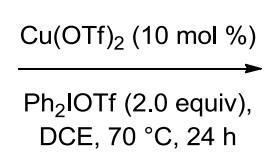

$73 \%$

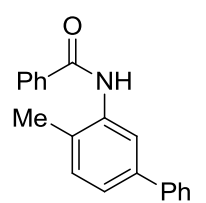

$39 a$

Scheme 1.15: Copper-catalyzed meta-arylation according to Gaunt.

The reaction mechanism has been discussed controversially and intensively, ${ }^{46}$ and in 2011 the group of Park has shown the reaction to occur in a meta-selective fashion also with heterogeneous recyclable copper catalyst $[\mathrm{Cu} / \mathrm{AlO}(\mathrm{OH})]$, which was composed from metal nanoparticles. ${ }^{47}$ The reaction could proceed smoothly only by raising the temperature $\left(80^{\circ} \mathrm{C}\right)$ and by adding an overstoichiometric amount (2.0 equiv) of the arylating reagent. It is important to note that even in the absence of a copper-source a high conversion has been detected.

\footnotetext{
${ }^{42}$ Zhang, Y.-H.; Shi, B.-F.; Yu, J.-Q. J. Am. Chem. Soc. 2009, 131, 5072-5074.

${ }^{43}$ For mechanistic DFT calculations, see: Zhang, S.; Shi, L.; Ding, Y. J. Am. Chem. Soc. 2011, 133, 20218-20229.

44 (a) Phipps, R. J.; Gaunt, M. J. Science 2009, 323, 1593-1597. (b) Highlighted in: Maleczka, R. E. Jr. Science 2009, 323, 1573.

${ }^{45}$ For meta-alkylation of aromatic $\alpha$-carbonyl compounds: Duong, H. A.; Gilligan, R. E.; Cooke, M. L.; Phipps, R. J.; Gaunt, M. J. Angew. Chem. Int. Ed. 2011, 50, 463-466

${ }^{46}$ For mechanistic DFT calculations, see: (a) Zhang, S.-l.; Ding, Y. Chin. J. Chem. Phys. 2011, 24, 711-723; (b) Chen, B.; Hou, X.-L.; Li, Y.-X.; Wu, Y.-D. J. Am. Chem. Soc. 2011, 133, 7668-7671.

${ }^{47}$ Young, E.; Park, J. Chem. Cat. Chem. 2011, 3, 1127-1129.
} 
Simultaneously, Gaunt and co-workers reported also on the copper-catalyzed para-selective arylations of phenol and aniline derivatives. ${ }^{48}$ The influence of copper in this reaction for the siteselective outcome can be discussed controversially and still remains under question, due to the fact that simple electrophilic aromatic substitution would lead to the observed para-selectivity as well.

Another transition metal-catalyzed meta-selective functionalization of $\mathrm{C}-\mathrm{H}$ bonds in simple arenes $\mathbf{4 0}$ has been invented by the groups of Marder and Hartwig and consisted of a two-step one-pot procedure. In this particullar case, a stereoselective iridium-catalyzed borylation ${ }^{49}$ followed by a Suzuki-Miyaura-type cross-coupling reaction was applied (Scheme 1.16). This approach has been used for meta-selective arylations, ${ }^{50}$ alkylations, allylations, benzylations ${ }^{51}$ and halogenations. ${ }^{52}$<smiles>[R]c1cccc([R])c1</smiles>

40

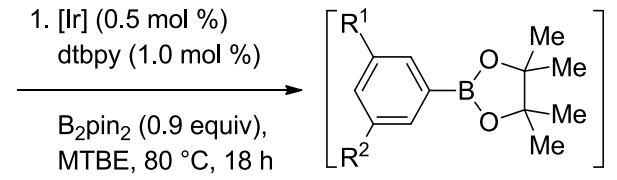

41

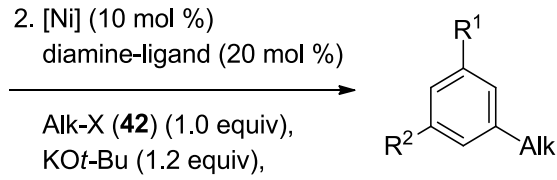

$\mathrm{THF}-\mathrm{H}_{2} \mathrm{O}, 60^{\circ} \mathrm{C}, 15 \mathrm{~h}$

43

Scheme 1.16: Two-step meta-selective alkylation of simple arenes $\mathbf{4 0 .}$

Obviously, although this transformation can be performed as a one-pot procedure, it needs various reagents and therefore should not be designated as an atom-economical reaction.

Concerning the ruthenium-catalyzed regioselective $\mathrm{C}-\mathrm{H}$ bond functionalization, only ortho-directed reactions, mainly arylations (see above, Chapter 1.1), have been known until recently. In 2011, Frost and co-workers have published the first example of a ruthenium-catalyzed meta-selective $\mathrm{C}-\mathrm{S}$ bond formation reaction in sulfonylations of 2-phenylpyridines 6 (Scheme 1.17). ${ }^{53}$ The authors proposed a combined $\mathrm{C}-\mathrm{H}$ activation $/ \mathrm{S}_{\mathrm{E}}{ }^{\mathrm{Ar}}$ mechanism, details of which will be discussed below in chapter 1.1.

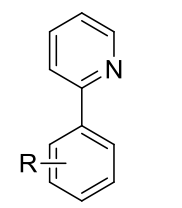

6

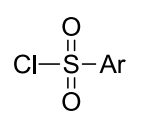

44

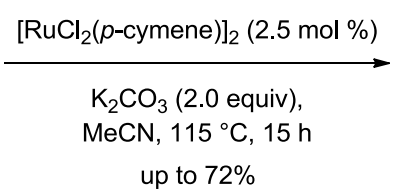

up to $72 \%$

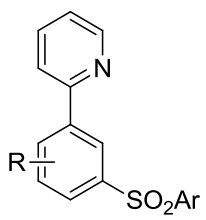

45

Scheme 1.17: Ruthenium-catalyzed meta-selective sulfonylation by Frost et al..

\footnotetext{
${ }^{48}$ Ciana, C.-L.; Phipps, R. J.; Brandt, J. R.; Meyer, F.-M.; Gaunt, M. J. Angew. Chem. Int. Ed. 2011, 50, $458-462$.

${ }^{49}$ Mkhalid, I. A. I.; Barnard, J. H.; Marder, T. B.; Murphy, J. M.; Hartwig, J. F. Chem. Rev. 2010, 110, 890-931

${ }^{50}$ Morris, J.; Steel, P. G.; Marder, T. B. Synlett 2009, 147-150.

${ }^{51}$ Robbins, D. W.; Hartwig, J. F. Angew. Chem. Int. Ed. 2012, 51, 933-937.

52 (a) Murphy, J. M.; Liao, X.; Hartwig, J. F. J. Am. Chem. Soc. 2007, 129, 15434-15435; (b) Partridge, B. M.; Hartwig, J. F. Org. Lett. 2013, 15, 140-143.

${ }^{53}$ Saidi, O.; Marafie, J.; Ledger, A. E. W.; Liu, P. M.; Mahon, M. F.; Kociok-Köhn, G.; Whittlesey, M. K.; Frost, C. G. J. Am. Chem. Soc. 2011, 133, 19298-19301.
} 
Nevertheless, the analogous meta-selective ruthenium-catalyzed direct $\mathrm{C}-\mathrm{C}$ bond formation reactions still remains ellusive.

\subsection{Transition Metal-Catalyzed Alkylation Reactions}

\section{Friedel-Crafts Alkylation}

Until now, the highly chemo- and regioselective introduction of alkyl chains on aromatic substrates remains a rather challeging objective. On industrial scale, the classical Friedel-Crafts chemistry is still the major player, although it involves the use of corrosive reagents, harsh reaction conditions and often undesired side-product formation. ${ }^{54}$ Scheme 1.18 demonstrates the alkylation of benzene (46) with ethylene (32b) affording ethylbenzene (47). This reaction is still one of the largest tonnage $C-C$ bond forming processes in industry (ca. $27 \mathrm{Mt} / \mathrm{a}$ in 2007).

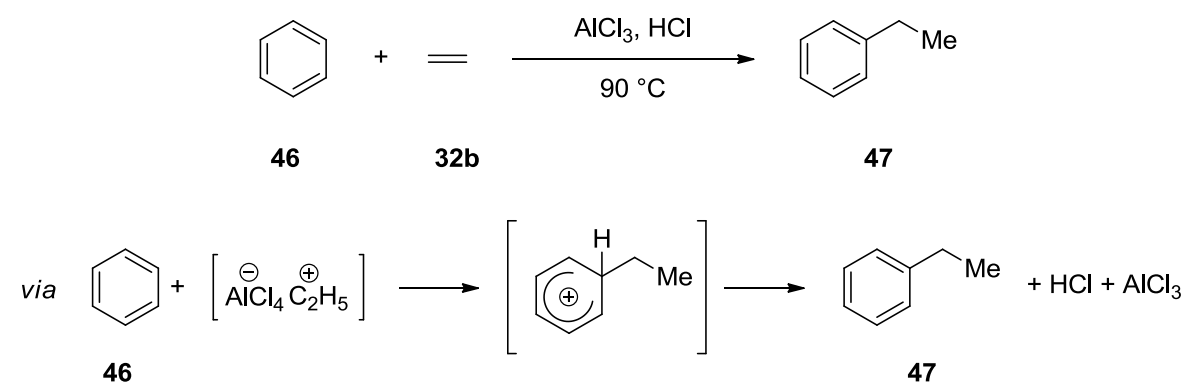

Scheme 1.18: Friedel-Crafts alkylation of benzene.

As generally accepted in $\mathrm{S}_{\mathrm{E}}{ }^{\mathrm{Ar}}$-type chemistry, electron-donating substituents on the arene moeity favor further substitution by increasing the electron density of the aromatic ring and thus lead to oligoalkylation products. In addition, alkylated carbocations tend to undergo Wagner-Meerwein rearrangements, to form the most stable cations, thus leading to a decreased chemoselectivity. Unsatisfactory aspects of this reaction on industrial scale, such as plant corrosion and chloridecontaining waste formation, represent an additional problem. In spite of this, tremendous progress has been made in the field of Friedel-Crafts alkylation ${ }^{55}$ since the first communications ${ }^{56}$ in 1877. Beside Lewis acids (e.g. $\mathrm{AlCl}_{3}, \mathrm{TiCl}_{4}, \mathrm{BF}_{3}$ etc.), strong Brønsted acids (e.g. $\mathrm{HF}, \mathrm{H}_{2} \mathrm{SO}_{4}$ etc.) have been used.

\footnotetext{
${ }^{54}$ Metal-Catalysis in Industrial Organic Processes (Eds.: Chiusoli, G. P.; Maitlis, P. M.), RSC: Cambridge, 2007, pp. 163-200.

${ }^{55}$ Rüping, M.; Nachtsheim, B. J. Beilstein J. Org. Syn. 2010, 6, 1-24.

${ }^{56}$ (a) Friedel, C.; Crafts, J. M. Compt. Rend. 1877, 84, 1392-1450; (b) Friedel, C.; Crafts, J. M. J. Chem. Soc. 1877, 32, 725-791.
} 
The first publication of a catalytic Friedel-Crafts alkylation using $\mathrm{Sc}(\mathrm{OTf})_{3}$ as Lewis acid-catalyst has been reported in $1996 . .^{57}$ Still immense further developments are ongoing within stereo- and enatioselective catalytic Friedel-Crafts alkylation. ${ }^{58}$ However, to circumvent the disadvantages of the acid-catalyzed reactions one can either switch to heterogeneous catalysts (for example, acidic zeolites) or use homogeneous transition metal catalysts as a promising alternative.

\section{Cross-Coupling Chemistry}

With regard to homogenous catalysis, metal-catalyzed cross-coupling chemistry is an important alternative to acid-catalyzed reactions between arenes and alkyl halides. ${ }^{59} \mathrm{~A}$ general catalytic cycle is represented in Scheme 1.19. In this introduction, only selected examples of alkylations via crosscoupling will be discussed.

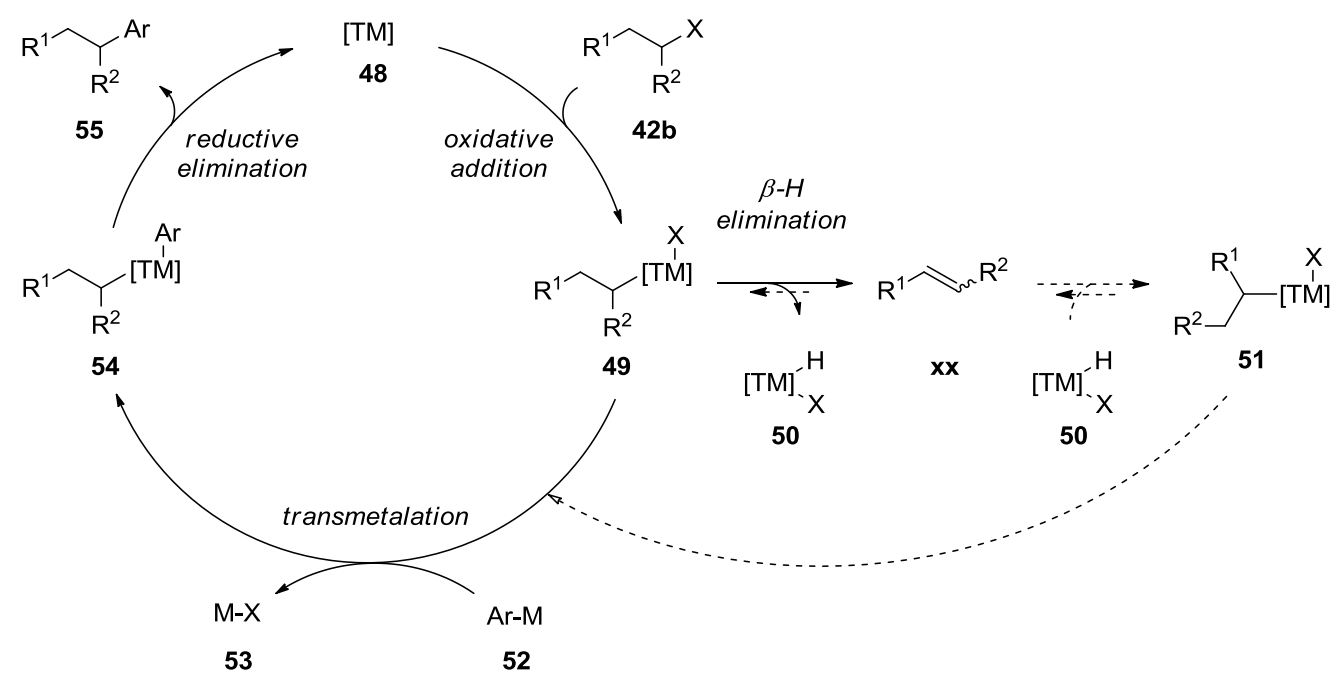

Scheme 1.19: General catalytic cycle for transition metal-catalyzed alkylation of arenes with alkyl halides.

Transition metal-catalyzed cross-couplings with unactivated alkyl (pseudo)halides bearing $\beta$-hydrogen atoms are not as easily accomplished as with aryl (pseudo)halides as electrophiles. On the one hand, these electrophiles may undergo competitive reactions like $\beta$-hydrogen elimination, which lead to a decreased efficiency and selectivity. On the other hand, they are less prone to undergo the oxidative addition due to their electron-rich character. ${ }^{60}$ of course, advantages of alkylations through traditional cross-coupling reactions can be listed: (a) Control of regioselectivity due to prefunctionalization of arenes, (b) milder reaction conditions as compared to classical Friedel-Crafts

\footnotetext{
57 Tsuchimoto, T.; Tobita, K.; Hiyama, T.; Fukuzawa, S.-I. Synlett 1996, 557-559.

${ }^{58}$ Catalytic Asymmetric Friedel-Crafts Alkylations (Eds.: Bandini, M.; Umani-Ronchi, A.), Wyley-VCH: Weinheim, 2009.

${ }^{59}$ Reviews: (a) Jana, R.; Pathak, T. P.; Sigman, M. S. Chem. Rev. 2011, 111, 1417-1492. For the use of secondary alkyl halides, see: (b) Rudolph, A.; Lautens, M. Angew. Chem. Int. Ed. 2009, 48, 2656-2670.

${ }^{60}$ Ackermann, L. Chem. Comm. 2010, 46, 4866-4877.
} 
chemistry and (c) a broad functional group tolerance.$^{61}$ Until recently, most transition metals used in this type of chemistry were palladium, nickel, iron, copper and cobalt.

The great potential of nickel-complexes as the catalyst for alkylations via cross-coupling reactions has recently been demonstrated by Xile $\mathrm{Hu}^{62}$ After publishing several examples for primary and secondary alkyl halides as coupling-partners, the research groups of Biscoe and Fu finally reported on nickel-catalyzed Kumada-Corriu and Suzuki-Miyaura cross-couplings with tertiary alkyl halides (58) as the electrophiles (Scheme 1.20). Thus, Biscoe disclosed the employment of air- and moisture-stable NHC-preligands.$^{63}$ However, the products 56 a were contaminated with isomerized $p$-alkylanizoles. On the contrary, such isomerization was not detected by Fu and co-workers, but the reaction needed overstoichiometric amounts of tert-butoxides to achieve efficient transformation. ${ }^{64}$

Biscoe 2011

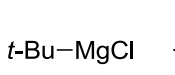

$52 a$<smiles>COc1ccc(Br)cc1</smiles>

$15 b$

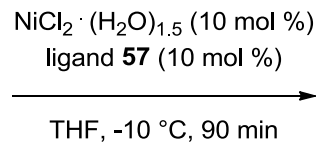

$75 \%$

(incl. $2 \% i$-Bu-anisole)

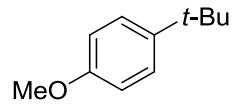

$56 a$

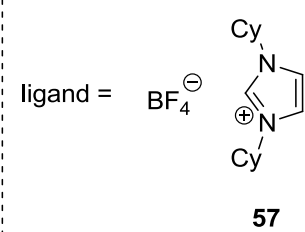

57

Fu 2013

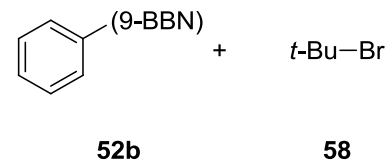

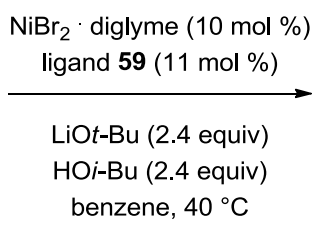

$84 \%$

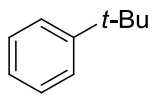

$56 b$

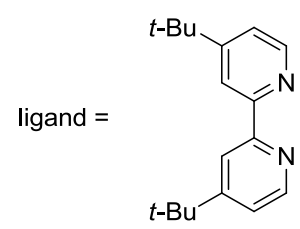

59

Scheme 1.20: Examples of nickel-catalyzed tert-alkylations via traditional cross-couplings.

Mechanistically these nickel-catalyzed reactions were shown to proceed via radical pathways. ${ }^{65}$

Furthermore, Fu et al. have made impressive progress within the field of nickel-catalyzed asymmetric alkylation-reactions. This group demonstrated the broad applicability of nickel catalysis for alkyl-alkyl

\footnotetext{
${ }^{61}$ (a) Modern Arylation Methods (Ed.: L. Ackermann), 1st ed., Wiley-VCH: Weinheim, 2009, pp. 155-181. For selected recent reviews on traditional cross-coupling reactions, see: (b) Li, H.; Johansson Seechurn, C. C. C.; Colacot, T. J. ACS Catal. 2012, 2, 1147-1164. (c) Shaikh, T. M.; Weng, C.-M.; Hong, F.-E. Coord. Chem. Rev. 2012, 256, 771-803. (d) Chem. Soc. Rev. 2011, 40, Special Issue 10 "Cross coupling reactions in organic synthesis", 4877-5208. (e) Rosen, B. M.; Quasdorf, K. W.; Wilson, D. A.; Zhang, N.; Resmerita, A.-M.; Garg, N. K.; Percec, V. Chem. Rev. 2011, 111, 1346-1416. (f) Acc. Chem. Res. 2008, 41, Special Issue 11 "Cross Coupling", 1439-1564.

${ }^{62} \mathrm{Hu}, \mathrm{X}$. Chem. Sci. 2011, 2, 1867-1886.

63 Joshi-Pangu, A.; Wang, C.-Y; Biscoe, M. R. J. Am. Chem. Soc. 2011, 133, 8478-8481.

${ }^{64}$ Zultanski, S. L.; Fu, G. C. J. Am. Chem. Soc., 2013, 135, 624-627.

${ }^{65}$ Taylor, B. L. H.; Jarvo, E. R. Synlett 2011, 19, 2761-2765.
} 
Negishi $^{66}$ - and Suzuki-Miyaura-type ${ }^{67}$ couplings, while $H u$ and co-workers have published a diastereoselective Kumada-Corriu-type ${ }^{68}$ coupling in 2012 (Scheme 1.21).

Hu 2012
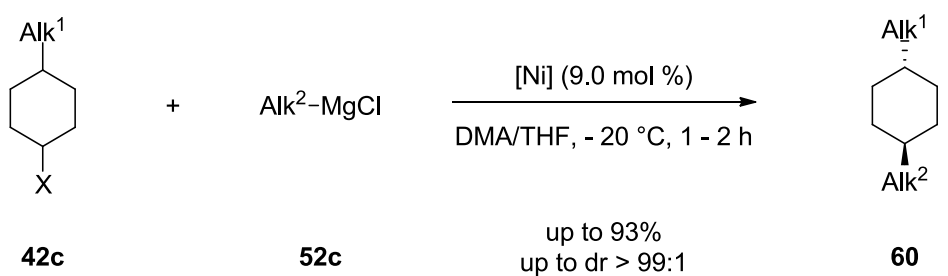

$[\mathrm{Ni}]=$

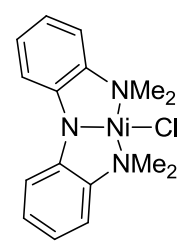

Scheme 1.21: Nickel-catalyzed stereoselective alkyl-alkyl Kumada-Corriu-type cross-coupling. ${ }^{68}$

Palladium complexes as the catalyst has been studied most intensively, ${ }^{69}$ however, these results will not be discussed herein. Very recently there has also been some evidence of using cobalt ${ }^{70}$ and copper $^{71}$ as catalysts by the groups of Nakamura, Liu and $\mathrm{Hu}$.

As an inexpensive alternative to the catalytic systems discussed above, iron complexes seem to be the most promising catalysts for the introduction of alkyl chains into arene moieties. Besides the classical (pseudo)nucleophiles like aryl halides, the groups of $\mathrm{Cook}^{72}$ and $\mathrm{Garg}^{73}$ have successively applied several phenol-based substrates, such as $\mathbf{7 b}$ and $\mathbf{1 5 d}$ in iron-catalyzed Kochi-like ${ }^{74}$ couplings (Scheme 1.22).

\footnotetext{
66 (a) Binder, J. T.; Cordier, C. J.; Fu, G. C. J. Am. Chem. Soc. 2012, 134, 17003-17006. (b) Choi, J.; Fu, G. C. J. Am. Chem. Soc. 2012, 134, 9102-9105. (c) Oelke, A. J.; Sun, J.; Fu, G. C. J. Am. Chem. Soc. 2012, 134, $2966-2969$. (d) Smith, S. W.; Fu, G. C. J. Am. Chem. Soc. 2008, 130, 12645-12647.

67 (a) Wilsily, A.; Tramutola, F.; Owston, N. A.; Fu, G. C. J. Am. Chem. Soc. 2012, 134, 5794-5797. (b) Zultanski S. L.; Fu, G. C. J. Am. Chem. Soc., 2011, 133, 15362-15364. (c) Saito, B.; Fu, G. C. J. Am. Chem. Soc. 2008, 130, 6694-6695. (d) Lu, S.; Fu, G. C. Angew Chem. In. Ed. 2010, 49, 6676-6678. (e) Saito, B.; Fu, G. C. J. Am. Chem. Soc. 2007, 129, 9602-9603.

${ }^{68}$ Perez Garcia, P. M.; Di Franco, T.; Orsino, A.; Ren, P.; Hu, X. Org. Lett. 2012, 14, 4286-4289.

69 (a) Palladium in Organic Synthesis (Ed.: Tsuji, J.) Springer-Verlag: Berlin-Heidelberg, 2005, pp. 85-108. (b) Handbook of Organopalladium Chemistry for Organic Synthesis (Ed.: Negishi, E.), Wiley-Interscience: New York, 2002, pp. 597-618.

${ }^{70}$ (a) Chen, Q.; Ilies, L.; Yoshikai, N.; Nakamura, E. Org. Lett. 2011, 13, 3232-3234. (b) Ilies, L.; Nakamura, E. J. Am. Chem. Soc. 2011, 133, 428-429.

71 (a) Yang, C.-T.; Zhang, Z.-Q.; Liang, J.; Liu, J.-H.; Lu, X.-Y.; Chen, H.-H.; Liu, L. J. Am. Chem. Soc. 2012, 134, 11124-11127. (b) Ren, P.; Stern, L.-A.; Hu, X. Angew. Chem. Int. Ed. 2012, 51, 9110-9113.

${ }^{72}$ Agrawal, T.; Cook, S. P. Org. Lett. 2013, 15, 96-99.

${ }^{73}$ Silberstein, A. L.; Ramgren, S. D.; Garg, N. K. Org. Lett. 2012, 14, 3796-3799.

${ }^{74}$ Tamura, M.; Kochi, J. K. J. Am. Chem. Soc. 1971, 93, 1487-1489.
} 

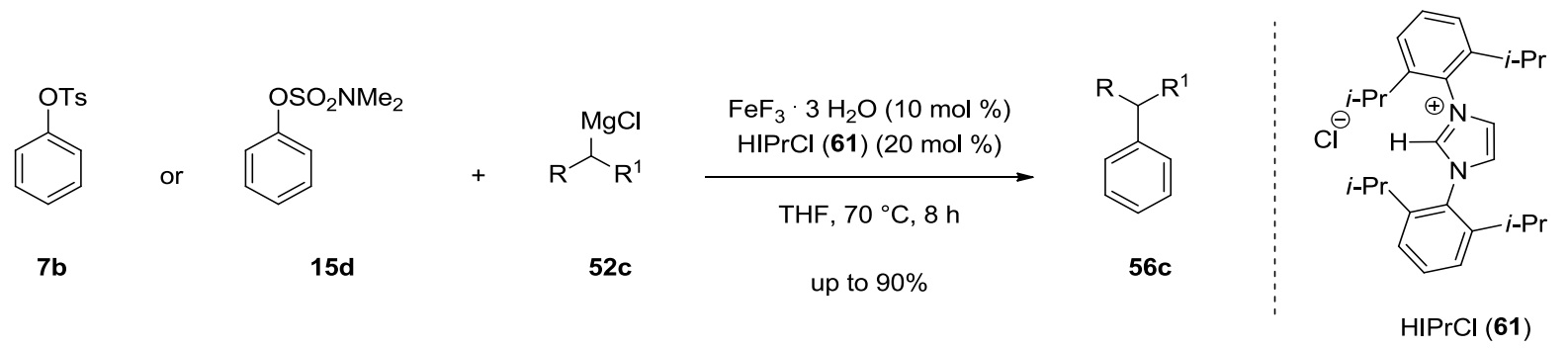

Scheme 1.22: Iron-catalyzed alkylation of arenes using phenol-derived substrates $\mathbf{7 b}$ or $\mathbf{1 5 d}$.

Although these reactions give high yields and utilize easily accessible starting materials, like tosylates, and easy-to-prepare air-stable NHC-preligands, they still face the main obstacles of transition metalcatalyzed cross-coupling chemistry in that they employ prefunctionalized substrates. However, certain progress has been made by several research groups to overcome these limitations discussed above in Chapter 1.1.

\section{Transition Metal-Catalyzed Alkylation via C-H Bond Functionalization}

Because of the disadvantages of classical cross-coupling chemistry, significant progress is expected in the development of direct $\mathrm{C}-\mathrm{H}$ bond alkylations of arenes and heteroarenes as an environmentally benign and economically more attractive strategy.

In contrast to the sufficiently well elaborated methods for transition metal-catalyzed direct $\mathrm{C}-\mathrm{H}$ bond arylations (see above, Chapter 1.1), the direct introduction of non-aromatics, especially saturated substituents, has received significant less attention.

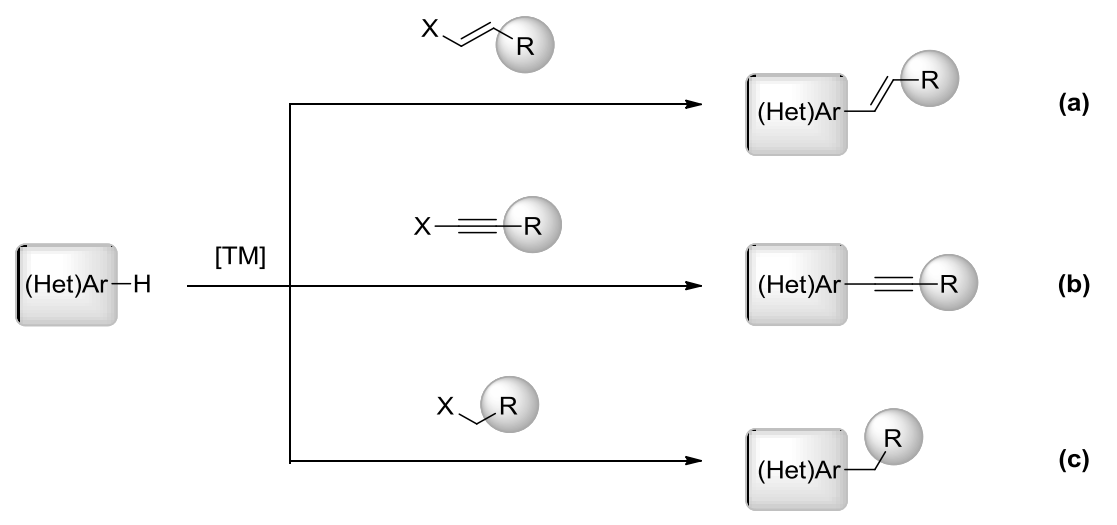

Scheme 1.23: Direct intermolecular alkenylation (a), alkynylation (b) and alkylation (c) of arenes.

Only few methods have been designed for direct alkenylation, alkynylation or even benzylation and alkylation using palladium, rhodium, ruthenium, nickel and copper catalysis (Scheme 1.23). ${ }^{75}$ As indicated above, the present study is focused on the catalytic activity of ruthenium complexes. Among the most prominent examples obtained employing other transition metals, impressive

\footnotetext{
${ }^{75}$ (a) Messaoudi, S.; Brion, J.-D.; Alami, M. Eur. J. Org. Chem. 2010, 6495-6516.
} 
progress in the catalytic direct alkylation of relatively acidic $\mathrm{C}-\mathrm{H}$ bonds in azoles $\mathbf{6 2}$, as reported by the groups of $\mathrm{Hu}^{76,77}$ as well as of Satoh and Miura, ${ }^{78}$ should be mentioned. Thus, in $2010 \mathrm{Hu}$ reported on the nickel/copper-catalyzed alkylations of heteroarenes using primary alkyl halides, ${ }^{77}$ and in 2012 the similar reactions were performed using less expensive copper catalysts. ${ }^{76}$ Miura and Satoh employed palladium-allyl complexes with additional phosphine ligands for these transformations (Scheme 1.24). ${ }^{78}$

Hu 2010

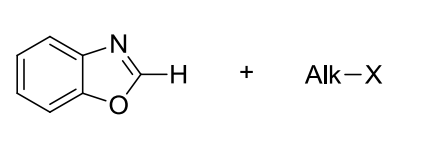

62

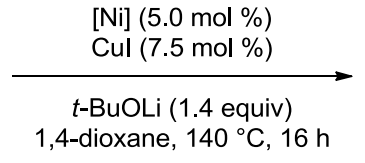

up to $86 \%$

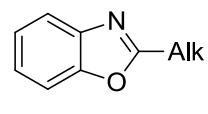

63

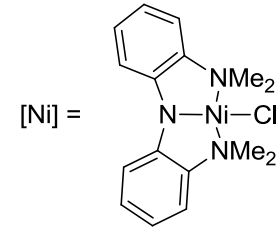

Miura 2010

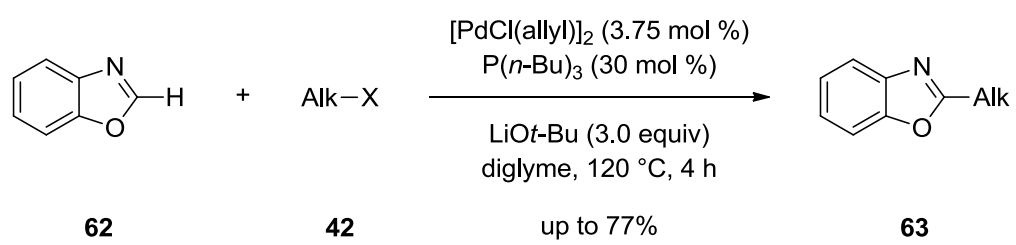

Scheme 1.24: Direct alkylation of acidic $\mathrm{C}-\mathrm{H}$ bonds in benzo[ $[\mathrm{d}]$ oxazole (62).

In both cases the authors demonstrated that a broad range of heterocycles could be selectively monoalkylated at the most acidic $\mathrm{C}-\mathrm{H}$ bond and that a variety of alkyl halides $(\mathbf{4 2}, \mathrm{X}=\mathrm{Cl}, \mathrm{Br}, \mathrm{I})$ was reactive under the reported reaction conditions. The main disadvantages herein is the necessity to use over-stoichiometric amounts of strong bases, like lithium tert-butoxide, and the impossibility to functionalize all non-acidic positions. A user-friendly modification of the nickel-catalyzed direct alkylation has been reported in 2011 by Ackermann et al. using [ $\mathrm{NiBr}_{2}$ (diglyme)] as the active catalyst. $^{79}$

In 2009, Fagnou reported on a palladium-catalyzed benzylation of heterocyclic compounds with benzyl chlorides. ${ }^{80}$ The group of Miura could also demonstrate that such a palladium-catalyzed benzylation could be performed using benzyl carbonates as reagents in the presence of $\mathrm{NaOAc}$ as the base. ${ }^{81}$ So far, the described methods strongly rely on the availability of a rather acidic $\mathrm{C}-\mathrm{H}$ bond.

\footnotetext{
${ }^{76}$ Ren, P.; Salihu, I.; Scopelliti, R.; Hu, X. Org. Lett, 2012, 14, 1748-1751.

${ }^{77}$ Vechorkin, O.; Proust, V.; Hu, X. Angew. Chem. Int. Ed. 2010, 49, 3061-3064.

${ }^{78}$ Yao, T.; Hirano, K.; Satoh, T.; Miura, M. Chem. Eur. J. 2010, 16, 12307-12311.

${ }^{79}$ Ackermann, L.; Punji, B.; Song, W. Adv. Synth. Catal. 2011, 353, 3325-3329.

${ }^{80}$ Lapointe, D.; Fagnou, K. Org. Lett. 2009, 11, 4160-4163.

${ }^{81}$ Mukai, T.; Hirano, K.; Satoh, T.; Miura, M. Org. Lett. 2010, 12, 1360-1363. See also: Ackermann, L.; Barfüßer, S.; Pospech, J. Org. Lett. 2010, 12, 724-726.
} 
Early experiments on palladium-mediated ortho-alkylation of acetanilides (64) and aldimines employing stoichiometric quantities of palladium acetate have been made by Tremont and coworkers in the 1980ies (Scheme 1.25)..$^{82,83}$

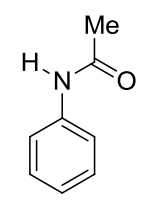

64

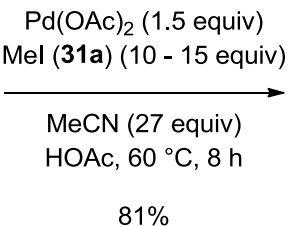

$81 \%$

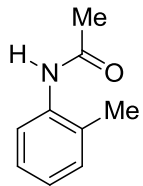

65

Scheme 1.25: ortho-Methylation of acetanilide $(4 \mathrm{~g})$ mediated by stoichiometric quantities of $\mathrm{Pd}(\mathrm{OAc})_{2}$, as reported by Tremont.

In 2003, Buchwald elaborated on the catalytic intramolecular cyclisations of anilides 66 towards the synthesis of oxindoles $\mathbf{6 7}$, which can be considered as palladium-catalyzed intramolecular versions of direct alkylation. ${ }^{84}$ In 2008, the Chang group reported on an analogous synthesis of condensed pyrroloindoles 70 (Scheme 1.26). ${ }^{85}$

Buchwald 2009<smiles>[R]N(C(=O)CCl)c1ccccc1</smiles>

66

Chang 2008<smiles>ClCc1ccccc1-n1cccc1</smiles>

69

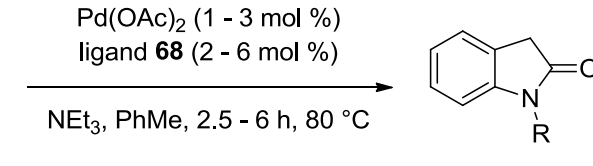

up to $99 \%$

67 ligand $\mathbf{6 8}(10$
$\mathrm{NEt}_{3}$, benzene,
$97 \%$

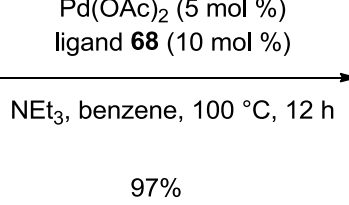

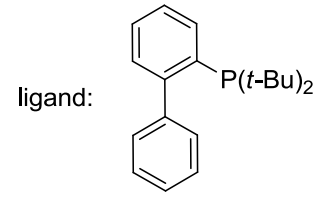

68

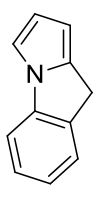

70

Scheme 1.26: Palladium-catalyzed intramolecular direct alkylation reactions.

In 2009, the group of $Y u$ disclosed reaction conditions for the palladium-catalyzed ortho-alkylation on benzoic acids 13 with selected $\alpha, \omega$-alkyldichlorides or alkyl chlorides (Scheme 1.27). The reaction

\footnotetext{
82 (a) Tremont, S. J.; Rahman, H. U. J. Am. Chem. Soc. 1984, 106, 5759-5760; (b) McCallum, J. S.; Gasdaska, J. R.; Liebeskind, L. S.; Tremont, S. J. Tetrahedron Lett. 1989, 30, 4085-4008.

${ }^{83}$ Nakamura described a similar catalytic alkylation using $\mathrm{Co}(\mathrm{acac})_{2}$ and Grignard-reagents: (a) Chen, Q.; Ilies, L.; Nakamura, E. J. Am. Chem. Soc. 2011, 133, 428-429; (b) Chen, Q.; Ilies, L.; Yoshikai, N.; Nakamura, E. Org. Lett. 2011, 13, 3232-3234.

${ }^{84}$ Hennessy, E. J.; Buchwald, S. L. J. Am. Chem. Soc. 2003, 125, 12084-12085.

${ }^{85}$ Hwang, S. J.; Cho, S. H.; Chang, S. J. Am. Chem. Soc. 2008, 130, 16158-16159.
} 
proceeds via an intra- or an intermolecular fashion, after esterification of benzoic acids $\mathbf{1 3}$ in a onepot procedure. ${ }^{86}$<smiles>O=C(O)c1c[R1]ccc1</smiles>

13

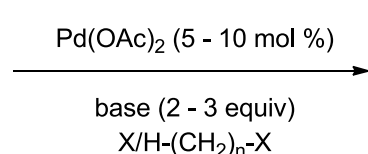

$115-140{ }^{\circ} \mathrm{C}, 36 \mathrm{~h}$ up to $92 \%$<smiles>O=C1OCCc2cc[R17]cc21</smiles>

71<smiles>O=C1OCc2cc[R]#cc21</smiles>

72

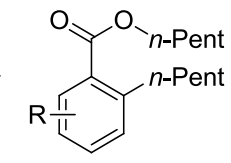

73

Scheme 1.27: One-pot procedure for esterification/ortho-alkylation sequence in benzoic acids 13 through palladium catalysis.

Beside carboxyl $n$-pentyl directing groups, in 2008, $Y u$ also demonstrated the possibility to utilize 2pyridyl directing groups and succeeded in an enatioselective alkylation in substrate $\mathbf{7 4}$ using mono- $\mathrm{N}$ protected amino acids (MPAA) 76 as chiral ligands (Scheme 1.28). ${ }^{87}$<smiles>C/C=C\C(=N)C(c1ccccc1C)c1ccccc1C</smiles>

74

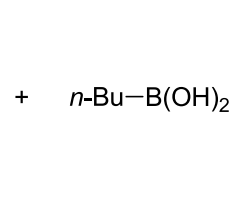

$52 d$

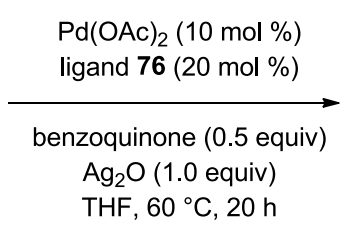

up to $91 \%$ up to $87 \%$ ee

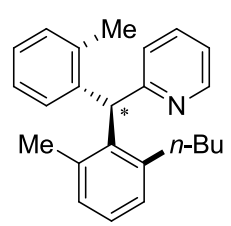

75<smiles>CC(C)CC(NC(=O)O)C(=O)O</smiles>

(-)-Menthyl

$76 a$

Scheme 1.28: Site- and eantio-selective palladium-catalyzed alkylation by $Y u$.

Under these reaction conditions, they have also performed an enantioselective $C\left(s p^{3}\right)-C\left(s p^{3}\right)$ bond formation, albeit with moderate yield and enantiomeric excess (38\%, 37\% ee). Later, in 2010 , the $Y u$ group has combined both concepts - the application of a carboxyl group as a DG and the enatioselective alkylation using chiral ligands - to accomplish a site- and enantio-selective FujiwaraMoritani alkenylation of sodium diphenylacetates 77 (Scheme 1.29). ${ }^{88}$
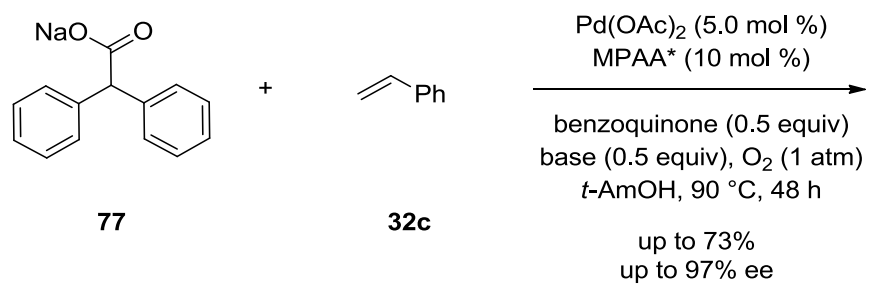

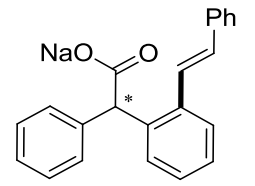

78

Scheme 1.29: Site- and enantio-selective oxidative alkenylation with carboxylate as the directing group.

\footnotetext{
${ }^{86}$ Zhang, Y.-H.; Shi, B.-F.; Yu, J.-Q. Angew. Chem. Int. Ed. 2009, 48, 6097-6100.

87 (a) Shi, B.-F.; Maugel, N.; Zhang, Y.-H.; Yu, J.-Q. Angew. Chem. Int. Ed. 2008, 47, 4882-4886; (b) for mechanistic DFT studies, see: Musaev, D. G.; Kaledin, A.; Shi, B.-F.; Yu, J.-Q. J. Am. Chem. Soc. 2012, 134, 1690-1698.

${ }^{88}$ Shi, B.-F.; Zhang, Y.-H.; Lam, J. K.; Wang, D.-H.; Yu, J.-Q. J. Am. Chem. Soc. 2010, 132, 460-461.
} 
Very recently, $\mathrm{Fu}$ described a palladium-catalyzed direct alkylation of pyridine $\mathrm{N}$-oxides $\mathbf{7 9}$ using the $\mathrm{N}$-oxide moiety as the directing group and secondary alkyl bromides $\mathbf{4 2} \mathbf{b}$ as electrophiles (Scheme $1.30)^{89}$<smiles>Cc1cccc[n+]1[O-]</smiles>

79<smiles>BrC1C[R]CCC1</smiles>

42b

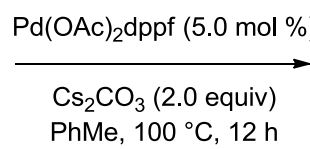

up to $90 \%$

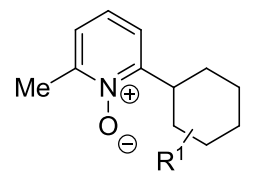

80 dppf

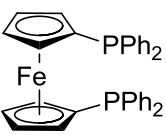

Scheme 1.30: Palladium-catalyzed direct alkylation on pyridine $\mathbf{N}$-oxides $\mathbf{7 9}$ with cyclohexyl bromide (42b).

\section{Ruthenium-Catalyzed Direct Alkylation of Arenes}

As this $\mathrm{PhD}$ thesis especially deals with ruthenium-catalyzed $\mathrm{C}-\mathrm{H}$ bond functionalizations, the overview of ruthenium-catalyzed reactions that allow the attachment of certain alkyl groups to the aromatic substrate will be presented below.

In 1986, the pioneering study by Lewis and Smith has disclosed the first atom-economical regioselective ortho-alkylation of simple phenol derivatives $\mathbf{8 1}$ with ethylene, via participation of an in-situ formed phosphite intermediate (Scheme 1.31)..$^{90,22}$

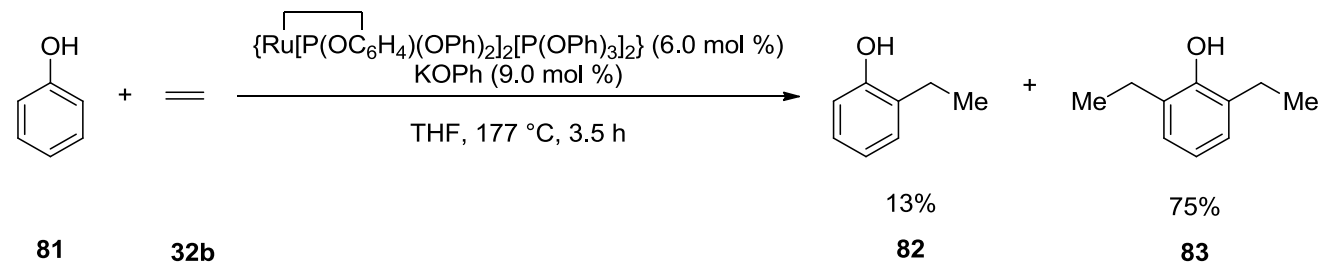

Scheme 1.31: Ruthenium-catalyzed hydroarylation of phenols 81 with ethylene (32b)

as reported by Lewis and Smith.

In 1993, Murai, Chatani, Kakiuchi and co-workers reported the addition of various alkenes 32 to aromatic ketones $\mathbf{8 4}$ using ruthenium hydride complexes as the catalysts. ${ }^{91}$ Today, this hydroarylation reaction is often called the Murai-reaction (Scheme 1.32).

\footnotetext{
${ }^{89}$ Xiao, B.; Liu, Z.-J.; Liu, L.; Fu, Y. J. Am. Chem. Soc. 2013, 135, 616-619.

90 Lewis, L. N.; Smith, J. F. J. Am. Chem. Soc. 1986, 108, 2728-2735.

91 (a) Murai, S.; Kakiuchi, F.; Sekine, S.; Tanaka, Y.; Kamatani, A.; Sonoda, M.; Chatani, N. Nature 1993, 366, 529-531. (b) Kakiuchi, F.; Murai, S. Acc. Chem. Res. 2002, 35, 826-834. For DFT-calculations, see: (c) Helmstedt, U.; Clot, E. Chem. Eur. J. 2012, 18, 11449-11458. For ruthenium-catalyzed Murai-type carbonylations, see: (d) Chatani, N.; le, Y.; Kakiuchi, F.; Murai, S. J. Org. Chem. 1997, 62, 2604-2610.
} 


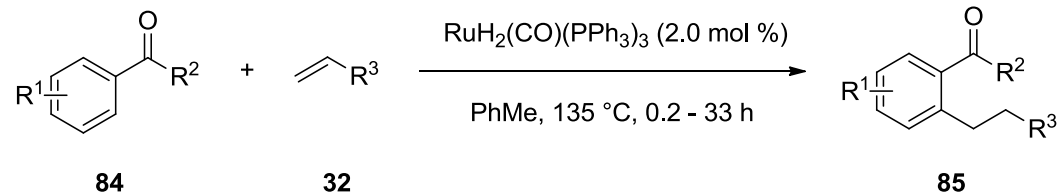

Scheme 1.32: Intermolecular hydroarylation of alkenes $\mathbf{3 2}$ with acetophenones $\mathbf{8 4}$ (Murai-reaction).

The coordination to the ruthenium center by the carbonyl group oxygen promotes the ortho- $\mathrm{C}-\mathrm{H}$ bond cleavage. Subsequent ruthenium coordination to alkene $\mathbf{3 2}$ followed by insertion into the Ru-H bond results in the hydroarylation, thereby giving access to anti-Markovnikov alkylation products $\mathbf{7 0}$.

In 2010, the group of Williamson has demonstrated the application of the Murai-type alkylation towards benzyl alcohols. In this particular case, the ruthenium complex catalyzed two separate reactions, i. e. (i) alcohol oxidation to benzaldehyde by hydrogen transfer to an excess of alkene and (ii) $\mathrm{C}-\mathrm{H}$ activation/alkene insertion. This reaction afforded the same product 85 (Scheme 1.32); however, in situ hydrogenation in the presence of formic acid as hydride source furnished the alkylated benzyl alcohols in high yields. ${ }^{92}$ The ruthenium-catalyzed regioselective direct alkylation of perylene bisimides - important class of dyes and pigments - at 2,5,8,11-positions, performed in cooperation of five Japanese research groups obviously demonstrated the user-friendly nature of the Murai-reaction. ${ }^{93}$

However, the search for a more convenient pre-catalyst than ruthenium hydride complexes for the Murai reaction remains challenging. Thus, an intramolecular ruthenium (III)-catalyzed electrophilic hydro-arylation applying $\mathrm{RuCl}_{3} / \mathrm{AgOTf}$ as the catalytic system has been elaborated by the group of Sames in $2004,{ }^{94}$ who have reported efficient formation of chromanes, tetralins, terpenoids and dihydrocoumarins via cyclisation of homo- and dihomoallylarenes.

Darses and Genet published a new efficient procedure for the Murai reaction in 2009. This protocol operates with the stable, commercially available $\left[\operatorname{RuCl}_{2}(p \text {-cymene })\right]_{2}$ complex as the precatalyst in combination with a phosphine ligand and sodium formiate, to form the catalytically active hydride complex in situ. ${ }^{95}$

\footnotetext{
${ }^{92}$ Watson, A. J. A.; Maxwell, A. C.; Williams, J. M. J. Org. Lett. 2010, 12, 3856-3859.

93 Nakazono, S.; Imazaki, Y.; Yoo, H.; Yang, J.; Sasamori, T.; Tokitoh, N.; Cédric, T.; Kageyama, H.; Kim, D.; Shinokubo, H.; Osuka, A. Chem. Eur. J. 2009, 15, 7530-7533.

${ }^{94}$ Youn, S. W.; Pastine, S. J.; Sames, D. Org. Lett. 2004, 6, 581-584.

${ }^{95}$ Martinez, R.; Chevalier, R.; Darses, S.; Genet, J.-P. Angew. Chem. Int. Ed. 2006, 45, 8232-8235.
} 
Very recently, Miura and Satoh developed a new procedure for a ruthenium-catalyzed hydroarylation of alkynes $\mathbf{8 8}$ using benzamides $\mathbf{8 6}$ or 2-phenylpyrazole (87) as hydroarylating agents and $\left[\mathrm{RuCl}_{2}(p \text {-cymene) }]_{2} / \mathrm{AgSbF}_{6}\right.$ as the catalytic system (Scheme 1.33$){ }^{96}$<smiles>[R16]C(=O)c1ccccc1</smiles>

86

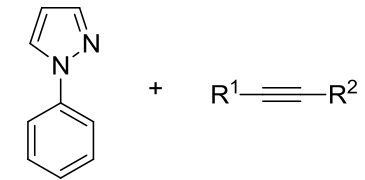

87

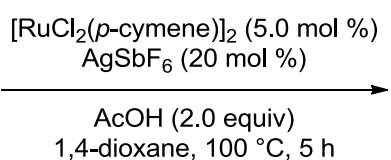

up to $96 \%$<smiles>[R]C=C([R])c1ccccc1C([R])=O</smiles>

89<smiles>[R]C=C([R])c1ccccc1-n1cccn1</smiles>

90

Scheme 1.33: Ruthenium-catalyzed hydroarylation of alkynes 88.

Moreover, Ackermann and co-workers reported on the ruthenium-catalyzed hydroarylation of methylenecyclopropanes $\mathbf{3 2 d}$ or unactivated alkenes $\mathbf{3 2}$ with 2-phenylpyridines $\mathbf{6}$ employing $\left[\mathrm{RuCl}_{2}(\mathrm{cod})\right]_{n} /$ phosphane and $\left[\mathrm{RuCl}_{2}(p \text {-cymene })\right]_{2} /$ carboxylate as the catalysts. Hydroarylations of substrate 6 proceeded smoothly with both types of catalysts and were characterized by complete conservation of all cyclopropane rings in the products $\mathbf{9 1}$, while hydroarylation of simple alkenes 32 required carboxylate assistance (Scheme 1.34). ${ }^{97}$

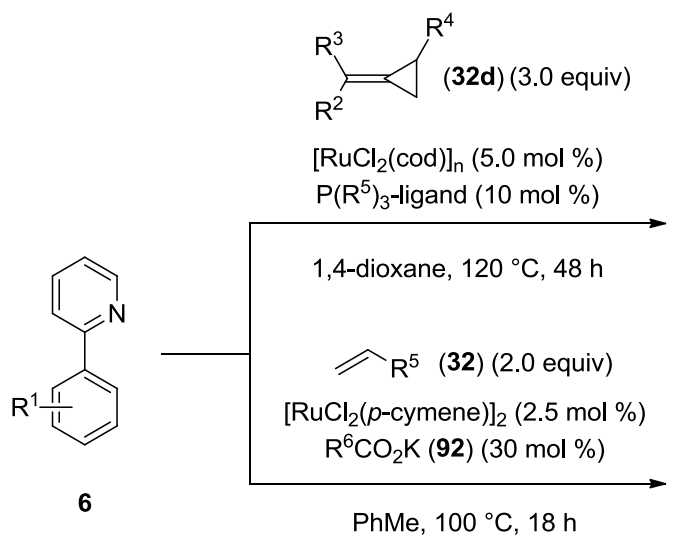

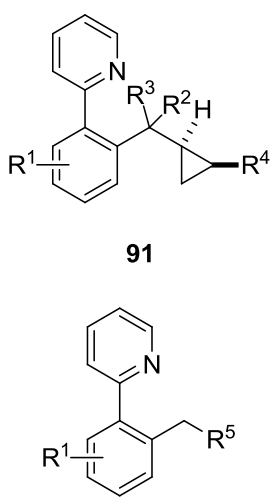

93

Scheme 1.34: Ruthenium-catalyzed hydroarylation of alkenes 32 according to Ackermann et al.

Another synthetic approach towards alkenylated arenes, besides the hydroarylation of alkynes (Scheme 1.33), was elaborated by Kakiuchi and Chatani using the ruthenium-catalyzed alkenylation

96 (a) Hashimoto, Y.; Hirano, K.; Satoh, T.; Kakiuchi, F.; Miura, M. J. Org. Chem. 2013, asap, DOI: 10.1021/jo3025237. (b) Hashimoto, Y.; Hirano, K.; Satoh, T.; Kakiuchi, F.; Miura, M. Org. Lett., 2012, 14, 2058-2061. For cobalt-catalyzed alkenylations with stoichiometric amounts of Grignard additives, see: (c) Lee, P.-S.; Fujita, T.; Yoshikai, N. J. Am. Chem. Soc. 2011, 133, 17283-17295. (d) Ding, Z.; Yoshikai, N. Synthesis 2011, 16, 2561-2566.

97 (a) Ackermann, L.; Kozhushkov, S. I.; Yufit, D. S. Chem Eur. J. 2012, 18, 12068-12077; (b) Kozhushkov, S. I.; Yufit, D. S.; Ackermann, L. Org. Lett. 2008, 10, 3409-3412; (c) Schinkel, M.; Marek, I.; Ackermann, L. Angew. Chem. Int. Ed. 2013, in press; (d) Schinkel, M. Dissertation, Universität Göttingen, 2013. 
with alkenyl acetates or boronates $32 e^{98}$ This method could be applied to aromatic ketones $\mathbf{8 4 a}$ (Scheme 1.35) or 2-phenylheteroarenes with heteroarene as a nitrogen-containing directing group.<smiles>[R20]c1ccccc1C(C)=O</smiles>

$84 a$<smiles>[R]C=CB1OCC(C)(C)CO1</smiles>

$32 \mathrm{e}$

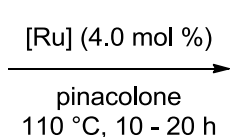
$110{ }^{\circ} \mathrm{C}, 10-20 \mathrm{~h}$<smiles>[R]C=Cc1cccc([R20])c1C(C)=O</smiles>

94

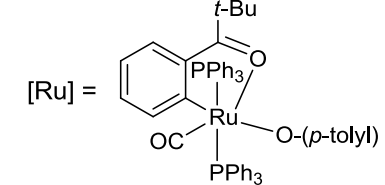

Scheme 1.35: Ruthenium-catalyzed direct alkenylation with alkenyl boronates $32 \mathrm{~d}$ as reported by Chatani and Kakiuchi.

In 2005, Inoue's group succeeded in an attempt of direct alkenylation of 2-aryloxazolines with alkenyl bromides. The resulting substituted arenes were isolated in moderate to excellent yields, but were contaminated with isomerized arylalkenes in all reported cases. ${ }^{99}$ In spite of this, the reaction appears to be promising as a highly step-economical, cost-efficient and sustainable process, and thus demands additional investigations.

An example for the direct ruthenium-catalyzed ortho-allylation of arenes 6 has been described by $O i$ and Inoue in 2006 (Scheme 1.36). ${ }^{100}$ They have demonstrated a direct allylation that proceeds in high yields, but with formation of isomerized by-products, which they believe were formed via the reorganization of an $\sigma$-allyl intermediate to a $\pi$-allylruthenium complex prior to an $\mathrm{C}-\mathrm{H}$ cycloruthenation.

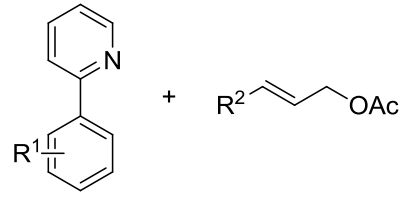

6

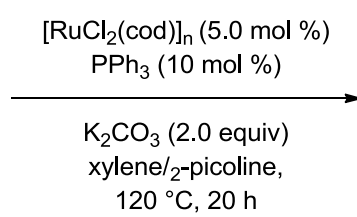

up to $93 \%$ up to $88: 12$

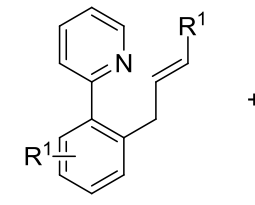

96

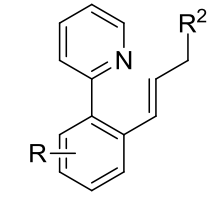

97

Scheme 1.36: Ruthenium-catalyzed allylation with acetates 95 as desribed by $O i$ and Inoue.

Very recently, the group of Chatani reported also on a procedure for a direct alkynylation on substrates bearing a nitrogen-containing DG and using an inexpensive ruthenium (II) complex as the catalyst and caesium pivalate for carboxylate assistance in the $\mathrm{C}-\mathrm{H}$ activation step. ${ }^{101}$

\footnotetext{
98 (a) Ueno, S.; Kochi, T.; Chatani, N.; Kakiuchi F. Org. Lett. 2009, 11, 855-858; (b) Matsuura, Y.; Tamura, M.; Kochi, T.; Sato, M., Chatani, N.; Kakiuchi, F. J. Am. Chem. Soc. 2007, 129, 9858-9859.

99 Oi, S.; Azaiwa,E.; Ogino, Y.; Inoue, Y. J. Org. Chem. 2005, 70, 3113-3119.

100 Oi, S.; Tanaka, Y.; Inoue, Y. Organometallics 2006, 25, 4773-4778.

101 Ano, Y. ; Tobisu, M.; Chatani, N. Synlett, 2012, 23, 2763-2767.
} 


\subsection{Transition Metal-Catalyzed Oxidative Couplings}

As discussed above, transition metal catalyzed direct functionalizations (see Chapter 1.1), such as direct arylations or alkylations, constitute an important and efficient synthetic method for the chemo- and site-selective $\mathrm{C}-\mathrm{C}$ bond formation (see above in Chapter 1.1). To enhance the atom economy and the sustainability of transition metal-catalyzed transformations, oxidative methods are promising advancements due to their low waste production and no requirement for prefunctionalization of the substrates.

Thus, in the 1960ies Fujiwara and Moritani have descibed the palladium-catalyzed oxidative Hecktype cross-coupling reaction using various alkenes and arenes as coupling partners (Scheme 1.37). ${ }^{102}$ Based on their pioneering work, a broad range of methodologies has been developed during the last decades.

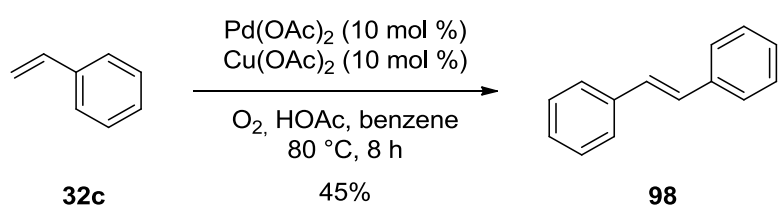

Scheme 1.37: Fujiwara-Moritani oxidative alkenylation.

The principle of transition metal-catalyzed oxidative coupling has been extended to metals other than palladium, such as rhodium or gold, and was used for homo- or cross-dehydrogenative couplings (CDC) of variuos substrates (Scheme 1.38). ${ }^{103}$

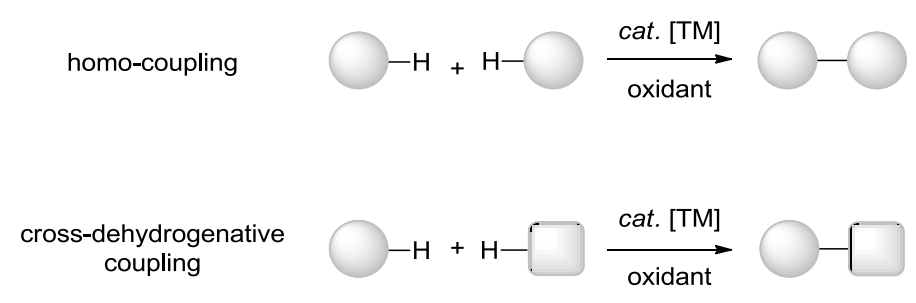

Scheme 1.38: Homo- and cross-dehydrogenative couplings.

This approach was also found useful for the efficient $\mathrm{C}-\mathrm{H} / \mathrm{Het}-\mathrm{H}$ bond functionalizations in an interor intramolecular fashion, thus allowing the one-pot preparation of synthetically and practically

\footnotetext{
102 (a) Moritani, I.; Fujiwara, Y. Tetrahedron Lett. 1967, 8, 1119-1122. (b) Fujiwara, Y.; Moritani, I.; Danno, S.; Asano, R.; Teranishi, S. J. Am. Chem. Soc. 1969, 91, 7166-7169. Reviews: (c) Le Bras, J.; Muzart, J. Chem. Rev. 2011, 111, 1170-1214. (d) Ferreira, E. M.; Zhang, H.; Stolz, B. M. Oxidative Heck-Type Reactions (FujiwaraMoritani Reactions). In The Mizoroki-Heck Reaction (ed.: Oestreich, M.), Wiley: Chichester, 2009, pp. 345382.

${ }^{103}$ (a) Klussmann, M.; Sureshkumar, D. Synthesis 2011, 353-369. (b) Yeung, C. S.; Dong, V. M. Chem. Rev. 2011, 111, 1215-1292.
} 
useful heterocycles, such as substituted isoquinolines, isoquinolones, isocoumarins, $\alpha$-pyrones and 2pyridones. ${ }^{104}$

Further development of the Fujiwara-Moritani reaction ${ }^{105}$ resulted in an elaboration of a number of approaches for oxidative alkenylations catalyzed by various transition metals. ${ }^{102 c-f}$ While the earlier protocols essentially required (super)stoichiometric amounts of peroxides, along with strong acids and/or high reaction temperatures, an important improvement of the oxidative palladium-catalyzed alkenylation has been made by de Vries and van Leeuwen in 2002, ${ }^{106}$ who accomplished selective ortho-olefinations of anilides $\mathbf{3 8}$ at ambient temperature using $n$-butyl acrylate (32e) as a coupling partner (Scheme 1.39).<smiles>[R]C(=O)Nc1cc[R1]cc1</smiles>

38

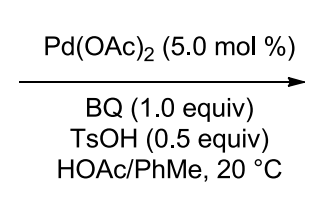

up to $91 \%$<smiles>[R]C(=O)Nc1c[R1]#ccc1/C=C/C(=O)OCC</smiles>

99

Scheme 1.39: Palladium-catalyzed ortho-alkenylations of anilides 38 under mild reaction conditions.

Among other directing groups, $Y u$ recently expanded the substrate scope of this reaction to include aryl urea derivatives. ${ }^{107} \mathrm{Yu}$ also reported on a complementary two-step method for the efficient synthesis of indolines. Beside nitrogen-containing directing groups, he presented in 2013 an oxidative alkenylation of aromatic alkyl ether $\mathbf{1 0 0}$ with weakly coordinating DG in excellent yield, while employing inexpensive MPAAs (76) as the ligands (Scheme 1.40). ${ }^{108}$<smiles>[R]C(OC)C([R])c1cc[R1]cc1</smiles>

100<smiles>CC=COCC</smiles>

32a

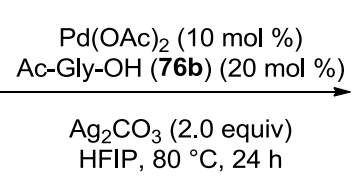

up to $76 \%$

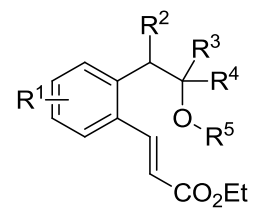

101

Scheme 1.40: Palladium-catalyzed oxidative ortho-alkenylation with alkyl ether directing groups.

In 2007, Satoh and Miura reported on the first rhodium-catalyzed oxidative alkenylation using easily accessible benzoic acid 13b as substrate and acrylates, acryl amides or nitriles as alkenylating reagent

\footnotetext{
104 Reviews: (a) Ackermann, L. Acc. Chem. Res. 2013, 46, DOI:10.1021/ar3002798. (b) Zhu, C.; Wang, R.; Falck, J. R. Chem. Asian J. 2012, 7, 1502-1514. (c) Wencel-Delord, J.; Dröge, T.; Liu, F.; Glorius, F. Chem. Soc. Rev. 2011, 40, 4740-4761. (d) Satoh, T.; M. Miura, M. Synthesis 2010, 3395-3409. (e) Satoh, T.; Ueura, K.; Miura, M. Pure Appl. Chem. 2008, 80, 1127-1134. (f) Nakamura, I., Yamamoto, Y. Chem. Rev. 2004, 104, 21272198. (g) Chiba, S. Chem. Lett. 2012, 41, 1554-1575.

105 Jia, C.; Piao, D.; Oyamada, J.; Lu, W.; Kitamura, T.; Fujiwara, Y. Science 2000, 287, 1992-1995.

${ }^{106}$ Boele, M. D. K.; van Strijdonck, G. P. F.; de Vries, A. H. M.; Kamer, P. C. J.; de Vries, J. G.; van Leeuwen, P. W. N. M. J. Am. Chem. Soc. 2002, 124, 1586-1587.

107 Wang, L.; Liu, S.; Li, Z.; Yu, Y. Org. Lett. 2011, 13, 6137-6139.

108 Li, G.; Leow, D.; Wan, L.; Yu, J.-Q. Angew. Chem. Int. Ed. 2013, 52, 1245-1247.
} 
(Scheme 1.41). ${ }^{109}$ Herein, a rhodacycle intermediate undergoes alkene insertion followed by $\beta$ hydride elimination to form the ortho-monovinylated benzoic acid. After a possible second oxidative alkenylation step (for acrylates 32a), the alkenylation products immediately underwent subsequent intramolecular oxa-Michael-reaction, affording divinylated products 102 along with side-product 103 or isobenzofuran-1(3H)-ones 104 , respectively.

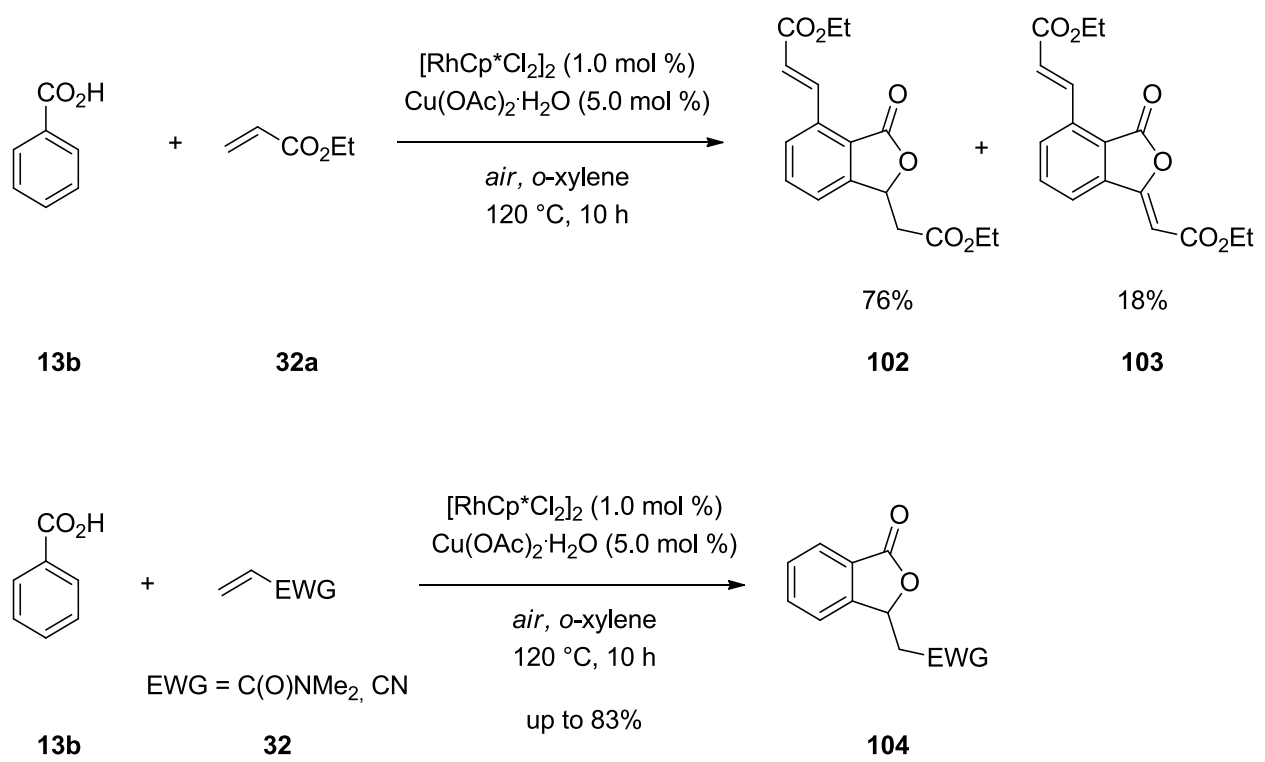

Scheme 1.41: First rhodium-catalyzed oxidative alkenylation by Satoh and Miura.

A similar tandem rhodium-catalyzed oxidative olefination-Michael-addition between benzamides and alkenes with $\mathrm{Ag}_{2} \mathrm{CO}_{3}$ as the oxidant was reported in 2010 by the group of $\mathrm{Li}^{110}$

Not only ethyl acrylates, but a broad range of alkenes could be used. For example, Bergman and Ellman succeeded in the first direct oxidative alkenylation of $O$-methyl oximes 105 with a broad range of alkenes 32, including unactivated ones, employing a highly efficient and selective, yet rather expensive rhodium catalyst (Scheme 1.42). ${ }^{111}$

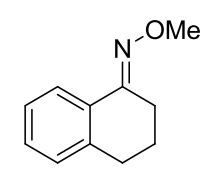

105

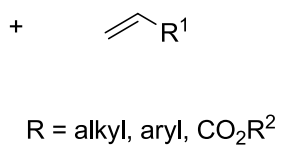

32

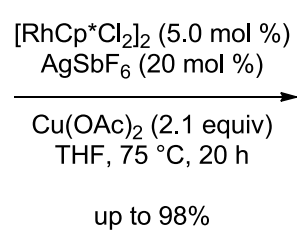

up to $98 \%$

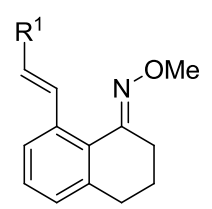

106

Scheme 1.42: Rhodium-catalyzed oxidative alkenylation of $O$-methyl oximes 105 with alkenes 32.

\footnotetext{
${ }^{109}$ Ueura, K.; Satoh, T.; Miura M. J. Org. Chem. 2007, 72, 5362-5367.

${ }^{110}$ Wang, F.; Song, G.; Li, X. Org. Lett. 2010, 12, 5430-5433.

111 Tsai, A. S.; Brasse, M.; Bergman, R. G.; Ellman, J. A. Org. Lett. 2011, 13, 540-542.
} 
Alkenylations of acetophenones and benzamides as substrates under comparable reaction conditions have been reported by Glorius and co-workers in $2010 .{ }^{112}$

In 2001, Milstein discovered the first example of ruthenium-catalyzed oxidative coupling of arenes with olefins under an oxygen atmosphere and harsh reaction-conditions (Scheme 1.43). ${ }^{113}$ According to this protocol, moderate yields of up to $47 \%$ with low site-selectivities were obtained from substituted arenes and Michael acceptors, while the yields even with activated alkenes were rather low.

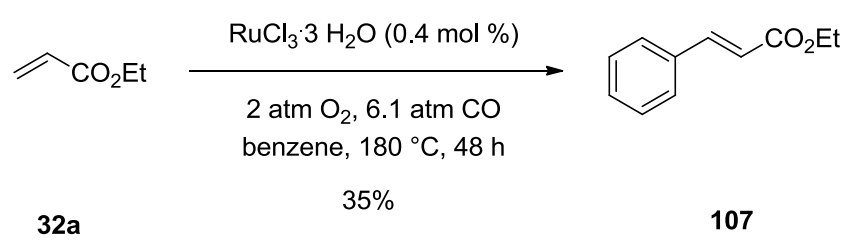

Scheme 1.43: First report on ruthenium-catalyzed oxidative alkenylation by Milstein.

In 2008, Inoue and Oi reported on a ruthenium-catalyzed oxidative homocoupling of arenes bearing nitrogen-containing directing groups in their attempted alkenylation with methallyl acetate. ${ }^{114}$ In this reaction methallyl acetate served as a hydrogen scavenger, and the homocoupled product was released via reductive elimination of a di-cycloruthenated intermediate.

The group of $L i$ reported in 2009 on the ruthenium-catalyzed oxidative homo-coupling of 2phenylpyridines 6 while employing stoichiometric amounts of iron (III) chloride as the oxidant. ${ }^{115}$ Further, Ackermann et. al could isolate the homocoupling-products, such as 109, as the main reaction products (Scheme 1.44)..$^{116}$ These finding have been made during their studies towards carboxylate-assisted ruthenium-catalyzed direct arylations.
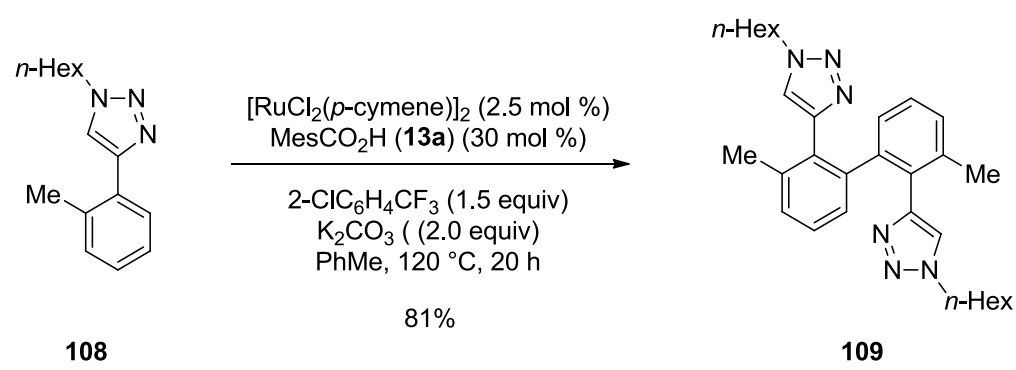

Scheme 1.44: Ruthenium-catalyzed oxidative homo-coupling of phenyltetrazoles (108) reported by Ackermann et al..

\footnotetext{
112 Patureau, F. W.; Besset, T.; Glorius, F. Angew. Chem. Int. Ed. 2010, 49, 1064-1067.

113 (a) Weissman, H.; Song, X.; Milstein, D. J. Am. Chem. Soc. 2001, 123, 337-338. Review: (b) Kozhushkov, S. I.; Ackermann, L. Chem. Sci. 2013, 4, DOI: 10.1039/C2SC21524A.

114 Oi, S.; Sato, H.; Sugawara, S.; Inoue, Y. Org. Lett. 2008, 10, 1823-1826.

${ }^{115}$ Guo, X.; Deng, G.; Li, C.-J. Adv. Synth. Catal. 2009, 351, 2071-2074.

${ }^{116}$ Ackermann, L.; Novák, P.; Vicente, R.; Pirovano, V.; Potukuchi, H. K. Synthesis 2010, 2245-2253.
} 
The researchers presented evidence that $\mathrm{Ar}-\mathrm{X}$, which normally acted as an arylating agent, in this particular case served as an oxidant, thus promoting the homocoupling. The reaction conditions were optimized to provide broad applicability and moderate to good yields for ortho-alkyl-substituted electron-rich substrates. Very recently, a rhodium- as well as a ruthenium-catalyzed oxidative crossdehydrogenative direct arylation have been published by You and co-workers using substrates with nitrogen-containing directing groups and 2-methylthiophenes as the coupling partner. ${ }^{117}$

Revisiting conception of atom-economy and sustainability in organic synthesis, multiple oxidative annulations form the basis for an intelligent approach for diverse heterocycle syntheses. For example, a number of synthetically valuable protocols have been discovered on the basis of the important Larock-type heterocyle synthesis (Scheme 1.45). ${ }^{118}$

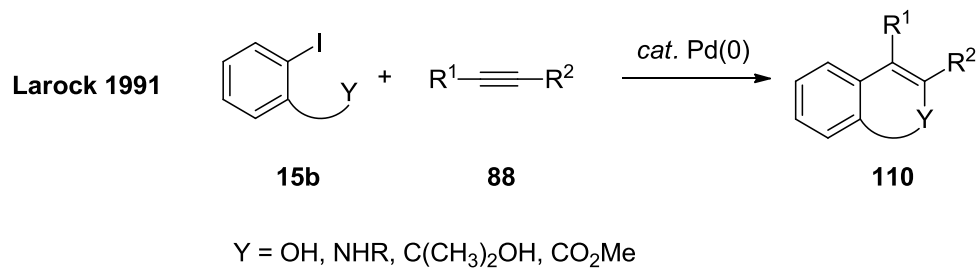

Scheme 1.45: Intermolecular palladium-catalyzed annulation with alkynes 88 as reported by Larock.

Further development demanded to bypass the well-known limitations of this methodology, such as the prefunctionalization of starting materials $\mathbf{1 5 b}$. Thus, a one-pot combination of transition metalcatalyzed $\mathrm{C}-\mathrm{H}$ bond metalation and annulation steps has become a challenging research target today. Most procedures have been performed with rhodium catalysts and $\mathrm{Cu}(\mathrm{OAc})_{2} \cdot \mathrm{H}_{2} \mathrm{O}$ as the oxidant. ${ }^{119}$ For example, Satoh and Miura have pioneered several practical applications of this synthetic strategy (Scheme 1.46). ${ }^{120}$

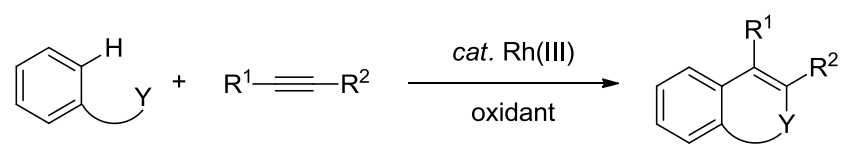<smiles>[R]c1oc(=O)c2ccccc2c1[R]</smiles>

Isocoumarins (Satoh \& Miura)

2007<smiles>[R]c1c([R])n(C)c2ccccc12</smiles>

Indoles (Fagnou)

2008<smiles>[R]c1nc([Tl])c2ccccc2c1[R]</smiles>

Isoquinolines Jones, Fagnou) Fangou, Rovis,

2009<smiles>[R]c1cc([R1])c([R])[nH]1</smiles>

(Fagnou, Glorius)

2010

2010<smiles>[R]c1ccc(=O)n([R])c1[R]</smiles><smiles>[R]C1=C([R])N([R])S(=O)(=O)c2ccccc21</smiles>

2-Pyridones

(Li, Rovis)

2010
Sultams (Cramer)

2012

Scheme 1.46: Selected examples of oxidative rhodium-catalyzed annulations.

\footnotetext{
117 Dong, J.; Long, Z.; Song, F.; Wu, N.; Guo, Q.; Lan, J.; You, J. Angew. Chem. Int. Ed. 2013, 52, 580-584.

118 (a) Larock, R. C.; Yum, E. K. J. Am. Chem. Soc. 1991, 113, 6689-6690; (b) Larock, R. C. Top. Organomet. Chem. 2005, 14, 147-182.

${ }^{119}$ Song, G.; Wang, F.; Li, X. Chem. Soc. Rev. 2012, 41, 3651-3678.

120 Satoh, T.; Miura, M. Chem. Eur. J. 2010, 16, 11212-11223, and references cited therein.
} 
A general reaction mechanism is presented in Scheme 1.47 for the formation of isocoumarins 114 via rhodium-catalyzed oxidative annulation.

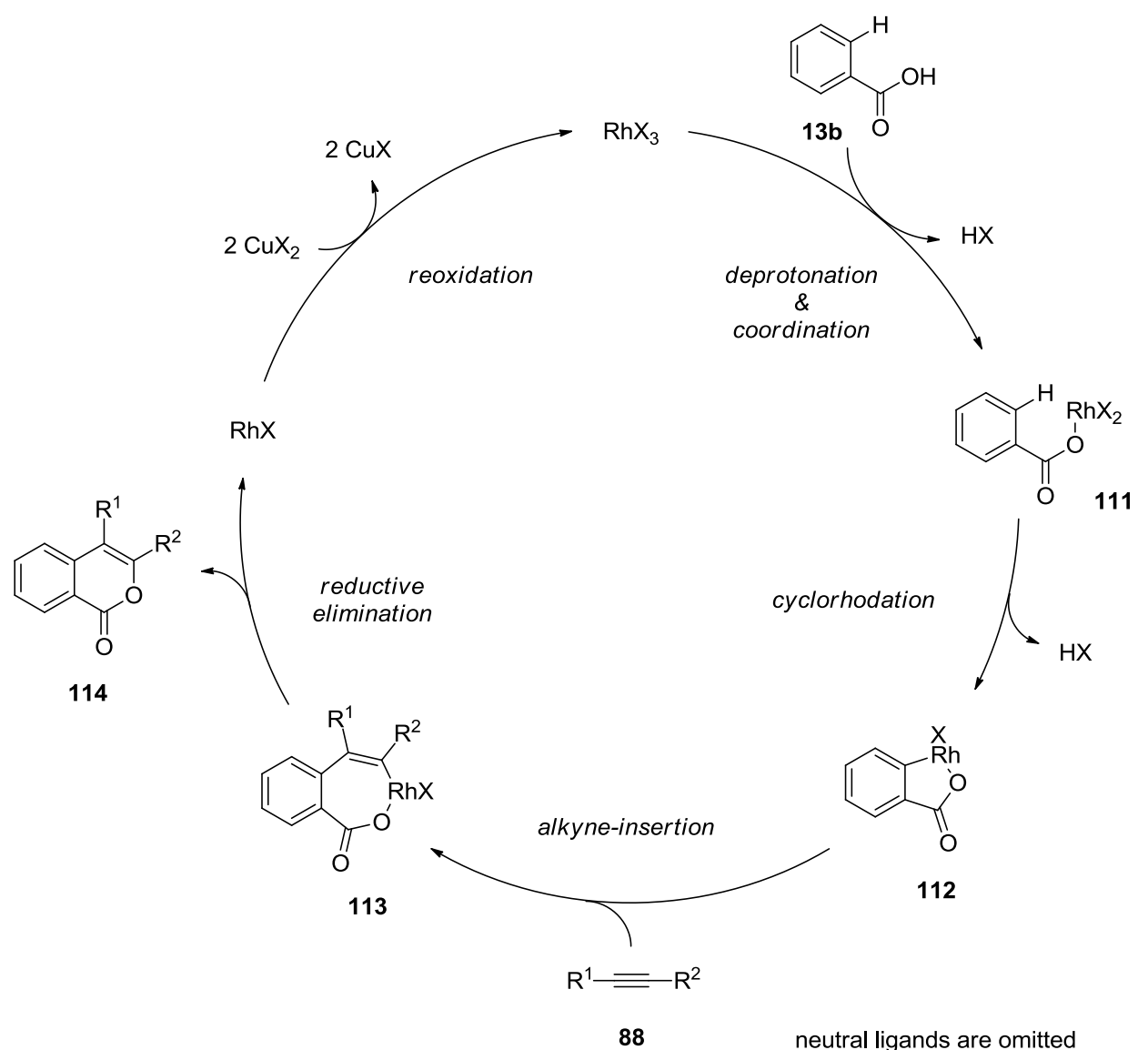

Scheme 1.47: General catalytic cycle for rhodium-catalyzed annulation for the synthesis of isocoumarins.

The catalytic-cycle is initiated via the coordination of the rhodium (III) catalyst to the benzoate to form intermediate 111. After the subsequent formation of intermediate $\mathbf{1 1 2}$ via cyclorhodation, coordination of the alkyne moiety followed by alkyne insertion gives intermediate 113. Reductive elimination releases the isocoumarin $\mathbf{1 1 4}$ and forms a rhodium (I)-species, which undergoes reoxidation by the copper (II) source. 


\section{Objectives}

Efficient, chemo- and site-selective $\mathrm{C}-\mathrm{C}$ bond formations are one of the major instruments in synthetic organic chemistry. Ongoing researches by the group of Prof. Ackermann and others showed that transition metal-catalyzed direct $\mathrm{C}-\mathrm{H}$ bond functionalization is a powerful tool to develop sustainable pathways to meet these challenges. Especially ruthenium catalysts showed remarkable results within the field of direct arylation of (hetero)arenes. Particularly, in the presence of carboxylic acids as cocatalytic additives direct arylations occurred in high yields and in a site-selective fashion. ${ }^{22}$

Recently, the unprecedented ruthenium-catalyzed alkylation of substituted arenes 6 via $\mathrm{C}-\mathrm{H}$ bond functionalizations applying the challenging unactivated primary alkyl bromides $\mathbf{4 2 a}$ as electrophiles proved to be viable, in spite of only a small substrate scope had been examined (Scheme 2.1). ${ }^{121}$ However, secondary alkyl halides provided only unsatisfactory results under similar reaction conditions.

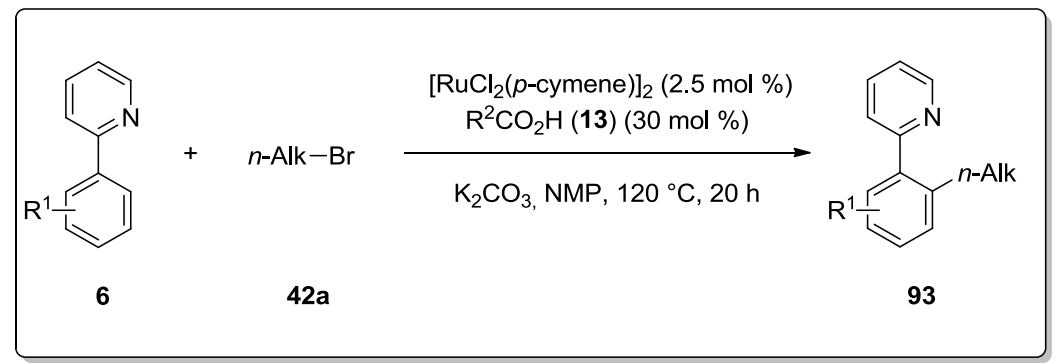

Scheme 2.1: Ruthenium-catalyzed direct ortho-alkylations with unactivated primary alkyl halides $\mathbf{4 2}$.

Hence, a major focus in the presented work was set on the extension of the substrate scope and the development of first generally applicable ruthenium-catalyzed direct alkylations of arenes $\mathbf{4}$ with secondary alkyl halides $\mathbf{4 2 b}$ via $\mathrm{C}-\mathrm{H}$ bond cleavages under non-acidic reaction conditions (Scheme 2.2).

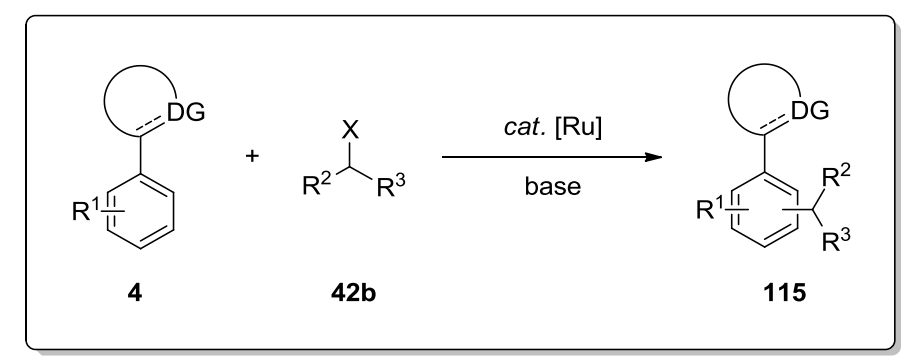

Scheme 2.2: Ruthenium-catalyzed direct alkylation with secondary alkyl halides $\mathbf{4 2 b}$ under basic reaction conditions.

\footnotetext{
${ }^{121}$ Ackermann, L.; Novák, P.; Vicente, R.; Hofmann, N. Angew. Chem. Int. Ed. 2009, 48, 6045-6048.
} 
In order to elucidate the working mode of this in-situ generated catalytic system for alkylation reactions in details, preparation of the corresponding intermediate cycloruthenated complexes and experiments with isotopically labeled starting materials were envisioned, which will provide insight into the catalytic cycle of direct alkylations.

Besides the functionalization of arenes with alkyl or aryl moieties, the sustainable heterocyclesynthesis via $\mathrm{C}-\mathrm{H}$ bond functionalizations still remains an under-explored field of research. Thus, several research groups around the world have exploited oxidative rhodium-catalyzed annulation reactions with alkynes to prepare a broad range of heteroarenes in an atom- and step-economic manner.

Since less expensive ruthenium complexes are known to enable the challenging direct double $\mathrm{C}-\mathrm{H}$ / $\mathrm{C}-\mathrm{H}$ bond arylations and alkenylations of arenes with ample scope, an additional part of this Ph.D. thesis was devoted to the development of unprecedented ruthenium-catalyzed annulation reactions via $\mathrm{C}-\mathrm{H} / \mathrm{N}-\mathrm{H}$ bond functionalizations for the development of new sustainable and economical synthetic approaches to bioactive heterocycles 117 (Scheme 2.3).

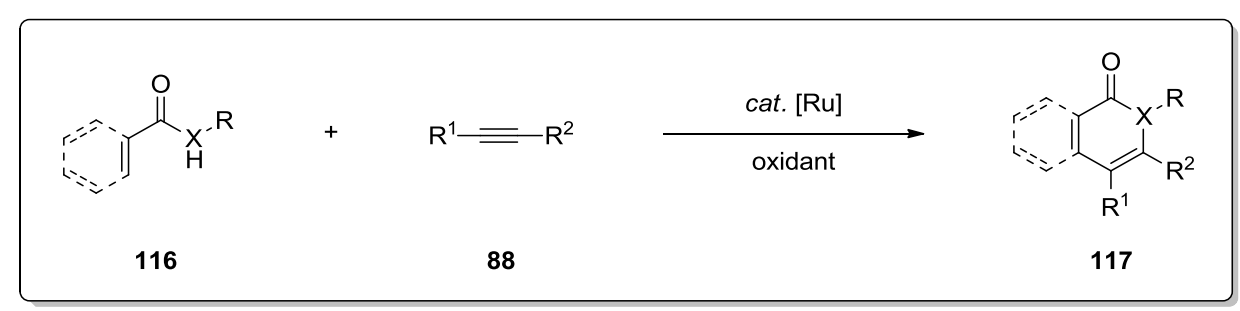

Scheme 2.3: Ruthenium-catalyzed oxidative annulation via $\mathrm{C}-\mathrm{H} / \mathrm{N}-\mathrm{H}$ bond functionalizations for a sustainable heterocycle synthesis.

Furthermore, examination of this new ruthenium-catalyzed reaction towards extension of its substrate scope and detailed mechanistic investigations, including intra- and intermolecular competition experiments, were planned in order to get insight into the catalysts' mode of action. 


\section{Results and Discussion - Ruthenium-Catalyzed Direct Alkylation Reactions}

\subsection{Ruthenium-Catalyzed Direct ortho-Alkylation}

Alkyl chains not only dramatically influence the lipophilicity of practically interesting organic compounds, but also affect the penetration rate of biologically active molecules through cell membranes. ${ }^{122}$ Due to this reasons, the site-selective $\mathrm{C}-\mathrm{C}$ bond formation between alkyl and aryl groups is an important goal in synthetic organic chemistry. Complementary to traditional crosscoupling chemistry, direct $\mathrm{C}-\mathrm{H}$ bond functionalizations are getting more and more into the focus of researcher's activity, however, still remain underdeveloped. The avoidance of a prefunctionalization of starting materials, minimized waste production and fewer side reactions make these transition metal-catalyzed reactions cost-efficient as well as step- and atom-economical.

Since the research group of Prof. Ackermann made a lot of progress within the ruthenium-catalyzed direct arylation under carboxylate-assistence (see chapter 1.1), we became attracted by challenging direct alkylations.

Until 2009, sparse reports on direct alkylations with unactivated alkyl halides as electrophiles prompted us to start our own investigations towards this direction keeping the carboxylate assistance effect in mind. An intensive screening for optimized reaction conditions by Novák, Vicente and Hofmann led to the first results on ortho-selective alkylation of 2-arylpyridines 6 and -pyrazoles 87 under relatively mild reaction conditions (Scheme 3.1). ${ }^{121}$

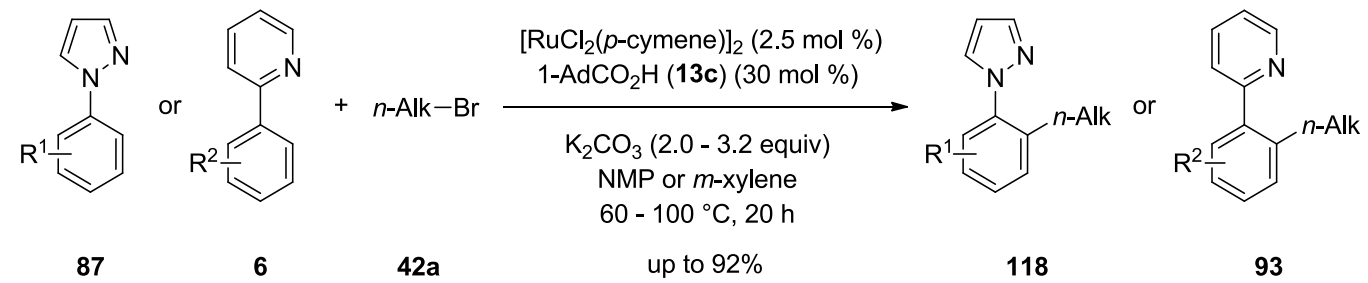

Scheme 3.1: Ruthenium-catalyzed direct alkylation of 2-arylpyridines 6 and -pyrazoles 87 according to Ackermann et al.

Detailed optimization studies disclosed that sterically demanding carboxylic acids, such as 1adamantyl carboxylic acid (13c), increased the productivity of the reaction, while NHC or phosphine ligands furnished only poor isolated yields.

122 Lipinski, C. A. Drug Discov. Today Technol. 2004, 1, 337-341. 
Mechanistic studies excluded an a priori likely elimination/hydroarylation mechanism. Thus, simple alkenes did not form the alkylated products 93 and 118 under otherwise identical reaction conditions, and also alkylations with neopentyl bromide could be accomplished. The tolerance towards ester functionalities in the electrophilic reaction partner under these reaction conditions was observed as well. ${ }^{121}$

The efficiency of this method for the benzylation of 2-aryloxazolines, -pyrazoles and -pyridines using benzyl chlorides 119 as inexpensive electrophiles was demonstrated by Petr Novák who obtained the desired benzylated products 120 in high yields (Scheme 3.2). ${ }^{123}$<smiles>[R1]1cccc1C1=NCCCC1</smiles>

4<smiles>[R]c1ccc(CCl)cc1</smiles>

119

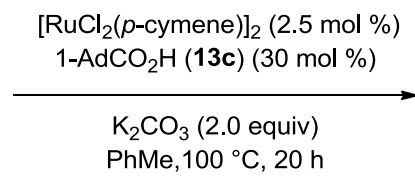

up to $91 \%$

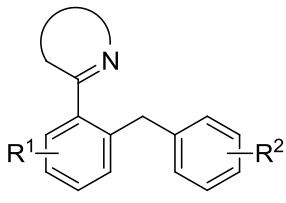

120

Scheme 3.2: Ruthenium-catalyzed direct benzylation by Novák.

Our preliminary studies showed that a variety of ketimines 121 could be monoalkylated under slightly modified reaction conditions as well. Subsequent one-pot reduction under mild reaction conditions yielded the corresponding secondary amines 122 as the product (Scheme 3.3). ${ }^{121,124,125}$

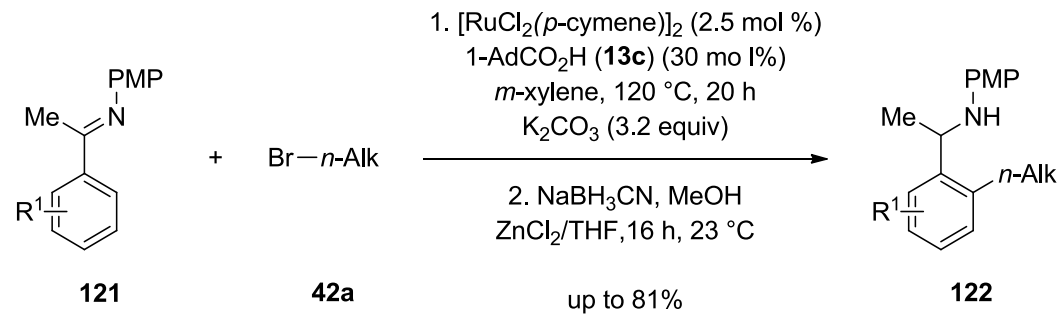

Scheme 3.3: Direct ruthenium-catalyzed ortho-alkylation of ketimines 121 and one-pot reduction.

\subsubsection{Synthesis of Starting Materials}

The standard substrates, which were not commercially available, were synthesized according to a published literature procedure without further optimization of the reaction conditions. ${ }^{126172}$ For the synthesis of 2-arylpyridines 6, a Kumada-Corriu cross-coupling approach was used. Various aryl

${ }^{123}$ Ackermann, L.; Novák, P. Org. Lett. 2009, 11, 4966-4969.

124 Ackermann, L.; Hofmann, N.; Vicente, R. Org. Lett. 2011, 13, 1875-1877.

125 Hofmann, N. Palladiumkatalysierte Intramolekulare $\alpha$-Arylierungen und Rutheniumkatalysierte Intermolekulare Direkte Alkylierungen. Diplomathesis, Universität Göttingen, 2009.

${ }^{126}$ Böhm, V. P. W.; Weskamp, T.; Gstöttmayr, C. W. K.; Herrmann, W. A. Angew. Chem. Int. Ed. 2000, 39, 16021604. 
bromides 15 were converted into the Grignard compounds 123, which immediately were used for the nickel-catalyzed coupling with 2-halopyridines 124 . As the ligand, $\mathrm{N}$-heterocyclic carbene (NHC) HIPrCl (61) was employed (Table 3.1).

Table 3.1: Kumada-Corriu cross-coupling for the synthesis of differently substituted 2-phenylpyridines 6.

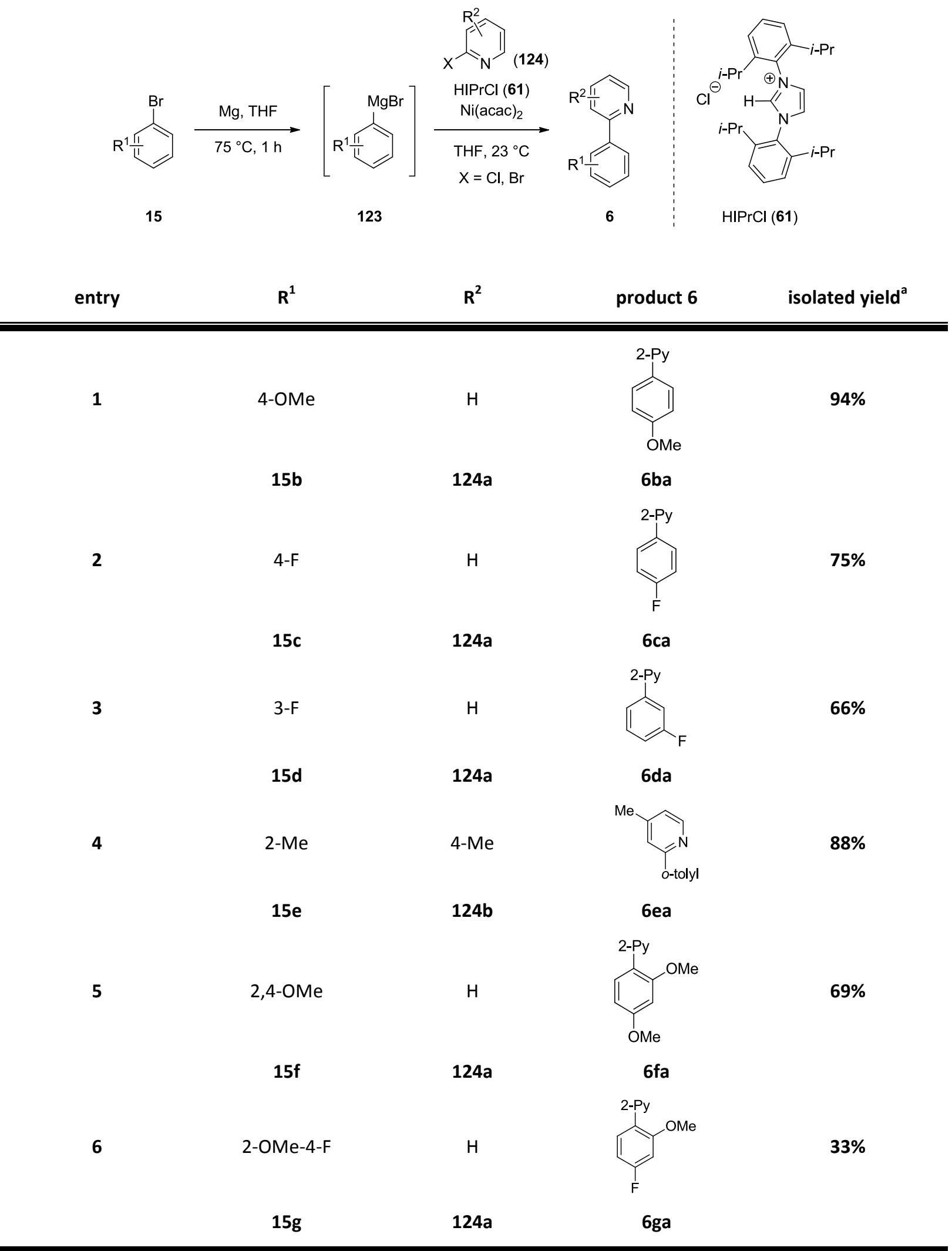




\begin{tabular}{|c|c|c|c|c|}
\hline entry & $\mathbf{R}^{1}$ & $\mathbf{R}^{2}$ & product 6 & isolated yield $^{\mathrm{a}}$ \\
\hline \multirow[t]{2}{*}{7} & 3-NMe ${ }_{2}$ & $\mathrm{H}$ & & $74 \%$ \\
\hline & $15 \mathrm{~h}$ & $124 a$ & 6 ha & \\
\hline \multirow[t]{2}{*}{8} & $4-t-B u$ & $\mathrm{H}$ & & $75 \%$ \\
\hline & $15 i$ & $124 a$ & $6 i a$ & \\
\hline \multirow[t]{2}{*}{9} & $2,3,4,5,6-D$ & $\mathrm{H}$ & & $64 \%$ \\
\hline & {$\left[D_{5}\right]-15 a$} & $124 a$ & {$\left[D_{5}\right]-6 a a$} & \\
\hline
\end{tabular}

${ }^{\text {a }}$ Reaction conditions: bromoarene 15 (1.67 equiv), Mg turnings ( 1.73 equiv), anhydrous THF $(2.5 \mathrm{M}), 75^{\circ} \mathrm{C}$ for $1 \mathrm{~h}$ then $\mathrm{Ni}(\mathrm{acac})_{2}(3.0 \mathrm{~mol} \%), \mathrm{HIPrCl}(61)(3.0 \mathrm{~mol} \%)$, 2-halopyridine 124 (1.0 equiv), anhydrous THF $(1.5 \mathrm{M})$ at $23^{\circ} \mathrm{C}$.

With the exception of phenylpyridine 6ga, the yields for electron-poor as well as for electron-rich aryl bromides 15 were good to very good.

Because of possible competitive side-reactions upon using Grignard compounds, the syntheses of starting materials with acetyl substituents were accomplished via palladium-catalyzed SuzukiMiyaura cross-coupling of easily accessible phenyl boronic acid (52e) with the appropriate 2-bromo$n$-acetylpyridine 124. In several particular cases indicated below, a reduction with inexpensive sodium borohydride followed by Williamson methylation with methyl iodide was furthermore performed (Scheme 3.4).<smiles>CC(=O)c1ccc(Br)nc1</smiles>

$52 e$

$124 z$

2e
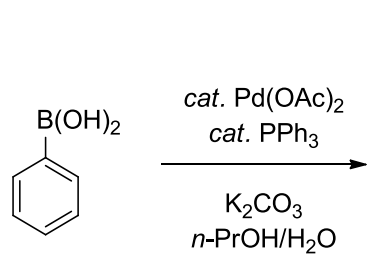

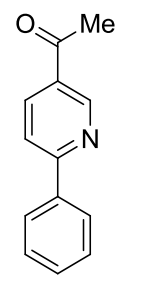

6bb

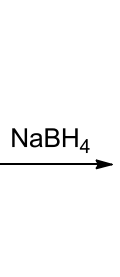

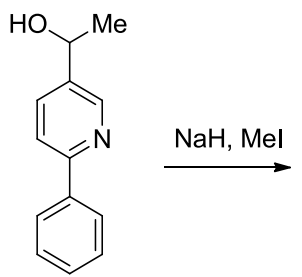

25b

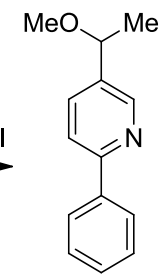

$126 b$

Scheme 3.4: Suzuki-Miyaura cross-coupling for the synthesis of acetyl-substituted 2-phenylpyridines $6 \mathbf{b b}$.

Ketimines 122, which studied earlier for direct ruthenium-catalyzed alkylation, ${ }^{121,124,125}$ were synthesized from acetophenone derivatives 84 and anisidin (127) through dehydration with $4 \AA$ molecular sieves. The final purification has been achieved either by recrystallization or column chromatography on silica gel that was deactivated with triethylamine. 


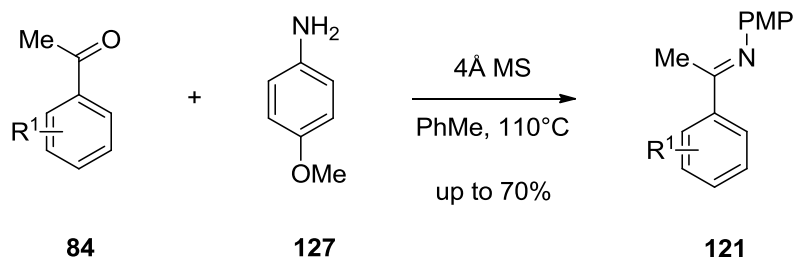

Scheme 3.5: Synthesis of ketimines 121.

\subsubsection{Direct ortho-Alkylation: Scope and Limitations}

Unprecedented ruthenium-catalyzed ortho-alkylations via $\mathrm{C}-\mathrm{H}$ bond activation has preliminary been examined by Ackermann, Novák, Vicente and Hofmann in 2009. ${ }^{121}$ An intensive screening for optimized reaction conditions highlighted a combination of the easy accessible $\left[\mathrm{RuCl}_{2}[p \text {-cymene) }]_{2}\right.$ as the catalyst and 1-adamantyl carboxylic acid (13c) as the additive to be most efficient. Reactions in the presence of stoichiometric amounts of inexpensive potassium carbonate as the base in polar NMP as solvent furnished alkylated arylpyridines $\mathbf{9 3}$ and -pyrazoles 118 in up to $92 \%$ isolated yield. Alkyl chains ranging from $n$-butyl to $n$-tetradecyl, including neopentyl, could be ortho-incorporated 2phenylpyridines (6). Beside alkyl bromides 42a, the reactivity of alkyl iodides and chlorides have been tested as well, but only more expensive $n$-hexyl iodide proved to be as reactive as the corresponding bromide. $^{121}$

Commercially available NMP containes impurities of its synthetic precursor, $\gamma$-butyrolactone (128). The latter (or carboxylate resulting from its hydrolysis) acted as a soluble carboxylate source that enhanced the rate of direct arylations in the same extent as did KOAc. ${ }^{127}$ To disprove or to support the same effect in direct alkylation reactions, the latter were reproduced in non-polar solvent $\mathrm{m}$ xylene with inter alia NMP as the additive. The results are summarized in Table 3.1.

Table 3.2: Studies for alternative additives.

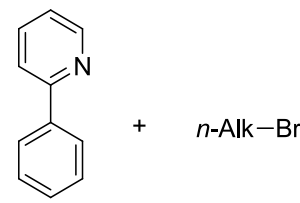

6

42a

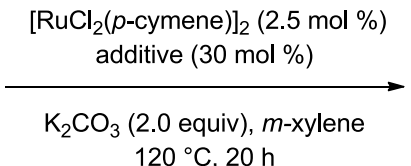

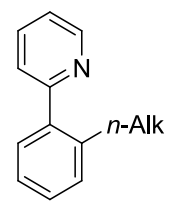

93

127 Ouellet, S. G.; Roy, A.; Molinaro, C.; Angelaud, R.; Marcoux, J.-F.; O'Shea, P. D.; Davies, I. W. J. Org. Chem. 2011, 76, 1436-1439. 


\begin{tabular}{|c|c|c|c|c|}
\hline entry & bromide $42 a$ & additive (equiv) & product 93 & isolated yield $^{a}$ \\
\hline \multirow[t]{2}{*}{1} & $n$-Oct-Br & 1- $\mathrm{AdCO}_{2} \mathrm{H}(0.3)$ & -Oct & $66 \%$ \\
\hline & 42aa & $13 c$ & 93aa & \\
\hline \multirow[t]{2}{*}{2} & $n$-Oct-Br & $\gamma$-butyrolacton (0.3) & & $(21)^{b}$ \\
\hline & 42aa & 128 & 93aa & \\
\hline 3 & $n$-Hex-Br & $\begin{array}{c}\text { 1- } \mathrm{AdCO}_{2} \mathrm{H}(0.3)+ \\
\mathrm{Nal}(1.5)\end{array}$ & & -- \\
\hline \multirow{3}{*}{4} & $42 a b$ & $13 c$ & 93ab & \\
\hline & $n$-Hex-Br & $\begin{array}{c}1-\mathrm{AdCO}_{2} \mathrm{H}(0.3)+ \\
\mathrm{KPF}_{6}(0.3)\end{array}$ & & -- \\
\hline & $42 a b$ & $13 c$ & 93ab & \\
\hline
\end{tabular}

${ }^{\text {a }}$ Reaction conditions: 2-phenylpyridine (6aa) $(0.5 \mathrm{mmol})$, alkyl bromide $42 \mathrm{a}(1.5 \mathrm{mmol}),\left[\mathrm{RuCl}_{2}(p \text {-cymene }]_{2}(2.5 \mathrm{~mol} \%)\right.$, additive $(30 \mathrm{~mol} \%), \mathrm{K}_{2} \mathrm{CO}_{3}(1.0 \mathrm{mmol}), \mathrm{m}$-xylene $(2.0 \mathrm{~mL}), 120^{\circ} \mathrm{C}, 20 \mathrm{~h}$, yield of isolated product;

${ }^{\mathrm{b}}$ conversion determined by GC-MS.

The alkylation in $m$-xylene instead of NMP as the solvent under otherwise identical reaction conditions afforded 93aa in $66 \%$ isolated yield (entry 1 ) which is comparable to the previously published yield of $80 \%$. This excludes a decisive role of NMP, or of its impurities, for the success of the reaction. Moreover, entry 2 obviously demonstrates that even pure $\gamma$-butyrolactone (128) as additive is not competent in $m$-xylene. Addition of sodium iodide (entry 3 ) as well as of cocatalytic amounts of potassium hexafluorophosphate (entry 3 ) completely shut down the catalytical activity of the ruthenium complex in spite of an expected acceleration due to a possible in situ Finkelstein-type reaction of the alkyl bromide (42a) or the formation of a more electrophilic, cationic ruthenium catalyst. ${ }^{128}$

To prove the ortho-selectivity of the ruthenium-catalyzed direct alkylation with primary alkyl bromides, detailed 2D-NMR studies were conducted side by side with X-ray diffraction analysis of 2(2-octylpheny)pyridinium oxalate (129) (Figure 3.1).

\footnotetext{
${ }^{128}$ Ackermann, L.; Wang, L.; Wolfram R.; Lygin, A.V. Org. Lett. 2012, 14, 728-731.
} 

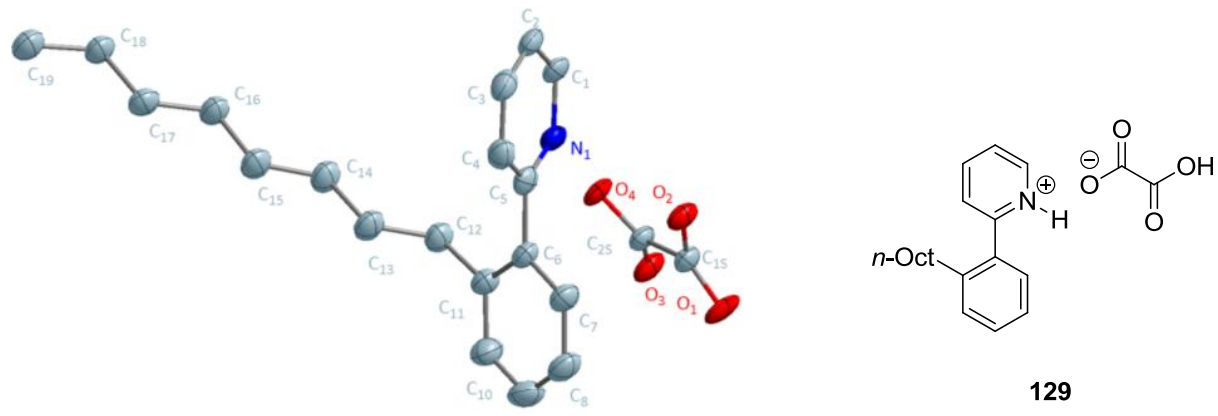

Figure 3.1: ORTEP plots (50\% probability thermal ellipsoids) of 2(2-octylpheny)pyridinium oxalate (129) in the crystal. All hydrogen atoms have been omitted for clarity. Numbering does not correspond to the IUPAC rules.

To illustrate the versatility of this new method for the regioselective alkylation of arenes, the substrate scope was tested (table 3.3). Electron-rich, electron-deficient as well as sterically demanding substrates including amino- or carbonyl-substituted 2-phenylpyridines 6 were thus examined.

Table 3.3: Scope of the ruthenium-catalyzed direct alkylation of substituted 2-phenylpyridines 6 .

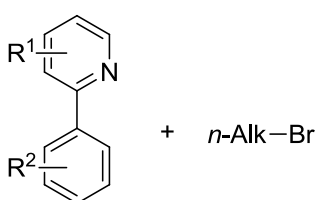

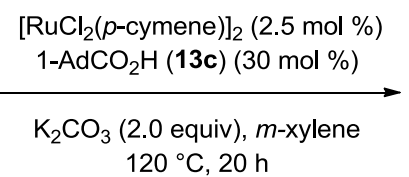
$120^{\circ} \mathrm{C}, 20 \mathrm{~h}$

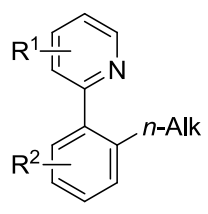

93

\section{entry}

substrate 6

bromide 42a

product 93

isolated yield $^{\mathrm{a}}$

1<smiles>COc1ccc(Br)cc1</smiles>

$n-\mathrm{Hex}-\mathrm{Br}$

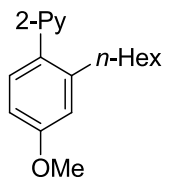

$53 \%^{\mathrm{b}}$

$[48 \%]^{c}$

$6 \mathrm{ba}$

42ab

93bb

2<smiles>COc1ccc([18O])c(OC)c1</smiles>

$n-\mathrm{Hex}-\mathrm{Br}$

\section{$6 f a$}<smiles>Fc1cc(Br)cc(F)c1F</smiles>

$n$-Oct-Br<smiles>COc1c(Br)cc(F)c(F)c1OC</smiles>

93ja
$87 \%$ 


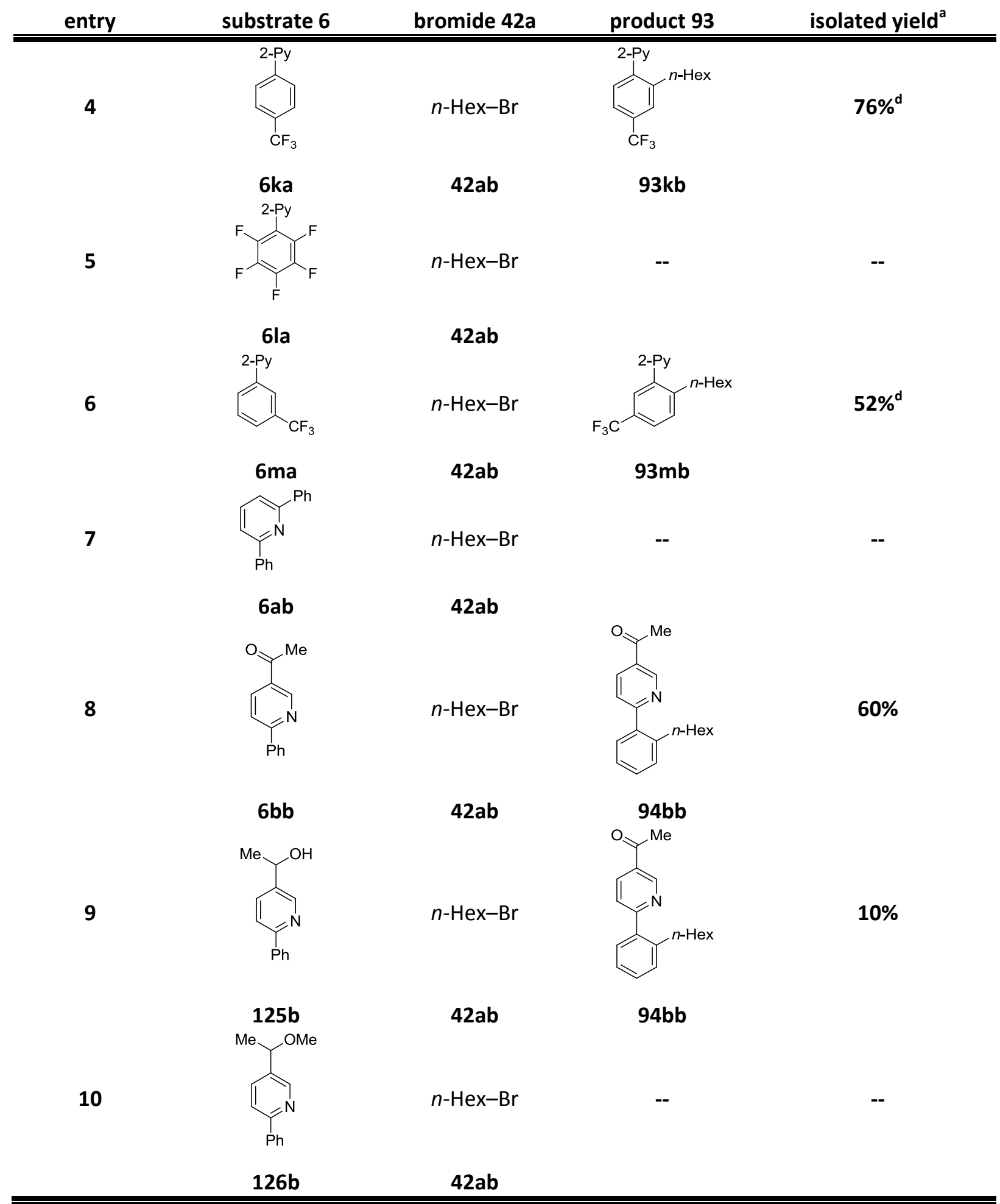

${ }^{\mathrm{a}}$ Reaction conditions: 6 (0.5 mmol), 42a (1.5 mmol), $\left[\mathrm{RuCl}_{2}(p \text {-cymene) }]_{2}(2.5 \mathrm{~mol} \%), 1-\mathrm{AdCO}_{2} \mathrm{H}(13 \mathrm{c})(30 \mathrm{~mol} \%), \mathrm{K}_{2} \mathrm{CO}_{3}\right.$ $(1.0 \mathrm{mmol}), \mathrm{m}$-xylene $(2.0 \mathrm{~mL}), 120{ }^{\circ} \mathrm{C}, 20 \mathrm{~h}$, yield of isolated product; ${ }^{\mathrm{b}}$ in NMP $(2.0 \mathrm{~mL}) ;{ }^{\mathrm{c}} \mathrm{MesCO}_{2} \mathrm{H}(13 \mathrm{a})(30 \mathrm{~mol} \%)$ as the additive in NMP $(2.0 \mathrm{~mL}){ }^{\mathrm{d}}$ at $100^{\circ} \mathrm{C}$.

In accordance with our previously reported results, ${ }^{121}$ electron-donating groups, such as methyl or methoxy groups, afforded the desired product 93 in moderate yields (entry 1). A further increase of the electron density on the aromatic moiety leads to complete loss of reactivity (entry 2). In contrast, substrates bearing electron-withdrawing substituents furnished high yields of up to $87 \%$ of the 
desired product (entries 3 and 4). Not surprisingly, pentafluorinated phenylpyridine 6la showed no reactivity (entry 5), since this would require a challenging C-F bond cleavage, which is a scarce reaction in ruthenium catalysis. ${ }^{129}$ Alkylation of trifluoromethylpyridine $(6 \mathrm{ma}$, entry 6$)$ delivered the product $93 \mathrm{mb}$ in moderate yield, but with excellent site-selectivity. The alkylation proceeded at the less sterically hindered position, i.e. para to the $\mathrm{CF}_{3}$ substituent.

An attempted examination of the influence of the pyridine substituents demonstrated that the second ortho-phenyl substituent in 2,6-diphenylpyridine (6ad) prevented the direct alkylation (entry 7), probably due to steric interactions, which can impede the formation of intermediate ruthenacycles of the type $\mathbf{1 4}$ or $\mathbf{1 6}$ (Scheme 1.7). However, the electron-withdrawing acetyl moiety on the pyridine ring in 3-acetyl-6-phenylpyridine (6bb) afforded the desired product $94 \mathbf{b b}$ in $60 \%$

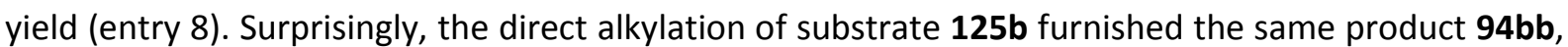
albeit in poor yield (entry 9), while the corresponding ether 126b showed no conversion at all (entry 10). Hence, the ruthenium complex catalyzed two separate reactions, that is (i) the alcohol oxidation to the acetyl derivative and (ii) the $\mathrm{C}-\mathrm{H}$ alkylation. A competition experiment between substrates $126 \mathrm{~b}$ and $\mathbf{6 b a}$ indicated no product formation (Scheme 3.6), which can be rationalized by substrate $126 \mathrm{~b}$ inhibiting the reaction.

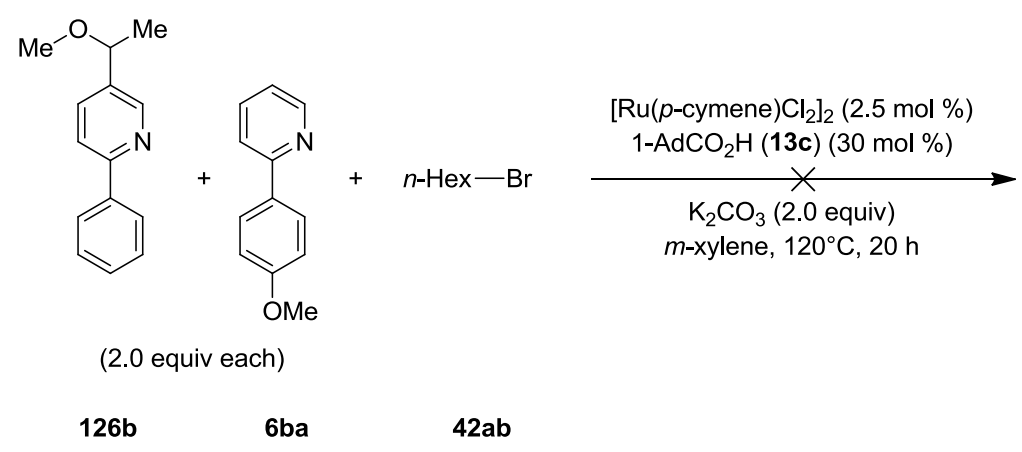

Scheme 3.6: Competition experiment between starting materials $126 \mathrm{~b}$ and $\mathbf{6 b a}$.

The same result was obtained upon attempted alkylation of guanidine-type substrates 127 . The reactions afforded no alkylated products (Scheme 3.7), probably because of the formation of a rather stable ruthenium complex prior to $\mathrm{C}-\mathrm{H}$ bond functionalization.

\footnotetext{
${ }^{129}$ (a) Whittlesey, M. K.; Perutz, R. N.; Greener, B.; Moore, M. H. Chem. Commun. 1997, 187-188. (b) Kirkham, M. S.; Mahon, M. F.; Whittlesey, M. K. Chem. Commun. 2001, 813-814. Review: (c) Clot, E.; Eisenstein, O.; Jasim, N.; Macgregor, S. A.; McGrady, J. E.; R. Perutz, N. Acc. Chem. Res. 2011, 44, 333-348.
} 


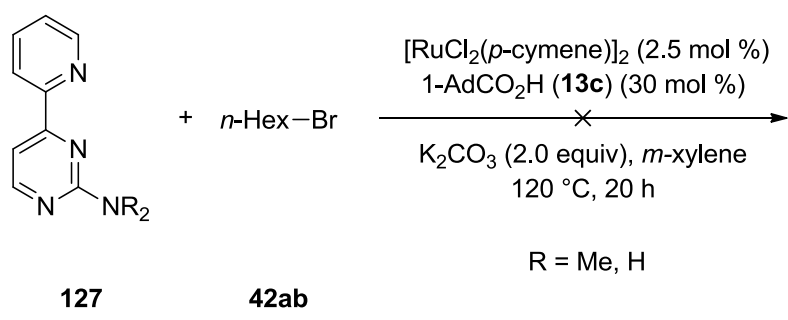

Scheme 3.7: Attempted direct alkylation of nitrogen-rich substrates 127.

To test whether a free $\mathrm{N}-\mathrm{H}$-functionality is tolerated by this reaction, the chemical behaviour of substrate 128 was tested under the alkylating reaction conditions (Scheme 3.8). The alkylation proceeded with low conversion, funishing a mixture of two products formed in almost the same isolated yield. The substitution pattern in $\mathbf{1 2 9}$ has been determined via careful 2D-NMR analysis. Thus, compound $\mathbf{1 2 9}$ resulted from the desired direct $\mathrm{C}-\mathrm{H}$ bond alkylation. The site-selective outcome of the alkylation product $\mathbf{1 2 9}$ might arise from the concerted action of the directing group and the higher acidity in $\alpha$-position to the nitrogen atom position of the pyrrole moiety. Pyrrole $\mathbf{1 3 0}$ was a product of a $\mathrm{N}-\mathrm{H}$ alkylation probably via nucleophilic substitution on hexyl bromide by the deprotonated substrate $128 .{ }^{130}$

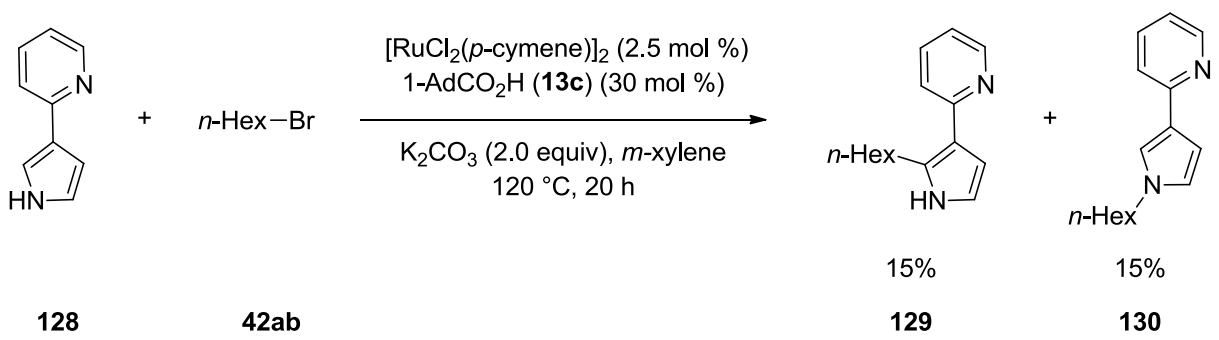

Scheme 3.8: Direct alkylation of $(N-H)$-free pyrrolopyridine (128).

In our previous studies on the direct alkylation of ketimines 122 , the possibility of replacing cocatalytic amounts of 1-adamantyl carboxylic acid (13c) with overstoichiometric quantities of inexpensive ${ }^{131}$ potassium acetate was demonstrated. ${ }^{125}$ Herein, this improvement was also tested for the alkylation of various 2-phenylpyridines 6 (Table 3.4).

First of all, the competence of potassium pivalate in co-catalytic amounts as additive in the presence of additional 2 equivalents of $\mathrm{K}_{2} \mathrm{CO}_{3}$ was examined (entry $1,51 \%$ yield). In spite of the somewhat lower yield, the level of efficiency was about the same as with 1-adamantyl carboxylic acid (13c) (Table 3.2, entry 1,66\% yield). Changing the additive to KOAc in the same cocatalytic amount, but without additional base, only a small amount of the alkylated product 93a could be isolated (entry 2 ).

\footnotetext{
${ }^{130}$ Lea, Z.-G.; Chen, Z.-C.; Hu, Y.; Zheng, Q.-G. Synthesis 2004, 1951-1954.

131 Price: Sigma-Aldrich.com, 12.01.13: KOAc, $1 \mathrm{~kg} \equiv 58.30 € ; 1-\mathrm{AdCO}_{2} \mathrm{H}, 100 \mathrm{~g} \equiv 160.00 €$.
} 
However, when applying 6.4 equivalents of KOAc, high conversion was detected and the yield drastically rose up to $76 \%$ (entry 3 ). The same almost held true for (trifluorophenyl)pyridine $\mathbf{6 j a}$ (entries 4 and 5), while for electron-rich substrates $60 \mathrm{a}$ and 6 ba the yield ranged from poor to moderate when using KOAc in overstoichiometric amounts (entries 6 and 7; see also Table 3.3, entry 1$)$.

Table 3.4: KOAc as the additive.

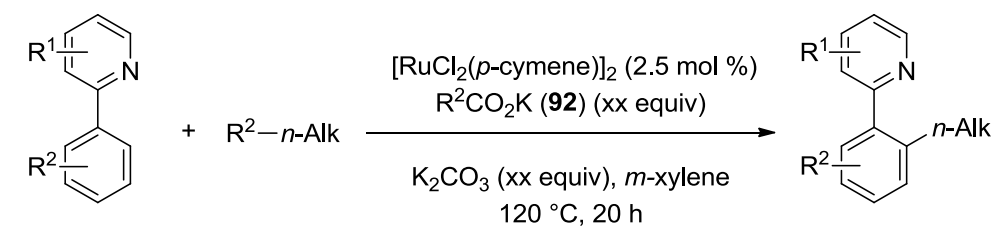

6

$42 a$

93

\begin{tabular}{|c|c|c|c|c|c|}
\hline entry & substrate 6 & bromide $42 a$ & $\begin{array}{c}\text { additive } 92 \\
\text { (equiv) }\end{array}$ & product 93 & isolated yield $^{\mathrm{a}}$ \\
\hline
\end{tabular}

1

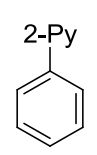

6aa<smiles>Fc1ccc(Br)cc1</smiles>

$6 \mathrm{ca}$<smiles>Fc1ccc(Br)cc1</smiles>

$6 c a$<smiles>Fc1cc(Br)cc(F)c1F</smiles>

6ja

5<smiles>Fc1cc(Br)cc(F)c1F</smiles>

6ja
$n$-Oct-Br

42aa

$n$-Oct-Br

42aa

$n-\mathrm{Hex}-\mathrm{Br}$

$42 a b$

$n-\mathrm{Hex}-\mathrm{Br}$

$42 a b$

n-Oct-Br

KOAc (6.4)

$\operatorname{KOAc}(0.3)$

KOAc (6.4)

$\operatorname{KOAc}(6.4)$

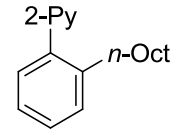

$51 \%$

\section{3aa}<smiles>CCOc1cc(F)ccc1Br</smiles>

$9 \%^{b}$

93ca

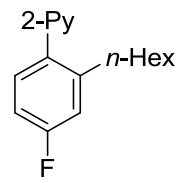

$76 \%$

93cb<smiles>CCc1c([18O])c(F)cc(F)c1F</smiles>

$48 \%$

93jb<smiles>CCOc1c(Br)cc(F)c(F)c1OCC</smiles>

$73 \%$

42aa

93ja 


\begin{tabular}{|c|c|c|c|c|c|}
\hline entry & substrate 6 & bromide $42 a$ & $\begin{array}{c}\text { additive } 92 \\
\text { (equiv) }\end{array}$ & product 93 & isolated yield $^{a}$ \\
\hline 6 & & $n-\mathrm{Hex}-\mathrm{Br}$ & KOAc (6.4) & & $15 \%$ \\
\hline \multirow{3}{*}{7} & $60 a$ & $42 \mathrm{ab}$ & & 93ob & \\
\hline & & $n-\mathrm{Hex}-\mathrm{Br}$ & KOAc (6.4) & & $49 \%$ \\
\hline & $6 \mathrm{ba}$ & $42 \mathrm{ab}$ & & $93 \mathrm{bb}$ & \\
\hline
\end{tabular}

${ }^{\mathrm{a}}$ Reaction conditions: $6(0.5 \mathrm{mmol}), 42 \mathrm{a}(1.5 \mathrm{mmol}),\left[\mathrm{RuCl}_{2}(p \text {-cymene })\right]_{2}(2.5 \mathrm{~mol} \%)$, additive, $\mathrm{K}_{2} \mathrm{CO}_{3}(1.0 \mathrm{mmol}), \mathrm{m}$-xylene $(2.0 \mathrm{~mL}), 120^{\circ} \mathrm{C}, 20 \mathrm{~h}$, yield of isolated product; ${ }^{\mathrm{b}}$ no base, $100^{\circ} \mathrm{C}$.

Furthermore, a catalytic system comprising $\left[\mathrm{RuCl}_{2}(p \text {-cymene })\right]_{2}$ and inexpensive $\mathrm{KOAc}$ was demonstrated to possess almost a high efficacy in the alkylation of (4-methoxyphenyl)pyrazol (87b) as well (Scheme 3.9).
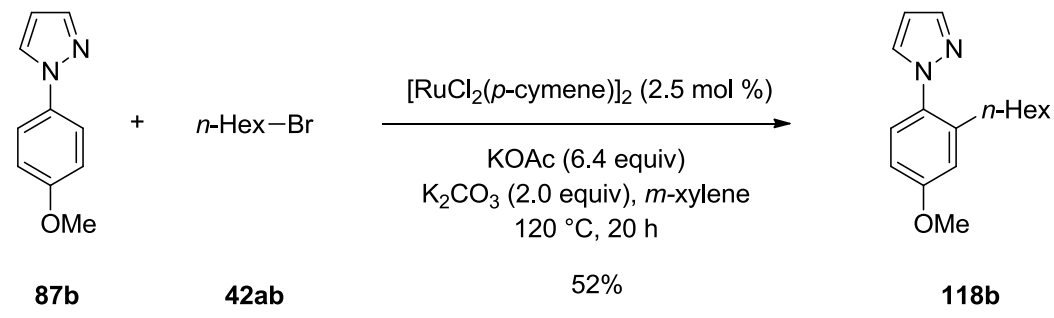

Scheme 3.9: Direct alkylation of (4-methoxyphenyl)pyrazol (87b) employing inexpensive KOAc as the additive.

The opportunity to perform organic reactions with water as an inexpensive, environmentally benign, nontoxic reaction medium is attractive. ${ }^{132}$ The idea of potential tolerance of ruthenium-catalyzed transformations was postulated by Ackermann in his experiments on arylations with $\mathrm{K}_{2} \mathrm{CO}_{3}$ as the base. ${ }^{133 a}$ After this, a number of ruthenium-catalyzed reactions such as $\mathrm{C}-\mathrm{H} / \mathrm{X}-\mathrm{H}$-annulations with alkynes, ${ }^{131 b, c}$ direct oxidative alkenylations ${ }^{131 d, e}$ and direct arylations ${ }^{131 f}$ were successively carried out in water. The ruthenium-catalyzed 3-alkylations of indoles in water ${ }^{134}$ and the dehydrative alkylation

\footnotetext{
132 Reviews: (a) Simon, M.-O.; Li, C.-J. Chem. Soc. Rev., 2012, 41, 1415-1427. (b) Organic Reactions in Water (ed.: Lindstorm, U. M.), Wiley-Blackwell: New York, 2007.

133 (a) Ackermann, L. Org. Lett. 2005, 7, 3123-3125. (b) Ackermann, L.; Lygin, A. V. Org. Lett. 2012, 14, $764-767$. (c) Ackermann, L; Fenner, S. Org. Lett. 2011, 13, 6548-6551. (d) Ackermann, L.; Wang, L.; Wolfram, R.; Lygin, A. V. Org. Lett. 2012, 14, 728-731. (e) Ackermann, L.; Pospech, J. Org. Lett. 2011, 13, 4153-4155. (f) Arockiam, P. B.; Fischmeister, C.; Bruneau, C.; Dixneuf, P. H. Angew. Chem. Int. Ed. 2010, 49, 6629-6632.

${ }^{134}$ Cadierno, V.; Francos, J.; Gimeno J. Chem. Commun. 2010, 46, 4175-4177.
} 
of phenols with alcohols ${ }^{135}$ have also been reported. However, ruthenium-catalyzed direct alkylation of arenes with alkyl halides in water had proven elusive. Indeed, as the bases were never pre-dried before employing in the ruthenium-catalyzed direct alkylation, it was necessary to examine, whether water could be used as the reaction medium. The results are summarized in Table 3.5.

Table 3.5: Direct alkylation of substrates 6 or 87 employing water as the reaction medium.

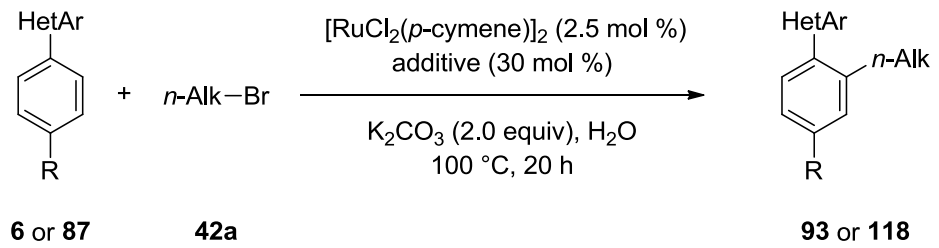

entry substrate bromide 42a

\footnotetext{
${ }^{135}$ Walton, J. W.; Williams, J. M. J. Angew. Chem. Int. Ed. 2012, 51, 12166-12168.
} 
a Reaction conditions: 6 or $87(0.5 \mathrm{mmol}), 42 \mathrm{a}(1.5 \mathrm{mmol})$, $\left[\mathrm{RuCl}_{2}(p \text {-cymene })\right]_{2}(2.5 \mathrm{~mol} \%)$, additive $(30 \mathrm{~mol} \%), \mathrm{K}_{2} \mathrm{CO}_{3}$ $(1.0 \mathrm{mmol}), \mathrm{H}_{2} \mathrm{O}(2.0 \mathrm{~mL}), 120{ }^{\circ} \mathrm{C}, 20 \mathrm{~h}$, yield of isolated product; ${ }^{\mathrm{b}} \mathrm{KOAc}(3.2 \mathrm{mmol})$ as the additive.

Fortunately, while using distilled and degassed water as the reaction medium, electron-poor (entries 1-3) and electron-rich (entry 4) substrates could be alkylated comparable high yield.

The nature of the additive did not significantly affect the outcome of the reaction. Indeed, even superstoichiometric quantities of KOAc can be used as the additive with water as the solvent (entry 3). 2-Phenylpyrazole 87a could also be alkylated in good yields under these reaction conditions (entry 5).

To estimate, whether a solvent mixture could influence the degree of conversion, mixtures of $m$ xylene or NMP and water were tested (Scheme 3.10). A mixture of water and $m$-xylene furnished essentially the same isolated yield of $93 \mathbf{c a}(68 \%)$ as in pure water $(66 \%)$, while in mixtures with NMP the isolated yield slightly decreased (53\%). Interestingly, the reactions run under neat conditions, that is in the absence of solvent, did not result in a dramatically decreased yield. However, due to agitation-effects of the reaction mixture, the latter protocol was subsequently not applied.

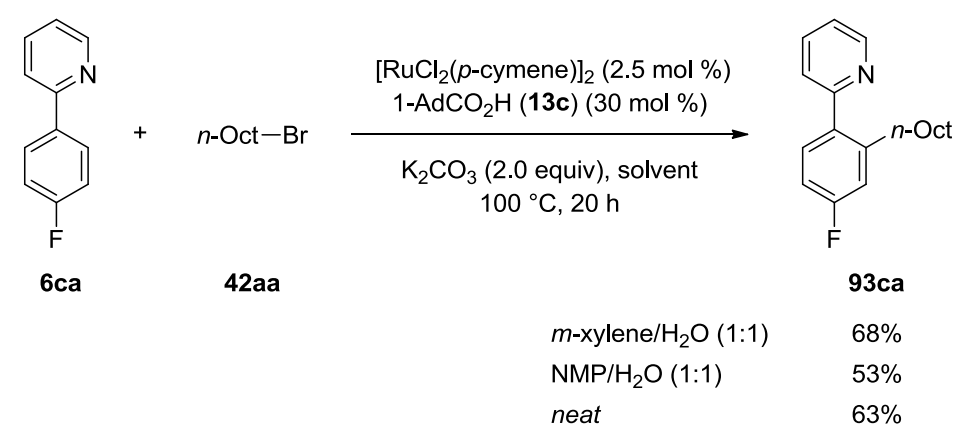

Scheme 3.10: Solvent effects for the direct alkylation.

A variety of other substrates was tested in the ruthenium-catalyzed direct alkylation reaction, but neither oxygen-containing directing groups (131-136) nor substrates that would rely on a 7membered ruthenacycle intermediate (137-141) were alkylated (Figure 3.2). 


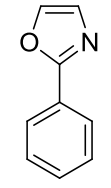<smiles>C1=NC(c2ccccc2)CO1</smiles>

131<smiles>c1cnc(-n2cccc2)nc1</smiles>

133<smiles>c1ccc(-n2cncn2)cc1</smiles>

134<smiles>c1ccc(-c2nnco2)cc1</smiles>

135<smiles>c1ccc(C2=NCCO2)cc1</smiles>

136<smiles>C1=NC(Cc2ccccc2)CO1</smiles>

137<smiles>c1ccc(Cc2ccccn2)cc1</smiles>

138<smiles>O=C(c1ccccc1)c1ccccn1</smiles>

138<smiles>c1ccc(C(c2ccccc2)c2ccccn2)cc1</smiles>

140<smiles>c1ccc(-c2cccc3cccnc23)cc1</smiles>

141

Figure 3.2: Unreactive substrates for the ruthenium-catalyzed direct ortho-alkylation.

\subsubsection{Ruthenium-Catalyzed Direct Allylation}

Thereafter, the alkylation with unsaturated bromides was investigated. In 2011, Ramana reported on a ruthenium-catalyzed direct propenylation of the pyridine ring in 2-phenylpyridine (6aa) under similar reaction conditions, applying allyl bromide (32g) (Scheme 3.11). ${ }^{136}$

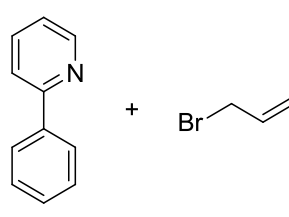

6 aa

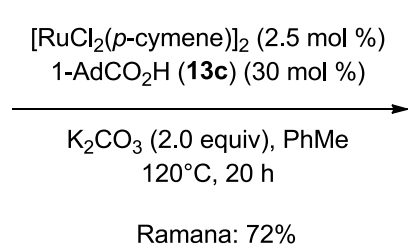

reproduced by N. Hofmann: $69 \%$

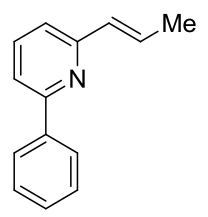

145

Scheme 3.11: Ruthenium-catalyzed direct propenylation of 2-phenylpyridine (6aa).

Indeed, compound 145 was formed in comparable yield, as indicated by ${ }^{1} \mathrm{H}-\mathrm{NMR}$ spectra. However, it was not possible to separate the product $\mathbf{1 4 5}$ completely from the side-product, presumably allyl adamantilate, by column chromatography. According to Ramana and Gorya, without adamantyl carboxylic acid the yield of $\mathbf{1 4 5}$ stayed at $\mathbf{7 2 \%} .{ }^{136}$ Surprisingly, attempted reproduction of these results did not afford any propenylated phenylpyridine 145 . Instead of this, $28 \%$ of the orthoallylated 2-phenylpyridine $93 \mathrm{~m}$ has been isolated as sole product, albeit in low yield (Scheme 3.12).

\footnotetext{
${ }^{136}$ Goriya, Y.; Ramana, C. V. Chem. Eur. J. 2012, 18, 13288-13292.
} 


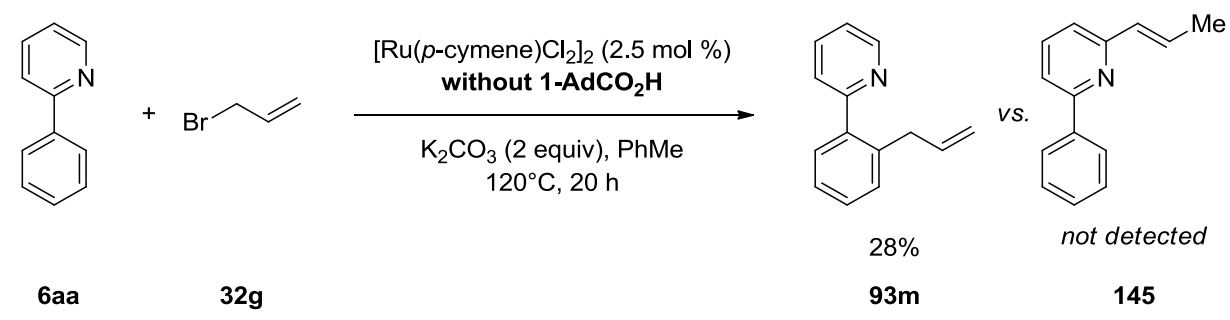

Scheme 3.12: Ruthenium-catalyzed direct allylation of 2-phenylpyridine (6aa).

With freshly distilled allyl bromide $(\mathbf{3 2 g})$, the formation of this allylated product $\mathbf{9 3 m}$ could be detected even at $70{ }^{\circ} \mathrm{C}$ and without any additive. With water as a solvent, compound $93 \mathrm{~m}$ was obtained in $20 \%$ isolated yield (Scheme 3.13 ).<smiles>c1ccc(-c2ccccc2)cc1</smiles>
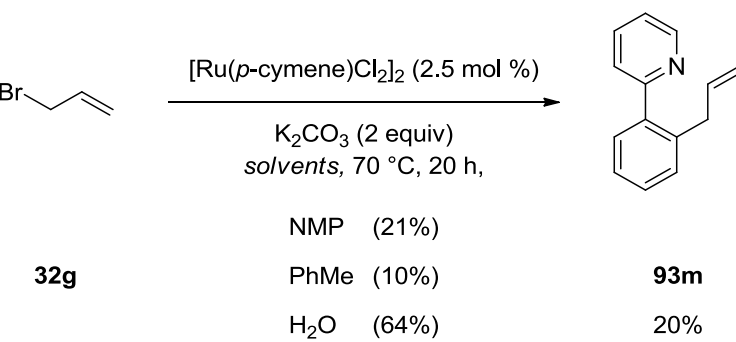

Scheme 3.13: Direct allylation of 2-phenylpyridin (6aa) (yields in brackets mean GC-MS-conversions of 6aa).

\subsubsection{Mechanistic Studies}

At the outset, the probability of a reaction pathway via initial dehydrobromination followed by hydroarylation according to Murai and co-workers, ${ }^{91}$ but under our optimized reaction conditions, was evaluated (Scheme 3.14)..$^{137}$

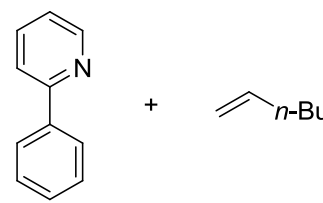

6aa

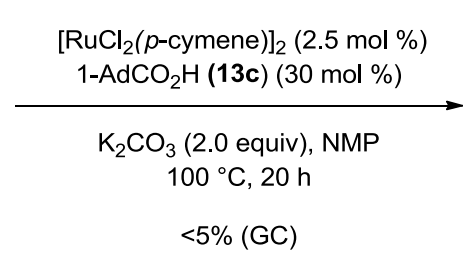

$<5 \%(\mathrm{GC})$

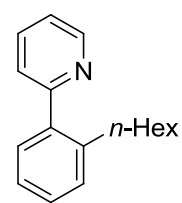

$93 a b$

Scheme 3.14: Attempted hydroarylation.

The conversion of substrate $6 \mathbf{a a}$ to the desired alkylated product 93ab was not detected when using 1-hexene (32f) as alkene, thus excluding a hydroarylation as a possible reaction pathway. To ascertain, whether a one-pot addition/direct alkylation sequence can be accomplished, the reaction was re-tested in the presence of potassium bromide and potassium bi carbonate as the additives (Scheme 3.15).

\footnotetext{
${ }^{137}$ Reaction was performed by Dr. R. Vicente.
} 


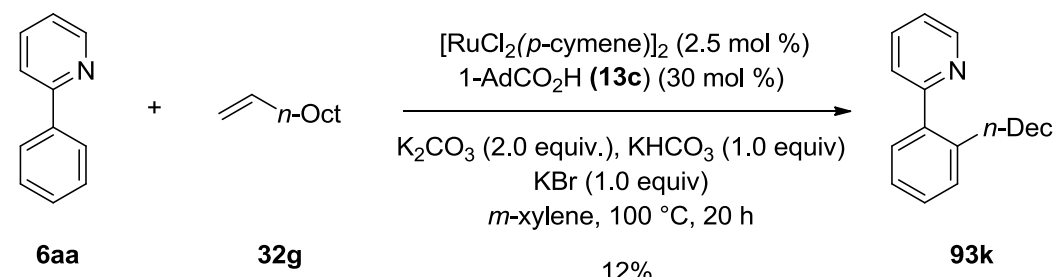

Scheme 3.15: Attempted alkylation via "one-pot" addition/direct alkylation sequence.

Under these reaction conditions only a very low yield of $93 \mathbf{k}(12 \%)$ has been obtained, which excluded the one-pot addition/direct alkylation procedure as a viable alternative.

Moreover, a ruthenium-catalyzed direct ortho-alkylation with ketimine 121a and 1-bromohexene $32 \mathrm{f}$ could be accomplished in good yield and high chemoselectivity without the formation of cyclized products (Scheme 3.16).<smiles>CC(=N)N=C(C)c1ccc(F)cc1</smiles>

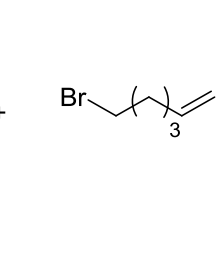

$121 \mathrm{a}$
$32 f$

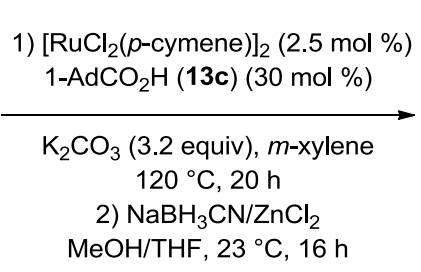

$62 \%$

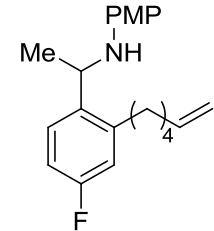

122a

Scheme 3.16: Ruthenium-catalyzed direct alkylation with bromohexene $32 \mathrm{f}$.

\subsubsection{Intramolecular Competition Experiments}

Intra- and intermolecular competitive direct alkylations of meta-substituted ketimines $\mathbf{1 2 1}$ as the substrates were performed with the aim (a) to evaluate the scope of these direct alkylations and (b) to shed light onto the mechanism of direct alkylations through intramolecular competition experiments, which can elucidate sterical and electronical aspects (Table 3.6).

Table 3.6: Intramolecular competition experiments with meta-substituted ketimines 121.
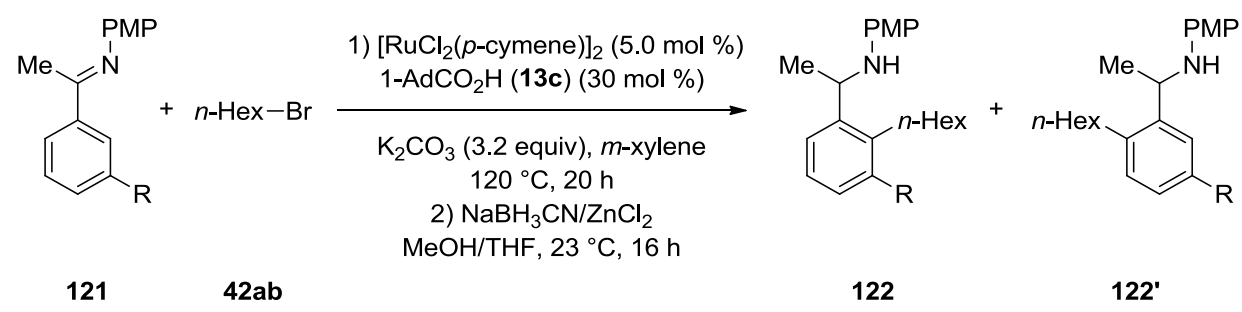

\begin{tabular}{|c|c|c|c|c|c|}
\hline entry & substrate 121 & product 122 & yield of $122^{a}$ & product $122^{\prime}$ & yield of $122^{\prime a}$ \\
\hline 1 & $\begin{aligned} & \text { PMPP } \\
1 & \stackrel{N}{N}\end{aligned}$ & $\begin{array}{l}\text { PMP } \\
1 \\
\text { NH }\end{array}$ & 74\% & -- & -- \\
\hline & $121 b$ & $122 b$ & & & \\
\hline
\end{tabular}




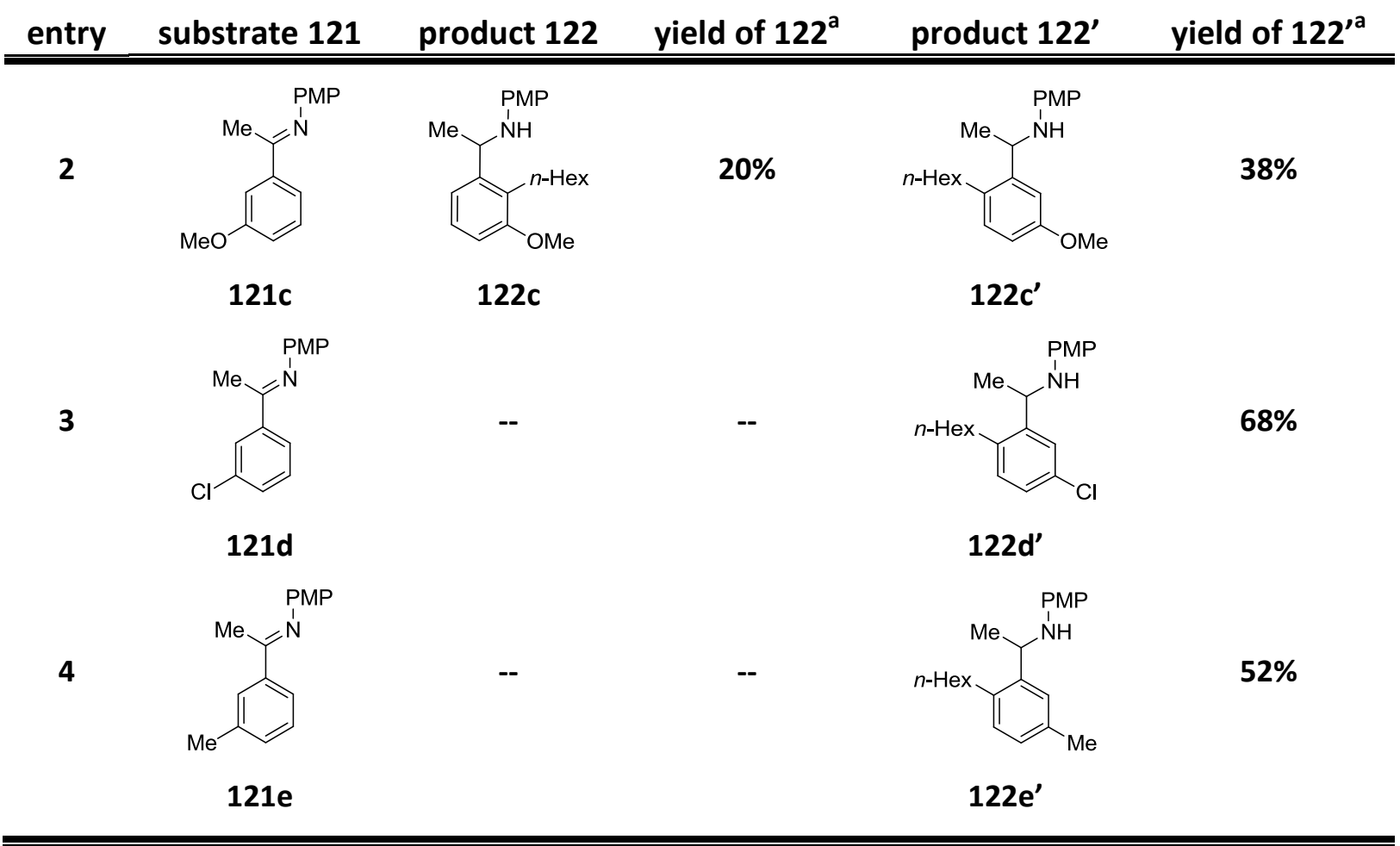

${ }^{a}$ Reaction conditions: 121 (0.5 mmol), 42ab (1.5 mmol), $\left[\mathrm{RuCl}_{2}(p-c y m e n e)\right]_{2}(5.0 \mathrm{~mol} \%), 1-\mathrm{AdCO}_{2} \mathrm{H}(13 \mathrm{c})(30 \mathrm{~mol} \%), \mathrm{K}_{2} \mathrm{CO}_{3}$ $(1.6 \mathrm{mmol}), \mathrm{m}$-xylene $(2.0 \mathrm{~mL}), 120^{\circ} \mathrm{C}, 20 \mathrm{~h}$, yield of isolated product.

As was shown in earlier studies, ${ }^{124,125}$ electron-deficient substrates are more reactive in rutheniumcatalyzed direct alkylation than are electron-rich ones. In the case of meta-substituted substrates, the same behavior was detected. A meta-fluoro substitution in substrate $\mathbf{1 2 1} \mathbf{b}$ resulted in 2alkylation (entry 1), which most probably resulted from the concerted action of the chelating effect of the imino moiety and the well-documented ortho-orienting influence of the fluorine substituents. ${ }^{138}$ Conversely, the larger meta-chlorine substituent in substrate $121 \mathrm{~d}$ (entry 3) or methyl substituent in 121e (entry 4) directed the alkylations to the less hindered 5-position. As a comparison, the alkylation of the substrate 121c with a meta-methoxy substituent led to a mixture of the 2- (122c) and 5-substituted (1226') products (entry 2). Formation of the former might be explained by a secondary chelating effect of the methoxy substituent. Electron-deficient substrates $121 \mathrm{~b}$ and $121 \mathrm{~d}$ afforded very good yields (entries 1 and 3 ).

\subsubsection{Intermolecular Competition Experiments}

To establish the reactivity-order and to establish priorities for arenes with different substituents and directing groups, intermolecular competition experiments were subsequently carried out (Table 3.7).

138 (a) Evans, M. E.; Burke, C. L.; Yaibuathes, S.; Clot, E.; Eisenstein, O.; Jones, W. D. J. Am. Chem. Soc. 2009, 131, 13464-13473; (b) Clot, E.; Mégret, C.; Eisenstein, O.; Perutz, R. N. J. Am. Chem. Soc. 2009, 131, 7817-7827. 
Table 3.7: Intermolecular competition experiments using substrates with various directing groups.<smiles>[R]c1cccc([C@H](C)O[Na])c1</smiles>

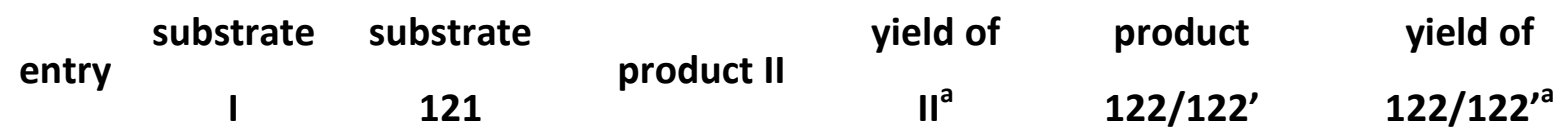<smiles>Fc1cccc(-c2ccccn2)c1</smiles><smiles>CC(=NP)c1cccc(F)c1</smiles>

$6 d a$

121b<smiles>Fc1cccc(C2=NCCO2)c1</smiles>

$136 a$<smiles>O=[W]=Nc1cccc(F)c1</smiles>

121b<smiles>OCc1c(F)cccc1-c1ccccn1</smiles>

93db<smiles>CCc1c(F)cccc1C1=NCCO1</smiles>

$143 a$
$55 \%$<smiles>C[C@H](NCc1ccccc1)c1cccc(F)c1CCN</smiles>

122b

$15 \%$

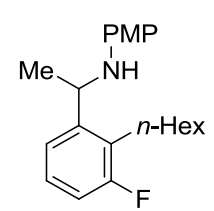

122b
3

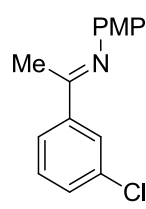

121d<smiles>O=[W]C(=N[PH2+])c1cccc(F)c1</smiles>

121b<smiles>O=[N+]([O-])C(=N[PH2+])c1cccc([N+](=O)[O-])c1</smiles>

$121 e$<smiles>CCc1ccc(Cl)cc1[C@H](C)C(=O)Nc1ccccc1</smiles>

122d'<smiles>Cc1ccc(Cl)cc1[C@H](N)Cc1ccccc1</smiles>

122d'
$20 \%$<smiles>CC(N)C(=O)Nc1cccc(F)c1C(=O)O</smiles>

$122 b$

$40 \%$

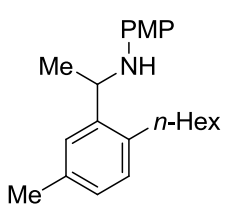

$122 e^{\prime}$

121d

mene) $]_{2}(5.0 \mathrm{~mol} \%), 1-\mathrm{AdCO}_{2} \mathrm{H}(\mathbf{1 3 c})$

${ }^{a}$ Reaction conditions: I and $121\left(1.0 \mathrm{mmol}\right.$ of each), $42 \mathrm{ab}(0.5 \mathrm{mmol}),\left[\mathrm{RuCl}_{2}(p \text {-cymene })\right]_{2}(5.0 \mathrm{~mol} \%)$,
$(30 \mathrm{~mol} \%), \mathrm{K}_{2} \mathrm{CO}_{3}(1.6 \mathrm{mmol}), \mathrm{m}$-xylene $(4.0 \mathrm{~mL}), 120^{\circ} \mathrm{C}, 20 \mathrm{~h}$, yield of isolated product.

Entries 1 and 2 clearly indicate that pyridyl (substrate $6 \mathrm{da}$ ) is a more powerful directing group than the ketimine (substrate 121b), which itself is better than the oxazoline (substrate 136a). It has to be mentioned, that 2-aryloxazoline (136) did not afford any product under the standard reaction conditions in an individual reaction. This led to the assumption that the ketimine moeity also acts as a ligand in this transformation (entry 2). Competition experiments between electron-rich and 
electron-poor ketimines (entries 3 and 4) illustrated that with-drawing substrates were significantly more reactive.

The results of another series of intermolecular competition experiments, which did not require the additional in situ reduction step, are show in Table 3.8.

Table 3.8: Intermolecular competition experiments with different directing groups.

$\mathrm{R}_{\mathrm{R}}^{\mathrm{DG}}+{ }_{\mathrm{R}}^{1} \mathrm{Hex- \textrm {Br }}$

I

II

42ab
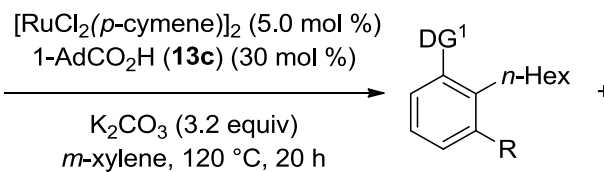<smiles>[R]c1cccc(Br)c1O</smiles>

P-I

P-II

\section{entry substrate I substrate II product $\mathrm{P}-\mathrm{I}$ yield of $\mathrm{P}-\mathrm{I}^{\mathrm{a}}$ product $\mathrm{P}-\mathrm{II} \quad$ yield of $\mathrm{P}-\mathrm{II}^{\mathrm{a}}$}

1<smiles>c1ccc(-c2ccccn2)cc1</smiles>

6aa

2<smiles>c1ccc(-c2ccccn2)cc1</smiles>

6aa<smiles>c1ccc(-n2cccn2)cc1</smiles>

$87 a$<smiles>Fc1cccc(-c2ccccn2)c1</smiles>

6da<smiles>Fc1cccc(-c2ccccn2)c1</smiles>

6da<smiles>c1ccc(C2=NCCO2)cc1</smiles>

136<smiles>c1ccc(-n2cccn2)cc1</smiles>

$87 a$<smiles>c1ccc(C2=NCCO2)cc1</smiles>

136<smiles>Fc1cccc(C2=NCCO2)c1</smiles>

136b<smiles>Fc1cccc(-n2cccn2)c1</smiles>

$87 c$<smiles>CCc1ccccc1-c1ccccn1</smiles>

93ab<smiles>CCc1ccccc1-c1ccccc1</smiles>

93ab

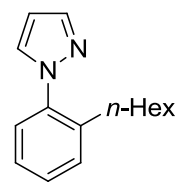

$118 a$<smiles>Oc1c(F)cccc1-c1ccccn1</smiles>

93db

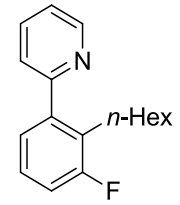

93db
$24 \%$

$36 \%$<smiles>CCc1ccccc1-n1cccn1</smiles>

$9 \%$

$118 a$

$31 \%$

$28 \%$

$17 \%$<smiles>O=Cc1c(F)cccc1-n1cccn1</smiles>

$17 \%$

$118 \mathrm{c}$ 


\section{entry substrate I substrate II product $\mathrm{P}-\mathrm{I}$ yield of $\mathrm{P}-\mathrm{I}^{\mathrm{a}}$ product $\mathrm{P}-\mathrm{II} \quad$ yield of $\mathrm{P}-\mathrm{II}^{\mathrm{a}}$}

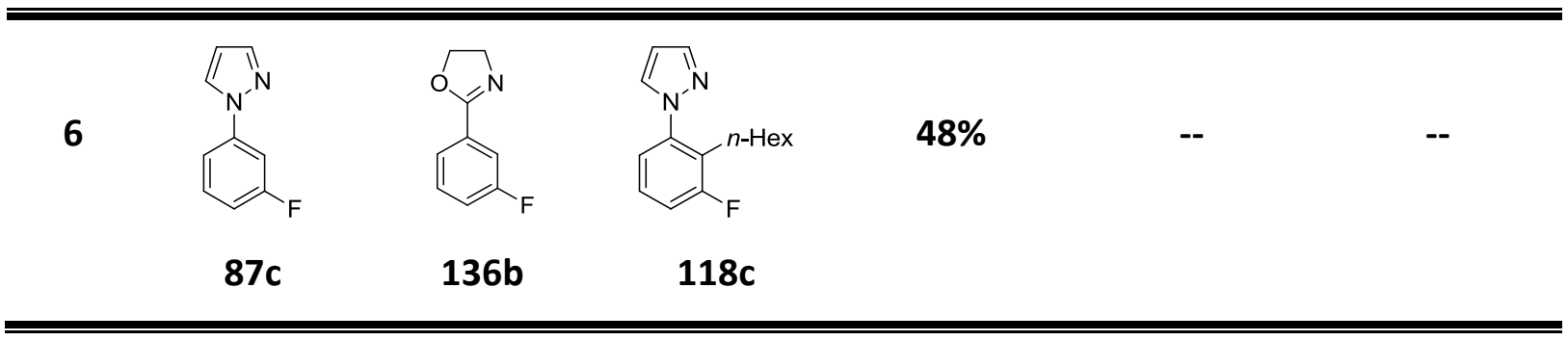

${ }^{a}$ Reaction conditions: I or II (1.0 mmol of each), 42ab (0.5 mmol), $\left[\mathrm{RuCl}_{2}(p-c y m e n e)\right]_{2}(2.5 \mathrm{~mol} \%), 1-\mathrm{AdCO}_{2} \mathrm{H}(13 \mathrm{c})(30 \mathrm{~mol}$ $\%), \mathrm{K}_{2} \mathrm{CO}_{3}(1.6 \mathrm{mmol}), m$-xylene $(4.0 \mathrm{~mL}), 120^{\circ} \mathrm{C}, 20 \mathrm{~h}$, yield of isolated product.

These results were in line with those summarized in Table 3.7 indicating the efficacy of directing groups to be in the following order: pyridine $\geq$ pyrazole > ketimine $\gg>>$ oxazoline (Figure 3.3).

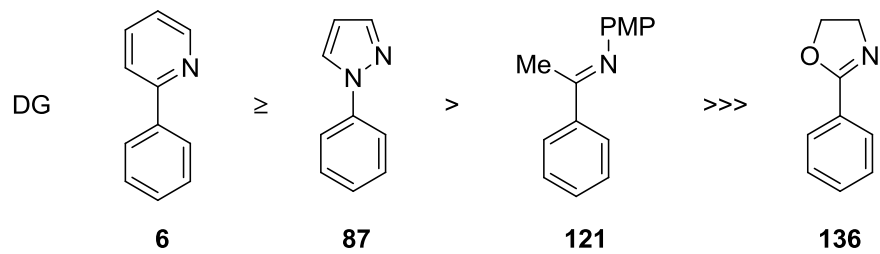

substituents: $\mathrm{F}>\mathrm{Cl}>\mathrm{OMe}>\mathrm{Me}$

Figure 3.3: Reactivity order for the direct ortho-alkylation derived from the results of competition experiments summarized in Table 3.7 and Table 3.8 .

The relative rates of ruthenium-catalyzed direct arylation and direct alkylation have been compared in the competition between bromobenzene (15a) and $n$-hexyl bromide (42ab) (Scheme 3.17). The reaction led to the formation of an inseparable mixture of mono- (143) and bis-arylated (144) products, while the alkylation product 93ab was not detected. This result indicates the direct arylation to be much faster than the direct alkylation reaction.

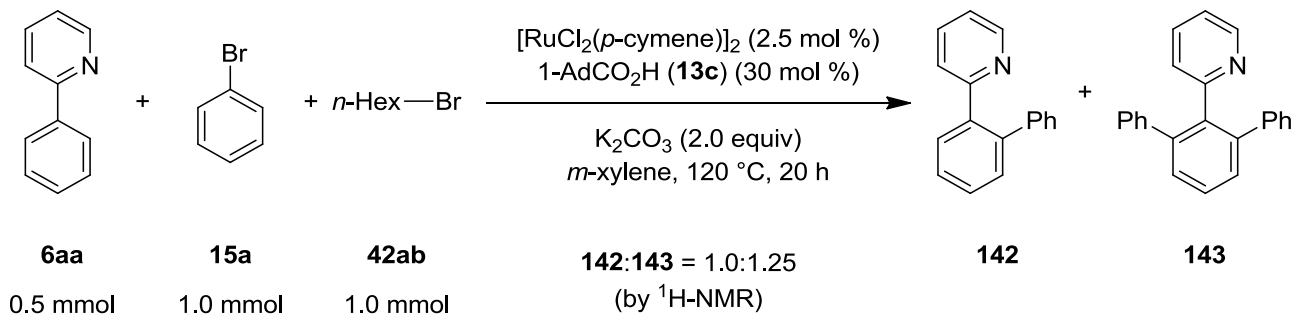

Scheme 3.17: Competition between direct arylation and alkylation reactions. 


\subsubsection{Experiments with Deuterium-Labeled Substrates}

Previously reported studies by $\mathrm{Dr}$. Rubén Vicente ${ }^{124}$ on $\mathrm{D} / \mathrm{H}$ exchange gave strong evidence for a reversible $\mathrm{C}-\mathrm{H}$ bond metalation step. As displayed in Scheme 3.18, the direct alkylation on deuterated substrate $\left[D_{5}\right]-6$ aa under optimized reaction conditions demonstrated $50 \%$ of H/Dexchange in the ortho-position. It is supposed, that the non-predried $\mathrm{K}_{2} \mathrm{CO}_{3}$ is acting as an additional proton-source besides the carboxylic acid.<smiles>[2H]c1c([2H])c(C)c(-c2ccccn2)c(C)c1[2H]</smiles>

$\left[D_{5}\right]-6 a a$
$n-\mathrm{Hex}-\mathrm{Br}$

42ab

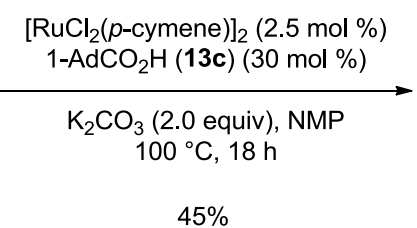

$45 \%$

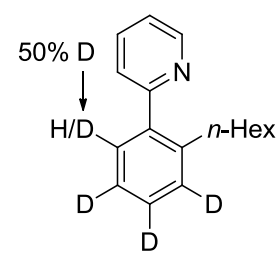

$\left[D_{n}\right]-93 a b$

Scheme 3.18: $\mathrm{D} / \mathrm{H}$-exchange experiment during direct alkylation of substrate $\left(\left[\mathrm{D}_{5}\right]-6 \mathrm{aa}\right)$.

The direct alkylation with $\left[D_{2}\right]-\mathbf{4 2 a b}$ showed no deuterium scrambling in the product (Scheme 3.19). This result supported once more the elimination/hydroarylation or the formation of carbene intermediates unlikely to be operative.<smiles>CNC(=O)N=C(C)c1ccccc1</smiles>

$121 f$

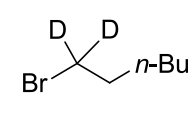

$\left[D_{2}\right]-42 a b$
1) $\left[\mathrm{RuCl}_{2}(p \text {-cymeme })\right]_{2}(2.5 \mathrm{~mol} \%)$ $1-\mathrm{AdCO}_{2} \mathrm{H}(13 \mathrm{c})(30 \mathrm{~mol} \%)$ $\mathrm{K}_{2} \mathrm{CO}_{3}$ (3.2 equiv) $m$-xylene, $120^{\circ} \mathrm{C}, 20 \mathrm{~h}$ 2) $\mathrm{NaBH}_{3} \mathrm{CN} / \mathrm{ZnCl}{ }_{2}$ $\mathrm{MeOH} / \mathrm{THF}, 23^{\circ} \mathrm{C}, 16 \mathrm{~h}$

$50 \%$

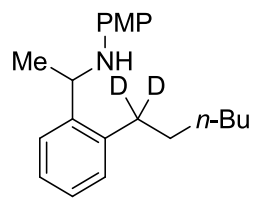

$\left[D_{2}\right]-122 f$

Scheme 3.19: Direct alkylation with 1,1-dideuteriohexyl bromide ([ $\left.\left.D_{2}\right]-42 a b\right)$.

\subsubsection{Experiments with Ruthenacycle 14a}

Previous studies on the ruthenium-catalyzed direct arylation by the group of Prof. Ackermann have demonstrated the capability of the ruthenacycle $14 a$ to catalyze the desired reaction. ${ }^{26 a}$ This complex has been synthesized and tested as the catalyst for the direct alkylation (Scheme 3.20). 


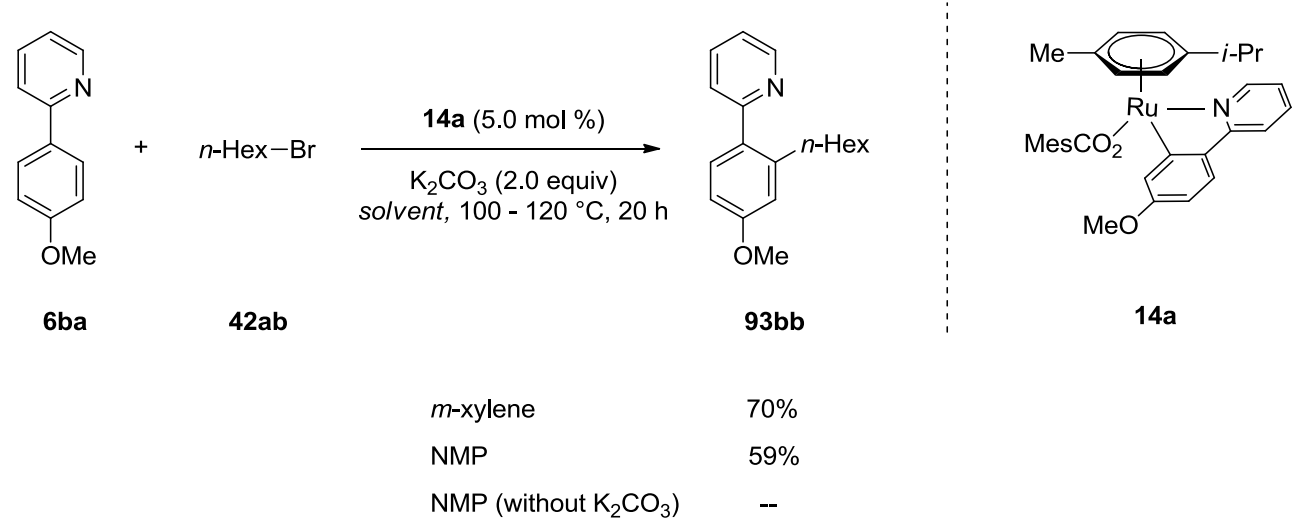

Scheme 3.20: Ruthenium-catalyzed direct alkylation with ruthenacycle 14a as the catalyst.

As shown in Scheme 3.20, the use of $5.0 \mathrm{~mol} \%$ of the isolated complex 14a gave high yields of the alkylated product $\mathbf{9 3 b b}$ with both $m$-xylene as well as NMP as the solvent. Furthermore, without the base $\mathrm{K}_{2} \mathrm{CO}_{3}$ no conversion of the substrates occurred. These results lead to the assumption that complex 14a participates in the catalytic cycle and that a stoichiometric amount of base is necessary.

\subsubsection{Proposed Catalytic Cycle}

Based on the mechanistic studies discussed above, the following catalytic cycle was proposed to account for the chemo- and site-selective outcome of the ruthenium-catalyzed direct alkylation with unactivated primary alkyl halides (Scheme 3.21). 


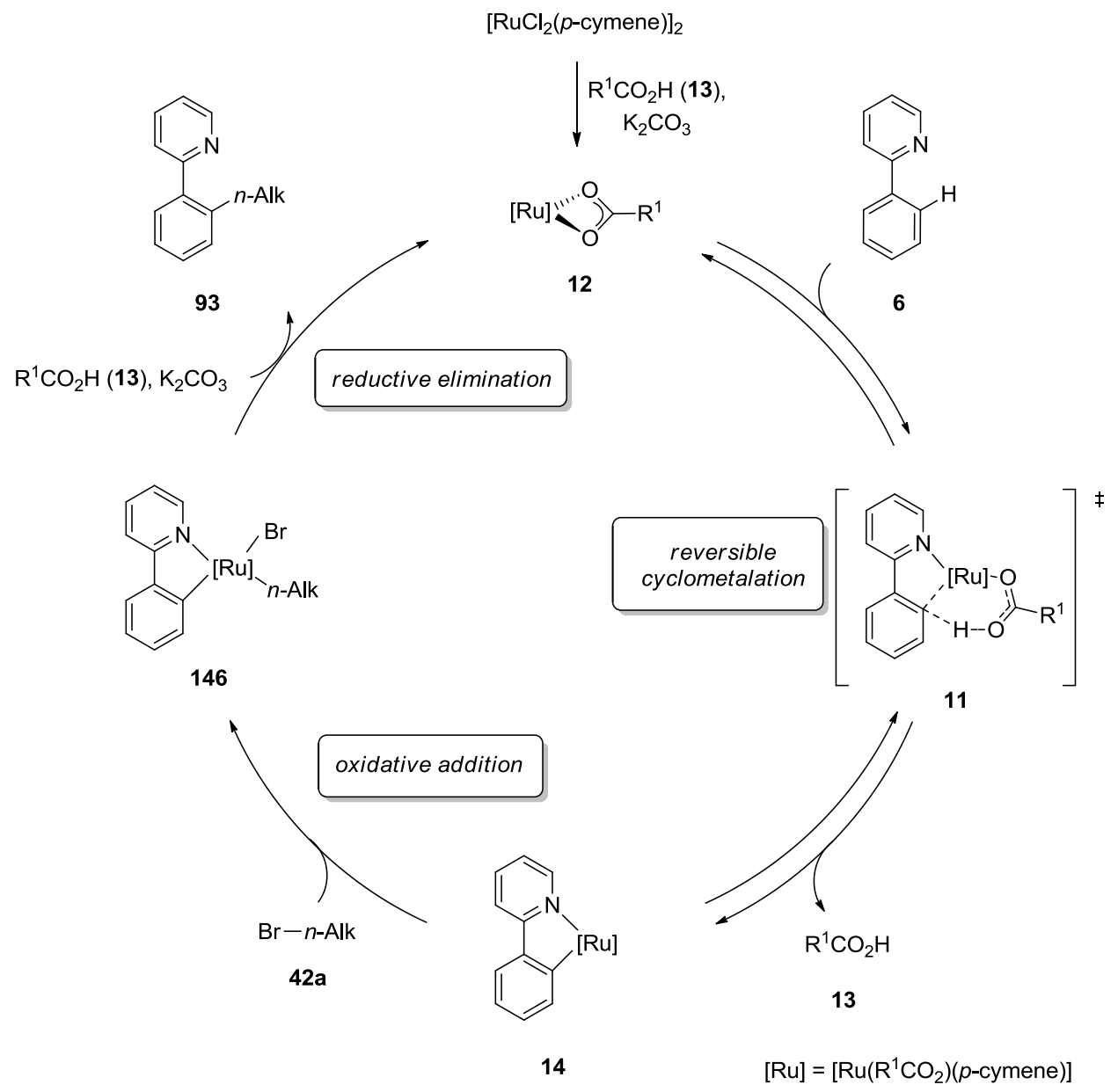

Scheme 3.21: Proposed catalytic cycle for direct ruthenium-catalyzed ortho-alkylation.

This catalytic cycle initiates by the formation of a stable ruthenium (II) carboxylate complex $\mathbf{1 2}$, in analogy to the published precedent by Ackermann et $a .^{26}$ This complex reversibly cyclometalates through a carboxylate-assisted deprotonation through intermediate 11, affording ruthenacycle 14 . Thereafter, complex 14 reacts with unactivated primary alkyl bromide 42a via either oxidative addition or SET-type process to yield intermediate 146. Finally, reductive elimination regioselectively gives rise to the alkylated arene 93, and thereby regenerates the catalytically active species $\mathbf{1 2}$. Importantly, catalytic amounts of carboxylate not only dramatically accelerate the $\mathrm{C}-\mathrm{H}$ bond activation step affording $\mathbf{1 4},{ }^{139}$ but facilitate the $\mathrm{C}-\mathrm{C}$ bond formation. Unfortunanely, the nature of the activation step with primary alkyl halides (42a) still remains unknown, as the corresponding experiments towards its elucidation were not yet successful. Also the nature of the rate-determining step - either the reductive elimination or the activation of the alkyl halide - still remains unknown.

139 (a) Li, B.; Feng, H.; Wang, N.; Ma, J.; Song, H.; Xu, S.; Wang, B. Chem. Eur. J., 2012, 18, 12873-12879. (b) Li, B.; Roisnel, T.; Darcel, C.; Dixneuf, P. H. Dalton Trans. 2012, 41, 10934-10937. 


\subsection{Ruthenium-Catalyzed Direct meta-Alkylation}

\subsubsection{Preliminary Observations}

As indicated in the introduction, the challenging ruthenium-catalyzed $\mathrm{C}-\mathrm{H}$ direct alkylations with unactivated primary alkyl halides are an important objective, which appeared to be highly ortho-siteselective. Nevertheless, in selected rare cases small quantities of a side-product were isolated (Table 3.9). Careful 2D-NMR studies disclosed these by-products as being formed by an unprecedented ruthenium-catalyzed meta-functionalization.

Table 3.9: Observation of meta-alkylated side-product $\mathbf{9 3 c ^ { \prime }}$.

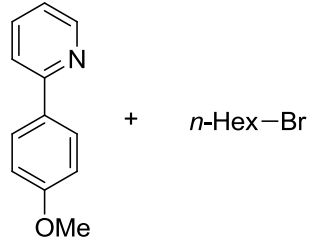

$6 b a$

42ab

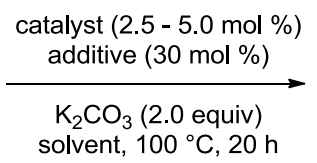
solvent, $100{ }^{\circ} \mathrm{C}, 20 \mathrm{~h}$

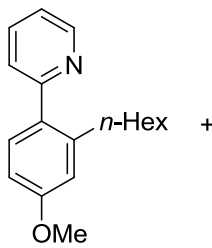

$93 \mathrm{bb}$

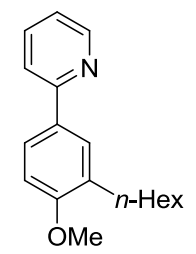

93bb'

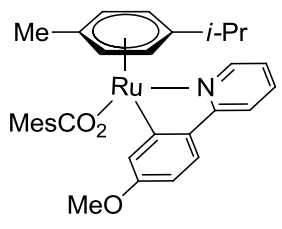

$14 a$

\begin{tabular}{cccccc} 
entry & catalyst (mol\%) & solvent & additive & yield $^{\text {a }}$ of 93bb & yield $^{\text {a }}$ of 93bb' \\
\hline \hline 1 & $\begin{array}{c}{\left[\mathrm{RuCl}_{2}(p-\mathrm{cymene})\right]_{2}} \\
(2.5 \mathrm{~mol} \%)\end{array}$ & $\mathrm{H}_{2} \mathrm{O}$ & $\mathrm{MesCO}_{2} \mathrm{H}$ & $\mathbf{4 5 \%}$ & $\mathbf{7 \%}$
\end{tabular}

$13 a$

2

$\left[\mathrm{RuCl}_{2}(p \text {-cymene })\right]_{2}$

(2.5 mol\%)

neat $\quad \mathrm{MesCO}_{2} \mathrm{H}$

$40 \%$

$6 \%$

$13 a$

3

$\left[\operatorname{RuCl}_{2}(p \text {-cymene })\right]_{2}$

(2.5 mol\%)

$\mathrm{H}_{2} \mathrm{O}$

$34 \%$

$\left({ }^{1} \mathrm{H}-\mathrm{NMR}\right.$ ratio $\left.=7.5: 1.0\right)$

4

$\left[\mathrm{RuCl}_{2}(p \text {-cymene })\right]_{2}$

$$
\text { (2.5 mol\%) }
$$

5 $m$-xylene $\quad \mathrm{MesCO}_{2} \mathrm{H}$

$13 a$

$m$-xylene $\quad 1-\mathrm{AdCO}_{2} \mathrm{H}$

$13 c$
$42 \%$

$\left({ }^{1} \mathrm{H}-\mathrm{NMR}\right.$ ratio $\left.=3.2: 1.0\right)$

$64 \%$

$4 \%$

\footnotetext{
${ }^{\mathrm{a}}$ Reaction conditions: $6 \mathrm{ba}(0.5 \mathrm{mmol}), 42 \mathrm{ab}(1.5 \mathrm{mmol}),[\mathrm{Ru}](5.0 \mathrm{~mol} \%)$, additive $(30 \mathrm{~mol} \%), \mathrm{K}_{2} \mathrm{CO}_{3}(1.0 \mathrm{mmol}), \mathrm{m}$-xylene
} $(2.0 \mathrm{~mL}), 100{ }^{\circ} \mathrm{C}, 20 \mathrm{~h}$, yield of isolated products.

Thus, while performing the alkylation of electron rich substrate $6 \mathbf{b a}$ in water as the reaction medium (entry 1), the unexpected meta-substituted side-product $\mathbf{9 3 \mathbf { b b }}$ ' was isolated in $\mathbf{7 \%}$ yield. All attempts 
to modify the reaction conditions to favor the formation of the meta-product were however unsuccessful. Thus, neither changing the solvent (entries 2 - 4) nor employing the highly active ruthenacycle 14a in combination with the most efficient additive 13c improved the yield of byproduct $\mathbf{9 3} \mathbf{3 b} \mathbf{b}$, while these conditions accelerated the formation of the ortho-alkylated product $\mathbf{9 3 \mathbf { b } b}$ (entry 5).

Surprisingly, in a competition experiment between bromo- (42ab) and chloroalkane (42d) (Scheme 3.22), the side-product $\mathbf{9 3} \mathbf{b b}^{\prime}$ could be isolated in comparable amounts as in entry 1 , Table 3.9. This experiment again demonstrated the higher reactivity of bromoalkanes as electrophiles in the ruthenium-catalyzed direct alkylation reaction.

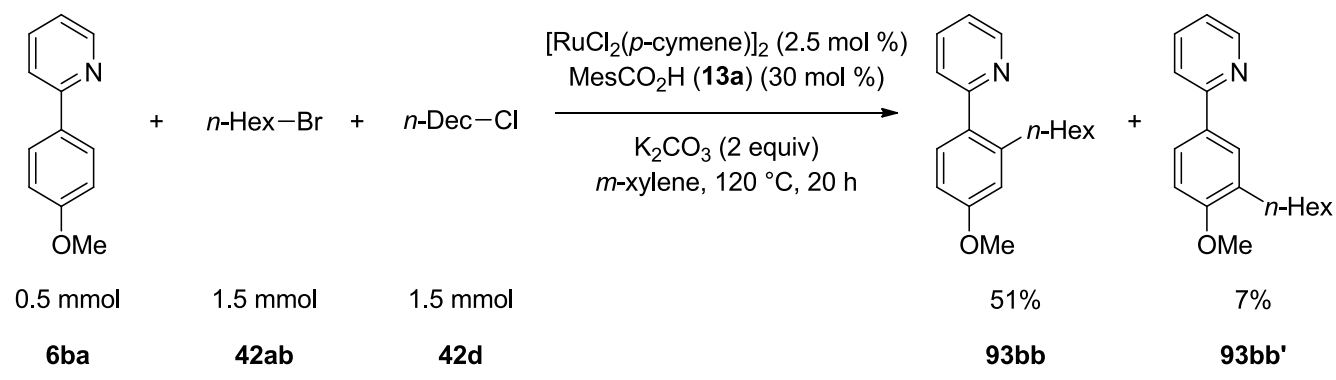

Scheme 3.22: Isolation of meta-derivative $\mathbf{9 3 c ^ { \prime }}$ as a side product in a competition experiment.

\subsubsection{Optimization Studies for the Direct meta-Alkylation}

Since the direct alkylation with primary alkyl halides $42 \mathrm{a}$ could not yet be optimized to deliver only the meta-alkylated product, we first tested the effect of various reaction conditions on the challenging direct alkylation of arene 6aa with secondary alkyl halides $\mathbf{4 2 b}$ (Table 3.10). Inexpensive and readily available carboxylic acids, which appeared to be efficient cocatalysts for rutheniumcatalyzed ortho-alkylations with primary alkyl bromides were first explored.

Table 3.10: Optimization studies towards the optimal cocatalyst with 2-bromooctane (42ba).<smiles>c1ccc(-c2ccccn2)cc1</smiles>

6aa<smiles>CC(Br)[Hg][Na]</smiles>

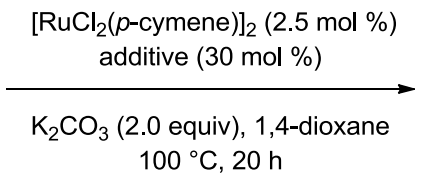

$100^{\circ} \mathrm{C}, 20 \mathrm{~h}$<smiles>CC(O)c1cccc(-c2ccccn2)c1</smiles>

147aa 


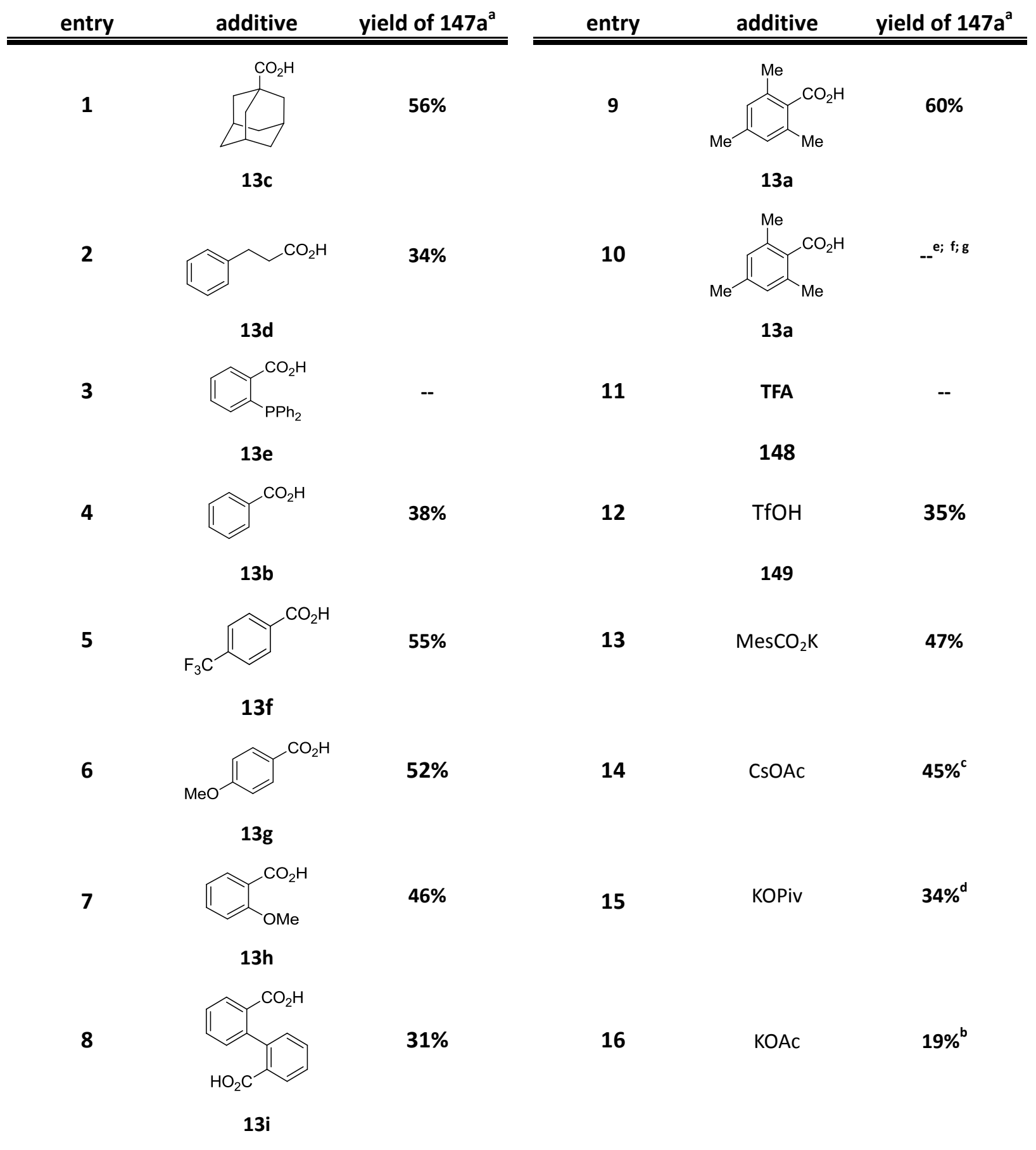

\footnotetext{
${ }^{\mathrm{a}}$ Reaction conditions: 6aa $(0.5 \mathrm{mmol}), 42 \mathrm{ba}(1.5 \mathrm{mmol}),\left[\mathrm{RuCl}_{2}(p \text {-cymene })\right]_{2}(2.5 \mathrm{~mol} \%)$, additive (30 mol \%), 1,4-dioxane (2.0 mL), $20 \mathrm{~h}, 100{ }^{\circ} \mathrm{C} ;{ }^{\mathrm{b}} \mathrm{KOAc}$ (2.0 equiv), no K $\mathrm{CO}_{3} ;{ }^{\mathrm{c}} \mathrm{CsOAc}$ (2.0 equiv), no K $\mathrm{CO}_{3} ;{ }^{\mathrm{d}}$ PivOK (2.0 equiv); ${ }^{e}$ no $\mathrm{K}_{2} \mathrm{CO}_{3} ;{ }^{\mathrm{f}}$ no $\left[\mathrm{RuCl}_{2}(p \text {-cymene })\right]_{2} ;{ }^{\mathrm{g}}$ no additive.

As a standard transformation, alkylation of 2-phenylpyridine (6aa) - one of the most active substrates in ortho-alkylations (Figure 3.3) - with challenging 2-bromooctane (42ba) has been selected. The reaction proceeded with most user-friendly $\left[\mathrm{RuCl}_{2}(p-c y m e n e)\right]_{2}$ as the ruthenium
} 
source in the presence of potassium carbonate (2.0 equiv) in 1,4-dioxane. The latter was proven to be the best solvent for these alkylations. ${ }^{140}$

According to 2D-NMR spectra, product 147 aa could be determined to be rather meta- than orthoalkylated. For the final prove of this unprecedented site-selectivity, the alkylation product 147aa was converted to its pyridium salt $\mathbf{1 4 8}$ employing oxalic acid. This salt has been crystallized by slow concentration of their solutions to afford crystals suitable for X-ray crystal structure analysis (Figure 3.4). ${ }^{141}$

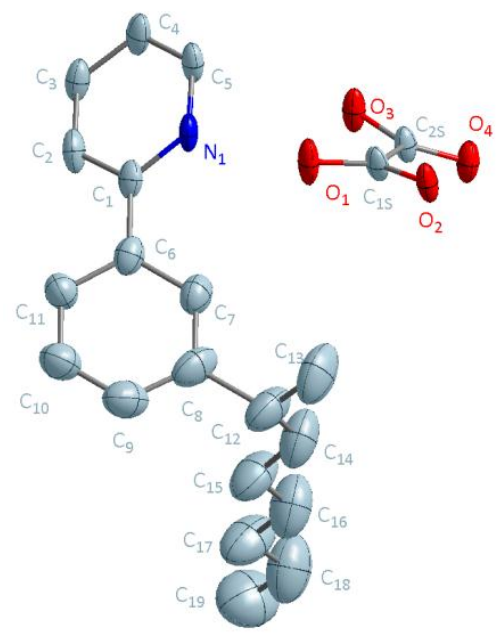

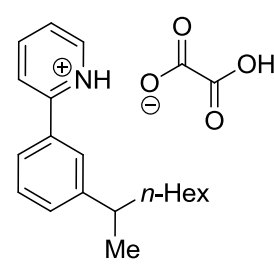

148

Figure 3.4 ORTEP plots (50\% probability thermal ellipsoids) of 2-[2-(octan-2-yl)phenyl]pyridinium oxalate (148) in the crystal. All hydrogen atoms have been omitted for clarity. Numbering does not correspond to the IUPAC rules.

The data from Table 3.10 obviously indicate that various aliphatic (entries 1 and 2), aromatic (entries 4-9) and triflic acids (entry 12) as well as their salts (entries 13-16) showed a catalytic activity. Among them, 1-adamantyl (13c) (entry 1) and mesityl carboxylic acid (13a) (entry 9) gave the best yields, while phosphine-substituted (entry 3 ) and strong trifluoroacetic acids (entry 11) provided no alkylation. The same effect was observed in the absence of the base, the additive or the ruthenium catalyst (entry 10). Some carboxylates showed high activity, especially potassium mesityl carboxylate, delivered roughly $50 \%$ yield (entry 13 ); however, less than applying in-situ generation of this salt (entry 9).

Besides, the reactivity of other electrophiles under these reaction conditions was examined (Scheme 3.23). Unfortunately, neither alkyl iodides or chlorides nor tosylates showed any conversion in the attempted direct ruthenium-catalyzed alkylation.

\footnotetext{
140 Preliminary screening for suitable solvents was performed in cooperation with Dr. R. Vicente.

141 For all other products synthesized by the ruthemiun-catalyzed direct alkylations with secondary alkyl bromides, the substitution pattern was verified applying 2D-NMR analysis and/or nOe-experiments.
} 


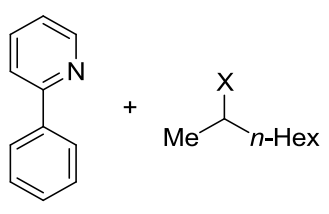

$6 a a$

$42 b$

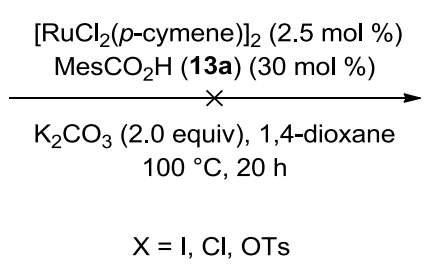

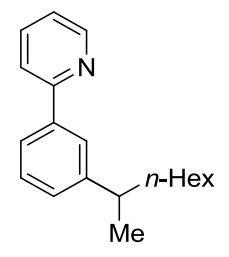

$147 a a$

Scheme 3.23: Screening of different leaving groups.

As indicated above, a degassed aqueous medium was well accepted for the ruthenium-catalyzed direct alkylation with primary alkyl halides. Therefore, a solvent screening was performed to determine, if water is tolerated to the same extent within the direct meta-alkylation (Scheme 3.24).

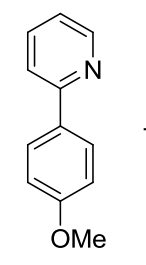

$6 \mathrm{ba}$<smiles>CCC(Br)[Pb]</smiles>

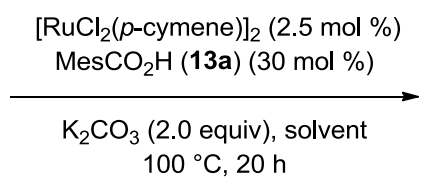

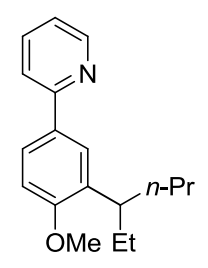

$147 b b$

$\begin{array}{lc}\text { 1,4-dioxane } & \\ \text { (without } \mathrm{MesCO}_{2} \mathrm{H} \text { ) } & 0 \% \\ \text { 1,4-dioxane } & 63 \% \\ \mathrm{H}_{2} \mathrm{O} & 49 \% \\ \text { neat } & \mathbf{7 0 \%}\end{array}$

Scheme 3.24: Direct meta-alkylation in different reaction media.

Under the standard reaction conditions applying 1,4-dioxane as the solvent, reaction of substrate 6ba with 3-bromopentane (42bb) furnished compound $147 \mathrm{bb}$ in a good yield (63\%), while in the absence of the carboxylic acid (13a) no product formation was observed. Employment of water as the reaction medium delivered $\mathbf{1 4 7 b b}$ in lower, but still good yield $(50 \%)$, whereas a reaction in the absence of solvent afforded the best yield of $70 \%$. Unfortunately, in further experiments the neat reaction conditions proved to be less suitable due to insufficient solubilities of several organic substrates.

\subsubsection{Direct meta-Alkylation: Scope \& Limitations}

In order to explore, to which extend this new reaction type is user-friendly and applicable, various substrates $\mathbf{6}$ and secondary alkyl bromides $\mathbf{4 2}$ b was tested under the optimized reaction conditions. First, the scope of secondary alkyl bromides was explored starting with cyclic aliphatic bromides (Table 3.11). 
Table 3.11: Scope of meta-alkylation with cyclic secondary alkyl bromides.<smiles>[R]c1ccc(-c2ccccn2)cc1</smiles>

6

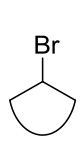

42b

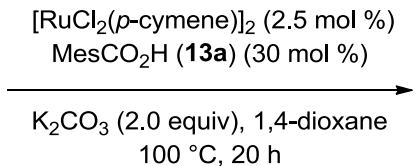
$100^{\circ} \mathrm{C}, 20 \mathrm{~h}$

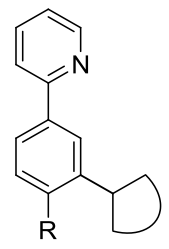

147

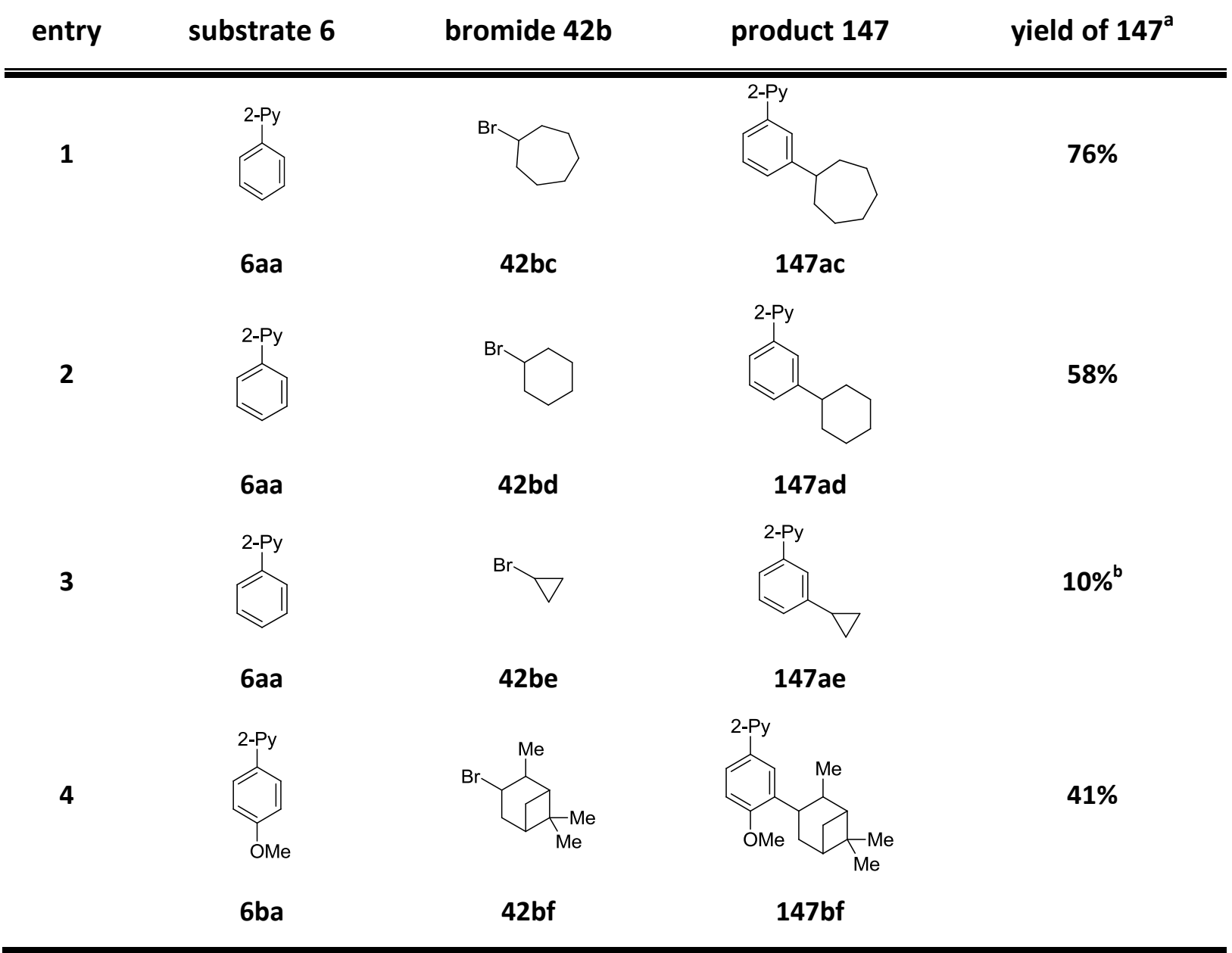

${ }^{a}$ Reaction conditions: 6 (0.5 mmol), $42 \mathrm{~b}$ (1.5 mmol), $\left[\mathrm{RuCl}_{2}(p \text {-cymene) }]_{2}(2.5 \mathrm{~mol} \%), \mathrm{MesCO}_{2} \mathrm{H}(13 \mathrm{a})(30 \mathrm{~mol} \%)\right.$, 1,4-dioxane $(2.0 \mathrm{~mL}), 20 \mathrm{~h}, 100{ }^{\circ} \mathrm{C} ;{ }^{\mathrm{b}}\left[\mathrm{RuCl}_{2}(p \text {-cymene })\right]_{2}(5.0 \mathrm{~mol} \%)$.

In ruthenium-catalyzed alkylations of 2-phenylpyridine (6aa) with bromocycloalkanes $\mathbf{4 2} \mathbf{b c} \mathbf{- 4 2} \mathbf{b f}$, ranging from 7-membered cycloheptyl (42bc) to 3-membered cyclopropyl bromide (42be) decreasing in the ring size smoothly decreased the yield from 76 to $10 \%$. This was not in line with the strain energies of the parent cyclic hydrocarbons cycloheptane, cyclohexane and cyclopropane, which are equal to $7.6,1.4,7.2$ and $28.1 \mathrm{kcal} \cdot \mathrm{mol}^{-1}$, respectively. ${ }^{142}$ However, this decreasing in yield appeared to be antithetic to the I-strain of corresponding bromides $\mathbf{4 2 b c - 4 2 b f .}{ }^{143}$ "I-strain" is that change in internal strain of a ring compound which results from a change in the coordination number (and the

\footnotetext{
${ }^{142}$ Schleyer, P. von R.; Williams, J. E., Jr.; Blanchard, K. P. J. Am. Chem. Soc. 1970, 92, 2377-2386.

${ }^{143}$ Brown, H. C.; Fletcher, R. S.; Johannesen, R. B. J. Am. Chem. Soc. 1951, 73, 212-221.
} 
preferred bond angle) of a ring atom involved in the reaction"144 and can in the first approximation be characterized by activity of the cyclic bromides in nucleophilic substitution reactions. For example, standard substitution protocols employed in larger ring systems are completely prohibitive in cyclopropane analogs $s^{145}$ or are highly disfavored in cyclobutane derivatives due to significant $s$ character. ${ }^{143}$ It should be mentioned that the formation of ring-opened products has not been detected. Sterically demanding substrate $\mathbf{4 2} \mathbf{b f}$, which has been synthesized from the corresponding racemic $\alpha$-pinen, was only able to alkylate the electron-rich substrate 147 bf (entry 4$)$.

The results of alkylations of 2-phenylpyridine (6aa) with acyclic secondary alkyl bromides $\mathbf{4 2 b}$ are presented in Table 3.12 .

Table 3.12: Scope of acyclic 2-bromoalkanes.<smiles>c1ccc(-c2ccccn2)cc1</smiles>

6aa<smiles>[R]C(Br)Br</smiles>

42b

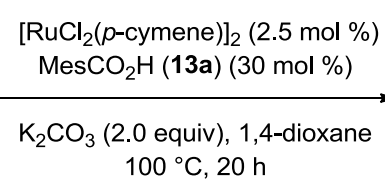

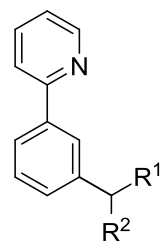

$147 a$
1<smiles>CCCCCCCCCCCCCCCCCCCCCCC</smiles>

2<smiles>CCC(Br)CC</smiles>

$42 \mathrm{bh}$

3<smiles>CCCPC(C)Br</smiles><smiles>CCCCC(CCCC)c1cccc(C(C)C)c1</smiles>

$147 \mathrm{ag}$<smiles>CCC(CC)c1cccc(Br)c1</smiles>

147ah<smiles>CCCCC(C)c1cccc(C(=O)c2ccccc2)c1</smiles>

$51 \%$

$42 \%$

\footnotetext{
144 Brown, H. C.; Gerstein, M. J. Am. Chem. Soc. 1950, 72, 2926-2933.

${ }^{145}$ Ryabchuk, P.; Rubina, M.; Xu, J.; Rubin, M. Org. Lett. 2012, 14, 1752-1755, and references cited therein.
} 


\section{$\begin{array}{llll}\text { entry bromide 42b } & \text { product } 147 a & \text { isolated yield }^{a}\end{array}$}

4<smiles>CCC(Br)[Pb]</smiles>

$42 b b$

5<smiles>CCC(C)c1cccc(Br)c1</smiles>

$147 a b$

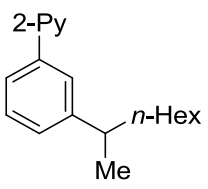

147aa
$26 \%$

$60 \%$

$42 \mathrm{ba}$

${ }^{\mathrm{a}}$ Reaction conditions: $6 \mathrm{aa}(0.5 \mathrm{mmol}), \mathbf{4 2 b}(1.5 \mathrm{mmol}),\left[\mathrm{RuCl}_{2}(p \text {-cymene })\right]_{2}(2.5 \mathrm{~mol} \%), \mathrm{MesCO}_{2} \mathrm{H}(13 \mathrm{a})(30 \mathrm{~mol} \%)$, 1,4-dioxane $(2.0 \mathrm{~mL}), 20 \mathrm{~h}, 100^{\circ} \mathrm{C}$.

Symmetric as well as unsymmetric secondary alkyl bromides were tested under the standard reaction conditions and provided results. Generally, the bromides 42 ba and $\mathbf{4 2}$ bg with longer hydrocarbon chains afforded better yield than homologous compounds $\mathbf{4 2}$ bi and $\mathbf{4 2}$ bh (entries 1 and 2, entries 3 and 5). Comparing reactivities of 2-bromopentane (42bi) (entry 3) and of 3bromopentane (42bb) (entry 4) resulted in the assumption, that the position of the leaving group in bromides $\mathbf{4 2} \mathbf{b}$ influenced the conversion to some extend as well.

As demonstrated above in Table 3.12 and Table 3.11, unsubstituted 2-phenylpyridine (6aa) itself was an appropriate substrate for the ruthenium-catalyzed direct meta-alkylation under mild reaction conditions. Furthermore, the influence of electron-donating and electron-withdrawing substituents in the phenyl moiety upon the efficiency of the alkylation was examined. The results of alkylations of electron-rich substrates (6) are shown in Table 3.13.

Table 3.13: Scope and limitations with para-substituted electron-rich phenylpyridines.

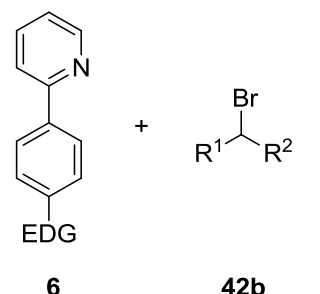

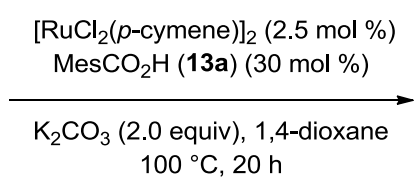

$100^{\circ} \mathrm{C}, 20 \mathrm{~h}$

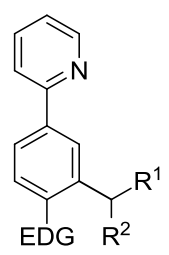

147

\section{$\begin{array}{llll}\text { entry substrate } 6 \quad \text { bromide } 42 \mathrm{~b} & \text { product } 147\end{array}$}

yield of $147^{\mathrm{a}}$

1




\begin{tabular}{|c|c|c|c|c|}
\hline entry & substrate 6 & bromide $42 b$ & product 147 & yield of $147^{a}$ \\
\hline 2 & & & & $70 \%$ \\
\hline 3 & & & & $60 \%$ \\
\hline 4 & & & & $56 \%$ \\
\hline \multirow[b]{2}{*}{5} & $6 \mathrm{ba}$ & $42 \mathrm{bk}$ & $7 \mathrm{bk}$ & \\
\hline & & & & $50 \%$ \\
\hline 6 & & & & $55 \%$ \\
\hline \multirow{3}{*}{7} & 6oa & $42 \mathrm{ba}$ & $1470 a$ & \\
\hline & & & -- & -- \\
\hline & 6ia & $42 \mathrm{ba}$ & & \\
\hline
\end{tabular}

${ }^{\mathrm{a}}$ Reaction conditions: 6 (0.5 mmol), $42 \mathrm{~b}(1.5 \mathrm{mmol}),\left[\mathrm{RuCl}_{2}(p \text {-cymene) }]_{2}(2.5 \mathrm{~mol} \%), \mathrm{MesCO}_{2} \mathrm{H}(13 \mathrm{a})(30 \mathrm{~mol} \%)\right.$, 1,4-dioxane $(2.0 \mathrm{~mL}), 20 \mathrm{~h}, 100^{\circ} \mathrm{C}$.

In general it can be emphasized that 2-phenylpyridines 6 with electron-donating para-substituents, such as methoxy or methyl, can be alkylated with a satisfying efficacy independently from the carbon chain length of the 2-bromoalkane 42b (entries 1-4,6). Sterically more demanding 5bromononane (42bg) gave slightly lower yields (entry 5), whereas a very bulky tert-butyl substituent completely inhibited the desired alkylation (entry 7).

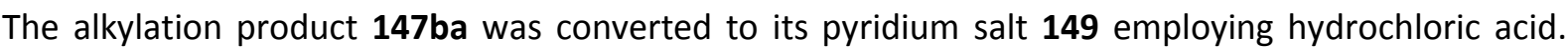
This salt was crystallized by slow evaporation of $\mathrm{DCM} / n$-hexane to afford crystals suitable for X-ray crystal structure analysis (Figure 3.5). 


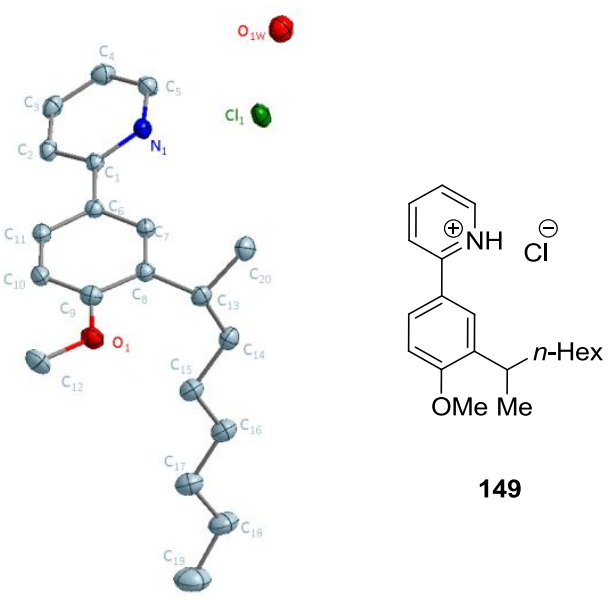

Figure 3.5: ORTEP plots (50\% probability thermal ellipsoids) of 2-[4-methoxy-2-(octan-2-yl)phenyl]pyridinium chloride (149) in the crystal. All hydrogen atoms have been omitted for clarity. Numbering does not correspond to the IUPAC rules.

Subsequent examination of electron-deficient 2-phenylpyridines (Table 3.14) showed that steric aspects seemed to affect the yield to larger extent than electronic ones in this newly developed reaction type. Comparison of the results from Table 3.13 with those from Table 3.14 clearly indicated this observation.

Table 3.14: meta-Alkylation of para-substituted electron-poor 2-phenylpyridines 6: Scope and limitations.

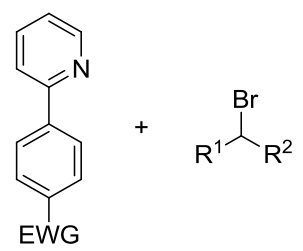

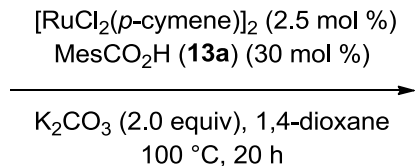

$100{ }^{\circ} \mathrm{C}, 20 \mathrm{~h}$

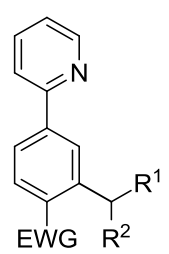

147

entry substrate $6 \quad$ bromide 42b




\begin{tabular}{|c|c|c|c|c|}
\hline entry & substrate 6 & bromide $42 b$ & product 147 & yield of $147^{a}$ \\
\hline 4 & & & & $50 \%$ \\
\hline \multirow[t]{2}{*}{5} & & & & $55 \%$ \\
\hline & $6 \mathrm{ka}$ & $42 b i$ & 147ki & \\
\hline \multirow[t]{2}{*}{6} & & & -- & - \\
\hline & 6ja & $42 \mathrm{ba}$ & & \\
\hline \multirow[t]{2}{*}{7} & & & & $63 \%$ \\
\hline & $6 p a$ & $42 b i$ & 147pi & \\
\hline \multirow[t]{2}{*}{8} & & $\mathrm{Me}_{n-\mathrm{Hex}}$ & -- & -- \\
\hline & $6 q a$ & $42 \mathrm{ba}$ & & \\
\hline \multirow[t]{2}{*}{9} & & & -- & -- \\
\hline & $6 r a$ & $42 \mathrm{bi}$ & & \\
\hline
\end{tabular}

${ }^{\mathrm{a}}$ Reaction conditions: 6 (0.5 mmol), $42 \mathrm{~b}(1.5 \mathrm{mmol}),\left[\mathrm{RuCl}_{2}(p \text {-cymene) }]_{2}(2.5 \mathrm{~mol} \%), \mathrm{MesCO}_{2} \mathrm{H}(13 \mathrm{a})(30 \mathrm{~mol} \%)\right.$, 1,4-dioxane $(2.0 \mathrm{~mL}), 20 \mathrm{~h}, 100{ }^{\circ} \mathrm{C}$.

2-(4-Fluorophenyl)pyridine (6ca) with decreased electron density of the arene moiety afforded good yields upon alkylation with various alkyl bromides $\mathbf{4 2 b}$ (entries 1 - 5), independently from the position of the bromine atom as well as from the carbon chain length in $\mathbf{4 2} \mathbf{b}$. Not surprisingly that (trifluorophenyl)pyridine 6ja showed no reactivity (entry 6), as this would involve a C-F bond activation step, which is a scarce reaction type in ruthenium catalysis. ${ }^{129}$

Not surprisingly, the nitrile group (entry 8 ) was not tolerated by this reaction, and the product formation was not detected. The chemical behavior of substrate $6 \mathrm{pa}$ with an ester functionality (entry 7) was of special interest because of two reasons. On the one hand, it demonstrated tolerance 
of functional groups towards ruthenium-catalyzed alkylation under basic reaction conditions and, on the other hand, such meta-alkylated carboxylate 147pi cannot be synthesized through Friedel-Crafts alkylations. Notably, the substrate $6 \mathrm{pa}$ furnished alkylated compound $147 \mathrm{pi}$ as the sole product without conversion of the ester group. For the comparison, the corresponding free acid did not give rise to any formation of the desired product, but only formed an ester with the alkyl bromide (entry 9).

The scope of the ruthenium-catalyzed carboxylate-assisted direct ortho-alkylation of metasubstituted ketimines 121 with $n$-hexyl bromide (42ab) has been discussed above (Table 3.6). Therefore, several meta-substituted arylpyridines $\mathbf{6}$ were alkylated with various 2-bromoalkanes $\mathbf{4 2 b}$ the optimized reaction conditions (Table 3.15).

Table 3.15: Substrate scope for meta-alkylation of meta-substituted 2-phenylpyridines.

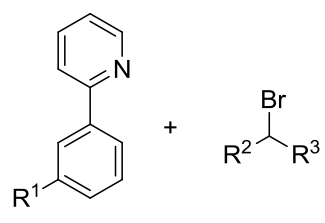

$$
\begin{gathered}
\underset{\left.\mathrm{RuCl}_{2}(p \text {-cymene })\right]_{2}(2.5-5.0 \mathrm{~mol} \%)}{\mathrm{MesCO}_{2} \mathrm{H}(13 \mathrm{a})(30 \mathrm{~mol} \%)} \\
\underset{\mathrm{K}_{2} \mathrm{CO}_{3}(2.0 \text { equiv }), 1,4 \text {-dioxane }}{100{ }^{\circ} \mathrm{C}, 20 \mathrm{~h}}
\end{gathered}
$$

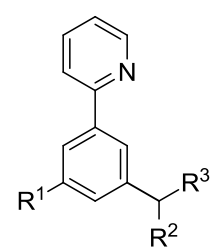

147

2




\begin{tabular}{|c|c|c|c|c|}
\hline entry & substrate 6 & bromide $42 b$ & product 147 & yield of $147^{a}$ \\
\hline \multirow{3}{*}{6} & $6 v a$ & 42bi & 147vi & \\
\hline & & & & $28 \%^{b}$ \\
\hline & $6 \mathrm{da}$ & 42bi & 147ai & \\
\hline
\end{tabular}

a Reaction conditions: 6 (0.5 mmol), $42 \mathrm{~b}(1.5 \mathrm{mmol}),\left[\mathrm{RuCl}_{2}(p \text {-cymene })\right]_{2}(2.5 \mathrm{~mol} \%), \mathrm{MesCO}_{2} \mathrm{H}(13 \mathrm{a})(30 \mathrm{~mol} \%)$, 1,4-dioxane $(2.0 \mathrm{~mL}), 20 \mathrm{~h}, 100{ }^{\circ} \mathrm{C} ;{ }^{\mathrm{b}}\left[\mathrm{RuCl}_{2}(p \text {-cymene })\right]_{2}(5.0 \mathrm{~mol} \%)$.

The direct alkylation of meta-substituted 2-phenylpyridine 6 proceeded with moderate yields of the desired products 147 (entries 1-3, 5, 6). Table 3.15 indicates, that the yields were almost unaffected by the electronic properties of the substituents in the substrates 6 . The lowest yield of $28 \%$ was obtained for electron-poor fluoro-substituted 2-phenylpyridine 6da (entry 6). Dimethylaminsubstituted arene 6ha completely failed in the direct alkylation (entry 4), presumably due to the formation of a stable ruthenium-complex.

In contrast to meta-substituted arylpyridines, in the case of their ortho-substituted analogues, two possible products corresponding to the two free meta-positions can be formed. The results on the chemical behavior of a variety of substrates 6 are summarized in Table 3.16.

Table 3.16: Substrate scope for meta-alkylation of ortho-substituted 2-phenylpyridines (6).<smiles>[R]c1ccnc(-c2ccccc2[R])c1</smiles>

6<smiles>[R]C([R])Br</smiles>

$42 b$

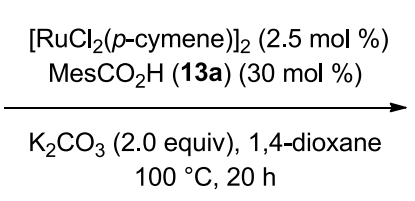
$100^{\circ} \mathrm{C}, 20 \mathrm{~h}$<smiles>[R]c1ccnc(-c2cc(C([R])[R])ccc2[R])c1</smiles>

147<smiles>[R]c1ccnc(-c2cccc(C([R])[R])c2[R])c1</smiles>

$147^{\prime}$

\section{entry substrate 6 bromide 42b product $147 \quad$ product 147'}

isolated yield

1

$6 z a$<smiles>CC(Br)CO</smiles><smiles>CC(C)c1ccc(F)c([18O])c1</smiles><smiles>CC(C)c1cccc(C(=O)c2ccccc2)c1F</smiles>

$19 \%$

$z a: z a^{\prime}=1 \cdot 0: 5 \cdot 3$

ratio $147: 147^{\text {a }}$

2

\section{$42 \mathrm{ba}$}

$147 z a$

147za'

6wa

$42 \mathrm{ba}$

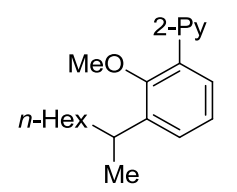

$43 \%$

wa:wa' =

1.0:1.2

Gwa 


entry substrate 6 bromide 42b

${ }^{a}$ Reaction conditions: 6 (0.5 mmol), $42 \mathrm{~b}$ (1.5 mmol), [RuCl $(p \text {-cymene) }]_{2}(2.5 \mathrm{~mol} \%), \mathrm{MesCO}_{2} \mathrm{H}(13 \mathrm{a})(30 \mathrm{~mol} \%)$, 1,4-dioxane $(2.0 \mathrm{~mL}), 20 \mathrm{~h}, 100{ }^{\circ} \mathrm{C}$; see, experimental part for the isolated yields of each isomer;

${ }^{\mathbf{b}}\left[\mathrm{RuCl}_{2}(p \text {-cymene })\right]_{2}(5.0 \mathrm{~mol} \%)$.

No general preference was detected for one of the two free meta-positions for all substrates 6 . Most substrate showed a slight priority for Only for the product 147', with three neighboring substituents. Only for the ortho-fluoro substrate 6za the product 147za' is clearly favoured, but the overall yield is unsatisfactory (entry 1). Yet, this electron-deficient substrate appeared to be less appropriate for alkylation than the electron-rich ones (entries 2-5). Among the latter, better yields were obtained for 2-phenylpyridines with less sterically demanding substituents (entries 2 and 3 ) than for $n$-octylsubstituted substrates 93a (entries 4 and 5). No transformation was observed upon attempted alkylation of ortho,ortho-dimethylated substrate 6ya (entry 6). In contrast to this, an additional methyl substituent on the pyridine ring did not influence the course of the alkylation (entry 7); an 1:2.9 mixture of compounds 147ea and 147ea' was isolated in good yield of $62 \%$ 
As the next important step, a variety of different directing groups was examined. First, the influence of the substitution pattern on the pyridine moiety was investigated. For this purpose, a broad range of 2-phenylpyridines 6 with substituents on the directing group were tested in alkylation under the optimized reaction conditions (Table 3.17).

Table 3.17 a: Substrate scope for meta-alkylation of 2-phenylpyridines substituted on the pyridine moieties.

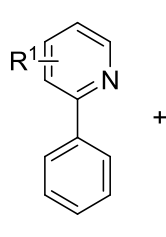

6<smiles>[R]C([R])Br</smiles>

42b
$\left[\mathrm{RuCl}_{2}(p \text {-cymene })\right]_{2}(2.5 \mathrm{~mol} \%)$ $\mathrm{MesCO}_{2} \mathrm{H}$ (13a) (30 mol \%)

$\mathrm{K}_{2} \mathrm{CO}_{3}$ (2.0 equiv), 1,4-dioxane $100^{\circ} \mathrm{C}, 20 \mathrm{~h}$<smiles>[R]C([R])c1cccc(-c2c[R1]ccn2)c1</smiles>

152<smiles>[R]C([R])c1cc(-c2[R17]ccn2)cc(C([R])[R])c1</smiles>

152

\section{entry substrate 6 \\ bromide}

$42 b$

\section{product 152}

yield of

$152^{\mathrm{a}}$ yield of

$152^{\prime a}$
1<smiles>COc1cccnc1-c1ccccc1</smiles><smiles>CCCCC(C)Br</smiles>

42 bj

2<smiles>COc1cccnc1-c1ccccc1</smiles><smiles>CCCC(C)Br</smiles>

$42 b i$

3<smiles>Cc1cccnc1-c1ccccc1</smiles>

$6 \mathrm{db}$<smiles>Cc1ccnc(-c2ccccc2)c1</smiles><smiles>BrC1CCCC1</smiles>

$6 e b$

4 42bj<smiles>COc1cccnc1-c1cccc(C(=O)N(C)C)c1</smiles>

152cj<smiles>CCCCCCC(C)c1cc(-c2ncccc2OC)cc(C(C(=O)c2ccccc2)[N+](=O)[O-])c1</smiles><smiles>CCCCCCC(C)C(=O)c1cccc(-c2ncccc2[N+](=O)[O-])c1</smiles>

152dj
$48 \%$

152cj'

$41 \%^{b}$

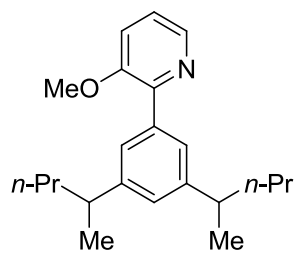

152ci'

5\%

$11 \%^{\mathrm{b}}$

$61 \%$<smiles>CCCCCCC(C)c1cc(-c2ncccc2C(C)C)cc(C(C)C(=O)c2ccccc2)c1</smiles>

152dj'
$\mathrm{Me}$

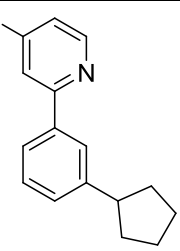

152ek
$38 \%$

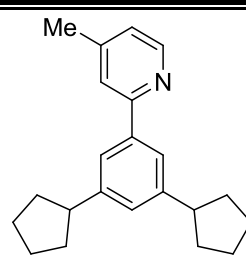

152ek' 


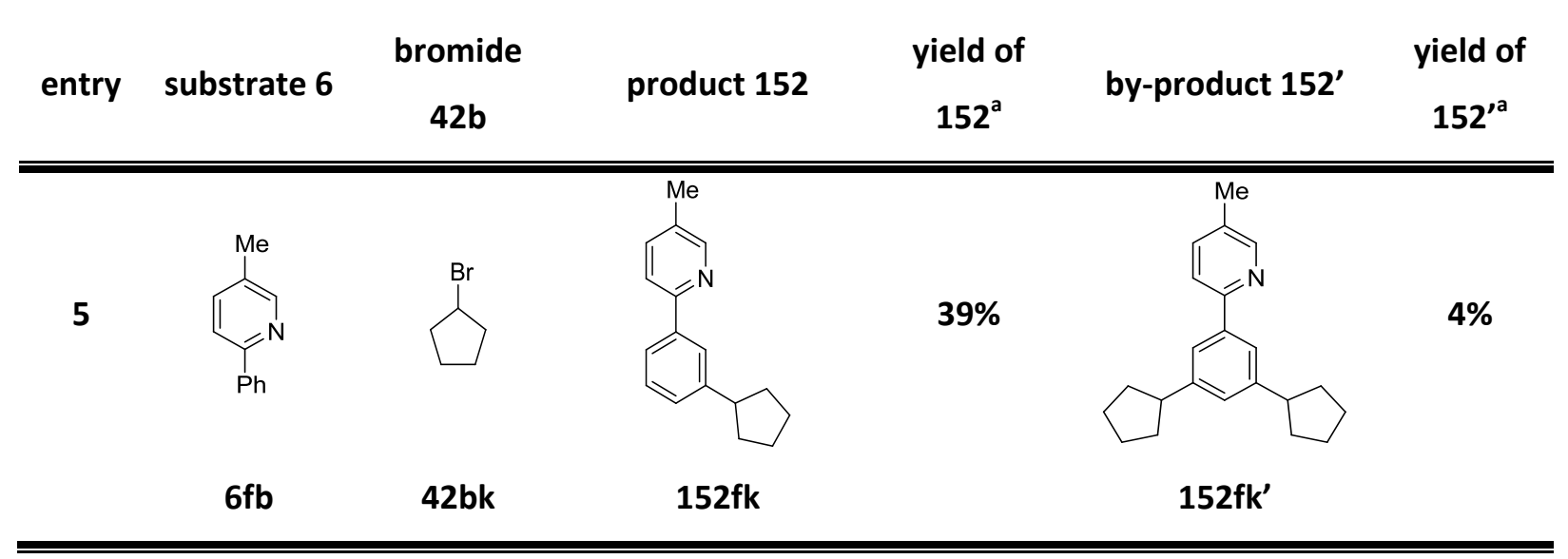

${ }^{\mathrm{a}}$ Reaction conditions: 6 (0.5 mmol), $42 \mathrm{~b}(1.5 \mathrm{mmol}),\left[\mathrm{RuCl}_{2}(p \text {-cymene })\right]_{2}(2.5 \mathrm{~mol} \%), \mathrm{MesCO}_{2} \mathrm{H}(13 \mathrm{a})(30 \mathrm{~mol} \%)$, 1,4-dioxane $(2.0 \mathrm{~mL}), 20 \mathrm{~h}, 100{ }^{\circ} \mathrm{C} ;{ }^{\mathrm{b}}\left[\mathrm{RuCl}_{2}(p \text {-cymene })\right]_{2}(5.0 \mathrm{~mol} \%)$.

Table 3.17 b

6




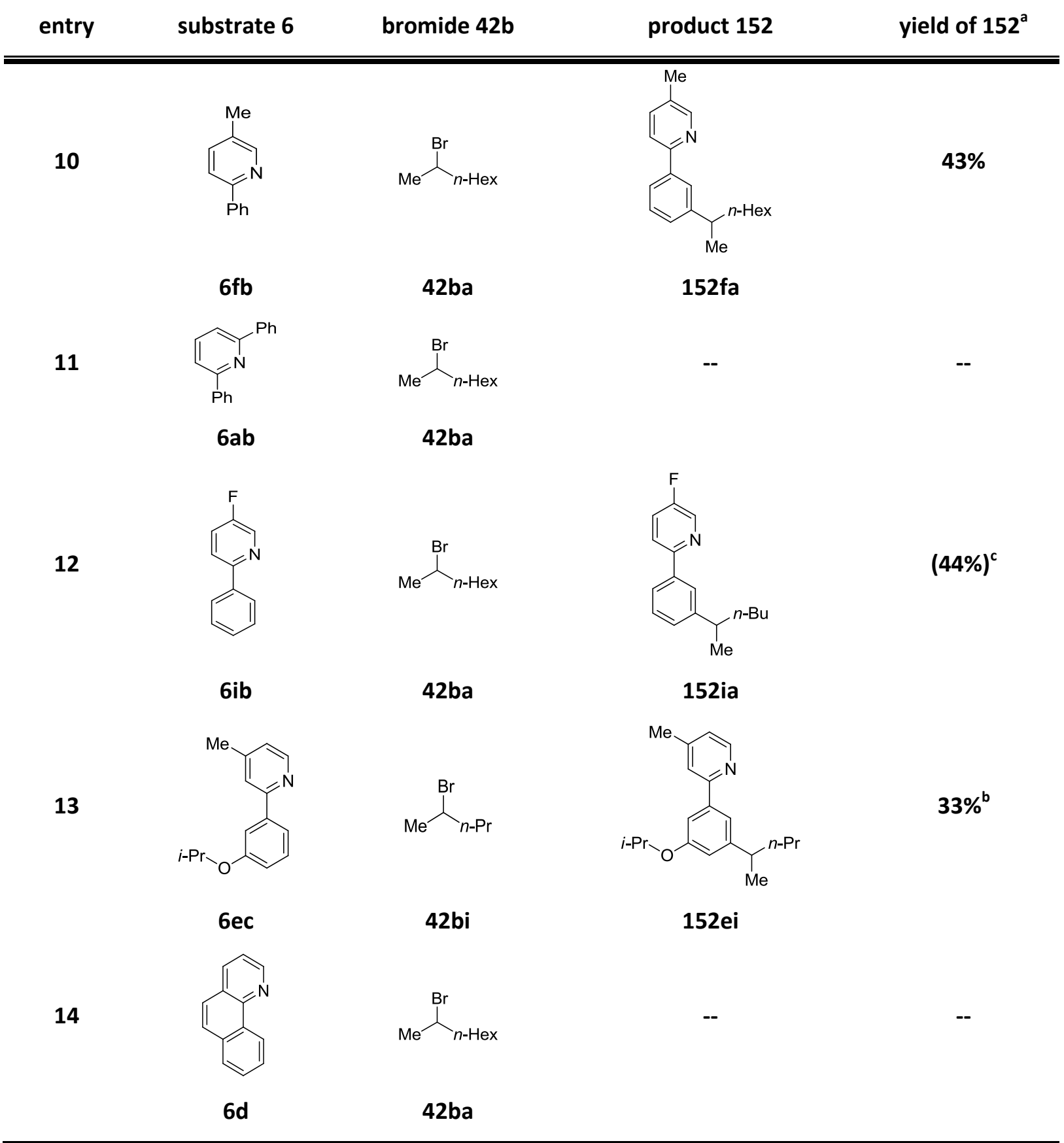

${ }^{\mathrm{a}}$ Reaction conditions: 6 (0.5 mmol), $42 \mathrm{~b}$ (1.5 mmol), $\left[\mathrm{RuCl}_{2}(p \text {-cymene) }]_{2}(2.5 \mathrm{~mol} \%), \mathrm{MesCO}_{2} \mathrm{H}(13 \mathrm{a})(30 \mathrm{~mol} \%)\right.$, 1,4-dioxane (2.0 mL), $20 \mathrm{~h}, 100{ }^{\circ} \mathrm{C} ;{ }^{\mathrm{b}}\left[\mathrm{RuCl}_{2}(p \text {-cymene })\right]_{2}(5.0 \mathrm{~mol} \%) ;{ }^{\mathrm{c}} \mathrm{GC}-\mathrm{MS}$ conversion.

Generally, substitution with methyl or methoxy groups on pyridine resulted in high conversions and moderate to good isolated yields (Table 3.17; entries 1 - 10). In several cases, including alkylations with cyclopentyl bromide (42bk) (Table 3.17; entries 4 and 5), formation of bis-alkylated products 152' in substantial amounts was detected (Table 3.17 a). 4-Methoxy and -methyl substituents (entries 6 and 7) decreased the reactivity of substrates 6 to some extent, while the second electrondonating substituent onto the carbocyclic ring (entry 13) did not affect the yield. Most probably, the higher electron density on the nitrogen atom could influence the stability of the possible intermediate ruthenacycles thus hampering the $\mathrm{C}-\mathrm{H}$ bond activation step, and this situation cannot 
be improved by additional substituent in a carbocyclic ring (entry 13). In contrast to this, 5- (entry 8 ) and 3-methylated substrates (entries 9 and 10) gave high conversions and afforded products $\mathbf{1 5 2 f a}$ and $\mathbf{1 5 2 f i}$ in improved yields, whereas 5-fluorosubstituted 2-phenylpyridine 6ib demonstrated a reduced reactivity (entry 12). The substrate 6 ab with a phenyl substituent in position 6 of the pyridine moiety (entry 11 ) and benzo[h]quinoline (6d) (entry 14) did not demonstrate any reactivity towards the desired alkylation. Presumably, sterical interactions and changing electron density on the ruthenium atom are capable to impede the formation of intermediate ruthenacycles in the former case, while rigidity of the skeleton of $\mathbf{6 d}$ completely excluded its meta-alkylation in the latter one.

In contrast to 2-arylpyridines 6, meta-alkylation of arenes activated by directing groups with two nitrogen atoms normally required a higher catalyst loading. Thus, 2-phenylpyrimidine (153) gave high conversion when using $5.0 \mathrm{~mol} \%$ of the ruthenium precursor under otherwise identical reaction conditions (Scheme 3.25). Surprisingly, relatively large amount of the bis-alkylated product 154' was formed.

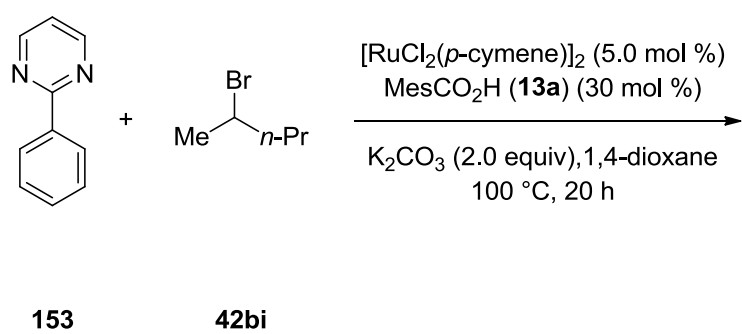

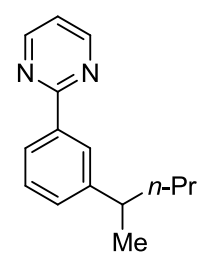

154

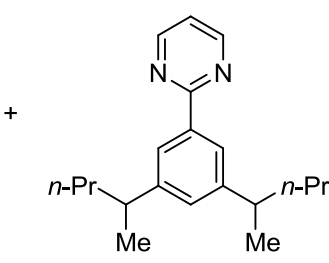

$154^{\prime}$

$12 \%$

Scheme 3.25: Ruthenium-catalyzed direct meta-alkylation of 2-phenylpyrimidine (153)

Since the alkylation of 2-phenylpyrimidine (153) proved to be less chemoselective, substrates with other directing groups have been tested (Scheme 3.26 and Figure 3.6).<smiles>Oc1ccccc1</smiles>

I

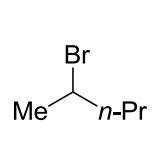

$42 b i$

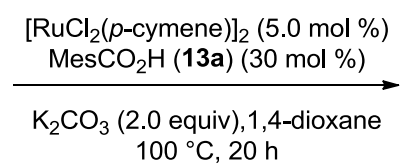

$100{ }^{\circ} \mathrm{C}, 20 \mathrm{~h}$<smiles>CCC(c1cccc([O-])c1)[N+](=O)[O-]</smiles>

II

Scheme 3.26: Examination of different nitrogen-containing directing groups. 


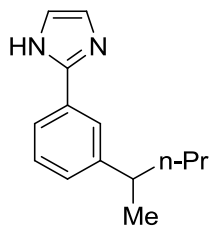

155

$44 \%$<smiles>N#CC(=O)c1cccc(-n2cccn2)c1</smiles>

156 $2.5 \mathrm{~mol} \%[\mathrm{Ru}]_{2}: \quad 0 \%$ $5.0 \mathrm{~mol} \%[\mathrm{Ru}]_{2}: \quad \mathbf{4 3} \%$ $10 \mathrm{~mol} \%[\mathrm{Ru}]_{2}: \mathbf{5 0} \%$<smiles>CCCC(C)c1cccc(-c2nc3ccccc3n2C(C)(F)F)c1</smiles>

157

$54 \%$

Figure 3.6: Results for substrates with other DG und the conditions mentioned in Scheme 3.26.

Summarizing the data from Figure 3.6, arenes with various directing groups, including unprotected imidazole (155), pyrazole (156) and $N$-methylated benzimidazole (157) proved to be reactive towards meta-alkylation under mild reaction conditions. The isolated yields could be raised up to $54 \%$ when applying $5.0 \mathrm{~mol} \%$ of the ruthenium precatalyst. Nevertheless, pyridine is still considered to be the most efficient directing group.

While previous results for the direct ortho-alkylation of electron-deficient ketimines $\mathbf{1 2 1}$ with primary alkyl bromides 42a afforded very good yields, the direct meta-alkylation of compound 121a with secondary alkyl bromides $\mathbf{4 2}$ ba and $\mathbf{4 2 b c}$ delivered unsatisfactory yields (Scheme 3.27).
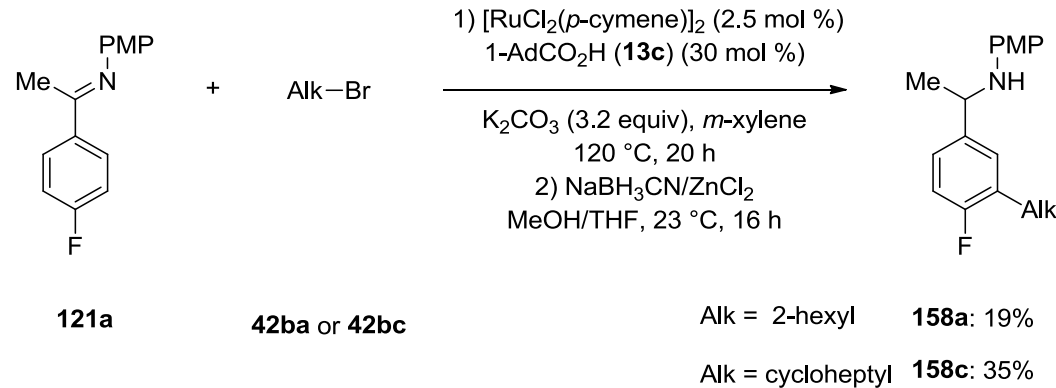

Scheme 3.27: Attempted ruthenium-catalyzed direct meta-alkylation of ketimine 121a as the substrate.

Among other potentially appropriate substrates 159-166 which were tested towards the direct ruthenium-catalyzed meta-alkylation with secondary alkyl bromides under the optimized reaction conditions (Figure 3.7), unfortunately, none of them demonstrated promising conversions to the desired alkylated product.<smiles>CC1(C)COC(c2ccccc2)=N1</smiles><smiles>c1ccc(-c2ncco2)cc1</smiles><smiles>c1ccc(C2=NCCN2)cc1</smiles><smiles>[R]n1nnnc1-c1ccccc1</smiles>

17<smiles>c1ccc(N=NN2CCCCC2)cc1</smiles>

161<smiles>Cc1cn(-c2ccccn2)c2ccccc12</smiles><smiles>c1ccc(Oc2ccccn2)cc1</smiles>

163<smiles>C(=C/c1ccccn1)\c1ccccc1</smiles>

$165 \quad 166$

Figure 3.7: Unreactive substrates for the ruthenium-catalyzed direct meta-alkylation. 


\subsubsection{Experiments towards Enantioselective Direct meta-Alkylation}

Upon this newly developed direct meta-selective ruthenium-catalyzed $\mathrm{C}-\mathrm{C}$ bond forming process, a new stereogenic benzylic carbon centre is generated. Therefore, several experiments towards the enantioselective $\mathrm{C}-\mathrm{H}$ bond functionalization were conducted.

First, enantiomerically pure 2-bromooctane [(S)-42ba] was used as electrophile to determine whether the stereochemical information was retained (Scheme 3.28).

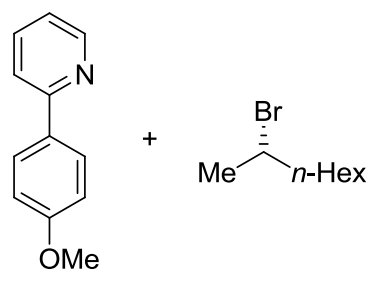

$6 \mathrm{ba}$

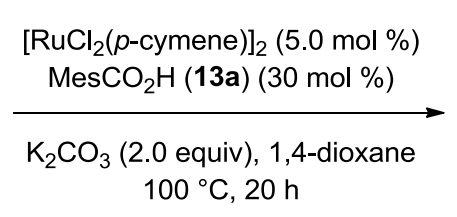

$53 \%$

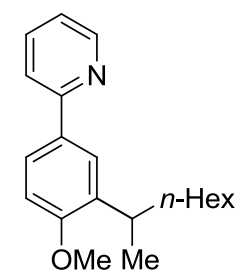

(rac)-147ba

Scheme 3.28: Ruthenium-catalyzed direct meta-alkylation with enantiopure (S)-42ba.

The formation of the racemic product was determined under the optimized reaction conditions. A radical pathway or the formation of a planary carbo-cation species can be hypothesized. The yield of the racemic product ( $r a c)-147$ ba in this experiment was in the same range as in the preparation with racemic 2-bromooctane (42ba) (Table 3.13).

For further experiments, a separation of the two enantiomeric products of the alkylation reaction using preparative chiral HPLC-techniques was carried out. The structure and absolute configuration for arbitrary selected $(R)$-enantiomere of the compound $147 \mathrm{bj}$ was established by X-ray crystal structure analysis of its hydrochloride (Figure 3.8).

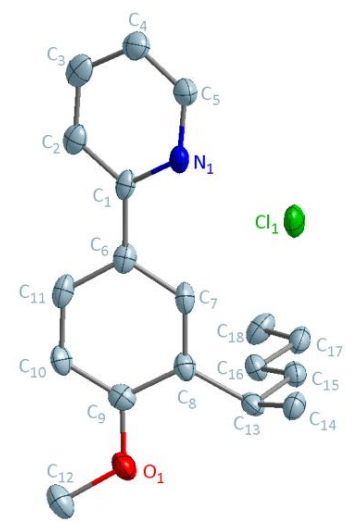

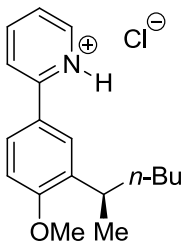

(R)-167

Figure 3.8: ORTEP plots (50\% probability thermal ellipsoids) of (R)-2-[4-methoxy-2-(hexan-2-yl)phenyl]pyridinium chloride $((R)$-167) in the crystal. Numbering does not correspond to the IUPAC rules. All hydrogen atoms have been omitted for clarity. 
To exclude racemization during the alkylation reaction, an enantioselective pure alkylation product (S)-147bj was submitted to the standard reaction conditions (Scheme 3.29).
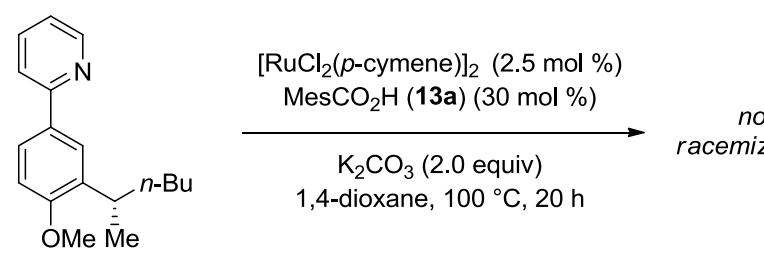

(S)-147bj

Scheme 3.29: Attempted racemization of $(S)-147 \mathrm{bj}$ under standard reaction conditions.

Under these reaction conditions, no racemization on the stereogenic centre was detected, according to results of HPLC analysis on chiral stationary phase. Such a configurative stability of stereogenic centre under the reaction conditions indicates the possibility to elaborate an enantioselective direct alkylation.

Next, it was tested, whether a chiral solvent could give access to enantiomerically an enriched product $147 \mathrm{ba}$. According to a published protocol, ${ }^{187187}$ enantiomerically pure benzyl ether $(R)-168$ was synthesized and degassed several times applying the Freeze-Pump-Thaw degassing procedure. However, no product formation was detected through alkylation under these slightly modified reaction conditions (Scheme 3.30).

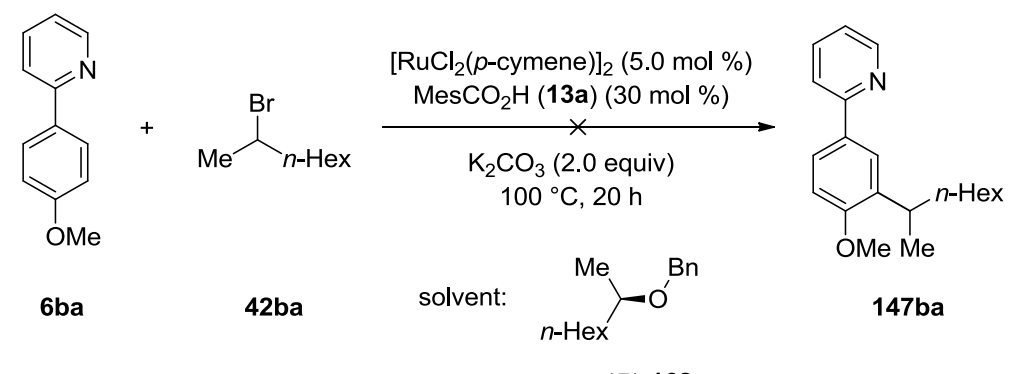

$(R)-168$

Scheme 3.30: Attempted meta-alkylation of 6 ba applying chiral solvent $(R)-168$.

\subsubsection{Chiral Amino Acid-derived Additives}

The invention of a enantioselective palladium-catalyzed direct alkylation employing mono-protected amino acids (MPAA) as chiral ligands by $Y u$ has attracted considerable attention. ${ }^{87}$

As these transformations afforded relatively high enantioselectivities and excellent yields, several MPAAs (76) were synthesized according to the published procedures and tested as additives for the ruthenium-catalyzed direct meta-alkylation (Table 3.18) together with chiral carboxylic acids 170, L172 and D-172 (entries 7, 9 and 10) with water or 1,4-dioxane as reaction medium. 
Table 3.18: Screening for most efficient chiral additive.<smiles>c1ccc(-c2ccccn2)cc1</smiles>

$6 a a$<smiles>CC(Br)OC#N</smiles>

$42 \mathrm{ba}$

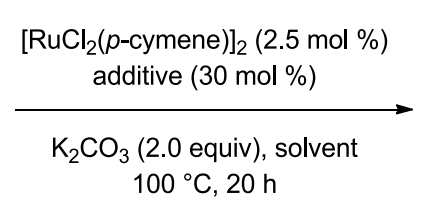

$100^{\circ} \mathrm{C}, 20 \mathrm{~h}$<smiles>CC(OCc1cccc(-c2ccccn2)c1)c1ccccc1</smiles>

147 aa

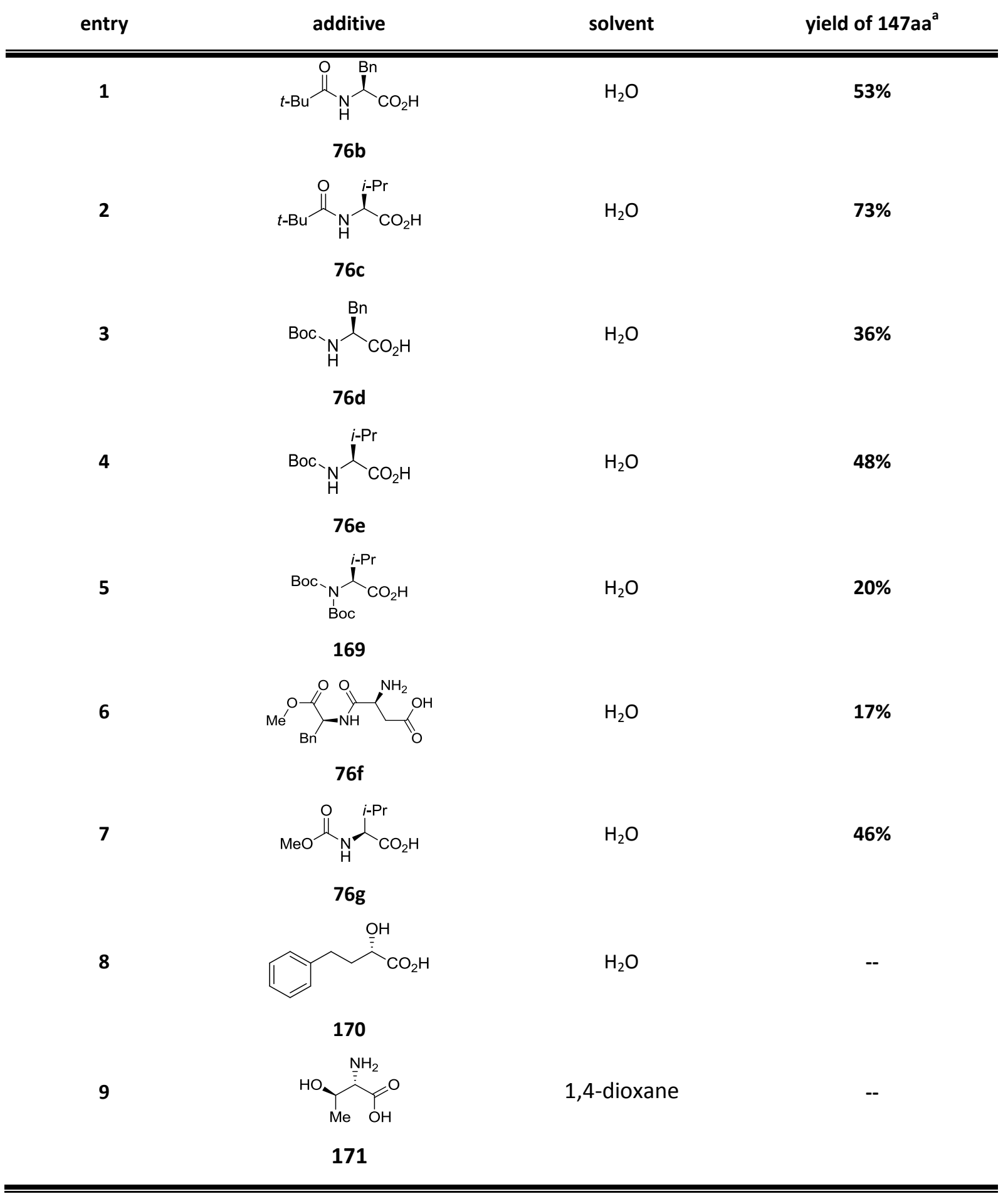




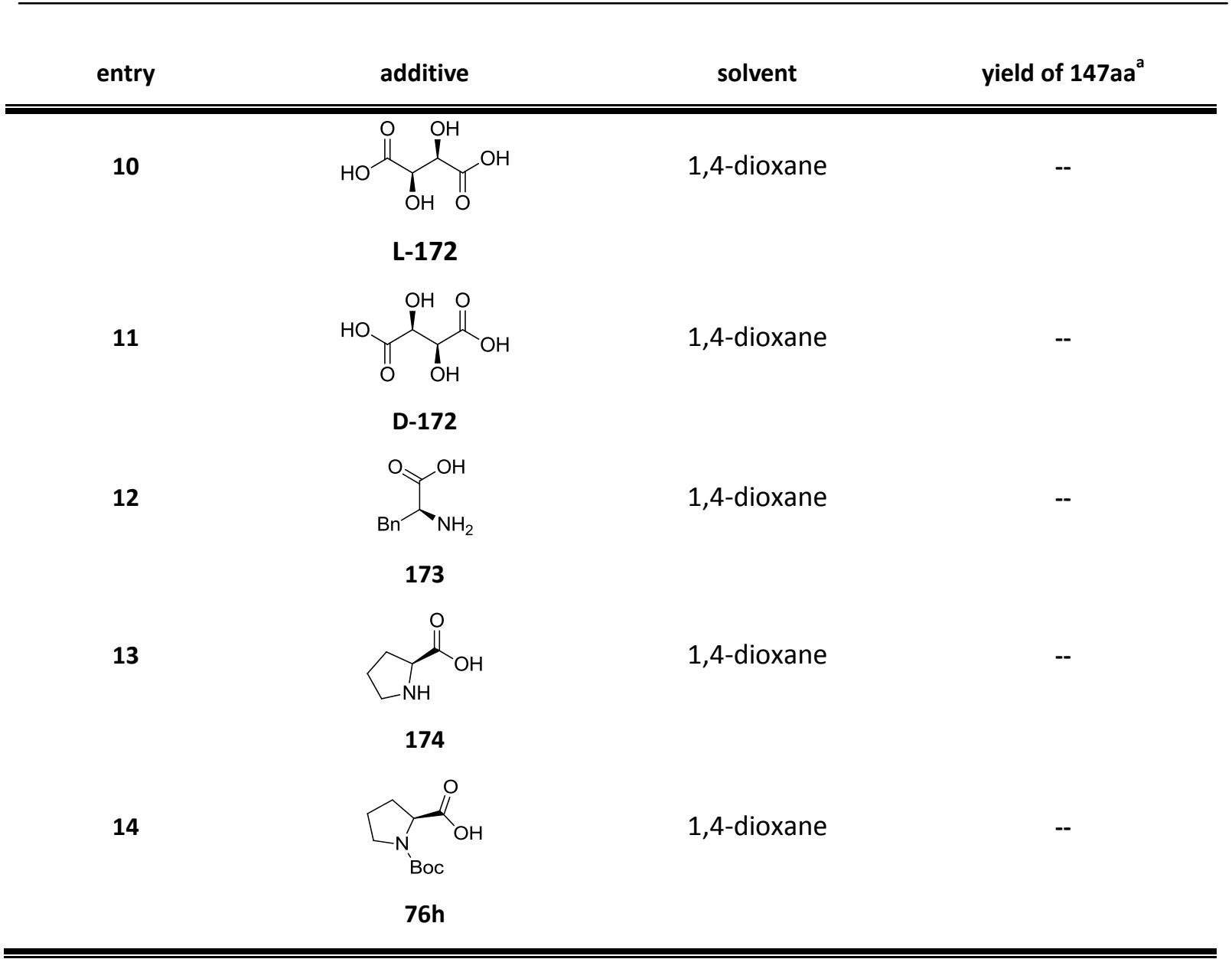

${ }^{a}$ Reaction conditions: $6 \mathrm{aa}(0.5 \mathrm{mmol}), 42 \mathrm{ba}(1.5 \mathrm{mmol}),\left[\mathrm{RuCl}_{2}(p \text {-cymene })\right]_{2}(2.5 \mathrm{~mol} \%)$, additive (30 mol \%), solvent $(2.0 \mathrm{~mL}), 20 \mathrm{~h}, 100^{\circ} \mathrm{C}$.

Several chiral amino acid-derived additives were tested to determine their efficiency as co-catalyst. Mono- $N$-protected phenylalanine- and leucine-derived additives $\mathbf{7 6 b - 7 6 e ~ p r o v e d ~ t o ~ g i v e ~ s a t i s f a c t o r y ~}$ results when using water as the solvent (entries 1 - 4). Among them, pivaloyl-protected leucine (76c) (entry 2) gave a better yield than the corresponding Boc-protected amino acid (76e) (entry 4).

The use of di-N-Boc-protected leucine $\mathbf{1 6 9}$ (entry 5) as well as of dipeptide $\mathbf{7 6 f}$ (entry 6) did not turn out to be beneficial. Free alcohol functionalities inhibited the reaction, and the product formation was observed neither with water nor with 1,4-dioxane as reaction medium (entries 8 - 10). The same result was obtained using unprotected proline (174), phenylalanine (173) and Boc-protected proline 76h as ligands in 1,4-dioxane.

Remarkably, upon alkylation of 2-phenylpyridine (6aa) as a standard substrate, MPAA 76c as a cocatalyst afforded a higher yield (73\%, entry 2 ) than mesityl carboxylic acid (13a) (60\%, Table 3.10), but with water as the reaction medium. Because of this, several additional screening experiments with mono-protected leucine $\mathbf{7 6 g}$ towards optimization of the reaction conditions was performed. Thus, the influence of the reagents ratio was investigated (Scheme 3.31). 


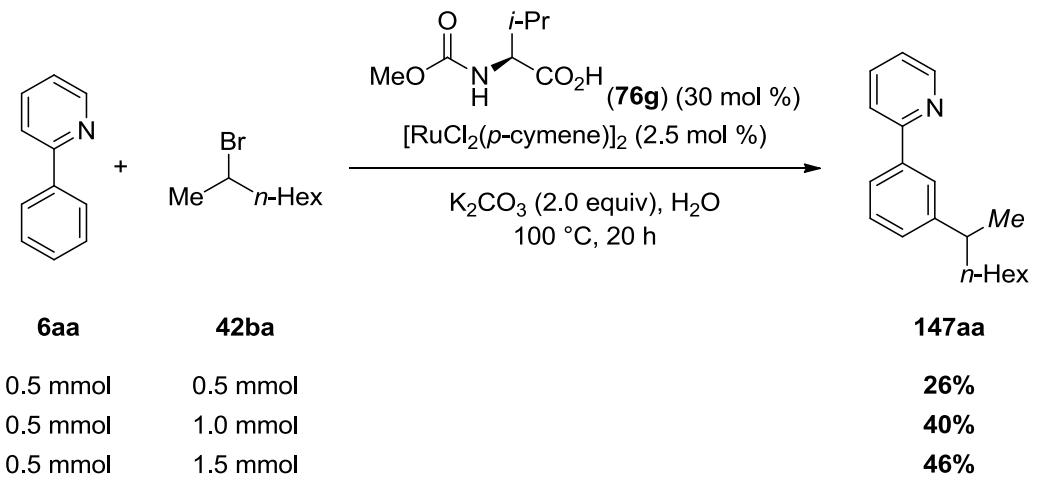

Scheme 3.31: Screening for the optimal ratio between 2-phenylpyridine (6aa) and 2-bromooctane (42ba).

The results shown in Scheme 3.31 obviously indicate that the ratio of 1:3 still remains the most efficient also for MPAAs as co-catalysts. Furthermore, a screening of co-catalyst loading and reaction temperature was performed with this most efficient amino acid derivative 76c (Table 3.19).

Table 3.19: Screening for optimal additive loading and reaction temperature.

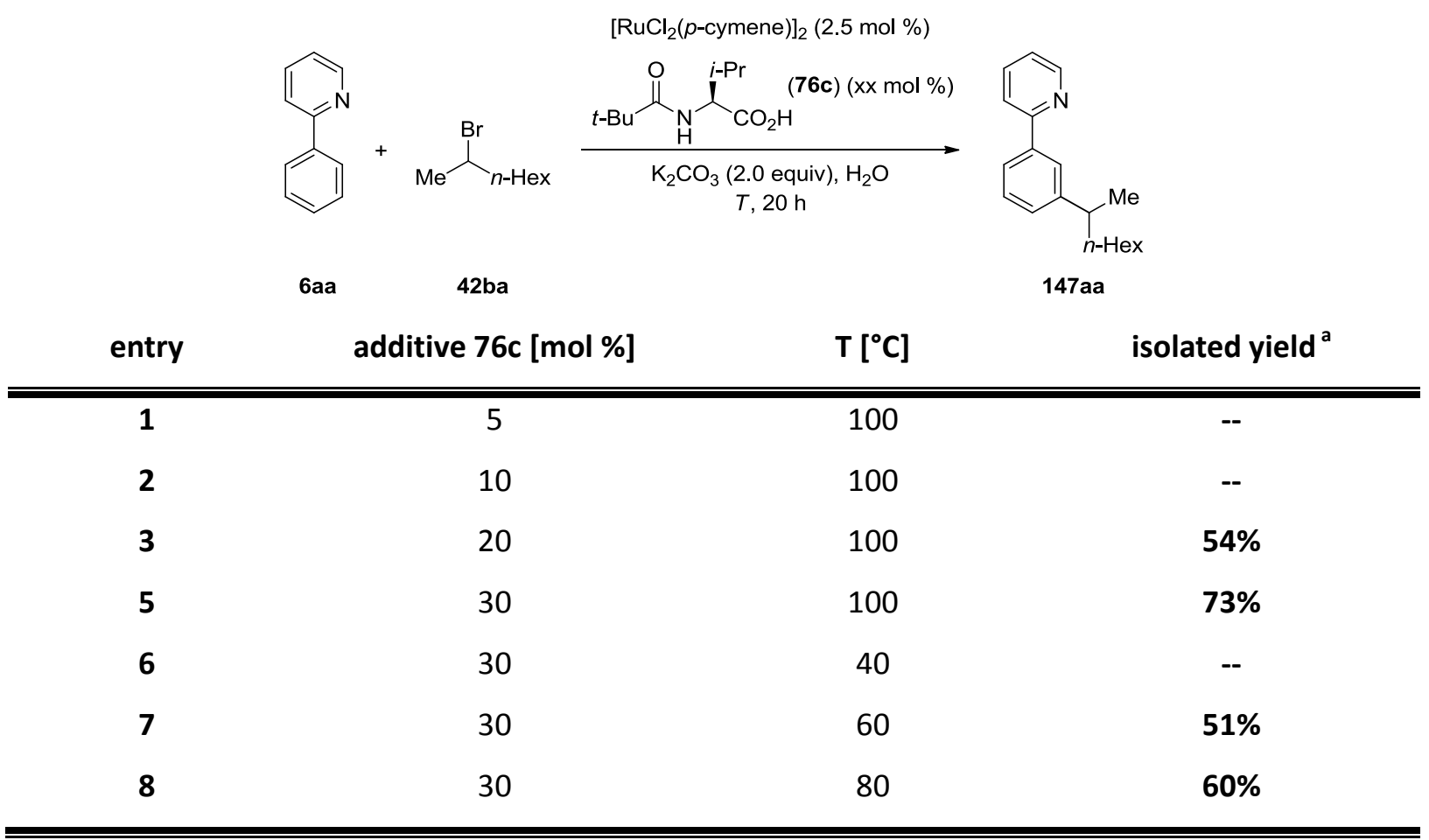

${ }^{\mathrm{a}}$ Reaction conditions: 6aa $(0.5 \mathrm{mmol}), 42 \mathrm{ba}(1.5 \mathrm{mmol}),\left[\mathrm{RuCl}_{2}(p \text {-cymene })\right]_{2}(2.5 \mathrm{~mol} \%), \mathrm{H}_{2} \mathrm{O}(2.0 \mathrm{~mL}), 20 \mathrm{~h}$.

Upon decreasing the cocatalyst loading to $20 \mathrm{~mol} \%$, the yield dropped to $54 \%$ (entry 3), while no conversion was detected applying less cocatalyst. It was also found that by rising the temperature to $60{ }^{\circ} \mathrm{C}$ the reaction still furnished the desired product in good yield.

An additional screening for solvents (Table 3.20) indicated no general rules for the optimal solvent. Thus, non-polar aromatic solvents (entries 2 and 5) appeared to be of similar efficacy as 1,4-dioxane (entry 1 ), while no transformation proceeded in non-polar $n$-hexane (entry 6 ), presumably because of 
solubility problems, as well as in polar DMA (entry 3), t-AmOH (entry 4) or methanol (entry 7). Degassed water still represented the most efficient solvent, however, control experiments without base, additive or ruthenium gave negative results (entry 9). Alternatively, triethylamine as the organic base was tested (entry 10), however, with moderate success.

Table 3.20: Solvent-screening with pivaloyl-protected leucine $\mathbf{7 6 c}$ as the additive.

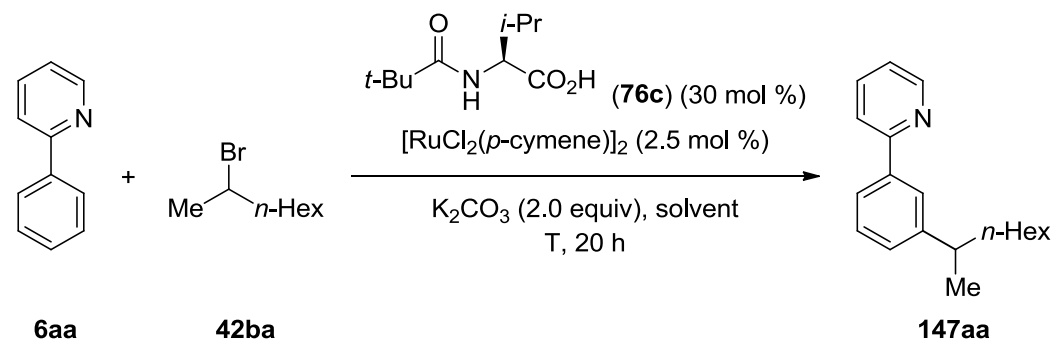

\begin{tabular}{|c|c|c|c|c|c|c|c|}
\hline entry & solvent & $\mathbf{T}$ & isolated yield $^{\mathrm{a}}$ & entry & solvent & $T$ & isolated yield $^{\mathrm{a}}$ \\
\hline 1 & 1,4-dioxane & $100^{\circ} \mathrm{C}$ & $61 \%$ & 6 & $n$-hexane & $65^{\circ} \mathrm{C}$ & -- \\
\hline 2 & PhMe & $100^{\circ} \mathrm{C}$ & $59 \%$ & 7 & $\mathrm{MeOH}$ & $65^{\circ} \mathrm{C}$ & -- \\
\hline 3 & DMA & $100^{\circ} \mathrm{C}$ & -- & 8 & $\mathrm{H}_{2} \mathrm{O}$ & $100^{\circ} \mathrm{C}$ & $73 \%$ \\
\hline 4 & $t-\mathrm{AmOH}$ & $100^{\circ} \mathrm{C}$ & -- & 9 & $\mathrm{H}_{2} \mathrm{O}$ & $100^{\circ} \mathrm{C}$ & $--{ }^{b}, c$, or d \\
\hline 5 & $m$-xylene & $100^{\circ} \mathrm{C}$ & $50 \%$ & 10 & $\mathrm{H}_{2} \mathrm{O}$ & $100^{\circ} \mathrm{C}$ & $32 \%{ }^{e}$ \\
\hline
\end{tabular}

${ }^{\mathrm{a}}$ Reaction conditions: 6aa $(0.5 \mathrm{mmol}), 42 \mathrm{ba}(1.5 \mathrm{mmol}),\left[\mathrm{RuCl}_{2}(p-c y m e n e)\right]_{2}(2.5 \mathrm{~mol} \%), \mathrm{H}_{2} \mathrm{O}(2.0 \mathrm{~mL}), 20 \mathrm{~h} ;{ }^{\mathrm{b}}$ no catalyst; ${ }^{c}$ no additive; ${ }^{d}$ no base; ${ }^{e} \mathrm{NEt}_{3}$ as base (2.0 equiv).

Applying the optimized reaction conditions, the electron-rich substrates $6 \mathrm{ba}$ and $\mathbf{6 c a}$ can be alkylated with higher yields in comparison with electron-deficient one 6oa, which furnished only moderate yield (Scheme 3.32). With a sterically demanding, but electron-donating substituent the product 147 can be obtained in a good yield, which was in the same range as with mesityl carboxylic acid (13a) as additive.
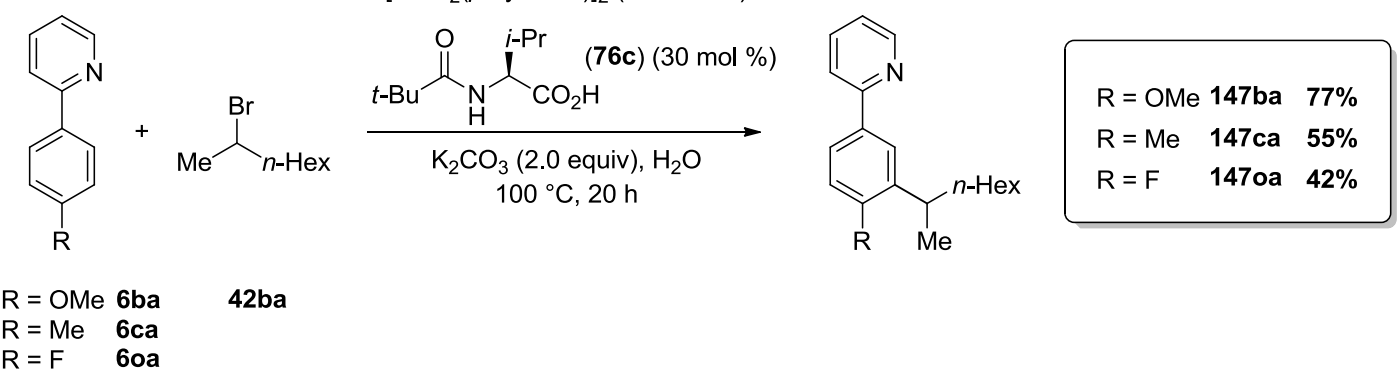

Scheme 3.32: Examples for the direct meta-Alkylation with additive 76c. 
Unfortunately, although in all reactions discussed above only enantiomerically pure L-amino acid derivatives were used, HPLC analysis on chiral stationary phase indicated exclusively the formation of racemic products without any enantiomeric excess.

Lipschutz, ${ }^{146}$ Scarso ${ }^{147}$ and others have demonstrated the beneficial effect of phase transfer catalysts, such as polyoxyethanyl $\alpha$-tocopheryl sebacate (PTS), for transition metal-catalyzed cross-couplings or asymmetric Bayer-Villiger oxidation reactions in water. Potential activity of PTS as an additional cocatalyst has also been tested in ruthenium-catalyzed direct meta-alkylation of 2-phenylpyridine (6aa) with pivaloyl-protected leucine (76c) as additive in water as a solvent (Scheme 3.33)

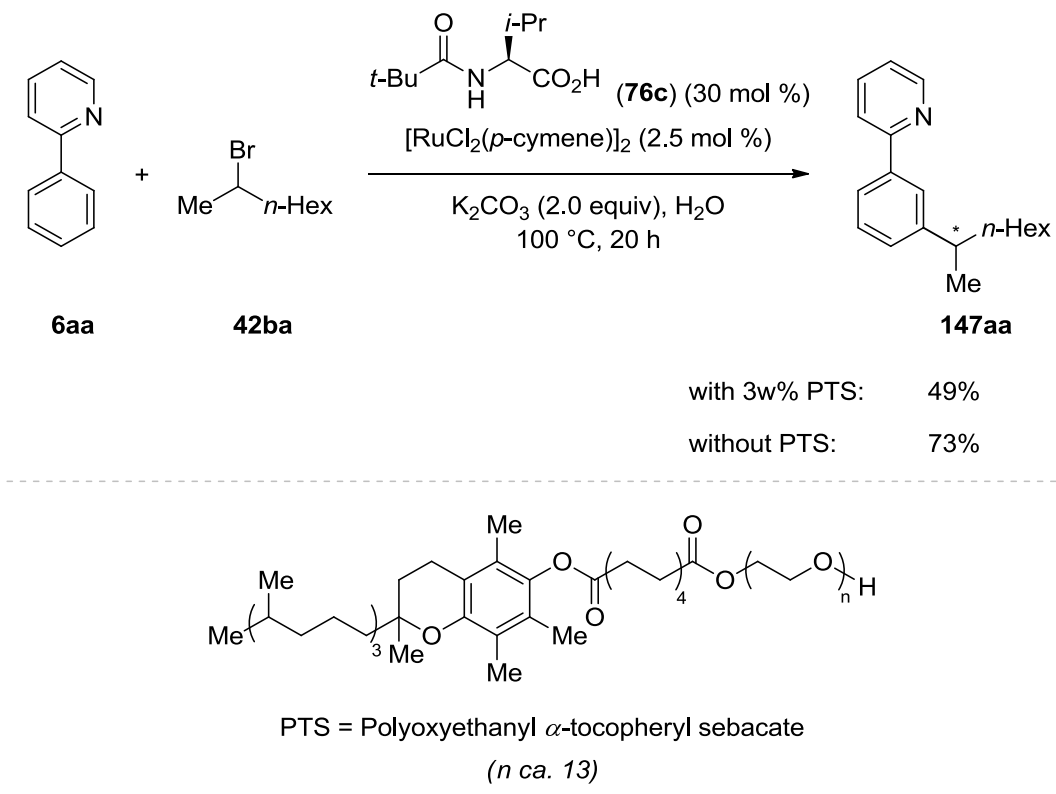

Scheme 3.33: Examining the influence of phase transfer catalyst PTS in the direct meta-alkylation with water as the solvent.

Decreasing the yield about roughly one third indicated that the reaction presumably proceeded rather on water than in water. ${ }^{148}$

\footnotetext{
146 Lipshutz, B. H.; Ghorai, S.; Leong, W. W. Y.; Taft, B. R.; Krogstad, D. V. J. Org. Chem. 2011, 76, 5061-5073.

${ }^{147}$ Cavarzan, A.; Bianchini, G.; Sgarbossa, P.; Lefort, L.; Gladiali, S.; Scarso, A.; Giorgio Strukul, G. Chem. Eur. J. 2009, 15, 7930-7939.

148 Reviews: (a) Butler, R. N.; Coyne, A. G. Chem. Rev. 2010, 110, 6302-6337. (b) Narayan, S.; Fokin, V. V.; Sharpless, K. B. In Organic Reactions in Water: Principles, Strategies and Applications (ed.: Lindström, U. M), Marcus Blackwell Publishing Ltd: N.-Y., 2007, pp. 350-365.
} 


\subsubsection{Phosphoric Acid Esters as Chiral Additives}

Since chiral MPAAs as additives afforded high yields of alkylated 2-phenylpyridines 147, but unfortunately only in racemic form, other prospective chiral acids were tested. One possibility is displayed by chiral phosphoric acids, which were used in numerous enantioselective transformations, for example in enantioselective organocatalytic reductive aminations. ${ }^{149}$ The phosphoric acids 175 appeared to be suitable co-catalysts for the desired direct alkylations performing meta-C-H bond functionalization in a comparable fashion to carboxylic acids (Table 3.21).

Table 3.21: Phosphoric acids as alternative additives for direct meta-alkylation.<smiles>[R]c1ccc(-c2ccccn2)cc1</smiles>

6

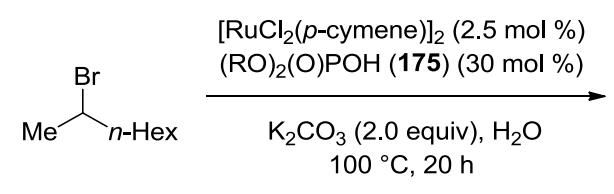

42ba

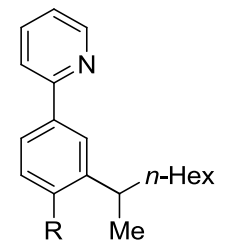

147 entry

1

OMe<smiles>O=P(O)(O)Oc1ccc2ccccc2c1-c1c(OP(=O)(O)O)ccc2ccccc12</smiles>

175a

2

OMe

$\mathrm{H}$

3

4

H

$$
\mathrm{Ph}-\mathrm{O}^{\prime} \mathrm{P}_{\mathrm{O}}^{\prime} \mathrm{O}_{\mathrm{O}}^{\mathrm{O}}
$$

175b

$$
\mathrm{Ph}-\mathrm{O}^{\prime} \mathrm{P}^{\prime} \mathrm{O}_{\mathrm{I}}^{\mathrm{O}} \mathrm{Ph}
$$

175b

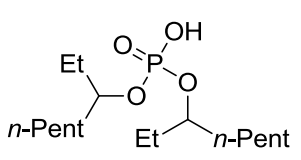

$58 \%$

175c

\footnotetext{
${ }^{149}$ Storer, R. I.; Carrera, D. E.; Ni, Y.; MacMillan, D. W. C. J. Am. Chem. Soc. 2006, 128, 84-86.
} 


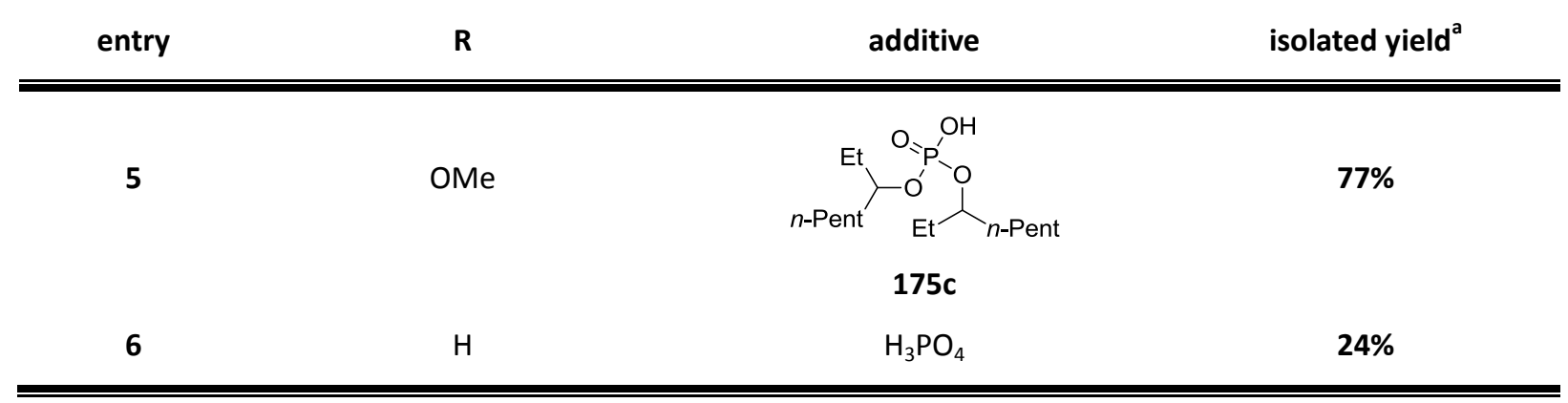

${ }^{\text {a }}$ Reaction conditions: 6 (0.5 mmol), 42 ba $(1.5 \mathrm{mmol}),\left[\mathrm{RuCl}_{2}(p \text {-cymene })\right]_{2}(2.5 \mathrm{~mol} \%)$, additive $(30 \mathrm{~mol} \%), \mathrm{H}_{2} \mathrm{O}(2.0 \mathrm{~mL})$, $20 \mathrm{~h}, 100^{\circ} \mathrm{C}$.

Thus, acyclic phosphoric acids $\mathbf{1 7 5 b}$ and $\mathbf{1 7 5 c}$ promoted efficient conversions and ensured high yields of 2-phenylpyridines 147aa and 147ba (entries 2, 4 and 5). Unfortunately, the application of enantiomerically pure $(R)$-BINOL-derived phosphoric acid 175a appeared not only to be less efficient, but resulted in the formation of racemic product, as indicated by HPLC analysis on chiral stationary phase (entry 1).

\subsubsection{Direct Ruthenium-Catalyzed meta-Benzylation}

Not only ruthenium-catalyzed alkylation with unactivated alkyl halides, but also direct benzylation represented an interesting objective. The pioneering studies by Ackermann and Novák demonstrated that arylpyridines 6 can easily be ortho-benzylated with primary benzyl chlorides $\mathbf{1 1 9}$ as inexpensive electrophiles. These carboxylate-assisted ruthenium-catalyzed $\mathrm{C}-\mathrm{H}$ functionalizations afforded benzylated 2-phenylpyridines 120 in good yields under relatively mild conditions (Scheme 3.34). ${ }^{123}$

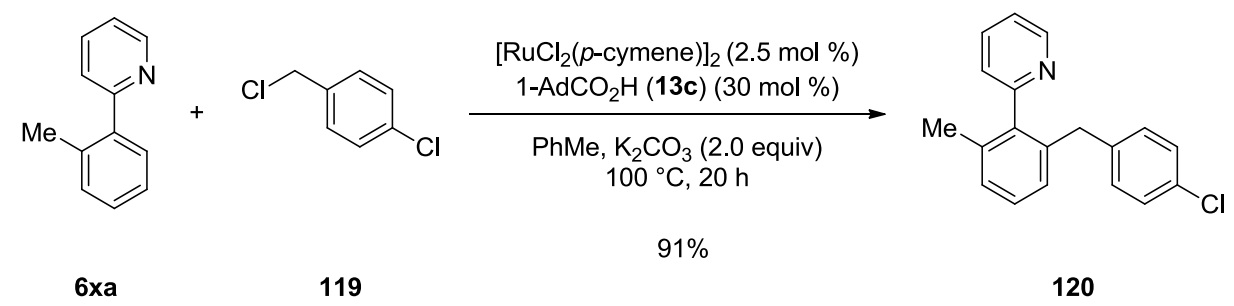

Scheme 3.34: Ruthenium-catalyzed direct ortho-benzylation with $p$-chlorobenzyl chloride (119) according to Ackermann and Novák.

However, ruthenium-catalyzed benzylation reactions with secondary benzyl halides remained unknown until recently, when they were demonstrated to proceed in a meta-functionalization mode, similarly to alkylations with unactivated secondary alkyl bromides. The benzylation with (1bromopentyl)benzene (176) - prepared in two steps adopting published procedures - was tested for suitable reaction conditions (Scheme 3.35). 


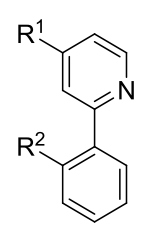<smiles>BrC(Br)c1ccccc1</smiles>

176

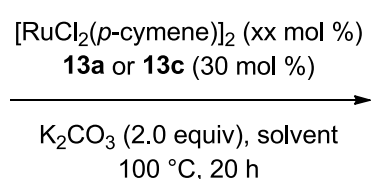
$100{ }^{\circ} \mathrm{C}, 20 \mathrm{~h}$

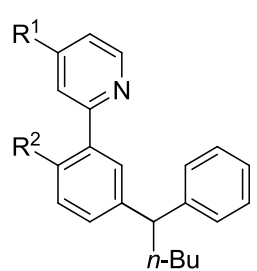

177

Scheme 3.35: Ruthenium-catalyzed benzylations with (1-bromopentyl)benzene (176).

Among the two tested standard acidic additives for the direct benzylation with secondary benzyl bromide 176, 1-adamantyl- (13c) and mesityl carboxylic acid (13a), the latter again provided the highest conversion of the starting material 6. Several solvents were tested, PhMe, NMP, water or 1,4dioxane, and 1,4-dioxane prove to give the best isolated yields. For high conversions of the subtrate $5 \mathrm{~mol} \%$ of the ruthenium-catalyst were necessary.

The meta-substitution mode in benzylations with secondary benzyl bromides was proved by careful 2D-NMR studies of the isolated products $177 .{ }^{150}$ It has to be emphesized that in spite of the high GCMS conversion, the isolation of the desired product in a pure form turned out to be difficult. The reason for this are side-reactions of (1-bromopentyl)benzene (176), such as dimerization, as indicated by mass spectrometry analyses. These products were not isolated in a pure form. Several examples which demonstrated the limited scope of such direct meta-benzylations are presented in Table 3.22.

Table 3.22: Scope of direct meta-benzylation with (1-bromopentyl)benzene (176).<smiles>[R1]1ccnc(-c2ccc[R1]n2)c1</smiles><smiles>CCCCC(Br)c1ccccc1</smiles>

176

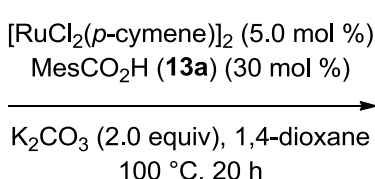

$100{ }^{\circ} \mathrm{C}, 20 \mathrm{~h}$

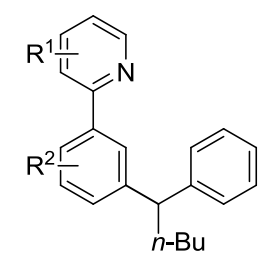

177

entry

substrate 6

product 176

yield of $177^{a}$

6ba

\footnotetext{
${ }^{150}$ For the detailed information, see: (a) Kuper, C. Bachelor thesis, Universität Göttingen, 2011; (b) Malzkuhn, S.
} Bachelor thesis, Universität Göttingen, 2012. 


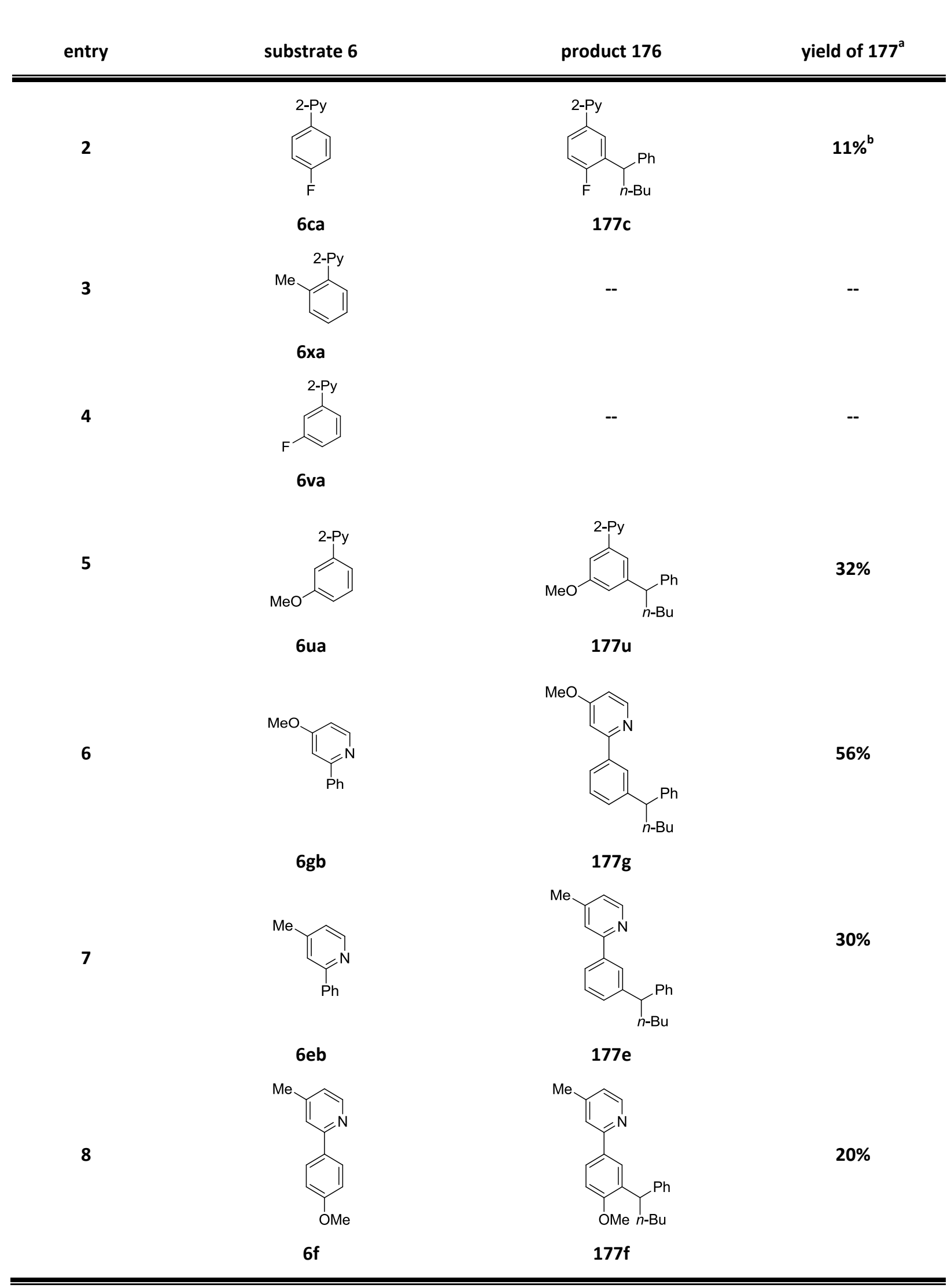

${ }^{\mathrm{a}}$ Reaction conditions: 6 (0.5 mmol), 176 (1.5 mmol), $\left[\mathrm{RuCl}_{2}(p \text {-cymene) }]_{2}(5.0 \mathrm{~mol} \%), \mathrm{MesCO}_{2} \mathrm{H}(13 \mathrm{a})(30 \mathrm{~mol} \%), \mathrm{H}_{2} \mathrm{O}\right.$ $(2.0 \mathrm{~mL}), 20 \mathrm{~h}, 100^{\circ} \mathrm{C} ;{ }^{\mathbf{b}}\left[\mathrm{RuCl}_{2}(p \text {-cymene })\right]_{2}(2.5 \mathrm{~mol} \%)$.

Electron-donating or electron-withdrawing substituents at the para-position of the phenyl ring (entries 1,2) influenced less the isolated yield than the substituents on the pyridine moiety (entries 
7 -9), while ortho-methyl (6xa) and meta-fluoro substituents (6va) seemed to inhibit the reaction (entry 3 and 4). Alternatively, methyl and methoxy substituents on the 4-position of pyridine appeared to favor the product formation to some extent (entries 6-8). meta-Methoxyphenylpyridine 6ua (entry 5) gave comparable yields for the meta-benzylated (32\%) and for the meta-alkylated products (40\%; see entry 3 in Table 3.15 ).

Nevertheless, the reaction of ortho-methoxyphenylpyridine (6wa) not only afforded the benzylated products $\mathbf{1 7 7 w}$ and $\mathbf{1 7 7} \mathbf{w}^{\prime}$ in a lower isolated yield, but also with inverted regioselectivity, as compared to meta-alkylation of the same substrate (Scheme 3.36; entry 2 in Table 3.16).
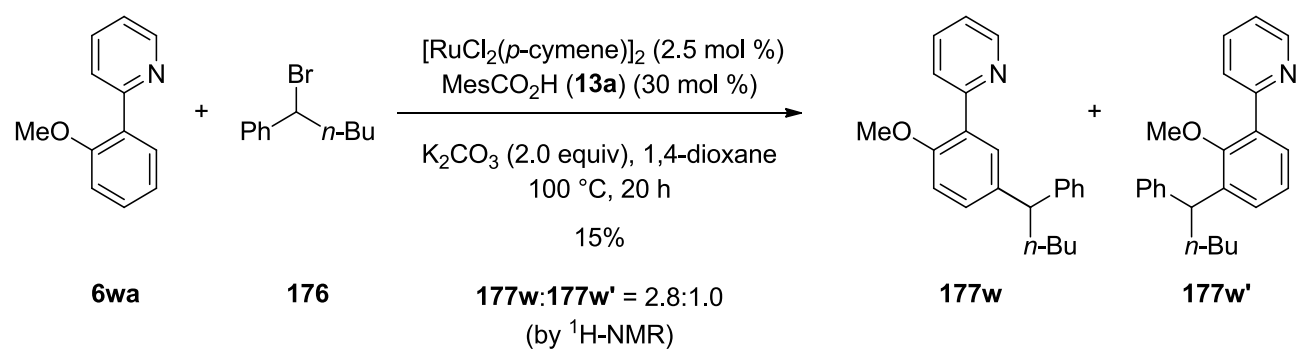

Scheme 3.36: Regioselectivity of the direct meta-benzylation of ortho-methoxyphenylpyridine 6wa: intramolecular competition experiment.

\subsubsection{Ruthenium-Catalyzed Direct Norbornylation}

exo-Bromonorbornane (42bl) is especially attractive for ruthenium-catalyzed direct alkylations, as application of this substrate allows to conclude, whether radical steps are involved in $\mathrm{C}-\mathrm{C}$ bond forming process. ${ }^{151}$ Under the standard reaction conditions, alkylations with this bicyclic secondary alkyl bromide $\mathbf{4 2} \mathrm{bl}$ resulted in high GC-MS conversion, however, isolation of pure products was possible only in a few cases.

Since para-fluoro- (6ca) and (para-methoxyphenyl)pyridine (6ba) appeared to be most reactive in reactions with unactivated secondary alkyl halides, they were selected for alkylations with exonorbornyl bromide $\mathbf{4 2} \mathbf{b l}$ as the electrophile (Scheme 3.37).

\footnotetext{
151 Jahn, U. Top. Curr. Chem. 2012, 320, 121-189.
} 


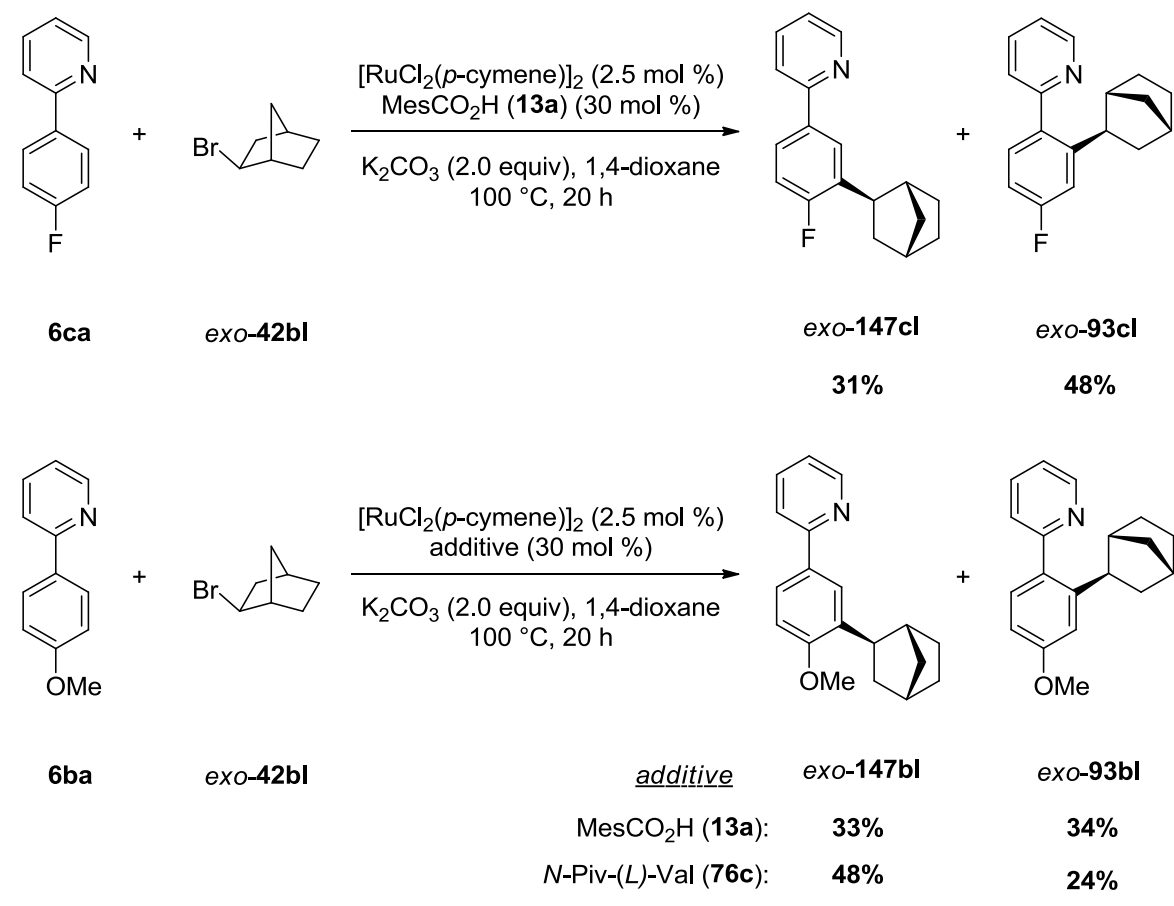

Scheme 3.37: Ruthenium-catalyzed Direct norbornylation of 2-phenylpyridines 6 ba and $6 \mathrm{ca}$.

Quantitative conversion of substrates $\mathbf{6} \mathbf{b}$ was detected and the products of the direct alkylation were obtained in both reactions. Surprisingly, not only the expected meta-alkylated products $147 \mathrm{bl}$ and $147 \mathrm{cl}$, but also the ortho-norbornylated compounds $93 \mathrm{bl}$ and $93 \mathrm{cl}$ were isolated. The ortho-alkylation was to some extent preferable for fluoro-substituted 2-phenylpyridine $6 \mathbf{c a}$, and almost equal amounts of the products were formed from the methoxy-substiututed substrate 6 ba. Interestingly, when $\mathrm{N}$-pivalyl-protected L-leucin (76c) was used as the additive, the meta/ortho ratio shifted from 1:1 to $2: 1$ in favor of the meta-alkylated product $147 \mathrm{bl}$.

Notably, the alkylations proceeded with a retention of configuration of the norbornyl moiety. Thus, only diastereomers with the sterically less demanding exo-substituted bicycle[2.2.1]heptyl fragment were obtained in each case. ${ }^{152}$

The catalytic cycle must differ to some extent from the catalytic cycle for secondary alkyl bromides. Indeed, the formation of ortho-norbornyl derivatives can be hardly interpreted via the proposed cooperative $\mathrm{C}-\mathrm{H}$-activation/ $\mathrm{S}_{\mathrm{E}}^{\mathrm{Ar}}$ mechanism (Scheme 3.49). A possible reaction pathway via initial dehydrobromination followed by hydroarylation according to the Murai-reaction was tested by performing the alkylation with norbornene (Scheme 3.38).

\footnotetext{
${ }^{152}$ For the discussion on reactivity of exo- and endo-substituted norbornanes see: Schreiner, P. R.; Schleyer, P. v. R.; Schaefer, H. F., III. J. Org. Chem. 1997, 62, 4216-4228. Steric substituent constants are equal to 4.98 (exo-norbornyl) and 6.20 (endo-norbornyl). See: Beckhaus, H. D. Angew. Chem. Int. Ed. Engl., 1978, 17, 593594.
} 


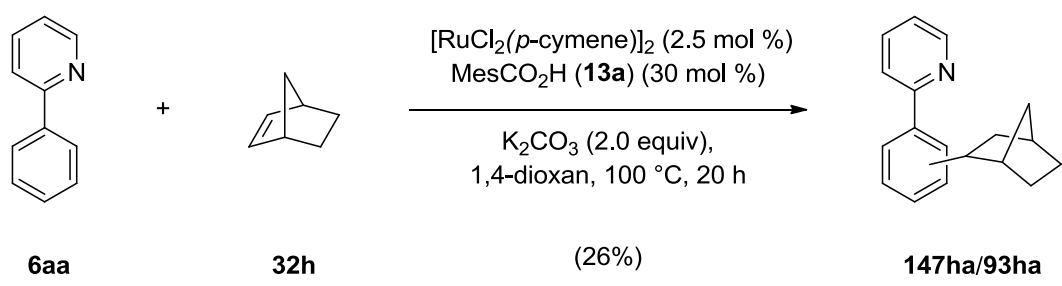

Scheme 3.38: Attempted norbornylation of 2-phenylpyridine (6aa) with norbornene (32h).

Under the standard reaction conditions with freshly distilled norbornene, only a low conversion was observed applying GC-MS spectrometry. This almost completely excluded a hydroarylation as a dominating reaction pathway. However, it should be pointed out that in the absence of the ruthenium species or the cocatalyst, 2-phenylpyridine (6aa) remained completely unchanged.

Since pyrazole could be used as a directing group for the ruthenium-catalyzed alkylations with primary and secondary alkyl bromides, the direct norbornylation of $\mathrm{N}$-phenylpyrazole (87a) with exobromonorbornane (42bl) was examined and disclosed to proceed with high efficacy (Scheme 3.39).

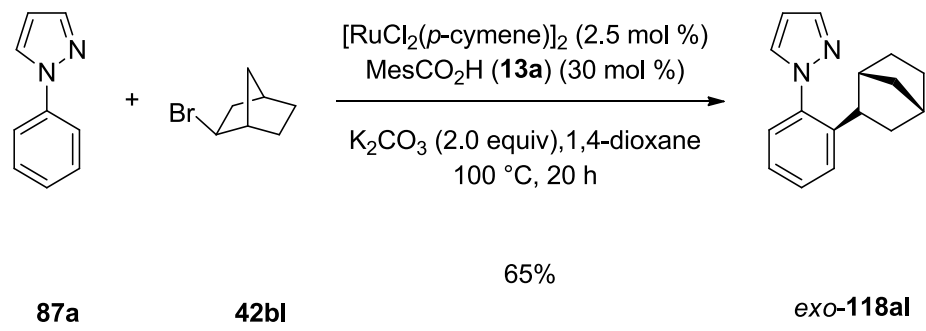

Scheme 3.39: Direct ruthenium-catalyzed norbonylation of 2-phenylpyrazole (87a).

Such an unexpectedly high site- and stereoselectivity of the reaction as well as exclusively high isolated yield of the product 118al was rather unexpected.

\subsubsection{Mechanistic Studies}

This newly discovered unexpected meta-selective direct ruthenium-catalyzed alkylations with secondary alkyl halides cannot proceed according to the same mechanism as the ortho-alkylations with primary alkyl halides. Elucidation of the possible reaction pathway needs mechanistic studies, such as intermolecular as well as intramolecular competition experiments, experiments with isotopically labeled starting materials and test reactions with special ruthenium complexes. 


\subsubsection{Competition Experiments}

Intermolecular competition experiments between para-substituted 2-phenylpyridines (6) were performed, in which a twofold excess of both substrates was treated with 2-bromooctane (42ba) as the limiting reagent under otherwise identical reaction conditions (Scheme 3.40). The GC-MS ratio of the products was in accordance with their yield determined by ${ }^{1} \mathrm{H}$ NMR after workup.

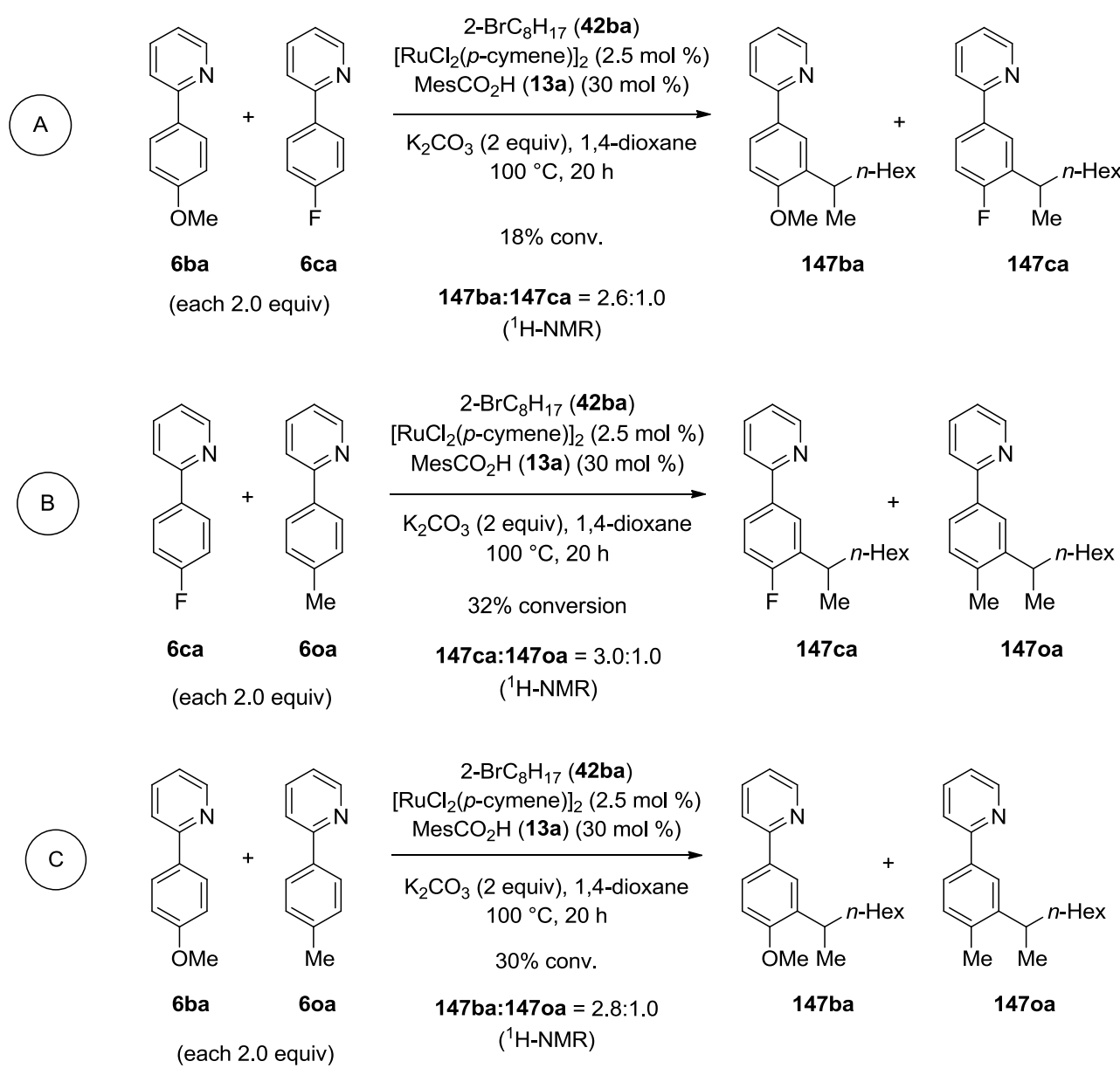

Scheme 3.40: Intermolecular competition experiment between substrates $6 \mathbf{b a}, \mathbf{6 c a}$ and $60 \mathrm{a}$.

Experiment $A$ disclosed the electron-rich substrate $6 \mathrm{ba}$ to be more reactive in comparison to the fluoro-substituted one $6 \mathrm{ca}$. The results of experiment B can show steric to be of relevance. ${ }^{153,154}$ However, the well-known ortho-orienting inductive effect of the fluorine-substituent can also play a certain role. ${ }^{138}$ The results of competition in experiments $A$ and $C$ can also be explained by the chelating effect of the methoxy substituent in $\mathbf{6}$ ba rather than by electronic or steric factors.

\footnotetext{
153 Beckhaus, H. D. Angew. Chem. Int. Ed. Engl. 1978, 17, 593-594.

${ }^{154}$ For comparable A-values/Conformational Energies for F: 0.25-0.42 kcal/mol; OMe: 0.55 - $0.75 \mathrm{kcal} / \mathrm{mol}$; Me: $1.74 \mathrm{kcal} / \mathrm{mol}$, see: Stereochemistry of Organic Compounds (Eds.: Eliel, L. E.; Wilen, S. H.) Wiley: New York, 1994, pp. 695-697.
} 
The hierarchy of reactivity derived from these experiments is shown here:

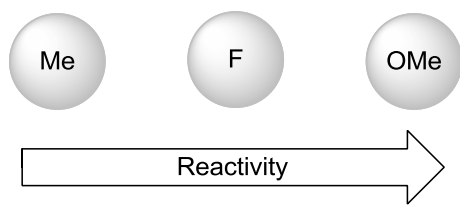

Figure 3.9: Substituents hierarchy as obtained from intermolecular competition experiments for meta-alkylation.

Direct competition experiment between ortho- and meta-alkylation of 2-phenylpyridine (6aa) with primary and secondary alkyl bromides 42ba and 42ab, respectively, did not reveal any favorite (Scheme 3.41$).{ }^{155}$ The reaction rates appeared to be almost equal for primary as well as for secondary alkyl bromides, while still conserving the individual regioselectivity mode for each electrophile.

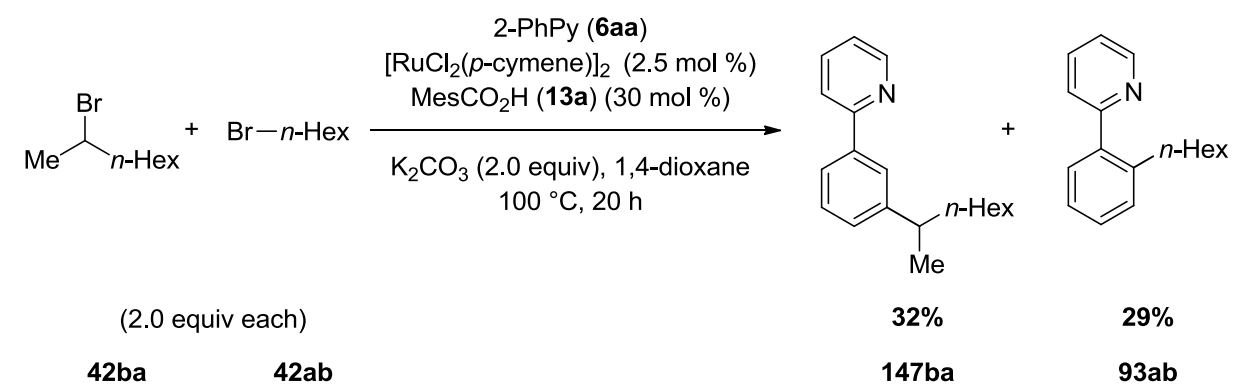

Scheme 3.41: Direct competition between ruthenium-catalyzed meta- and ortho-alkylations.

\subsubsection{Experiments with Isotopically Labeled Substrates}

The determination of the kinetic isotope effect (KIE) is often used as a routine method to decide which is the the rate-determining or the product-determining step in a catalytic cycle. ${ }^{156} \mathrm{D} / \mathrm{H}-$ exchange experiments with deuterium labeled substrates can thus provide valuable informations concerning the mechanistic course of a $\mathrm{C}-\mathrm{H}$ bond functionalization reaction.

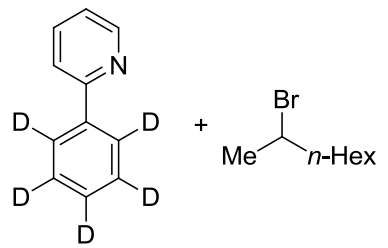

$\left[\operatorname{RuCl}_{2}(p \text {-cymene })\right]_{2}(2.5 \mathrm{~mol} \%)$ $\mathrm{MesCO}_{2} \mathrm{H}(13 \mathrm{a})(30 \mathrm{~mol} \%)$

$\mathrm{K}_{2} \mathrm{CO}_{3}$ (2.0 equiv), 1,4-dioxane $100^{\circ} \mathrm{C}, 20 \mathrm{~h}$

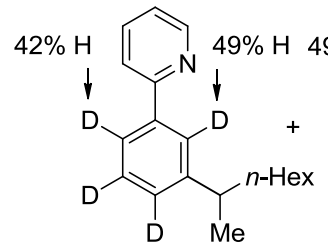

$29 \%$

$\left[D_{n}\right]-147 a a$

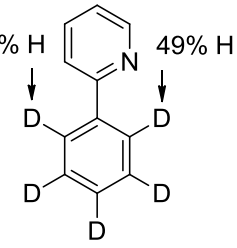

$54 \%$

$\left[D_{n}\right]-6 a a$

$\left[D_{5}\right]-6 a a$ 42ba

Scheme 3.42. Direct meta-alkylation of (pentadeuteriophenyl)pyridine $\left[\mathrm{D}_{5}\right]-6 \mathrm{aa}$.

\footnotetext{
${ }^{155}$ Additionally, ortho- $n$-Octyl-substituted product 93 aa has been isolated in $2 \%$ yield.

${ }^{156}$ Simmons, E. M.; Hartwig, J. F. Angew. Chem. Int. Ed. 2012, 51, 3066-3072.
} 
As shown in Scheme 3.42, the direct alkylation of deuterated 2-(pentadeuteriophenyl)pyridine $\left(\left[D_{5}\right]-\right.$ 6aa) under the optimized reaction conditions showed almost $50 \%$ of $\mathrm{D} / \mathrm{H}$-exchange in the orthoposition. However, the meta-Alkylation of 2-(pentadeuteriophenyl)pyridine ([D $\left.\left.\mathrm{D}_{5}\right]-6 a a\right)$ afforded the meta-alkylated product $\left[D_{n}\right]-147$ aa in a somewhat. Similar to the ortho-alkylation of $\left[D_{5}\right]-6 a a$ with primary alkyl bromides (Scheme 3.18), a significant H/D-exchange in the ortho positions was observed to the same extent in both product $\left[D_{n}\right]-147$ aa $(42 \%$ and $47 \%)$ and the recovered starting material $\left[\mathrm{D}_{n}\right]$-6aa $(49 \%)$, as determined by ${ }^{1} \mathrm{H}-\mathrm{NMR}$ studies. This indicates a reversible $\mathrm{C}-\mathrm{H}$ bond metalation step in the ortho-position to the directing group to proceed with comparable rates in both meta- and ortho-selective alkylations. While in the latter reaction such a $\mathrm{C}-\mathrm{H}$ bond activation was considered as a necessary first step in the proposed catalytic cycle (Scheme 3.21), its involvement in the former can only be speculated about (see below). It is assumed that the potassium carbonate can also serve as proton-source for the H/D-exchange.

To exclude the C-D activation step from the mechanistic examinations, meta-alkylation of $(3,4,5-$ trideuteriophenyl)pyridine $\left(\left[\mathrm{D}_{3}\right]-6 \mathrm{aa}\right)$ was investigated. The latter has been prepared applying the ruthenium-catalyzed D/H-exchange in substrate $\left[D_{5}\right]$-6aa as a preparative method (Scheme 3.43 ).

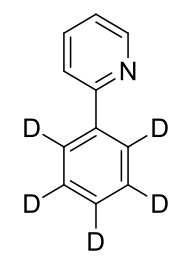

$\left[D_{5}\right]-6 a a$

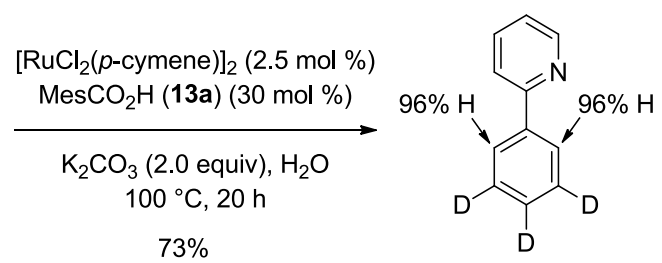

$\left[\mathrm{D}_{3}\right]-6 \mathrm{aa}$

Scheme 3.43: Preparation of (3,4,5-trideuteriophenyl)pyridine $\left[D_{3}\right]-6 a a$.

Thus, employing the standard reaction conditions with water as the reaction medium, but in the absence of an organic halide, a regioselective $\mathrm{D} / \mathrm{H}$-exchange was accomplished in high yield.

meta-Selective alkylation of the substrate $\left[D_{3}\right]-6 a a$ under the optimized reaction conditions furnished compound $\left[D_{2}\right]-147$ ai in $52 \%$ isolated yield (Scheme 3.44 ), which was comparable with the result obtained applying the undeuterated substrate 6aa. Moreover, no further $\mathrm{D} / \mathrm{H}$-scrambling in the isolated product $\left[D_{2}\right]-\mathbf{1 4 7 a i}$ was observed. This allowed the assumption, that the $C-C$ forming step might be not the rate-determining step in the reaction. 
<smiles>[2H]c1cc(-c2ccccn2)cc([2H])c1[2H]</smiles>

$\left[D_{3}\right]-6 \mathbf{a a}$<smiles>CC(Br)Br</smiles>

$42 b$

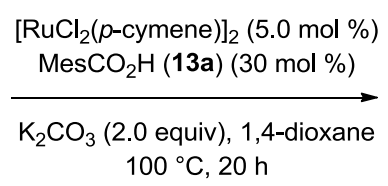

$52 \%$<smiles>[2H]c1cc(-c2ccccn2)cc(C(C)C(=O)OCc2ccccc2)c1[2H]</smiles>

$\left[D_{2}\right]-147 a i$

Scheme 3.44: Ruthenium-catalyzed direct meta-alkylation of (trideiteriophenyl)pyridine $\left[\mathrm{D}_{3}\right]-6 a a$.

To provide evidence to this hypothesis, an intermolecular competition experiment using 2phenylpyridines $6 \mathrm{aa}$ and $\left[\mathrm{D}_{3}\right]-6 \mathrm{aa}$ in equimolar amounts was performed under the standard reaction conditions (Scheme 3.44).<smiles>[2H]c1cc(-c2ccccn2)cc([2H])c1[2H]</smiles>

(2.0 equiv each)

6aa $\quad\left[\mathrm{D}_{3}\right]-6 \mathrm{aa}$

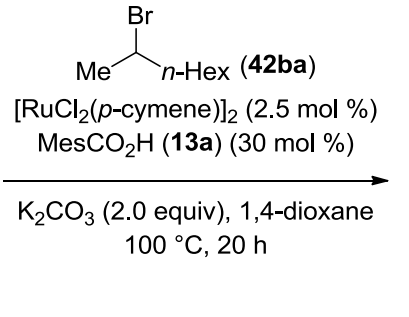

$$
\text { D }
$$

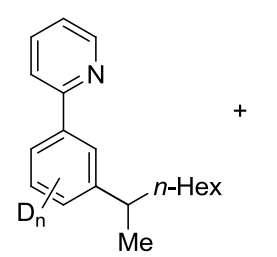

$26 \%$$$
26 \%
$$$$
=1: 1
$$<smiles>c1ccc(-c2ccccn2)nc1</smiles>

$46 \%$

$\left[\mathrm{D}_{0}\right]-6 \mathrm{aa}:\left[\mathrm{D}_{3}\right]-6 \mathrm{aa}$

$=1: 1$

Scheme 3.45: Intermolecular competition experiment between undeuterated 2-phenylpyridine 6aa and [ $\left.D_{3}\right]-6 a a$.

The slightly lower isolated yield of the meta-alkylated product $\left[D_{n}\right]-147 a a$ in this reaction was not surprising, as commonly observed when applying an excess of the arennes $\mathbf{6}$. Careful analysis of the ${ }^{1} \mathrm{H}-\mathrm{NMR}$ spectra of the product $\left[D_{n}\right]-147$ aa as well as of the recovered substrate $\left[D_{n}\right]-6$ aa revealed both to be an 1:1 mixture of undeuterated and partially deuterated compounds. Moreover, no further H/D-scrambling was detected for both: Therefore, the KIE was determined to be $\approx 1$. As a consequence, the $\mathrm{C}-\mathrm{H}$ bond activation step can neither in the ortho- nor in the meta-position be rate-determining.

\subsubsection{Well-Defined Ruthenium (II) Complexes as the Catalysts}

Besides identifying the rate-determining step, the nature of the active ruthenium catalytst should also be elucidated prior to postulating a reaction mechanism. Thus, well-defined ruthenium (II) carboxylate complex 12 was prepared from $\left[\mathrm{RuCl}_{2}(p \text {-cymene) }]_{2}\right.$ and mesityl carboxylic acid (13a) in a simple one-step procedure, ${ }^{26 a}$ and was then applied under otherwise identical reaction conditions (Scheme 3.46) 


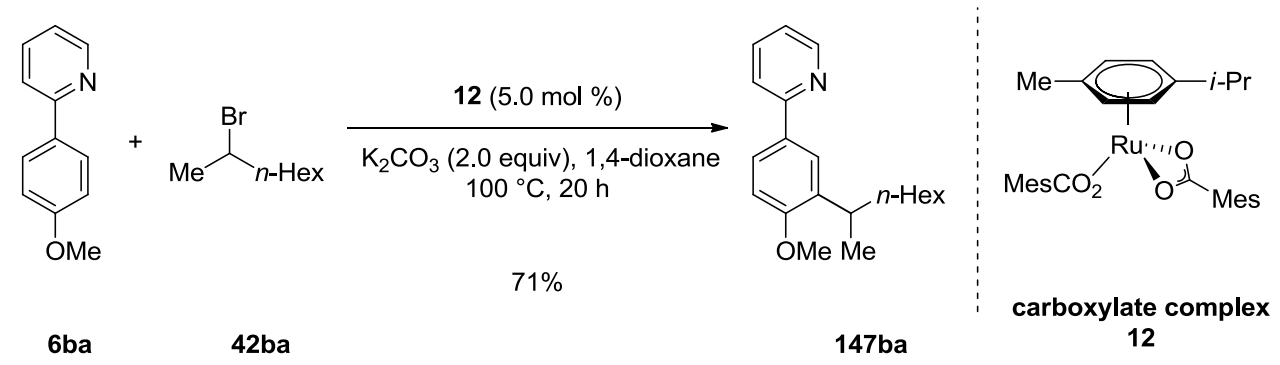

Scheme 3.46: Direct meta-alkylation with ruthenium (II) biscarboxylate complex 12.

The reaction proceeded smoothly and gave aa improved yield of the product 147 ba $(71 \%)$ as compared to the in-situ $\left[\mathrm{RuCl}_{2}(p \text {-cymene })\right]_{2} / \mathrm{MesCO}_{2} \mathrm{H}$ system $(60 \%$; entry 3 in Table 3.12$)$. This indicated an initial formation of carboxylates 12 from $\left[\mathrm{RuCl}_{2}(p \text {-cymene })\right]_{2}$ and $\mathrm{MesCO}_{2} \mathrm{H}$ as most probable initial reaction step. The in-situ formed carboxylate $\mathbf{1 2}$ might act as the active ruthenium catalyst.

Furthermore, the ruthenacyclic carboxylate complex 14a was synthesized and examined in the reaction (Scheme 3.47).<smiles>COc1ccc(-c2ccccn2)cc1</smiles>

6ba<smiles>CC(Br)Br</smiles>

42ba

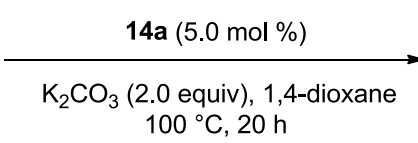

$69 \%$

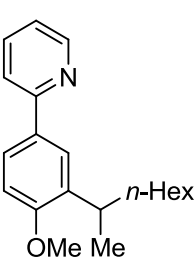

$147 \mathrm{ba}$

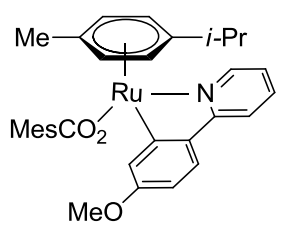

cycloruthenated complex

Scheme 3.47: Direct meta-alkylation with cycloruthenated carboxylate complex 14a.

Without an additional co-catalysts, this complex 14 a gave product 147 ba in a comparable isolated yield as the simple carboxylate complex 12. This consequently suggests, that the cyclometalated species $14 a$ is involved in the catalytic cycle.

As a control experiment, another easily available ruthenacycle $\mathbf{1 7 8}$ of essentially the same structure, but without a carboxylate ligand, was used and did not deliver the alkylated product 147ba (Scheme 3.48).<smiles>COc1ccc(-c2ccccn2)cc1</smiles><smiles>CC(Br)[Hg][Mg]</smiles><smiles></smiles>
$100^{\circ} \mathrm{C}, 20 \mathrm{~h}$

$6 b a$
$42 \mathrm{ba}$

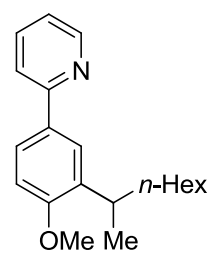

147ba

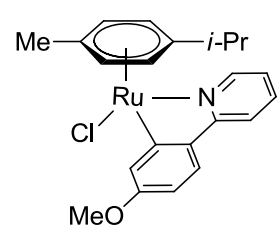

cycloruthenated complex 178

$$
\begin{array}{rc}
\text { without additive : } & \mathbf{0 \%} \\
\text { with } \mathrm{MesCO}_{2} \mathrm{H}(\mathbf{1 3 a})(30 \mathrm{~mol} \%): & \mathbf{4 3 \%}
\end{array}
$$


However, upon employing the complex 178 in the presence of mesityl carboxylic acid (13a) as

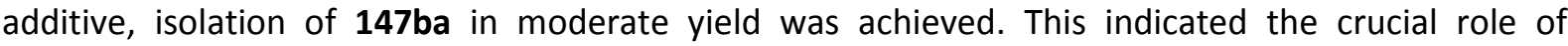
carboxylate assistance in the mechanism of meta-alkylations.

\subsubsection{Proposed Catalytic Cycle}

Based on the experimental studies summarized above and by comparison of the results obtained by Frost and co-workers on the ruthenium-catalyzed meta-sulfonylation, ${ }^{53}$ the possible mechanistic rationalization of regioselective meta-alkylation can be proposed (Scheme 3.49). This mechanism stated below can be described as followed.

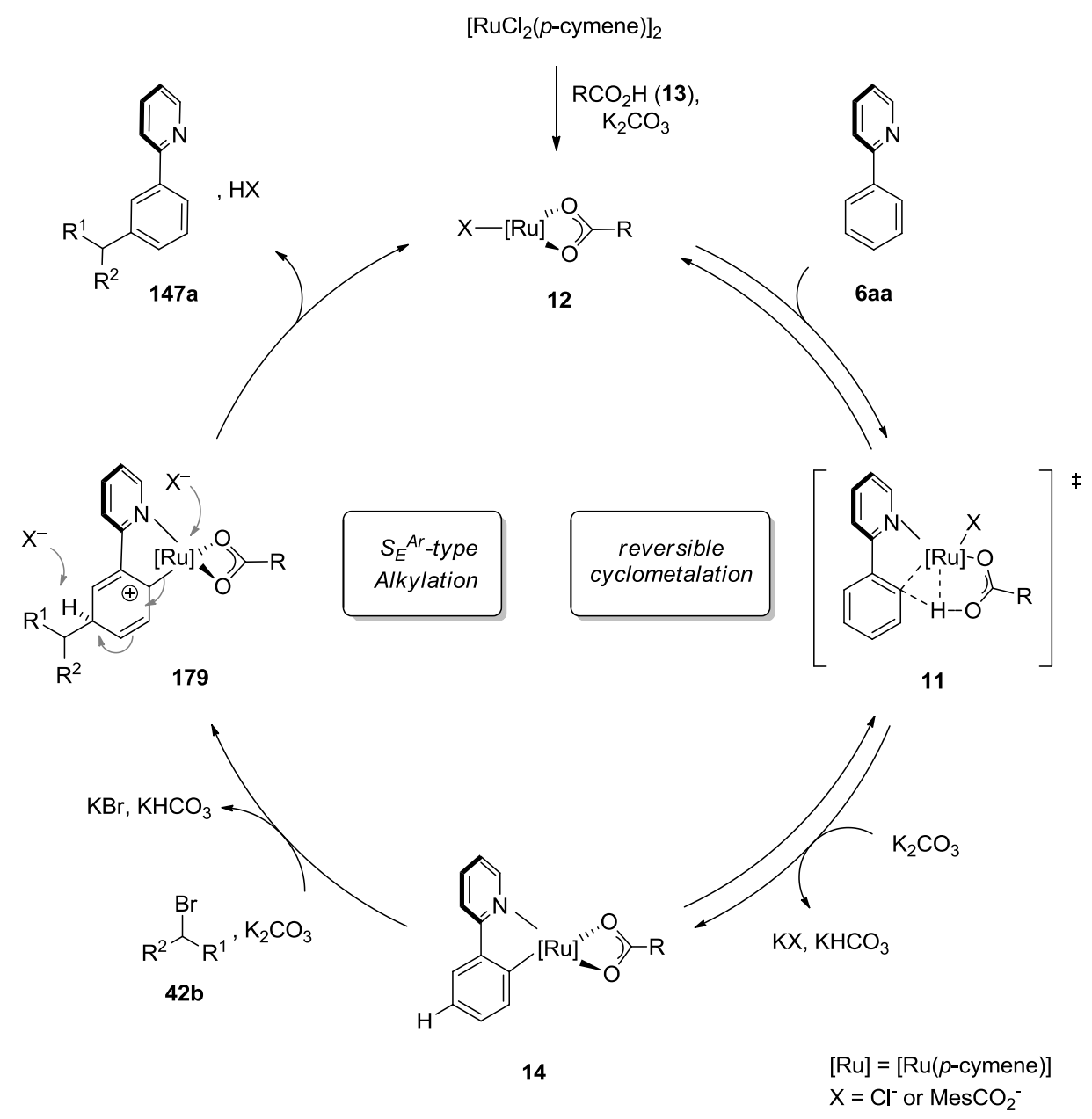

Scheme 3.49: Mechanistic proposals for the ruthenium-catalyzed direct meta-alkylation of 2-phenylpyridine (6aa) with secondary alkyl bromides (42b).

Initially, the $\left[\mathrm{RuCl}_{2}(p \text {-cymene })\right]_{2}$ was converted into the ruthenium (II) carboxylate complex 12 , which was coordinated by the nitrogen atom of the pyridine directing group. After the ruthenium centre was in close proximity to the ortho- $\mathrm{C}-\mathrm{H}$ bond, a carboxylate-assisted reversible cyclometalation via transition state $\mathbf{1 1}$ occurred according to the AMLA mechanism. This resulted in the formation of the 
corresponding cyclometalated ruthenium complex 14. In 1998 Coudret and co-workers have reported on stoichiometric electrophilic functionalization of similar ruthenacycles. ${ }^{157}$ Remarkably, such complexes underwent selective halogenations, oxidative dimerizations and nitrations on the less sterically hindered reaction center, thus in meta-position to the pyridyl and the para-position to $\mathrm{Ru}-\mathrm{C} \sigma$-bond.

Taking into account these results as well as the results of experiments with isotopically labeled starting materials, the next step in the catalytic cycle can be assumed to proceed through an electrophilic aromatic substitution-type mechanism. Finally, the re-aromatization step regenerates the active species and delivers the meta-alkylated product 147 a, presumably via protodemetalation. It is still not fully clear, which of the two final steps - the formation of the Wheland-type intermediate $179^{158}$ or the re-aromatization step - is the rate-determining one. The exact mechanism of activation for the secondary alkyl bromide $\mathbf{4 2 b}$ must be elucidated as well; for example, a SET radical pathway can be considered. Since the enantioselective fashion of meta-alkylation still remains elusive, the formation of a planar carbocationic or radical intermediates from the secondary alkyl halide is not completely excluded.

Recently, Johnson and co-workers reported on the Lewis acid-catalyzed shift of a phenyl group to the meta-position in substituted arenes. ${ }^{159}$ However, no transformation was detected upon attempted isomerization of the ortho-alkylated 2-phenylpyridine 147aa under the reported reaction conditions.

\footnotetext{
157 Coudret, C.; Fraysse, S.; Launay, J.-P. Chem. Commun. 1998, 663-664; and references cited therein.

${ }^{158}$ Wheland, G. W. J. Am. Chem. Soc. 1942, 64, 900-908.

159 Ajaz, A.; McLaughlin, E. C.; Skraba, S. L.; Thamatam, R.; Johnson, R. P. J. Org. Chem. 2012, 77, 9487-9495.
} 


\section{Ruthenium-Catalyzed Oxidative Transformations via $\mathrm{C}-\mathrm{H} / \mathrm{N}-\mathrm{H}$ bond Cleavage}

Besides direct transition metal-catalyzed $\mathrm{C}-\mathrm{H}$ bond functionalizations, oxidative transition metalcatalyzed $\mathrm{C}-\mathrm{H} / \mathrm{O}-\mathrm{H}$ or $\mathrm{C}-\mathrm{H} / \mathrm{N}-\mathrm{H}$ bond functionalizations utilizing arenes or alkenes $\mathbf{8 8}$ under mild reaction conditions represent an even more sustainable strategy, since no prefunctionalization steps have to be performed and mild reaction conditions are possible (Scheme 4.1). ${ }^{104}$<smiles>[X]C(=O)c1ccccc1</smiles>

116

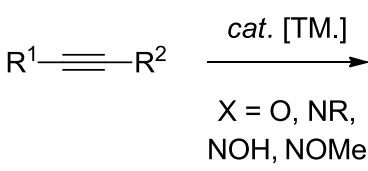

88<smiles></smiles>

117

Scheme 4.1: Oxidative annulations by $\mathrm{C}-\mathrm{H} / \mathrm{O}-\mathrm{H}$ or $\mathrm{C}-\mathrm{H} / \mathrm{N}-\mathrm{H}$ bond functionalizations.

Pioneering research in rhodium-catalysis was accomplished by the groups of Miura and Sato, Fagnou and Jones. ${ }^{120}$ These groups reported on efficient annulation reactions of alkynes by $\mathrm{C}-\mathrm{H} / \mathrm{O}-\mathrm{H}$ or $\mathrm{C}-\mathrm{H} / \mathrm{N}-\mathrm{H}$ bond functionalization catalyzed by rather efficient and selective, yet relatively expensive rhodium catalysts. In contrast, significantly less expensive ruthenium complexes previously not been exploited as catalysts for oxidative $\mathrm{C}-\mathrm{H} / \mathrm{O}-\mathrm{H}$ or $\mathrm{C}-\mathrm{H} / \mathrm{N}-\mathrm{H}$ bond functionalizations. ${ }^{101 a, 160}$

\subsection{Ruthenium-Catalyzed Oxidative Annulations}

As demonstrated by Satoh and Miura, ${ }^{120}$ benzamides 86 are suitable substrates for the rhodiumcatalyzed annulation with alkynes 88 via $\mathrm{C}-\mathrm{H} / \mathrm{N}-\mathrm{H}$ bond cleavages, thereby giving sustainable excess to key structural motifs such as isoquinolones $\mathbf{1 8 0}$.

The alternative ruthenium-based catalytic system for assembling the isoquinolinone skeleton along this route was examined by Ackermann, Lygin and Hofmann. Intensive studies towards optimization of this reaction indicated the conditions shown in Scheme 4.2 to be the most efficient.

\footnotetext{
${ }^{160}$ http://www.ebullionguide.com (17.01.13; average last 30 days): 1 ounce of ruthenium = 87.85 USD; 1 ounce
} of rhodium $=1081.90$ USD. 


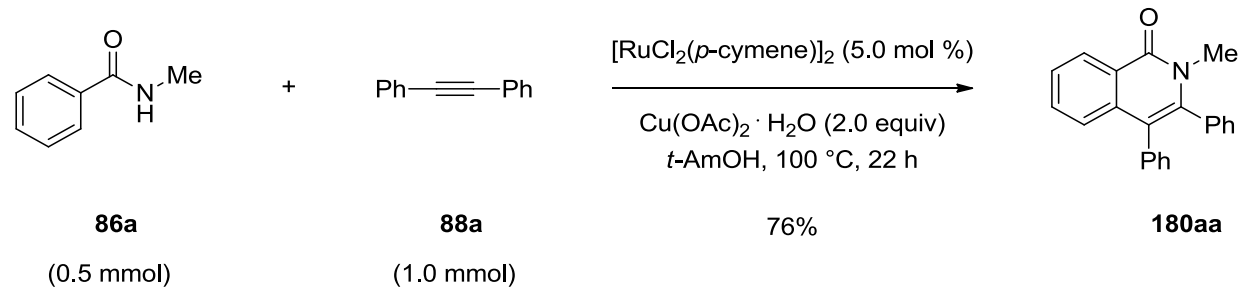

Scheme 4.2: Optimized reaction conditions for the ruthenium-catalyzed oxidative synthesis of isoquinolone 180aa.

Thus, it was disclosed that $5.0 \mathrm{~mol} \%$ of $\left[\mathrm{RuCl}_{2}(p \text {-cymene })\right]_{2}$ in combination with copper acetate in stoichiometric amounts was a competent catalytic system for the oxidative annulation of alkynes $\mathbf{8 8}$ with benzamides 86. Different oxidants, such as more expensive silver salts, demonstrated rather inhibiting than accelerating effects and afforded ring opened by-products. Detailed description of this newly developed ruthenium-catalyzed reaction required additional investigations to determine scope and limitations of these annulations as well as to explain its mode of action.

\subsubsection{Synthesis of starting materials}

A variety of starting materials was synthesized according to published protocols. Benzamides $\mathbf{8 6}$ were prepared from the corresponding carboxylic acids and differentially substituted alkynes $\mathbf{8 8}$ by classical organic methods or by transition metal-catalyzed Sonogashira-Hagihara coupling. ${ }^{161,162}$ The starting material synthesis will not be discussed within this context since no optimization of the reaction conditions was performed.

\subsubsection{Ruthenium-Catalyzed Synthesis of Isoquinolin-2-ones: Scope and Limitations}

$\mathrm{N}$-methylbenzamide (86a) was treated with different symmetrically substituted alkynes $\mathbf{8 8}$, with electron-rich as well as electron-deficient arenes, under the previously optimized reaction conditions. (Scheme 4.3).

\footnotetext{
${ }^{161}$ Mio, M. J.; Kopel, L. C.; Braun, J. B.; Gadzikwa, T. L.; Hull, K. L.; Brisbois, R. G.; Markworth, C. J.; Grieco, P. A. Org. Lett. 2002, 4, 3199-3202.

162 Goeschke, R.; Stutz, S.; Rasetti, V.; Cohen, N.-C.; Rahuel, J.; Rigollier, P.; Baum, H.-P.; Forgiarini, P.; Schnell, C. R.; Wagner, T.; Gruetter, M. G.; Fuhrer, W.; Schilling, W.; Cumin, F.; Wood, J. M.; Maibaum, J. J. Med. Chem. 2007, 50, 4818-4831.
} 


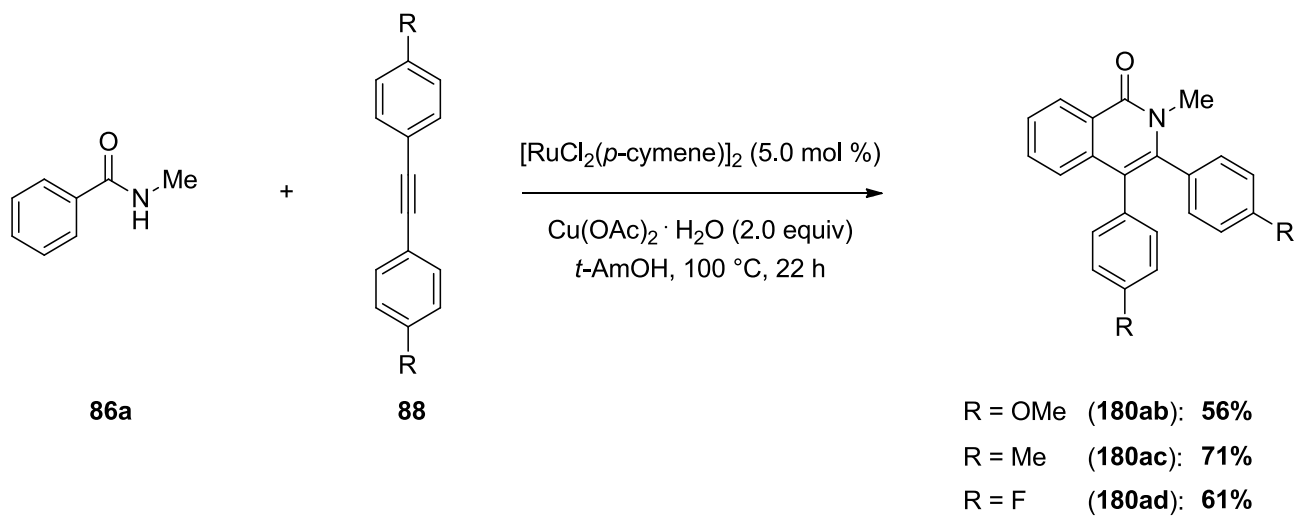

Scheme 4.3: Scope of annulation of $N$-methylbenzamide (86a) with symetrically substituted alkynes $\mathbf{8 8 .}$

According to these experiments, the electron density on the aryl substituents in alkynes $\mathbf{8 8}$ appeared to exert a minimal influence on the formation of the desired products $180 \mathrm{ab}-180 \mathrm{ad}$, as not only unsubstituted tolane (88a), but also electron-rich as well as electron-deficient alkynes $\mathbf{8 8 b} \mathbf{b} / \mathbf{8 8 c}$ and $\mathbf{8 8 d}$ furnished isoquinolones $\mathbf{1 8 0 a b}$ - 180ad in rather high yields. These promising results prompted us to prove the applicability of unsymmetrically substituted alkynes in these cyclisations (Table 4.1). ${ }^{163}$

Table 4.1: Annulation of unsymetrically substituted alkynes $\mathbf{8 8}$ with $\mathbf{N}$-methylbenzamide (86a).<smiles>CNC(=O)c1ccccc1</smiles>

$86 a$

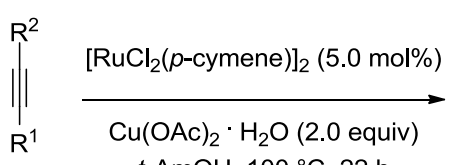
$t$-AmOH, $100{ }^{\circ} \mathrm{C}, 22 \mathrm{~h}$

88<smiles>[R]c1c([R])n(C)c(=O)c2ccccc12</smiles>

180<smiles>[R]c1c([R])n(C)c(=O)c2ccccc12</smiles>

$180^{\prime}$

entry alkyne 88

product 180

product 180'

ratio $180: 180^{\prime b}$

combined yield $^{a}$

(180ae

${ }^{163}$ Ackermann, L.; Lygin, A. V.; Hofmann, N. Angew. Chem. Int. Ed. 2011, 50, 6379-6382. 


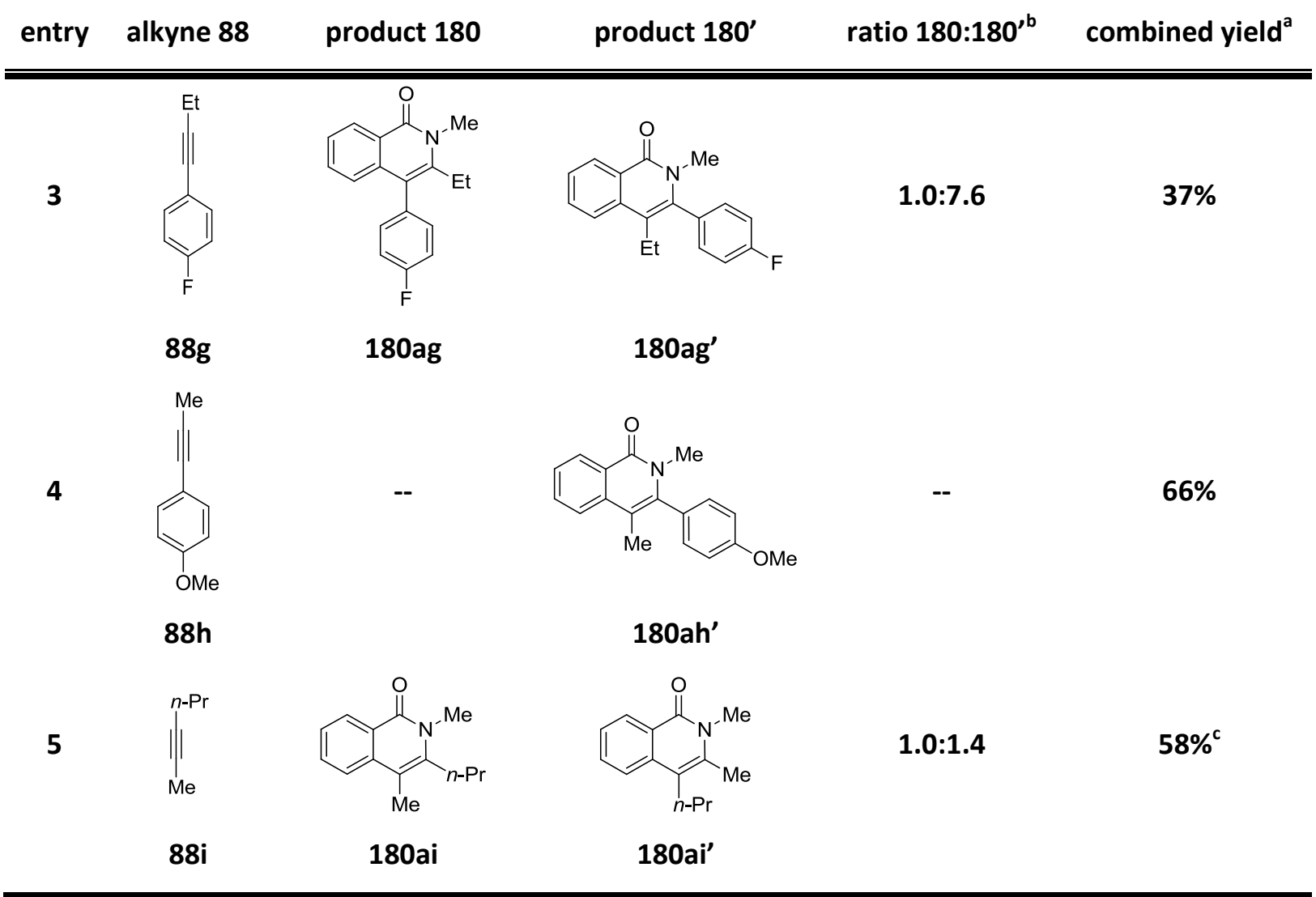

${ }^{a}$ Reaction conditions: 88 (0.5 mmol), 180 (1.0 mmol), $\left[\mathrm{RuCl}_{2}(p \text {-cymene })\right]_{2}(5.0 \mathrm{~mol} \%), \mathrm{Cu}(\mathrm{OAc})_{2} \mathrm{H}_{2} \mathrm{O}(2.0$ equiv), $t$ - $\mathrm{AmOH}(2.0 \mathrm{~mL}), 22 \mathrm{~h}, 100{ }^{\circ} \mathrm{C} ;{ }^{\mathrm{b}}$ The ratios 180:180' have been determined by nOe, if no separation could be acomplished; ${ }^{c}$ Compounds 180ai and 180ai' were isolated in pure form in 24 and $34 \%$ yield, respectively.

The yields of isoquinolones $\mathbf{1 8 0}$ listed in Table 4.1 ranged from good to very good, except the cyclisation with fluorophenyl alkyne $\mathbf{8 8 g}$ (entry 3). It is noteworthy that the ruthenium-catalyzed annulation of unsymmetrically substituted Alk-C $\equiv C-A r 88$ delivered mixtures of 4- (180a) and 3arylsubstituted (180a') regioisomeric products in ratios from 1:10 (entry 2) to 1:7 (entry 1). A methoxy substituent in alkyne $\mathbf{8 8 \mathrm { h }}$ resulted in a lower yield, but provided a better regioselectivity of the reaction (entry 4$)$.

Generally, symmetrically substituted dialkylalkynes $\mathbf{8 8}$ appeared to be rather suitable substrates for the oxidative annulations. ${ }^{163}$ The testing reaction of methyl-n-propyl alkyne $(\mathbf{8 8 i})$ with $\mathrm{N}$ methylbenzamide (86a) afforded the 3-n-propyl- (180ai') and the 4-n-propylisoquinolone (180ai) in comparable quantities and in a ratio of 1.4:1.0 (entry 5). This observation is in accordance with the steric substituent constants, being equal to 0.89 ( $n$-propyl) and 0.0 (methyl). ${ }^{153}$

The reactivity of the enyne $\mathbf{8 8 \mathbf { j }}$ under the optimized reaction conditions was of special interest, as such experiments could allow (i) to determine the general tolerance of enynes towards $\mathrm{C}-\mathrm{H} / \mathrm{N}-\mathrm{H}$ bond functionalizations, (ii) to compare reactivity of a double and of a triple bond in $\mathbf{8 8 \mathbf { j }}$ and (iii) to 
open new horizons towards further functionalizations of the products $\mathbf{1 8 0}$. Several examples of variously substituted (cyclohexen-1-yl)alkynes were studied (Scheme 4.4).

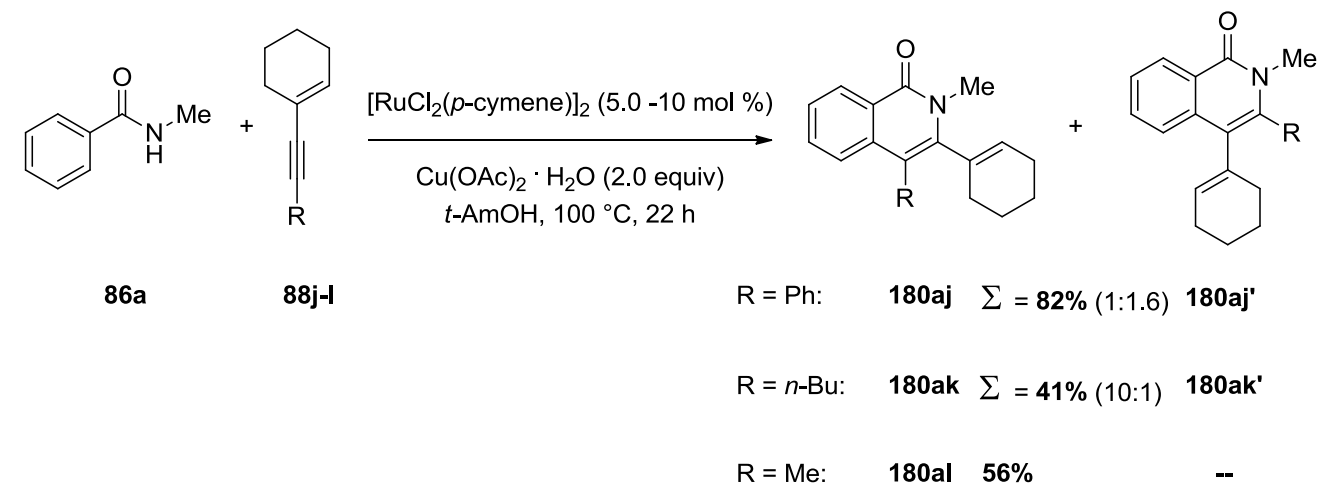

Scheme 4.4: Enynes $\mathbf{8 8 j - 8 8 I ~ a s ~ c o u p l i n g ~ p a r t n e r s ~ f o r ~ t h e ~ r u t h e n i u m - c a t a l y z e d ~ a n n u l a t i o n ~}$ with $N$-methylbenzamide (86a).

Depending on the nature of the second substituent on the alkyne moiety, moderate to very good

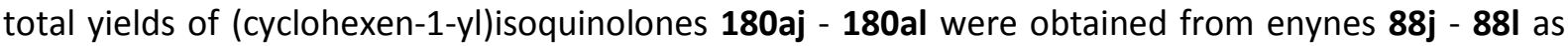
cyclization partners. Importantly, while (cyclohexen-1-yl)phenylalkyne (88j) afforded the products 180aj and 180aj' in high total yield of $82 \%$, but with poor regioselectivity in favor of 3 phenylheterocycle 180aj', the yields upon cyclizations with (cyclohexen-1-yl)alkylalkynes $\mathbf{8 8} \mathbf{k}$ and $\mathbf{8 8} \mathbf{I}$ were lower (41 and 56\%, respectively). However, the latter two transformations demonstrated much better regioselectivity with the predominant formation of the 3-(cyclohexen-1-yl)isoquinolones 180ak and 180al. This obviously indicates the very important function of a cyclohexen-1-yl substituent. While a double bond did not participate in the cyclization, cyclohexen-1-yl possessed almost the same regiochemistry-determining orienting power as an aryl substituent (see Table 4.1).

\subsubsection{Ruthenium-Catalyzed Synthesis of 2-Pyridones}

As this novel ruthenium-catalyzed oxidative annulation showed remarkable potential in the isoquinolone synthesis, other possible heterocycles syntheses were considered to be accomplished by this method. Since pyridone are omnipresent in a number of pharmaceuticals and biologically active natural products, ${ }^{164}$ this structural motif represented an intriguing synthetic target. Indeed, ruthenium-catalyzed oxidative annulations with alkynes via $\mathrm{C}-\mathrm{H} / \mathrm{N}-\mathrm{H}$ bond functionalizations appeared to be possible also with acrylamides as the substrates. Importantly, no product formation was detected without the oxidant or in the absence of the ruthenium catalyst. To elaborate the

\footnotetext{
164 (a) Jessen, H. J.; Gademann, K. Nat. Prod. Rep. 2010, 27, 1168-1185. (b) Nagle, P. S.; Pawar, Y. A.; Sonawane, A. E.; Bhosale, S. M.; More, D. H. Med. Chem. Res. 2012, 21, 1395-1402. (c) Tamura, R.; Yamada, Y.; Nakao, Y.; Hiyama, T. Angew. Chem. Int. Ed. 2012, 51, 5679-5682.
} 
optimized reaction conditions for this transformation, cyclization of $\mathrm{N}$-methyl methacrylamide (181a) with tolane (88a) was selected as the standard reaction (Scheme 4.5). ${ }^{165}$

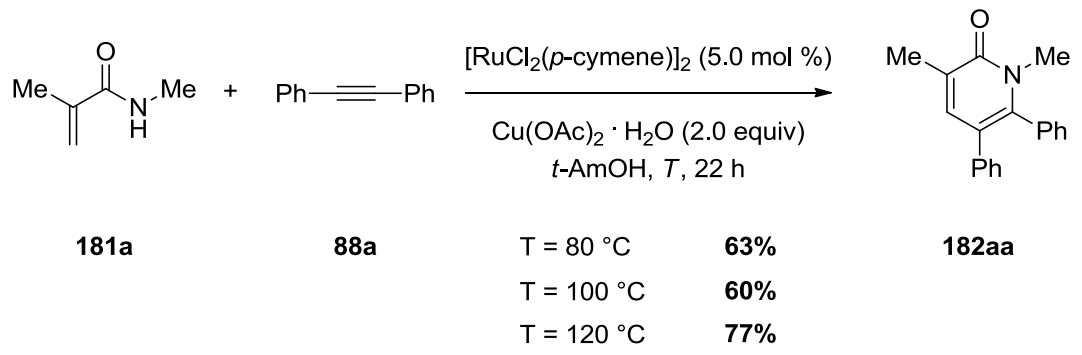

Scheme 4.5: Temperature optimization for ruthenium-catalyzed oxidative synthesis of 2-pyridone 182aa.

Testing the influence of the reaction temperature upon the course of the annulation, the temperature of $120^{\circ} \mathrm{C}$ was revealed to be optimal for this highly chemo-selective oxidative coupling (Scheme 4.5). Further experiments indicated that the amount of oxidant could be reduced with inverted ratio of $\mathrm{N}$-methyl methacrylamide (181a) and tolane (88a). Only one equivalent of copper acetate is actually necessary to obtain product 182aa in very high yield (Scheme 4.6).

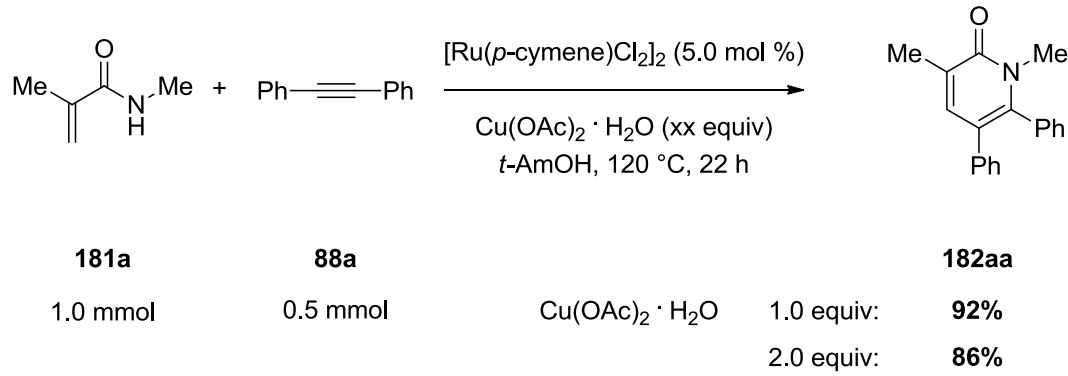

Scheme 4.6: Effect of $\mathrm{Cu}(\mathrm{COA})_{2} \mathrm{H}_{2} \mathrm{O}$ on the oxidative annulation.

Since rhodium-catalyzed versions of this reaction were known to possess several limitations, such as low selectivities for unsymmetrically substituted alkynes or for $\mathrm{N}$-substituted acrylamides with electron-withdrawing substituents, the scope and limitations of this novel ruthenium-catalyzed synthesis of 2-pyridones $\mathbf{1 8 2}$ was tested. First, oxidative cyclization of symmetrically diarylsubstituted alkynes $\mathbf{8 8}$ with $N$-phenyl methacrylamide (181b) was studied (Table 4.2).

Table 4.2: Synthesis of 2-pyridones 182 with symmetrically substituted diarylalkynes 88 .

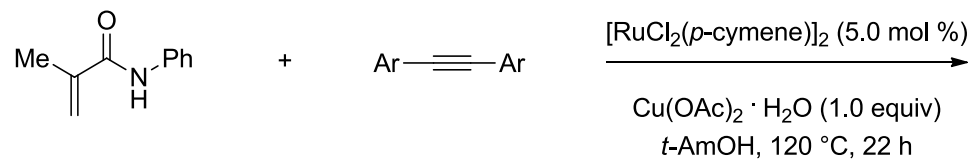

$181 \mathrm{~b}$
88<smiles>Cc1cc(Br)c(Br)n(-c2ccccc2)c1=O</smiles>

182

\footnotetext{
${ }^{165}$ Ackermann, L.; Lygin, A. V.; Hofmann, N. Org. Lett. 2011, 13, 3278-3281.
} 


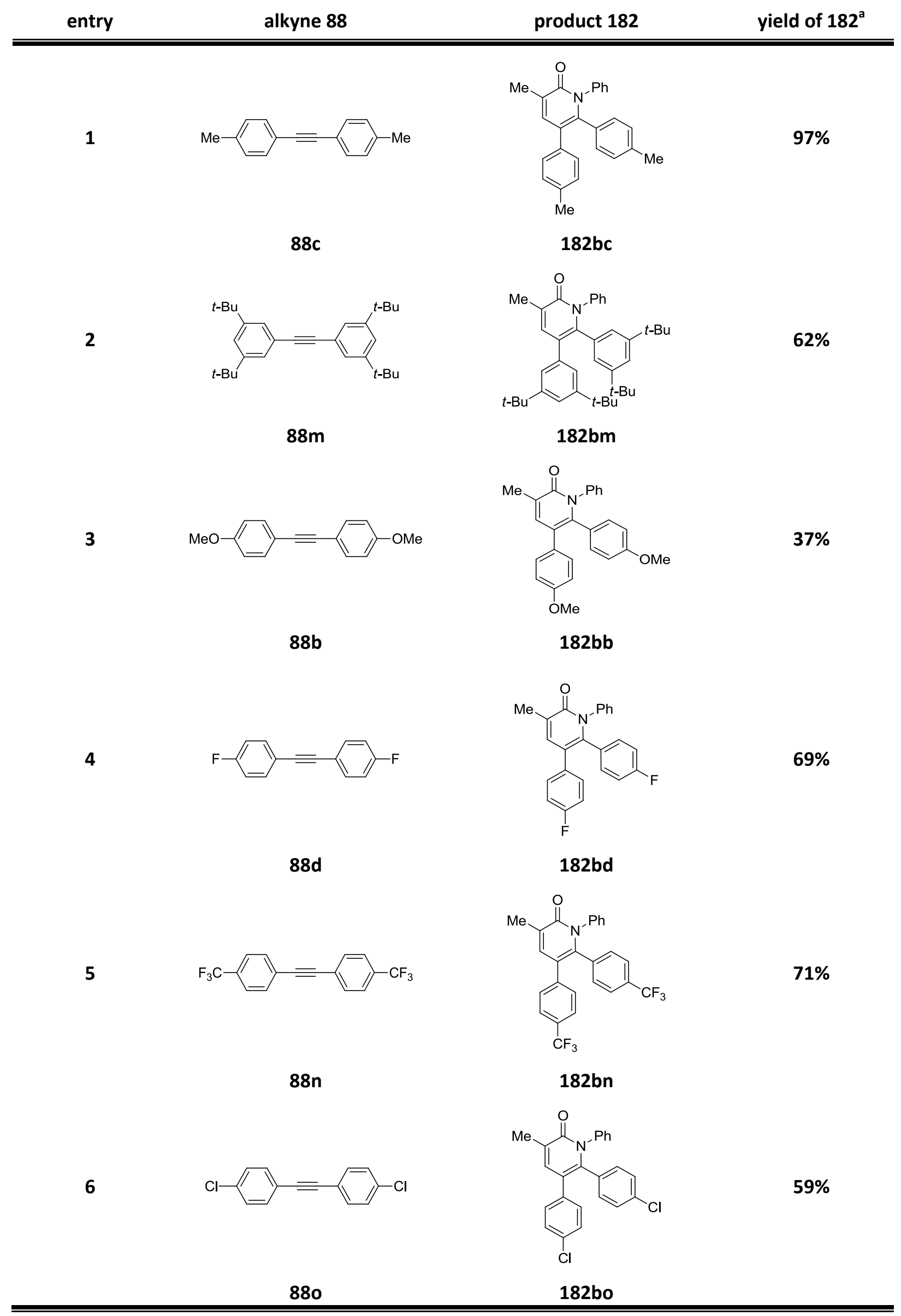


${ }^{\mathrm{a}}$ Reaction conditions: $181 \mathrm{~b}(1.0 \mathrm{mmol}), 880(0.5 \mathrm{mmol}),\left[\mathrm{RuCl}_{2}(p \text {-cymene })\right]_{2}(5.0 \mathrm{~mol} \%), \mathrm{Cu}(\mathrm{OAc})_{2}{ }^{\cdot} \mathrm{H}_{2} \mathrm{O}(1.0$ equiv), $t$-AmOH $(2.0 \mathrm{~mL}), 20 \mathrm{~h}, 120^{\circ} \mathrm{C}$.

A broad range of symmetrical diarylsubstituted alkynes $\mathbf{8 8}$ gave satisfactory results applying the optimized reaction conditions. Electron-rich (entries 1 - 3) as well as electron-deficient (entries 4 -6) alkynes could be annulated in high yields. The electron-rich di-p-tolylacetylene (88c) furnished 2pyridone $\mathbf{1 8 2}$ bc in virtually quantitative yield, whereas the reaction with electron-rich, but sterically demanding alkyne 88m demonstrated a reduced efficiency (entries 1 and 2). Only the methoxysubstituted substrate $\mathbf{8 8 b}$ afforded the corresponding product $\mathbf{1 8 2} \mathbf{b b}$ in moderate yield (entry 3 ). Good results were obtained in the annulation of diarylalkynes with electron-withdrawing substituents $\mathbf{8 8 d}$ and $\mathbf{8 8 n}$ (entry 4 and 5), and even a chloro-substituted starting material $\mathbf{8 8 0}$ was tolerated and showed no side-transformations, like direct arylations (entry 6).

Symmetrical dialkylalkynes such as hex-3-yne (88p) and oct-4-yne (88q) proved to be feasible substrates for the ruthenium-catalyzed annulation as well (Scheme 4.7).

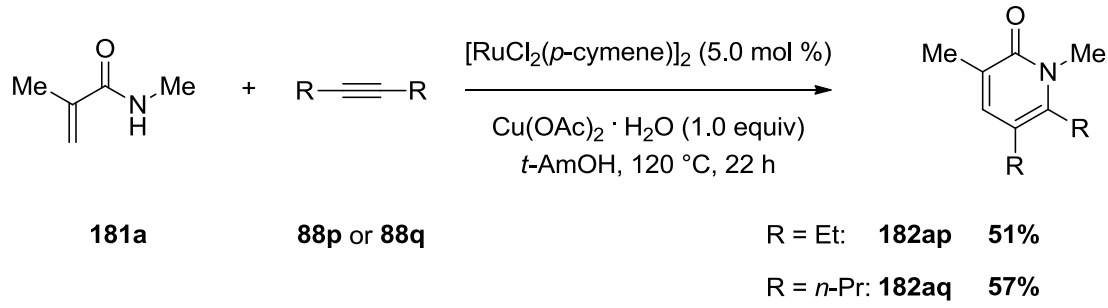

Scheme 4.7: Symmetrical dialkylalkynes $\mathbf{8 8 p}$ and $\mathbf{8 8 q}$ as starting materials in ruthenium-catalyzed oxidative synthesis of 2-pyridones 182

Likewise, the potential application of unsymmetrically-substituted substrates was in the rutheniumcatalyzed oxidative synthesis of 2-pyridones 182 (Table 4.3).

Table 4.3: Ruthenium-catalyzed annulations of acrylamides 181 with unsymmetrically substituted alkynes 88 .

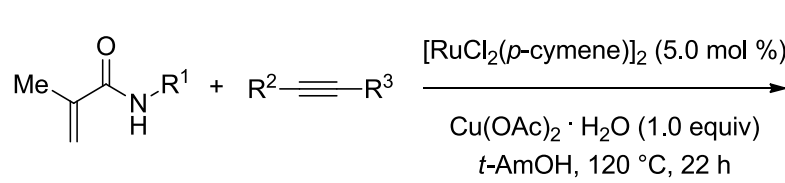

181
88

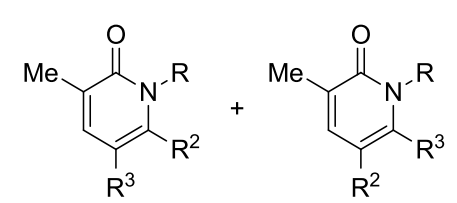

182
182

entry alkyne 88

product 182

product 182'

ratio $180: 180^{\prime}$

combined yield $^{\mathrm{a}}$

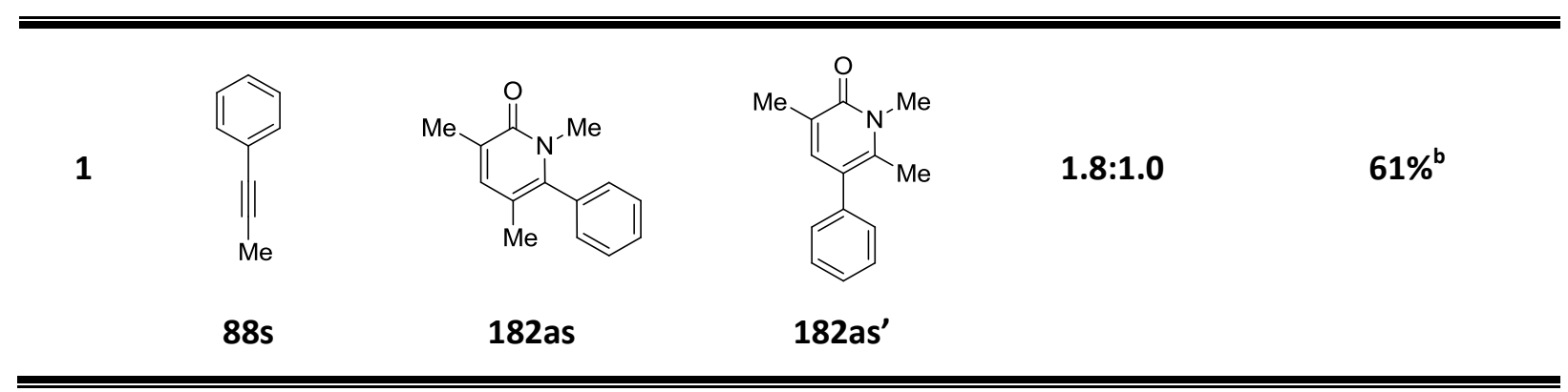




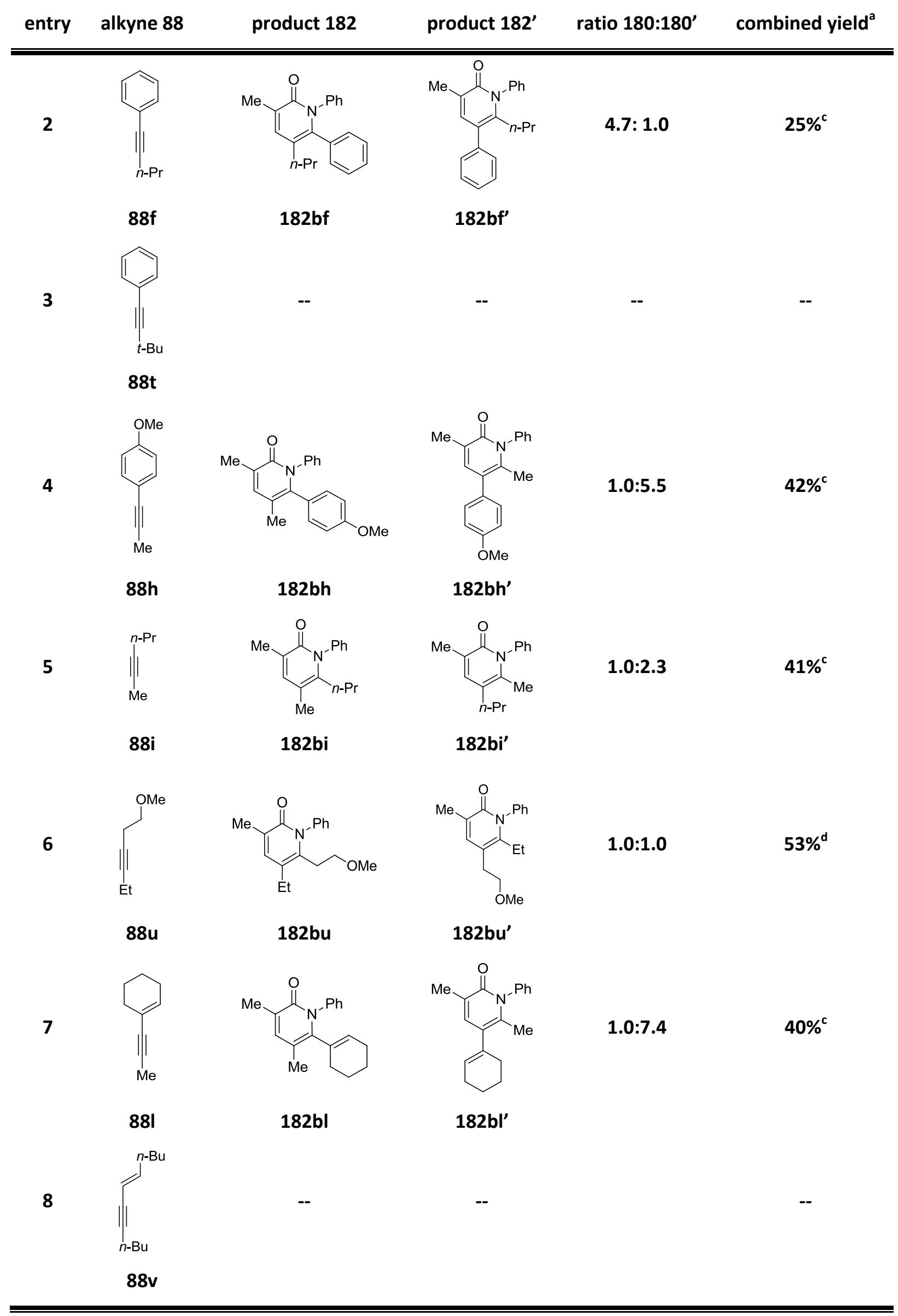




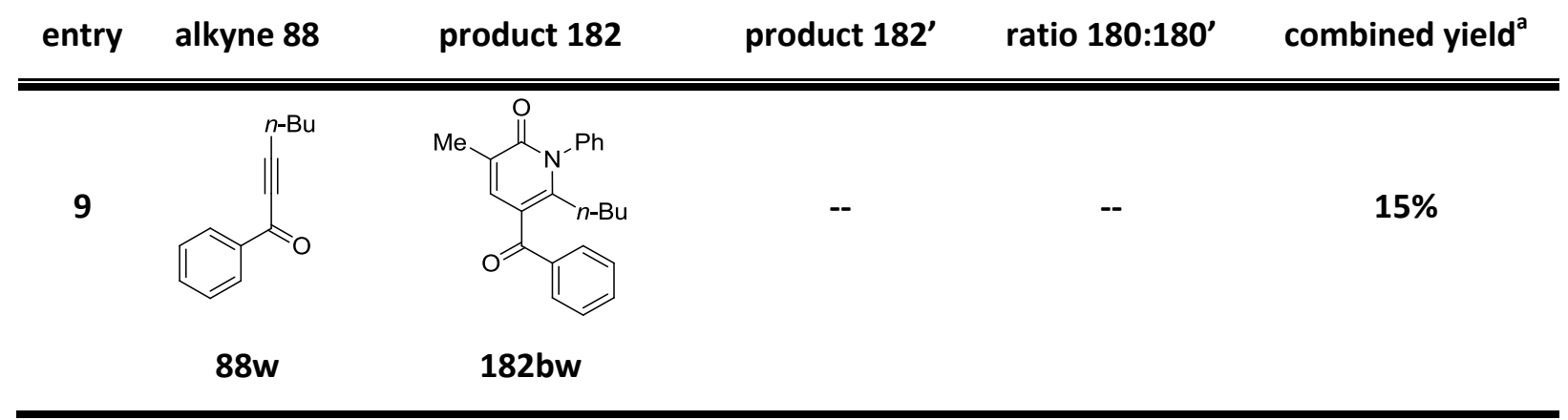

${ }^{a}$ Reaction conditions: 88 (1.0 mmol), $182(0.5 \mathrm{mmol}),\left[\mathrm{RuCl}_{2}(p \text {-cymene })\right]_{2}(5.0 \mathrm{~mol} \%), \mathrm{Cu}(\mathrm{OAc})_{2} \mathrm{H}_{2} \mathrm{O}(1.0$ equiv), t-AmOH $(2.0 \mathrm{~mL}), 20 \mathrm{~h}, 120^{\circ} \mathrm{C} ;{ }^{\mathrm{b}}$ Compounds $182 \mathrm{as}$ and 182as' were isolated in pure form in $39 \%$ and $22 \%$ yield, respectively; ${ }^{\mathrm{c}}$ ratios are calculated by comparision with ${ }^{1} \mathrm{H}-\mathrm{NMR}$-spectra from pure isolated compounds; ${ }^{\text {d }}$ Products $\mathbf{1 8 2}$ bu and $\mathbf{1 8 2}$ bu' were isolated in pure form in $26 \%$ and $27 \%$ yield, respectively.

Under these reaction conditions, the scope of unsymmetrically substituted alkynes $\mathbf{8 8}$ appeared to be rather limited. While 1-phenyl-1-propyne (88s) still gave a good total yield of the products 182as and 182as', albeit with low regioselectivity (entry 1), increasing the size of the alkyl substituent dramatically decreased the conversion (entries 2, 3). Besides the poor regioselectivity, the separation of isomers was only possible in few rare cases (endries 1 and 6). Annulations with unsymetrical dialkylalkynes $\mathbf{8 8} \mathbf{i}$ and $\mathbf{8 8} \mathrm{u}$ were almost not regeoselective (entries 5 and 6), although the total yield of the products was still moderate. While the reactivity of 1-(cyclohexen-1-yl)-1-propyne (88I) (entry 7)and methylalkylalkynes 88i (entry 5) was essentially the same as in the annulation with $\mathrm{N}$ methylbenzamide (86a) (see Scheme 4.4), acyclic enyne 88v did furnish the desired product (entry 8). However, carbonyl functionality on the acetylenic reactant was tolerated, albeit the isolated yield was rather low (entry 9).

Besides the broad scope for the substitution pattern in the acrylamides $\mathbf{1 8 1}$ in their annulations with aryl-substituted alkynes, as was demonstrated by Ackermann, Lygin and co-workers, ${ }^{165}$ better versatility of these ruthenium-catalyzed oxidative syntheses of 2-pyridones $\mathbf{1 8 2}$ in comparison with the rhodium-catalyzed ones was illustrated by applying the challenging $\alpha$-methylacrylamides $\mathbf{1 8 1 d}$ and 181e with nitro or ester functionality, respectively (Table 4.4).

Table 4.4: Some examples for the scope of acrylamides 181.

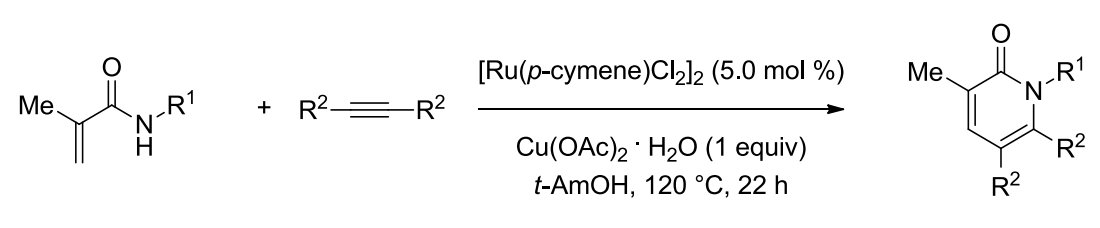




entry acrylamide 181 yield of 182

${ }^{\mathrm{a}}$ Reaction conditions: 181 (1.0 mmol), $88(0.5 \mathrm{mmol}),\left[\mathrm{RuCl}_{2}(p \text {-cymene })\right]_{2}(5.0 \mathrm{~mol} \%), \mathrm{Cu}(\mathrm{OAc})_{2} \cdot \mathrm{H}_{2} \mathrm{O}(1.0$ equiv), $t$-AmOH $(2.0 \mathrm{~mL}), 20 \mathrm{~h}, 120^{\circ} \mathrm{C}$.

The success of these oxidative $\mathrm{C}-\mathrm{H} / \mathrm{N}-\mathrm{H}$ bond functionalizations was found to be highly depending upon the substitution mode on a double bond moiety in acrylamide. Thus, while annulations of $\alpha$ -

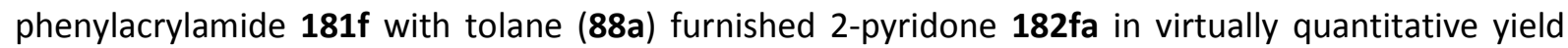
(Scheme 4.8 ), an acceptable yield in the reaction of isomeric $\beta$-phenylacrylamide $\mathbf{1 8 1} \mathbf{g}(51 \%)$ could be obtained only when using a higher loading of the oxidant and prolonged heating. The unsubstituted acrylamide $181 \mathrm{~h}$ demonstrated only poor conversion under the standard condition (Scheme 4.8). ${ }^{166}$<smiles>C[C+](Cc1ccccc1)NC(=O)/C=C/c1ccccc1</smiles>

$181 \mathrm{~g}$

$88 a$

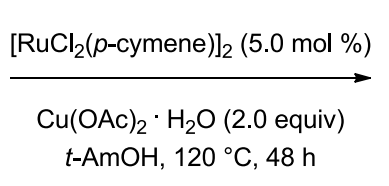

$51 \%$<smiles>Cn1c(-c2ccccc2)c(-c2ccccc2)c(-c2ccccc2)cc1=O</smiles>

182ga<smiles>C=CC(=O)NC(C)(C)C[P+](=Cc1ccccc1)c1ccccc1</smiles>

181h

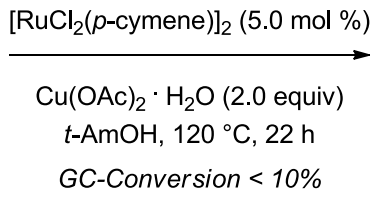

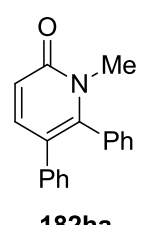

182ha

\footnotetext{
${ }^{166}$ Reactions performed by Dr. A. V. Lygin.
} 
Scheme 4.8 a: Influence of the substitution on the double bond in acrylamide upon the efficiency of annulation.

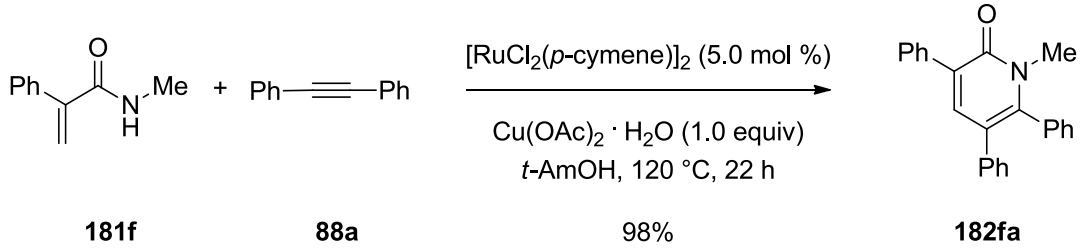

Scheme 4.8: Influence of the substitution on the double bond in acrylamide upon the efficiency of annulation.

Furthermore, annulations of $(E)$-N,2-dimethylbut-2-enamide (181i) were tested with various solvents, reaction temperature and oxidants, as summarized in Table 4.5.

Table 4.5: Optimization-studies for $\alpha, \beta$-dimethylsubstituted $N$-methylacrylamide 181i.

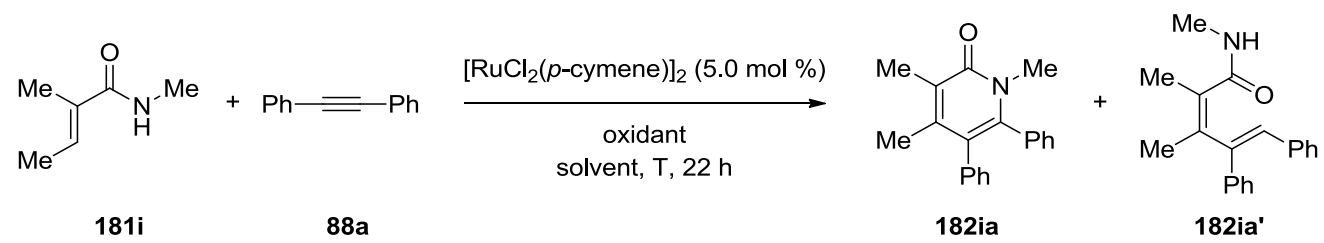

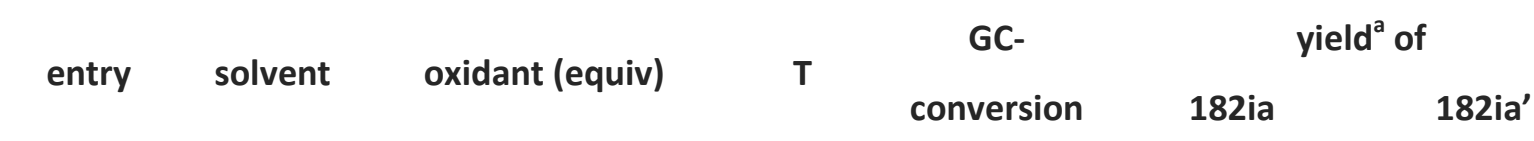

\begin{tabular}{|c|c|c|c|c|c|c|c|}
\hline 1 & $t-\mathrm{AmOH}$ & $\mathrm{Cu}(\mathrm{OAc})_{2}(0.1)$ & $120^{\circ} \mathrm{C}$ & $(40)$ & & $--^{b}$ & \\
\hline 2 & $t-\mathrm{AmOH}$ & $\mathrm{Cu}(\mathrm{OAc})_{2}(2.0)$ & $120^{\circ} \mathrm{C}$ & (87) & $57 \%$ & & $16 \%$ \\
\hline 3 & $t-\mathrm{AmOH}$ & -- & $120^{\circ} \mathrm{C}$ & $(<5)$ & & -- & \\
\hline 4 & $t-\mathrm{AmOH}$ & air & $120^{\circ} \mathrm{C}$ & $(<5)$ & & -- & \\
\hline 5 & $t-\mathrm{AmOH}$ & $\mathrm{AgOAc}(2.0)$ & $120^{\circ} \mathrm{C}$ & (65) & & $--^{b}$ & \\
\hline 6 & $\mathrm{MeOH}$ & $\mathrm{Cu}(\mathrm{OAc})_{2}(2.0)$ & $70^{\circ} \mathrm{C}$ & $(44)$ & & $--^{b}$ & \\
\hline 7 & DME & $\mathrm{Cu}(\mathrm{OAc})_{2}(2.0)$ & $70^{\circ} \mathrm{C}$ & $(<5)$ & & -- & \\
\hline 8 & DME & Benzochinone (2.0) & $120^{\circ} \mathrm{C}$ & $(<5)$ & & -- & \\
\hline 9 & -- & Pinacolone (2.0) & $120^{\circ} \mathrm{C}$ & $(<5)$ & & -- & \\
\hline
\end{tabular}

${ }^{\mathrm{a}}$ Reaction conditions: 181i(1.0 mmol), 88a (0.5 mmol), $\left[\mathrm{RuCl}_{2}(p \text {-cymene })\right]_{2}(5.0 \mathrm{~mol} \%), 22 \mathrm{~h} ;{ }^{\mathrm{b}}$ not determined.

Interestingly, only the use of two equivalents of copper acetate gave a satisfactory yield (entry 2). Notably, compound 182ia' was isolated in $16 \%$ yield as well. This ring-opened minor by-product resulted from hydroalkenylation of tolane (88a) under these conditions.

Since this novel ruthenium-catalyzed annulation reactions appeared to be highly efficient in a variety of oxidative $\mathrm{C}-\mathrm{H} / \mathrm{N}-\mathrm{H}$ bond functionalizations of differently substituted benzamides 86 and 
acrylamides 181 , the analogous $\mathrm{C}-\mathrm{H} / \mathrm{O}-\mathrm{H}$ bond activations with readily available and inexpensive methacrylic acids 183 was put on the agenda (Scheme 4.9).

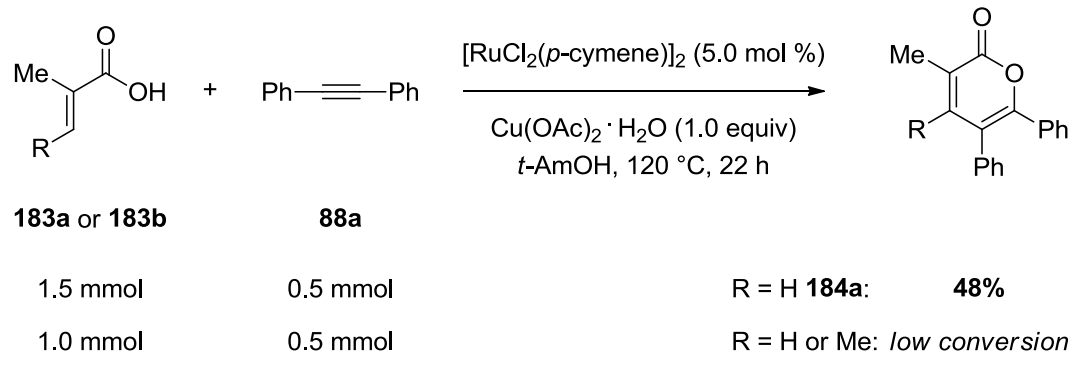

Scheme 4.9: Ruthenium-catalyzed oxidative synthesis of $\alpha$-pyrones $184 a$ via oxidative $\mathrm{C}-\mathrm{H} / \mathrm{O}-\mathrm{H}$ bond functionalizations.

Initial studies indicated that the expected $a$-pyrone 184 a could be obtained in $48 \%$ isolated yield when using three equivalents of acrylic acid 183a already under non-optimized reaction conditions. Upon further developed of this project by the Ackermann group, this reaction was adopted towards the synthesis of variously substituted isocoumarines as well. ${ }^{167}$

\subsubsection{Mechanistic Studies}

To gain insight into the mechanistic course of the ruthenium-catalyzed oxidative annulation of alkynes 88 with benzamides 86 or acrylamides 181 via $\mathrm{C}-\mathrm{H} / \mathrm{N}-\mathrm{H}$ bond cleavages, several intermolecular competition experiments were performed (Scheme 4.10).

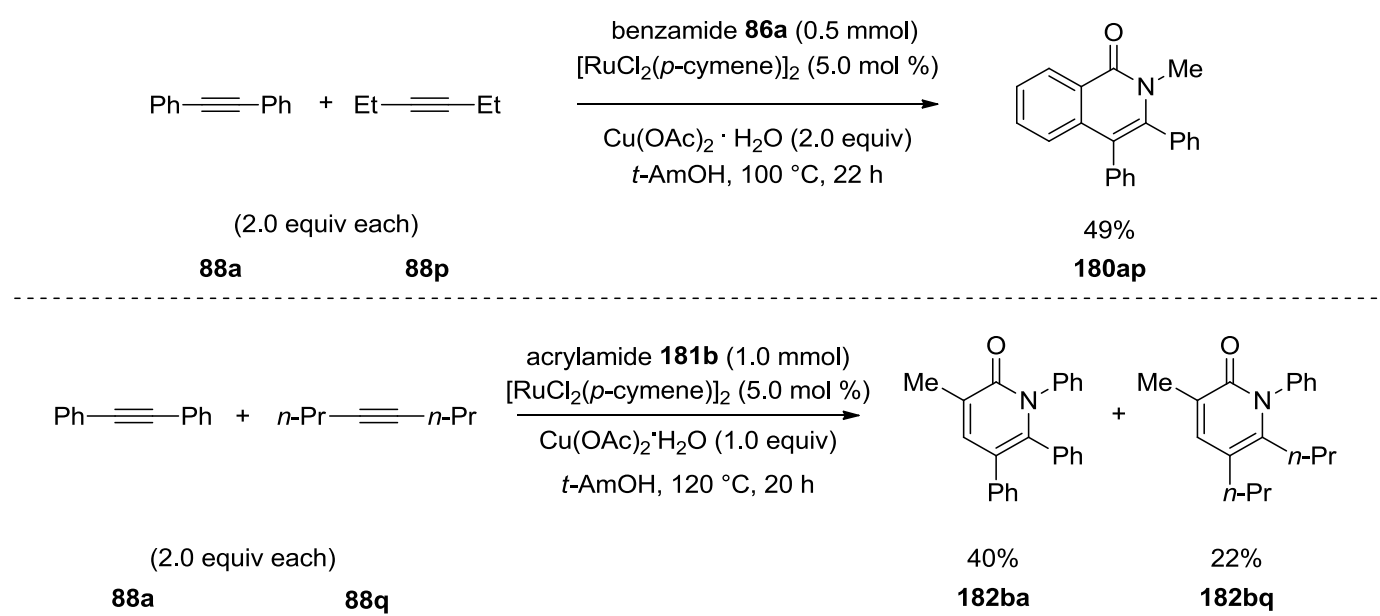

Scheme 4.10: Intermolecular competition experiment between diphenyl- (88a) and dialkylalkynes $\mathbf{8 8 p}$ and $\mathbf{8 8 q}$.

The competitive annulation of tolane (88a) and diethylacetylene (88p) with $\mathrm{N}$-methylbenzamide (86a) (Scheme 4.10, top) or of tolane (88a) and di-n-propylacetylene (88q) with $\mathrm{N}$ -

167 (a) Ackermann, L.; Pospech, J.; Graczyk, K.; Rauch, K. Org. Lett. 2012, 14, 930-933. (b) Deponti, M.; Kozhushkov, S. I.; Yufit, D.; Ackermann, L. Org. Biomol. Chem. 2013, 11, 142-148. 
phenylmethacrylamide (181b) (Scheme 4.10, bottom) showed a predominant formation of the diphenylated product $180 \mathrm{ap}$ or $182 \mathrm{ba}$, respectively. This might arise from stabilization of an intermediate due to conjugation effects (see below in Scheme 4.12).

Intermolecular competition experiments on reactivity of electron-rich (88c) and electron-deficient alkynes (88d) towards $N$-phenylmethacrylamide (181b) clearly indicated the preferential conversion of the former one (Scheme 4.11).
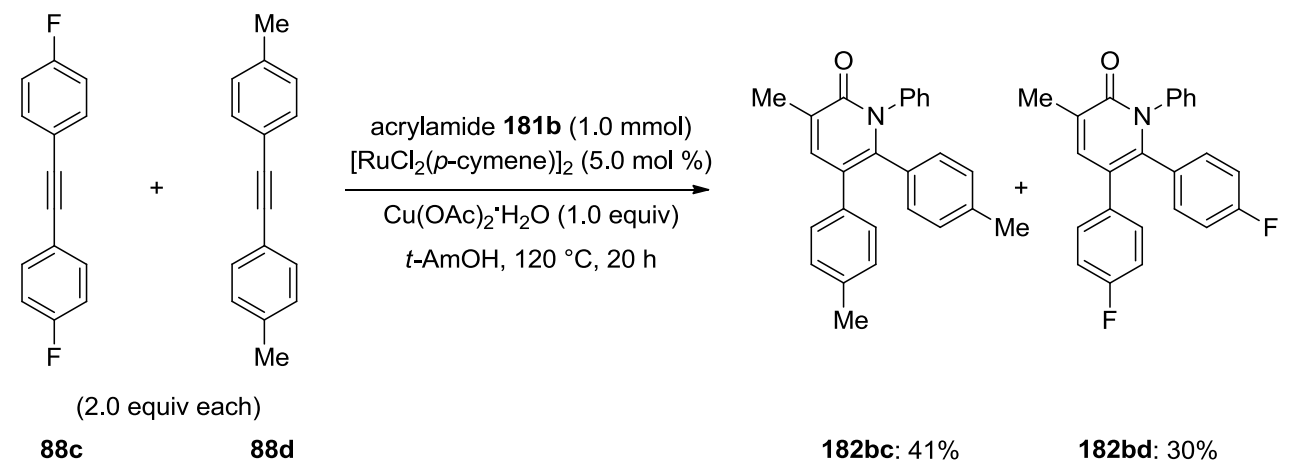

Scheme 4.11: Intermolecular competition with electron-rich rich (88d) and electron-deficient alkyne (88c).

Moreover, benzamides with electron-deficient substituents were shown to be favored substrates for the oxidative annulation. ${ }^{163}$ This excluded the electrophilic activation of the $\mathrm{C}-\mathrm{H}$ bond as a possible mechanistic step. Yet, experiments with isotopically labeled substrates and solvents indicated an irreversible $\mathrm{C}-\mathrm{H}$ bond metalation step with a $k_{\mathrm{H}} / k_{\mathrm{D}} \approx 2.6,{ }^{168}$ which was of comparable value as for the concerted acetate-assisted metalation. ${ }^{169}$ The necessity of such acetate assistance for the success of transformation was also supported in the course of optimization studies, as no product formation was observed in the absence of acetate (Table 4.5; entries 3, 4, 8 and 9).

On the basis of these experimental observations, the following catalytic cycle for the rutheniumcatalyzed carboxylate-assisted synthesis of isoquinolones 180 and 2-pyridones 182 via oxidative $\mathrm{C}-\mathrm{H} /$ $\mathrm{N}-\mathrm{H}$ bond functionalizations is proposed (Scheme 4.12).

Initially, the ruthenium-dimer is expected to form an acetate complex 12b similar to those observed in the ruthenium-catalyzed carboxylate-assisted direct alkylation (see Scheme 3.21 and Scheme 3.49). Subsequently, carboxylate-assisted irreversible $\mathrm{C}-\mathrm{H}$ bond metalation via transition state 184 with a loss of one molecule of acetic acid upon deprotonation of the amide group formed ruthenacycle $\mathbf{1 8 5}$. After coordination of alkyne $\mathbf{8 8}$, regioselective migratory insertion deliveres as the

\footnotetext{
${ }^{168}$ Experiments performed by Dr. A. V. Lygin.

${ }^{169}$ For palladium-catalyzed acetate-assisted C-H metalation, see: Ryabov, A. D.; Sakodinskaya, I. K.; Yatsimirsky, A. K. Dalton. Trans. 1985, 2629-2638.
} 
key intermediate seven-membered rutenacycle 186. Surprisingly, to the best of our knowledge, no attempts to explain the mechanism and regioselectivity of this migratory insertion has thus far been untertaken, in spite of its prime importance for the general regioselectivity of the annulation. The intermediate 186 releases the desired product 181/182 through reductive elimination which is followed by subsequent re-oxidation of the resulting ruthenium (0) species core by the copper (II)acetate.

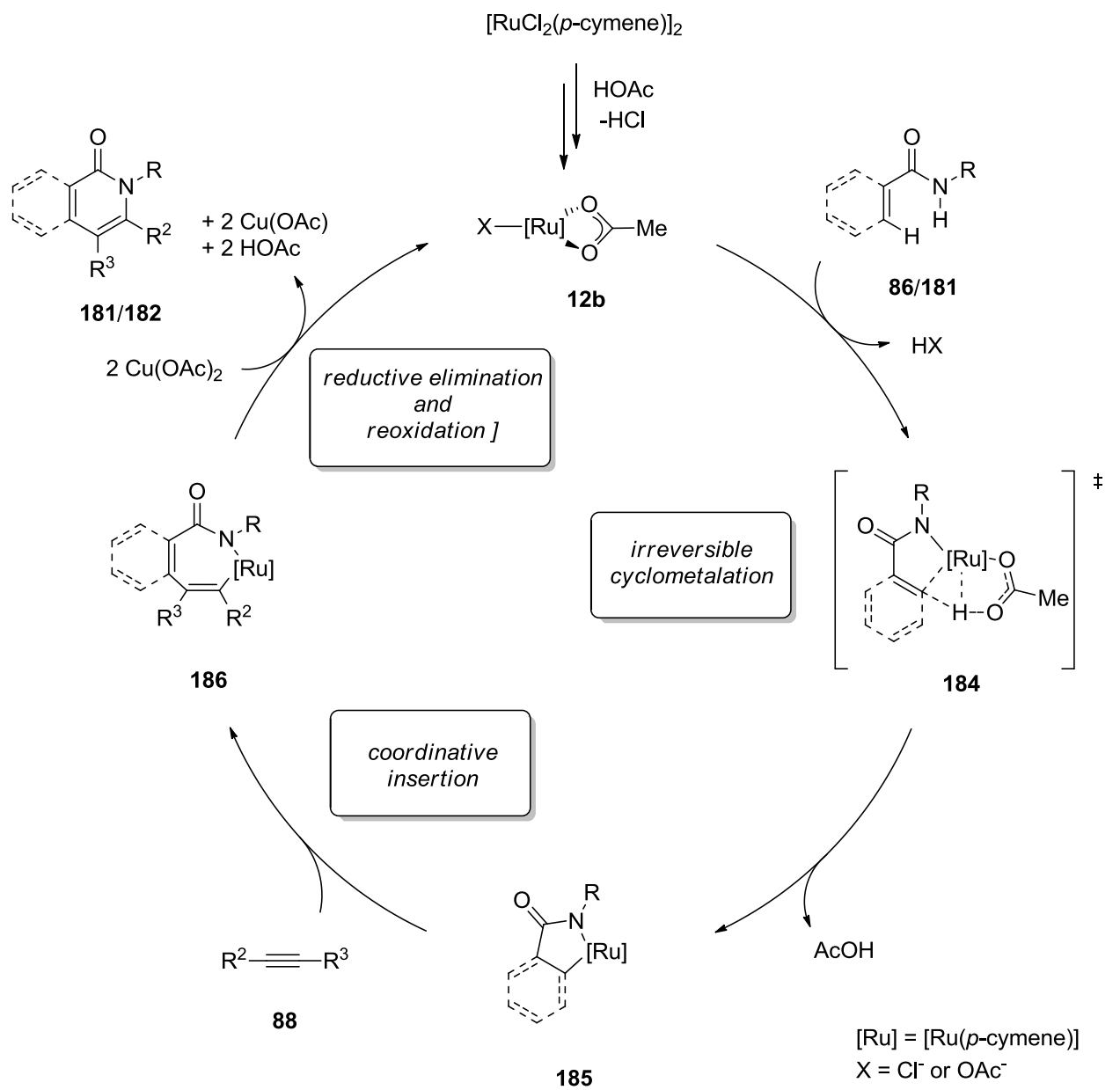

Scheme 4.12: Proposed catalytic cycle for the ruthenium-catalyzed oxidative $\mathrm{C}-\mathrm{H} / \mathrm{N}-\mathrm{H}$ bond functionalizations. 


\section{Summary and Outlook}

Within this thesis, the development of new synthetic methods has been guided in general by the principles of green chemistry. Among others, the atom- and step-economical ruthenium-catalyzed $\mathrm{C}-\mathrm{H}$ bond functionalizations in non-toxic reaction media arguably constitute one of the most sustainable synthetic methods in preparative organic chemistry.

In the first project, the main efforts were focused on the ruthenium-catalyzed direct alkylation with unactivated primary alkyl halides $\mathbf{4 2 a}$ under basic reaction conditions. The development of the generally applicable site-selective formation of $\mathrm{C}($ alkyl) $-\mathrm{C}($ aryl) bonds through direct $\mathrm{C}-\mathrm{H}$ bond functionalizations was selected as a central goal of this project. Thus, the substrate scope was shown to include unsaturated electrophiles and acetyl-substituted phenylpyridines among others (Scheme $5.1)$.

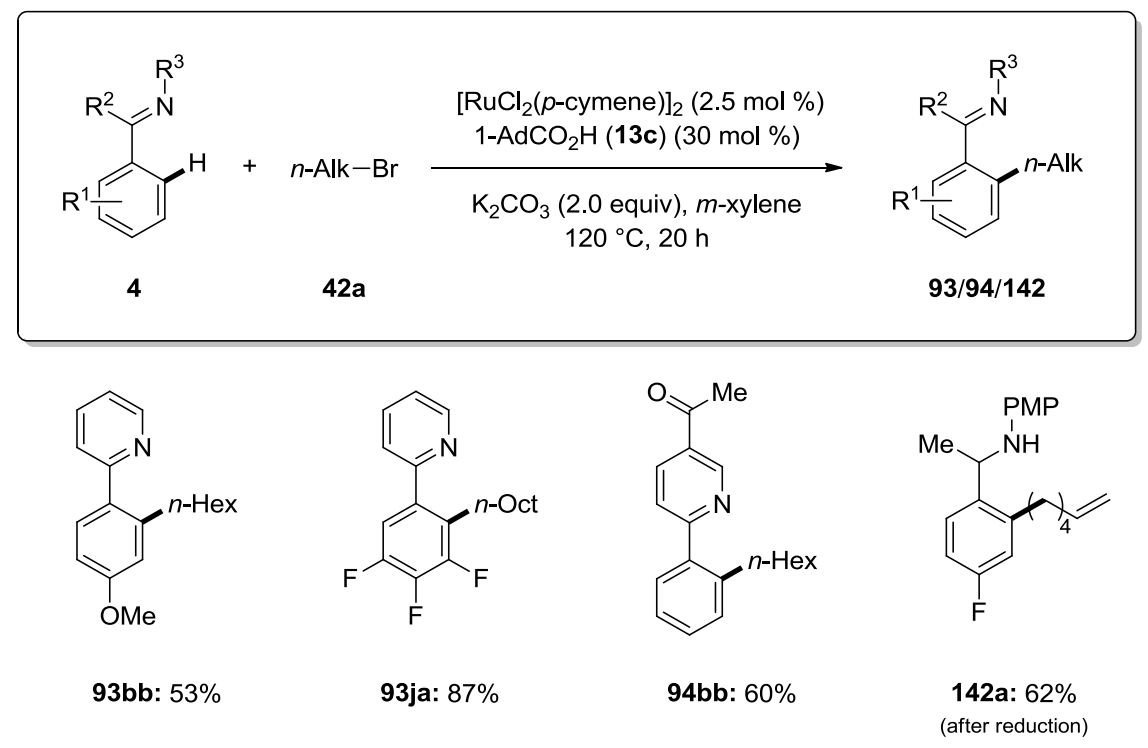

Scheme 5.1: The ruthenium-catalyzed direct ortho-alkylation with primary alkyl halides 42a.

The application of inexpensive KOAc as an additive in the direct alkylation of ( $p$-fluorophenyl)pyridine (6ca) afforded the desired ortho-alkylated product $93 \mathrm{cb}$ in a high yield as well (Scheme 5.2). Furthermore, it was demonstrated that water could be employed as reaction medium. 


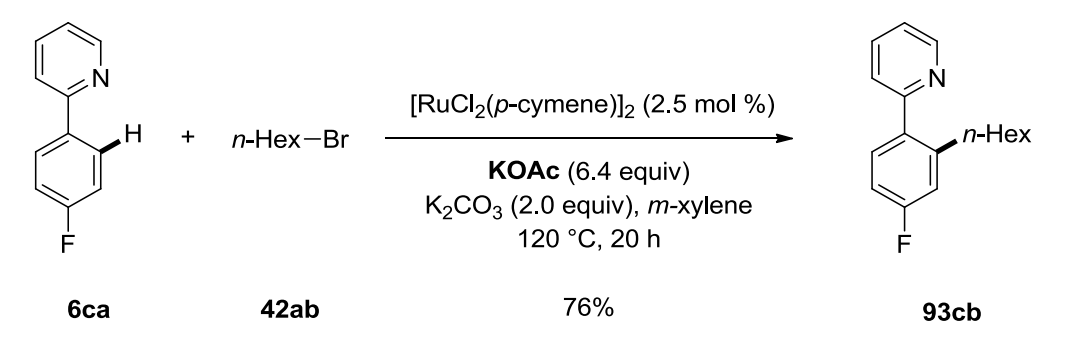

Scheme 5.2: Carboxylate-assisted direct alkylation with inexpensive KOAc as additive.

Mechanistic studies showed the higher reactivity of electron poor substrates. The following order of reactivity of different directing groups (DGs) was derived from intermolecular competition experiments (Scheme 5.3).

DG<smiles>c1ccc(-c2ccccn2)cc1</smiles>

6<smiles>c1ccc(-n2cccn2)cc1</smiles>

87<smiles>CC(=N[PH3])c1ccccc1</smiles>

121<smiles>c1ccc(C2=NCCO2)cc1</smiles>

136

Scheme 5.3: Order of reactivity for different DGs.

Furthermore, ruthenacycle 14a was shown to be catalytically competent (Scheme 5.4). Detailed mechanistic studies suggest the catalytic cycle to involve a carboxylate-assisted reversible $\mathrm{C}-\mathrm{H}$ bond activation followed by activation of the alkyl halide $42 \mathrm{a}$ and final reductive elimination.
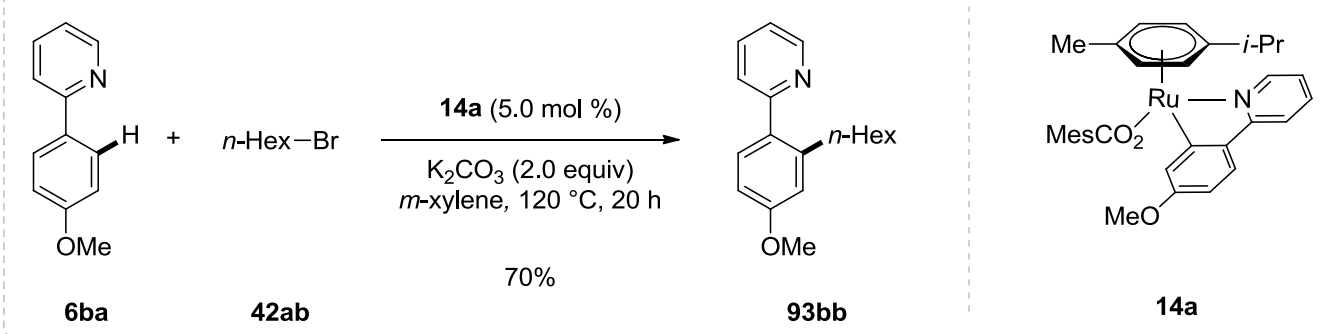

Scheme 5.4: Direct ortho-alkylation with cycloruthenated complex 14a as the catalyst.

Future development of the ruthenium-catalyzed direct ortho-alkylations with unactivated primary alkyl halides should be focused on extending the substrate scope to include inter alia substrates with oxygen-containing directing groups.

Subsequently, an unprecedented meta-selective direct alkylation with various cyclic as well as acyclic secondary alkyl bromides $\mathbf{4 2 b}$ as inexpensive electrophiles was devised (Scheme 5.5). 


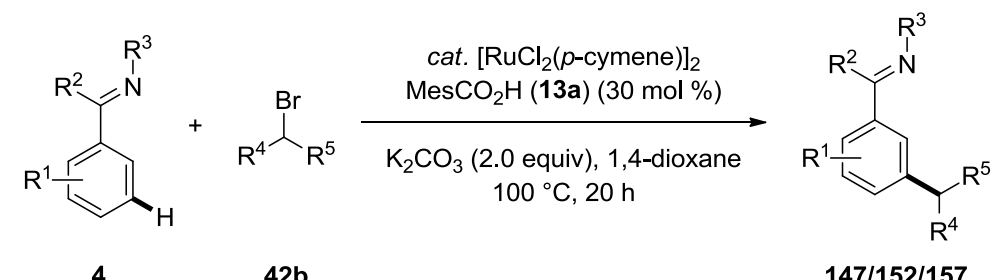

Scheme 5.5: Ruthenium-catalyzed direct meta-alkylation with secondary alkyl bromides $\mathbf{4 2 b .}$
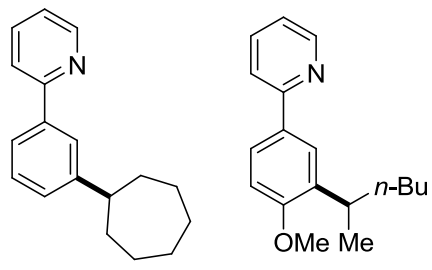

147ac: $76 \%$

147bj: $70 \%$

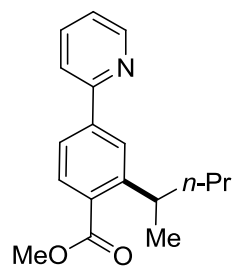

147pi: $63 \%$

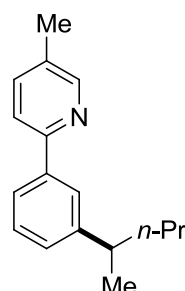

152fi: $56 \%$

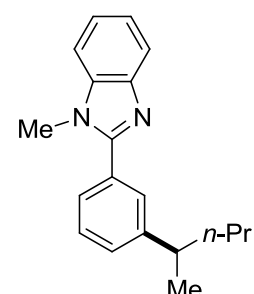

157: $54 \%$

Figure 5.1: Selected examples for the ruthenium-catalyzed direct meta-alkylation.

A broad range of substrates, including ester-substituted arenes and different $\mathrm{N}$-containing directing groups were capable of furnishing selectively meta-alkylated products. Detailed mechanistic studies were suggested of a reaction manifold, relying on the carboxylate-assisted ortho- $\mathrm{C}-\mathrm{H}$ activation, and subsequent electrophilic aromatic-type substitution.

Various protected amino acids $\mathbf{7 6}$ or phosphoric acid diesters $\mathbf{1 7 5}$ were shown to serve as effective ligands for the meta-selective direct alkylations, employing water as an environmentally benign reaction medium (Scheme 5.6).<smiles>c1ccc(-c2ccccn2)cc1</smiles><smiles></smiles>

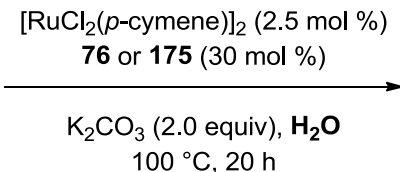

6aa

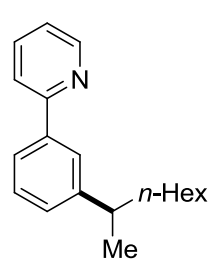

147 aa<smiles>CC(C)C(NC(=O)C(C)(C)C)C(=O)O</smiles>

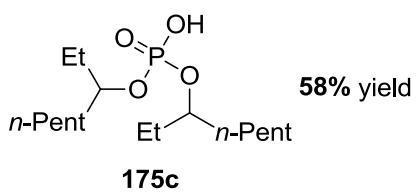

Scheme 5.6: Direct meta-alkylation using amino acid $\mathbf{7 6 c}$ or phosphoric acid diester $\mathbf{1 7 5 c}$ as cocatalyst on water.

Further development of the ruthenium-catalyzed direct meta-alkylations with unactivated secondary alkyl bromides 42b should involve enantioselective transformations. As the first step towards achieving enantioselectivity, direct norbornylations bear great potential, which was already demonstrated by high exo-stereoselectivities but yet poor regioselectivities. 
Further, the future investigations of the ruthenium-catalyzed carboxylate-assisted direct metaalkylation should address understanding of the mode of action of the $\mathrm{C}-\mathrm{C}$ bond forming step and the activation of the alkyl halide.

In the final project of this thesis, unprecedented ruthenium-catalyzed oxidative alkyne annulations were developed (Scheme 5.7). Application of this new catalytic system allowed for the atom- and step-economical syntheses of isoquinolones $\mathbf{1 8 0}$ and 2-pyridones $\mathbf{1 8 2}$ in high yields and with ample scope.

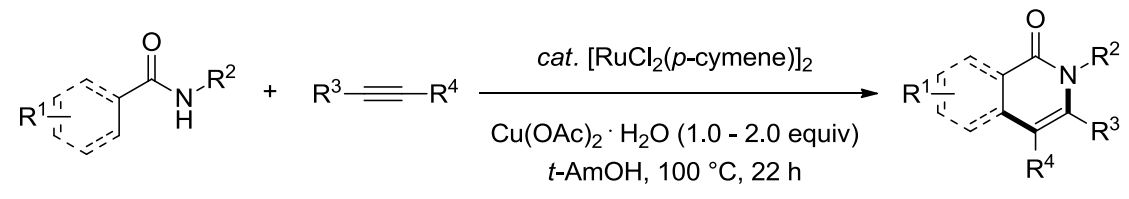

$86 / 181 \quad 88 \quad 180 / 182$<smiles></smiles><smiles>[R]c1ccc(-c2c(-c3ccc(P)cc3)c3ccccc3c(=O)n2C)cc1</smiles>

180ah': $66 \%$

$$
\begin{array}{ll}
R=\text { OMe } & \text { 180ab: } 56 \% \\
R=M e & 180 \text { ac: } 71 \% \\
R=F & 180 \text { ad: } 61 \%
\end{array}
$$<smiles>Cn1c(C2CCCCC2)c(N)c2ccccc2c1=O</smiles>

180al: $56 \%$<smiles>[R]c1ccc(-c2cc(C)c(=O)n(-c3ccccc3)c2-c2ccc([R])cc2)cc1</smiles>

$\mathrm{R}=\mathrm{Cl}$ 182bo: $59 \%$

$\mathrm{R}=\mathrm{Me}$ 182bc: $87 \%$

$\mathrm{R}=\mathrm{H} \quad$ 182aa: $92 \%$<smiles>[R]c1ccc(-n2c(C(=O)P)c(C)cc(C)c2=O)cc1</smiles>

$\mathrm{R}=\mathrm{NO}_{2} \quad$ 182dq: $91 \%$

$\mathrm{R}=\mathrm{CO}_{2}$ Et 182eq: $78 \%$

Scheme 5.7: Ruthenium-catalyzed oxidative annulation for the synthesis of isoquinolones 180 and 2-pyridones 182.

Thus, variously substituted benzamides 86 , acrylamides 181 and benzoic acids 183 were reacted with dialkyl- and diarylalkynes 88 furnishing the desired isoquinolones 180, 2-pyridones 182 or a-pyrones 184, respectively, via ruthenium-catalyzed carboxylate-assisted $\mathrm{C}-\mathrm{H} / \mathrm{N}-\mathrm{H}$ or $\mathrm{C}-\mathrm{H} / \mathrm{O}-\mathrm{H}$ bond cleavage.* Since the regioselectivities with unsymmetrically-substituted alkynes remained rather poor, this methodology should be further developed in future studies, towards improving the regioselectivity and towards enlarging the scope for the use of terminal alkynes. 
*After publication of the results presented herein, several further developments of this chemistry have been reported by the Ackermann group and others. ${ }^{170}$

170 (a) Deponti, M.; Kozhushkov, S. I.; Yufit, D. S.; Ackermann, L. Org. Biomol. Chem. 2013, 11, 142-148. (b) Wang, L.; Ackermann, L. Org. Lett. 2013, 15, 176-179. (c) Li, B.; Wang, N.; Yujie, L.; Xu, S.; Wang, B. Org. Lett. 2013, 15, 136-139. (d) Ma, W.; Graczyk, K.; Ackermann, L. Org. Lett. 2012, 14, 6318-6321. (e) Chidipudi, S. R.; Khan, I.; Lam, H. W. Angew. Chem. Int. Ed. 2012, 51, 12115-12119. (f) Zhao, P.; Wang, F.; Han, K.; Li, X. Org. Lett. 2012, 14, 5506-5509. (g) Kornhaaß, C.; Li, J.; Ackermann, L. J. Org. Chem. 2012, 77, 9190-9198. (h) Chinnagolla, R. K.; Jeganmohan, M. Eur. J. Org. Chem. 2012, 417-423. (i) Parthasarathy, K.; Senthilkumar, N.; Jayakumar, J.; Cheng, C.-H. Org. Lett. 2012, 14, 3478-3481. (j) Thirunavukkarasu, V. S.; Donati, M.; Ackermann, L. Org. Lett. 2012, 14, 3416-3419; (k) Chinnagolla, R. K.; Pimparkar, S.; Jeganmohan, M. Org. Lett. 2012, 14, 3032-3035. (I) Ackermann, L.; Lygin, A. V. Org. Lett. 2012, 14, 764-767. (m) Chinnagolla, R. K.; Jeganmohan, M. Chem. Commun. 2012, 48, 2030-2032. (m) Ackermann, L.; Pospech, J.; Graczyk, K.; Rauch, K. Org. Lett. 2012, 14, 930-933. (n) Ackermann, L.; Wang, L.; Lygin, A. V. Chem. Sci. 2012, 3, 177-180. (o) Ackermann, L.; Fenner, S. Org. Lett. 2011, 13, 6548-6551. (p) Li, B.; Feng, H.; Xu, S.; Wang, B. Chem. Eur. J. 2011, 17, 12573-12577. 


\section{Experimental Section}

\subsection{General Remarks}

All reactions involving moisture- or air-sensitive reagents or products were performed under a $\mathrm{N}_{2}$ atmosphere using pre-dried glassware and standard Schlenk techniques. Syringes for handling of dry solvents were flushed with dry nitrogen threefold prior to use.

\section{Solvents}

All solvents for reactions involving moisture-sensitive reagents were dried, distilled and stored under inert atmosphere (argon or nitrogen) according to the following standard procedures.

solvent

tert-Amylalcohol

Dichloromethan

$\mathbf{N}, \mathbf{N}$-Dimethylformamide

N-Methyl-2-pyrrolidone

Methanol

Tetrahydrofuran

Toluene

Water

1,4-Dioxane

\section{drying method}

was stirred over sodium chips for $5 \mathrm{~h}$ at $120^{\circ} \mathrm{C}$ and distilled under ambient pressure.

was purified using an solvent purification system (SPS) from MBRAUN. was dried over $\mathrm{CaH}_{2}$ for $8 \mathrm{~h}$, degassed and distilled under reduced pressure.

was stirred for $4 \mathrm{~h}$ at $150{ }^{\circ} \mathrm{C}$ over $\mathrm{CaH}_{2}$ and subsequently distilled under reduced pressure.

was stirred over $\mathrm{Mg}$ chips for $3 \mathrm{~h}$ at $65^{\circ} \mathrm{C}$ prior to distillation. was purified using an SPS solvent purification system from MBRAUN. was either predried over $\mathrm{KH}$ followed by distillation from sodium benzophenone ketyl or purified using a solvent purification system from MBRAUN.

was degassed before its use applying repeated Freeze-Pump-Thaw degassing procedure.

was dried by distillation from sodium benzophenone ketyl.

\section{Vacuum}

The following pressures were measured on the used vacuum pump and were not corrected: membrane pump vacuum (MPV): 0.5 mbar, oil pump vacuum (OPV): 0.1 mbar. 


\section{Melting Points}

Melting points were measured using a Stuart ${ }^{\circledR}$ Melting Point Apparatus SMP3 from BARLOWORLD SCIENTIFIC. Reported values are uncorrected and are given as a range (M.r.), if the melting occurred not at a specific melting point (M.p.).

\section{Chromatography}

Analytical thin layer chromatography (TLC) was performed on $0.25 \mathrm{~mm}$ silica gel 60F-plates (MACHEREY-NAGEL) with $254 \mathrm{~nm}$ fluorescent indicator from MERCK. Plates were visualized under UVlight and developed by treatment with a $\mathrm{KMnO}_{4}$ solution followed by careful applying a heat gun. Chromatographic purification of products was accomplished by flash column chromatography on MERCK silica gel, grade 60 (0.040-0.063 mm and 0.063-0.200 mm, 70-230 mesh astimated).

\section{High Performance Liquid Chromatography}

Preparative and analytical separations were performed on an HPLC-System from KNAUER (Smartline Pump 100, Dynamic Mixing Chamber, Injection- and Control-Valve, Smartline UV Detector 2500). Separation column ChiralPak IC $(250 \times 20 \mathrm{~mm}$ or $4.6 \times 250 \mathrm{~mm})$ from DAICEL CHEM. IND. (LTD) was used. Organic solvents of HPLC grade were employed. All samples were filtered through Polytetrafluorethylen Filter from ROTH $(\varnothing 25 \mathrm{~mm}, 0.2 \mu \mathrm{m})$ or VWR $(\varnothing 13 \mathrm{~mm}, 0.2 \mu \mathrm{m})$ prior to separation.

\section{Gas Chromatograpgy}

The conversion of the reactions was monitored applying coupled gas chromatography/mass spectrometry using G1800C GCDplus with mass detector HP 5971, 5890 Series II with mass detector HP 5972 from HEWLETT-PACKARD and 7890A GC-System with mass detector 5975C (Triplex-AxisDetector) from AGILENT TECHNOLOGIES equipped with HP-5MS columns (30 $\mathrm{m} \times 0.25 \mathrm{~mm} \times 0.25 \mu \mathrm{m})$ were used.

\section{Nuclear Magnetic Resonance Spectroscopy}

Nuclear magnetic resonance (NMR) spectroscopy was performed at 300 or $600 \mathrm{MHz}\left({ }^{1} \mathrm{H}-\mathrm{NMR}\right), 75.5$ or $125 \mathrm{MHz}\left({ }^{13} \mathrm{C}-\mathrm{NMR}, \mathrm{APT}\right)$ and $282 \mathrm{MHz}\left({ }^{19} \mathrm{~F}\right.$-NMR) on BRUKER AM 250, VARIAN Unity-300 and Inova 500 instruments. Chemical shifts are reported as $\delta$-values in ppm relative to the residual proton peak of the deuterated solvent or its carbon atom, respectively, or the standard trimethylsilyl (TMS) peak. 


\section{${ }^{1} \mathrm{H}-\mathrm{NMR} \quad{ }^{13} \mathrm{C}-\mathrm{NMR}$ \\ $\mathrm{CDCl}_{3}: 7.26 \mathrm{ppm} \quad 77.0 \mathrm{ppm}$ \\ DMSO-D $_{6}$ : 2.49 ppm 49.5 ppm}

For characterization of the observed resonance multiplicities the following abbrevations were applied: $s$ (singlet), $d$ (doublet), $t$ (triplet), $q$ (quartet), $m$ (multiplet), $d d$ (doublet of doublet), $d t$ (doublet of triplet), or analogue representations. The coupling constants $J$ are reported in Hertz $(\mathrm{Hz})$.

\section{Infrared Spectroscopy}

Infrared spectra were recorded on a BRUKER Alpha-P ATR-spectrometer. Liquid probes have been measured as film and solid probes neat. Analysis of the spectral data has been done by using the OPUS 3.1 software from BRUKER, respectively OPUS 6. Absorption $(\tilde{v})$ is given in wave numbers $\left(\mathrm{cm}^{-1}\right)$. Spectra were recorded in the range of 4000 to $400 \mathrm{~cm}^{-1}$.

\section{Mass Spectrometry}

EI- and EI-HR-MS spectra were measured on a Time-of-Flight mass spectrometer AccuTOF from JOEL. ESI-mass spectra were recorded on an Ion-Trap mass spectrometer LCQ from FINNIGAN or on a Timeof-Flight mass spectrometer microTOF from BRUKER. ESI-HR-MS spectra were recorded on a BRUKER APEX IV or a BRUKER DALTONIC (7T, Transform Ion Cyclotron Resonance (FTICR)) mass spectrometer. The ratios of mass to charge are indicated, intensities relative to the base peak $(I=100)$ are written in parentheses.

\section{Optical Rotatory Power}

Optical rotations were measured with digital polarimeters PERKIN-ELMER 241 or JASCO P-2000 in a 1 $\mathrm{dm}$ cell. The optical rotary powers $\alpha$ in the indicated solvents are given in ${ }^{\circ}$ at the indicated temperatures.

\section{Crystal Structure Analysis}

Crystals for X-ray diffraction crystals of compounds 129, 148, 149 and $(R)$-167 were obtained by slow evaporation of their solutions in DCM/n-octane. The single crystal X-ray data were collected on a BRUKER SMART-CCD 6000 diffractometer at 120.0(2) K using graphite monochromator with Mo-K $\mathrm{K}_{\alpha}$ radiation $(\lambda=0.71073 \AA$ ). All structures were solved by direct method and refined by full-matrix least 
squares on $\mathrm{F}^{2}$ for all data. All non-hydrogen atoms were refined with anisotropic displacement parameters. $\mathrm{H}$-atoms were located on the difference map and refined isotropically. Absolute configuration of the compound $\mathbf{1 4 7 b j}$ was determined on the basis of X-ray data. Crystal and data collection parameters are summarized in the Table S-1.

\section{Reagents}

Chemicals obtained from commercial sources with purity above $95 \%$ were used without further purification.

The following compounds were synthesized according to known literature procedures and were pure by comparison with the published The analytical data:

Alkyl halides (42b), ${ }^{171}$ 2-phenylpyridines (various 6), ${ }^{172}$ 3-methoxy-2-phenylpyridin (6cb), ${ }^{173}$ alkynes (88c-880), ${ }^{174}$ complex [bis(2,4,6-trimethylbenzoyloxy)(p-cymene)-ruthenium(II)] (12) and complex $\left\{\left[5\right.\right.$-methoxy-2-(pyridine-2-yl)phenyl](2,4,6-trimethylbenzoyloxy)(p-cymene)ruthenium(II)\} (14a), ${ }^{175}$ complex [2-(pyridine-2-yl)phenyl](p-cymene)ruthenium(II)chloride $1 \mathbf{1 7 8},{ }^{176}$ amino acid derivatives (variuos 76), ${ }^{177} \mathrm{~N}$-methylbenzamide (86a), ${ }^{178}(E)-\mathrm{N}, 2$-dimethylbut-2-enamide (181i), ${ }^{179}$ pent-1-yn-1ylbenzene (88f), ${ }^{180}$ (E)-dodec-5-en-7-yne (88v), ${ }^{181}$ (cyclohex-1-en-1-ylethynyl)-benzene (88j), ${ }^{182}{ }^{1-}$ methoxy-4-(prop-1-yn-1-yl)benzene (88h), ${ }^{183}$ 1-(prop-1-yn-1-yl)cyclohex-1-ene (88I), ${ }^{184}$ (3S)-3-bromo2,6,6-trimethylbicyclo[3.1.1] heptanes (42bf), ${ }^{185}(R)$-[(octan-2-yloxy)methyl]benzene (168), ${ }^{186}$ octan-2-

\footnotetext{
${ }^{171}$ Sankaranarayanan, S.; Sharma, A.; Chattopadhyay, S. Tetrahedron: Asymmetry 2002, 13, 1373-1378.

172 Böhm, V. P. W.; Weskamp, T.; Gstöttmayr, C. W. K.; Herrmann, W. A. Angew. Chem. Int. Ed. 2000, 39, 16021604.

${ }^{173}$ Finkentey, C.; Langhals, E.; Langhals, F. Chem. Ber. 1983, 116, 2394-2397.

${ }^{174}$ Mio, M. J.; Kopel, L. C.; Braun, J. B.; Gadzikwa, T. L.; Hull, K. L.; Brisbois, R. G.; Markworth, C. J.; Grieco, P. A. Org. Lett. 2002, 4, 3199-3202.

175 Ackermann, L.; Vicente, R.; Potukuchi, H.K.; Pirovano, V. Org. Lett. 2010, 12, 5032-5035.

176 Boutadla, Y.; Al-Duaij, O.; Davies, D. L.; Griffith, G. A.; Singh, K. Organometallics, 2009, 28, 433-440.

177 Shi, B.-F.; Maugel, N.; Zhang, Y.-H.; Yu, J.-Q. Angew.Chem. Int. Ed. 2008, 47, 4882-4886.

178 Dehmlow, E.V.; Winterfeldt, A. Z. Naturforsch. B 1989, 44, 455-458.

179 Beak, P.; Kempf, D. J.; Wilson, K. D. J. Am. Chem. Soc. 1985, 107, 4745-4756.

${ }^{180}$ Freeburger, M. E.; Spialter, L. J. Org. Chem. 1970, 35, 652-657.

181 Yang, C.; Nolan, S. P. J. Org. Chem. 2002, 67, 591-593.

182 Yoshida, M.; Hayashi, M.; Shishido, K. Org. Lett. 2007, 9, 1643-1646.

183 Zhang, Z.; Orita, A.; Mineyama, H.; Otera, J. Synlett 2007, 12, 1909-1912.

184 Tang, X.; Woodward, S.; Krause, N. Eur. J. Org. Chem. 2009, 17, 2836-2844.

${ }^{185}$ Ranu, B. C.; Jana, R. Eur. J. Org. Chem. 2005, 755-758.

${ }^{186}$ Dellaportas, P.; Jones, R. G.; Holder, S. J. Macromol. Rapid. Commun. 2002, 23, 99-103.
} 
yl-4-methylbenzenesulfonate, ${ }^{187} \quad$ 2-iodooctane, $^{188} \quad$ 2-chlorooctane, $^{189} \quad$ 2-(1H-pyrrol-3-yl)-pyridine $(\mathbf{1 2 8}),^{190}$

The following compounds were obtained by the generous courtesy of the persons named below:

Dr. Alexander V. Lygin: 1,2-Bis(3,5-di-tert-butylphenyl)ethyne $(\mathbf{8 8 m}), \mathbf{N}$-iso-propylmethacrylamide (181c), N-phenylmethacrylamide (181b)

Dr. Benudhar Punji: 2-(3-n-Propoxyphenyl)pyridine (6sa), 2-(3-iso-propoxyphenyl)pyridine (6ta).

Dipl.-Chem. Marvin Schinkel: 2-(3-Fluorophenyl)pyridine (3da), 2-(3-methoxyphenyl)pyridine (6ua), 3-methoxy-2-phenylpyridine (6cb), 3-methyl-2-phenylpyridine (6db), 5-methyl-2-phenylpyridine (6fb), 2-(3-(trifluoromethyl)phenyl)pyridine (6ma), 5-fluoro-2-phenylpyridine (6ib), 2,5diphenylpyridine (6ab), 2-phenylpyrimidine (153),

B.Sc. Christian Kuper: (1-Bromopentyl)benzene benzene (176).

B.Sc. Sabine Malzkuhn: 4-(Pyridin-2-yl)benzonitrile benzene (6qa), 2-(4-methoxyphenyl)-4methylpyridine benzene (6f), (1-bromopentyl)benzene benzene (176).

B.Sc. Michael Hendrich: 2-(2-Fluorophenyl)pyridine (6va).

B.Sc. Kris Bielefeld: 2-(m-Tolyl)pyridine (6va').

Karsten Rauch: $\left[\mathrm{RuCl}_{2}(p \text {-cymene })\right]_{2}$.

\footnotetext{
187 Jalalian, N.; Olofsson, B. Tetrahedron 2010, 66, 5793-5800.

188 Irifune, S.; Kibayashi, T.; Ishii, Y.; Ogawa, M. Synthesis 1988, 5, 366-369.

189 Bottoni, A.; Lombardo, M.; Neri, A.; Trombini, C. J. Org. Chem. 2003, 68, 3397-3405.

190 Smith, N. D.; Huang, D.; Cosford, N. D. P. Org. Lett. 2002, 4, 3537-3539.
} 


\subsection{General Procedures}

\section{General procedure A:}

\section{Nickel-Catalyzed Kumada-Corriu Cross-Coupling for the Synthesis of 2-Phenyl- pyridines 6}

Under vigorous stirring and an atmosphere of $\mathrm{N}_{2}$, a solution of bromoarene 15 (1.67 equiv) in anhydrous THF was added dropwise to the suspension of Mg turnings (1.73 equiv) in anhydrous THF (2.5 $\mathrm{M}$ with resp. to 15$)$. The reaction mixture was stirred and heated at $75^{\circ} \mathrm{C}$ for an additional $1 \mathrm{~h}$. After cooling to ambient temperature, the obtained Grignard solution was added dropwise to the stirred ice-cold solution of $\mathrm{Ni}(\mathrm{acac})_{2}(3.0 \mathrm{~mol} \%), \mathrm{HIPrCl}(61)(3.0 \mathrm{~mol} \%)$ and halopyridine 124 in anhydrous THF (1.5 M with resp. to 124) under an atmosphere of $\mathrm{N}_{2}$. The resulting solution was stirred at ambient temperature untill complete conversion of the starting material was detected by TLC. A saturated aqueous solution of $\mathrm{NH}_{4} \mathrm{Cl}(75 \mathrm{~mL})$ was added, and the aqueous layer was extracted with EtOAc $(3 \times 75 \mathrm{~mL})$. The combined organic layers were washed with brine $(75 \mathrm{~mL})$, dried over $\mathrm{Na}_{2} \mathrm{SO}_{4}$, filtered and concentrated under reduced pressure. The residue was purified by column chromatography on silica gel followed by Kugelrohr distillation to yield the desired product 6 .

\section{General procedure B:}

\section{Preparation of Ketimines $121^{191}$}

A solution of the ketone 84 (1.0 equiv) and para-methoxyaniline (127) (1.25 equiv) in PhMe (0.2 M with resp. to 84) with $4 \AA \mathrm{MS}\left(6 \mathrm{~g} / 25 \mathrm{~mL}\right.$ PhMe) was stirred and heated at $110^{\circ} \mathrm{C}$ overnight. After cooling to ambient temperature, filtration, concentration under reduced pressure and purification by column chromatography on silica gel deactivated with $\mathrm{NEt}_{3}$ (10 vol \% in $n$-hexane), eluent $n$-hexane, yielded the corresponding ketimines 121.

\section{General procedure C:}

\section{Ruthenium-Catalyzed Direct ortho-Selective Alkylation}

A suspension of $\left[\mathrm{RuCl}_{2}(p \text {-cymene) }]_{2}(2.5 \mathrm{~mol} \%), \mathrm{AdCO}_{2} \mathrm{H}\right.$ (13c) (30 mol \%), $\mathrm{K}_{2} \mathrm{CO}_{3}$ (2.0 equiv), respective substrate 6 (1.0 equiv) and primary alkyl bromide 42a (3.0 equiv) in $m$-xylene, if not otherwise specified $\left(0.25 \mathrm{M}\right.$ with resp. to 6) was stirred at $120^{\circ} \mathrm{C}$ for $20 \mathrm{~h}$ under $\mathrm{N}_{2}$. EtOAc $(50 \mathrm{~mL})$

${ }^{191}$ Malkov, A. V.; Vranková, K.; Stončius, S.; Kočovský, P. J. Org. Chem. 2009, 74, 5839-5849. 
and $\mathrm{H}_{2} \mathrm{O}(50 \mathrm{~mL})$ were added to the reaction mixture at ambient temperature. The separated aqueous phase was extracted with EtOAc $(2 \times 50 \mathrm{~mL})$. The combined organic layers were washed with brine $(50 \mathrm{~mL})$, dried over $\mathrm{Na}_{2} \mathrm{SO}_{4}$ and concentrated in vacuo. The residue residue was purified by column chromatography on silica gel ( $n$-hexane/EtOAc) to yield the desired product 93.

\section{General Procedure D:}

\section{Ruthenium-Catalyzed Direct Alkylations of Ketimines 121}

A suspension of $\left[\mathrm{RuCl}_{2}(p \text {-cymene) }]_{2}\right.$ (2.5 mol \%), 1- $\mathrm{AdCO}_{2} \mathrm{H}$ (13c) (30 mol \%), $\mathrm{K}_{2} \mathrm{CO}_{3}$ (3.2 equiv), respective ketimine 121 (1.0 equiv) and alkyl bromide 42 (3.0 equiv) in $m$-xylene (0.25 $\mathrm{M}$ with resp. to 121) was stirred under $\mathrm{N}_{2}$ for $20 \mathrm{~h}$ at $120^{\circ} \mathrm{C}$. A solution of $\mathrm{ZnCl}_{2}$ in THF (1.7 M, 1.0 equiv with resp. to 121), $\mathrm{NaBH}_{3} \mathrm{CN}$ (2.0 equiv with resp. to 121) and $\mathrm{MeOH}(0.25 \mathrm{M}$ with resp. to 121) were successively added to the reaction mixture at ambient temperature. The reaction mixture was stirred for an additional $16 \mathrm{~h}$ at ambient temperature and then distributed between between addition of $\mathrm{Et}_{2} \mathrm{O}$ (15 $\mathrm{mL})$ and sat. aq. $\mathrm{K}_{2} \mathrm{CO}_{3}(15 \mathrm{~mL})$. The aqueous phase was extracted with $\mathrm{Et}_{2} \mathrm{O}(2 \times 20 \mathrm{~mL})$, the combined organic layers were dried over $\mathrm{Na}_{2} \mathrm{SO}_{4}$ and concentrated in vacuo. The residue was purified by column chromatography on silica gel.

\section{General procedure E:}

\section{Ruthenium-Catalyzed Direct meta-Selective Alkylation}

A suspension of $\left[\mathrm{RuCl}_{2}(p \text {-cymene })\right]_{2}(2.5 \mathrm{~mol} \%), \mathrm{MesCO}_{2} \mathrm{H}$ (13a) (30 mol \%), $\mathrm{K}_{2} \mathrm{CO}_{3}$ (2.0 equiv), substrate 6 (1.0 equiv) and secondary alkyl bromide $\mathbf{4 2 b}$ (3.0 equiv) in 1,4-dioxane, if not otherwise specified ( $0.25 \mathrm{M}$ with resp. to 6), was stirred at $100^{\circ} \mathrm{C}$ for $20 \mathrm{~h}$ under $\mathrm{N}_{2}$. After cooling to ambient temperature, the reaction mixture was distributed between EtOAc $(50 \mathrm{~mL})$ and $\mathrm{H}_{2} \mathrm{O}(50 \mathrm{~mL})$. The aqueous phase was extracted with EtOAc $(2 \times 50 \mathrm{~mL})$, the combined organic layers were washed with brine $(50 \mathrm{~mL})$, dried over $\mathrm{Na}_{2} \mathrm{SO}_{4}$ and concentrated in vacuo. The residue was purified by column chromatography on silica gel ( $n$-hexane/EtOAc) to yield the desired product 147.

\section{The general procedure F:}

\section{Ruthenium-Catalyzed Annulation of Alkynes $\mathbf{8 8}$ with Benzamides 86}

A mixture of benzamide 86 (1.0 equiv), alkyne 88 (2.0 equiv), $\left[\mathrm{RuCl}_{2}(p \text {-cymene })\right]_{2}(5.0 \mathrm{~mol} \%)$ and $\mathrm{Cu}(\mathrm{OAc})_{2} \cdot \mathrm{H}_{2} \mathrm{O}$ (2.0 equiv) in $t-\mathrm{AmOH}\left(0.25 \mathrm{M}\right.$ with resp. to 86) was stirred at $100{ }^{\circ} \mathrm{C}$ for $22 \mathrm{~h}$ under $\mathrm{N}_{2}$ atmosphere. After cooling the reaction mixture to ambient temperature, it was diluted with aq. $\mathrm{NH}_{3}$ solution $(75 \mathrm{~mL}, 1.0 \mathrm{wt} \%)$ and extracted with EtOAc $(3 \times 75 \mathrm{~mL})$. The combined organic extracts were 
washed with brine $(50 \mathrm{~mL})$ and dried over $\mathrm{Na}_{2} \mathrm{SO}_{4}$. After filtration and evaporation of the solvents in vacuo, the residue was purified by column chromatography on silica gel.

\section{The general procedure G:}

\section{Ruthenium-Catalyzed Annulation of Alkynes 88 with Acrylamides 181}

A mixture of acrylamide (181) (2.0 equiv), alkyne (88) (1.0 equiv), $\left[\mathrm{RuCl}_{2}(p \text {-cymene) }]_{2}(5.0 \mathrm{~mol} \%)\right.$ and $\mathrm{Cu}(\mathrm{OAc})_{2} \cdot \mathrm{H}_{2} \mathrm{O}$ (1.0 equiv) in $t$ - $\mathrm{AmOH}\left(0.25 \mathrm{M}\right.$ with resp. to 88) was stirred under $\mathrm{N}_{2}$ atmosphere for $20 \mathrm{~h}$ at $120^{\circ} \mathrm{C}$. At ambient temperature, the reaction mixture was diluted with saturated aq. $\mathrm{NH}_{4} \mathrm{Cl}$ solution $(75 \mathrm{~mL})$ and extracted with EtOAc $(3 \times 75 \mathrm{~mL})$. The combined organic phase was washed with brine $(50 \mathrm{~mL})$ and dried over $\mathrm{Na}_{2} \mathrm{SO}_{4}$. After filtration and evaporation of the solvents in vacuo, the remaining residue was purified by column chromatography on silica gel. 


\section{Experimental Procedures and Analytical Data}

\subsection{The Analytical Data for Starting Materials}

Synthesis of (S)-2-Bromooctane $[(S)-42 \mathrm{ba}]^{171}$

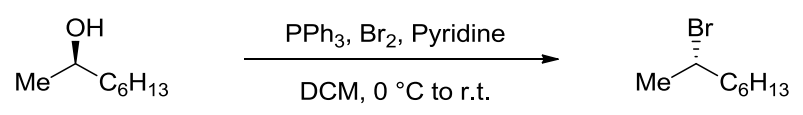

(S)-42ba

To the stirred solution of $\mathrm{PPh}_{3}(7.93 \mathrm{~g}, 30.2 \mathrm{mmol})$ in DCM $(25 \mathrm{~mL}), \mathrm{Br}_{2}(2.3 \mathrm{~mL}, 28 \mathrm{mmol})$ was added dropwise at $0{ }^{\circ} \mathrm{C}$. After stirring for an additional $0.5 \mathrm{~h}$ at $0{ }^{\circ} \mathrm{C}$, a solution of $(R)$-octan-2-ol $(3.2 \mathrm{~g}$, $25 \mathrm{mmol})$ and pyridine $(2.3 \mathrm{~mL}, 28 \mathrm{mmol})$ in $\mathrm{DCM}(12 \mathrm{~mL})$ was added dropwise at $0{ }^{\circ} \mathrm{C}$, and the mixture was stirred for an additional $3 \mathrm{~h}$ at ambient temperature. The reaction mixture was concentrated in vacuo, the residue was vigorously stirred with $n$-hexane $(50 \mathrm{~mL})$, filtered and concentrated again. This operation was repeated twice. Column chromatography of the residue on silica gel (eluent $n$-hexane) yielded the product [(S)-42ba] (3.53 g, 73\%) as a colorless liquid.

${ }^{1} \mathrm{H}-\mathrm{NMR}\left(300 \mathrm{MHz}, \mathrm{CDCl}_{3}\right): \delta=4.14(\mathrm{ddd}, J=8.1,6.7,5.3 \mathrm{~Hz}, 1 \mathrm{H}), 1.98-1.64(\mathrm{~m}, 5 \mathrm{H}), 1.56-1.17(\mathrm{~m}$, $8 \mathrm{H}), 0.88(\mathrm{t}, J=5.8 \mathrm{~Hz}, 3 \mathrm{H})$.

${ }^{13} \mathrm{C}-\mathrm{NMR}(75 \mathrm{MHz}, \mathrm{CDCl}): \delta=52.6(\mathrm{CH}), 41.8\left(\mathrm{CH}_{2}\right), 32.3\left(\mathrm{CH}_{2}\right), 29.2\left(\mathrm{CH}_{2}\right), 28.3\left(\mathrm{CH}_{2}\right), 27.0\left(\mathrm{CH}_{3}\right), 23.2$ $\left(\mathrm{CH}_{2}\right), 14.6\left(\mathrm{CH}_{3}\right)$.

$\left[\alpha^{23}\right]=+34.4^{\circ}(\mathrm{MeOH})$.

MS (EI) $m / z$ (relative intensity): 113 (26) [M-Br ], 71 (99), 57 (100), 43 (86).

HR-MS (ESI) $m / z$ calculated for $\mathrm{C}_{8} \mathrm{H}_{17} \mathrm{Br}-\mathrm{H}^{+}$: 191.0435; found: 191.0444 .

The The analytical data are in accordance with those reported in the literature. ${ }^{192}$

\section{Synthesis of 2-(4-Methoxyphenyl)pyridine (6ba)}

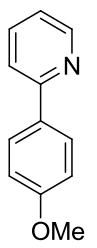

192 Denton, R. M.; An, J.; Adeniran, B.; Blake, A. J.; Lewis, W.; Poulton, A. M. J. Org. Chem. 2011, 76, 6749-6767. 
The general procedure $\mathbf{A}$ was followed using 1-bromo-4-methoxybenzene (15b) $(6.3 \mathrm{~mL}, 50 \mathrm{mmol})$ and 2-chloropyridine 124a) $(3.52 \mathrm{~g}, 34.0 \mathrm{mmol})$. Purification by column chromatography ( $n$ hexane/EtOAc 5:1) followed by Kugelrohr distillation yielded 6 ba (5.25 g, 94\%) as a white solid.

M.p.: $53-54{ }^{\circ} \mathrm{C}\left[\right.$ Lit.: $\left.53-55^{\circ} \mathrm{C}\right] .{ }^{193}$

${ }^{1} \mathrm{H}-\mathrm{NMR}\left(300 \mathrm{MHz}, \mathrm{CDCl}_{3}\right): \delta=8.69(\mathrm{ddd}, J=4.8,1.7,1.0 \mathrm{~Hz}, 1 \mathrm{H}), 7.82-7.67(\mathrm{~m}, 2 \mathrm{H}), 7.63-7.49(\mathrm{~m}$, $2 \mathrm{H}), 7.38(\mathrm{t}, J=7.9 \mathrm{~Hz}, 1 \mathrm{H}), 7.29-7.18(\mathrm{~m}, 1 \mathrm{H}), 6.97$ (ddd, $J=8.2,2.6,1.0 \mathrm{~Hz}, 1 \mathrm{H}), 3.90(\mathrm{~s}, 3 \mathrm{H})$.

${ }^{13} \mathrm{C}-N M R\left(75 \mathrm{MHz}, \mathrm{CDCl}_{3}\right): \delta=160.1\left(\mathrm{C}_{\mathrm{q}}\right), 157.2\left(\mathrm{C}_{\mathrm{q}}\right), 149.6(\mathrm{CH}), 140.9\left(\mathrm{C}_{\mathrm{q}}\right), 137.0(\mathrm{CH}), 129.7(\mathrm{CH})$, $122.2(\mathrm{CH}), 120.7\left(\mathrm{CH}, 119.3(\mathrm{CH}), 115.1(\mathrm{CH}), 112.0(\mathrm{CH}), 55.4\left(\mathrm{CH}_{3}\right)\right.$.

MS (EI) m/z (relative intensity): 184 (100) [M-H'], 154 (77), 140 (32), 115 (17), 78 (24).

HR-MS (EI): $m / z$ calculated for $\mathrm{C}_{12} \mathrm{H}_{12} \mathrm{NO}^{+}:$186.0919; found: 186.0915 .

The analytical data are in accordance with those reported in the literature. ${ }^{193}$

\section{Synthesis of 2-(4-Fluorophenyl)pyridine (6ca)}<smiles>Fc1ccc(-c2ccccn2)cc1</smiles>

The general procedure A was followed using 1-bromo-4-fluorobenzene (15c) $(8.79 \mathrm{~g}, 50.0 \mathrm{mmol}$ ) and 2-chloropyridine (124a) (3.39 g, $30.0 \mathrm{mmol})$. Purification by column chromatography ( $n$ hexane/EtOAc 5:1) followed by Kugelrohr distillation yielded $6 \mathrm{ca}(3.88 \mathrm{~g}, 75 \%)$ as a white solid.

M.p.: $40{ }^{\circ} \mathrm{C}\left[\right.$ Lit.: $\left.38-39^{\circ} \mathrm{C}\right] .{ }^{194}$

${ }^{1} \mathrm{H}-\mathrm{NMR}\left(300 \mathrm{MHz}, \mathrm{CDCl}_{3}\right): \delta=8.53$ (ddd, $\left.J=4.8,1.7,0.9 \mathrm{~Hz}, 1 \mathrm{H}\right), 8.00-7.91(\mathrm{~m}, 2 \mathrm{H}), 7.71$ (ddd, $J=7.2$, 7.4, $1.7 \mathrm{~Hz}, 1 \mathrm{H})$, 7.67-7.62 (m, $1 \mathrm{H})$, 7.25-7.09 (m, 3H).

${ }^{13} \mathrm{C}-\mathrm{NMR}\left(75 \mathrm{MHz}, \mathrm{CDCl}_{3}\right): \delta=163.3\left(\mathrm{~d}, \mathrm{~J}_{\mathrm{C}-\mathrm{F}}=248 \mathrm{~Hz}, \mathrm{C}_{\mathrm{q}}\right.$ ), $156.3\left(\mathrm{C}_{\mathrm{q}}\right), 149.5(\mathrm{CH}), 136.7(\mathrm{CH}), 135.4(\mathrm{~d}$, $\left.J_{C-F}=3 \mathrm{~Hz}, C_{q}\right), 128.6\left(d, J_{C-F}=8 \mathrm{~Hz}, \mathrm{CH}\right), 121.9(\mathrm{CH}), 120.1(\mathrm{CH}), 115.5\left(\mathrm{~d}, J_{\mathrm{C}-\mathrm{F}}=22 \mathrm{~Hz}, \mathrm{CH}\right)$.

MS (El) m/z (relative intensity): $173(100)\left[\mathrm{M}^{+}\right], 146$ (7), 121 (5), 75 (6).

HR-MS (EI) $m / z$ calculated for $\mathrm{C}_{11} \mathrm{H}_{8} \mathrm{FN}^{+}:$: 173.0641; found: 173.0639 .

The analytical data are in accordance with those reported in the literature. ${ }^{194}$

\footnotetext{
193 Riggio, G.; Hopff, W.; Herbert, H.; Alfred, A.; Waser, P. G. Helv. Chim. Acta 1983, 66, 1039-1045.

${ }^{194}$ Xu, J.; Cheng, G.; Su, D.; Liu, Y.; Wang, X.; Hu, Y. Chem. Eur. J. 2009, 13105-13110.
} 


\section{Synthesis of 2-(3-Fluorophenyl)pyridine (6da)}

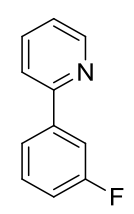

The general procedure A was followed using 1-bromo-3-flourobenzene (15d) (8.86 g, $51.0 \mathrm{mmol})$ and 2-chloropyridine (124a) $(3.37 \mathrm{~g}, 30.0 \mathrm{mmol})$. Purification by column chromatography ( $n$ hexane/EtOAc 5:1) followed by Kugelrohr distillation yielded $\mathbf{6 d a}(3.43 \mathrm{~g}, 66 \%)$ as a colorless oil.

${ }^{1} \mathrm{H}-\mathrm{NMR}\left(300 \mathrm{MHz}, \mathrm{CDCl}_{3}\right): \delta=8.68(\mathrm{ddd}, J=4.8,1.7,0.9 \mathrm{~Hz}, 1 \mathrm{H}), 7.79-7.63(\mathrm{~m}, 4 \mathrm{H}), 7.41$ (ddd, $J=8.2$, $8.2,6.0 \mathrm{~Hz}, 1 \mathrm{H}$ ), 7.26 (ddd, $J_{\mathrm{C}-\mathrm{F}}=6.7,4.8,1.5 \mathrm{~Hz}, 1 \mathrm{H}$ ), 7.11 (ddd, $J=8.3,2.6,0.9 \mathrm{~Hz}, 1 \mathrm{H}$ ).

${ }^{13} \mathrm{C}-\mathrm{NMR}\left(75 \mathrm{MHz}, \mathrm{CDCl}_{3}\right): \delta=163.3\left(\mathrm{~d}, \mathrm{~J}_{\mathrm{C}-\mathrm{F}}=245 \mathrm{~Hz}, \mathrm{C}_{\mathrm{q}}\right.$ ), $156.0\left(\mathrm{~d}, \mathrm{~J}_{\mathrm{C}-\mathrm{F}}=3 \mathrm{~Hz}, \mathrm{C}_{\mathrm{q}}\right.$ ), $149.7(\mathrm{CH}), 141.7$ $\left(\mathrm{d}, J_{\mathrm{C}-\mathrm{F}}=8 \mathrm{~Hz}, \mathrm{C}_{\mathrm{q}}\right), 136.8(\mathrm{CH}), 130.2\left(\mathrm{~d}, \mathrm{~J}_{\mathrm{C}-\mathrm{F}}=8 \mathrm{~Hz}, \mathrm{CH}\right), 122.6(\mathrm{CH}), 122.4\left(\mathrm{~d}, \mathrm{~J}_{\mathrm{C}-\mathrm{F}}=3 \mathrm{~Hz}, \mathrm{CH}\right), 120.5$ $(\mathrm{CH}), 115.7\left(\mathrm{~d}, \mathrm{~J}_{\mathrm{C}-\mathrm{F}}=21 \mathrm{~Hz}, \mathrm{CH}\right), 113.8\left(\mathrm{~d}, \mathrm{~J}_{\mathrm{C}-\mathrm{F}}=23 \mathrm{~Hz}, \mathrm{CH}\right)$.

MS (EI) m/z (relative intensity): 173 (100) [M+], 154 (11), 146 (15), 125 (8), 120 (9), 75 (7).

HR-MS (EI): $m / z$ calculated for $\mathrm{C}_{11} \mathrm{H}_{8} \mathrm{FN}^{+}:$: 173.0641; found: 173.0642 .

The analytical data are in accordance with those reported in the literature. ${ }^{172}$

\section{Synthesis of 4-Methyl-2-(o-tolyl)pyridine (6eb)}<smiles>Cc1ccnc(-c2ccccc2C)c1</smiles>

The general procedure A was followed using 1-bromo-2-methylbenzene (15e) $(1.05 \mathrm{~g}, 6.30 \mathrm{mmol})$ and 2-bromo-4-methylpyridine (124b) $(0.59 \mathrm{~g}, 3.30 \mathrm{mmol})$. Purification by column chromatography ( $n$-hexane/EtOAc 5:1) followed by Kugelrohr distillation yielded $6 \mathrm{eb}(0.53 \mathrm{~g}, 88 \%)$ as a colorless oil.

${ }^{1} \mathrm{H}-\mathrm{NMR}\left(300 \mathrm{MHz}, \mathrm{CDCl}_{3}\right): \delta=8.54(\mathrm{dd}, J=5.1,0.8 \mathrm{~Hz}, 1 \mathrm{H}), 7.41-7.34(\mathrm{~m}, 1 \mathrm{H}), 7.30-7.23(\mathrm{~m}, 3 \mathrm{H})$, 7.23-7.18 (m, 1H), 7.07 (ddd, $J=5.0,1.7,0.8 \mathrm{~Hz}, 1 \mathrm{H}), 2.40(\mathrm{~s}, 3 \mathrm{H}), 2.36(\mathrm{~s}, 3 \mathrm{H})$.

${ }^{13} \mathrm{C}$-NMR $\left(75 \mathrm{MHz}, \mathrm{CDCl}_{3}\right): \delta=160.1\left(\mathrm{C}_{\mathrm{q}}\right), 149.1(\mathrm{CH}), 147.3\left(\mathrm{C}_{\mathrm{q}}\right), 140.7\left(\mathrm{C}_{\mathrm{q}}\right), 135.9\left(\mathrm{C}_{\mathrm{q}}\right), 130.8(\mathrm{CH})$, 129.7 (CH), $128.3(\mathrm{CH}), 125.9(\mathrm{CH}), 125.1(\mathrm{CH}), 122.8(\mathrm{CH}), 21.3\left(\mathrm{CH}_{3}\right), 20.4\left(\mathrm{CH}_{3}\right)$.

MS (EI) m/z (relative intensity): $183(62)\left[\mathrm{M}^{+}\right], 167$ (100), 152 (19), 115 (10), 89 (15).

HR-MS (EI) $m / z$ calculated for $\mathrm{C}_{13} \mathrm{H}_{13} \mathrm{~N}^{+}$: 183.1048; found: 183.1047. 
The analytical data are in accordance with those reported in the literature. ${ }^{195}$

\section{Synthesis of 2-(2,4-Dimethoxyphenyl)pyridine (6fa)}

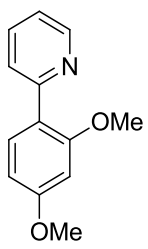

The general procedure A was followed using 1-bromo-2,4-dimethoxybenzene (15f) (1.89 g, $8.70 \mathrm{mmol})$ and 2-chloropyridine (124a) $(0.69 \mathrm{~g}, 6.10 \mathrm{mmol})$. Purification by column chromatography ( $n$-hexane/EtOAc 1:1) followed by Kugelrohr distillation yielded $6 \mathrm{fa}(0.91 \mathrm{~g}, 69 \%)$ as a colorless oil.

${ }^{1} \mathrm{H}-\mathrm{NMR}\left(300 \mathrm{MHz}, \mathrm{CDCl}_{3}\right): \delta=8.66$ (ddd, $\left.J=4.8,1.8,0.9 \mathrm{~Hz}, 1 \mathrm{H}\right), 7.92-7.72(\mathrm{~m}, 2 \mathrm{H}), 7.66$ (ddd, $J=8.1$, 7.4, $1.9 \mathrm{~Hz}, 1 \mathrm{H}$ ), 7.15 (ddd, $J=7.4,4.9,1.2 \mathrm{~Hz}, 1 \mathrm{H}$ ), 6.62 (dd, $J=8.5,2.4 \mathrm{~Hz}, 1 \mathrm{H}), 6.56(\mathrm{~d}, J=2.4 \mathrm{~Hz}$, $1 \mathrm{H}), 3.86(\mathrm{~s}, 3 \mathrm{H}), 3.85(\mathrm{~s}, 3 \mathrm{H})$.

${ }^{13} \mathrm{C}$-NMR $\left(75 \mathrm{MHz}, \mathrm{CDCl}_{3}\right): \delta=161.0\left(\mathrm{C}_{\mathrm{q}}\right), 157.8\left(\mathrm{C}_{\mathrm{q}}\right), 155.5\left(\mathrm{C}_{\mathrm{q}}\right), 148.9(\mathrm{CH}), 135.3(\mathrm{CH}), 131.7(\mathrm{CH})$, $124.4(\mathrm{CH}), 121.8\left(\mathrm{C}_{\mathrm{q}}\right), 120.8(\mathrm{CH}), 104.9(\mathrm{CH}), 98.6(\mathrm{CH}), 55.3\left(\mathrm{CH}_{3}\right), 55.2\left(\mathrm{CH}_{3}\right)$.

MS (EI) m/z (relative intensity): 214 (100) [M-H'], 200 (14), 185 (47), 170 (47), 142 (53), 80 (30).

HR-MS (EI) $\mathrm{m} / \mathrm{z}$ calculated for $\mathrm{C}_{13} \mathrm{H}_{13} \mathrm{NO}_{2}-\mathrm{H}^{+}:$214.0868; found: 214.0867.

The analytical data are in accordance with those reported in the literature. ${ }^{196}$

\section{Synthesis of 2-(4-Fluoro-2-methoxyphenyl)pyridine (6ga)}

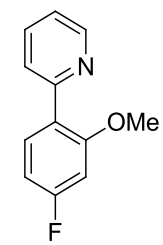

The general procedure A was followed using 1-bromo-4-flouro-2-methoxybenzene $\mathbf{1 5 g}$ ) (2.06 g, $10.0 \mathrm{mmol}$ ) and 2-chloropyridine (124a) $(1.14 \mathrm{~g}, 9.90 \mathrm{mmol})$. Purification by column chromatography ( $n$-hexane/EtOAc 1:1) followed by Kugelrohr distillation yielded $6 \mathrm{ga}(0.67 \mathrm{~g}, 33 \%)$ as a colorless oil.

\footnotetext{
195 Ackermann, L.; Potukuchi, H. K.; Kapdi, A. R.; Schulzke, C. Chem. Eur. J. 2010, 16, 3300-3303.

196 (a) Maeyama, K. Rec. Res. Dev. Org. Chem. 2003, 7, 43-51; (b) Terashima, M. Chem. Pharm. Bull. 1985, 33, 1009-1015.
} 
${ }^{1} \mathrm{H}-\mathrm{NMR}\left(300 \mathrm{MHz}, \mathrm{CDCl}_{3}\right): \delta=8.67(\mathrm{ddd}, J=4.9,1.9,1.0 \mathrm{~Hz}, 1 \mathrm{H}), 7.79-7.72(\mathrm{~m}, 2 \mathrm{H}), 7.67$ (ddd, $J=8.0$, 7.4, $1.9 \mathrm{~Hz}, 1 \mathrm{H}$ ), 7.18 (ddd, $J=7.4,4.9,1.3 \mathrm{~Hz}, 1 \mathrm{H}), 6.85-6.55(\mathrm{~m}, 2 \mathrm{H}), 3.83(\mathrm{~s}, 3 \mathrm{H})$.

${ }^{13} \mathrm{C}-\mathrm{NMR}\left(126 \mathrm{MHz}, \mathrm{CDCl}_{3}\right): \delta=164.0\left(\mathrm{~d}, \mathrm{~J}_{\mathrm{C}-\mathrm{F}}=248 \mathrm{~Hz}, \mathrm{C}_{\mathrm{q}}\right), 158.2\left(\mathrm{~d}, \mathrm{~J}_{\mathrm{C}-\mathrm{F}}=10 \mathrm{~Hz}, \mathrm{C}_{\mathrm{q}}\right), 155.3\left(\mathrm{C}_{\mathrm{q}}\right), 149.5$ (CH), $135.8(\mathrm{CH}), 132.4\left(\mathrm{~d}, J_{\mathrm{C}-\mathrm{F}}=10 \mathrm{~Hz}, \mathrm{CH}\right), 125.3\left(\mathrm{~d}, \mathrm{~J}_{\mathrm{C}-\mathrm{F}}=3 \mathrm{~Hz}, \mathrm{C}_{\mathrm{q}}\right.$ ), $124.9(\mathrm{CH}), 121.7(\mathrm{CH}), 107.6(\mathrm{~d}$, $\left.J_{C-F}=21 \mathrm{~Hz}, \mathrm{CH}\right), 99.5\left(\mathrm{~d}, \mathrm{~J}_{\mathrm{C}-\mathrm{F}}=26 \mathrm{~Hz}, \mathrm{CH}\right), 55.9\left(\mathrm{CH}_{3}\right)$.

${ }^{19} \mathrm{~F}-\mathrm{NMR}\left(282 \mathrm{MHz}, \mathrm{CDCl}_{3}\right): \delta=-109.40-111.63(\mathrm{~m})$.

HR-MS (ESI) $\mathrm{m} / \mathrm{z}$ calculated for $\mathrm{C}_{12} \mathrm{H}_{10} \mathrm{FNO}+\mathrm{H}^{+}:$204.0819; found: 204.0824 .

\section{Synthesis of $N, N$-Dimethyl-3-(pyridin-2-yl)aniline (6ha)}

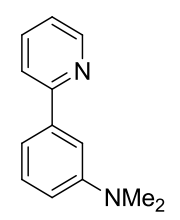

The general procedure A was followed using 3-bromo- $\mathrm{N}, \mathrm{N}$-dimethylaniline (15h) $(5.00 \mathrm{~g}, 25.0 \mathrm{mmol})$ and 2-chloropyridine (124a) $(2.24 \mathrm{~g}, 19.8 \mathrm{mmol})$. Purification by column chromatography ( $n$ hexane/EtOAc 9:1) followed by Kugelrohr distillation yielded 6 ha ( $2.92 \mathrm{~g}, 74 \%)$ as yellow oil.

${ }^{1} \mathrm{H}-\mathrm{NMR}\left(300 \mathrm{MHz}, \mathrm{CDCl}_{3}\right): \delta=8.77-8.54(\mathrm{~m}, 1 \mathrm{H}), 7.81-7.68(\mathrm{~m}, 2 \mathrm{H}), 7.45(\mathrm{dd}, J=2.7,1.6 \mathrm{~Hz}, 1 \mathrm{H})$, 7.39-7.17 (m, 3H), $6.84(\mathrm{ddd}, J=8.0,2.7,1.2 \mathrm{~Hz}, 1 \mathrm{H}), 3.04(\mathrm{~s}, 6 \mathrm{H})$.

${ }^{13} \mathrm{C}-\mathrm{NMR}\left(75 \mathrm{MHz}, \mathrm{CDCl}_{3}\right): \delta=158.5\left(\mathrm{C}_{\mathrm{q}}\right), 151.5\left(\mathrm{C}_{\mathrm{q}}\right), 149.6(\mathrm{CH}), 140.3\left(\mathrm{C}_{\mathrm{q}}\right), 137.5(\mathrm{CH}), 130.0(\mathrm{CH})$, $122.6(\mathrm{CH}), 121.6(\mathrm{CH}), 116.2(\mathrm{CH}), 114.2(\mathrm{CH}), 111.9(\mathrm{CH}), 41.4\left(\mathrm{CH}_{3}\right)$.

MS (EI) m/z (relative intensity): 198 (100) [M+], 183 (72), 168 (12), 154 (38), 127 (14), 91 (14), 43 (15).

HR-MS (EI) $m / z$ calculated for $\mathrm{C}_{13} \mathrm{H}_{14} \mathrm{~N}_{2}-\mathrm{H}^{+}$: 197.1079; found: 197.1081 .

The analytical data were in accordance with those reported in the literature. ${ }^{197}$

\section{Synthesis of 2-(4-tert-Butylphenyl)pyridine (6ia)}

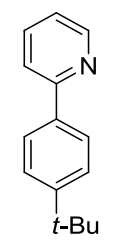

${ }^{197}$ Yoshikai, N.; Asako, S.; Yamakawa, T.; llies, L.; Nakamura, E. Chem. Asian J. 2011, 6, 3059-3065. 
The general procedure A was followed using 1-bromo-4-tert-butylbenzene (15i) (5.40 g, $25.3 \mathrm{mmol})$ and 2-chloropyridine (124a) $(2.34 \mathrm{~g}, 20.7 \mathrm{mmol})$. Purification by column chromatography ( $n$ hexane/EtOAc 9:1) followed by Kugelrohr distillation yielded 6ia (3.3 g, 75\%) as a colorless oil.

${ }^{1} \mathrm{H}-\mathrm{NMR}\left(300 \mathrm{MHz}, \mathrm{CDCl}_{3}\right): \delta=8.68(\mathrm{dt}, J=4.9,1.4 \mathrm{~Hz}, 1 \mathrm{H}), 8.00-7.83(\mathrm{~m}, 2 \mathrm{H}), 7.78-7.64(\mathrm{~m}, 2 \mathrm{H}), 7.58-$ $7.41(\mathrm{~m}, 2 \mathrm{H}), 7.21$ (ddd, $J=5.8,4.9,2.7 \mathrm{~Hz}, 1 \mathrm{H}), 1.36(\mathrm{~s}, 9 \mathrm{H})$.

${ }^{13} \mathrm{C}$-NMR $\left(75 \mathrm{MHz}, \mathrm{CDCl}_{3}\right): \delta=157.6\left(\mathrm{C}_{\mathrm{q}}\right), 152.3\left(\mathrm{C}_{\mathrm{q}}\right), 149.7(\mathrm{CH}), 136.8(\mathrm{CH}), 136.7\left(\mathrm{C}_{\mathrm{q}}\right), 126.7(2 \times \mathrm{CH})$, $125.9(\mathrm{CH}), 121.9(\mathrm{CH}), 120.5(\mathrm{CH}), 34.8\left(\mathrm{C}_{\mathrm{q}}\right), 31.5\left(\mathrm{CH}_{3}\right)$.

MS (EI) m/z (relative intensity): 211 (24) [M+], 196 (100), 181 (10), 168 (11).

HR-MS (ESI) $\mathrm{m} / \mathrm{z}$ calculated for $\mathrm{C}_{15} \mathrm{H}_{17} \mathrm{~N}^{+}: 211.1361$; found: 211.1363 .

The analytical data are in accordance with those reported in the literature. ${ }^{198}$

\section{Synthesis of 2-(2,3,4,5,6-Pentadeuterophenyl)pyridin ([ $\left.\left.D_{5}\right]-6 a a\right)$}<smiles>[2H]c1c([2H])c([2H])c(-c2ccccn2)c([2H])c1[2H]</smiles>

The general procedure $\mathbf{A}$ was followed using 1-bromo-2,3,4,5,6-pentadeuterobenzene ([ $\left.\left.D_{5}\right]-15 a\right)$ (2.32 $\mathrm{g}, 14.3 \mathrm{mmol})$ and 2-chloropyridine (124a) $(1.21 \mathrm{~g}, 10.7 \mathrm{mmol})$. Purification by column chromatography ( $n$-hexane/EtOAc 5:1) followed by Kugelrohr distillation yielded [ $\left.D_{5}\right]-6 a a(1.1$ g, 64\%) as a colorless oil.

${ }^{1} \mathrm{H}-\mathrm{NMR}\left(300 \mathrm{MHz}, \mathrm{CDCl}_{3}\right): \delta=8.70(\mathrm{ddd}, J=4.8,1.4,0.3, \mathrm{~Hz}, 1 \mathrm{H}), 7.80-7.71(\mathrm{~m}, 2 \mathrm{H}), 7.25-7.21(\mathrm{~m}$, $1 \mathrm{H})$.

${ }^{13} \mathrm{C}-\mathrm{NMR}\left(75 \mathrm{MHz}, \mathrm{CDCl}_{3}\right): \delta=156.9\left(\mathrm{C}_{\mathrm{q}}\right), 149.2(\mathrm{CH}), 138.8\left(\mathrm{C}_{\mathrm{q}}\right), 136.3(\mathrm{CH}), 128.0\left(\mathrm{t}, \mathrm{J}_{\mathrm{C}-\mathrm{D}}=25 \mathrm{~Hz}, \mathrm{C}_{\mathrm{q}}\right)$, $127.8\left(\mathrm{t}, J_{C-D}=25 \mathrm{~Hz}, \mathrm{CD}\right), 126.1\left(\mathrm{t}, J_{C-D}=25 \mathrm{~Hz}, \mathrm{CD}\right), 121.7(\mathrm{CH}), 120.1(\mathrm{CH})$.

HR-MS (EI) $m / z$ calculated for $\mathrm{C}_{11} \mathrm{H}_{4} \mathrm{D}_{5} \mathrm{~N}^{+}$: 161.1127 ; found: 161.1122 .

The analytical data were in accordance with those reported in the literature. ${ }^{199}$

\footnotetext{
198 Kobayashi, O.; Uraguchi, D.; Yamakawa, T. Org. Lett. 2009, 11, 2679-2682.

199 Kozhushkov, S. I.; Yufit, D. S.; Ackermann, L. Org. Lett. 2008, 10, 3409-3412.
} 


\section{Synthesis of 4-(Pyridin-2-yl)pyrimidin-2-amine (127a) $)^{200}$}<smiles>CN(C)/C=C/C(=O)c1ccccn1</smiles>

a<smiles>CCON=C(N)[N+](=O)[O-]</smiles>

b<smiles>Nc1nccc(-c2ccccn2)n1</smiles>

$127 a$

A solution of guanidinine nitrate $\mathbf{b}(3.14 \mathrm{~g}, 25.0 \mathrm{mmol})$ in abs. EtOH $(20 \mathrm{~mL})$ was added to a stirred solution of pyridylpropenone a $(3.5 \mathrm{~g}, 20.0 \mathrm{mmol})$ in boiling abs. EtOH $(30 \mathrm{~mL})$ and stirring was continued for $20 \mathrm{~min}$. To this mixture $\mathrm{Na}(0.9 \mathrm{~g}, 40 \mathrm{mmol})$ in EtOH $(20 \mathrm{~mL})$ was added and the reaction mixture stirred at $80^{\circ} \mathrm{C}$ for $16 \mathrm{~h}$. The solution was allowed to cool to ambient temperature and the precipitate was removed by filtration followed by concentration of the filtrate under reduced pressure. After purification by column chromatography (EtOAc/DCM 95:5) the product 127a (1.72 g, $50 \%)$ was isolated as a yellow solid.

M.r.: $133-134^{\circ} \mathrm{C}\left[\right.$ Lit: $\left.132-137^{\circ} \mathrm{C}\right] .{ }^{200}$

${ }^{1} \mathrm{H}-\mathrm{NMR}\left(300 \mathrm{MHz}, \mathrm{CDCl}_{3}\right): \delta=8.69(\mathrm{ddd}, J=4.8,1.8,0.9 \mathrm{~Hz}, 1 \mathrm{H}), 8.43(\mathrm{~d}, J=5.1 \mathrm{~Hz}, 1 \mathrm{H}), 8.31(\mathrm{dt}, J=$ 7.9, $1.1 \mathrm{~Hz}, 1 \mathrm{H}$ ), $7.80(\mathrm{td}, J=7.8,1.8 \mathrm{~Hz}, 1 \mathrm{H}), 7.62(\mathrm{~d}, J=5.2 \mathrm{~Hz}, 1 \mathrm{H}), 7.35$ (ddd, J = 7.6, 4.8, $1.2 \mathrm{~Hz}$, $1 \mathrm{H}), 5.35(\mathrm{~s}, 2 \mathrm{H})$.

${ }^{13} \mathrm{C}$-NMR $\left(75 \mathrm{MHz}, \mathrm{CDCl}_{3}\right): \delta=164.2\left(\mathrm{C}_{\mathrm{q}}\right), 163.3\left(\mathrm{C}_{\mathrm{q}}\right), 159.5(\mathrm{CH}), 154.5\left(\mathrm{C}_{\mathrm{q}}\right), 149.6(\mathrm{CH}), 137.0(\mathrm{CH})$, $125.2(\mathrm{CH}), 121.6(\mathrm{CH}), 108.2(\mathrm{CH})$.

MS (EI) m/z (relative intensity): 172 (100) [ $\left.\mathrm{M}^{+}\right], 145$ (12), 131 (10), 103 (19), 79 (21).

HR-MS (EI) $\mathrm{m} / \mathrm{z}$ calculated for $\mathrm{C}_{9} \mathrm{H}_{8} \mathrm{~N}_{4}{ }^{+}:$: 172.0749; found: 172.0746 .

The analytical data are in accordance with those reported in the literature. ${ }^{200}$

Synthesis of $N$-Methyl-4-(pyridin-2-yl)-pyrimidin-2-amine (127b) \& N,N-Dimethyl-4-(pyridin-2-yl)pyrimidin-2-amine (127c)

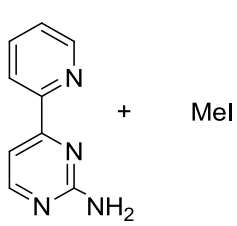

$127 a$

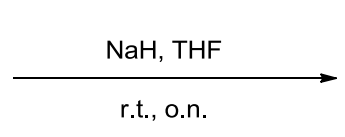

r.t., o.n

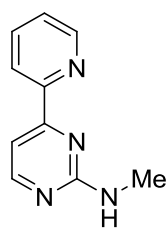

$127 b$

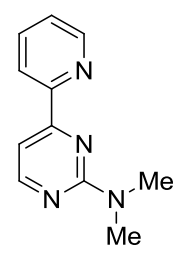

$127 \mathrm{c}$

200 D’Amora, A.; Fanfoni, L.; Cozzula, D.; Guidolin, N.; Zangrando, E.; Felluga, F.; Gladiali, S.; Benedetti, F.; Milani, B. Organometallics 2010, 29, 4472-4485. 
To a stirred solution of $127 \mathrm{a}(1.7 \mathrm{~g}, 10 \mathrm{mmol})$ in dry THF $(50 \mathrm{~mL})$ was added $\mathrm{NaH}(1.0 \mathrm{~g}, 25 \mathrm{mmol})$ in one portion. The reaction mixture was stirred for $8 \mathrm{~h}$ at ambient temperature. Mel (1.6 mL, $25 \mathrm{mmol}$ ) was added dropwise and the solution was stirred over night. After addition of aq. $\mathrm{NH}_{4} \mathrm{Cl}$-solution $(50 \mathrm{~mL})$ and separation of the organic layer, the aq. layer was extracted with EtOAc $(2 \times 50 \mathrm{~mL})$. The combined organic phase was washed with $\mathrm{H}_{2} \mathrm{O}(50 \mathrm{~mL})$ and brine $(50 \mathrm{~mL})$ and then dried over anhydrous $\mathrm{Na}_{2} \mathrm{SO}_{4}$. After filtration and evaporation, column chromatography and Kugelrohr distillation gave $127 \mathrm{~b}(0.48 \mathrm{~g}, 24 \%)$ and $127 \mathrm{c}(0.79 \mathrm{~g}, 43 \%)$ as yellow oils.

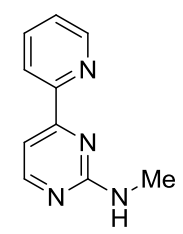

(127b)

${ }^{1} \mathrm{H}-\mathrm{NMR}\left(600 \mathrm{MHz}, \mathrm{CDCl}_{3}\right): \delta=8.68(\mathrm{ddd}, J=4.7,1.8,0.9 \mathrm{~Hz}, 1 \mathrm{H}), 8.43(\mathrm{~d}, J=5.1 \mathrm{~Hz}, 1 \mathrm{H}), 8.38(\mathrm{~d}, J=$ $7.9 \mathrm{~Hz}, 1 \mathrm{H}), 7.80(\mathrm{td}, J=7.7,1.8 \mathrm{~Hz}, 1 \mathrm{H}), 7.56(\mathrm{~d}, J=5.1 \mathrm{~Hz}, 1 \mathrm{H}), 7.34$ (ddd, $J=7.5,4.8,1.2 \mathrm{~Hz}, 1 \mathrm{H}$ ), $5.37(\mathrm{~s}, 1 \mathrm{H}), 3.06(\mathrm{~d}, J=5.0 \mathrm{~Hz}, 3 \mathrm{H})$.

${ }^{13} \mathrm{C}$-NMR $\left(75 \mathrm{MHz}, \mathrm{CDCl}_{3}\right): \delta=163.7\left(\mathrm{C}_{\mathrm{q}}\right), 163.3\left(\mathrm{C}_{\mathrm{q}}\right), 159.2(\mathrm{CH}), 155.0\left(\mathrm{C}_{\mathrm{q}}\right), 149.4(\mathrm{CH}), 136.9(\mathrm{CH})$, $125.0(\mathrm{CH}), 121.5(\mathrm{CH}), 106.9(\mathrm{CH}), 28.6\left(\mathrm{CH}_{3}\right)$.

MS (EI) m/z (relative intensity): 186 (100) [M+], 157 (52), 130 (36), 105 (10), 79 (20).

HR-MS (El) $\mathrm{m} / z$ calculated for $\mathrm{C}_{10} \mathrm{H}_{10} \mathrm{~N}_{4}{ }^{+}$: 186.0905; found: 186.0903 .

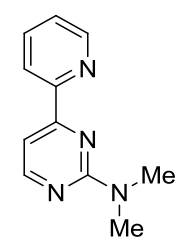

(127c)

${ }^{1} \mathrm{H}-\mathrm{NMR}\left(300 \mathrm{MHz}, \mathrm{CDCl}_{3}\right): \delta=8.66(\mathrm{ddd}, J=4.8,1.8,0.9 \mathrm{~Hz}, 1 \mathrm{H}), 8.46(\mathrm{~d}, J=5.1 \mathrm{~Hz}, 1 \mathrm{H}), 8.42(\mathrm{dt}, J=$ 7.9, $1.1 \mathrm{~Hz}, 1 \mathrm{H}$ ), 7.79 (td, $J=7.7,1.8 \mathrm{~Hz}, 1 \mathrm{H}), 7.50$ (d, $J=5.0 \mathrm{~Hz}, 1 \mathrm{H}), 7.33$ (ddd, $J=7.5,4.8,1.2 \mathrm{~Hz}$, $1 \mathrm{H}), 3.26(\mathrm{~s}, 6 \mathrm{H})$.

${ }^{13} \mathrm{C}$-NMR $\left(75 \mathrm{MHz}, \mathrm{CDCl}_{3}\right): \delta=163.5\left(\mathrm{C}_{\mathrm{q}}\right), 162.9\left(\mathrm{C}_{\mathrm{q}}\right), 159.3(\mathrm{CH}), 155.8\left(\mathrm{C}_{\mathrm{q}}\right), 149.7(\mathrm{CH}), 137.3(\mathrm{CH})$, $125.3(\mathrm{CH}), 121.9(\mathrm{CH}), 105.7(\mathrm{CH}), 37.6\left(2 \times \mathrm{CH}_{3}\right)$.

MS (EI) m/z (relative intensity): 200 (100) [M+], 185 (67), 171 (79), 156 (36), 111 (14), 97 (21), 79 (25), 69 (30), 57 (39), 43 (51).

HR-MS (EI) $\mathrm{m} / \mathrm{z}$ calculated for $\mathrm{C}_{11} \mathrm{H}_{12} \mathrm{~N}_{4}{ }^{+}$: 200.1062; found: 200.1068 . 
The analytical data are in accordance with those reported in the literature. ${ }^{201}$

\section{Synthesis of 1-(6-Bromopyridin-3-yl)ethanone (124z)}<smiles>Nc1ccc(Br)nc1</smiles>

To a stirred solution of 2,5-dibromopyridine $(10.6 \mathrm{~g}, 44.7 \mathrm{mmol})$ in dry $\mathrm{Et}_{2} \mathrm{O}(200 \mathrm{~mL})$ at $-78{ }^{\circ} \mathrm{C}$ was added dropwise a solution of $t$-BuLi (1.6 M, $29 \mathrm{~mL}, 45 \mathrm{mmol})$ in $n$-pentane over $10 \mathrm{~min}$. After $30 \mathrm{~min}$ of stirring at $-78^{\circ} \mathrm{C}$, DMA $(5.2 \mathrm{~mL}, 50 \mathrm{mmol})$ was added and stirring continued for $1.5 \mathrm{~h}$. The resulting mixture was warmed to ambient temperature and poured into water $(50 \mathrm{~mL})$. The organic phase was washed with water $(2 \times 30 \mathrm{~mL})$. The aqueous layer was extracted with $\mathrm{Et}_{2} \mathrm{O}(3 \times 30 \mathrm{~mL})$. The combined organic layers were dried over $\mathrm{Na}_{2} \mathrm{SO}_{4}$. Removal of the solvent under reduced pressure gave a yellow solid $(4.1 \mathrm{~g}, 46 \%)$, which was used without further purification.

M.r.: $127-128^{\circ} \mathrm{C}$ [Lit.: $\left.127-128^{\circ} \mathrm{C}\right]$.

${ }^{1} \mathrm{H}-\mathrm{NMR}\left(300 \mathrm{MHz}, \mathrm{CDCl}_{3}\right): \delta=8.89(\mathrm{~d}, J=2.5 \mathrm{~Hz}, 1 \mathrm{H}), 8.07(\mathrm{dd}, J=8.3,2.5 \mathrm{~Hz}, 1 \mathrm{H}), 7.76-7.52(\mathrm{~m}, 1 \mathrm{H})$, $2.62(\mathrm{~s}, 3 \mathrm{H})$.

${ }^{13} \mathrm{C}-\mathrm{NMR}\left(75 \mathrm{MHz}, \mathrm{CDCl}_{3}\right): \delta=195.7\left(\mathrm{C}_{\mathrm{q}}\right), 150.5(\mathrm{CH}), 147.1\left(\mathrm{C}_{\mathrm{q}}\right), 137.8(\mathrm{CH}), 131.6\left(\mathrm{C}_{\mathrm{q}}\right), 128.7(\mathrm{CH})$, $26.9\left(\mathrm{CH}_{3}\right)$.

MS (EI) m/z (relative intensity): 199 (35) [M+], 185 (100), 157 (48), 91 (43), 72 (39).

HR-MS (EI) $\mathrm{m} / z$ calculated for $\mathrm{C}_{7} \mathrm{H}_{6} \mathrm{BrNO}^{+}:$198.9633; found: 198.9633 .

The analytical data are in accordance with those reported in the literature. ${ }^{202}$

\section{Synthesis of 1-(6-Phenylpyridin-3-yl)ethanone (6ze)}<smiles>CC(=O)c1ccc(Br)nc1</smiles>

$124 z$<smiles>Oc1ccccc1</smiles>

$52 e$

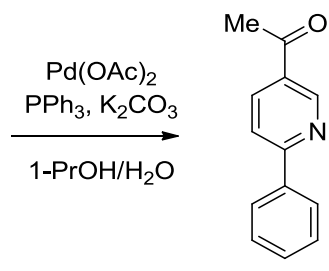

$6 b b$

\footnotetext{
201 Muller, K.; Schubert, A.; Jozak, T.; Ahrens-Botzong, A.; Schnemann, V.; Thiel, W. R. Chem. Cat. Chem 2011, 3 , 887-892.

202 El-Deeb, I.M.; Lee, S. H. Bioorg. Med. Chem. 2010, 18, 3860-3874.
} 
$\mathrm{Pd}(\mathrm{OAc})_{2}(80 \mathrm{mg}, 0.35 \mathrm{mmol}), \mathrm{PPh}_{3}(0.08 \mathrm{~g}, 0.25 \mathrm{mmol})$, aq. solution of $\mathrm{K}_{2} \mathrm{CO}_{3}(2.0 \mathrm{M}, 16 \mathrm{~mL}, 32 \mathrm{mmol})$ and distilled water $(32 \mathrm{~mL})$ were added to a degassed solution of 5-acetyl-6-bromopyridine (124z) $(4.2 \mathrm{~g}, 21 \mathrm{mmol})$ and phenylboronic acid (52e) $(3.22 \mathrm{~g}, 27.0 \mathrm{mmol})$ in 1-propanol $(50 \mathrm{~mL})$, and the mixture was refluxed over night. After cooling to ambient temperature, distilled water $(50 \mathrm{~mL})$ was added and the mixture was extracted with EtOAc $(2 \times 50 \mathrm{~mL})$. The organic layer was dried over anhydrous $\mathrm{Na}_{2} \mathrm{SO}_{4}$, and the solvent was evaporated to give the crude ketone, which was purified by recrystallisation from $\mathrm{MeOH} / \mathrm{DCM}$ to give $6 z e(1.9 \mathrm{~g}, 46 \%)$ as colorless plates.

M.p.: $119^{\circ} \mathrm{C}$ [Lit.: $\left.119-120^{\circ} \mathrm{C}\right]$.

${ }^{1} \mathrm{H}-\mathrm{NMR}\left(300 \mathrm{MHz}, \mathrm{CDCl}_{3}\right): \delta=9.23(\mathrm{dd}, J=2.3,0.9 \mathrm{~Hz}, 1 \mathrm{H}), 8.29(\mathrm{dd}, J=8.4,2.3 \mathrm{~Hz}, 1 \mathrm{H}), 8.10-8.02$ $(\mathrm{m}, 2 \mathrm{H}), 7.84(\mathrm{dd}, J=8.4,0.9 \mathrm{~Hz}, 1 \mathrm{H}), 7.59-7.43(\mathrm{~m}, 3 \mathrm{H}), 2.66(\mathrm{~s}, 3 \mathrm{H})$.

${ }^{13} \mathrm{C}-\mathrm{NMR}\left(75 \mathrm{MHz}, \mathrm{CDCl}_{3}\right): \delta=197.0\left(\mathrm{C}_{\mathrm{q}}\right), 161.5\left(\mathrm{C}_{\mathrm{q}}\right), 150.7(\mathrm{CH}), 138.7\left(\mathrm{C}_{\mathrm{q}}\right), 136.9(\mathrm{CH}), 131.2\left(\mathrm{C}_{\mathrm{q}}\right)$, 130.6 (CH), $129.5(2 \times C H), 127.9(2 \times C H), 120.7(\mathrm{CH}), 27.3\left(\mathrm{CH}_{3}\right)$.

MS (EI) m/z (relative intensity): 197 (68) [M+], 182 (100), 154 (45), 127 (50), 77 (23), 43 (29).

HR-MS (EI) $m / z$ calculated for $\mathrm{C}_{13} \mathrm{H}_{11} \mathrm{NO}^{+}: 197.0841$; found: 197.0837 .

The analytical data are in accordance with those reported in the literature. ${ }^{202}$

\section{Synthesis of 1-(6-Phenylpyridin-3-yl)ethanol (125b)}<smiles>Cc1ccc(-c2ccccc2)nc1</smiles>

$\mathrm{NaBH}_{4}(0.4 \mathrm{~g}, 10.6 \mathrm{mmol})$ was added portionwise to a stirred solution of 6 xe $(1.8 \mathrm{~g}, 9.1 \mathrm{mmol})$ in EtOH $(10 \mathrm{~mL})$. The reaction mixture was stirred at ambient temperature for $2 \mathrm{~h}$. After evaporation the remaining residue was washed with brine $(10 \mathrm{~mL})$ and extracted with DCM $(2 \times 25 \mathrm{~mL})$. The organic layer was dried over anhydrous $\mathrm{Na}_{2} \mathrm{SO}_{4}$ and filtered. After evaporation of the solvent 125xe could be isolated quantitatively as a yellow oil and was used without further purification.

${ }^{1} \mathrm{H}-\mathrm{NMR}\left(300 \mathrm{MHz}, \mathrm{CDCl}_{3}\right): \delta=8.53(\mathrm{~d}, J=2.2 \mathrm{~Hz}, 1 \mathrm{H}), 8.01-7.81(\mathrm{~m}, 2 \mathrm{H}), 7.70(\mathrm{dd}, J=8.3,2.2 \mathrm{~Hz}, 1 \mathrm{H})$, $7.61(\mathrm{dd}, J=8.2,0.8 \mathrm{~Hz}, 1 \mathrm{H}), 7.49-7.32(\mathrm{~m}, 3 \mathrm{H}), 4.88(\mathrm{q}, J=6.6 \mathrm{~Hz}, 1 \mathrm{H}), 3.62(\mathrm{~s}, 1 \mathrm{H}), 1.48(\mathrm{~d}, J=6.6 \mathrm{~Hz}$, $3 \mathrm{H})$. 
${ }^{13} \mathrm{C}-\mathrm{NMR}\left(75 \mathrm{MHz}, \mathrm{CDCl}_{3}\right): \delta=156.6\left(\mathrm{C}_{\mathrm{q}}\right), 147.3(\mathrm{CH}), 139.8\left(\mathrm{C}_{\mathrm{q}}\right), 139.1(\mathrm{CH}), 134.2(\mathrm{CH}), 129.0(\mathrm{CH})$, $128.8(\mathrm{CH}), 127.0(\mathrm{CH}), 120.6(\mathrm{CH}), 67.7(\mathrm{CH}), 25.2\left(\mathrm{CH}_{3}\right)$.

MS (El) m/z (relative intensity): 199 (45) [M+], 184 (100), 156 (52), 127 (10), 78 (11), 43 (11).

HR-MS (EI) $m / z$ calculated for $\mathrm{C}_{13} \mathrm{H}_{13} \mathrm{NO}^{+}$: 199.0997; found: 199.0992.

\section{Synthesis of 5-(1-Methoxyethyl)-2-phenylpyridine (126b)}<smiles>COc1ccc(-c2ccccc2)nc1</smiles>

To a stirred solution of the respective alcohol 125xe $(1.6 \mathrm{~g}, 8.0 \mathrm{mmol})$ in dry THF $(25 \mathrm{~mL}) \mathrm{NaH}(0.55 \mathrm{~g}$ of a $60 \%$ suspension in mineral oil, $13.5 \mathrm{mmol}$ ) was added in one portion. The reaction mixture was stirred for $8 \mathrm{~h}$ at ambient temperature. Mel $(0.85 \mathrm{~mL}, 13.5 \mathrm{mmol})$ was added dropwise and the solution was stirred over night. After addition of aq. $\mathrm{NH}_{4} \mathrm{Cl}$-solution $(30 \mathrm{~mL})$ and separation of the organic layer, the aq. layer was extracted with EtOAc $(2 \times 30 \mathrm{~mL})$. The combined organic phase was washed with $\mathrm{H}_{2} \mathrm{O}(30 \mathrm{~mL})$ and brine $(30 \mathrm{~mL})$ and was dried over anhydrous $\mathrm{Na}_{2} \mathrm{SO}_{4}$. Filtration, evaporation, column chromatography ( $n$-hexane/EtOAc 3:2) and Kugelrohr distillation gave 126b $(1.7 \mathrm{~g}, 99 \%)$ as a yellow oil.

${ }^{1} \mathrm{H}-\mathrm{NMR}\left(300 \mathrm{MHz}, \mathrm{CDCl}_{3}\right): \delta=8.61(\mathrm{dd}, J=1.6 \mathrm{~Hz}, 1 \mathrm{H}), 8.07-7.91(\mathrm{~m}, 2 \mathrm{H}), 7.73(\mathrm{~d}, J=1.6 \mathrm{~Hz}, 2 \mathrm{H})$, 7.53-7.36 (m, 3H), 4.39 (q, J = 6.5 Hz, 1H), $3.27(\mathrm{~s}, 3 \mathrm{H}), 1.50(\mathrm{~d}, J=6.5 \mathrm{~Hz}, 3 \mathrm{H})$.

${ }^{13} \mathrm{C}-\mathrm{NMR}\left(75 \mathrm{MHz}, \mathrm{CDCl}_{3}\right): \delta=157.1\left(\mathrm{C}_{\mathrm{q}}\right), 148.3(\mathrm{CH}), 139.3\left(\mathrm{C}_{\mathrm{q}}\right), 137.2\left(\mathrm{C}_{\mathrm{q}}\right), 134.7(\mathrm{CH}), 129.0(\mathrm{CH})$, $128.9(\mathrm{CH}), 127.0(\mathrm{CH}), 120.6(\mathrm{CH}), 77.3(\mathrm{CH}), 56.7\left(\mathrm{CH}_{3}\right), 23.7\left(\mathrm{CH}_{3}\right)$.

MS (EI) m/z (relative intensity): $213(20)\left[\mathrm{M}^{+}\right], 198$ (100), 182 (37), 154 (12), 127 (12), 43 (13).

HR-MS (EI) $\mathrm{m} / \mathrm{z}$ calculated for $\mathrm{C}_{14} \mathrm{H}_{15} \mathrm{NO}^{+}: 213.1154$; found: 213.1159 .

\section{Synthesis of Methyl-4-(pyridin-2-yl)-benzoate (6pa) ${ }^{203}$}

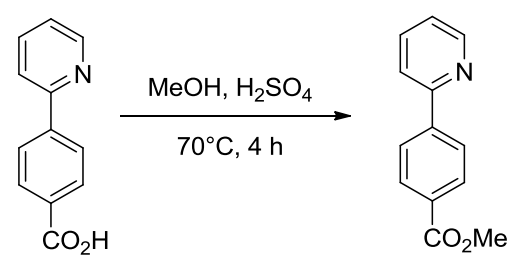

203 Deshmukh, M.; Patil, S.; Banerjee, K.; Oulkar, D.; Shripanavar, D. Der Pharmacia Lettre 2011, 3, $264-266$. 
To a solution of 4-(pyridin-2-yl)benzoic acid (6ra) $(0.80 \mathrm{~g}$, $4.0 \mathrm{mmol})$ in $\mathrm{MeOH}(5.0 \mathrm{~mL})$ conc. $\mathrm{H}_{2} \mathrm{SO}_{4}$ $(0.25 \mathrm{~mL})$ was added and the reaction mixture was stirred at $70{ }^{\circ} \mathrm{C}$ for an additional $7 \mathrm{~h}$. After completion of the reaction, the mixture was cooled to ambient temperature and neutralized with aq. $\mathrm{NaHCO}_{3}(25 \mathrm{~mL})$. The remaining residue was extracted with chloroform $(2 \times 50 \mathrm{~mL})$. The solvent was removed under reduced pressure to give $6 \mathrm{pa}(0.39 \mathrm{~g}, 46 \%)$ as an off-white solid.

M.p.: $99^{\circ} \mathrm{C}\left[\right.$ Lit.: $\left.98-99^{\circ} \mathrm{C}\right] .^{204}$

${ }^{1} \mathrm{H}-\mathrm{NMR}\left(600 \mathrm{MHz}, \mathrm{CDCl}_{3}\right): \delta=8.72(\mathrm{ddd}, J=4.9,1.4,1.3 \mathrm{~Hz}, 1 \mathrm{H}), 8.26-8.10(\mathrm{~m}, 2 \mathrm{H}), 8.09-8.00(\mathrm{~m}$, $2 \mathrm{H}), 7.83-7.71(\mathrm{~m}, 2 \mathrm{H}), 7.36-7.20(\mathrm{~m}, 1 \mathrm{H}), 3.94(\mathrm{~s}, 3 \mathrm{H})$.

${ }^{13} \mathrm{C}$-NMR $\left(75 \mathrm{MHz}, \mathrm{CDCl}_{3}\right): \delta=167.0\left(\mathrm{C}_{\mathrm{q}}\right), 156.3\left(\mathrm{C}_{\mathrm{q}}\right), 150.0(\mathrm{CH}), 143.6\left(\mathrm{C}_{\mathrm{q}}\right), 137.1(\mathrm{CH}), 130.5\left(\mathrm{C}_{\mathrm{q}}\right)$, $130.2(\mathrm{CH}), 127.0(\mathrm{CH}), 123.0(\mathrm{CH}), 121.1(\mathrm{CH}), 52.3\left(\mathrm{CH}_{3}\right)$.

MS (EI) $m / z$ (relative intensity): $213(63)\left[\mathrm{M}^{+}\right], 182$ (100), 154 (54), 127 (24), 77 (11).

HR-MS (EI) $m / z$ calculated for $\mathrm{C}_{13} \mathrm{H}_{11} \mathrm{NO}_{2}{ }^{+}: 213.0790$; found: 213.0794 .

The analytical data are in accordance with those reported in the literature. ${ }^{204}$

\section{Synthesis of 4-(Pyridin-2-yl)benzoic acid (6ra)}

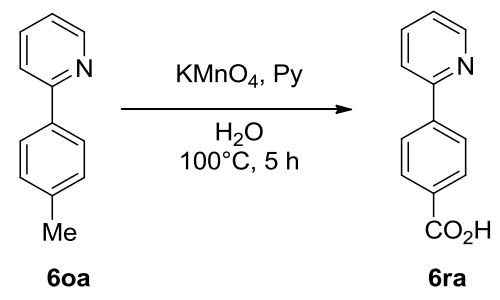

A solution of 2-p-tolylpyridine (6oa) $(1.99 \mathrm{~g}, 11.8 \mathrm{mmol})$ and pyridine $(5.9 \mathrm{~mL})$ in water $(30 \mathrm{~mL})$ was heated at $100^{\circ} \mathrm{C} . \mathrm{KMnO}_{4}(5.88 \mathrm{~g}, 37.2 \mathrm{mmol})$ was added in one portion and the reaction mixture was stirred at $100^{\circ} \mathrm{C}$ for an additional $5 \mathrm{~h}$. After cooling to ambient temperature, the solution was filtered and the filtrate acidified with conc. aq. $\mathrm{HCl}$ to $\mathrm{pH}$ 5. Filtration and evaporation yielded $6 \mathrm{ra}(0.94 \mathrm{~g}$, $40 \%)$ as a white solid.

M.p.: $241^{\circ} \mathrm{C}$. [Lit.: $\left.236-238^{\circ} \mathrm{C}\right] .^{205}$

${ }^{1} \mathrm{H}-\mathrm{NMR}\left(300 \mathrm{MHz}\right.$, DMSO- $\left.\mathrm{d}_{6}\right): \delta=12.96(\mathrm{~s}, 1 \mathrm{H}), 8.71(\mathrm{~d}, J=4.7 \mathrm{~Hz}, 1 \mathrm{H}), 8.49-7.65(\mathrm{~m}, 6 \mathrm{H}), 7.41(\mathrm{dd}, J$ $=6.1,6.1 \mathrm{~Hz}, 1 \mathrm{H}$ ).

\footnotetext{
204 Nunez, A.; Sanchez, A.; Burgos, C.; Alvarez-Builla, J. Tetrahedron 2004, 60, 6217-6224.

205 Bailey, T. R. Tetrahedron Lett. 1986, 27, 4407-4410.
} 
${ }^{13} \mathrm{C}-\mathrm{NMR}\left(75 \mathrm{MHz}, \mathrm{DMSO}-\mathrm{d}_{6}\right): \delta=167.0\left(\mathrm{C}_{\mathrm{q}}\right), 154.7\left(\mathrm{C}_{\mathrm{q}}\right), 149.5(\mathrm{CH}), 142.3\left(\mathrm{C}_{\mathrm{q}}\right), 137.5(\mathrm{CH}), 131.1\left(\mathrm{C}_{\mathrm{q}}\right)$, $129.6(\mathrm{CH}), 126.6(\mathrm{CH}), 123.3(\mathrm{CH}), 120.9(\mathrm{CH})$.

MS (EI) m/z (relative intensity): 199 (100) [ $\left.\mathrm{M}^{+}\right], 182$ (46), 154 (70), 127 (24).

HR-MS (El) $m / z$ calculated for $\mathrm{C}_{12} \mathrm{H}_{9} \mathrm{NO}_{2}{ }^{+}: 199.0633$; found: 199.0637.

The analytical data were in accordance with those reported in the literature. ${ }^{206}$

Synthesis of (E)-N-[1-(4-Fluorophenyl)ethylidene]-4-methoxyaniline (121a)<smiles>COc1ccc(/N=C(\C)c2ccc(F)cc2)cc1</smiles>

The general procedure $\mathbf{B}$ was followed using 4-fluoroacetophenone $(0.71 \mathrm{~g}, 5.1 \mathrm{mmol})$ and anisidine $(0.77 \mathrm{~g}, 6.3 \mathrm{mmol})$ in PhMe (25 mL). Purification by column chromatography ( $n$-hexane) yielded 121a $(0.75 \mathrm{~g}, 60 \%)$ as a yellow solid.

M.r.: $75-81^{\circ} \mathrm{C}$.

${ }^{1} \mathrm{H}-\mathrm{NMR}\left(300 \mathrm{MHz}, \mathrm{CDCl}_{3}\right): \delta=7.97-7.92(\mathrm{~m}, 2 \mathrm{H}), 7.09(\mathrm{~d}, J=8.6 \mathrm{~Hz}, 2 \mathrm{H}), 6.89(\mathrm{dd}, J=9.0,2.4 \mathrm{~Hz}, 2 \mathrm{H}$ ), 6.73 (ddd, $J=9.0,2.4,2.4 \mathrm{~Hz}, 2 \mathrm{H}), 3.80(\mathrm{~s}, 3 \mathrm{H}), 2.22(\mathrm{~s}, 3 \mathrm{H})$.

${ }^{13} \mathrm{C}-\mathrm{NMR}\left(75 \mathrm{MHz}, \mathrm{CDCl}_{3}\right): \delta=164.3\left(\mathrm{C}_{\mathrm{q}}\right), 164.1\left(\mathrm{~d}, \mathrm{~J}_{\mathrm{C}-\mathrm{F}}=259 \mathrm{~Hz}, \mathrm{C}_{\mathrm{q}}\right), 155.9\left(\mathrm{C}_{\mathrm{q}}\right), 144.5\left(\mathrm{C}_{\mathrm{q}}\right), 135.8\left(\mathrm{C}_{\mathrm{q}}\right)$, $129.1\left(\mathrm{~d}, \mathrm{~J}_{\mathrm{C}-\mathrm{F}}=9 \mathrm{~Hz}, \mathrm{CH}\right), 120.7(\mathrm{CH}), 115.1\left(\mathrm{~d}, \mathrm{~J}_{\mathrm{C}-\mathrm{F}}=20 \mathrm{~Hz}, \mathrm{CH}\right), 114.2(\mathrm{CH}), 55.5\left(\mathrm{CH}_{3}\right), 17.3\left(\mathrm{CH}_{3}\right)$.

${ }^{19} \mathrm{~F}-\mathrm{NMR}\left(282 \mathrm{MHz}, \mathrm{CDCl}_{3}\right): \delta=-110.7--110.8(\mathrm{~m})$.

IR (ATR): $\tilde{v}=3389,2988,2945,2902,2831,1716,1506,1363,1028,840,813,729,567 \mathrm{~cm}^{-1}$. MS (EI) m/z (relative intensity): 243 (68) [M+], 228 (100), 213 (5), 185 (5), 77 (5).

HR-MS (ESI) $m / z$ calculated for $\mathrm{C}_{15} \mathrm{H}_{14} \mathrm{FNO}+\mathrm{H}^{+}: 244.1132$; found: 244.1133 .

\section{Synthesis of (E)-N-[1-(3-Fluorophenyl)ethylidene]-4-methoxyaniline (121b)}<smiles>COc1ccc(N=C(c2cccc(F)c2)[N+](=O)[O-])cc1</smiles>

\footnotetext{
${ }^{206}$ Gong, Y.; Pauls, H. W. Synlett 2000, 829-831.
} 
The general procedure $\mathbf{B}$ was followed using 3-fluoroacetophenone $(0.65 \mathrm{~g}, 4.7 \mathrm{mmol})$ and anisidine ( $0.79 \mathrm{~g}, 6.4 \mathrm{mmol})$ in PhMe $(25 \mathrm{~mL})$. Purification by column chromatography ( $n$-hexane) yielded 121b $(0.71 \mathrm{~g}, 62 \%)$ as a yellow oil.

${ }^{1} \mathrm{H}-\mathrm{NMR}\left(300 \mathrm{MHz}, \mathrm{CDCl}_{3}\right): \delta=7.71-7.67(\mathrm{~m}, 2 \mathrm{H}), 7.41-7.31(\mathrm{~m}, 1 \mathrm{H}), 7.16-7.10(\mathrm{~m}, 1 \mathrm{H}), 6.93-6.86(\mathrm{~m}$, $2 \mathrm{H}), 6.76-6.72(\mathrm{~m}, 2 \mathrm{H}), 3.79(\mathrm{~s}, 3 \mathrm{H}), 2.22(\mathrm{~s}, 3 \mathrm{H})$.

${ }^{13} \mathrm{C}-\mathrm{NMR}\left(75 \mathrm{MHz}, \mathrm{CDCl}_{3}\right): \delta=164.2\left(\mathrm{C}_{\mathrm{q}}\right), 162.8\left(\mathrm{~d}, \mathrm{~J}_{\mathrm{C}-\mathrm{F}}=246 \mathrm{~Hz}, \mathrm{C}_{\mathrm{q}}\right), 156.1\left(\mathrm{C}_{\mathrm{q}}\right), 144.2\left(\mathrm{C}_{\mathrm{q}}\right), 142.0\left(\mathrm{C}_{\mathrm{q}}\right)$, $129.7(\mathrm{CH}), 122.7(\mathrm{CH}), 120.6(\mathrm{CH}), 117.1\left(\mathrm{~d}, J_{\mathrm{C}-\mathrm{F}}=22 \mathrm{~Hz}, \mathrm{CH}\right), 114.1\left(\mathrm{~d}, J_{\mathrm{C}-\mathrm{F}}=23 \mathrm{~Hz}, \mathrm{CH}\right), 113.8(\mathrm{CH})$, $55.4\left(\mathrm{CH}_{3}\right), 17.3\left(\mathrm{CH}_{3}\right)$.

${ }^{19}$ F-NMR $\left(282 \mathrm{MHz}, \mathrm{CDCl}_{3}\right): \delta=-113.00--113.21(\mathrm{~m})$.

IR (ATR): $\tilde{v}=3071,3036,3000,2954,2910,2835,1690,1631,1586,1503,1442,843,755,686 \mathrm{~cm}^{-1}$. MS (EI) m/z (relative intensity): $243(61)$ [ $\left.\mathrm{M}^{+}\right], 228$ (100), 92 (15), 77 (19), 64 (16).

HR-MS (ESI) $\mathrm{m} / \mathrm{z}$ calculated for $\mathrm{C}_{15} \mathrm{H}_{14} \mathrm{FNO}+\mathrm{H}^{+}$: 244.1138; found: 244.1133 .

The analytical data are in accordance with those reported in the literature. ${ }^{207}$

\section{Synthesis of (E)-4-Methoxy- $N$-[1-(3-methoxyphenyl)-ethylidene]aniline (121c)}<smiles>COc1ccc(/N=C(\C)c2cccc(OC)c2)cc1</smiles>

The general procedure B was followed using 3-methoxyacetophenone $(0.76 \mathrm{~g}, 5.1 \mathrm{mmol})$ and anisidine $(0.79 \mathrm{~g}, 6.4 \mathrm{mmol})$ in PhMe $(25 \mathrm{~mL})$. Purification by column chromatography ( $n$-hexane) yielded $121 \mathrm{c}(0.91 \mathrm{~g}, 70 \%)$ as an orange oil.

${ }^{1} \mathrm{H}-\mathrm{NMR}\left(300 \mathrm{MHz}, \mathrm{CDCl}_{3}\right): \delta=7.65-7.55(\mathrm{~m}, 1 \mathrm{H}), 7.50-7.46(\mathrm{~m}, 1 \mathrm{H}), 7.32(\mathrm{dd}, J=8.0,8.0 \mathrm{~Hz}, 1 \mathrm{H})$, 7.01-6.97 (m, 1H), 6.92-6.87 (m, 2H), 6.76-6.71 (m, 2H), $3.86(\mathrm{~s}, 3 \mathrm{H}), 3.80(\mathrm{~s}, 3 \mathrm{H}), 2.22(\mathrm{~s}, 3 \mathrm{H})$.

${ }^{13} \mathrm{C}-\mathrm{NMR}\left(75 \mathrm{MHz}, \mathrm{CDCl}_{3}\right): \delta=165.8\left(\mathrm{C}_{\mathrm{q}}\right), 159.9\left(\mathrm{C}_{\mathrm{q}}\right), 156.2\left(\mathrm{C}_{\mathrm{q}}\right), 145.0\left(\mathrm{C}_{\mathrm{q}}\right), 141.5\left(\mathrm{C}_{\mathrm{q}}\right), 129.5(\mathrm{CH})$, $120.9(\mathrm{CH}), 120.0(\mathrm{CH}), 116.9(\mathrm{CH}), 114.5(\mathrm{CH}), 112.0(\mathrm{CH}), 55.7\left(\mathrm{CH}_{3}\right), 55.6\left(\mathrm{CH}_{3}\right), 17.7\left(\mathrm{CH}_{3}\right)$.

IR (ATR): $\tilde{v}=3069,3033,2969,2912,2840,1735,1692,1635,1592,1506,1235,920,806,720 \mathrm{~cm}^{-1}$. MS (El) m/z (relative intensity): 255 (19) [M+], 240 (24), 150 (62), 135 (100), 123 (26), 107 (36), 77 (27).

HR-MS (ESI) $m / z$ calculated for $\mathrm{C}_{16} \mathrm{H}_{17} \mathrm{NO}_{2}+\mathrm{H}^{+}$: 256.1338; found: 256.1332 .

The analytical data were in accordance with those reported in the literature. ${ }^{208}$

\footnotetext{
${ }^{207}$ Lee, P. S.; Fujita, T.; Yoshikai, N. J. Am. Chem. Soc. 2011, 133, 17283-17295

${ }^{208}$ Moessner, C.; Bolm, C. Angew. Chem. Int. Ed. 2005, 44, 7564-7567.
} 


\section{Synthesis of (E)-N-[1-(3-Chlorophenyl)-ethylidene]-4-methoxyaniline (121d)}

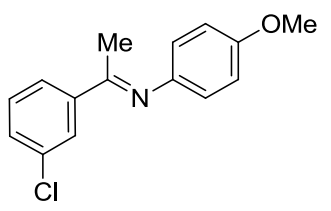

The general procedure B was followed using 3-chloroacetophenone $(1.54 \mathrm{~g}, 10.0 \mathrm{mmol})$ and anisidine ( $1.55 \mathrm{~g}, 12.5 \mathrm{mmol})$ in PhMe $(25 \mathrm{~mL})$. Purification by column chromatography ( $n$-hexane) yielded 121d (1.45 $\mathrm{g}, 56 \%)$ as a yellow solid.

M.r.: $66^{\circ} \mathrm{C}$ [Lit.: $\left.64-65^{\circ} \mathrm{C}\right]$.

${ }^{1} \mathrm{H}-\mathrm{NMR}\left(300 \mathrm{MHz}, \mathrm{CDCl}_{3}\right) \delta=7.97(\mathrm{dd}, J=2.9,2.3 \mathrm{~Hz}, 1 \mathrm{H}), 7.82$ (ddd, $J=8.0,1.7,1.7 \mathrm{~Hz}, 1 \mathrm{H}$ ), 7.49$7.30(\mathrm{~m}, 2 \mathrm{H}), 6.95-6.85(\mathrm{~m}, 2 \mathrm{H}), 6.82-6.63(\mathrm{~m}, 2 \mathrm{H}), 3.82(\mathrm{~s}, 3 \mathrm{H}), 2.24(\mathrm{~s}, 3 \mathrm{H})$.

${ }^{13} \mathrm{C}-\mathrm{NMR}\left(75 \mathrm{MHz}, \mathrm{CDCl}_{3}\right) \delta=164.4\left(\mathrm{C}_{\mathrm{q}}\right), 156.2\left(\mathrm{C}_{\mathrm{q}}\right), 144.3\left(\mathrm{C}_{\mathrm{q}}\right), 141.6\left(\mathrm{C}_{\mathrm{q}}\right), 134.6\left(\mathrm{C}_{\mathrm{q}}\right), 130.3(\mathrm{CH}), 129.6$ $(\mathrm{CH}), 127.4(\mathrm{CH}), 125.3(\mathrm{CH}), 120.8(\mathrm{CH}), 114.4(\mathrm{CH}), 55.5\left(\mathrm{CH}_{3}\right), 17.4\left(\mathrm{CH}_{3}\right)$.

MS (EI) m/z (relative intensity): 259 (53) [ $\left.\mathrm{M}^{+}\right], 244$ (100), 148 (15), 92 (15), 64 (13), 43 (40).

HR-MS (El) $m / z$ calculated for $\mathrm{C}_{15} \mathrm{H}_{14} \mathrm{CINO}^{+}: 259.0764$; found: 259.0755 .

The analytical data are in accordance with those reported in the literature. ${ }^{209}$

\section{Synthesis of (E)-4-Methoxy-N-(1-m-tolylethylidene)aniline (121e)}<smiles>COc1ccc(N=C(c2cccc([N+](=O)[O-])c2)[N+](=O)[O-])cc1</smiles>

General procedure B was followed using 3-methylacetophenone $(0.70 \mathrm{~g}, 5.2 \mathrm{mmol})$ and anisidine $(0.78 \mathrm{~g}, 6.3 \mathrm{mmol})$ in PhMe $(25 \mathrm{~mL})$. Purification by column chromatography ( $n$-hexane) yielded 121e $(0.59 \mathrm{~g}, 47 \%)$ as a yellow solid.

M.p.: $59-61^{\circ} \mathrm{C}$. [Lit.: $60-62^{\circ} \mathrm{C}$ ]. ${ }^{210}$

${ }^{1} \mathrm{H}-\mathrm{NMR}\left(300 \mathrm{MHz}, \mathrm{CDCl}_{3}\right): \delta=7.84(\mathrm{~s}, 1 \mathrm{H}), 7.73(\mathrm{~d}, J=7.5 \mathrm{~Hz}, 1 \mathrm{H}), 7.37-7.21(\mathrm{~m}, 2 \mathrm{H}), 6.90$ (ddd, $J=$ 9.3, 2.2, $2.2 \mathrm{~Hz}, 2 \mathrm{H}), 6.77$ (ddd, J = 9.3, 2.2, $2.2 \mathrm{~Hz}, 2 \mathrm{H}), 3.78(\mathrm{~s}, 3 \mathrm{H}), 2.41(\mathrm{~s}, 3 \mathrm{H}), 2.23(\mathrm{~s}, 3 \mathrm{H})$.

\footnotetext{
${ }^{209}$ Yoshikai, N.; Matsumoto, A.; Norinder, J.; Nakamura, E. Angew. Chem. Int. Ed. 2009, 48, 2925-2928.

${ }^{210}$ Chen, F.; Ding, Z.; He, Y.; Qin, J.; Wang, T.; Fan, Q.-H. Tetrahedron 2012, 68, 5248-5257.
} 
${ }^{13} \mathrm{C}-\mathrm{NMR}\left(75 \mathrm{MHz}, \mathrm{CDCl}_{3}\right): \delta=165.5\left(\mathrm{C}_{\mathrm{q}}\right), 155.6\left(\mathrm{C}_{\mathrm{q}}\right), 144.5\left(\mathrm{C}_{\mathrm{q}}\right), 139.4\left(\mathrm{C}_{\mathrm{q}}\right), 137.6\left(\mathrm{C}_{\mathrm{q}}\right), 130.8(\mathrm{CH})$, $127.9(\mathrm{CH}), 127.3(\mathrm{CH}), 124.1(\mathrm{CH}), 120.5(\mathrm{CH}), 113.9(\mathrm{CH}), 55.2\left(\mathrm{CH}_{3}\right), 21.3\left(\mathrm{CH}_{3}\right), 17.2\left(\mathrm{CH}_{3}\right)$.

IR (ATR): $\tilde{v}=2983,2926,2839,1668,1504,1284,1237,1054,1036,840,754,695 \mathrm{~cm}^{-1}$. MS (EI) m/z (relative intensity): 239 (50) [ $\left.\mathrm{M}^{+}\right], 224$ (100), 148 (10), 92 (12), 77 (16), 64 (13).

HR-MS (ESI) $m / z$ calculated for $\mathrm{C}_{16} \mathrm{H}_{17} \mathrm{NO}+\mathrm{H}^{+}: 240.1383$; found: 240.1383 .

The analytical data were in accordance with those reported in the literature. ${ }^{210}$ 


\subsection{The Analytical Data for the Products of the Ruthenium-Catalyzed ortho- Alkylation}

Synthesis of 2-(2-n-Octylphenyl)pyridine (93aa)

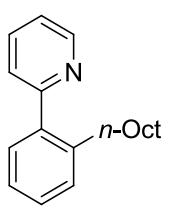

The general procedure $\mathbf{C}$ was followed using $6 \mathrm{aa}(75.6 \mathrm{mg}, 0.49 \mathrm{mmol}), 42 \mathrm{aa}(291 \mathrm{mg}, 1.51 \mathrm{mmol})$, $\left[\operatorname{RuCl}_{2}(p \text {-cymene })\right]_{2}(7.8 \mathrm{mg}, 2.5 \mathrm{~mol} \%)$ and $1-\mathrm{AdCO}_{2} \mathrm{H}(13 \mathrm{c})(27 \mathrm{mg}, 0.15 \mathrm{mmol}, 31 \mathrm{~mol} \%)$ in $\mathrm{m}$ xylene $(2.0 \mathrm{~mL}$ ). Purification by column chromatography ( -hexane/EtOAc 15:1) yielded 93aa (86 mg, $66 \%)$ as a colorless oil.

The general procedure $\mathbf{C}$ was followed using $6 \mathrm{aa}(81.6 \mathrm{mg}, 0.53 \mathrm{mmol})$, $42 \mathrm{aa}(285 \mathrm{mg}, 1.47 \mathrm{mmol}$ ) and $\left[\mathrm{RuCl}_{2}(p \text {-cymene })\right]_{2}(7.8 \mathrm{mg}, 2.4 \mathrm{~mol} \%)$ in $m$-xylene $(2.0 \mathrm{~mL})$ with KOPiv $(20.7 \mathrm{mg}, 0.15 \mathrm{mmol})$ and $\mathrm{K}_{2} \mathrm{CO}_{3}(138 \mathrm{~g}, 1.00 \mathrm{mmol}$ ). Purification by column chromatography ( $n$-hexane/EtOAc 9:1) yielded 93aa (72 mg, 51\%).

${ }^{1} \mathrm{H}-\mathrm{NMR}\left(300 \mathrm{MHz}, \mathrm{CDCl}_{3}\right): \delta=8.68$ (ddd, $\left.J=4.9,1.7,0.9 \mathrm{~Hz}, 1 \mathrm{H}\right), 7.71(\mathrm{td}, J=7.7,1.8 \mathrm{~Hz}, 1 \mathrm{H}$ ), $7.54-$ $7.02(\mathrm{~m}, 6 \mathrm{H}), 2.75-2.67(\mathrm{~m}, 2 \mathrm{H}), 1.46-1.43(\mathrm{~m}, 2 \mathrm{H}), 1.36-0.98(\mathrm{~m}, 10 \mathrm{H}), 0.85(\mathrm{t}, J=7.0 \mathrm{~Hz}, 3 \mathrm{H})$.

${ }^{13} \mathrm{C}-\mathrm{NMR}\left(75 \mathrm{MHz}, \mathrm{CDCl}_{3}\right): \delta=160.1\left(\mathrm{C}_{\mathrm{q}}\right), 148.8(\mathrm{CH}), 140.5\left(\mathrm{C}_{\mathrm{q}}\right), 140.1\left(\mathrm{C}_{\mathrm{q}}\right), 135.7(\mathrm{CH}), 129.5(\mathrm{CH})$, $129.4(\mathrm{CH}), 128.0(\mathrm{CH}), 125.4(\mathrm{CH}), 123.8(\mathrm{CH}), 121.3(\mathrm{CH}), 32.8\left(\mathrm{CH}_{2}\right), 31.7\left(\mathrm{CH}_{2}\right), 31.1\left(\mathrm{CH}_{2}\right), 29.3$ $\left(\mathrm{CH}_{2}\right), 29.1\left(\mathrm{CH}_{2}\right), 29.0\left(\mathrm{CH}_{2}\right), 22.5\left(\mathrm{CH}_{2}\right), 14.0\left(\mathrm{CH}_{3}\right)$.

IR (ATR): $\tilde{v}=3059,2925,2854,1586,1562,1468,1425,751,449,420 \mathrm{~cm}^{-1}$. MS (EI) $m / z$ (relative intensity): 267 (31) [M+], 182 (100), 167 (41).

HR-MS (ESI) $m / z$ calculated for $\mathrm{C}_{19} \mathrm{H}_{25} \mathrm{~N}+\mathrm{H}^{+}$: 268.2065; found: 268.2060 .

The analytical data are in accordance with those reported in the literature. ${ }^{121}$

Synthesis of 2-(4-Methoxy-2-n-octylphenyl)-pyridine (93ba)

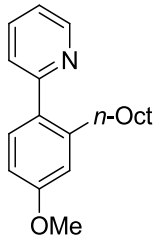


The general procedure $\mathbf{C}$ was followed using 6 ba $(90.0 \mathrm{mg}, 0.49 \mathrm{mmol}), 42 \mathrm{aa}(285 \mathrm{mg}, 1.47 \mathrm{mmol})$ and $\left[\mathrm{RuCl}_{2}(p \text {-cymene })\right]_{2}(7.9 \mathrm{mg}, 2.6 \mathrm{~mol} \%)$, in $\mathrm{H}_{2} \mathrm{O}(2.0 \mathrm{~mL})$. Purification by column chromatography ( $n$-hexane/EtOAc 9:1) yielded 93ba (88 mg, 61\%) as a colorless oil.

The general procedure $\mathbf{E}$ was followed using $[\mathrm{Ru}(p$-cymene)(MesCO 2$)\{2-(4$-methoxyphenyl)pyridyl\}] (14a) $(15.3 \mathrm{mg}, 5.0 \mathrm{~mol} \%), \mathrm{K}_{2} \mathrm{CO}_{3}(140 \mathrm{mg}, 1.01 \mathrm{mmol}), 6$ ba $(95.2 \mathrm{mg}, 0.52 \mathrm{mmol}$ ) and 42aa (284 mg, $1.47 \mathrm{mmol})$ in NMP (2.0 mL). Purification by column chromatography ( $n$-hexane/EtOAc 15:1) yielded 93ba (91 mg, 59\%) as a colorless oil.

${ }^{1} \mathrm{H}-\mathrm{NMR}\left(300 \mathrm{MHz}, \mathrm{CDCl}_{3}\right): \delta=8.66(\mathrm{ddd}, J=4.9,1.9,1.0 \mathrm{~Hz}, 1 \mathrm{H}), 7.70(\mathrm{dd}, J=7.7,1.8 \mathrm{~Hz}, 1 \mathrm{H}$ ), $7.40-$ $7.26(\mathrm{~m}, 2 \mathrm{H}), 7.20(\mathrm{ddd}, J=7.5,4.9,1.2 \mathrm{~Hz}, 1 \mathrm{H}), 6.96-6.63(\mathrm{~m}, 2 \mathrm{H}), 3.83(\mathrm{~s}, 3 \mathrm{H}), 2.80-2.56(\mathrm{~m}, 2 \mathrm{H})$, 1.52-1.36 (m, 2H), 1.31-1.06 (m, 10H), $0.86(t, J=6.9 \mathrm{~Hz}, 3 \mathrm{H})$.

${ }^{13} \mathrm{C}-\mathrm{NMR}\left(75 \mathrm{MHz}, \mathrm{CDCl}_{3}\right): \delta=159.8\left(\mathrm{C}_{\mathrm{q}}\right), 159.2\left(\mathrm{C}_{\mathrm{q}}\right), 149.4(\mathrm{CH}), 142.5\left(\mathrm{C}_{\mathrm{q}}\right), 135.8(\mathrm{CH}), 133.0\left(\mathrm{C}_{\mathrm{q}}\right)$, $125.6(\mathrm{CH}), 121.6(2 \times \mathrm{CH}), 112.0(2 \times \mathrm{CH}), 55.3\left(\mathrm{CH}_{3}\right), 33.9\left(\mathrm{CH}_{2}\right), 32.0\left(\mathrm{CH}_{2}\right), 31.1\left(\mathrm{CH}_{2}\right), 29.6\left(\mathrm{CH}_{2}\right), 29.3$ $\left(\mathrm{CH}_{2}\right), 29.2\left(\mathrm{CH}_{2}\right), 22.8\left(\mathrm{CH}_{2}\right), 14.24\left(\mathrm{CH}_{3}\right)$.

IR (ATR): $\tilde{v}=3003,2954,2923,1852,1606,1587,1426,1377,1277,1234,786,747 \mathrm{~cm}^{-1}$. MS (EI) m/z (relative intensity): 297 (56) [M+], 226 (12), 212 (100), 197 (41), 168 (12), 154 (22). HR-MS (ESI) $m / z$ calculated for $\mathrm{C}_{20} \mathrm{H}_{27} \mathrm{NO}^{+}: 297.2093$; found: 297.2100 .

The analytical data are in accordance with those reported in the literature.Fehler! Textmarke nicht efiniert.

Synthesis of 2-(2-n-Hexyl-4-methoxyphenyl)pyridine (93bb) and 2-(3-n-Hexyl-4-methoxyphenyl)pyridine (93bb')

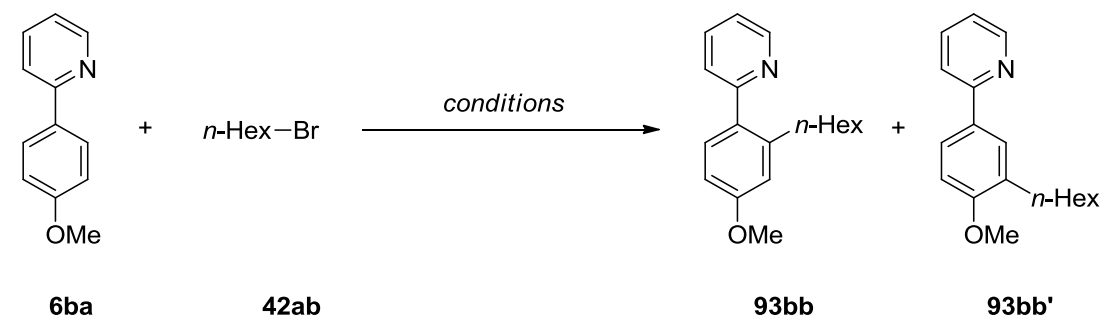

The general procedure $\mathbf{C}$ was followed using $\left[\mathrm{RuCl}_{2}(p \text {-cymene })\right]_{2}(7.8 \mathrm{mg}, 2.5 \mathrm{~mol} \%), \mathrm{MesCO}_{2} \mathrm{H}$ (13a) (24 mg, $0.15 \mathrm{mmol}, 29 \mathrm{~mol} \%)$, methoxyphenylpyridine $6 \mathrm{ba}(94.0 \mathrm{mg}, 0.51 \mathrm{mmol}$ ) and 42ab (236 mg, $1.43 \mathrm{mmol}$ ) in $\mathrm{H}_{2} \mathrm{O}(2.0 \mathrm{~mL}$ ). Purification by column chromatography ( $n$-hexane/EtOAc 15:1) yielded 93bb (62 mg, 45\%) and 93bb' (9 mg, 7\%) as colorless oils. 
The general procedure $\mathbf{C}$ was followed using $\left[\mathrm{RuCl}_{2}(p \text {-cymene) }]_{2}(7.8 \mathrm{mg}, 2.5 \mathrm{~mol} \%), 1-\mathrm{AdCO}_{2} \mathrm{H}(\mathbf{1 3 c})\right.$ $(24 \mathrm{mg}, 0.15 \mathrm{mmol}), 6$ ba $(95.0 \mathrm{mg}, 0.51 \mathrm{mmol})$ and $42 \mathrm{ab}(237 \mathrm{mg}, 1.44 \mathrm{mmol})$ in NMP $(2.0 \mathrm{~mL})$. Purification by column chromatography ( $n$-hexane/EtOAc 15:1) yielded $93 \mathbf{b b}$ (66 mg, 48\%).

The general procedure $\mathbf{E}$ was followed using $\left[\mathrm{Ru}\left(p\right.\right.$-cymene) $\left(\mathrm{MesCO}_{2}\right)\{2-(4$-methoxyphenyl)pyridyl\}] 14a (15.3 mg, $5.0 \mathrm{~mol} \%), \mathrm{K}_{2} \mathrm{CO}_{3}(140 \mathrm{mg}, 1.01 \mathrm{mmol}), 6 \mathrm{ba}(97.7 \mathrm{mg}, 0.53 \mathrm{mmol}$ ) and $42 \mathrm{ab}(278 \mathrm{mg}$, $1.68 \mathrm{mmol}$ ) in $m$-xylene $(2.0 \mathrm{~mL})$. Purification by column chromatography ( $n$-hexane/EtOAc 15:1) yielded $\mathbf{9 3 b b}$ (100 mg, 70\%).

The general procedure $\mathbf{C}$ was followed using $\left[\mathrm{RuCl}_{2}(p \text {-cymene) }]_{2}(7.8 \mathrm{mg}, 2.5 \mathrm{~mol} \%), 6\right.$ ba $(94.5 \mathrm{mg}$, $0.51 \mathrm{mmol}$ ) and $42 \mathrm{ab}(246 \mathrm{mg}, 1.48 \mathrm{mmol})$ in $m$-xylene $(2.0 \mathrm{~mL})$ with KOAc (319 mg, $3.25 \mathrm{mmol})$. Purification by column chromatography ( $n$-hexane/EtOAc 15:1) yielded $93 \mathbf{b b}$ ( $67 \mathrm{mg}, 49 \%$ ).

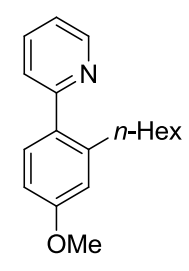

(93bb)

${ }^{1} \mathrm{H}-\mathrm{NMR}\left(600 \mathrm{MHz}, \mathrm{CDCl}_{3}\right): \delta=8.63(\mathrm{~d}, J=4.7 \mathrm{~Hz}, 1 \mathrm{H}), 7.68(\mathrm{ddd}, J=7.7,1.9,1.8 \mathrm{~Hz}, 1 \mathrm{H}), 7.32(\mathrm{~d}, J=$ $7.8 \mathrm{~Hz}, 1 \mathrm{H}), 7.27(\mathrm{~d}, J=8.4 \mathrm{~Hz}, 1 \mathrm{H}), 7.20-7.15(\mathrm{~m}, 1 \mathrm{H}), 6.82(\mathrm{~d}, J=2.6 \mathrm{~Hz}, 1 \mathrm{H}), 6.78(\mathrm{dd}, J=8.4,2.7 \mathrm{~Hz}$, $1 \mathrm{H}), 3.82(\mathrm{~s}, 3 \mathrm{H}), 2.75-2.62(\mathrm{~m}, 2 \mathrm{H}), 1.49-1.34(\mathrm{~m}, 2 \mathrm{H}), 1.22-1.07(\mathrm{~m}, 6 \mathrm{H}), 0.79(\mathrm{t}, J=7.1 \mathrm{~Hz}, 3 \mathrm{H})$.

${ }^{13} \mathrm{C}$-NMR $\left(75 \mathrm{MHz}, \mathrm{CDCl}_{3}\right): \delta=160.0\left(\mathrm{C}_{\mathrm{q}}\right), 159.4\left(\mathrm{C}_{\mathrm{q}}\right), 149.0(\mathrm{CH}), 142.4\left(\mathrm{C}_{\mathrm{q}}\right), 135.9(\mathrm{CH}), 133.1\left(\mathrm{C}_{\mathrm{q}}\right)$, $131.0(\mathrm{CH}), 124.1(\mathrm{CH}), 121.2(\mathrm{CH}), 115.2(\mathrm{CH}), 110.9(\mathrm{CH}), 55.2\left(\mathrm{CH}_{3}\right), 33.1\left(\mathrm{CH}_{2}\right), 31.4\left(\mathrm{CH}_{2}\right), 31.1$ $\left(\mathrm{CH}_{2}\right), 29.0\left(\mathrm{CH}_{2}\right), 22.4\left(\mathrm{CH}_{2}\right), 14.0\left(\mathrm{CH}_{3}\right)$.

IR (ATR): $\tilde{v}=2927,2855,1587,1505,1465,1427,1280,1236,1162,1045 \mathrm{~cm}^{-1}$.

MS (EI) $m / z$ (relative intensity): 269 (33) [M+1], 226 (9), 212 (100), 197 (18), 154 (10).

HR-MS (ESI) $m / z$ calculated for $\mathrm{C}_{18} \mathrm{H}_{23} \mathrm{NO}+\mathrm{H}^{+}: 270.1858$; found: 270.1852 .

The analytical data are in accordance with those reported in the literature.Fehler! Textmarke nicht efiniert.

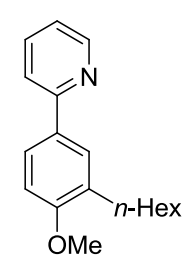




\section{$\left(93 b b^{\prime}\right)$}

${ }^{1} \mathrm{H}-\mathrm{NMR}\left(600 \mathrm{MHz}, \mathrm{CDCl}_{3}\right): \delta=8.63(\mathrm{~d}, J=4.6 \mathrm{~Hz}, 1 \mathrm{H}), 7.83-7.74(\mathrm{~m}, 2 \mathrm{H}), 7.60-7.47(\mathrm{~m}, 2 \mathrm{H}), 7.10(\mathrm{~m}$, $1 \mathrm{H}), 6.90(\mathrm{~d}, J=8.2 \mathrm{~Hz}, 1 \mathrm{H}), 3.81(\mathrm{~s}, 3 \mathrm{H}), 2.72-2.59(\mathrm{~m}, 2 \mathrm{H}), 1.65-1.54(\mathrm{~m}, 2 \mathrm{H}), 1.41-1.25(\mathrm{~m}, 6 \mathrm{H}), 0.86$ $(\mathrm{t}, J=7.0 \mathrm{~Hz}, 3 \mathrm{H})$.

${ }^{13} \mathrm{C}-\mathrm{NMR}\left(75 \mathrm{MHz}, \mathrm{CDCl}_{3}\right): \delta=158.4\left(\mathrm{C}_{\mathrm{q}}\right), 157.4\left(\mathrm{C}_{\mathrm{q}}\right), 149.4(\mathrm{CH}), 136.6(\mathrm{CH}), 131.7\left(\mathrm{C}_{\mathrm{q}}\right), 131.5\left(\mathrm{C}_{\mathrm{q}}\right)$, $128.4(\mathrm{CH}), 125.4(\mathrm{CH}), 121.2(\mathrm{CH}), 119.9(\mathrm{CH}), 110.3(\mathrm{CH}), 55.4\left(\mathrm{CH}_{3}\right), 31.8\left(\mathrm{CH}_{2}\right), 30.4\left(\mathrm{CH}_{2}\right), 29.9$ $\left(\mathrm{CH}_{2}\right), 29.4\left(\mathrm{CH}_{2}\right), 22.6\left(\mathrm{CH}_{2}\right), 14.1\left(\mathrm{CH}_{3}\right)$.

IR (ATR): $\tilde{v}=3176,3003,2954,1606,1587,1426,1279,1149,1129,1019 \mathrm{~cm}^{-1}$.

MS (EI) m/z (relative intensity): 269 (77) [M+], 226 (16), 198 (100), 168 (65), 154 (19), 43 (15).

HR-MS (ESI) $m / z$ calculated for $\mathrm{C}_{18} \mathrm{H}_{23} \mathrm{NO}^{+}: 269.1780$; found: 269.1780.

\section{Synthesis of 2-(4-Fluoro-2-n-octylphenyl)pyridine (93ca)}

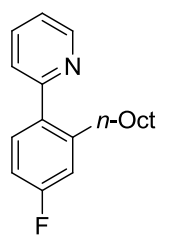

The general procedure $C$ was followed using $6 \mathrm{ca}(120 \mathrm{mg}, 0.69 \mathrm{mmol}), 42 \mathrm{aa}(280 \mathrm{mg}, 1.45 \mathrm{mmol})$, $\left[\mathrm{RuCl}_{2}(p \text {-cymene) }]_{2}(8.0 \mathrm{mg}, 1.9 \mathrm{~mol} \%), \mathrm{KOAc}(20.6 \mathrm{mg}, 0.21 \mathrm{mmol}, 30 \mathrm{~mol} \%)\right.$ and $\mathrm{K}_{2} \mathrm{CO}_{3}(190.7 \mathrm{mg}$, $1.38 \mathrm{mmol}$ ) in $\mathrm{H}_{2} \mathrm{O}(2.0 \mathrm{~mL}$ ). Purification by column chromatography ( $n$-hexane/EtOAc 9:1) yielded 93ca (118 mg, 60\%) as a colorless oil.

ortho-Alkylations of ( $p$-fluorophenyl)pyridine $(6 \mathrm{ca})$ with $n$-octyl bromide according to The general procedure $\mathrm{C}$ in $\mathrm{H}_{2} \mathrm{O}, m$-xylene $/ \mathrm{H}_{2} \mathrm{O}(2.0 \mathrm{~mL}, 1: 1), \mathrm{NMP} / \mathrm{H}_{2} \mathrm{O}(2.0 \mathrm{~mL}, 1: 1)$ or neat furnished the product $93 \mathrm{ca}$ in $66,68,53$ and $63 \%$ isolated yield, respectively.

${ }^{1} \mathrm{H}-\mathrm{NMR}\left(300 \mathrm{MHz}, \mathrm{CDCl}_{3}\right): \delta=8.71-8.56(\mathrm{~m}, 1 \mathrm{H}), 7.71$ (ddd, $\left.J=7.7,1.9,1.8 \mathrm{~Hz}, 1 \mathrm{H}\right), 7.41-7.28(\mathrm{~m}$, $2 \mathrm{H}), 7.26-7.16(\mathrm{~m}, 1 \mathrm{H}), 7.06-6.86(\mathrm{~m}, 2 \mathrm{H}), 2.74-2.58(\mathrm{~m}, 2 \mathrm{H}), 1.55-1.32(\mathrm{~m}, 2 \mathrm{H}), 1.31-1.07(\mathrm{~m}, 10 \mathrm{H})$, $0.96-0.67(m, 3 H)$.

${ }^{13} \mathrm{C}-\mathrm{NMR}\left(75 \mathrm{MHz}, \mathrm{CDCl}_{3}\right): \delta=162.8\left(\mathrm{~d}, \mathrm{~J}_{\mathrm{C}-\mathrm{F}}=247 \mathrm{~Hz}, \mathrm{C}_{\mathrm{q}}\right), 159.5\left(\mathrm{C}_{\mathrm{q}}\right), 149.3(\mathrm{CH}), 143.6\left(\mathrm{~d}, \mathrm{~J}_{\mathrm{C}-\mathrm{F}}=7 \mathrm{~Hz}\right.$, $\left.C_{q}\right), 136.5\left(d, J_{C-F}=3 \mathrm{~Hz}, C_{q}\right), 136.2(C H), 131.5\left(d, J_{C-F}=8 \mathrm{~Hz}, \mathrm{CH}\right), 124.2(\mathrm{CH}), 121.8(\mathrm{CH}), 116.2\left(\mathrm{~d}, J_{\mathrm{C}-F}\right.$ $=21 \mathrm{~Hz}, \mathrm{CH}), 112.6\left(\mathrm{~d}, \mathrm{~J}_{\mathrm{C}-\mathrm{F}}=21 \mathrm{~Hz}, \mathrm{CH}\right), 33.0\left(\mathrm{~d}, \mathrm{~J}_{\mathrm{C}-\mathrm{F}}=2 \mathrm{~Hz}, \mathrm{CH}\right), 31.9\left(\mathrm{CH}_{2}\right), 31.0\left(\mathrm{CH}_{2}\right), 31.0\left(\mathrm{CH}_{2}\right), 29.4$ $\left(\mathrm{CH}_{2}\right), 29.3\left(\mathrm{CH}_{2}\right), 29.2\left(\mathrm{CH}_{2}\right), 22.7\left(\mathrm{CH}_{2}\right), 14.2\left(\mathrm{CH}_{3}\right)$.

${ }^{19} \mathrm{~F}-\mathrm{NMR}\left(282 \mathrm{MHz}, \mathrm{CDCl}_{3}\right): \delta=-107.80--124.10(\mathrm{~m})$.

IR (ATR): $\tilde{v}=2954,2924,2854,1588,1501,1465,1219,1114,870,822,747,566 \mathrm{~cm}^{-1}$. 
MS (EI) m/z (relative intensity): 285 (39) [M+], 256 (10), 214 (11), 200 (100), 185 (67).

HR-MS (ESI) $\mathrm{m} / \mathrm{z}$ calculated for $\mathrm{C}_{19} \mathrm{H}_{24} \mathrm{FN}+\mathrm{H}^{+}: 286.1971$; found: 286.1970 .

\section{Synthesis of 2-(4-Fluoro-2-n-hexylphenyl)pyridine (93cb)}

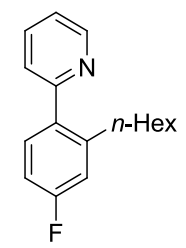

The general procedure $\mathbf{C}$ was followed using $6 \mathrm{ca}(83.9 \mathrm{mg}, 0.48 \mathrm{mmol}), 42 \mathrm{ab}(247 \mathrm{mg}, 1.50 \mathrm{mmol})$, $\left[\mathrm{RuCl}_{2}(p \text {-cymene) }]_{2}(7.3 \mathrm{mg}, 2.5 \mathrm{~mol} \%), \mathrm{MesCO}_{2} \mathrm{H}\right.$ (13a) $(24.3 \mathrm{mg}, 0.15 \mathrm{mmol}, 30 \mathrm{~mol} \%)$ and $\mathrm{K}_{2} \mathrm{CO}_{3}$ (139 mg, $1.01 \mathrm{mmol}$ ) in $\mathrm{H}_{2} \mathrm{O}(2.0 \mathrm{~mL}$ ). Purification by column chromatography ( $n$-hexane/EtOAc 9:1) yielded $93 \mathrm{cb}$ (82 $\mathrm{mg}, 66 \%$ ) as a colorless oil.

The general procedure $\mathbf{C}$ was followed using $6 \mathrm{ca}(87.1 \mathrm{mg}, 0.50 \mathrm{mmol})$, 42ab $(255 \mathrm{mg}, 1.54 \mathrm{mmol})$, $\left[\mathrm{RuCl}_{2}(p \text {-cymene })\right]_{2}(7.9 \mathrm{mg}, 2.6 \mathrm{~mol} \%), \mathrm{KOAc}(314.1 \mathrm{mg}, 3.2 \mathrm{mmol})$ and $\mathrm{K}_{2} \mathrm{CO}_{3}(138 \mathrm{mg}, 1.00 \mathrm{mmol})$ in $m$-xylene $(2.0 \mathrm{~mL}$ ). Purification by column chromatography ( $n$-hexane/EtOAc 9:1) yielded $93 \mathrm{cb}$ (98 mg, 76\%).

${ }^{1} \mathrm{H}-\mathrm{NMR}\left(300 \mathrm{MHz}, \mathrm{CDCl}_{3}\right): \delta=8.65$ (ddd, $J=4.8,1.9,0.9 \mathrm{~Hz}, 1 \mathrm{H}$ ), 7.70 (ddd, $J=7.7,1.8,1.7 \mathrm{~Hz}, 1 \mathrm{H}$ ), 7.35-7.14 (m, 3H), 7.02-6.84 (m, 2H), 2.74-2.57 (m, 2H), 1.53-1.32 (m, 2H), 1.25-1.04 (m, 6H), $0.80(\mathrm{t}$, $J=8.3 \mathrm{~Hz}, 3 \mathrm{H})$.

${ }^{13} \mathrm{C}-\mathrm{NMR}\left(75 \mathrm{MHz}, \mathrm{CDCl}_{3}\right): \delta=162.8\left(\mathrm{~d}, \mathrm{~J}_{\mathrm{C}-\mathrm{F}}=247 \mathrm{~Hz}, \mathrm{C}_{\mathrm{q}}\right), 159.5\left(\mathrm{C}_{\mathrm{q}}\right), 149.3(\mathrm{CH}), 143.6\left(\mathrm{~d}, \mathrm{~J}_{\mathrm{C}-\mathrm{F}}=8 \mathrm{~Hz}\right.$, $\left.\mathrm{C}_{\mathrm{q}}\right), 136.5\left(\mathrm{~d}, \mathrm{~J}_{\mathrm{C}-\mathrm{F}}=3 \mathrm{~Hz}, \mathrm{C}_{\mathrm{q}}\right), 136.3(\mathrm{CH}), 131.5\left(\mathrm{~d}, \mathrm{~J}_{\mathrm{C}-\mathrm{F}}=8 \mathrm{~Hz}, \mathrm{CH}\right), 124.2(\mathrm{CH}), 121.8(\mathrm{CH}), 116.2\left(\mathrm{~d}, J_{\mathrm{C}-\mathrm{F}}\right.$ $=21 \mathrm{~Hz}, \mathrm{CH}), 112.7\left(\mathrm{~d}, \mathrm{~J}_{\mathrm{C}-\mathrm{F}}=21 \mathrm{~Hz}, \mathrm{CH}\right), 33.1\left(\mathrm{~d}, \mathrm{~J}_{\mathrm{C}-\mathrm{F}}=1 \mathrm{~Hz}, \mathrm{CH}_{2}\right), 31.5\left(\mathrm{CH}_{2}\right), 31.0\left(\mathrm{CH}_{2}\right), 29.1\left(\mathrm{CH}_{2}\right)$, $22.6\left(\mathrm{CH}_{2}\right), 14.1\left(\mathrm{CH}_{3}\right)$.

${ }^{19} \mathrm{~F}-\mathrm{NMR}\left(282 \mathrm{MHz}, \mathrm{CDCl}_{3}\right): \delta=-114.28--114.60(\mathrm{~m})$.

IR (ATR): $\tilde{v}=2955,2926,2856,1608,1588,1465,1427,1269,1150,868,822,565 \mathrm{~cm}^{-1}$. MS (EI) m/z (relative intensity): 257 (42) [M+], 214 (16), 200 (100), 185 (64).

HR-MS (EI) $\mathrm{m} / \mathrm{z}$ calculated for $\mathrm{C}_{17} \mathrm{H}_{20} \mathrm{FN}-\mathrm{H}^{+}$: 256.1502; found: 256.1503. 


\section{Synthesis of 2-(3,4,5-Trifluoro-2-n-octylphenyl)pyridine (93ja)}

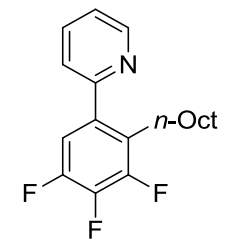

The general procedure $\mathbf{C}$ was followed using 6ja (106 mg, $0.51 \mathrm{mmol})$, 42aa (295 mg, $1.53 \mathrm{mmol})$, $\left[\mathrm{RuCl}_{2}(p \text {-cymene) }]_{2}(7.8 \mathrm{mg}, 2.5 \mathrm{~mol} \%), 1-\mathrm{AdCO}_{2} \mathrm{H}(13 \mathrm{c})(27.6 \mathrm{mg}, 0.15 \mathrm{mmol}, 30 \mathrm{~mol} \%)\right.$ and $\mathrm{K}_{2} \mathrm{CO}_{3}$ (141 mg, $1.02 \mathrm{mmol}$ ) in $m$-xylene $(2.0 \mathrm{~mL})$. Purification by column chromatography ( $n$-hexane/EtOAc 9:1) yielded $93 \mathrm{ja}$ (142 $\mathrm{mg}, 87 \%$ ) as a colorless oil.

The general procedure $\mathbf{C}$ was followed using $6 \mathrm{ja}(103 \mathrm{mg}, 0.49 \mathrm{mmol})$, 42aa (280 mg, $1.45 \mathrm{mmol})$, $\left[\mathrm{RuCl}_{2}(p \text {-cymene) }]_{2}(7.8 \mathrm{mg}, 2.6 \mathrm{~mol} \%), \mathrm{KOAc}\left(320 \mathrm{mg}, 3.26 \mathrm{mmol}, 6.4\right.\right.$ equiv) and $\mathrm{K}_{2} \mathrm{CO}_{3}(138 \mathrm{mg}$, $1.00 \mathrm{mmol}$ ) in $m$-xylene $(2.0 \mathrm{~mL}$ ). Purification by column chromatography ( $n$-hexane/EtOAc 9:1) yielded 93ja (115 mg, 73\%).

${ }^{1} \mathrm{H}-\mathrm{NMR}\left(300 \mathrm{MHz}, \mathrm{CDCl}_{3}\right): \delta=8.74-8.58(\mathrm{~m}, 1 \mathrm{H}), 7.75$ (ddd, $\left.J=7.7,1.8,1.7 \mathrm{~Hz}, 1 \mathrm{H}\right), 7.35-7.17(\mathrm{~m}$, $2 \mathrm{H}), 6.98$ (ddd, $J=10.6,7.2,2.2 \mathrm{~Hz}, 1 \mathrm{H}), 2.76-2.58(\mathrm{~m}, 2 \mathrm{H}), 1.50-1.33(\mathrm{~m}, 2 \mathrm{H}), 1.33-1.01(\mathrm{~m}, 10 \mathrm{H})$, $0.84(t, J=7.5 \mathrm{~Hz}, 3 \mathrm{H})$.

${ }^{13} \mathrm{C}-\mathrm{NMR}\left(75 \mathrm{MHz}, \mathrm{CDCl}_{3}\right) \delta=157.5\left(\mathrm{~d}, J_{\mathrm{C}-\mathrm{F}}=3 \mathrm{~Hz}, \mathrm{C}_{\mathrm{q}}\right.$ ), 151.1 (ddd, $\left.J_{\mathrm{C}-\mathrm{F}}=100,10,4 \mathrm{~Hz}, \mathrm{C}_{\mathrm{q}}\right), 149.5(\mathrm{CH})$ ), 147.8 (ddd, $J=100,10,4 \mathrm{~Hz}, \mathrm{C}_{\mathrm{q}}$ ), 139.8 (ddd, $J_{\mathrm{C}-\mathrm{F}}=252,17,15 \mathrm{~Hz}, \mathrm{C}_{\mathrm{q}}$ ), $136.6(\mathrm{CH}), 136.4-135.7\left(\mathrm{~m}, \mathrm{C}_{\mathrm{q}}\right.$ ), 126.3 (ddd, $\left.J_{C-F}=14,4,1 \mathrm{~Hz}, \mathrm{C}_{\mathrm{q}}\right), 124.0(\mathrm{CH}), 122.6(\mathrm{CH}), 113.3\left(\mathrm{dd}, \mathrm{J}_{\mathrm{C}-\mathrm{F}}=18,4 \mathrm{~Hz}, \mathrm{CH}\right), 31.9\left(\mathrm{CH}_{2}\right)$, $30.1\left(\mathrm{~d}, \mathrm{~J}_{\mathrm{C}-\mathrm{F}}=1 \mathrm{~Hz}, \mathrm{CH}_{2}\right), 29.4\left(\mathrm{CH}_{2}\right), 29.2\left(\mathrm{CH}_{2}\right), 29.1\left(\mathrm{CH}_{2}\right), 25.7\left(\mathrm{t}, \mathrm{J}_{\mathrm{C}-\mathrm{F}}=2 \mathrm{~Hz}, \mathrm{CH}_{2}\right), 22.7\left(\mathrm{CH}_{2}\right), 14.1$ $\left(\mathrm{CH}_{3}\right)$.

${ }^{19}$ F-NMR $\left(282 \mathrm{MHz}, \mathrm{CDCl}_{3}\right): \delta=-136.87--138.10(\mathrm{~m}),-138.75(\mathrm{ddd}, J=21,11,6 \mathrm{~Hz}),-160.99(\mathrm{td}, J=$ $21,7 \mathrm{~Hz})$.

IR (ATR): $\tilde{v}=3059,2955,2925,2855,1567,1515,1425,1359,1151,1035,792,733 \mathrm{~cm}^{-1}$. MS (EI) m/z (relative intensity): $321(41)\left[\mathrm{M}^{+}\right], 292$ (10), 245 (12), 236 (100), 221 (76).

HR-MS (EI) $m / z$ calculated for $\mathrm{C}_{19} \mathrm{H}_{22} \mathrm{~F}_{3} \mathrm{~N}^{+}$: 321.1704; found: 321.1703 . 


\section{Synthesis of 2-(3,4,5-Trifluoro-2-n-hexylphenyl)pyridine (93jb)}

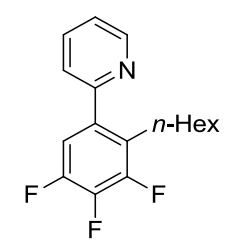

The general procedure $\mathbf{C}$ was followed using $6 \mathrm{ja}$ (105 mg, $0.50 \mathrm{mmol}), 42 \mathrm{ab}(259 \mathrm{mg}, 1.57 \mathrm{mmol})$, $\left[\mathrm{RuCl}_{2}(p \text {-cymene })\right]_{2}(7.6 \mathrm{mg}, 2.5 \mathrm{~mol} \%), \mathrm{KOAc}\left(314 \mathrm{mg}, 3.20 \mathrm{mmol}, 6.4\right.$ equiv) and $\mathrm{K}_{2} \mathrm{CO}_{3}(138 \mathrm{mg}$, $1.00 \mathrm{mmol}$ ) in $m$-xylene $(2.0 \mathrm{~mL}$ ). Purification by column chromatography ( $n$-hexane/EtOAc 9:1) yielded $93 \mathbf{i}(70 \mathrm{mg}, 48 \%)$ as a colorless oil.

${ }^{1} \mathrm{H}-\mathrm{NMR}\left(300 \mathrm{MHz}, \mathrm{CDCl}_{3}\right): \delta=8.67(\mathrm{ddd}, J=4.9,1.9,1.0 \mathrm{~Hz}, 1 \mathrm{H}), 7.76(\mathrm{ddd}, J=7.8,1.9,1.8 \mathrm{~Hz}, 1 \mathrm{H}$ ), 7.39-7.26 (m, 2H), 6.99 (ddd, $J=10.5,7.2,2.2 \mathrm{~Hz}, 1 \mathrm{H}$ ), 2.78-2.59 (m, 2H), 1.41 (ddd, $J=10.0,7.5,5.6$ $\mathrm{Hz}, 2 \mathrm{H}), 1.29-1.04(\mathrm{~m}, 6 \mathrm{H}), 0.81(\mathrm{t}, J=7.7 \mathrm{~Hz}, 3 \mathrm{H})$.

${ }^{13} \mathrm{C}-\mathrm{NMR}\left(75 \mathrm{MHz}, \mathrm{CDCl}_{3}\right): \delta=157.5\left(\mathrm{C}_{\mathrm{q}}\right), 150.5$ (ddd, $\mathrm{J}_{\mathrm{C}-\mathrm{F}}=167,10,4 \mathrm{~Hz}, \mathrm{C}_{\mathrm{q}}$ ), $149.5(\mathrm{CH}), 148.5$ (ddd, $\left.J_{C-F}=168,10,4 \mathrm{~Hz}, C_{q}\right), 139.9\left(\mathrm{ddd}, J_{\mathrm{C}-\mathrm{F}}=252,17,15 \mathrm{~Hz}, \mathrm{C}_{\mathrm{q}}\right.$ ), $136.6(\mathrm{CH}), 136.2\left(\mathrm{dt}, J_{\mathrm{C}-\mathrm{F}}=7,5 \mathrm{~Hz}, \mathrm{C}_{\mathrm{q}}\right.$ ), $126.3\left(\mathrm{ddd}, J_{\mathrm{C}-\mathrm{F}}=14,4,1 \mathrm{~Hz}, \mathrm{C}_{\mathrm{q}}\right.$ ), $124.1(\mathrm{CH}), 122.6(\mathrm{CH}), 113.3\left(\mathrm{dd}, J_{\mathrm{C}-\mathrm{F}}=18,4 \mathrm{~Hz}, \mathrm{CH}\right), 31.4\left(\mathrm{CH}_{2}\right)$, $30.1\left(\mathrm{CH}_{2}\right), 29.1\left(\mathrm{CH}_{2}\right), 25.7\left(\mathrm{CH}_{2}\right), 22.5\left(\mathrm{CH}_{2}\right), 14.1\left(\mathrm{CH}_{3}\right)$.

${ }^{19} \mathrm{~F}-\mathrm{NMR}\left(282 \mathrm{MHz}, \mathrm{CDCl}_{3}\right): \delta=-136.87--138.10(\mathrm{~m}),-138.75$ (ddd, $\left.J=21,11,6 \mathrm{~Hz}\right),-160.99(\mathrm{td}, J=$ $21,7 \mathrm{~Hz})$.

IR (ATR): $\tilde{v}=2957,2928,2857,1515,1468,1443,1359,1117,1059,791,747,665 \mathrm{~cm}^{-1}$.

MS (EI) $m / z$ (relative intensity): $292(24)\left[\mathrm{M}^{+}\right], 250$ (14), 236 (100), 221 (79).

HR-MS (EI) $\mathrm{m} / z$ calculated for $\mathrm{C}_{17} \mathrm{H}_{18} \mathrm{~F}_{3} \mathrm{~N}-\mathrm{H}^{+}:$292.1313; found: 292.1324.

\section{Synthesis of 2-[2-n-Hexyl-4-(trifluoromethyl)phenyl]pyridine (93kb)}<smiles>CC(C)(C)c1ccc(-c2ccccn2)c(C(C)(F)F)c1</smiles>

The general procedure C was followed using $6 \mathbf{k a}(113 \mathrm{mg}, 0.51 \mathrm{mmol}), 42 \mathrm{ab}(243 \mathrm{mg}, 1.47 \mathrm{mmol})$, $\left[\mathrm{RuCl}_{2}(p \text {-cymene })\right]_{2}(7.8 \mathrm{mg}, 2.5 \mathrm{~mol} \%), 1-\mathrm{AdCO}_{2} \mathrm{H}(\mathbf{1 3 c})(28 \mathrm{mg}, 0.15 \mathrm{mmol}, 30 \mathrm{~mol} \%)$ and $\mathrm{K}_{2} \mathrm{CO}_{3}$ (141 mg, $1.02 \mathrm{mmol})$ in $m$-xylene $(2.0 \mathrm{~mL}$ ). Purification by column chromatography ( $n$-hexane/EtOAc 5:1) yielded 93ka (119 $\mathrm{mg}, 76 \%$ ) as a colorless oil. 
${ }^{1} \mathrm{H}-\mathrm{NMR}\left(300 \mathrm{MHz}, \mathrm{CDCl}_{3}\right): \delta=8.79-8.56(\mathrm{~m}, 1 \mathrm{H}), 7.77$ (ddd, $\left.J=7.7,2.1,0.9 \mathrm{~Hz}, 1 \mathrm{H}\right), 7.59-7.21(\mathrm{~m}$, $5 \mathrm{H}), 2.80-2.64(\mathrm{~m}, 2 \mathrm{H}), 1.56-1.34(\mathrm{~m}, 2 \mathrm{H}), 1.31-1.04(\mathrm{~m}, 6 \mathrm{H}), 0.81(\mathrm{t}, J=7.7 \mathrm{~Hz}, 3 \mathrm{H})$.

${ }^{13} \mathrm{C}$-NMR $\left(75 \mathrm{MHz}, \mathrm{CDCl}_{3}\right): \delta=158.9\left(\mathrm{C}_{\mathrm{q}}\right), 149.3(\mathrm{CH}), 143.6\left(\mathrm{C}_{\mathrm{q}}\right), 141.8\left(\mathrm{C}_{\mathrm{q}}\right), 136.3(\mathrm{CH}), 130.5\left(\mathrm{q}, \mathrm{J}_{\mathrm{C}-\mathrm{F}}=\right.$ $32 \mathrm{~Hz}, \mathrm{C}_{\mathrm{q}}$ ), $130.1(\mathrm{CH}), 126.4$ (d, J = $4 \mathrm{~Hz}, \mathrm{CH}$ ), 124.2 (q, J J-F $=272 \mathrm{~Hz}, \mathrm{C}_{\mathrm{q}}$ ), $123.9(\mathrm{CH}), 122.5$ (d, J = $4 \mathrm{~Hz}$, $\mathrm{CH}), 122.2(\mathrm{CH}), 32.9\left(\mathrm{CH}_{2}\right), 31.4\left(\mathrm{CH}_{2}\right), 30.9\left(\mathrm{CH}_{2}\right), 29.0\left(\mathrm{CH}_{2}\right), 22.4\left(\mathrm{CH}_{2}\right), 13.9\left(\mathrm{CH}_{3}\right)$.

${ }^{19} \mathrm{~F}-\mathrm{NMR}\left(282 \mathrm{MHz}, \mathrm{CDCl}_{3}\right): \delta=-62.55(\mathrm{~s})$.

IR (ATR): $\tilde{v}=2956,2928,2858,1587,1505,1328,1162,1120,1091,791 \mathrm{~cm}^{-1}$.

MS (ESI) m/z (relative intensity): 637 (20) [2×M+Na $\left.{ }^{+}\right], 615$ (80), 308 (100), 204 (26).

HR-MS (ESI) $\mathrm{m} / \mathrm{z}$ calculated for $\mathrm{C}_{18} \mathrm{H}_{20} \mathrm{~F}_{3} \mathrm{~N}+\mathrm{H}^{+}: 308.1621$; found: 308.1625 .

\section{Synthesis of 2-[2-n-Hexyl-5-(trifluoromethyl)phenyl]pyridine $(93 \mathrm{mb})$}<smiles>CCCCCCCCCCCc1ccc(C(F)(F)F)cc1-c1ccccn1</smiles>

The general procedure $C$ was followed using $6 \mathrm{ma}(110 \mathrm{mg}, 0.49 \mathrm{mmol}), 42 \mathrm{ab}(246 \mathrm{mg}, 1.49 \mathrm{mmol})$, $\left[\mathrm{RuCl}_{2}(p \text {-cymene })\right]_{2}(7.5 \mathrm{mg}, 2.5 \mathrm{~mol} \%), 1-\mathrm{AdCO}_{2} \mathrm{H}(\mathbf{1 3 c})(28 \mathrm{mg}, 0.15 \mathrm{mmol}, 31 \mathrm{~mol} \%)$ and $\mathrm{K}_{2} \mathrm{CO}_{3}$ $(138 \mathrm{mg}, 1.00 \mathrm{mmol})$ in $m$-xylene $(2.0 \mathrm{~mL})$. Purification by column chromatography ( $n$-hexane/EtOAc $5: 1$ ) yielded $93 f(79 \mathrm{mg}, 52 \%)$ as a colorless oil.

${ }^{1} \mathrm{H}-\mathrm{NMR}\left(300 \mathrm{MHz}, \mathrm{CDCl}_{3}\right): \delta=8.77-8.62(\mathrm{~m}, 1 \mathrm{H}), 7.75(\mathrm{td}, J=7.7,1.8 \mathrm{~Hz}, 1 \mathrm{H}), 7.63-7.49(\mathrm{~m}, 2 \mathrm{H}), 7.38$ (t, $J=7.3 \mathrm{~Hz}, 2 \mathrm{H}), 7.32-7.18(\mathrm{~m}, 1 \mathrm{H}), 2.72(\mathrm{dd}, J=9.1,6.7 \mathrm{~Hz}, 2 \mathrm{H}), 1.57-1.34(\mathrm{~m}, 2 \mathrm{H}), 1.27-1.02(\mathrm{~m}$, $6 \mathrm{H}), 0.80(\mathrm{t}, J=6.6 \mathrm{~Hz}, 3 \mathrm{H})$.

${ }^{13} \mathrm{C}-\mathrm{NMR}\left(75 \mathrm{MHz}, \mathrm{CDCl}_{3}\right): \delta=159.0\left(\mathrm{C}_{\mathrm{q}}\right), 149.5(\mathrm{CH}), 145.2\left(\mathrm{~d}, \mathrm{~J}_{\mathrm{C}-\mathrm{F}}=2 \mathrm{~Hz}, \mathrm{C}_{\mathrm{q}}\right), 140.9\left(\mathrm{C}_{\mathrm{q}}\right), 136.5(\mathrm{CH})$, $130.3(\mathrm{CH}), 128.2\left(\mathrm{q}, J_{\mathrm{C}-\mathrm{F}}=32 \mathrm{~Hz}, \mathrm{C}_{\mathrm{q}}\right), 126.8\left(\mathrm{q}, J_{\mathrm{C}-\mathrm{F}}=4 \mathrm{~Hz}, \mathrm{CH}\right), 125.0$ (q, J $\left.\mathrm{J}_{\mathrm{C}-\mathrm{F}}=4 \mathrm{~Hz}, \mathrm{CH}\right), 124.4$ (q, J J-F $=$ $273 \mathrm{~Hz}, \mathrm{C} q), 124.2(\mathrm{CH}), 122.3(\mathrm{CH}), 33.0\left(\mathrm{CH}_{2}\right), 31.5\left(\mathrm{CH}_{2}\right), 31.1\left(\mathrm{CH}_{2}\right), 29.1\left(\mathrm{CH}_{2}\right), 22.6\left(\mathrm{CH}_{2}\right), 14.1$ $\left(\mathrm{CH}_{3}\right)$.

${ }^{19}$ F-NMR $\left(282 \mathrm{MHz}, \mathrm{CDCl}_{3}\right): \delta=-62.30(\mathrm{~s})$.

IR (ATR): $\tilde{v}=2956,2928,2857,1467,1334,1259,1119,1057,747 \mathrm{~cm}^{-1}$.

MS (ESI) $m / z$ (relative intensity): 637 (81) [2×M+Na+], 616 (100), 330 (64), 308 (54).

HR-MS (ESI) $\mathrm{m} / \mathrm{z}$ calculated for $\mathrm{C}_{18} \mathrm{H}_{20} \mathrm{~F}_{3} \mathrm{~N}+\mathrm{H}^{+}: 308.1621$; found: 308.1619 . 


\section{Synthesis of 2-(2-n-Hexyl-4-methylphenyl)pyridine (93ob)}

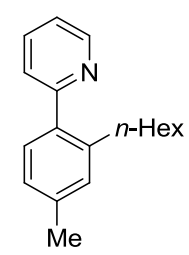

The general procedure $\mathbf{C}$ was followed using $60 \mathrm{a}(88.5 \mathrm{mg}, 0.52 \mathrm{mmol})$, 42ab (250 mg, $1.51 \mathrm{mmol})$ and $\left[\mathrm{RuCl}_{2}(p \text {-cymene })\right]_{2}(8.0 \mathrm{mg}, 2.5 \mathrm{~mol} \%), \mathrm{KOAc}(319 \mathrm{mg}, 3.25 \mathrm{mmol})$ and $\mathrm{K}_{2} \mathrm{CO}_{3}(143 \mathrm{mg}$, $1.04 \mathrm{mmol}$ ) in $m$-xylene $(2.0 \mathrm{~mL}$ ). Purification by column chromatography ( $n$-hexane/EtOAc 9:1) yielded $930 b$ ( $20 \mathrm{mg}, 15 \%$ ) as a colorless oil.

${ }^{1} \mathrm{H}-\mathrm{NMR}\left(300 \mathrm{MHz}, \mathrm{CDCl}_{3}\right): \delta=8.66(\mathrm{ddd}, J=4.9,1.8,0.9 \mathrm{~Hz}, 1 \mathrm{H}), 7.70(\mathrm{dt}, J=7.7,1.9 \mathrm{~Hz}, 1 \mathrm{H}), 7.34$ $(\mathrm{td}, J=7.8,1.0 \mathrm{~Hz}, 1 \mathrm{H}), 7.25-7.17(\mathrm{~m}, 2 \mathrm{H}), 7.12-7.03(\mathrm{~m}, 2 \mathrm{H}), 2.66(\mathrm{dd}, J=8.1,7.8 \mathrm{~Hz}, 2 \mathrm{H}), 2.36(\mathrm{~s}$, $3 \mathrm{H}), 1.48-1.37(\mathrm{~m}, 2 \mathrm{H}), 1.26-1.10(\mathrm{~m}, 6 \mathrm{H}), 0.81(\mathrm{t}, J=6.5 \mathrm{~Hz}, 3 \mathrm{H})$.

${ }^{13} \mathrm{C}$-NMR $\left(75 \mathrm{MHz}, \mathrm{CDCl}_{3}\right): \delta=160.3\left(\mathrm{C}_{\mathrm{q}}\right), 149.0(\mathrm{CH}), 140.6\left(\mathrm{C}_{\mathrm{q}}\right), 137.9\left(\mathrm{C}_{\mathrm{q}}\right), 137.5\left(\mathrm{C}_{\mathrm{q}}\right), 135.9(\mathrm{CH})$, $130.4(\mathrm{CH}), 129.7(\mathrm{CH}), 126.4(\mathrm{CH}), 124.1(\mathrm{CH}), 121.3(\mathrm{CH}), 32.9\left(\mathrm{CH}_{2}\right), 31.5\left(\mathrm{CH}_{2}\right), 31.3\left(\mathrm{CH}_{2}\right), 29.1$ $\left(\mathrm{CH}_{2}\right), 22.5\left(\mathrm{CH}_{2}\right), 21.2\left(\mathrm{CH}_{3}\right), 14.0\left(\mathrm{CH}_{3}\right)$.

IR (ATR): $\tilde{v}=2954,2925,2855,1613,1586,1466,1426,1026,823,787,748 \mathrm{~cm}^{-1}$.

MS (EI) m/z (relative intensity): 253 (20) [M+], 210 (4), 196 (100), 181 (45), 167 (10), 97 (5).

HR-MS (ESI) $m / z$ calculated for $\mathrm{C}_{18} \mathrm{H}_{23} \mathrm{~N}+\mathrm{H}^{+}: 254.1909$; found: 254.1902.

The analytical data are in accordance with those reported in the literature.Fehler! Textmarke nicht efiniert.

\section{Synthesis of 1-[6-(2-n-Hexylphenyl)pyridin-3-yl]ethanone (94bb)}<smiles>CCCCCCCc1ccccc1-c1ccc(C(C)=O)cn1</smiles>

The general procedure $\mathbf{C}$ was followed using $6 \mathrm{bb}(94.5 \mathrm{mg}, 0.48 \mathrm{mmol}), 42 \mathrm{ab}(235 \mathrm{mg}, 1.42 \mathrm{mmol})$, $\left[\mathrm{RuCl}_{2}(p \text {-cymene) }]_{2}(7.8 \mathrm{mg}, 2.7 \mathrm{~mol} \%), 1-\mathrm{AdCO}_{2} \mathrm{H}(\mathbf{1 3 c})(28 \mathrm{mg}, 0.15 \mathrm{mmol}, 31 \mathrm{~mol} \%)\right.$ and $\mathrm{K}_{2} \mathrm{CO}_{3}$ (133 $\mathrm{mg}, 0.96 \mathrm{mmol})$ in $\mathrm{m}$-xylene $(2.0 \mathrm{~mL}$ ). Purification by column chromatography ( $n$-hexane/EtOAc $3: 2$ ) yielded $94 \mathrm{bb}(81 \mathrm{mg}, 60 \%)$ as a light brown oil. 
The general procedure $\mathbf{C}$ was followed using 1-[6-(2-hexylphenyl)-pyridin-3-yl]-ethanol (125b) (101 mg, $0.51 \mathrm{mmol}), 42 \mathrm{ab}$ (253 mg, $1.53 \mathrm{mmol}),\left[\mathrm{RuCl}_{2}(p \text {-cymene) }]_{2}(7.8 \mathrm{mg}, 2.5 \mathrm{~mol} \%), 1-\mathrm{AdCO}_{2} \mathrm{H}\right.$ (13c) $(28 \mathrm{mg}, 0.15 \mathrm{mmol}, 30 \mathrm{~mol} \%)$ and $\mathrm{K}_{2} \mathrm{CO}_{3}(141 \mathrm{mg}, 1.02 \mathrm{mmol})$ in $m$-xylene $(2.0 \mathrm{~mL})$. Purification by column chromatography ( $n$-hexane/EtOAc 5:1 to $1: 1$ ) yielded $94 \mathbf{b b}(15 \mathrm{mg}, 10 \%)$.

${ }^{1} \mathrm{H}-\mathrm{NMR}\left(300 \mathrm{MHz}, \mathrm{CDCl}_{3}\right): \delta=9.21(\mathrm{dd}, J=2.3,0.9 \mathrm{~Hz}, 1 \mathrm{H}), 8.27(\mathrm{dd}, J=8.2,2.3 \mathrm{~Hz}, 1 \mathrm{H}), 7.48(\mathrm{dd}, J=$ 8.2, 0.9 Hz, $1 \mathrm{H}), 7.40-7.17(\mathrm{~m}, 4 \mathrm{H}), 2.77-2.58(\mathrm{~m}, 5 \mathrm{H}), 1.55-1.35(\mathrm{~m}, 2 \mathrm{H}), 1.26-1.05(\mathrm{~m}, 6 \mathrm{H}), 0.79(\mathrm{t}, J=$ $6.8 \mathrm{~Hz}, 3 \mathrm{H})$.

${ }^{13} \mathrm{C}$-NMR $\left(75 \mathrm{MHz}, \mathrm{CDCl}_{3}\right): \delta=196.7\left(\mathrm{C}_{\mathrm{q}}\right), 164.5\left(\mathrm{C}_{\mathrm{q}}\right), 149.6(\mathrm{CH}), 141.1\left(\mathrm{C}_{\mathrm{q}}\right), 139.4\left(\mathrm{C}_{\mathrm{q}}\right), 135.8(\mathrm{CH})$, $130.3\left(\mathrm{C}_{\mathrm{q}}\right), 130.1(\mathrm{CH}), 129.8(\mathrm{CH}), 129.1(\mathrm{CH}), 126.0(\mathrm{CH}), 124.1(\mathrm{CH}), 33.1\left(\mathrm{CH}_{2}\right), 31.6\left(\mathrm{CH}_{2}\right), 31.4$ $\left(\mathrm{CH}_{2}\right), 29.2\left(\mathrm{CH}_{2}\right), 26.8\left(\mathrm{CH}_{2}\right), 22.6\left(\mathrm{CH}_{2}\right), 14.1\left(\mathrm{CH}_{3}\right)$.

IR (ATR): $\tilde{v}=2954,2925,2855,1686,1588,1550,1466,1371,1259,1087,750 \mathrm{~cm}^{-1}$.

MS (EI) m/z (relative intensity): 281 (26) [M+1, 238 (10), 224 (100), 209 (30), 180 (10), 167 (14).

HR-MS (EI) $m / z$ calculated for $\mathrm{C}_{19} \mathrm{H}_{23} \mathrm{NO}^{+}: 281.1780$; found: 281.1777 .

\section{Synthesis of 1-(2-n-Octylphenyl)-1H-pyrazole (118a)}

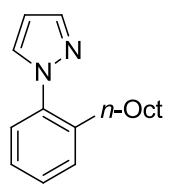

The general procedure $\mathbf{C}$ was followed using $87 \mathrm{a}(72.1 \mathrm{mg}, 0.50 \mathrm{mmol})$, 42aa $(296 \mathrm{mg}, 1.53 \mathrm{mmol})$, $\mathrm{RuCl}_{2}(p \text {-cymene) }]_{2}(7.9 \mathrm{mg}, 2.6 \mathrm{~mol} \%), 1-\mathrm{AdCO}_{2} \mathrm{H}(13 \mathrm{c})(27.7 \mathrm{mg}, 0.15 \mathrm{mmol}, 30 \mathrm{~mol} \%)$ and $\mathrm{K}_{2} \mathrm{CO}_{3}$ (139 mg, $1.01 \mathrm{mmol}$ ) in $\mathrm{H}_{2} \mathrm{O}(2.0 \mathrm{~mL})$. Purification by column chromatography ( $n$-hexane/EtOAc 9:1) yielded 118 a ( $85 \mathrm{mg}, 62 \%$ ) as a colorless oil.

${ }^{1} \mathrm{H}-\mathrm{NMR}\left(300 \mathrm{MHz}, \mathrm{CDCl}_{3}\right): \delta=7.69(\mathrm{~d}, J=1.9 \mathrm{~Hz}, 1 \mathrm{H}), 7.55(\mathrm{~d}, J=2.3 \mathrm{~Hz}, 1 \mathrm{H}), 7.37-7.28(\mathrm{~m}, 2 \mathrm{H}), 7.29-$ $7.20(\mathrm{~m}, 2 \mathrm{H}), 6.41(\mathrm{dd}, J=2.1,2.1 \mathrm{~Hz}, 1 \mathrm{H}), 2.56-2.44(\mathrm{~m}, 2 \mathrm{H}), 1.40(\mathrm{~s}, 1 \mathrm{H}), 1.19(\mathrm{~d}, J=4.6 \mathrm{~Hz}, 11 \mathrm{H})$, $0.85(\mathrm{t}, J=6.8 \mathrm{~Hz}, 3 \mathrm{H})$.

${ }^{13} \mathrm{C}-\mathrm{NMR}\left(75 \mathrm{MHz}, \mathrm{CDCl}_{3}\right): \delta=140.2(\mathrm{CH}), 139.8\left(\mathrm{C}_{\mathrm{q}}\right), 139.1\left(\mathrm{C}_{\mathrm{q}}\right), 130.8(\mathrm{CH}), 130.4(\mathrm{CH}), 128.7(\mathrm{CH})$, $126.7(\mathrm{CH}), 126.5(\mathrm{CH}), 106.2(\mathrm{CH}), 31.9\left(\mathrm{CH}_{2}\right), 31.4\left(\mathrm{CH}_{2}\right), 30.7\left(\mathrm{CH}_{2}\right), 29.5\left(\mathrm{CH}_{2}\right), 29.3\left(\mathrm{CH}_{2}\right), 29.2$ $\left(\mathrm{CH}_{2}\right), 22.8\left(\mathrm{CH}_{2}\right), 14.2\left(\mathrm{CH}_{3}\right)$.

IR (ATR): $\tilde{v}=2953,2923,2854,1516,1456,1393,1043,938,746,623 \mathrm{~cm}^{-1}$. MS (El) m/z (relative intensity): 256 (24) [M+], 185 (10), 171 (100), 158 (19), 130 (17).

HR-MS (EI) $m / z$ calculated for $\mathrm{C}_{17} \mathrm{H}_{24} \mathrm{~N}_{2}-\mathrm{H}^{+}$: 255.1861; found: 255.1860 . 


\section{Synthesis of 1-(2-n-Hexyl-4-methoxyphenyl)-1H-pyrazole (118b)}

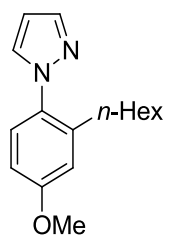

The general procedure $\mathbf{C}$ was followed using $87 \mathrm{~b}(86.9 \mathrm{mg}, 0.50 \mathrm{mmol}), 42 \mathrm{ab}(237 \mathrm{mg}, 1.44 \mathrm{mmol})$, $\left[\operatorname{RuCl}_{2}(p \text {-cymene) }]_{2}(7.3 \mathrm{mg}, 2.4 \mathrm{~mol} \%), \mathrm{KOAc}\left(314 \mathrm{mg}, 3.2 \mathrm{mmol}, 6.4\right.\right.$ equiv) and $\mathrm{K}_{2} \mathrm{CO}_{3}(138 \mathrm{mg}$, $1.00 \mathrm{mmol}$ ) in $\mathrm{m}$-xylene $(2.0 \mathrm{~mL}$ ). Purification by column chromatography ( $n$-hexane/EtOAc 9:1) yielded $118 \mathrm{~b}(67 \mathrm{mg}, 52 \%)$ as a colorless oil.

${ }^{1} \mathrm{H}-\mathrm{NMR}\left(300 \mathrm{MHz}, \mathrm{CDCl}_{3}\right): \delta=7.68(\mathrm{~d}, J=1.8 \mathrm{~Hz}, 1 \mathrm{H}), 7.51(\mathrm{dd}, J=2.3,0.6 \mathrm{~Hz}, 1 \mathrm{H}), 7.20(\mathrm{~d}, J=8.6 \mathrm{~Hz}$, $1 \mathrm{H}), 6.83(\mathrm{~d}, J=2.8 \mathrm{~Hz}, 1 \mathrm{H}), 6.77(\mathrm{dd}, J=8.6,2.9 \mathrm{~Hz}, 1 \mathrm{H}), 6.40(\mathrm{dd}, J=2.1,2.0 \mathrm{~Hz}, 1 \mathrm{H}), 3.83(\mathrm{~s}, 3 \mathrm{H})$, 2.51-2.40 (m, 2H), 1.51-1.33 (m, 2H), 1.33-1.08 (m, 6H), $0.83(\mathrm{t}, J=7.5 \mathrm{~Hz}, 3 \mathrm{H})$.

${ }^{13} \mathrm{C}-\mathrm{NMR}\left(75 \mathrm{MHz}, \mathrm{CDCl}_{3}\right): \delta=159.7\left(\mathrm{C}_{\mathrm{q}}\right), 140.9\left(\mathrm{C}_{\mathrm{q}}\right), 140.0(\mathrm{CH}), 133.2\left(\mathrm{C}_{\mathrm{q}}\right), 131.1(\mathrm{CH}), 128.0(\mathrm{CH})$, $115.4(\mathrm{CH}), 111.4(\mathrm{CH}), 105.9(\mathrm{CH}), 55.6\left(\mathrm{CH}_{2}\right), 31.6\left(\mathrm{CH}_{2}\right), 31.6\left(\mathrm{CH}_{2}\right), 30.6\left(\mathrm{CH}_{2}\right), 29.2\left(\mathrm{CH}_{2}\right), 22.6$ $\left(\mathrm{CH}_{2}\right), 14.1\left(\mathrm{CH}_{3}\right)$.

IR (ATR): $\tilde{v}=2955,2927,2856,1503,1464,1235,1041,943,810,747,612 \mathrm{~cm}^{-1}$.

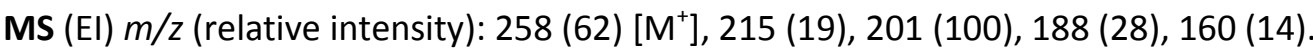
HR-MS (ESI) $m / z$ calculated for $\mathrm{C}_{16} \mathrm{H}_{22} \mathrm{~N}_{2} \mathrm{O}^{+}$: 258.1732; found: 258.1731 .

\section{Synthesis of $\boldsymbol{N}$-\{1-[4-Fluoro-2-(hex-5-en-1-yl)phenyl]ethyl\}-4-methoxyaniline (122a)}

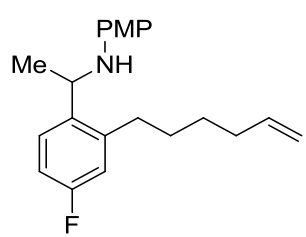

The general procedure $\mathbf{D}$ was followed using 4-flouro- $N$-(1-phenylethylidene)-aniline (121a) (124 mg, $0.51 \mathrm{mmol}), 1$-bromohex-5-ene (32f) $(247 \mathrm{mg}, 1.51 \mathrm{mmol}),\left[\mathrm{RuCl}_{2}(p \text {-cymene) }]_{2}\right.$ (7.8 mg, $\left.2.5 \mathrm{~mol} \%\right), 1$ $\mathrm{AdCO}_{2} \mathrm{H}(13 \mathrm{c})(28 \mathrm{mg}, 0.15 \mathrm{mmol}, 30 \mathrm{~mol} \%)$ in $m$-xylene $(2.0 \mathrm{~mL})$. Reduction and purification by column chromato-graphy ( $n$-hexane/EtOAc 9:1) yielded 122a (104 mg, 62\%) as a red oil. 
${ }^{1} \mathrm{H}-\mathrm{NMR}\left(300 \mathrm{MHz}, \mathrm{CDCl}_{3}\right): \delta=7.45(\mathrm{dd}, J=8.5,6.0 \mathrm{~Hz}, 1 \mathrm{H}), 6.95-6.76(\mathrm{~m}, 2 \mathrm{H}), 6.76-6.59(\mathrm{~m}, 2 \mathrm{H}), 6.46$ $(\mathrm{d}, J=9.1 \mathrm{~Hz}, 2 \mathrm{H}), 5.82(\mathrm{ddt}, J=16.9,10.1,6.7 \mathrm{~Hz}, 1 \mathrm{H}), 5.14-4.85(\mathrm{~m}, 2 \mathrm{H}), 4.61(\mathrm{q}, J=6.6 \mathrm{~Hz}, 1 \mathrm{H}), 3.71$ $(\mathrm{s}, 3 \mathrm{H}), 2.70(\mathrm{td}, J=7.3,3.9 \mathrm{~Hz}, 2 \mathrm{H}), 2.23-1.99(\mathrm{~m}, 3 \mathrm{H}), 1.81-1.59(\mathrm{~m}, 2 \mathrm{H}), 1.59-1.41(\mathrm{~m}, 5 \mathrm{H})$.

${ }^{13} \mathrm{C}$-NMR $\left(75 \mathrm{MHz}, \mathrm{CDCl}_{3}\right): \delta=161.8\left(\mathrm{~d}, \mathrm{~J}_{\mathrm{C}-\mathrm{F}}=244 \mathrm{~Hz}, \mathrm{C}_{\mathrm{q}}\right), 152.5\left(\mathrm{C}_{\mathrm{q}}\right), 141.7\left(\mathrm{~d}, J_{\mathrm{C}-\mathrm{F}}=7 \mathrm{~Hz}, \mathrm{C}_{\mathrm{q}}\right), 140.7$ $\left(\mathrm{C}_{\mathrm{q}}\right), 138.7(\mathrm{CH}), 137.9\left(\mathrm{C}_{\mathrm{q}}\right), 130.7(\mathrm{CH}), 127.0\left(\mathrm{~d}, \mathrm{~J}_{\mathrm{C}-\mathrm{F}}=8 \mathrm{~Hz}, \mathrm{CH}\right), 125.9(\mathrm{CH}), 116.0\left(\mathrm{~d}, J_{\mathrm{C}-\mathrm{F}}=21 \mathrm{~Hz}, \mathrm{CH}\right)$, $115.1(\mathrm{CH}), 114.9(\mathrm{CH}), 114.8\left(\mathrm{CH}_{2}\right), 113.3\left(\mathrm{~d}, \mathrm{~J}_{\mathrm{C}-\mathrm{F}}=21 \mathrm{~Hz}, \mathrm{CH}\right), 55.8\left(\mathrm{CH}_{3}\right), 50.4(\mathrm{CH}), 33.7\left(\mathrm{CH}_{2}\right), 32.0$ $\left(\mathrm{CH}_{2}\right), 30.4\left(\mathrm{CH}_{2}\right), 29.0\left(\mathrm{CH}_{2}\right), 24.1\left(\mathrm{CH}_{3}\right)$.

${ }^{19} \mathrm{~F}-\mathrm{NMR}\left(282 \mathrm{MHz}, \mathrm{CDCl}_{3}\right) \delta=-116.75(\mathrm{~s})$.

MS (EI) m/z (relative intensity): 327 (10) [M+], 150 (28), 137 (57), 123 (100), 108 (24), 55 (23).

HR-MS (EI) $m / z$ calculated for $\mathrm{C}_{21} \mathrm{H}_{26} \mathrm{FNO}^{+}: 327.1998$; found: 327.2000 .

\section{Synthesis of $N$-[1-(3-Fluoro-2-n-hexylphenyl)ethyl]-4-methoxyaniline (122b)}<smiles>CC(NP)c1cccc(F)c1C=O</smiles>

The general procedure D was followed using $N$-[1-(3-fluorophenyl)ethylidene]-4-methoxyaniline (121b) (122 mg, $0.50 \mathrm{mmol}), 42 \mathrm{ab}(244 \mathrm{mg}, 1.48 \mathrm{mmol}),\left[\mathrm{RuCl}_{2}(p \text {-cymene) }]_{2}(7.7 \mathrm{mg}, 2.5 \mathrm{~mol} \%), 1-\right.$ $\mathrm{AdCO}_{2} \mathrm{H}(13 \mathrm{c})(27 \mathrm{mg}, 0.15 \mathrm{mmol}, 30 \mathrm{~mol} \%)$ in $m$-xylene $(2.0 \mathrm{~mL})$. Purification by column chromatography ( $n$-hexane/EtOAc 9:1) yielded 122b (122 mg, 74\%) as a colorless oil.

${ }^{1} \mathrm{H}-\mathrm{NMR}\left(300 \mathrm{MHz}, \mathrm{CDCl}_{3}\right): \delta=7.26(\mathrm{~d}, J=7.7 \mathrm{~Hz}, 1 \mathrm{H}), 7.11(\mathrm{dd}, J=8.3,6.1 \mathrm{~Hz}, 1 \mathrm{H}), 6.90$ (ddd, $J=8.3$, 1.7, $1.7 \mathrm{~Hz}, 1 \mathrm{H}), 6.71(\mathrm{~d}, J=8.9 \mathrm{~Hz}, 2 \mathrm{H}), 6.44(\mathrm{~d}, J=8.9 \mathrm{~Hz}, 2 \mathrm{H}), 4.64(\mathrm{q}, J=6.6 \mathrm{~Hz}, 1 \mathrm{H}), 3.71(\mathrm{~s}, 3 \mathrm{H})$, 2.87-2.64 (m, 2H), 1.74-1.55 (m, 2H), 1.53-1.23 (m, 9H), $0.92(\mathrm{t}, J=7.0 \mathrm{~Hz}, 3 \mathrm{H})$.

$(\mathrm{N}-\mathrm{H}$ was not detected)

${ }^{13} \mathrm{C}$-NMR $\left(75 \mathrm{MHz}, \mathrm{CDCl}_{3}\right): \delta=161.3\left(\mathrm{~d}, \mathrm{~J}_{\mathrm{C}-\mathrm{F}}=243 \mathrm{~Hz}, \mathrm{C}_{\mathrm{q}}\right), 151.9\left(\mathrm{C}_{\mathrm{q}}\right), 145.0\left(\mathrm{C}_{\mathrm{q}}\right), 141.2\left(\mathrm{C}_{\mathrm{q}}\right), 127.2(\mathrm{~d}$, $\left.J_{C-F}=8 \mathrm{~Hz}, \mathrm{CH}\right), 126.8\left(\mathrm{~d}, J_{\mathrm{C}-\mathrm{F}}=16 \mathrm{~Hz}, \mathrm{C}_{\mathrm{q}}\right), 120.4(2 \times \mathrm{CH}), 114.7(2 \times \mathrm{CH}), 114.4(\mathrm{CH}), 113.4\left(\mathrm{~d}, J_{\mathrm{C}-\mathrm{F}}=22 \mathrm{~Hz}\right.$, $\mathrm{CH}), 55.7\left(\mathrm{CH}_{3}\right), 50.2(\mathrm{CH}), 31.7\left(\mathrm{CH}_{2}\right), 30.4\left(\mathrm{CH}_{2}\right), 29.7\left(\mathrm{CH}_{2}\right), 24.9\left(\mathrm{CH}_{2}\right), 24.3\left(\mathrm{CH}_{3}\right), 22.7\left(\mathrm{CH}_{2}\right), 14.1$ $\left(\mathrm{CH}_{3}\right)$.

${ }^{19}$ F-NMR $\left(282 \mathrm{MHz}, \mathrm{CDCl}_{3}\right): \delta=-117.75--117.54(\mathrm{~m})$.

IR (ATR): $\tilde{v}=3403,2960,2930,2871,2859,2244,1579,1512,1464,1238,1040,910,739 \mathrm{~cm}^{-1}$. MS (EI) m/z (relative intensity): 329 (17) [M+], 314 (18), 150 (12), 136 (47), 123 (100), 108 (25).

HR-MS (ESI) $\mathrm{m} / \mathrm{z}$ calculated for $\mathrm{C}_{21} \mathrm{H}_{28} \mathrm{FNO}+\mathrm{H}^{+}$: 330.2233; found: 330.2227 . 
Synthesis of $N$-[1-(2-n-Hexyl-5-methoxyphenyl)ethyl]-4-methoxyaniline (122c) and $N$-[1-(2-n-Hexyl3-methoxyphenyl)ethyl]-4-methoxyaniline (122c')

The general procedure D was followed using 4-methoxy- $N$-[1-(3-methoxyphenyl)ethylidene]aniline (121c) (117 mg, $0.46 \mathrm{mmol}), 42 \mathrm{ab}$ (248 mg, $1.50 \mathrm{mmol}),\left[\mathrm{RuCl}_{2}(p-\text { cymene })\right]_{2}(7.0 \mathrm{mg}, 2.5 \mathrm{~mol} \%), 1-$ $\mathrm{AdCO}_{2} \mathrm{H}(13 \mathrm{c})(24.9 \mathrm{mg}, 0.138 \mathrm{mmol}, 30 \mathrm{~mol} \%)$ in $m$-xylene $(2.0 \mathrm{~mL})$. Purification by column chromatography ( $n$-hexane/EtOAc 9:1) yielded 122c (60 mg, 38\%) and 122c (31 mg, 20\%) as colorless oils.<smiles>COc1ccc(C)c(C(C)NPC(=O)c2ccccc2)c1</smiles>

(122c)

${ }^{1} \mathrm{H}-\mathrm{NMR}\left(300 \mathrm{MHz}, \mathrm{CDCl}_{3}\right): \delta=7.09(\mathrm{~d}, J=8.7 \mathrm{~Hz}, 1 \mathrm{H}), 7.02(\mathrm{~d}, J=2.8 \mathrm{~Hz}, 1 \mathrm{H}), 6.72(\mathrm{dd}, J=8.7,2.8 \mathrm{~Hz}$, $1 \mathrm{H}), 6.68(\mathrm{~d}, J=8.9 \mathrm{~Hz}, 2 \mathrm{H}), 6.43(\mathrm{~d}, J=8.9 \mathrm{~Hz}, 2 \mathrm{H}), 4.60(\mathrm{q}, J=6.6 \mathrm{~Hz}, 1 \mathrm{H}), 3.73(\mathrm{~s}, 3 \mathrm{H}), 3.69(\mathrm{~s}, 3 \mathrm{H})$, $2.66(\mathrm{dt}, J=8.7,4.2 \mathrm{~Hz}, 2 \mathrm{H}), 1.71-1.56(\mathrm{~m}, 2 \mathrm{H}), 1.45(\mathrm{~d}, J=6.6 \mathrm{~Hz}, 3 \mathrm{H}), 1.43-1.23(\mathrm{~m}, 6 \mathrm{H}), 0.91(\mathrm{t}, J=$ $6.9 \mathrm{~Hz}, 3 \mathrm{H})$.

${ }^{13} \mathrm{C}$-NMR $\left(75 \mathrm{MHz}, \mathrm{CDCl}_{3}\right): \delta=158.1\left(\mathrm{C}_{\mathrm{q}}\right), 151.7\left(\mathrm{C}_{\mathrm{q}}\right), 144.0\left(\mathrm{C}_{\mathrm{q}}\right), 141.5\left(\mathrm{C}_{\mathrm{q}}\right), 131.3\left(\mathrm{C}_{\mathrm{q}}\right), 130.4(\mathrm{CH})$, $114.7(\mathrm{CH}), 114.3(\mathrm{CH}), 111.6(\mathrm{CH}), 110.6(\mathrm{CH}), 55.7\left(\mathrm{CH}_{3}\right), 55.1\left(\mathrm{CH}_{3}\right), 50.3(\mathrm{CH}), 31.8\left(\mathrm{CH}_{2}\right), 31.5\left(\mathrm{CH}_{2}\right)$, $31.5\left(\mathrm{CH}_{2}\right), 29.5\left(\mathrm{CH}_{2}\right), 24.2\left(\mathrm{CH}_{3}\right), 22.7\left(\mathrm{CH}_{2}\right), 14.2\left(\mathrm{CH}_{3}\right)$.

IR (ATR): $\tilde{v}=2985,2940,2899,1741,1514,1456,1373,1241,1097,1047,847 \mathrm{~cm}^{-1}$. MS (EI) m/z (relative intensity): 341 (50) [M+], 326 (21), 227 (14), 218 (100), 175 (38), 149 (78), 123 (39), 105 (17).

HR-MS (EI) $m / z$ calculated for $\mathrm{C}_{22} \mathrm{H}_{31} \mathrm{NO}_{2}+\mathrm{H}^{+}: 342.2433$; found: 342.2426 .

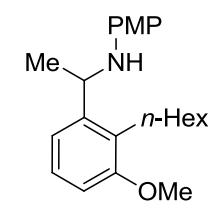

$\left(122 c^{\prime}\right)$

${ }^{1} \mathrm{H}-\mathrm{NMR}\left(300 \mathrm{MHz}, \mathrm{CDCl}_{3}\right): \delta=7.12(\mathrm{dd}, J=8.0,7.7 \mathrm{~Hz}, 1 \mathrm{H}), 7.08(\mathrm{dd}, J=8.0,1.5 \mathrm{~Hz}, 1 \mathrm{H}), 6.75(\mathrm{dd}, J=$ 7.7, $1.5 \mathrm{~Hz}, 1 \mathrm{H}), 6.69(\mathrm{~d}, J=9.0 \mathrm{~Hz}, 2 \mathrm{H}), 6.47(\mathrm{~d}, J=9.0 \mathrm{~Hz}, 2 \mathrm{H}), 4.67(\mathrm{q}, J=6.6 \mathrm{~Hz}, 1 \mathrm{H}), 3.82(\mathrm{~s}, 3 \mathrm{H})$, $3.72(\mathrm{~s}, 3 \mathrm{H}), 2.89-2.52(\mathrm{~m}, 2 \mathrm{H}), 1.69-1.52(\mathrm{~m}, 2 \mathrm{H}), 1.51-1.22(\mathrm{~m}, 9 \mathrm{H}), 0.92(\mathrm{t}, J=7.0 \mathrm{~Hz}, 3 \mathrm{H})$. 
${ }^{13} \mathrm{C}$-NMR $\left(75 \mathrm{MHz}, \mathrm{CDCl}_{3}\right): \delta=157.6\left(\mathrm{C}_{\mathrm{q}}\right), 151.8\left(\mathrm{C}_{\mathrm{q}}\right), 143.8\left(\mathrm{C}_{\mathrm{q}}\right), 141.5\left(\mathrm{C}_{\mathrm{q}}\right), 128.4\left(\mathrm{C}_{\mathrm{q}}\right), 126.8(\mathrm{CH})$, 117.1 (CH), $114.7(\mathrm{CH}), 114.5(\mathrm{CH}), 108.7(\mathrm{CH}), 55.7\left(\mathrm{CH}_{3}\right), 55.4\left(\mathrm{CH}_{3}\right), 50.4(\mathrm{CH}), 31.7\left(\mathrm{CH}_{2}\right), 29.9\left(\mathrm{CH}_{2}\right)$, $29.9\left(\mathrm{CH}_{2}\right), 25.4\left(\mathrm{CH}_{2}\right), 24.2\left(\mathrm{CH}_{3}\right), 22.6\left(\mathrm{CH}_{2}\right), 14.1\left(\mathrm{CH}_{3}\right)$.

IR (ATR): $\tilde{v}=3396,2954,2926,2856,1581,1465,1372,1231,1177 \mathrm{~cm}^{-1}$.

MS (EI) m/z (relative intensity): $341(55)\left[\mathrm{M}^{+}\right], 326$ (41), 218 (80), 157 (34), 149 (100), 123 (72), 108 (24), $91(21)$.

HR-MS (EI) $\mathrm{m} / \mathrm{z}$ calculated for $\mathrm{C}_{22} \mathrm{H}_{31} \mathrm{NO}_{2}^{+}: 341.2355$; found: 341.2363 .

\section{Synthesis of $N$-[1-(5-Chloro-2-n-hexylphenyl)ethyl]-4-methoxyaniline (122d')}

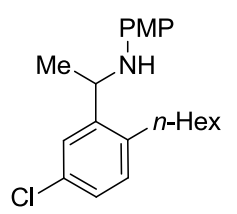

The general procedure D was followed using 4-methoxy- $N$-[1-(3-chlorophenyl)ethylidene]aniline (121d) (128 mg, $0.51 \mathrm{mmol})$, 42ab (243 mg, $1.47 \mathrm{mmol}),\left[\mathrm{RuCl}_{2}(p \text {-cymene) }]_{2}(7.5 \mathrm{mg}, 2.5 \mathrm{~mol} \%), 1-\right.$ $\mathrm{AdCO}_{2} \mathrm{H}(\mathbf{1 3 c})(27 \mathrm{mg}, 0.15 \mathrm{mmol}, 30 \mathrm{~mol} \%)$ in $m$-xylene $(2.0 \mathrm{~mL})$. Purification by column chromatography ( $n$-hexane/EtOAc 9:1) yielded 122d' (116 mg, 68\%) as a colorless oil.

${ }^{1} \mathrm{H}-\mathrm{NMR}\left(300 \mathrm{MHz}, \mathrm{CDCl}_{3}\right): \delta=7.44(\mathrm{~d}, J=1.2 \mathrm{~Hz}, 1 \mathrm{H}), 7.14-7.10(\mathrm{~m}, 2 \mathrm{H}), 6.69(\mathrm{~d}, J=9.0 \mathrm{~Hz}, 2 \mathrm{H}), 6.41$ $(\mathrm{d}, J=9.0 \mathrm{~Hz}, 2 \mathrm{H}), 4.58(\mathrm{q}, J=6.6 \mathrm{~Hz}, 1 \mathrm{H}), 3.69(\mathrm{~s}, 3 \mathrm{H}), 2.75-2.59(\mathrm{~m}, 2 \mathrm{H}), 1.77-1.54(\mathrm{~m}, 2 \mathrm{H}), 1.49-1.19$ $(\mathrm{m}, 9 \mathrm{H}), 0.92-0.81(\mathrm{~m}, 3 \mathrm{H})$.

${ }^{13} \mathrm{C}-\mathrm{NMR}\left(75 \mathrm{MHz}, \mathrm{CDCl}_{3}\right): \delta=152.2\left(\mathrm{C}_{\mathrm{q}}\right), 144.5\left(\mathrm{C}_{\mathrm{q}}\right), 140.9\left(\mathrm{C}_{\mathrm{q}}\right), 137.7\left(\mathrm{C}_{\mathrm{q}}\right), 132.2\left(\mathrm{C}_{\mathrm{q}}\right), 130.9(\mathrm{CH})$, 126.8 (CH), $125.2(\mathrm{CH}), 114.8(\mathrm{CH}), 114.7(\mathrm{CH}), 55.6\left(\mathrm{CH}_{3}\right), 50.5(\mathrm{CH}), 31.7\left(\mathrm{CH}_{2}\right), 31.6\left(\mathrm{CH}_{2}\right), 31.0\left(\mathrm{CH}_{2}\right)$, $29.4\left(\mathrm{CH}_{2}\right), 24.0\left(\mathrm{CH}_{2}\right), 22.6\left(\mathrm{CH}_{2}\right), 14.1\left(\mathrm{CH}_{3}\right)$.

IR (ATR): $\tilde{v}=3401,2954,2927,2856,1592,1509,1464,1374,1233,1120,1038,815,518 \mathrm{~cm}^{-1}$.

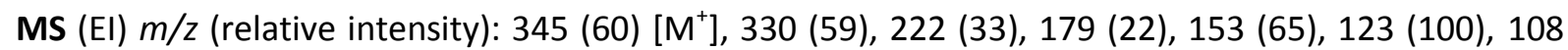
(53), $43(20)$.

HR-MS (ESI): $m / z$ calculated for $\mathrm{C}_{21} \mathrm{H}_{28} \mathrm{CINO}^{+}: 345.1859$; found: 345.1860 .

\section{Synthesis of $N$-[1-(2-n-Hexyl-5-methylphenyl)ethyl]-4-methoxyaniline (122e')}

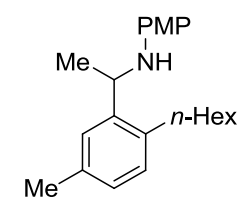


The general procedure D was followed using 4-methoxy- $N$-(1-m-tolylethylidene)aniline (121e) (130 mg, $0.54 \mathrm{mmol}), 42 \mathrm{ab}$ (246 mg, $1.49 \mathrm{mmol}),\left[\mathrm{RuCl}_{2}(p \text {-cymene) }]_{2}(7.9 \mathrm{mg}, 2.4 \mathrm{~mol} \%), 1-\mathrm{AdCO}_{2} \mathrm{H}\right.$ (13c) $(28 \mathrm{mg}, 0.15 \mathrm{mmol}, 29 \mathrm{~mol} \%)$ in $m$-xylene $(2.0 \mathrm{~mL})$. Purification by column chromatography $(n-$ hexane/EtOAc 9:1) yielded 122e' (92 mg, 52\%) as a colorless oil.

${ }^{1} \mathrm{H}-\mathrm{NMR}\left(300 \mathrm{MHz}, \mathrm{CDCl}_{3}\right): \delta=7.26(\mathrm{~d}, J=1.6 \mathrm{~Hz}, 1 \mathrm{H}), 7.06(\mathrm{~d}, J=7.7 \mathrm{~Hz}, 1 \mathrm{H}), 6.97(\mathrm{dd}, J=7.7,1.6 \mathrm{~Hz}$, $1 \mathrm{H}), 6.70(\mathrm{~d}, J=8.8 \mathrm{~Hz}, 2 \mathrm{H}), 6.46(\mathrm{~d}, J=8.8 \mathrm{~Hz}, 2 \mathrm{H}), 4.63(\mathrm{q}, J=6.4 \mathrm{~Hz}, 1 \mathrm{H}), 3.69(\mathrm{~s}, 3 \mathrm{H}), 2.73-2.62(\mathrm{~m}$, $2 \mathrm{H}), 2.26(\mathrm{~s}, 3 \mathrm{H}), 1.72-1.54(\mathrm{~m}, 2 \mathrm{H}), 1.50-1.22(\mathrm{~m}, 9 \mathrm{H}), 0.90(\mathrm{t}, J=6.9 \mathrm{~Hz}, 3 \mathrm{H})$.

${ }^{13} \mathrm{C}$-NMR $\left(75 \mathrm{MHz}, \mathrm{CDCl}_{3}\right): \delta=151.7\left(\mathrm{C}_{\mathrm{q}}\right), 142.2\left(\mathrm{C}_{\mathrm{q}}\right), 141.6\left(\mathrm{C}_{\mathrm{q}}\right), 136.2\left(\mathrm{C}_{\mathrm{q}}\right), 135.6\left(\mathrm{C}_{\mathrm{q}}\right), 129.4(\mathrm{CH})$, 127.4 (CH), $125.4(\mathrm{CH}), 114.7(\mathrm{CH}), 114.4(\mathrm{CH}), 55.8\left(\mathrm{CH}_{3}\right), 50.2(\mathrm{CH}), 32.0\left(\mathrm{CH}_{2}\right), 31.8\left(\mathrm{CH}_{2}\right), 31.4\left(\mathrm{CH}_{2}\right)$, $29.6\left(\mathrm{CH}_{2}\right), 24.1\left(\mathrm{CH}_{3}\right), 22.7\left(\mathrm{CH}_{2}\right), 21.3\left(\mathrm{CH}_{3}\right), 14.2\left(\mathrm{CH}_{3}\right)$.

IR (ATR): $\tilde{v}=3395,2955,2928,2856,1511,1464,1305,1236,1168,1039,909,818,733,647 \mathrm{~cm}^{-1}$. MS (EI) m/z (relative intensity): 325 (41) [M+], 310 (26), 202 (57), 159 (19), 133 (100), 123 (62).

HR-MS (ESI): $\mathrm{m} / z$ calculated for $\mathrm{C}_{22} \mathrm{H}_{31} \mathrm{NO}+\mathrm{H}^{+}: 326.2484$; found: 326.2478 .

Synthesis of 2-(2-n-Hexyl-1H-pyrrol-3-yl)pyridine (129) and 2-(1-n-Hexyl-1H-pyrrol-3-yl)pyridine (130)

The general procedure $\mathbf{C}$ was followed using $128(74.0 \mathrm{mg}, 0.51 \mathrm{mmol})$, 42ab (248 $\mathrm{mg}, 1.50 \mathrm{mmol})$, $\left[\mathrm{RuCl}_{2}(p \text {-cymene })\right]_{2}(7.7 \mathrm{mg}, 2.5 \mathrm{~mol} \%), 1-\mathrm{AdCO}_{2} \mathrm{H}(\mathbf{1 3 c})(28 \mathrm{mg}, 0.15 \mathrm{mmol}, 30 \mathrm{~mol} \%)$ and $\mathrm{K}_{2} \mathrm{CO}_{3}$ (141 mg, $1.02 \mathrm{mmol}$ ) in $m$-xylene $(2.0 \mathrm{~mL}$ ). Purification by column chromatography ( $n$-hexane/EtOAc 5:1) yielded 129 (18 mg, 15\%) and 130 (17 mg, 15\%) as a colorless oils.

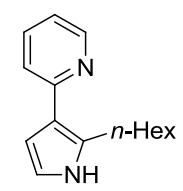

(129)

${ }^{1} \mathrm{H}-\mathrm{NMR}\left(300 \mathrm{MHz}, \mathrm{CDCl}_{3}\right): \delta=8.55$ (ddd, $\left.J=4.9,1.9,1.0 \mathrm{~Hz}, 1 \mathrm{H}\right), 8.21(\mathrm{~s}, 1 \mathrm{H}), 7.66-7.51(\mathrm{~m}, 1 \mathrm{H}), 7.39$ (dt, J=8.0, $1.1 \mathrm{~Hz}, 1 \mathrm{H}$ ), 6.99 (ddd, $J=7.4,4.9,1.2 \mathrm{~Hz}, 1 \mathrm{H}), 6.72-6.61(\mathrm{~m}, 1 \mathrm{H}), 6.54(\mathrm{t}, J=2.9 \mathrm{~Hz}, 1 \mathrm{H})$, 3.10-2.87 (m, 2H), 1.71-1.47 (m, 2H), 1.44-1.08 (m, 6H), $0.85(\mathrm{t}, J=7.7 \mathrm{~Hz}, 3 \mathrm{H})$.

${ }^{13} \mathrm{C}-\mathrm{NMR}\left(75 \mathrm{MHz}, \mathrm{CDCl}_{3}\right): \delta=156.8\left(\mathrm{C}_{\mathrm{q}}\right), 149.7(\mathrm{CH}), 136.5(\mathrm{CH}), 132.9\left(\mathrm{C}_{\mathrm{q}}\right), 121.3(\mathrm{CH}), 120.3\left(\mathrm{C}_{\mathrm{q}}\right)$, $120.0(\mathrm{CH}), 116.5(\mathrm{CH}), 109.1(\mathrm{CH}), 32.2\left(\mathrm{CH}_{2}\right), 30.1\left(\mathrm{CH}_{2}\right), 29.7\left(\mathrm{CH}_{2}\right), 27.8\left(\mathrm{CH}_{2}\right), 23.1\left(\mathrm{CH}_{2}\right), 14.6$ $\left(\mathrm{CH}_{3}\right)$.

IR (ATR): $\tilde{v}=3227,2924,2854,1692,1588,1497,1465,1424,787,740 \mathrm{~cm}^{-1}$. 
HR-MS (ESI) $m / z$ calculated for $\mathrm{C}_{15} \mathrm{H}_{20} \mathrm{~N}_{2}+\mathrm{H}^{+}$: 229.1705; found: 229.1703 .

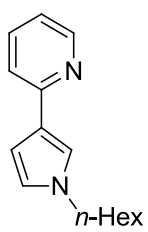

(130)

${ }^{1} \mathrm{H}-\mathrm{NMR}\left(300 \mathrm{MHz}, \mathrm{CDCl}_{3}\right): \delta=8.50(\mathrm{ddd}, J=5.0,1.8,0.9 \mathrm{~Hz}, 1 \mathrm{H}), 7.68-7.52(\mathrm{~m}, 1 \mathrm{H}), 7.44$ (ddd, $J=8.0$, $1.1,1.1 \mathrm{~Hz}, 1 \mathrm{H}$ ), 7.31 (dd, $J=2.0,2.0 \mathrm{~Hz}, 1 \mathrm{H}), 7.00$ (ddd, $J=7.4,4.9,1.2 \mathrm{~Hz}, 1 \mathrm{H}), 6.67$ (dd, $J=2.5$, $2.5 \mathrm{~Hz}, 1 \mathrm{H}), 6.60(\mathrm{dd}, J=2.8,1.8 \mathrm{~Hz}, 1 \mathrm{H}), 4.04-3.78(\mathrm{~m}, 2 \mathrm{H}), 1.96-1.61(\mathrm{~m}, 2 \mathrm{H}), 1.43-1.16(\mathrm{~m}, 6 \mathrm{H}), 0.88$ $(\mathrm{t}, J=7.7 \mathrm{~Hz}, 3 \mathrm{H})$.

${ }^{13} \mathrm{C}$-NMR $\left(75 \mathrm{MHz}, \mathrm{CDCl}_{3}\right): \delta=154.9\left(\mathrm{C}_{\mathrm{q}}\right), 149.4(\mathrm{CH}), 136.4(\mathrm{CH}), 124.9\left(\mathrm{C}_{\mathrm{q}}\right), 122.0(\mathrm{CH}), 120.1(\mathrm{CH})$, $120.0(\mathrm{CH}), 118.9(\mathrm{CH}), 106.6(\mathrm{CH}), 50.2\left(\mathrm{CH}_{2}\right), 31.5\left(\mathrm{CH}_{2}\right), 31.5\left(\mathrm{CH}_{2}\right), 26.5\left(\mathrm{CH}_{2}\right), 22.6\left(\mathrm{CH}_{2}\right), 14.1$ $\left(\mathrm{CH}_{3}\right)$.

IR (ATR): $\tilde{v}=2928,2857,1701,1590,1544,1466,1400,1365,1234,930,769 \mathrm{~cm}^{-1}$.

HR-MS (ESI) $m / z$ calculated for $\mathrm{C}_{15} \mathrm{H}_{20} \mathrm{~N}_{2}+\mathrm{H}^{+}$: 229.1705; found: 229.1704 .

Intermolecular Competition Experiments

Intermolecular Competition Experiment with meta-substituted Ketimines (121e) \& (121d)

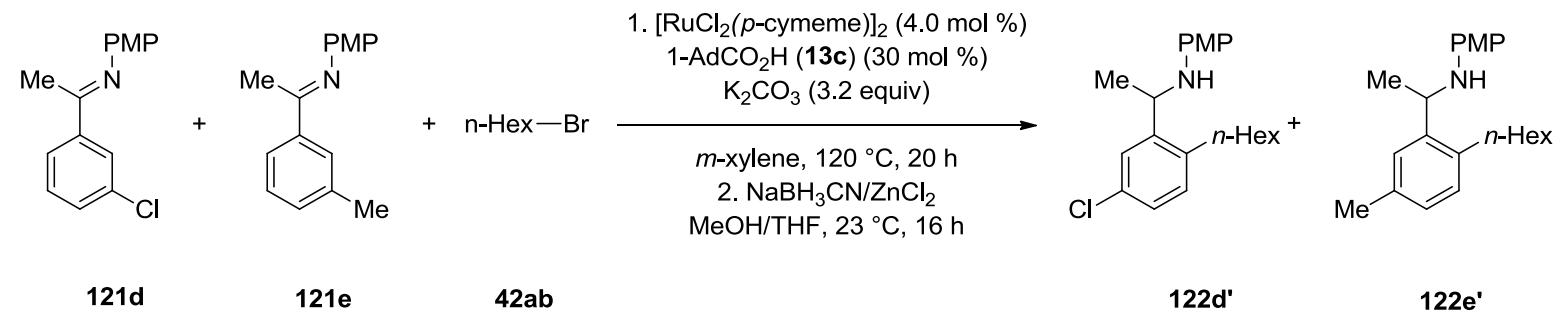

A suspension of $\left[\mathrm{RuCl}_{2}(p \text {-cymene })\right]_{2}(15.4 \mathrm{mg}, 25 \mu \mathrm{mol}, 3.9 \mathrm{~mol} \%), 1-\mathrm{AdCO}_{2} \mathrm{H}$ (13c) $(27.6 \mathrm{mg}$, $0.15 \mathrm{mmol}, 30 \mathrm{~mol} \%), \mathrm{K}_{2} \mathrm{CO}_{3}(225 \mathrm{mg}, 1.62 \mathrm{mmol}), 121 \mathrm{~d}(254 \mathrm{mg}, 0.98 \mathrm{mmol}), 121 \mathrm{e}(224 \mathrm{mg}, 0.94$ $\mathrm{mmol}$ ) and 42ab (106 mg, $0.64 \mathrm{mmol})$ in $\mathrm{m}$-xylene $(3.0 \mathrm{~mL})$ was stirred under $\mathrm{N}_{2}$ for $20 \mathrm{~h}$ at $120^{\circ} \mathrm{C}$. A solution of $\mathrm{ZnCl}_{2}$ in THF (0.65 mL, $1.10 \mathrm{mmol}, 1.7 \mathrm{M}$ ), $\mathrm{NaBH}_{3} \mathrm{CN}$ (126 mg, $2.00 \mathrm{mmol}$ ) and $\mathrm{MeOH}$ (4.0 $\mathrm{mL}$ ) was added to the cooled reaction mixture and the resulting mixture was stirred at ambient temperature. Analysis by GC showed that $\mathbf{1 2 2} \mathbf{d}^{\prime}$ and $\mathbf{1 2 2} \mathbf{e}^{\prime}$ were formed in a ratio of 4.4:1.0. $\mathrm{Et}_{2} \mathrm{O}$ (30 $\mathrm{mL}$ ) and sat. aq. $\mathrm{K}_{2} \mathrm{CO}_{3}(30 \mathrm{~mL})$ were added to the cold reaction mixture. The separated aqueous phase was extracted with $\mathrm{Et}_{2} \mathrm{O}(2 \times 40 \mathrm{~mL})$. The combined organic layers were dried over $\mathrm{Na}_{2} \mathrm{SO}_{4}$ and 
concentrated in vacuo. Purification by column chromatography on silica gel ( $n$-hexane/EtOAc 9:1) yielded 122d' (88 $\mathrm{mg}, 40 \%$ ) as a colorless oil.

Intermolecular Competition Experiment with meta-substituted Ketimines (121b) \& (121d)

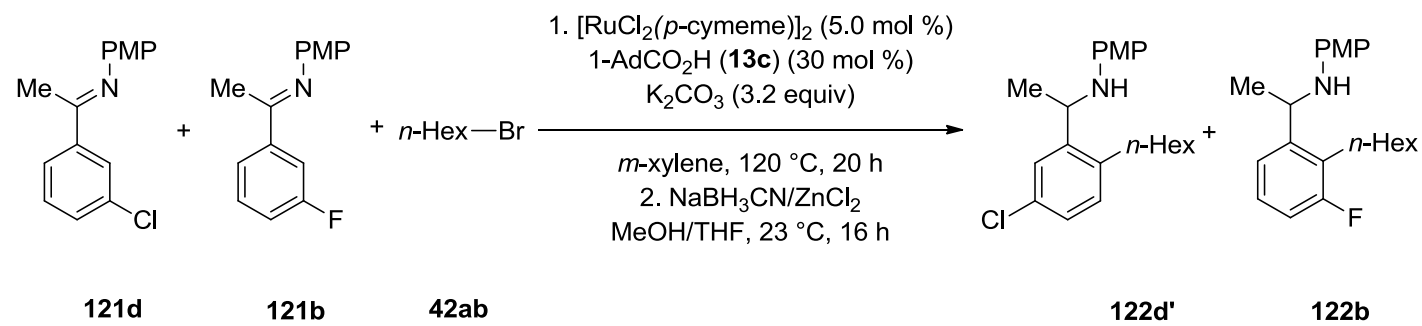

A suspension of $\left[\mathrm{RuCl}_{2}(p \text {-cymene })\right]_{2}(15.0 \mathrm{mg}, 25 \mu \mathrm{mol}, 4.3 \mathrm{~mol} \%), 1-\mathrm{AdCO}_{2} \mathrm{H}$ (13c) $(26.3 \mathrm{mg}$, $0.15 \mathrm{mmol}, 30 \mathrm{~mol} \%), \mathrm{K}_{2} \mathrm{CO}_{3}(226 \mathrm{mg}, 1.64 \mathrm{mmol}), 121 \mathrm{~d}(244 \mathrm{mg}, 1.00 \mathrm{mmol}), 121 \mathrm{~b}(252 \mathrm{mg}$, $0.97 \mathrm{mmol}$ ) and $42 \mathrm{ab}(97 \mathrm{mg}, 0.59 \mathrm{mmol})$ in $\mathrm{m}$-xylene $\left(3.0 \mathrm{~mL}\right.$ ) was stirred under $\mathrm{N}_{2}$ for $20 \mathrm{~h}$ at 120 ${ }^{\circ} \mathrm{C}$. A solution of $\mathrm{ZnCl}_{2}$ in THF (0.65 mL, $\left.1.10 \mathrm{mmol}, 1.7 \mathrm{M}\right), \mathrm{NaBH}_{3} \mathrm{CN}(126 \mathrm{mg}, 2.00 \mathrm{mmol})$ and $\mathrm{MeOH}$ $(4.0 \mathrm{~mL})$ was added to the cooled reaction mixture and the resulting mixture was stirred at ambient temperature. Analysis by GC showed that $\mathbf{1 2 2} \mathbf{b}$ and $\mathbf{1 2 2} \mathbf{d}^{\prime}$ were formed in a ratio of 3.2:1.0. $\mathrm{Et}_{2} \mathrm{O}$ $(30 \mathrm{~mL})$ and sat. aq. $\mathrm{K}_{2} \mathrm{CO}_{3}(30 \mathrm{~mL})$ were added to the cold reaction mixture. The separated aqueous phase was extracted with $\mathrm{Et}_{2} \mathrm{O}(2 \times 40 \mathrm{~mL})$. The combined organic layers were dried over $\mathrm{Na}_{2} \mathrm{SO}_{4}$ and concentrated in vacuo. Purification by column chromatography on silica gel ( $n$-hexane/EtOAc 10:1) yielded $\mathbf{1 2 2 b}$ (107 mg, 56\%) and 122d' (42 mg, 20\%) as a colorless oils.

Intermolecular Competition Experiment between 1-Bromohexane (42ab) and 1-Chlorodecane (42d)

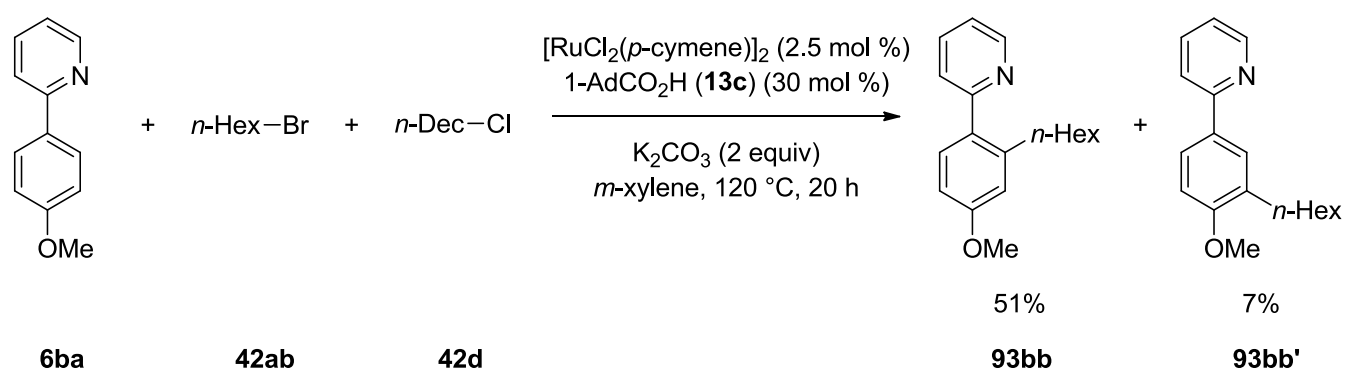

The competition experiment between 42ab $(250 \mathrm{mg}, 1.52 \mathrm{mmol})$ and $42 \mathrm{~d}(274 \mathrm{mg}, 1.55 \mathrm{mmol})$ with $\left[\mathrm{RuCl}_{2}[p \text {-cymene) }]_{2}(7.9 \mathrm{mg}, 13 \mu \mathrm{mol}, 2.5 \mathrm{~mol} \%), 1-\mathrm{AdCO}_{2} \mathrm{H}\right.$ (13c) $(27.4 \mathrm{mg}, 0.15 \mathrm{mmol}, 30 \mathrm{~mol} \%)$, $\mathrm{K}_{2} \mathrm{CO}_{3}(139 \mathrm{mg}, 1.00 \mathrm{mmol})$ and 6 ba $(91.7 \mathrm{mg}, 0.50 \mathrm{mmol})$ in $m$-xylene $(3.0 \mathrm{~mL})$ yielded after purification by column chromatography ( $n$-hexane/EtOAc $9: 1$ to $3: 1$ ) $93 \mathbf{b b}$ (71 $\mathrm{mg}, 51 \%$ ) and $\mathbf{9 3 b b}$ (9 mg, 7\%). 
Intermolecular Competition Experiment between 2-Phenylpyridine (6aa) and 1-Phenyl-1H-pyrazole (87a)

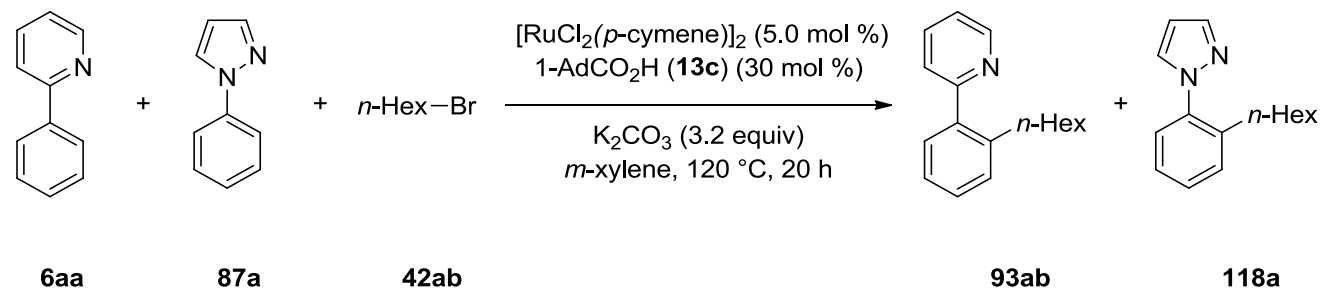

The competition experiment between 87a (135 mg, $0.94 \mathrm{mmol})$ and 6aa $(140 \mathrm{mg}, 0.91 \mathrm{mmol})$ with $\left[\mathrm{RuCl}_{2}[p \text {-cymene) }]_{2}(15.3 \mathrm{mg}, 25 \mu \mathrm{mol}, 4.3 \mathrm{~mol} \%), 1-\mathrm{AdCO}_{2} \mathrm{H}(13 \mathrm{c})(27.8 \mathrm{mg}, 0.15 \mathrm{mmol}, 30 \mathrm{~mol} \%)\right.$, $\mathrm{K}_{2} \mathrm{CO}_{3}(137 \mathrm{mg}, 0.99 \mathrm{mmol})$ and $42 \mathrm{ab}(96.1 \mathrm{mg}, 0.58 \mathrm{mmol})$ in $\mathrm{m}$-xylene $(3.0 \mathrm{~mL})$ yielded after and purification by column chromatography ( -hexane/EtOAc 9:1) 118a (12 mg, 9\%) and 93ab (50 mg, $36 \%)$ as a colorless oils.

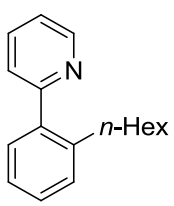

(93ab)

${ }^{1} \mathrm{H}-\mathrm{NMR}\left(300 \mathrm{MHz}, \mathrm{CDCl}_{3}\right): \delta=8.71(\mathrm{ddd}, J=4.9,1.8,1.0 \mathrm{~Hz}, 1 \mathrm{H}), 7.69(\mathrm{td}, J=7.7,1.8 \mathrm{~Hz}, 1 \mathrm{H}), 7.50-$ $7.07(\mathrm{~m}, 6 \mathrm{H}), 2.72-2.64(\mathrm{~m}, 2 \mathrm{H}), 1.57-1.29(\mathrm{~m}, 2 \mathrm{H}), 1.29-0.99(\mathrm{~m}, 6 \mathrm{H}), 0.80(\mathrm{t}, J=6.8 \mathrm{~Hz}, 3 \mathrm{H})$.

${ }^{13} \mathrm{C}-\mathrm{NMR}\left(75 \mathrm{MHz}, \mathrm{CDCl}_{3}\right): \delta=160.2\left(\mathrm{C}_{\mathrm{q}}\right), 148.9(\mathrm{CH}), 140.6\left(\mathrm{C}_{\mathrm{q}}\right), 140.2\left(\mathrm{C}_{\mathrm{q}}\right), 135.8(\mathrm{CH}), 129.5(\mathrm{CH})$, $129.5(\mathrm{CH}), 128.1(\mathrm{CH}), 125.5(\mathrm{CH}), 123.9(\mathrm{CH}), 121.4(\mathrm{CH}), 32.7\left(\mathrm{CH}_{2}\right), 31.3\left(\mathrm{CH}_{2}\right), 31.0\left(\mathrm{CH}_{2}\right), 28.9$ $\left(\mathrm{CH}_{2}\right), 22.3\left(\mathrm{CH}_{2}\right), 13.9\left(\mathrm{CH}_{3}\right)$.

IR (ATR): $\tilde{v}=3059,2926,2856,1586,1562,1468,1377,795,751,474,457,441 \mathrm{~cm}^{-1}$.

MS (EI) $m / z$ (relative intensity): 239 (21) [M+], 182 (100), 167 (89).

HR-MS (ESI) $m / z$ calculated for $\mathrm{C}_{17} \mathrm{H}_{21} \mathrm{~N}+\mathrm{H}^{+}$: 240.1752; found: 240.1746 .

The analytical data are in accordance with those reported in the literature. ${ }^{121}$<smiles>Oc1ccccc1-n1cccn1</smiles> 
${ }^{1} \mathrm{H}-\mathrm{NMR}\left(300 \mathrm{MHz}, \mathrm{CDCl}_{3}\right): \delta=7.71(\mathrm{ddd}, J=1.8,0.7,0.7 \mathrm{~Hz}, 1 \mathrm{H}), 7.60-7.49(\mathrm{~m}, 1 \mathrm{H}), 7.41-7.21(\mathrm{~m}$, $4 \mathrm{H}), 6.51-6.31(\mathrm{~m}, 1 \mathrm{H}), 2.61-2.45(\mathrm{~m}, 2 \mathrm{H}), 1.51-1.31(\mathrm{~m}, 2 \mathrm{H}), 1.31-1.11(\mathrm{~m}, 6 \mathrm{H}), 0.84(\mathrm{t}, J=7.4 \mathrm{~Hz}, 3 \mathrm{H})$. ${ }^{13} \mathrm{C}-\mathrm{NMR}\left(75 \mathrm{MHz}, \mathrm{CDCl}_{3}\right): \delta=140.3(\mathrm{CH}), 139.8\left(\mathrm{C}_{\mathrm{q}}\right), 139.1\left(\mathrm{C}_{\mathrm{q}}\right), 130.8(\mathrm{CH}), 130.4(\mathrm{CH}), 128.7(\mathrm{CH})$, $126.8(\mathrm{CH}), 126.5(\mathrm{CH}), 106.2(\mathrm{CH}), 31.6\left(\mathrm{CH}_{2}\right), 31.4\left(\mathrm{CH}_{2}\right), 30.7\left(\mathrm{CH}_{2}\right), 29.2\left(\mathrm{CH}_{2}\right), 22.6\left(\mathrm{CH}_{2}\right), 14.2$ $\left(\mathrm{CH}_{2}\right)$.

IR (ATR): $\tilde{v}=2955,2925,2856,1516,1498,1418,1394,1043,938,746 \mathrm{~cm}^{-1}$.

MS (EI) m/z (relative intensity): $228(26)\left[\mathrm{M}^{+}\right], 171$ (100), 158 (26), 130 (20), 43 (17).

HR-MS (EI) $m / z$ calculated for $\mathrm{C}_{15} \mathrm{H}_{20} \mathrm{~N}_{2}-\mathrm{H}^{+}: 227.1548$; found: 227.1549 .

Intermolecular Competition Experiment between 2-Phenylpyridine (6aa) and 2-Phenyl-4,5dihydrooxazole (136)

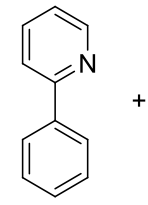

6aa

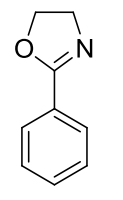

136

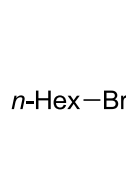

42ab

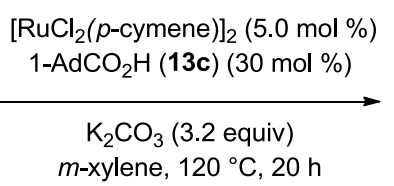

$m$-xylene, $120^{\circ} \mathrm{C}, 20 \mathrm{~h}$

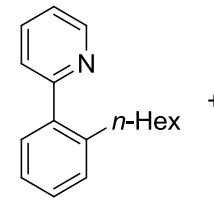

93ab

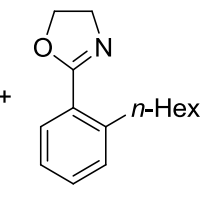

$146 a$

The competition experiment between 6aa $(149 \mathrm{mg}, 0.96 \mathrm{mmol})$ and $136(136 \mathrm{mg}, 0.92 \mathrm{mmol})$ with $\left[\mathrm{RuCl}_{2}[p \text {-cymene) }]_{2}(15.9 \mathrm{mg}, 26 \mu \mathrm{mol}, 5.0 \mathrm{~mol} \%) 1-\mathrm{AdCO}_{2} \mathrm{H}\right.$ (13c) $(27.0 \mathrm{mg}, 0.15 \mathrm{mmol}, 30 \mathrm{~mol} \%)$, $\mathrm{K}_{2} \mathrm{CO}_{3}(138 \mathrm{mg}, 1.00 \mathrm{mmol})$ and $42 \mathrm{ab}(95.1 \mathrm{mg}, 0.58 \mathrm{mmol})$ in $m$-xylene $(3.0 \mathrm{~mL}$ ) gave after purification by column chromatography ( $n$-hexane/EtOAc 9:1) 93ab (33 mg, 24\%) as a colorless oil.

Intermolecular Competition Experiment between 2-Phenyl-4,5-dihydrooxazole (136) an 1-Phenyl$1 \mathrm{H}$-pyrazole (118a)

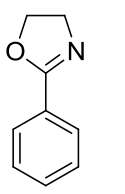

136

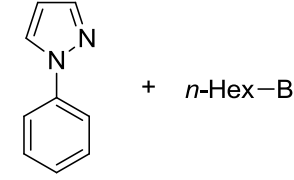

$87 a$

42ab

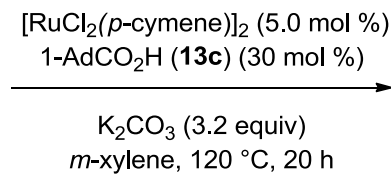

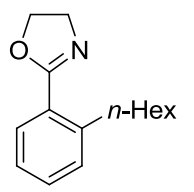

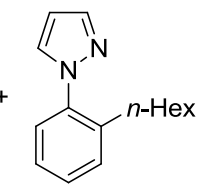

$164 a$

$118 a$

The competition-experiment between 136 (138 mg, $0.94 \mathrm{mmol}$ ) and 87a (148 mg, $1.03 \mathrm{mmol}$ ) with $\left[\mathrm{RuCl}_{2}[p \text {-cymene }]_{2}(15.0 \mathrm{mg}, 0.025 \mathrm{mmol}, 4.5 \mathrm{~mol} \%), 1-\mathrm{AdCO}_{2} \mathrm{H} \quad\right.$ (13c) (26.8 mg, $0.15 \mathrm{mmol}$, $30 \mathrm{~mol} \%), \mathrm{K}_{2} \mathrm{CO}_{3}(138 \mathrm{mg}, 1.00 \mathrm{mmol})$ and 42ab $(91.0 \mathrm{mg}, 0.55 \mathrm{mmol})$ in $m$-xylene $(3.0 \mathrm{~mL})$ gave 
after purification by column chromatography ( $n$-hexane/EtOAc 9:1) 118a (39 mg, 31\%) as a colorless oil.

Intermolecular Competition Experiment between 1-(3-Fluorophenyl)-1H-pyrazole (87c) an 2-(3Fluorophenyl)pyridine (6da)

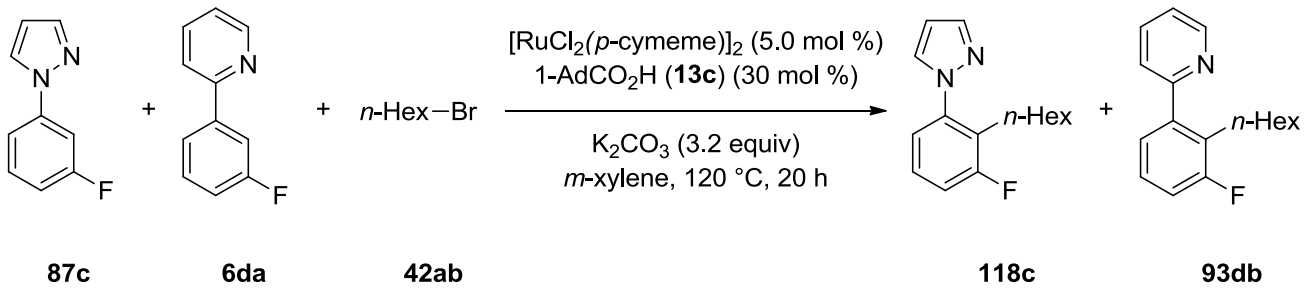

The competition experiment between 87c (165 mg, $1.02 \mathrm{mmol})$ and $6 \mathrm{da}(175 \mathrm{mg}, 1.00 \mathrm{mmol})$ with $\left[\mathrm{RuCl}_{2}[p \text {-cymene })\right]_{2} \quad(15.1 \mathrm{mg}, 0.025 \mathrm{mmol}, 5.0 \mathrm{~mol} \%), 1-\mathrm{AdCO}_{2} \mathrm{H} \quad$ (13c) $\quad(26.0 \mathrm{mg}, 0.14 \mathrm{mmol}$, $29 \mathrm{~mol} \%), \mathrm{K}_{2} \mathrm{CO}_{3}(144 \mathrm{mg}, 1.04 \mathrm{mmol})$ and $42 \mathrm{ab}(89.1 \mathrm{mg}, 0.50 \mathrm{mmol})$ in $m$-xylene $(3.0 \mathrm{~mL})$ gave after purification by column chromatography ( $n$-hexane/EtOAc 9:1) 93db (24 mg, 17\%) and 118c (22 mg, $17 \%)$ as colorless oils.<smiles>Oc1c(F)cccc1-c1ccccn1</smiles>

\section{(93db)}

${ }^{1} \mathrm{H}-\mathrm{NMR}\left(300 \mathrm{MHz}, \mathrm{CDCl}_{3}\right): \delta=8.79-8.62(\mathrm{~m}, 1 \mathrm{H}), 7.76$ (dddd, $J=9.5,7.6,4.6,2.3 \mathrm{~Hz}, 2 \mathrm{H}$ ), 7.33-7.00 $(\mathrm{m}, 4 \mathrm{H}), 2.79-2.58(\mathrm{~m}, 2 \mathrm{H}), 1.56-1.35(\mathrm{~m}, 2 \mathrm{H}), 1.33-1.00(\mathrm{~m}, 6 \mathrm{H}), 0.81(\mathrm{t}, J=6.7 \mathrm{~Hz}, 3 \mathrm{H})$.

${ }^{13} \mathrm{C}-\mathrm{NMR}\left(75 \mathrm{MHz}, \mathrm{CDCl}_{3}\right): \delta=161.7\left(\mathrm{~d}, \mathrm{~J}_{\mathrm{C}-\mathrm{F}}=244 \mathrm{~Hz}, \mathrm{C}_{\mathrm{q}}\right), 159.3\left(\mathrm{~d}, \mathrm{~J}_{\mathrm{C}-\mathrm{F}}=3 \mathrm{~Hz}, \mathrm{C}_{\mathrm{q}}\right), 149.3(\mathrm{CH}), 142.7$ (d, $\left.J_{C-F}=5 \mathrm{~Hz}, C_{q}\right), 136.3(\mathrm{CH}), 128.6\left(\mathrm{~d}, J_{\mathrm{C}-\mathrm{F}}=16 \mathrm{~Hz}, \mathrm{C}_{\mathrm{q}}\right), 126.9\left(\mathrm{~d}, J_{\mathrm{C}-\mathrm{F}}=9 \mathrm{~Hz}, \mathrm{CH}\right), 125.5\left(\mathrm{~d}, J_{\mathrm{C}-\mathrm{F}}=3 \mathrm{~Hz}, \mathrm{CH}\right)$, 124.2 (CH), $122.1(\mathrm{CH}), 115.2\left(\mathrm{~d}, \mathrm{~J}_{\mathrm{C}-\mathrm{F}}=24 \mathrm{~Hz}, \mathrm{CH}\right), 31.5\left(\mathrm{CH}_{2}\right), 30.3\left(\mathrm{CH}_{2}\right), 29.3\left(\mathrm{CH}_{2}\right), 25.8\left(\mathrm{~d}, \mathrm{~J}_{\mathrm{C}-\mathrm{F}}=3 \mathrm{~Hz}\right.$, $\left.\mathrm{CH}_{2}\right), 22.6\left(\mathrm{CH}_{2}\right), 14.2\left(\mathrm{CH}_{3}\right)$.

${ }^{19}$ F-NMR $\left(282 \mathrm{MHz}, \mathrm{CDCl}_{3}\right): \delta=-117.17--117.88(\mathrm{~m})$. IR (ATR): $\tilde{v}=2954,2926,2857,1564,1482,1423,1277,991,883,772,746,700 \mathrm{~cm}^{-1}$. MS (EI) m/z (relative intensity): 257 (41) [M+1], 214 (18), 200 (100), 185 (79), 157 (9). HR-MS (EI) $\mathrm{m} / z$ calculated for $\mathrm{C}_{17} \mathrm{H}_{20} \mathrm{FN}-\mathrm{H}^{+}$: 256.1502; found: 256.1597. 


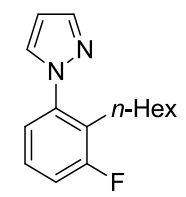

(118c)

${ }^{1} \mathrm{H}-\mathrm{NMR}\left(300 \mathrm{MHz}, \mathrm{CDCl}_{3}\right): \delta=7.71(\mathrm{~d}, J=1.8 \mathrm{~Hz}, 1 \mathrm{H}), 7.60-7.52(\mathrm{~m}, 1 \mathrm{H}), 7.28-7.16(\mathrm{~m}, 1 \mathrm{H}), 7.16-7.02$ (m, 2H), 6.48-6.39 (m, 1H), 2.61-2.44 (m, 2H), 1.53-1.31 (m, 2H), 1.31-1.02 (m, 6H), $0.84(\mathrm{t}, J=7.3 \mathrm{~Hz}$, $3 \mathrm{H})$.

${ }^{13} \mathrm{C}-\mathrm{NMR}\left(75 \mathrm{MHz}, \mathrm{CDCl}_{3}\right): \delta=161.6\left(\mathrm{~d}, \mathrm{~J}_{\mathrm{C}-\mathrm{F}}=246 \mathrm{~Hz}, \mathrm{C}_{\mathrm{q}}\right), 141.1\left(\mathrm{~d}, \mathrm{~J}_{\mathrm{C}-\mathrm{F}}=7 \mathrm{~Hz}, \mathrm{C}_{\mathrm{q}}\right), 140.6(\mathrm{CH}), 130.9$ $(\mathrm{CH}), 127.4\left(\mathrm{~d}, J_{\mathrm{C}-\mathrm{F}}=18 \mathrm{~Hz}, \mathrm{C}_{\mathrm{q}}\right), 127.0\left(\mathrm{~d}, J_{\mathrm{C}-\mathrm{F}}=10 \mathrm{~Hz}, \mathrm{CH}\right), 122.4\left(\mathrm{~d}, J_{\mathrm{C}-\mathrm{F}}=4 \mathrm{~Hz}, \mathrm{CH}\right), 115.6\left(\mathrm{~d}, J_{\mathrm{C}-\mathrm{F}}=\right.$ $23 \mathrm{~Hz}, \mathrm{CH}), 106.5(\mathrm{CH}), 31.4\left(\mathrm{CH}_{2}\right), 29.9\left(\mathrm{~d}, \mathrm{~J}_{\mathrm{C}-\mathrm{F}}=1 \mathrm{~Hz}, \mathrm{CH}_{2}\right), 29.3\left(\mathrm{CH}_{2}\right), 24.7\left(\mathrm{~d}, \mathrm{~J}_{\mathrm{C}-\mathrm{F}}=3 \mathrm{~Hz}, \mathrm{CH}_{2}\right), 22.6$ $\left(\mathrm{CH}_{2}\right), 14.1\left(\mathrm{CH}_{3}\right)$.

${ }^{19} \mathrm{~F}-\mathrm{NMR}\left(282 \mathrm{MHz}, \mathrm{CDCl}_{3}\right): \delta=-114.64--116.37(\mathrm{~m})$.

IR (ATR): $\tilde{v}=2956,2927,2857,1517,1480,1393,1240,1042,855,788,747,622 \mathrm{~cm}^{-1}$.

MS (EI) m/z (relative intensity): 246 (59) [ $\left.\mathrm{M}^{+}\right], 203$ (24), 189 (100), 176 (39), 148 (36), 135 (14).

HR-MS (El) $m / z$ calculated for $\mathrm{C}_{15} \mathrm{H}_{19} \mathrm{FN}_{2}{ }^{+}$: 246.1532; found: 246.1532 .

Intermolecular Competition Experiment between 1-(3-Fluorophenyl)-1H-pyrazole (87c) and 2-(3Fluorophenyl)-4,5-dihydrooxazole (136b)

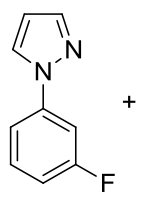

87c

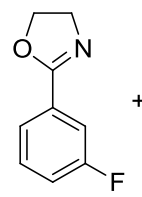

$136 \mathrm{~b}$

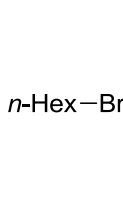

42ab

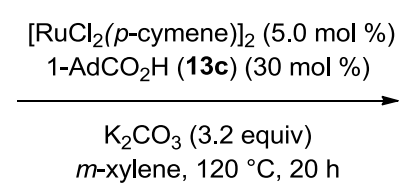

$m$-xylene, $120^{\circ} \mathrm{C}, 20 \mathrm{~h}$

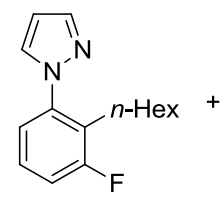

118c

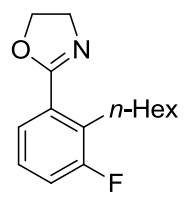

146c

The competition experiment between 87c $(161 \mathrm{mg}, 0.99 \mathrm{mmol})$ and 136b (146 mg, $0.88 \mathrm{mmol})$ with $\left[\mathrm{RuCl}_{2}[p \text {-cymene })\right]_{2} \quad(15.0 \mathrm{mg}, 0.025 \mathrm{mmol}, 4.6 \mathrm{~mol} \%), 1-\mathrm{AdCO}_{2} \mathrm{H} \quad$ (13c) $\quad(26.7 \mathrm{mg}, 0.15 \mathrm{mmol}$, $30 \mathrm{~mol} \%), \mathrm{K}_{2} \mathrm{CO}_{3}(140 \mathrm{mg}, 1.03 \mathrm{mmol})$ and $42 \mathrm{ab}(82.2 \mathrm{mg}, 0.54 \mathrm{mmol})$ in $\mathrm{m}$-xylene $(3.0 \mathrm{~mL})$ gave after purification by column chromatography ( $n$-hexane/EtOAc 9:1) 118c (59 mg, 48\%) as a colorless oil. 
Intermolecular Competition Experiment between 2-(3-Fluorophenyl)-4,5-dihydrooxazole (136b) \& 2-(3-Fluorophenyl)pyridine (6da)<smiles>Fc1cccc(C2=NCCO2)c1</smiles><smiles>Fc1cccc(-c2ccccn2)c1</smiles>

6da
$n-\mathrm{Hex}-\mathrm{Br}$

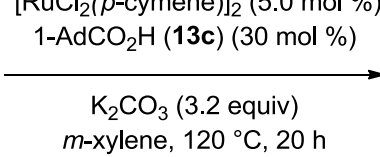

42ab

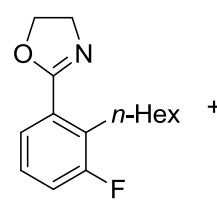

$146 c$

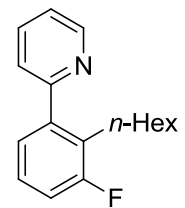

$93 \mathrm{db}$

The competition experiment between 136b (158 mg, $0.96 \mathrm{mmol}$ ) and 6da (166 mg, $0.96 \mathrm{mmol})$ with $\left[\mathrm{RuCl}_{2}[p \text {-cymene }]_{2} \quad(15.4 \mathrm{mg}, 0.025 \mathrm{mmol}, 4.5 \mathrm{~mol} \%), 1-\mathrm{AdCO}_{2} \mathrm{H} \quad\right.$ (13c) $\quad(27.1 \mathrm{mg}, 0.15 \mathrm{mmol}$, $30 \mathrm{~mol} \%), \mathrm{K}_{2} \mathrm{CO}_{3}(146 \mathrm{mg}, 1.06 \mathrm{mmol})$ and $42 \mathrm{ab}(90.5 \mathrm{mg}, 0.55 \mathrm{mmol})$ in $m$-xylene $(3.0 \mathrm{~mL})$ gave after purification by column chromatography ( $n$-hexane/EtOAc 9:1 to $1: 1)$ 93db (39 mg, 28\%) as a colorless oil.

Intermolecular Competition Experiment between 2-(3-Fluorophenyl)pyridine (6da) and (E)- $\mathrm{N}$-[1-(3Fluorophenyl)ethylidene]-4-methoxyaniline (121b)<smiles>Fc1cccc(-c2ccccn2)c1</smiles>

6da<smiles>CC(=NP)c1cccc(F)c1</smiles>

$121 \mathrm{~d}$

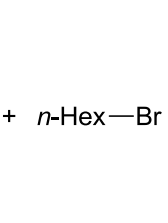

42ab
1. $\left[\mathrm{RuCl}_{2}(p \text {-cymeme })\right]_{2}(5.0 \mathrm{~mol} \%)$ 1-AdCO ${ }_{2} \mathrm{H}(13 \mathrm{c})(30 \mathrm{~mol} \%)$ $\mathrm{K}_{2} \mathrm{CO}_{3}$ (3.2 equiv)

$m$-xylene, $120^{\circ} \mathrm{C}, 20 \mathrm{~h}$ 2. $\mathrm{NaBH}_{3} \mathrm{CN} / \mathrm{ZnCl} 2$ $\mathrm{MeOH} / \mathrm{THF}, 23^{\circ} \mathrm{C}, 16 \mathrm{~h}$

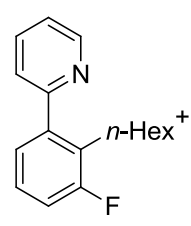

$93 \mathrm{db}$<smiles>CC(NP)c1cccc(F)c1OCc1ccccc1</smiles>

$122 b$

The competition experiment between 121d (246 mg, $1.01 \mathrm{mmol}$ ) and 6da (182 mg, $1.05 \mathrm{mmol})$ with $\left[\mathrm{RuCl}_{2}(p \text {-cymene })\right]_{2} \quad(15.1 \mathrm{mg}, \quad 0.025 \mathrm{mmol}, 4.2 \mathrm{~mol} \%), 1-\mathrm{AdCO}_{2} \mathrm{H} \quad$ (13c) $\quad(27.5 \mathrm{mg}, 0.15 \mathrm{mmol}$, $30 \mathrm{~mol} \%), \mathrm{K}_{2} \mathrm{CO}_{3}(141 \mathrm{mg}, 1.02 \mathrm{mmol})$ and 42ab (101 mg, $\left.0.61 \mathrm{mmol}\right)$ in $m$-xylene $(3.0 \mathrm{~mL})$ gave after purification by column chromatography ( $n$-hexane/EtOAc 9:1) $93 \mathrm{db}(87 \mathrm{mg}, 55 \%)$ and $122 \mathrm{~b}(44 \mathrm{mg}$, $22 \%)$ as a colorless oils. 
Intermolecular Competition Experiment between (E)- $\mathrm{N}$-[1-(3-Fluorophenyl)ethylidene]-4-methoxyaniline (121b) and 2-(3-Fluorophenyl)-4,5-dihydrooxazole (136a)<smiles>Fc1cccc(C2=NCCO2)c1</smiles>

$136 a$<smiles>CC(=NP)c1cccc(F)c1</smiles>

121b

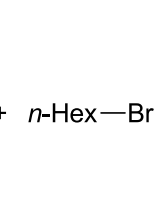

42ab
1. $\left[\mathrm{RuCl}_{2}(p \text {-cymeme })\right]_{2}(5.0 \mathrm{~mol} \%)$ $1-\mathrm{AdCO}_{2} \mathrm{H}(13 \mathrm{c})(30 \mathrm{~mol} \%)$ $\mathrm{K}_{2} \mathrm{CO}_{3}$ (3.2 equiv)

$m$-xylene, $120^{\circ} \mathrm{C}, 20 \mathrm{~h}$ 2. $\mathrm{NaBH}_{3} \mathrm{CN} / \mathrm{ZnCl}_{2}$, $\mathrm{MeOH} / \mathrm{THF}, 23^{\circ} \mathrm{C}, 16 \mathrm{~h}$

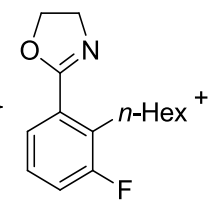<smiles>CC(NC(=O)O)c1ccccc1F</smiles>

$143 a$

$122 b$

The competition experiment between 136a (165 mg, $1.00 \mathrm{mmol}$ ) and 121b (253 mg, $1.04 \mathrm{mmol})$ with $\left[\mathrm{RuCl}_{2}[p \text {-cymene) }]_{2}(15.0 \mathrm{mg}, 0.025 \mathrm{mmol}, 4.2 \mathrm{~mol} \%), 1-\mathrm{AdCO}_{2} \mathrm{H}(27.0 \mathrm{mg}, 0.15 \mathrm{mmol}, 30 \mathrm{~mol} \%)\right.$, $\mathrm{K}_{2} \mathrm{CO}_{3}$ (139 $\left.\mathrm{mg}, 1.01 \mathrm{mmol}\right)$ and $42 \mathrm{ab}(99.0 \mathrm{mg}, 0.60 \mathrm{mmol})$ in $m$-xylene $(3.0 \mathrm{~mL}$ ) gave after purification by column chromatography ( $n$-hexane/EtOAc 9:1 to 1:1) 143a (22 mg, 15\%) and 122b (83 mg, 42\%) as a colorless oils.

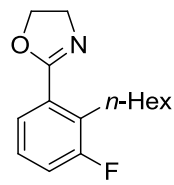

\section{2-(3-Fluoro-2-n-hexylphenyl)-4,5-dihydrooxazole (143a)}

${ }^{1} \mathrm{H}-\mathrm{NMR}\left(300 \mathrm{MHz}, \mathrm{CDCl}_{3}\right): \delta=7.58-7.48(\mathrm{~m}, 1 \mathrm{H}), 7.22-7.03(\mathrm{~m}, 2 \mathrm{H})$, 4.49-4.29 (m, 2H), 4.15-3.97 (m, $2 \mathrm{H}), 3.09-2.76(\mathrm{~m}, 2 \mathrm{H}), 1.62-1.47(\mathrm{~m}, 2 \mathrm{H}), 1.43-1.19(\mathrm{~m}, 6 \mathrm{H}), 0.91-0.84(\mathrm{~m}, 3 \mathrm{H})$.

${ }^{13} \mathrm{C}-\mathrm{NMR}\left(75 \mathrm{MHz}, \mathrm{CDCl}_{3}\right): \delta=164.5\left(\mathrm{~d}, \mathrm{~J}_{\mathrm{C}-\mathrm{F}}=3 \mathrm{~Hz}, \mathrm{C}_{\mathrm{q}}\right), 161.5\left(\mathrm{~d}, \mathrm{~J}_{\mathrm{C}-\mathrm{F}}=243 \mathrm{~Hz}, \mathrm{C}_{\mathrm{q}}\right), 131.0\left(\mathrm{~d}, \mathrm{~J}_{\mathrm{C}-\mathrm{F}}=18 \mathrm{~Hz}\right.$, $\left.C_{\mathrm{q}}\right), 129.5\left(\mathrm{~d}, J_{\mathrm{C}-\mathrm{F}}=5 \mathrm{~Hz}, \mathrm{C}_{\mathrm{q}}\right), 126.7\left(\mathrm{~d}, J_{\mathrm{C}-\mathrm{F}}=9 \mathrm{~Hz}, \mathrm{CH}\right), 125.8\left(\mathrm{~d}, J_{\mathrm{C}-\mathrm{F}}=3 \mathrm{~Hz}, \mathrm{CH}\right), 117.5\left(\mathrm{~d}, J_{\mathrm{C}-\mathrm{F}}=24 \mathrm{~Hz}\right.$, $\mathrm{CH}), 67.3\left(\mathrm{CH}_{2}\right), 55.5\left(\mathrm{CH}_{2}\right), 31.7\left(\mathrm{CH}_{2}\right), 30.4\left(\mathrm{CH}_{2}\right), 29.5\left(\mathrm{CH}_{2}\right), 26.2\left(\mathrm{CH}_{2}\right), 22.7\left(\mathrm{CH}_{2}\right), 14.2\left(\mathrm{CH}_{3}\right)$.

${ }^{19} \mathrm{~F}-\mathrm{NMR}\left(282 \mathrm{MHz}, \mathrm{CDCl}_{3}\right): \delta=-116.94--117.32(\mathrm{~m})$. IR (ATR): $\tilde{v}=2954,2928,2857,1646,1512,1454,1352,1254,1085,981,797,736 \mathrm{~cm}^{-1}$. MS (EI) m/z (relative intensity): 249 (29) [M+], 206 (25), 192 (100), 179 (32), 164 (23), 149 (65), 135 (18), 123 (22), 109 (24).

HR-MS (EI) $m / z$ calculated for $\mathrm{C}_{15} \mathrm{H}_{20} \mathrm{FNO}^{+}:$249.1529; found: 249.1520 . 


\section{Products of Direct Allylation}

\section{Synthesis of 2-(2-Allylphenyl)pyridine (93m)}<smiles>C=CCc1ccccc1-c1ccccn1</smiles>

$\left[\operatorname{RuCl}_{2}(p \text {-cymene })\right]_{2}(7.8 \mathrm{mg}, 13 \mu \mathrm{mol}, 2.9 \mathrm{~mol} \%)$ was added to a suspension of $6 \mathrm{aa}$ (68.8 $\mathrm{mg}$, $0.44 \mathrm{mmol}, 1.0$ equiv) and $\mathrm{K}_{2} \mathrm{CO}_{3}(140 \mathrm{mg}, 1.0 \mathrm{mmol}, 2.0$ equiv) in dry toluene $(2 \mathrm{~mL})$. The reaction mixture was degassed with $\mathrm{N}_{2}$ for $10 \mathrm{~min}$ and allyl bromide (32g) (300 mg, $2.48 \mathrm{mmol}, 5.6$ equiv) was added. The resulting solution was stirred for $20 \mathrm{~h}$ at $120^{\circ} \mathrm{C}$. The reaction mixture was poured into a mixture of diethyl ether and ice-cold water. The aqueous layer was extracted $(3 \times 5 \mathrm{~mL})$ with diethyl ether. The combined organic layers were dried over $\mathrm{Na}_{2} \mathrm{SO}_{4}$ and concentrated under reduced pressure. The crude material was purified using column chromatography through silica gel ( $5 \%$ to $7 \%$ EtOAc in $n$-hexane) to afford compound $93 \mathrm{~m}$ ( $24 \mathrm{mg}, 28 \%$ ) as a yellow oil.

${ }^{1} \mathrm{H}-\mathrm{NMR}\left(300 \mathrm{MHz}, \mathrm{CDCl}_{3}\right): \delta=8.67(\mathrm{ddd}, J=4.9,1.9,1.0 \mathrm{~Hz}, 1 \mathrm{H}), 7.74-7.63(\mathrm{~m}, 1 \mathrm{H}), 7.42-7.18(\mathrm{~m}$, $6 \mathrm{H}), 6.01-5.67(\mathrm{~m}, 1 \mathrm{H}), 5.04-4.75(\mathrm{~m}, 2 \mathrm{H}), 3.47(\mathrm{dt}, J=6.4,1.6 \mathrm{~Hz}, 2 \mathrm{H})$.

${ }^{13} \mathrm{C}-\mathrm{NMR}\left(75 \mathrm{MHz}, \mathrm{CDCl}_{3}\right): \delta=159.9\left(\mathrm{C}_{\mathrm{q}}\right), 149.2(\mathrm{CH}), 140.5\left(\mathrm{C}_{\mathrm{q}}\right), 137.8\left(\mathrm{C}_{\mathrm{q}}\right), 137.7(\mathrm{CH}), 136.3(\mathrm{CH})$, 130.2 (CH), $130.0(\mathrm{CH}), 128.6(\mathrm{CH}), 126.4(\mathrm{CH}), 124.3(\mathrm{CH}), 121.9(\mathrm{CH}), 115.7\left(\mathrm{CH}_{2}\right), 37.5\left(\mathrm{CH}_{2}\right)$.

IR (ATR): $\tilde{v}=3059,3007,2918,1636,1585,1492,1440,1023,989,911,746 \mathrm{~cm}^{-1}$. MS (EI) m/z (relative intensity): 194 (78) [M+], 180 (100), 167 (38), 154 (55), 43 (28).

HR-MS (ESI) $\mathrm{m} / z$ calculated for $\mathrm{C}_{14} \mathrm{H}_{13} \mathrm{~N}+\mathrm{H}^{+}$: 196.1126; found: 196.1124 .

The analytical data are in accordance with those reported in the literature. ${ }^{211}$

Attempted Synthesis of (E)-2-Phenyl-6-(prop-1-en-1-yl)pyridine (145)Fehler! Textmarke nicht efiniert. $^{136}$

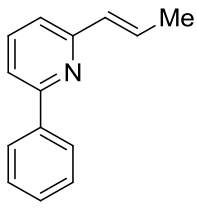

${ }^{211}$ Oi, S.; Tanaka, Y.; Inoue, Y. Organometallics 2006, 25, 4773-4778. 
Following a procedure by Ramana et al., $\left[\mathrm{RuCl}_{2}(p \text {-cymene })\right]_{2}(15.4 \mathrm{mg}, 25 \mu \mathrm{mol}, 2.3 \mathrm{~mol} \%)$ was added to a suspension of $6 \mathrm{aa}$ (167 mg, $1.08 \mathrm{mmol}, 1.0$ equiv), 1- $\mathrm{AdCO}_{2} \mathrm{H}(55.5 \mathrm{mg}, 0.31 \mathrm{mmol}, 29 \mathrm{~mol} \%$ ) and $\mathrm{K}_{2} \mathrm{CO}_{3}$ (277 mg, $2.00 \mathrm{mmol}, 1.85$ equiv) in dry toluene $(5 \mathrm{~mL})$. The reaction mixture was degassed with $\mathrm{N}_{2}$ for $10 \mathrm{~min}$ and allyl bromide $(605 \mathrm{mg}, 5.00 \mathrm{mmol}, 4.6$ equiv) was added. The resulting solution was stirred at $120{ }^{\circ} \mathrm{C}$ for $20 \mathrm{~h}$. The reaction mixture was poured into a mixture of diethyl ether and ice-cold water. The aqueous layer was extracted $(3 \times 10 \mathrm{~mL})$ with diethyl ether. The combined organic layers were dried over $\mathrm{Na}_{2} \mathrm{SO}_{4}$ and concentrated under reduced pressure. The crude material was purified twice by column chromatography through silica gel (5\% to $7 \%$ EtOAc in $n$ hexane) to afford compound 145 (149 mg, calc. ${ }^{1} \mathrm{H}-\mathrm{NMR}$-yield: 69\%) as a yellow oil including remainings of the formed allyl 1-adamantane-1-carboxylate.

The NMR data were in accordance with those reported in the literature. ${ }^{136}$ 


\subsection{Analytical Data for the Ruthenium-Catalyzed meta-Alkylation}

\section{Synthesis of 2-[3-(Octan-2-yl)phenyl]pyridine (147aa)}

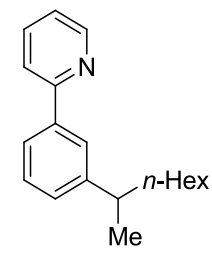

The general procedure $\mathbf{E}$ was followed, using $\left[\mathrm{RuCl}_{2}(p \text {-cymene })\right]_{2}(7.90 \mathrm{mg}, 0.013 \mathrm{mmol}, 2.5 \mathrm{~mol} \%)$, 6aa $(87.5 \mathrm{mg}, 0.56 \mathrm{mmol}), 2$-bromooctane (42ba) (294 mg, $1.52 \mathrm{mmol}), \mathrm{MesCO}_{2} \mathrm{H}$ (13a) (25 mg, $0.15 \mathrm{mmol}, 26 \mathrm{~mol} \%)$ and $\mathrm{K}_{2} \mathrm{CO}_{3}(138 \mathrm{mg}, 1.00 \mathrm{mmol})$. After $20 \mathrm{~h}$, purification by column chromatography ( $n$-hexane/EtOAc 9:1) yielded 147aa (89 mg, 60\%) as a colorless oil.

The general procedure $\mathbf{E}$ with $(S)$-3-methyl-2-pivalamidobutanoic acid (76a) $(31.0 \mathrm{mg}, 0.15 \mathrm{mmol}$, $30 \mathrm{~mol} \%)$ as additive in water $(2 \mathrm{~mL})$ at $100{ }^{\circ} \mathrm{C}$ gave $73 \%$ isolated yield.

The general procedure $\mathbf{E}$ with di-nonan-3-yl hydrogen phosphate $(\mathbf{1 7 5 c})(54.0 \mathrm{mg}, 0.17 \mathrm{mmol}$, $34 \mathrm{~mol} \%)$ as additive in water $(2 \mathrm{~mL})$ at $100{ }^{\circ} \mathrm{C}$ gave $58 \%$ isolated yield.

${ }^{1} \mathrm{H}-\mathrm{NMR}\left(300 \mathrm{MHz}, \mathrm{CDCl}_{3}\right): \delta=8.71(\mathrm{dt}, J=4.8,1.4 \mathrm{~Hz}, 1 \mathrm{H}), 7.85(\mathrm{t}, J=1.8 \mathrm{~Hz}, 1 \mathrm{H}), 7.79(\mathrm{dt}, J=7.7$, $1.5 \mathrm{~Hz}, 1 \mathrm{H}), 7.73(\mathrm{dd}, J=4.1,1.2 \mathrm{~Hz}, 2 \mathrm{H}), 7.40(\mathrm{t}, J=7.7 \mathrm{~Hz}, 1 \mathrm{H}), 7.31-7.10(\mathrm{~m}, 2 \mathrm{H}), 2.79$ (qt, $J=7.1$, $7.0 \mathrm{~Hz}, 1 \mathrm{H}), 1.76-1.55(\mathrm{~m}, 2 \mathrm{H}), 1.38-1.10(\mathrm{~m}, 8 \mathrm{H}), 1.30(\mathrm{~d}, J=7.0 \mathrm{~Hz}, 3 \mathrm{H}), 0.86(\mathrm{t}, J=7.0 \mathrm{~Hz}, 3 \mathrm{H})$.

${ }^{13} \mathrm{C}-\mathrm{NMR}\left(75 \mathrm{MHz}, \mathrm{CDCl}_{3}\right): \delta=157.7\left(\mathrm{C}_{\mathrm{q}}\right), 149.4(\mathrm{CH}), 148.5\left(\mathrm{C}_{\mathrm{q}}\right), 139.1\left(\mathrm{C}_{\mathrm{q}}\right), 136.8(\mathrm{CH}), 128.6(\mathrm{CH})$, $127.6(\mathrm{CH}), 125.7(\mathrm{CH}), 124.4(\mathrm{CH}), 121.9(\mathrm{CH}), 120.7(\mathrm{CH}), 40.1(\mathrm{CH}), 38.4\left(\mathrm{CH}_{2}\right), 31.8\left(\mathrm{CH}_{2}\right), 29.4$ $\left(\mathrm{CH}_{2}\right), 27.7\left(\mathrm{CH}_{2}\right), 22.6\left(\mathrm{CH}_{2}\right), 22.3\left(\mathrm{CH}_{3}\right), 14.0\left(\mathrm{CH}_{3}\right)$.

IR (ATR): $\tilde{\boldsymbol{V}}=2956,2924,2854,1584,1566,1461,1434,772,742,700 \mathrm{~cm}^{-1}$. MS (EI) m/z (relative intensity): 267 (13) [M+'], 196 (32), 182 (100), 167 (58), 78 (13).

HRMS (EI) m/z calculated for $\mathrm{C}_{19} \mathrm{H}_{25} \mathrm{~N}+\mathrm{H}^{+}$: 268.2060; found: 268.2063 .

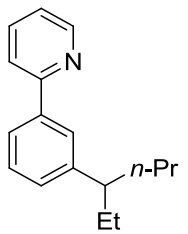


The general procedure $\mathbf{E}$ was followed, using $\left[\mathrm{RuCl}_{2}(p \text {-cymene) }]_{2}(7.9 \mathrm{mg}, 0.013 \mathrm{mmol}, 2.5 \mathrm{~mol} \%)\right.$, $\mathrm{MesCO}_{2} \mathrm{H}$ (13a) (25 mg, $\left.0.15 \mathrm{mmol}, 30 \mathrm{~mol} \%\right), 6$ aa $(77.5 \mathrm{mg}, 0.50 \mathrm{mmol}$ ) and 3-bromohexane (42bb) (242 $\mathrm{mg}, 1.47 \mathrm{mmol}$ ). After $20 \mathrm{~h}$, purification by column chromatography ( $n$-hexane/EtOAc 9:1) yielded $147 \mathrm{bb}$ ( $31 \mathrm{mg}, 26 \%$ ) as a colorless oil.

${ }^{1} \mathrm{H}-\mathrm{NMR}\left(300 \mathrm{MHz}, \mathrm{CDCl}_{3}\right): \delta=8.85-8.61(\mathrm{~m}, 1 \mathrm{H})$, 7.98-7.64 $(\mathrm{m}, 4 \mathrm{H})$, 7.49-7.34 $(\mathrm{m}, 1 \mathrm{H})$, 7.32-7.11 (m, $2 \mathrm{H}), 2.53(\mathrm{dt}, J=8.7,5.8 \mathrm{~Hz}, 1 \mathrm{H}), 1.85-1.52(\mathrm{~m}, 4 \mathrm{H}), 1.39-1.10(\mathrm{~m}, 2 \mathrm{H}), 0.93-0.74(\mathrm{~m}, 6 \mathrm{H})$.

${ }^{13} \mathrm{C}-\mathrm{NMR}\left(75 \mathrm{MHz}, \mathrm{CDCl}_{3}\right): \delta=158.0\left(\mathrm{C}_{\mathrm{q}}\right), 149.7(\mathrm{CH}), 146.8\left(\mathrm{C}_{\mathrm{q}}\right), 139.4\left(\mathrm{C}_{\mathrm{q}}\right), 136.7(\mathrm{CH}), 128.7(\mathrm{CH})$, $128.5(\mathrm{CH}), 126.6(\mathrm{CH}), 124.6(\mathrm{CH}), 122.0(\mathrm{CH}), 120.8(\mathrm{CH}), 47.9(\mathrm{CH}), 39.0\left(\mathrm{CH}_{2}\right), 29.8\left(\mathrm{CH}_{2}\right), 20.9$ $\left(\mathrm{CH}_{2}\right), 14.3\left(\mathrm{CH}_{3}\right), 12.4\left(\mathrm{CH}_{3}\right)$.

IR (ATR): $\tilde{v}=3050,2956,2926,2871,1584,1566,1460,1434,769,741 \mathrm{~cm}^{-1}$.

MS (EI) m/z (relative intensity): 239 (24) [M+], 210 (58), 196 (68), 182 (21), 168 (100).

HR-MS (ESI) $m / z$ calculated for $\mathrm{C}_{17} \mathrm{H}_{21} \mathrm{~N}+\mathrm{H}^{+}$: 240.1752; found: 240.1747.

\section{Synthesis of 2-(3-Cycloheptylphenyl)pyridine (147ac)}

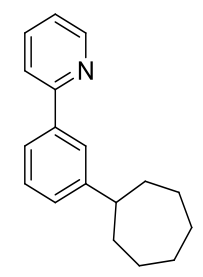

The general procedure $\mathbf{E}$ was followed, using $\left[\mathrm{RuCl}_{2}(p \text {-cymene })\right]_{2}(8.10 \mathrm{mg}, 0.013 \mathrm{mmol}, 2.5 \mathrm{~mol} \%)$, $\mathrm{MesCO}_{2} \mathrm{H}$ (13a) (25 mg, $0.15 \mathrm{mmol}, 29 \mathrm{~mol} \%$ ), 6aa $(80.3 \mathrm{mg}, 0.52 \mathrm{mmol}$ ) and bromocycloheptane (42bc) $(270 \mathrm{mg}, 1.52 \mathrm{mmol})$. After $20 \mathrm{~h}$, purification by column chromatography ( $n$-hexane/EtOAc 9:1) yielded 147 ac (99 $\mathrm{mg}, 76 \%$ ) as a colorless oil.

${ }^{1} \mathrm{H}-\mathrm{NMR}\left(300 \mathrm{MHz}, \mathrm{CDCl}_{3}\right): \delta=8.68(\mathrm{dd}, J=4.8,1.4,1.4 \mathrm{~Hz}, 1 \mathrm{H}), 7.84(\mathrm{dd}, J=1.9,1.8 \mathrm{~Hz}, 1 \mathrm{H}), 7.78-$ $7.65(\mathrm{~m}, 3 \mathrm{H}), 7.36(\mathrm{dd}, J=7.7,7.7 \mathrm{~Hz}, 1 \mathrm{H}), 7.27-7.13(\mathrm{~m}, 2 \mathrm{H}), 2.84-2.65(\mathrm{~m}, 1 \mathrm{H}), 2.06-1.88(\mathrm{~m}, 2 \mathrm{H})$, 1.88-1.47 (m, 10H).

${ }^{13} \mathrm{C}$-NMR $\left(75 \mathrm{MHz}, \mathrm{CDCl}_{3}\right): \delta=158.0\left(\mathrm{C}_{\mathrm{q}}\right), 150.7\left(\mathrm{C}_{\mathrm{q}}\right), 149.7(\mathrm{CH}), 139.5\left(\mathrm{C}_{\mathrm{q}}\right), 136.7(\mathrm{CH}), 128.8(\mathrm{CH})$, $127.5(\mathrm{CH}), 125.6(\mathrm{CH}), 124.3(\mathrm{CH}), 122.0(\mathrm{CH}), 120.8(\mathrm{CH}), 47.3(\mathrm{CH}), 37.0\left(\mathrm{CH}_{2}\right), 28.0\left(\mathrm{CH}_{2}\right), 27.4$ $\left(\mathrm{CH}_{2}\right)$.

IR (ATR): $\tilde{V}=3059,2918,2852,1584,1564,1460,1434,1151,990,769,741,699 \mathrm{~cm}^{-1}$.

MS (El) m/z (relative intensity): 251 (100) [M+], 236 (15), 222 (40), 208 (65), 194 (77), 182 (74), 169 (75), $155(38)$. 
HRMS (ESI) $\mathrm{m} / \mathrm{z}$ calculated for $\mathrm{C}_{18} \mathrm{H}_{21} \mathrm{~N}-\mathrm{H}^{+}: 250.1596$; found 250.1594 .

\section{Synthesis of 2-(3-Cyclohexylphenyl)pyridine (147ad)}

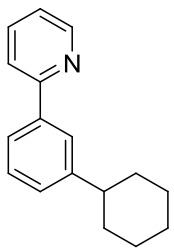

The general procedure $\mathbf{E}$ was followed, using $\left[\operatorname{RuCl}_{2}(p \text {-cymene })\right]_{2}(7.70 \mathrm{mg}, 0.013 \mathrm{mmol}, 2.3 \mathrm{~mol} \%)$, $\mathrm{MesCO}_{2} \mathrm{H}$ (13a) (25 mg, $\left.0.15 \mathrm{mmol}, 27 \mathrm{~mol} \%\right), 6$ aa $(86.4 \mathrm{mg}, 0.56 \mathrm{mmol}$ ) and bromocyclohexane (42bd) (271 mg, $1.66 \mathrm{mmol})$. After $20 \mathrm{~h}$, purification by column chromatography ( $n$-hexane/EtOAc 9:1) yielded $147 \mathrm{ad}$ (77 $\mathrm{mg}, 58 \%$ ) as a colorless oil.

${ }^{1} \mathrm{H}-\mathrm{NMR}\left(300 \mathrm{MHz}, \mathrm{CDCl}_{3}\right): \delta=8.70(\mathrm{ddd}, J=4.8,1.4,1.4 \mathrm{~Hz}, 1 \mathrm{H}), 7.88(\mathrm{dd}, J=1.8,1.8 \mathrm{~Hz}, 1 \mathrm{H}$ ), $7.82-$ $7.66(\mathrm{~m}, 3 \mathrm{H}), 7.40(\mathrm{dd}, J=7.4,7.4 \mathrm{~Hz}, 1 \mathrm{H}), 7.31-7.24(\mathrm{~m}, 1 \mathrm{H}), 7.24-7.17(\mathrm{~m}, 1 \mathrm{H}), 2.60-2.61(\mathrm{~m}, 1 \mathrm{H})$, 2.04-1.69 (m, 5H), 1.62-1.16 (m, 5H).

${ }^{13} \mathrm{C}-\mathrm{NMR}\left(75 \mathrm{MHz}, \mathrm{CDCl}_{3}\right): \delta=157.8\left(\mathrm{C}_{\mathrm{q}}\right), 149.6(\mathrm{CH}), 148.6\left(\mathrm{C}_{\mathrm{q}}\right), 139.3\left(\mathrm{C}_{\mathrm{q}}\right), 136.6(\mathrm{CH}), 128.6(\mathrm{CH})$, $127.4(\mathrm{CH}), 125.6(\mathrm{CH}), 124.4(\mathrm{CH}), 121.9(\mathrm{CH}), 120.6(\mathrm{CH}), 44.7(\mathrm{CH}), 34.4\left(\mathrm{CH}_{2}\right), 26.9\left(\mathrm{CH}_{2}\right), 26.1$ $\left(\mathrm{CH}_{2}\right)$.

IR (ATR): $\tilde{v}=3050,2921,2849,1583,1564,1448,1434,1414,1267,882,769,698,642,613 \mathrm{~cm}^{-1}$. MS (EI) m/z (relative intensity): 237 (100) [ $\left.\mathrm{M}^{+}\right], 208$ (36), 194 (38), 182 (71), 169 (27), 155 (16).

HR-MS (ESI) $m / z$ calculated for $\mathrm{C}_{17} \mathrm{H}_{19} \mathrm{~N}+\mathrm{H}^{+}$: 238.1596; found: 238.1589 .

\section{Synthesis of 2-(3-Cyclopropylphenyl)pyridine (147ae)}

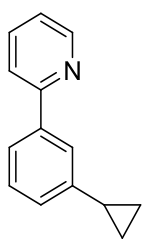

The general procedure $\mathbf{E}$ was followed in a sealed tube, using $\left[\operatorname{RuCl}_{2}(p \text {-cymene })\right]_{2}(15.3 \mathrm{mg}$, $0.025 \mathrm{mmol}, 5.0 \mathrm{~mol} \%$ ), MesCO $2 \mathrm{H} \mathrm{(13a)}(25 \mathrm{mg}, 0.15 \mathrm{mmol}, 28 \mathrm{~mol} \%), 6$ aa (82.3 mg, $0.53 \mathrm{mmol}$ ) and bromocyclopropane (42 be) $(189 \mathrm{mg}, 1.56 \mathrm{mmol})$. After $20 \mathrm{~h}$, purification by column chromatography ( $n$-hexane/EtOAc 9:1) yielded 147ae (10 mg, 10\%) as a colorless oil. 
${ }^{1} \mathrm{H}-\mathrm{NMR}\left(300 \mathrm{MHz}, \mathrm{CDCl}_{3}\right): \delta=8.72(\mathrm{ddd}, J=4.9,1.9,1.0 \mathrm{~Hz}, 1 \mathrm{H}), 7.86-7.63(\mathrm{~m}, 1 \mathrm{H}), 7.55(\mathrm{dd}, J=7.8$, $1.2 \mathrm{~Hz}, 1 \mathrm{H}$ ), 7.42 (ddd, $J=7.2,1.5,1.2 \mathrm{~Hz}, 1 \mathrm{H}), 7.37-7.15(\mathrm{~m}, 3 \mathrm{H}), 7.00$ (dd, $J=7.6,1.4 \mathrm{~Hz}, 1 \mathrm{H}$ ), 2.13$1.96(\mathrm{~m}, 1 \mathrm{H}), 0.89-0.74(\mathrm{~m}, 2 \mathrm{H}), 0.74-0.58(\mathrm{~m}, 2 \mathrm{H})$.

${ }^{13} \mathrm{C}-\mathrm{NMR}\left(75 \mathrm{MHz}, \mathrm{CDCl}_{3}\right): \delta=159.7\left(\mathrm{C}_{\mathrm{q}}\right), 149.1(\mathrm{CH}), 141.0(\mathrm{CH}), 140.9(\mathrm{CH}), 136.0(\mathrm{CH}), 129.6(\mathrm{CH})$, $128.5(\mathrm{CH}), 125.5(\mathrm{CH}), 124.7(\mathrm{CH}), 124.6(\mathrm{CH}), 121.6(\mathrm{CH}), 13.3(\mathrm{CH}), 9.3\left(\mathrm{CH}_{2}\right)$.

IR (ATR): $\tilde{v}=3060,3003,1584,1562,1467,1424,1020,899,794,746 \mathrm{~cm}^{-1}$.

MS (EI) $m / z$ (relative intensity): 194 (17) [M- $\left.\mathrm{H}^{+}\right], 180$ (22), 167 (100), 139 (11).

HR-MS (ESI) $m / z$ calculated for $\mathrm{C}_{14} \mathrm{H}_{13} \mathrm{~N}+\mathrm{H}^{+}$: 196.1126; found: 196.1122 .

\section{Synthesis of 2-[3-(Nonan-5-yl)phenyl]pyridine (147ag)}

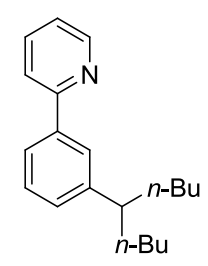

The general procedure $\mathbf{E}$ was followed, using $\left[\mathrm{RuCl}_{2}(p \text {-cymene })\right]_{2}(8.20 \mathrm{mg}, 0.013 \mathrm{mmol}, 2.6 \mathrm{~mol} \%)$, $\mathrm{MesCO}_{2} \mathrm{H}$ (13a) (25 mg, $\left.0.15 \mathrm{mmol}, 30 \mathrm{~mol} \%\right), 6$ aa $(71.5 \mathrm{mg}, 0.46 \mathrm{mmol}$ ) and 5-bromononane (42bg) (318 mg, $1.54 \mathrm{mmol}$ ). After $20 \mathrm{~h}$, purification by column chromatography ( $n$-hexane/EtOAc 5:1) yielded 147ag (66 mg, 51\%) as a colorless oil.

${ }^{1} \mathrm{H}-\mathrm{NMR}\left(300 \mathrm{MHz}, \mathrm{CDCl}_{3}\right): \delta=8.68(\mathrm{dd}, J=4.8,1.4 \mathrm{~Hz}, 1 \mathrm{H}), 7.82-7.75(\mathrm{~m}, 2 \mathrm{H}), 7.74-7.65(\mathrm{~m}, 2 \mathrm{H}), 7.37$ (dd, $J=8.5,7.6 \mathrm{~Hz}, 1 \mathrm{H}), 7.23-7.14(\mathrm{~m}, 2 \mathrm{H}), 2.64-2.49(\mathrm{~m}, 1 \mathrm{H}), 1.76-1.50(\mathrm{~m}, 4 \mathrm{H}), 1.36-1.01(\mathrm{~m}, 8 \mathrm{H})$, $0.81(\mathrm{t}, J=7.0 \mathrm{~Hz}, 6 \mathrm{H})$.

${ }^{13} \mathrm{C}$-NMR $\left(75 \mathrm{MHz}, \mathrm{CDCl}_{3}\right): \delta=157.9\left(\mathrm{C}_{\mathrm{q}}\right), 149.6(\mathrm{CH}), 147.0\left(\mathrm{C}_{\mathrm{q}}\right), 139.2\left(\mathrm{C}_{\mathrm{q}}\right), 136.6(\mathrm{CH}), 128.5(\mathrm{CH})$, $128.2(\mathrm{CH}), 126.3(\mathrm{CH}), 124.4(\mathrm{CH}), 121.9(\mathrm{CH}), 120.6(\mathrm{CH}), 46.2(\mathrm{CH}), 36.6\left(\mathrm{CH}_{2}\right), 29.9\left(\mathrm{CH}_{2}\right), 22.8$ $\left(\mathrm{CH}_{2}\right), 14.0\left(\mathrm{CH}_{3}\right)$.

IR (ATR): $\tilde{v}=2955,2925,2856,1584,1566,1461,1435,1416,770,741 \mathrm{~cm}^{-1}$.

MS (El) m/z (relative intensity): 281 (56) [ $\left.\mathrm{M}^{+}\right], 238$ (25), 224 (100), 168 (82).

HRMS (EI) $\mathrm{m} / \mathrm{z}$ calculated for $\mathrm{C}_{20} \mathrm{H}_{27} \mathrm{~N}^{+}: 281.2143$; found: 281.2140 . 


\section{Synthesis of 2-[3-(Pentan-3-yl)phenyl]pyridine (147ah)}

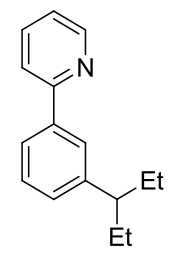

The general procedure $\mathbf{E}$ was followed, using $\left[\operatorname{RuCl}_{2}(p \text {-cymene })\right]_{2}(8.00 \mathrm{mg}, 0.013 \mathrm{mmol}, 2.5 \mathrm{~mol} \%)$, $\mathrm{MesCO}_{2} \mathrm{H}$ (13a) $(27 \mathrm{mg}, 0.15 \mathrm{mmol}, 26 \mathrm{~mol} \%), 6$ aa $(87.0 \mathrm{mg}, 0.56 \mathrm{mmol}$ ) and 3-bromopentane (42bh) $(235 \mathrm{mg}, 1.55 \mathrm{mmol})$. After $20 \mathrm{~h}$, purification by column chromatography ( $n$-hexane/EtOAc 9:1) yielded 147ah (53 $\mathrm{mg}, 42 \%$ ) as a colorless oil.

${ }^{1}$ H-NMR $\left(300 \mathrm{MHz}, \mathrm{CDCl}_{3}\right): \delta=8.74-8.64(\mathrm{~m}, 1 \mathrm{H})$, 7.85-7.76 (m, 2H), 7.75-7.66 (m, 2H), 7.38 (dd, $J=$ 8.0, $8.0 \mathrm{~Hz}, 1 \mathrm{H}), 7.24-7.12(\mathrm{~m}, 2 \mathrm{H}), 2.51-2.32(\mathrm{~m}, 1 \mathrm{H}), 1.83-1.52(\mathrm{~m}, 4 \mathrm{H}), 0.79(\mathrm{t}, J=8.1 \mathrm{~Hz}, 6 \mathrm{H})$.

${ }^{13} \mathrm{C}-\mathrm{NMR}\left(75 \mathrm{MHz}, \mathrm{CDCl}_{3}\right): \delta=158.0\left(\mathrm{C}_{\mathrm{q}}\right), 149.7(\mathrm{CH}), 146.5\left(\mathrm{C}_{\mathrm{q}}\right), 139.3\left(\mathrm{C}_{\mathrm{q}}\right), 136.8(\mathrm{CH}), 128.7(\mathrm{CH})$, $128.5(\mathrm{CH}), 126.7(\mathrm{CH}), 124.6(\mathrm{CH}), 122.1(\mathrm{CH}), 120.8(\mathrm{CH}), 50.0(\mathrm{CH}), 29.4\left(\mathrm{CH}_{2}\right), 12.4\left(\mathrm{CH}_{3}\right)$.

IR (ATR): $\tilde{v}=3050,2959,2926,2872,1584,1565,1461,1435,1152,767,700 \mathrm{~cm}^{-1}$. MS (EI) m/z (relative intensity): 225 (29) [M+], 196 (100), 168 (30), 78 (10), 41 (14). HR-MS (ESI) $m / z$ calculated for $\mathrm{C}_{16} \mathrm{H}_{19} \mathrm{~N}+\mathrm{H}^{+}$: 226.1596; found: 226.1593.

\section{Synthesis 2-[3-(Pentan-2-yl)phenyl]pyridine (147ai)}

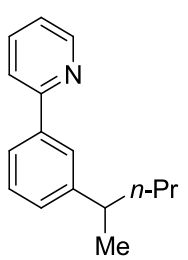

An up-scaled version of The general procedure E with less catalyst loading was followed, using $\left[\operatorname{RuCl}_{2}(p \text {-cymene })\right]_{2} \quad(14.6 \mathrm{mg}, 0.024 \mathrm{mmol}, 5.0 \mathrm{~mol} \%), \mathrm{MesCO}_{2} \mathrm{H} \quad$ (13a) $(24.6 \mathrm{mg}, 0.15 \mathrm{mmol}$, $30 \mathrm{~mol} \%), \mathrm{K}_{2} \mathrm{CO}_{3}(1.39 \mathrm{mg}, 9.80 \mathrm{mmol}), 6 \mathrm{aa}(0.75 \mathrm{~g}, 4.82 \mathrm{mmol})$ and 2-bromopentane (42bi) (2.32 g, $15.4 \mathrm{mmol}$ ). After $48 \mathrm{~h}$, purification by column chromatography ( $n$-hexane/EtOAc 9:1) yielded 147ai $(0.47 \mathrm{~g}, 43 \%)$ as a colorless oil.

${ }^{1} \mathrm{H}-\mathrm{NMR}\left(300 \mathrm{MHz}, \mathrm{CDCl}_{3}\right): \delta=8.70(\mathrm{ddd}, J=5.0,1.5,1.4 \mathrm{~Hz}, 1 \mathrm{H}), 7.89-7.65(\mathrm{~m}, 4 \mathrm{H}), 7.39$ (ddd, $J=7.6$, 3.1, 3.0 Hz, 1H), 7.30-7.15 (m, 2H), 2.81 (qt, $J=7.0,6.9 \mathrm{~Hz}, 1 \mathrm{H}), 1.77-1.48(\mathrm{~m}, 2 \mathrm{H}), 1.40-1.11(\mathrm{~m}, 2 \mathrm{H})$, $1.30(\mathrm{~d}, J=7.0 \mathrm{~Hz}, 3 \mathrm{H}), 0.88(\mathrm{t}, J=7.3 \mathrm{~Hz}, 3 \mathrm{H})$. 
${ }^{13} \mathrm{C}-\mathrm{NMR}\left(75 \mathrm{MHz}, \mathrm{CDCl}_{3}\right): \delta=157.9\left(\mathrm{C}_{\mathrm{q}}\right), 149.7(\mathrm{CH}), 148.6\left(\mathrm{C}_{\mathrm{q}}\right), 139.5\left(\mathrm{C}_{\mathrm{q}}\right), 136.7(\mathrm{CH}), 128.8(\mathrm{CH})$, $127.7(\mathrm{CH}), 125.9(\mathrm{CH}), 124.5(\mathrm{CH}), 122.0(\mathrm{CH}), 120.7(\mathrm{CH}), 40.8\left(\mathrm{CH}_{2}\right), 39.9(\mathrm{CH}), 22.4\left(\mathrm{CH}_{2}\right), 21.0$ $\left(\mathrm{CH}_{3}\right), 14.2\left(\mathrm{CH}_{3}\right)$.

IR (ATR): $\tilde{v}=3049,2956,2927,2870,1603,1584,1461,1434,1415,914,771,742,699,614 \mathrm{~cm}^{-1}$.

MS (70 eV, El) m/z (relative intensity): 225 (34) [M+', 196 (31), 182 (100), 167 (18), 154 (15), 77 (22), 43 (20).

HR-MS (ESI) $m / z$ calculated for $\mathrm{C}_{16} \mathrm{H}_{19} \mathrm{~N}^{+}$: 225.1517; found: 225.1513 .

Synthesis of 2-[4-Methoxy-3-(octan-2-yl)phenyl]pyridine (147ba)

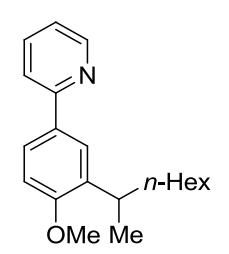

The general procedure $\mathbf{E}$ was followed, using $\left[\mathrm{RuCl}_{2}(p \text {-cymene })\right]_{2}(7.30 \mathrm{mg}, 0.012 \mathrm{mmol}, 2.3 \mathrm{~mol} \%)$, $\mathrm{MesCO}_{2} \mathrm{H}$ (13a) (24 mg, $\left.0.15 \mathrm{mmol}, 28 \mathrm{~mol} \%\right), 6$ ba (95.0 mg, $0.51 \mathrm{mmol}$ ) and 2-bromooctane (42ba) (287 mg, $1.48 \mathrm{mmol}$ ). After $20 \mathrm{~h}$, purification by column chromatography ( $n$-hexane/EtOAc 9:1) yielded $147 \mathrm{ba}$ ( $91 \mathrm{mg}, 60 \%$ ) as a colorless oil.

The general procedure $\mathbf{E}$ was followed, using [Ru(p-cymene) $\left.\left(\mathrm{MesCO}_{2}\right)_{2}\right](\mathbf{1 2})(15.0 \mathrm{mg}, 0.027 \mathrm{mmol})$, 6ba ( $96.2 \mathrm{mg}, 0.52 \mathrm{mmol}$ ) and 2-bromooctane (42ba) (282 mg, $1.43 \mathrm{mmol}$ ). After $20 \mathrm{~h}$, purification by column chromatography ( $n$-hexane/EtOAc 9:1) yielded 147ba (110 mg, 71\%).

The general procedure $\mathbf{E}$ was followed, using [Ru(p-cymene)(MesCO $\left.\mathrm{CO}_{2}\right)\{2$-(4-methoxy-phenyl)pyridyl\}] (14a) (15.8 mg, $0.027 \mathrm{mmol}, 5.0 \mathrm{~mol} \%), 6$ ba $(102.9 \mathrm{mg}, 0.56 \mathrm{mmol}$ ) and 2-bromooctane (42ba) (300 mg, $1.55 \mathrm{mmol}$ ). After $20 \mathrm{~h}$, purification by column chromatography ( $n$-hexane/EtOAc 9:1) yielded 147ba (114 mg, 69\%).

The general procedure $\mathrm{E}$ was followed, using [Ru(p-cymene)(2-phenylpyridyl)Cl] (178) (10.9 mg, $0.026 \mathrm{mmol}, 2.5 \mathrm{~mol} \%), \mathrm{MesCO}_{2} \mathrm{H}$ (13a) $(25.0 \mathrm{mg}, 0.15 \mathrm{mmol}, 30 \mathrm{~mol} \%), 6$ ba (98.0 mg, $0.53 \mathrm{mmol}$ ) and 2-bromooctane (42ba) (300 mg, $1.55 \mathrm{mmol}$ ). After $20 \mathrm{~h}$, purification by column chromatography ( $n$-hexane/EtOAc 9:1 to 5:1) yielded 147ba (68 mg, 43\%).

The general procedure $\mathbf{E}$ with $(S)$-3-methyl-2-pivalamidobutanoic acid $(\mathbf{7 6 c})(31.0 \mathrm{mg}, 0.15 \mathrm{mmol})$ in

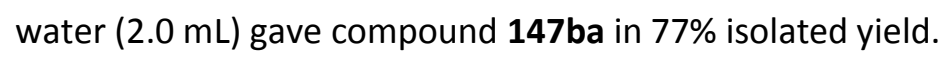


The general procedure $\mathbf{E}$ with dinona-3-yl hydrogen phosphate (175c) $(54.0 \mathrm{mg}, 0.17 \mathrm{mmol})$ gave compound 147 ba in $77 \%$ isolated yield.

${ }^{1} \mathrm{H}-\mathrm{NMR}\left(300 \mathrm{MHz}, \mathrm{CDCl}_{3}\right): \delta=8.66(\mathrm{ddd}, J=4.4,1.4,1.0 \mathrm{~Hz}, 1 \mathrm{H}), 7.84(\mathrm{~d}, J=2.0 \mathrm{~Hz}, 1 \mathrm{H}), 7.80(\mathrm{dt}, J=$ 8.5, $1.8 \mathrm{~Hz}, 1 \mathrm{H}), 7.75-7.63(\mathrm{~m}, 2 \mathrm{H}), 7.19-7.11(\mathrm{~m}, 1 \mathrm{H}), 6.94(\mathrm{dd}, J=8.4,1.2 \mathrm{~Hz}, 1 \mathrm{H}), 3.87(\mathrm{~s}, 3 \mathrm{H}), 3.23$ (qt, $J=7.1,6.9 \mathrm{~Hz}, 1 \mathrm{H}), 1.79-1.50(\mathrm{~m}, 2 \mathrm{H}), 1.39-1.16(\mathrm{~m}, 8 \mathrm{H}), 1.26(\mathrm{~d}, J=6.9 \mathrm{~Hz}, 3 \mathrm{H}), 0.86(\mathrm{t}, J=$ $6.4 \mathrm{~Hz}, 3 \mathrm{H})$.

${ }^{13} \mathrm{C}$-NMR $\left(75 \mathrm{MHz}, \mathrm{CDCl}_{3}\right): \delta=158.0\left(\mathrm{C}_{\mathrm{q}}\right), 157.6\left(\mathrm{C}_{\mathrm{q}}\right), 149.4(\mathrm{CH}), 136.5\left(\mathrm{C}_{\mathrm{q}}\right), 136.5(\mathrm{CH}), 131.7(\mathrm{CH})$, $125.5\left(\mathrm{C}_{\mathrm{q}}\right), 125.2(\mathrm{CH}), 121.1(\mathrm{CH}), 119.9(\mathrm{CH}), 110.5(\mathrm{CH}), 55.5\left(\mathrm{CH}_{3}\right), 37.1\left(\mathrm{CH}_{2}\right), 32.1(\mathrm{CH}), 31.8\left(\mathrm{CH}_{2}\right)$, $29.4\left(\mathrm{CH}_{2}\right), 27.7\left(\mathrm{CH}_{2}\right), 22.6\left(\mathrm{CH}_{2}\right), 20.9\left(\mathrm{CH}_{3}\right), 14.1\left(\mathrm{CH}_{3}\right)$.

IR (ATR): $\tilde{v}=2956,2927,2856,1606,1563,1502,1464,1431,1271,1245,781 \mathrm{~cm}^{-1}$. MS (El) m/z (relative intensity): 297 (27) [ $\left.\mathrm{M}^{+}\right], 212$ (100), 197 (15), 167 (30).

HRMS (El) m/z calculated for $\mathrm{C}_{20} \mathrm{H}_{27} \mathrm{NO}^{+}$: 297.2093; found: 297.2094.

\section{Direct meta-Alkylation of $6 \mathrm{ba}$ using enantiopure $(S)-42 \mathrm{ba}$}

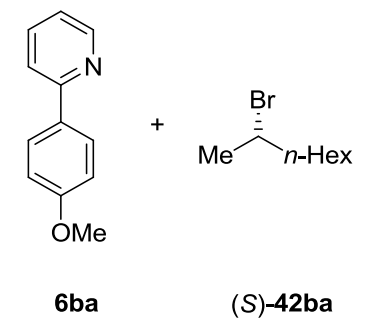

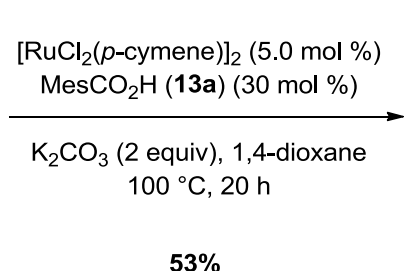

$53 \%$

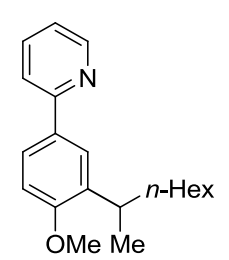

(rac)-147ba

The general procedure $\mathbf{E}$ was followed, using $\left[\mathrm{RuCl}_{2}(p \text {-cymene })\right]_{2}(14.8 \mathrm{mg}, 0.024 \mathrm{mmol}, 5.0 \mathrm{~mol} \%)$, 6ba (94.8 mg, $0.51 \mathrm{mmol}$ ) and (S)-2-bromooctane (S)-42ba) (298 mg, $1.54 \mathrm{mmol})$. After $20 \mathrm{~h}$, purification by column chromatography ( $n$-hexane/EtOAc 9:1) yielded ( $\mathrm{rac}$ )-147ba ( $81 \mathrm{mg}, 53 \%$ ) as a colorless oil. The racemization was confirmed by analytical HPLC on chiral stationary phase.

\section{Synthesis of 2-[3-(Hexan-3-yl)-4-methoxyphenyl]pyridine (147bb)}<smiles>CCC(C)C(C)C(=O)OC</smiles>

The general procedure $\mathbf{E}$ was followed, using $\left[\mathrm{RuCl}_{2}(p \text {-cymene })\right]_{2}(8.10 \mathrm{mg}, 0.013 \mathrm{mmol}, 2.5 \mathrm{~mol} \%)$, $\mathrm{MesCO}_{2} \mathrm{H}$ (13a) (26 mg, $\left.0.13 \mathrm{mmol}, 30 \mathrm{~mol} \%\right), 6$ ba $(92.4 \mathrm{mg}, 0.50 \mathrm{mmol})$ and 3-bromohexane (42bb) 
$(242 \mathrm{mg}, 1.46 \mathrm{mmol})$. After $20 \mathrm{~h}$, purification by column chromatography ( -hexane/EtOAc 9:1) yielded $147 \mathrm{bb}$ ( $85 \mathrm{mg}, 63 \%$ ) as a colorless oil.

The general procedure $\mathbf{E}$ in water $(2.0 \mathrm{~mL})$ gave $49 \%$ isolated yield.

The general procedure $\mathbf{E}$ neat gave $70 \%$ isolated yield.

The general procedure $\mathbf{E}$ was followed, using $\left[\mathrm{Ru}(p\right.$-cymene $\left.)\left(\mathrm{MesCO}_{2}\right)_{2}\right](\mathbf{1 2})(14.8 \mathrm{mg}, 0.026 \mathrm{mmol}$, $5.0 \mathrm{~mol} \%), 6$ ba $(98.3 \mathrm{mg}, 0.53 \mathrm{mmol}$ ) and 3-bromohexane (42bb) (256 mg, $1.55 \mathrm{mmol})$. After $20 \mathrm{~h}$, purification by column chromatography ( $n$-hexane/EtOAc 9:1) yielded $147 \mathrm{bb}$ ( $84 \mathrm{mg}, 60 \%$ ).

${ }^{1} \mathrm{H}-\mathrm{NMR}\left(300 \mathrm{MHz}, \mathrm{CDCl}_{3}\right): \delta=8.66(\mathrm{ddd}, J=4.9,1.7,1.2 \mathrm{~Hz}, 1 \mathrm{H}), 7.84-7.76(\mathrm{~m}, 2 \mathrm{H}), 7.74-7.62(\mathrm{~m}$, $2 \mathrm{H}), 7.15(\mathrm{ddd}, J=6.7,4.9,2.0 \mathrm{~Hz}, 1 \mathrm{H}), 6.94(\mathrm{~d}, J=8.4 \mathrm{~Hz}, 1 \mathrm{H}), 3.85(\mathrm{~s}, 3 \mathrm{H}), 3.13-2.98(\mathrm{~m}, 1 \mathrm{H}), 1.80-$ $1.49(\mathrm{~m}, 4 \mathrm{H}), 1.38-1.09(\mathrm{~m}, 2 \mathrm{H}), 0.85(\mathrm{t}, J=7.4 \mathrm{~Hz}, 3 \mathrm{H}), 0.80(\mathrm{t}, J=7.4 \mathrm{~Hz}, 3 \mathrm{H})$.

${ }^{13} \mathrm{C}-\mathrm{NMR}\left(75 \mathrm{MHz}, \mathrm{CDCl}_{3}\right): \delta=158.8\left(\mathrm{C}_{\mathrm{q}}\right), 157.7\left(\mathrm{C}_{\mathrm{q}}\right), 149.5(\mathrm{CH}), 136.5(\mathrm{CH}), 134.6\left(\mathrm{C}_{\mathrm{q}}\right), 131.7\left(\mathrm{C}_{\mathrm{q}}\right)$, $126.2(\mathrm{CH}), 125.1(\mathrm{CH}), 121.2(\mathrm{CH}), 119.9(\mathrm{CH}), 110.6(\mathrm{CH}), 55.6\left(\mathrm{CH}_{3}\right), 39.3(\mathrm{CH}), 37.7\left(\mathrm{CH}_{2}\right), 28.5$ $\left(\mathrm{CH}_{2}\right), 20.7\left(\mathrm{CH}_{2}\right), 14.2\left(\mathrm{CH}_{3}\right), 12.1\left(\mathrm{CH}_{3}\right)$.

IR (ATR): $\tilde{\boldsymbol{V}}=3003,2956,2870,1605,1585,1502,1462,1430,1242,1028,779 \mathrm{~cm}^{-1}$.

MS (EI) m/z (relative intensity): 269 (61) [M+], 240 (32), 226 (84), 212 (24), 198 (100), 167 (34).

HRMS (EI) $\mathrm{m} / \mathrm{z}$ calculated for $\mathrm{C}_{18} \mathrm{H}_{23} \mathrm{NO}^{+}: 269.1780$; found: 269.1778 .

\section{Synthesis of 2-\{4-Methoxy-3-(2,6,6-trimethylbicyclo[3.1.1]heptan-3-yl)phenyl\}pyridine (147bf)}

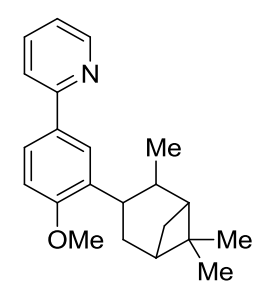

The general procedure $\mathbf{E}$ was followed, using $\left[\mathrm{RuCl}_{2}(p \text {-cymene })\right]_{2}(7.60 \mathrm{mg}, 0.013 \mathrm{mmol}, 2.5 \mathrm{~mol} \%)$, $\mathrm{MesCO}_{2} \mathrm{H}$ (13a) $(25 \mathrm{mg}, 0.15 \mathrm{mmol}, 28 \mathrm{~mol} \%), 6$ ba $(96.7 \mathrm{mg}, 0.52 \mathrm{mmol}$ ) and 3-bromo-2,6,6trimethylbicyclo[3.1.1] heptane (42 bf) $(332 \mathrm{mg}, 1.53 \mathrm{mmol})$. After $20 \mathrm{~h}$, purification by column chromatography ( $n$-hexane/EtOAc 9:1) yielded 147 bf (68 $\mathrm{mg}, 41 \%$ ) as a colorless oil.

${ }^{1} \mathrm{H}-\mathrm{NMR}\left(300 \mathrm{MHz}, \mathrm{CDCl}_{3}\right): \delta=8.75-8.59(\mathrm{~m}, 1 \mathrm{H}), 7.96(\mathrm{~d}, J=2.4 \mathrm{~Hz}, 1 \mathrm{H}), 7.80(\mathrm{dd}, J=8.5,2.3 \mathrm{~Hz}, 1 \mathrm{H}$ ), 7.76-7.63 (m, 2H), 7.23-7.12 (m, 1H), $6.95(\mathrm{~d}, J=8.5 \mathrm{~Hz}, 1 \mathrm{H}), 3.88(\mathrm{~s}, 3 \mathrm{H}), 3.59(\mathrm{dt}, J=8.2,8.1 \mathrm{~Hz}, 1 \mathrm{H})$, 
2.49-2.22 (m, 3H), 2.08-1.81 (m, 3H), $1.39(\mathrm{~d}, J=9.4 \mathrm{~Hz}, 1 \mathrm{H}), 1.29(\mathrm{~s}, 3 \mathrm{H}), 1.22(\mathrm{~s}, 3 \mathrm{H}), 0.98(\mathrm{t}, J=$ $7.1 \mathrm{~Hz}, 3 \mathrm{H})$.

${ }^{13} \mathrm{C}$-NMR $\left(75 \mathrm{MHz}, \mathrm{CDCl}_{3}\right): \delta=158.6\left(\mathrm{C}_{\mathrm{q}}\right), 157.6\left(\mathrm{C}_{\mathrm{q}}\right), 149.5(\mathrm{CH}), 137.4\left(\mathrm{C}_{\mathrm{q}}\right), 136.9(\mathrm{CH}), 131.9\left(\mathrm{C}_{\mathrm{q}}\right)$, 128.6 (CH), $125.5(\mathrm{CH}), 121.4(\mathrm{CH}), 120.1(\mathrm{CH}), 111.0(\mathrm{CH}), 55.6\left(\mathrm{CH}_{3}\right), 48.7(\mathrm{CH}), 44.0(\mathrm{CH}), 42.5(\mathrm{CH})$, $39.5\left(\mathrm{C}_{\mathrm{q}}\right), 37.6(\mathrm{CH}), 36.0\left(\mathrm{CH}_{2}\right), 34.5\left(\mathrm{CH}_{2}\right), 28.9\left(\mathrm{CH}_{3}\right), 23.3\left(\mathrm{CH}_{3}\right), 21.4\left(\mathrm{CH}_{3}\right)$.

IR (ATR): $\tilde{v}=2899,2869,2836,1723,1586,1463,1440,1270,1244,1128,1029,779,600 \mathrm{~cm}^{-1}$.

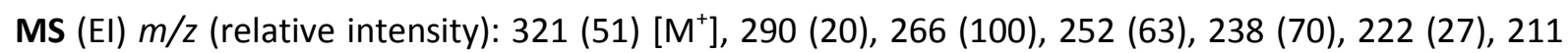
(83), 196 (32), 167 (26), 147 (43).

HR-MS (EI) $m / z$ calculated for $\mathrm{C}_{22} \mathrm{H}_{27} \mathrm{NO}^{+}$: 321.2093; found: 321.2105 .

\section{Synthesis of 2-[4-Methoxy-3-(nonan-5-yl)phenyl]pyridine (147bg)}

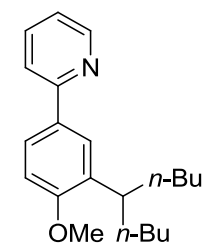

The general procedure $\mathbf{E}$ was followed, using $\left[\mathrm{RuCl}_{2}(p \text {-cymene })\right]_{2}(7.70 \mathrm{mg}, 0.013 \mathrm{mmol}, 2.5 \mathrm{~mol} \%)$, MesCO ${ }_{2} \mathrm{H}$ (13a) $(25 \mathrm{mg}, 0.15 \mathrm{mmol}, 30 \mathrm{~mol} \%), 6$ ba $(92.5 \mathrm{mg}, 0.50 \mathrm{mmol}$ ) and 5-bromononane (42bg) (312 mg, $1.51 \mathrm{mmol}$ ). After $20 \mathrm{~h}$, purification by column chromatography ( $n$-hexane/EtOAc 9:1) yielded $147 \mathrm{bg}$ ( $66 \mathrm{mg}, 42 \%$ ) as a colorless oil.

${ }^{1} \mathrm{H}-\mathrm{NMR}\left(300 \mathrm{MHz}, \mathrm{CDCl}_{3}\right): \delta=8.69-8.61(\mathrm{~m}, 1 \mathrm{H}), 7.85-7.76(\mathrm{~m}, 2 \mathrm{H}), 7.76-7.62(\mathrm{~m}, 2 \mathrm{H}), 7.15(\mathrm{ddd}, J=$ 6.6, 4.8, $1.9 \mathrm{~Hz}, 1 \mathrm{H}), 6.94(\mathrm{~d}, J=8.4 \mathrm{~Hz}, 1 \mathrm{H}), 3.85(\mathrm{~s}, 3 \mathrm{H}), 3.19-3.04(\mathrm{~m}, 1 \mathrm{H}), 1.72-1.59(\mathrm{~m}, 4 \mathrm{H}), 1.38-$ $1.05(\mathrm{~m}, 8 \mathrm{H}), 0.83(\mathrm{t}, J=7.1 \mathrm{~Hz}, 6 \mathrm{H})$.

${ }^{13} \mathrm{C}-\mathrm{NMR}\left(75 \mathrm{MHz}, \mathrm{CDCl}_{3}\right): \delta=158.7\left(\mathrm{C}_{\mathrm{q}}\right), 157.7(\mathrm{CH}), 149.5(\mathrm{CH}), 136.5\left(\mathrm{C}_{\mathrm{q}}\right), 135.1\left(\mathrm{C}_{\mathrm{q}}\right), 131.7(\mathrm{CH})$, $126.2(\mathrm{CH}), 125.1(\mathrm{CH}), 121.1(\mathrm{CH}), 119.9(\mathrm{CH}), 110.7(\mathrm{CH}), 55.6\left(\mathrm{CH}_{3}\right), 37.8(\mathrm{CH}), 35.5\left(\mathrm{CH}_{2}\right), 29.8$ $\left(\mathrm{CH}_{2}\right), 22.8\left(\mathrm{CH}_{2}\right), 14.1\left(\mathrm{CH}_{3}\right)$.

IR (ATR): $\tilde{v}=2954,2927,2856,1586,1502,1463,1431,1269,1242,1028,779 \mathrm{~cm}^{-1}$. MS (El) m/z (relative intensity): 311 (32) [ $\left.\mathrm{M}^{+}\right], 254$ (76), 198 (100), 168 (27).

HR-MS (EI) $m / z$ calculated for $\mathrm{C}_{21} \mathrm{H}_{29} \mathrm{NO}^{+}$: 311.2249; found: 311.2251 . 


\section{Synthesis of 2-[4-Methoxy-3-(pentan-2-yl)-phenyl]-pyridine (147bi)}

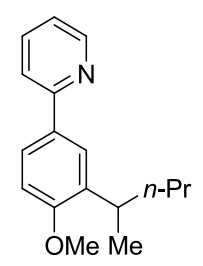

The general procedure $\mathbf{E}$ was followed, using $\left[\mathrm{RuCl}_{2}(p \text {-cymene })\right]_{2}(8.10 \mathrm{mg}, 0.013 \mathrm{mmol}, 2.5 \mathrm{~mol} \%)$, MesCO ${ }_{2} \mathrm{H}$ (13a) (25 mg, $\left.0.15 \mathrm{mmol}, 29 \mathrm{~mol} \%\right)$, 6 ba $(95.0 \mathrm{mg}, 0.51 \mathrm{mmol}$ ) and 2-bromopentane (42bi) (223 mg, $1.48 \mathrm{mmol}$ ). After $20 \mathrm{~h}$, purification by chromatography ( $n$-hexane/EtOAc 9:1) yielded 147bi (81 $\mathrm{mg}, 62 \%)$ as a colorless oil.

${ }^{1} \mathrm{H}-\mathrm{NMR}\left(300 \mathrm{MHz}, \mathrm{CDCl}_{3}\right): \delta=8.66(\mathrm{dt}, J=4.9,1.5 \mathrm{~Hz}, 1 \mathrm{H}), 7.86(\mathrm{~d}, J=2.4 \mathrm{~Hz}, 1 \mathrm{H}), 7.80(\mathrm{dd}, J=8.5$, $2.3 \mathrm{~Hz}, 1 \mathrm{H}), 7.75-7.54(\mathrm{~m}, 2 \mathrm{H}), 7.15$ (ddd, $J=6.1,4.8,2.5 \mathrm{~Hz}, 1 \mathrm{H}), 6.94(\mathrm{~d}, J=8.5 \mathrm{~Hz}, 1 \mathrm{H}), 3.87(\mathrm{~s}, 3 \mathrm{H})$, 3.27 (qt, $J=7.1,7.0 \mathrm{~Hz}, 1 \mathrm{H}), 1.82-1.46(\mathrm{~m}, 2 \mathrm{H}), 1.42-1.15(\mathrm{~m}, 2 \mathrm{H}), 1.27(\mathrm{~d}, J=7.0 \mathrm{~Hz}, 3 \mathrm{H}), 0.90(\mathrm{t}, J=$ $7.3 \mathrm{~Hz}, 3 \mathrm{H})$.

${ }^{13} \mathrm{C}-\mathrm{NMR}\left(75 \mathrm{MHz}, \mathrm{CDCl}_{3}\right): \delta=157.9\left(\mathrm{C}_{\mathrm{q}}\right), 157.6(\mathrm{CH}), 149.4(\mathrm{CH}), 136.5\left(\mathrm{C}_{\mathrm{q}}\right), 136.4(\mathrm{CH}), 131.7(\mathrm{CH})$, $125.5(\mathrm{CH}), 125.1(\mathrm{CH}), 121.1(\mathrm{CH}), 119.8(\mathrm{CH}), 110.5(\mathrm{CH}), 55.4\left(\mathrm{CH}_{3}\right), 39.4\left(\mathrm{CH}_{2}\right), 31.8(\mathrm{CH}), 20.8$ $\left(\mathrm{CH}_{2}\right), 20.8\left(\mathrm{CH}_{3}\right), 14.2\left(\mathrm{CH}_{3}\right)$.

IR (ATR): $\tilde{V}=2956,2929,2869,2837,1584,1501,1462,1243,1158,1028 \mathrm{~cm}^{-1}$. MS (EI) m/z (relative intensity): 255 (59) [M+], 212 (100), 197 (17), 167 (36).

HRMS (EI) m/z calculated for $\mathrm{C}_{17} \mathrm{H}_{21} \mathrm{NO}^{+}$: 255.1623; found: 255.1623 .

\section{Synthesis of 2-[3-(Hexan-2-yl)-4-methoxyphenyl]pyridine (147bj)}

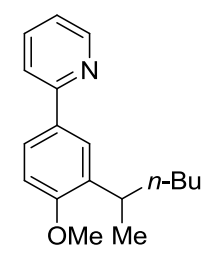

The general procedure $\mathbf{E}$ was followed, using $\left[\mathrm{RuCl}_{2}(p \text {-cymene })\right]_{2}(7.70 \mathrm{mg}, 0.013 \mathrm{mmol}, 2.8 \mathrm{~mol} \%)$, $\mathrm{MesCO}_{2} \mathrm{H}$ (13a) (26 mg, $\left.0.15 \mathrm{mmol}, 28 \mathrm{~mol} \%\right), 6$ ba $(98.4 \mathrm{mg}, 0.53 \mathrm{mmol}$ ) and 2-bromohexane (42bj) (249 $\mathrm{mg}, 1.51 \mathrm{mmol}$ ). After $20 \mathrm{~h}$, purification by column chromatography ( $n$-hexane/EtOAc 9:1) yielded $147 \mathrm{bj}$ (100 $\mathrm{mg}, 70 \%$ ) as a colorless oil. 
The enantiomers of $\mathbf{1 4 7 b j}$ were separated using preparative chiral HPLC [column: Chiralpak IC: eluent: $n$-hexane/EtOAc 97:3, $15 \mathrm{ml} / \mathrm{min} ; t_{\text {ret }}=14.2$ and $15.8 \mathrm{~min}$ ]. The absolute configuration of the arbitrary selected enantiomer with $t_{\text {ret }}=14.2$ min was established to be $(R)-\mathbf{1 4 7 b j}$ by means of X-ray crystal structure analysis of its hydrochloride 149.

${ }^{1} \mathrm{H}-\mathrm{NMR}\left(300 \mathrm{MHz}, \mathrm{CDCl}_{3}\right): \delta=8.66(\mathrm{dd}, J=4.8,1.5 \mathrm{~Hz}, 1 \mathrm{H}), 7.84(\mathrm{~d}, J=2.4 \mathrm{~Hz}, 1 \mathrm{H}), 7.82-7.77(\mathrm{~m}, 1 \mathrm{H})$, 7.75-7.64 (m, 2H), 7.16 (ddd, $J=6.4,4.8,1.5 \mathrm{~Hz}, 1 \mathrm{H}), 6.94(\mathrm{dd}, J=8.5,1.1 \mathrm{~Hz}, 1 \mathrm{H}), 3.87(\mathrm{~s}, 3 \mathrm{H}), 3.22$ (qt, $J=7.0,6.9 \mathrm{~Hz}, 1 \mathrm{H}), 1.81-1.47(\mathrm{~m}, 2 \mathrm{H}), 1.42-1.09(\mathrm{~m}, 4 \mathrm{H}), 1.26(\mathrm{~d}, J=7.0 \mathrm{~Hz}, 3 \mathrm{H}), 0.87(\mathrm{t}, J=$ $7.0 \mathrm{~Hz}, 3 \mathrm{H})$.

${ }^{13} \mathrm{C}-\mathrm{NMR}\left(75 \mathrm{MHz}, \mathrm{CDCl}_{3}\right): \delta=171.2\left(\mathrm{C}_{\mathrm{q}}\right), 158.1\left(\mathrm{C}_{\mathrm{q}}\right), 157.8\left(\mathrm{C}_{\mathrm{q}}\right), 149.6(\mathrm{CH}), 136.6(\mathrm{CH}), 131.9\left(\mathrm{C}_{\mathrm{q}}\right)$, $125.7(\mathrm{CH}), 125.3(\mathrm{CH}), 121.3(\mathrm{CH}), 120.0(\mathrm{CH}), 110.7(\mathrm{CH}), 55.6\left(\mathrm{CH}_{3}\right), 36.9\left(\mathrm{CH}_{2}\right), 32.3(\mathrm{CH}), 30.1$ $\left(\mathrm{CH}_{2}\right), 22.9\left(\mathrm{CH}_{2}\right), 21.0\left(\mathrm{CH}_{3}\right), 14.2\left(\mathrm{CH}_{3}\right)$.

IR (ATR): $\widetilde{v}=2956,2927,2869,2857,1585,1501,1462,1242,1156,1028,604 \mathrm{~cm}^{-1}$.

MS (EI) m/z (relative intensity): 269 (55) [M+], 212 (100), 197 (23), 182 (11), 167 (36).

HRMS (EI) $\mathrm{m} / \mathrm{z}$ calculated for $\mathrm{C}_{18} \mathrm{H}_{23} \mathrm{NO}^{+}: 269.1780$; found: 269.1784 .

\section{Attempted Racemisation of Compound $(S)-(147 \mathrm{bj})$ under Optimized Reaction Conditions}
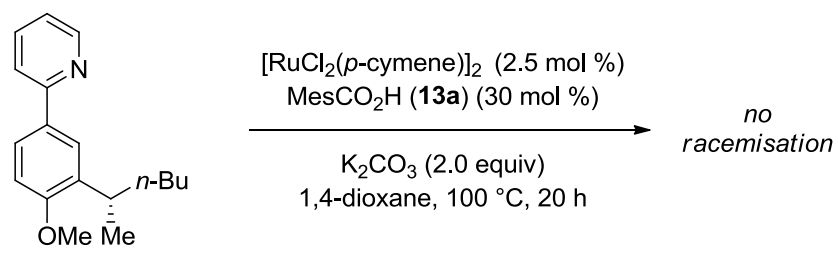

(S)-147bj

Following the general procedure $E$ with $(S)-147 b j\left(t_{\text {ret }}=15.8 \mathrm{~min}\right)(20.0 \mathrm{mg}, 0.07 \mathrm{mmol})$, $\mathrm{MesCO}_{2} \mathrm{H}$ (13a) (3.8 mg, $0.02 \mathrm{mmol}, 31 \mathrm{~mol} \%)$ and $\left[\mathrm{RuCl}_{2}(p \text {-cymene) }]_{2}(1.3 \mathrm{mg}, 2.8 \mathrm{~mol} \%)\right.$. Analysis by analytical HPLC on chiral stationary phase displayed no racemisation of (S)-147bj.

\section{Synthesis of 2-[4-Methoxy-3-(nonan-2-yl)phenyl]pyridine (147bk)}

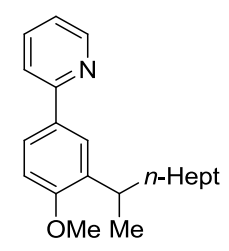


The general procedure $\mathbf{E}$ was followed, using $\left[\mathrm{RuCl}_{2}(p \text {-cymene })\right]_{2}(8.00 \mathrm{mg}, 0.013 \mathrm{mmol}, 2.5 \mathrm{~mol} \%)$, $\mathrm{MesCO}_{2} \mathrm{H}$ (13a) (25 mg, $\left.0.15 \mathrm{mmol}, 30 \mathrm{~mol} \%\right), 6$ ba (95.1 mg, $0.51 \mathrm{mmol}$ ) and 2-bromononane (42bk) (316 mg, $1.53 \mathrm{mmol}$ ). After $20 \mathrm{~h}$, purification by column chromatography ( $n$-hexane/EtOAc 9:1) yielded 147 bk ( $89 \mathrm{mg}, 56 \%$ ) as a colorless oil.

${ }^{1} \mathrm{H}-\mathrm{NMR}\left(300 \mathrm{MHz}, \mathrm{CDCl}_{3}\right): \delta=8.66(\mathrm{dd}, J=4.9,1.5 \mathrm{~Hz}, 1 \mathrm{H}), 7.84(\mathrm{~d}, J=2.4 \mathrm{~Hz}, 1 \mathrm{H}), 7.80(\mathrm{dd}, J=8.4$, $2.4 \mathrm{~Hz}, 1 \mathrm{H}), 7.74-7.65(\mathrm{~m}, 2 \mathrm{H}), 7.15(\mathrm{ddd}, J=6.7,4.9,2.1 \mathrm{~Hz}, 1 \mathrm{H}), 6.94(\mathrm{~d}, J=8.5 \mathrm{~Hz}, 1 \mathrm{H}), 3.87(\mathrm{~s}, 3 \mathrm{H})$, $3.22(\mathrm{qt}, J=7.1,6.9 \mathrm{~Hz}, 1 \mathrm{H}), 1.78-1.46(\mathrm{~m}, 2 \mathrm{H}), 1.33-1.16(\mathrm{~m}, 10 \mathrm{H}), 1.26(\mathrm{~d}, J=6.9 \mathrm{~Hz}, 3 \mathrm{H}), 0.86(\mathrm{t}, J=$ $6.6 \mathrm{~Hz}, 3 \mathrm{H})$.

${ }^{13} \mathrm{C}$-NMR $\left(75 \mathrm{MHz}, \mathrm{CDCl}_{3}\right): \delta=158.0\left(\mathrm{C}_{\mathrm{q}}\right), 157.6\left(\mathrm{C}_{\mathrm{q}}\right), 149.5(\mathrm{CH}), 136.5\left(\mathrm{C}_{\mathrm{q}}\right), 136.5(\mathrm{CH}), 131.7\left(\mathrm{C}_{\mathrm{q}}\right)$, $125.5(\mathrm{CH}), 125.2(\mathrm{CH}), 121.2(\mathrm{CH}), 119.9(\mathrm{CH}), 110.5(\mathrm{CH}), 55.5\left(\mathrm{CH}_{3}\right), 37.1\left(\mathrm{CH}_{2}\right), 32.1(\mathrm{CH}), 31.9$ $\left(\mathrm{CH}_{2}\right), 29.7\left(\mathrm{CH}_{2}\right), 29.3\left(\mathrm{CH}_{2}\right), 27.7\left(\mathrm{CH}_{2}\right), 22.6\left(\mathrm{CH}_{2}\right), 20.9\left(\mathrm{CH}_{3}\right), 14.1\left(\mathrm{CH}_{3}\right)$.

IR (ATR): $\tilde{v}=2956,2924,2854,1606,1585,1563,1501,1463,1028,779,740 \mathrm{~cm}^{-1}$.

MS (EI) m/z (relative intensity): 311 (39) [M+], 226 (15), 212 (100), 198 (17), 167 (25).

HRMS (EI) m/z calculated for $\mathrm{C}_{21} \mathrm{H}_{29} \mathrm{NO}^{+}: 311.2249$; found: 311.2254 .

\section{Synthesis of 2-[4-Fluoro-3-(octan-2-yl)phenyl]pyridine (147ca)}

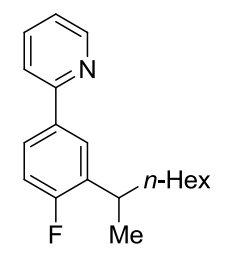

The general procedure $\mathbf{E}$ was followed, using $\left[\mathrm{RuCl}_{2}(p \text {-cymene })\right]_{2}(7.60 \mathrm{mg}, 0.013 \mathrm{mmol}, 2.4 \mathrm{~mol} \%)$, $\mathrm{MesCO}_{2} \mathrm{H}$ (13a) (25 mg, $\left.0.15 \mathrm{mmol}, 29 \mathrm{~mol} \%\right), 6 \mathrm{ca}(89.8 \mathrm{mg}, 0.52 \mathrm{mmol}$ ) and 2-bromooctane (42ba) (291 mg, $1.51 \mathrm{mmol}$ ). After $20 \mathrm{~h}$, purification by column chromatography ( $n$-hexane/EtOAc 19:1 to $5: 1$ ) yielded $147 \mathrm{ca}(83 \mathrm{mg}, 56 \%$ ) as a colorless oil.

The general procedure $\mathbf{E}$ with $(S)$-3-methyl-2-pivalamidobutanoic acid $(76 \mathrm{c})(31.0 \mathrm{mg}, 0.15 \mathrm{mmol}$, $30 \mathrm{~mol} \%)$ as additive in water $(2 \mathrm{~mL})$ at $100{ }^{\circ} \mathrm{C}$ gave $42 \%$ isolated yield.

${ }^{1} \mathrm{H}-\mathrm{NMR}\left(300 \mathrm{MHz}, \mathrm{CDCl}_{3}\right): \delta=8.68(\mathrm{dt}, J=4.9,1.3 \mathrm{~Hz}, 1 \mathrm{H}), 7.87(\mathrm{dd}, J=7.2,2.3 \mathrm{~Hz}, 1 \mathrm{H}), 7.79-7.62(\mathrm{~m}$, $3 \mathrm{H}), 7.29-7.15(\mathrm{~m}, 1 \mathrm{H}), 7.09$ (dd, $J=10.1,8.5 \mathrm{~Hz}, 1 \mathrm{H}), 3.11$ (qt, $J=7.2,7.1 \mathrm{~Hz}, 1 \mathrm{H}), 1.79-1.57(\mathrm{~m}, 2 \mathrm{H})$, 1.41-1.12 (m, 8H), $1.31(\mathrm{~d}, J=7.1 \mathrm{~Hz}, 3 \mathrm{H}), 0.85(\mathrm{t}, J=7.2 \mathrm{~Hz}, 3 \mathrm{H})$.

${ }^{13} \mathrm{C}-\mathrm{NMR}\left(75 \mathrm{MHz}, \mathrm{CDCl}_{3}\right): \delta=161.6\left(\mathrm{~d}, \mathrm{~J}_{\mathrm{C}-\mathrm{F}}=247 \mathrm{~Hz}, \mathrm{C}_{\mathrm{q}}\right.$ ), $156.9\left(\mathrm{C}_{\mathrm{q}}\right), 149.6(\mathrm{CH}), 136.6(\mathrm{CH}), 135.4(\mathrm{~d}$, $\left.J_{C-F}=3 \mathrm{~Hz}, C_{q}\right), 134.7\left(d, J_{C-F}=15 \mathrm{~Hz}, \mathrm{CH}\right), 126.9\left(\mathrm{~d}, J_{\mathrm{C}-\mathrm{F}}=6 \mathrm{~Hz}, \mathrm{CH}\right), 125.8\left(\mathrm{~d}, J_{\mathrm{C}-\mathrm{F}}=9 \mathrm{~Hz}, \mathrm{CH}\right), 121.8(\mathrm{CH})$, 
$120.3(\mathrm{CH}), 115.6\left(\mathrm{~d}, \mathrm{~J}_{\mathrm{C}-\mathrm{F}}=24 \mathrm{~Hz}, \mathrm{CH}\right), 37.1\left(\mathrm{CH}_{2}\right), 33.0(\mathrm{CH}), 31.8\left(\mathrm{CH}_{2}\right), 29.3\left(\mathrm{CH}_{2}\right), 27.7\left(\mathrm{CH}_{2}\right), 22.6$ $\left(\mathrm{CH}_{2}\right), 20.9\left(\mathrm{CH}_{3}\right), 14.0\left(\mathrm{CH}_{3}\right)$.

${ }^{19}$ F-NMR $\left(282 \mathrm{MHz}, \mathrm{CDCl}_{3}\right): \delta=-117.62--119.83(\mathrm{~m})$.

IR (ATR): $\tilde{V}=2958,2926,2856,1586,1464,1433,1262,1224,825,779 \mathrm{~cm}^{-1}$.

MS (EI) m/z (relative intensity): 285 (14) [M+], 214 (31), 200 (100), 185 (50), 78 (17).

HRMS (ESI) $\mathrm{m} / \mathrm{z}$ calculated for $\mathrm{C}_{19} \mathrm{H}_{24} \mathrm{FN}+\mathrm{H}^{+}: 286.1971$; measured: 286.1975 .

\section{Synthesis of 2-[4-Fluoro-3-(hexan-3-yl)-phenyl]-pyridine (147cb)}

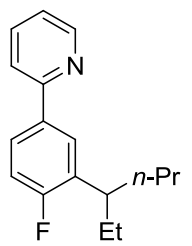

The general procedure $\mathbf{E}$ was followed, using $\left[\operatorname{RuCl}_{2}(p \text {-cymene })\right]_{2}(7.70 \mathrm{mg}, 0.013 \mathrm{mmol}, 2.5 \mathrm{~mol} \%)$, $\mathrm{MesCO}_{2} \mathrm{H}$ (13a) (26 mg, $\left.0.15 \mathrm{mmol}, 30 \mathrm{~mol} \%\right), 6 \mathrm{ca}(85.3 \mathrm{mg}, 0.50 \mathrm{mmol}$ ) and 3-bromohexane (42bb) ( $252 \mathrm{mg}, 1.52 \mathrm{mmol}$ ). After $20 \mathrm{~h}$, purification by column chromatography ( $n$-hexane/EtOAc 9:1) yielded $147 \mathrm{cb}$ (60 $\mathrm{mg}, 47 \%$ ) as a colorless oil.

${ }^{1} \mathrm{H}-\mathrm{NMR}\left(300 \mathrm{MHz}, \mathrm{CDCl}_{3}\right): \delta=8.68(\mathrm{ddd}, J=4.8,1.8,1.0 \mathrm{~Hz}, 1 \mathrm{H}), 7.86-7.64(\mathrm{~m}, 4 \mathrm{H}), 7.20$ (ddd, $J=7.0$, 4.8, $1.5 \mathrm{~Hz}, 1 \mathrm{H}), 7.09$ (dd, $J=9.9,8.5 \mathrm{~Hz}, 1 \mathrm{H}), 2.92(\mathrm{dt}, J=8.8,6.0 \mathrm{~Hz}, 1 \mathrm{H}), 1.85-1.56(\mathrm{~m}, 4 \mathrm{H}), 1.29-$ $1.13(\mathrm{~m}, 2 \mathrm{H}), 0.95-0.74(\mathrm{~m}, 6 \mathrm{H})$.

${ }^{13} \mathrm{C}-\mathrm{NMR}\left(75 \mathrm{MHz}, \mathrm{CDCl}_{3}\right): \delta=62.2\left(\mathrm{~d}, \mathrm{~J}_{\mathrm{C}-\mathrm{F}}=247 \mathrm{~Hz}, \mathrm{C}_{\mathrm{q}}\right), 156.9\left(\mathrm{C}_{\mathrm{q}}\right), 149.6(\mathrm{CH}), 136.6(\mathrm{CH}), 135.4(\mathrm{~d}$, $\left.J_{C-F}=3 \mathrm{~Hz}, C_{q}\right), 132.8\left(d, J_{C-F}=15 \mathrm{~Hz}, C_{q}\right), 127.4\left(d, J_{C-F}=6 \mathrm{~Hz}, C H\right), 125.7\left(d, J_{C-F}=9 \mathrm{~Hz}, \mathrm{CH}\right), 121.8(\mathrm{CH})$, $120.3(\mathrm{CH}), 115.6\left(\mathrm{~d}, \mathrm{~J}_{\mathrm{C}-\mathrm{F}}=24 \mathrm{~Hz}, \mathrm{CH}\right), 40.2(\mathrm{CH}), 37.7\left(\mathrm{~d}, \mathrm{~J}_{\mathrm{C}-\mathrm{F}}=2 \mathrm{~Hz}, \mathrm{CH}_{2}\right), 28.6\left(\mathrm{~d}, \mathrm{~J}_{\mathrm{C}-\mathrm{F}}=1 \mathrm{~Hz}, \mathrm{CH}_{2}\right), 20.7$ $\left(\mathrm{CH}_{2}\right), 14.1\left(\mathrm{CH}_{3}\right), 12.2\left(\mathrm{CH}_{3}\right)$.

${ }^{19}$ F-NMR $\left(282 \mathrm{MHz}, \mathrm{CDCl}_{3}\right): \delta=-117.53--119.88(\mathrm{~m})$.

IR (ATR): $\tilde{v}=3053,2958,2930,2872,1586,1433,1403,1225,778,741 \mathrm{~cm}^{-1}$. MS (EI) m/z (relative intensity): 257 (23) [ $\left.\mathrm{M}^{+}\right], 228$ (36), 214 (41), 186 (100).

HR-MS (ESI) $\mathrm{m} / \mathrm{z}$ calculated for $\mathrm{C}_{17} \mathrm{H}_{20} \mathrm{FN}+\mathrm{Na}^{+}$: 280.1477; found: 280.1472 .

\section{Synthesis of 2-[4-Fluoro-3-(nonan-5-yl)phenyl]pyridine (147cg)}

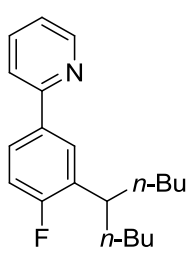


The general procedure $\mathbf{E}$ was followed, using $\left[\mathrm{RuCl}_{2}(p \text {-cymene })\right]_{2}(8.30 \mathrm{mg}, 0.013 \mathrm{mmol}, 2.6 \mathrm{~mol} \%)$, $\mathrm{MesCO}_{2} \mathrm{H}$ (13a) (24 mg, $\left.0.15 \mathrm{mmol}, 28 \mathrm{~mol} \%\right), 6 \mathrm{ca}(90.1 \mathrm{mg}, 0.52 \mathrm{mmol}$ ) and 5-bromononane (42bg) (313 mg, $1.51 \mathrm{mmol}$ ). After $20 \mathrm{~h}$, purification by column chromatography ( $n$-hexane/EtOAc 5:1) yielded $147 \mathrm{cg}(78 \mathrm{mg}, 50 \%)$ as a colorless oil.

${ }^{1} \mathrm{H}-\mathrm{NMR}\left(300 \mathrm{MHz}, \mathrm{CDCl}_{3}\right): \delta=8.66(\mathrm{ddd}, J=4.8,1.8,1.0 \mathrm{~Hz}, 1 \mathrm{H}), 7.86-7.59(\mathrm{~m}, 4 \mathrm{H}), 7.19$ (ddd, $J=7.2$, 4.8, $1.5 \mathrm{~Hz}, 1 \mathrm{H}), 7.07(\mathrm{dd}, J=9.9,8.5 \mathrm{~Hz}, 1 \mathrm{H}), 3.05-2.84(\mathrm{~m}, 1 \mathrm{H}), 1.73-1.56(\mathrm{~m}, 4 \mathrm{H}), 1.37-1.03(\mathrm{~m}, 8 \mathrm{H})$, $0.82(\mathrm{t}, J=7.1 \mathrm{~Hz}, 6 \mathrm{H})$.

${ }^{13} \mathrm{C}-\mathrm{NMR}\left(75 \mathrm{MHz}, \mathrm{CDCl}_{3}\right): \delta=162.0\left(\mathrm{~d}, \mathrm{~J}_{\mathrm{C}-\mathrm{F}}=246.7 \mathrm{~Hz}, \mathrm{C}_{\mathrm{q}}\right), 156.9(\mathrm{CH}), 149.6(\mathrm{CH}), 136.7(\mathrm{CH}), 135.4$ $\left(d, J_{C-F}=3.2 \mathrm{~Hz}, C_{q}\right), 133.2\left(d, J_{C-F}=15.5 \mathrm{~Hz}, C_{q}\right), 127.4\left(d, J_{C-F}=6.0 \mathrm{~Hz}, C H\right), 125.8\left(d, J_{C-F}=8.7 \mathrm{~Hz}, \mathrm{CH}\right)$, $121.8(\mathrm{CH}), 120.3(\mathrm{CH}), 115.6\left(\mathrm{~d}, \mathrm{~J}_{\mathrm{C}-\mathrm{F}}=24.2 \mathrm{~Hz}, \mathrm{CH}\right), 38.7(\mathrm{CH}), 35.5\left(\mathrm{CH}_{2}\right), 29.9\left(\mathrm{CH}_{2}\right), 22.7\left(\mathrm{CH}_{2}\right), 14.0$ $\left(\mathrm{CH}_{3}\right)$.

${ }^{19}$ F-NMR $\left(282 \mathrm{MHz}, \mathrm{CDCl}_{3}\right) \delta=-118.34(\mathrm{~m})$.

IR (ATR): $\tilde{\boldsymbol{V}}=2956,2929,2857,1586,1567,1499,1463,1433,1225,825,779 \mathrm{~cm}^{-1}$.

MS (EI) m/z (relative intensity): 299 (18) [M+], 256 (11), 242 (100), 200 (14), 186 (69).

HRMS (El: $\mathrm{m} / \mathrm{z}$ calculated for $\mathrm{C}_{20} \mathrm{H}_{26} \mathrm{FN}^{+}$: 299.2049; found 299.2059.

\section{Synthesis of 2-[4-Fluoro-3-(hexan-2-yl)phenyl]pyridine (147cj)}

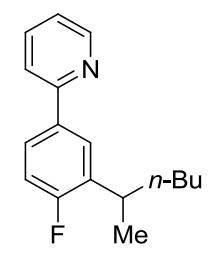

The general procedure $\mathbf{E}$ was followed, using $\left[\mathrm{RuCl}_{2}(p \text {-cymene })\right]_{2}(7.70 \mathrm{mg}, 0.013 \mathrm{mmol}, 2.5 \mathrm{~mol} \%)$, $\mathrm{MesCO}_{2} \mathrm{H}$ (13a) (25 mg, $\left.0.15 \mathrm{mmol}, 30 \mathrm{~mol} \%\right), 6 \mathrm{ca}(87.3 \mathrm{mg}, 0.50 \mathrm{mmol}$ ) and 2-bromohexane (42bj) (253 mg, $1.53 \mathrm{mmol}$ ). After $20 \mathrm{~h}$, purification by column chromatography ( $n$-hexane/EtOAc 7:1) yielded $147 \mathrm{cj}$ ( $80 \mathrm{mg}, 62 \%$ ) as a colorless oil.

${ }^{1} \mathrm{H}-\mathrm{NMR}\left(300 \mathrm{MHz}, \mathrm{CDCl}_{3}\right.$ ): $\delta=8.68$ (ddd, $J=4.9,1.8,1.0 \mathrm{~Hz}, 1 \mathrm{H}$ ), $7.87(\mathrm{dd}, J=7.2,2.4 \mathrm{~Hz}, 1 \mathrm{H}$ ), $7.80-$ $7.64(\mathrm{~m}, 3 \mathrm{H}), 7.21$ (ddd, J = 7.1, 4.9, $1.4 \mathrm{~Hz}, 1 \mathrm{H}$ ), 7.09 (dd, $J=10.1,8.5 \mathrm{~Hz}, 1 \mathrm{H}$ ), 3.11 (qt, $J=7.1,6.9 \mathrm{~Hz}$, $1 \mathrm{H}), 1.77-1.55(\mathrm{~m}, 2 \mathrm{H}), 1.39-1.13(\mathrm{~m}, 4 \mathrm{H}), 1.31(\mathrm{~d}, J=6.9 \mathrm{~Hz}, 3 \mathrm{H}), 0.87(\mathrm{t}, J=7.1 \mathrm{~Hz}, 3 \mathrm{H})$.

${ }^{13} \mathrm{C}-\mathrm{NMR}\left(75 \mathrm{MHz}, \mathrm{CDCl}_{3}\right): \delta=161.7\left(\mathrm{~d}, \mathrm{~J}_{\mathrm{C}-\mathrm{F}}=247 \mathrm{~Hz}, \mathrm{C}_{\mathrm{q}}\right.$ ), $157.0\left(\mathrm{C}_{\mathrm{q}}\right), 149.7(\mathrm{CH}), 136.8(\mathrm{CH}), 135.6$ (d, $\left.J_{C-F}=3 \mathrm{~Hz}, C_{q}\right), 134.8\left(d, J_{C-F}=15 \mathrm{~Hz}, C_{q}\right), 127.0\left(d, J_{C-F}=6 \mathrm{~Hz}, C H\right), 125.9\left(d, J_{C-F}=9 \mathrm{~Hz}, C H\right), 121.9(\mathrm{CH})$, $120.3(\mathrm{CH}), 115.7\left(\mathrm{~d}, \mathrm{~J}_{\mathrm{C}-\mathrm{F}}=24 \mathrm{~Hz}, \mathrm{CH}\right), 37.0\left(\mathrm{CH}_{2}\right), 33.1(\mathrm{CH}), 30.0\left(\mathrm{CH}_{2}\right), 22.8\left(\mathrm{CH}_{2}\right), 21.0\left(\mathrm{CH}_{3}\right), 14.1$ $\left(\mathrm{CH}_{3}\right)$. 
${ }^{19}$ F-NMR $\left(282 \mathrm{MHz}, \mathrm{CDCl}_{3}\right): \delta=-117.64-119.88(\mathrm{~m})$.

IR (ATR): $\tilde{v}=2959,2928,2971,2858,1586,1567,1499,1464,1433,1261,1225,1099,779 \mathrm{~cm}^{-1}$.

MS (EI) m/z (relative intensity): 257 (20) [M+], 214 (16), 200 (100), 185 (39).

HRMS (EI) $\mathrm{m} / \mathrm{z}$ calculated for $\mathrm{C}_{17} \mathrm{H}_{20} \mathrm{FN}^{+}: 257.1580$, found: 257.1576 .

\section{Synthesis of 2-[3-Fluoro-5-(pentan-2-yl)phenyl]pyridine (147di)}<smiles>CC(C)c1cc(F)cc(-c2ccccn2)c1</smiles>

The general procedure $\mathbf{E}$ was followed, using $\left[\mathrm{RuCl}_{2}(p \text {-cymene })\right]_{2}(15.1 \mathrm{mg}, 0.025 \mathrm{mmol}, 5.0 \mathrm{~mol} \%)$, MesCO ${ }_{2} \mathrm{H}$ (13a) $(25 \mathrm{mg}, 0.15 \mathrm{mmol}, 31 \mathrm{~mol} \%), 6 \mathrm{da}(83.7 \mathrm{mg}, 0.48 \mathrm{mmol}$ ) and 2-bromopentane (42bi) (234 mg, $1.55 \mathrm{mmol})$. After $20 \mathrm{~h}$, purification by column chromatography ( $n$-hexane/EtOAc 9:1) yielded 147di (33 mg, 28\%) as a colorless oil.

${ }^{1} \mathrm{H}-\mathrm{NMR}\left(300 \mathrm{MHz}, \mathrm{CDCl}_{3}\right): \delta=8.67(\mathrm{ddd}, J=4.8,1.8,1.0 \mathrm{~Hz}, 1 \mathrm{H}), 7.77-7.65(\mathrm{~m}, 2 \mathrm{H}), 7.61-7.57(\mathrm{~m}, 1 \mathrm{H}), 7.48$ (ddd, $J=9.9,2.5,1.6 \mathrm{~Hz}, 1 \mathrm{H}), 7.22$ (ddd, $J=7.2,4.8,1.5 \mathrm{~Hz}, 1 \mathrm{H}), 6.98-6.87(\mathrm{~m}, 1 \mathrm{H}), 2.78(\mathrm{qt}, J=7.1,6.9 \mathrm{~Hz}$, 1H), 1.76-1.41 (m, 2H), 1.41-1.10 (m, 2H), $1.27(\mathrm{~d}, J=6.9 \mathrm{~Hz}, 3 \mathrm{H}), 0.86(\mathrm{t}, J=7.3 \mathrm{~Hz}, 3 \mathrm{H})$.

${ }^{13} \mathrm{C}-\mathrm{NMR}\left(75 \mathrm{MHz}_{\mathrm{CDCl}}\right): \delta=163.4\left(\mathrm{~d}, J_{\mathrm{C}-\mathrm{F}}=245 \mathrm{~Hz}, \mathrm{C}_{\mathrm{q}}\right), 156.5\left(\mathrm{~d}, J_{\mathrm{C}-\mathrm{F}}=3 \mathrm{~Hz}, \mathrm{C}_{\mathrm{q}}\right), 151.0\left(\mathrm{~d}, J_{\mathrm{C}-\mathrm{F}}=7 \mathrm{~Hz}\right.$, $\left.\mathrm{C}_{\mathrm{q}}\right), 149.7(\mathrm{CH}), 141.3\left(\mathrm{~d}, J_{\mathrm{C}-\mathrm{F}}=8 \mathrm{~Hz}, \mathrm{C}_{\mathrm{q}}\right), 136.8(\mathrm{CH}), 122.4(\mathrm{CH}), 121.4\left(\mathrm{~d}, J_{\mathrm{C}-\mathrm{F}}=2 \mathrm{~Hz}, \mathrm{CH}\right), 120.6(\mathrm{CH})$, $114.1\left(\mathrm{~d}, J_{\mathrm{C}-\mathrm{F}}=21 \mathrm{~Hz}, \mathrm{CH}\right), 111.2\left(\mathrm{~d}, J_{\mathrm{C}-\mathrm{F}}=23 \mathrm{~Hz}, \mathrm{CH}\right), 40.5\left(\mathrm{CH}_{2}\right), 39.8\left(\mathrm{~d}, J_{\mathrm{C}-\mathrm{F}}=2 \mathrm{~Hz}, \mathrm{CH}\right), 22.1\left(\mathrm{CH}_{2}\right)$, $20.7\left(\mathrm{CH}_{3}\right), 14.1\left(\mathrm{CH}_{3}\right)$.

${ }^{19}$ F-NMR $\left(282 \mathrm{MHz}, \mathrm{CDCl}_{3}\right): \delta=-113.84(\mathrm{t}, J=9.9 \mathrm{~Hz})$.

IR (ATR): $\tilde{v}=2958,2929,2872,1718,1585,1438,1439,1265,1171,1082,783,543 \mathrm{~cm}^{-1}$. MS (El) m/z (relative intensity): 243 (45) [M+], 214 (15), 200 (100), 185 (62), 164 (13), 146 (22).

HRMS (EI) m/z calculated for $\mathrm{C}_{16} \mathrm{H}_{18} \mathrm{FN}^{+}$: 243.1423; found: 243.1424.

2-[5-(Hexan-2-yl)-2-methylphenyl]-4-methylpyridine (147ea) and 2-[3-(Hexan-2-yl)-2-methylphenyl]-4-methylpyridine (147ea')

The general procedure $\mathbf{E}$ was followed, using $\left[\mathrm{RuCl}_{2}(p \text {-cymene })\right]_{2}(15.3 \mathrm{mg}, 0.025 \mathrm{mmol}, 5.0 \mathrm{~mol} \%)$, $\mathrm{MesCO}_{2} \mathrm{H}$ (13a) (25 mg, $\left.0.15 \mathrm{mmol}, 26 \mathrm{~mol} \%\right), 6 \mathrm{eb}$ (105 mg, $0.57 \mathrm{mmol}$ ) and 2-bromohexane (42ba) 
(251 mg, $1.52 \mathrm{mmol}$ ). After $20 \mathrm{~h}$, purification by column chromatography ( -hexane/EtOAc 9:1) yielded 147ea (25 mg, 16\%) and 147ea' (70 mg, 46\%) as a colorless oils.<smiles>Cc1ccnc(-c2cc(C(=O)O)ccc2C(=O)OCc2ccccc2)c1</smiles>

\section{2-[5-(Hexan-2-yl)-2-methylphenyl]-4-methylpyridine (147ea)}

${ }^{1} \mathrm{H}-\mathrm{NMR}\left(300 \mathrm{MHz}, \mathrm{CDCl}_{3}\right): \delta=8.54(\mathrm{dd}, J=5.1,0.7 \mathrm{~Hz}, 1 \mathrm{H}), 7.23-7.15(\mathrm{~m}, 3 \mathrm{H}), 7.15-7.09(\mathrm{~m}, 1 \mathrm{H})$, 7.09-7.02 (m, 1H), $2.68(q t, J=7.0,6.9 \mathrm{~Hz}, 1 \mathrm{H}), 2.41(\mathrm{~s}, 3 \mathrm{H}), 2.32(\mathrm{~s}, 3 \mathrm{H}), 1.65-1.49(\mathrm{~m}, 2 \mathrm{H}), 1.35-1.08$ $(\mathrm{m}, 4 \mathrm{H}), 1.26(\mathrm{~d}, J=6.9 \mathrm{~Hz}, 3 \mathrm{H}), 0.90-0.80(\mathrm{~m}, 3 \mathrm{H})$.

${ }^{13}$ C-NMR $\left(75 \mathrm{MHz}, \mathrm{CDCl}_{3}\right): \delta=160.8\left(\mathrm{C}_{\mathrm{q}}\right), 149.5(\mathrm{CH}), 147.6\left(\mathrm{C}_{\mathrm{q}}\right), 146.0\left(\mathrm{C}_{\mathrm{q}}\right), 140.9\left(\mathrm{C}_{\mathrm{q}}\right), 133.5\left(\mathrm{C}_{\mathrm{q}}\right)$, $131.1(\mathrm{CH}), 128.8(\mathrm{CH}), 127.2(\mathrm{CH}), 125.6(\mathrm{CH}), 123.1(\mathrm{CH}), 40.1\left(\mathrm{CH}_{3}\right), 38.7\left(\mathrm{CH}_{2}\right), 30.6\left(\mathrm{CH}_{2}\right), 23.4$ $\left(\mathrm{CH}_{2}\right), 22.9\left(\mathrm{CH}_{3}\right), 21.7(\mathrm{CH}), 20.4\left(\mathrm{CH}_{3}\right), 14.6\left(\mathrm{CH}_{3}\right)$.

IR (ATR): $\widetilde{v}=2956,2924,2857,1599,1559,1500,1454,1378,886,821 \mathrm{~cm}^{-1}$.

MS (EI) $m / z$ (relative intensity): 266 (100) [M- $\left.\mathrm{H}^{+}\right], 252$ (13), 210 (75), 195 (36), 181 (14).

HR-MS (ESI) $\mathrm{m} / z$ calculated for $\mathrm{C}_{19} \mathrm{H}_{25} \mathrm{~N}-\mathrm{H}^{+}$: 266.1909; found: 266.2064.<smiles></smiles>

2-[3-(Hexan-2-yl)-2-methylphenyl]-4-methylpyridine (147ea')

${ }^{1} \mathrm{H}-\mathrm{NMR}\left(300 \mathrm{MHz}, \mathrm{CDCl}_{3}\right): \delta=8.53(\mathrm{dd}, J=5.0,0.8 \mathrm{~Hz}, 1 \mathrm{H}), 7.29-7.21(\mathrm{~m}, 2 \mathrm{H}), 7.21-7.17(\mathrm{~m}, 1 \mathrm{H}), 7.14$ (dd, $J=6.7,2.3 \mathrm{~Hz}, 1 \mathrm{H}$ ), 7.06 (ddd, $J=5.1,1.7,0.8 \mathrm{~Hz}, 1 \mathrm{H}$ ), 3.07 (qt, $J=7.0,6.9 \mathrm{~Hz}, 1 \mathrm{H}$ ), 2.40 (d, $J=0.7$ $\mathrm{Hz}, 3 \mathrm{H}), 2.24(\mathrm{~s}, 3 \mathrm{H}), 1.78-1.48(\mathrm{~m}, 2 \mathrm{H}), 1.38-1.15(\mathrm{~m}, 4 \mathrm{H}), 1.26(\mathrm{~d}, J=6.9 \mathrm{~Hz}, 3 \mathrm{H}), 0.89(\mathrm{t}, J=6.9 \mathrm{~Hz}$, $3 \mathrm{H})$.

${ }^{13} \mathrm{C}-\mathrm{NMR}\left(75 \mathrm{MHz}, \mathrm{CDCl}_{3}\right): \delta=161.2\left(\mathrm{C}_{\mathrm{q}}\right), 148.8(\mathrm{CH}), 147.1\left(\mathrm{C}_{\mathrm{q}}\right), 146.9\left(\mathrm{C}_{\mathrm{q}}\right), 141.4\left(\mathrm{C}_{\mathrm{q}}\right), 133.0\left(\mathrm{C}_{\mathrm{q}}\right)$, $127.0(\mathrm{CH}), 125.6(\mathrm{CH}), 125.4(\mathrm{CH}), 125.3(\mathrm{CH}), 122.5(\mathrm{CH}), 37.7\left(\mathrm{CH}_{2}\right), 34.6\left(\mathrm{CH}_{3}\right), 30.1\left(\mathrm{CH}_{2}\right), 23.0$ $\left(\mathrm{CH}_{2}\right), 21.9\left(\mathrm{CH}_{3}\right), 21.2(\mathrm{CH}), 16.2\left(\mathrm{CH}_{3}\right), 14.2\left(\mathrm{CH}_{3}\right)$.

IR (ATR): $\tilde{v}=3049,2957,2925,2858,1601,1557,1458,1377,991,826,797,727,519 \mathrm{~cm}^{-1}$. MS (EI) m/z (relative intensity): 266 (35) [M-H $\left.\mathrm{H}^{+}\right], 252$ (27), 238 (30), 224 (100), 210 (70), 195 (25), 181 (16). 
HR-MS (ESI) $m / z$ calculated for $\mathrm{C}_{19} \mathrm{H}_{25} \mathrm{~N}-\mathrm{H}^{+}$: 266.1909; found: 266.1918 .

\section{Synthesis of 2-[3-(Pentan-2-yl)-4-(trifluoromethyl)phenyl]pyridine (147ki)}

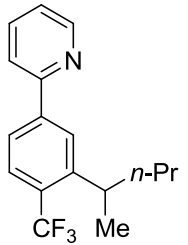

The general procedure $\mathbf{E}$ was followed, using $\left[\mathrm{RuCl}_{2}(p \text {-cymene })\right]_{2}(7.50 \mathrm{mg}, 0.012 \mathrm{mmol}, 2.3 \mathrm{~mol} \%)$, $\mathrm{MesCO}_{2} \mathrm{H}$ (13a) (25 mg, $0.15 \mathrm{mmol}, 30 \mathrm{~mol} \%$ ), 6ka (113 mg, $0.51 \mathrm{mmol}$ ) and 2-bromopentane (42bi) $(218 \mathrm{mg}, 1.45 \mathrm{mmol})$. After $20 \mathrm{~h}$, purification by column chromatography ( -hexane/EtOAc 9:1) yielded 147ki ( $82 \mathrm{mg}, 55 \%$ ) as a colorless oil.

${ }^{1} \mathrm{H}-\mathrm{NMR}\left(300 \mathrm{MHz}, \mathrm{CDCl}_{3}\right): \delta=8.71(\mathrm{~d}, J=4.9 \mathrm{~Hz}, 1 \mathrm{H}), 8.07-8.04(\mathrm{~m}, 1 \mathrm{H}), 7.85-7.80(\mathrm{~m}, 1 \mathrm{H}), 7.80-7.70(\mathrm{~m}$, $2 \mathrm{H}$ ), $7.68(\mathrm{~d}, J=8.3 \mathrm{~Hz}, 2 \mathrm{H}$ ), 7.26 (ddd, $J=7.1,5.0,2.0 \mathrm{~Hz}, 1 \mathrm{H}$ ), 3.22 (qt, $J=6.8,6.7 \mathrm{~Hz}, 1 \mathrm{H}$ ), 1.84-1.50 (m, $2 \mathrm{H}), 1.45-1.02(\mathrm{~m}, 2 \mathrm{H}), 1.29(\mathrm{~d}, J=6.8 \mathrm{~Hz}, 3 \mathrm{H}), 0.86(\mathrm{t}, J=7.3 \mathrm{~Hz}, 3 \mathrm{H})$.

${ }^{13} \mathrm{C}-\mathrm{NMR}\left(75 \mathrm{MHz}, \mathrm{CDCl}_{3}\right): \delta=156.3\left(\mathrm{C}_{\mathrm{q}}\right) 149.8(\mathrm{CH}), 147.9\left(\mathrm{C}_{\mathrm{q}}\right), 142.7\left(\mathrm{C}_{\mathrm{q}}\right), 136.8(\mathrm{CH}), 128.3\left(\mathrm{q}, J_{\mathrm{C}-\mathrm{F}}=\right.$ $29.2 \mathrm{~Hz}, \mathrm{C}_{\mathrm{q}}$ ), 126.0 (q, J $\mathrm{J}_{\mathrm{F}}=5.6 \mathrm{~Hz}, \mathrm{CH}$ ), $126.0(\mathrm{CH}), 124.7$ (q, J $\mathrm{C}_{-\mathrm{F}}=273.8 \mathrm{~Hz}, \mathrm{C}_{\mathrm{q}}$ ), $124.0(\mathrm{CH}), 122.8$ $(\mathrm{CH}), 120.9(\mathrm{CH}), 40.5\left(\mathrm{CH}_{2}\right), 34.6\left(\mathrm{q}, \mathrm{J}_{\mathrm{C}-\mathrm{F}}=2.0 \mathrm{~Hz}, \mathrm{CH}\right), 22.8\left(\mathrm{CH}_{3}\right), 20.8\left(\mathrm{CH}_{2}\right), 14.1\left(\mathrm{CH}_{3}\right)$.

${ }^{19} \mathrm{~F}-\mathrm{NMR}\left(282 \mathrm{MHz}, \mathrm{CDCl}_{3}\right): \delta=-58.53(\mathrm{~m})$.

IR (ATR): $\widetilde{v}=2960,2930,2873,1614,1587,1564,1467,1309,1142,1110,1032,781 \mathrm{~cm}^{-1}$. MS (EI) m/z (relative intensity): 293 (24) [M+], 264 (17), 250 (100), 230 (43), 224 (42), 210 (20).

HRMS (ESI) m/z calculated for $\mathrm{C}_{17} \mathrm{H}_{18} \mathrm{~F}_{3} \mathrm{~N}^{+}$: 293.1391; found: 293.1391.

\section{Synthesis of 2-[4-Methyl-3-(octan-2-yl)phenyl]pyridine (147oa)}

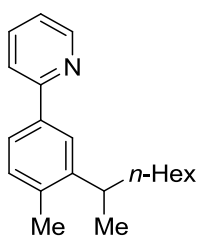

The general procedure $\mathbf{E}$ was followed, using $\left[\operatorname{RuCl}_{2}(p \text {-cymene })\right]_{2}(8.20 \mathrm{mg}, 0.013 \mathrm{mmol}, 2.6 \mathrm{~mol} \%)$, $\mathrm{MesCO}_{2} \mathrm{H}$ (13a) (26 mg, $\left.0.15 \mathrm{mmol}, 30 \mathrm{~mol} \%\right), 60 a(83.0 \mathrm{mg}, 0.49 \mathrm{mmol}$ ) and 2-bromooctane (42ba) (283 mg, $1.47 \mathrm{mmol}$ ). After $20 \mathrm{~h}$, purification by column chromatography ( $n$-hexane/EtOAc 9:1) yielded $1470 a$ ( $76 \mathrm{mg}, 55 \%$ ) as a colorless oil. 
The general procedure $\mathbf{E}$ with $(S)$-3-methyl-2-pivalamidobutanoic acid $(76 \mathrm{c})(31.0 \mathrm{mg}, 0.15 \mathrm{mmol}$, $30 \mathrm{~mol} \%)$ as additive in water $(2 \mathrm{~mL})$ at $100{ }^{\circ} \mathrm{C}$ gave $55 \%$ isolated yield.

${ }^{1} \mathrm{H}-\mathrm{NMR}\left(300 \mathrm{MHz}, \mathrm{CDCl}_{3}\right): \delta=8.70$ (ddd, $\left.J=6.4,3.4,2.1 \mathrm{~Hz}, 1 \mathrm{H}\right), 7.87(\mathrm{~d}, J=2.0 \mathrm{~Hz}, 1 \mathrm{H}), 7.74-7.68$ $(\mathrm{m}, 3 \mathrm{H}), 7.38-7.01(\mathrm{~m}, 2 \mathrm{H}), 3.02(\mathrm{qt}, J=7.1,6.9 \mathrm{~Hz}, 1 \mathrm{H}), 2.38(\mathrm{~s}, 3 \mathrm{H}), 1.79-1.54(\mathrm{~m}, 2 \mathrm{H}), 1.42-1.01(\mathrm{~m}$, $8 \mathrm{H}), 1.28(\mathrm{~d}, J=6.9 \mathrm{~Hz}, 3 \mathrm{H}), 0.87(\mathrm{t}, J=6.0 \mathrm{~Hz}, 3 \mathrm{H})$.

${ }^{13} \mathrm{C}-\mathrm{NMR}\left(75 \mathrm{MHz}, \mathrm{CDCl}_{3}\right): \delta=157.9\left(\mathrm{C}_{\mathrm{q}}\right), 149.5(\mathrm{CH}), 146.5\left(\mathrm{C}_{\mathrm{q}}\right), 137.3\left(\mathrm{C}_{\mathrm{q}}\right), 136.5(\mathrm{CH}), 136.3\left(\mathrm{C}_{\mathrm{q}}\right)$, $130.5(\mathrm{CH}), 123.8(\mathrm{CH}), 123.8(\mathrm{CH}), 121.6(\mathrm{CH}), 120.3(\mathrm{CH}), 37.8\left(\mathrm{CH}_{2}\right), 34.6\left(\mathrm{CH}_{3}\right), 31.8\left(\mathrm{CH}_{2}\right), 29.4$ $\left(\mathrm{CH}_{2}\right), 27.8\left(\mathrm{CH}_{2}\right), 22.6\left(\mathrm{CH}_{2}\right), 21.5(\mathrm{CH}), 19.4\left(\mathrm{CH}_{3}\right), 14.0\left(\mathrm{CH}_{3}\right)$.

IR (ATR): $\tilde{\boldsymbol{V}}=2956,2924,2854,1585,1501,1465,909,777,732 \mathrm{~cm}^{-1}$.

MS (EI) m/z (relative intensity): 281 (22) [M+], 210 (19), 196 (100), 181 (26), 40 (14).

HRMS (ESI) $\mathrm{m} / \mathrm{z}$ calculated for $\mathrm{C}_{20} \mathrm{H}_{27} \mathrm{~N}+\mathrm{H}^{+}: 282.2222$; found: 282.2216 .

\section{Synthesis of Methyl 2-(pentan-2-yl)-4-(pyridin-2-yl)benzoate (147pi)}

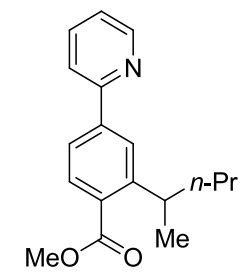

The general procedure $\mathbf{E}$ was followed, using $\left[\operatorname{RuCl}_{2}(p \text {-cymene })\right]_{2}(7.8 \mathrm{mg}, 0.013 \mathrm{mmol}, 2.5 \mathrm{~mol} \%)$, MesCO ${ }_{2} \mathrm{H}$ (13a) (25 mg, $\left.0.15 \mathrm{mmol}, 30 \mathrm{~mol} \%\right), 6 \mathrm{pa}$ (109 mg, $0.51 \mathrm{mmol}$ ) and 2-bromopentane (42bi) $(232 \mathrm{mg}, 1.54 \mathrm{mmol})$. After $20 \mathrm{~h}$, purification by column chromatography ( $n$-hexane/EtOAc 9:1) yielded 147pi (91 mg, 63\%) as a colorless oil.

${ }^{1} \mathrm{H}-\mathrm{NMR}\left(300 \mathrm{MHz}, \mathrm{CDCl}_{3}\right): \delta=8.70$ (ddd, $\left.J=4.8,1.7,1.0 \mathrm{~Hz}, 1 \mathrm{H}\right), 8.00(\mathrm{dd}, J=1.1 \mathrm{~Hz}, 1 \mathrm{H}), 7.80(\mathrm{~d}, J=$ $1.1 \mathrm{~Hz}, 2 \mathrm{H}$ ), 7.78-7.70 (m, 3H), 7.24 (ddd, $J=6.1,4.8,2.4 \mathrm{~Hz}, 1 \mathrm{H}$ ), $3.89(\mathrm{~s}, 3 \mathrm{H}), 3.64$ (qt, $J=7.0,6.9 \mathrm{~Hz}$, 1H), 1.81-1.49 (m, 2H), 1.43-1.11 (m, 2H), $1.30(\mathrm{~d}, J=6.9 \mathrm{~Hz}, 3 \mathrm{H}), 0.85(\mathrm{t}, J=7.2 \mathrm{~Hz}, 3 \mathrm{H})$.

${ }^{13} \mathrm{C}-\mathrm{NMR}\left(75 \mathrm{MHz}, \mathrm{CDCl}_{3}\right): \delta=168.7\left(\mathrm{C}_{\mathrm{q}}\right), 156.6\left(\mathrm{C}_{\mathrm{q}}\right), 149.7(\mathrm{CH}), 149.5\left(\mathrm{C}_{\mathrm{q}}\right), 142.2\left(\mathrm{C}_{\mathrm{q}}\right), 136.8(\mathrm{CH})$, $130.6\left(\mathrm{C}_{\mathrm{q}}\right), 130.2(\mathrm{CH}), 125.3(\mathrm{CH}), 123.8(\mathrm{CH}), 122.6(\mathrm{CH}), 120.9(\mathrm{CH}), 52.0\left(\mathrm{CH}_{3}\right), 40.6\left(\mathrm{CH}_{2}\right), 34.5$ (CH), $22.1\left(\mathrm{CH}_{3}\right), 20.8\left(\mathrm{CH}_{2}\right), 14.1\left(\mathrm{CH}_{3}\right)$.

IR (ATR): $\tilde{v}=2955,2929,2870,1718,1586,1559,1464,1431,1242,1078,772 \mathrm{~cm}^{-1}$.

MS (EI) m/z (relative intensity): 283 (24) [M+], 252 (42), 240 (55), 222 (62), 208 (100), 180 (40), 167 (19), 152 (14).

HRMS (El) $\mathrm{m} / \mathrm{z}$ calculated for $\mathrm{C}_{18} \mathrm{H}_{21} \mathrm{NO}_{2}^{+}$: 283.1572; found: 283.1582 . 


\section{Synthesis of 2-[3-(Hexan-2-yl)-5-n-propoxyphenyl]pyridine (147si)}

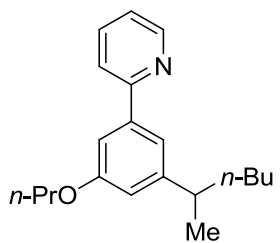

The general procedure $\mathbf{E}$ was followed, using $\left[\operatorname{RuCl}_{2}(p \text {-cymene })\right]_{2}(7.70 \mathrm{mg}, 0.013 \mathrm{mmol}, 2.5 \mathrm{~mol} \%)$, $\mathrm{MesCO}_{2} \mathrm{H}$ (13a) (25mg, $0.15 \mathrm{mmol}, 32 \mathrm{~mol} \%$ ), 6sa (104 mg, $0.47 \mathrm{mmol}$ ) and 2-bromohexane (42bi) (243 mg, $1.48 \mathrm{mmol}$ ). After $20 \mathrm{~h}$, purification by column chromatography ( $n$-hexane/EtOAc 5:1) yielded 147si (57 mg, 39\%) as a colorless oil.

${ }^{1} \mathrm{H}-\mathrm{NMR}\left(300 \mathrm{MHz}, \mathrm{CDCl}_{3}\right): \delta=8.69(\mathrm{ddd}, J=4.8,1.4,1.4 \mathrm{~Hz}, 1 \mathrm{H}), 7.78-7.68(\mathrm{~m}, 2 \mathrm{H}), 7.45-7.35(\mathrm{~m}$, $2 \mathrm{H}), 7.25-7.17(\mathrm{~m}, 1 \mathrm{H}), 6.86-6.75(\mathrm{~m}, 1 \mathrm{H}), 4.02(\mathrm{t}, J=6.6 \mathrm{~Hz}, 2 \mathrm{H}), 2.73(\mathrm{qt}, J=6.9,6.9 \mathrm{~Hz}, 1 \mathrm{H}), 1.94-$ $1.76(\mathrm{~m}, 2 \mathrm{H}), 1.71-1.48(\mathrm{~m}, 2 \mathrm{H}), 1.37-1.14(\mathrm{~m}, 4 \mathrm{H}), 1.28(\mathrm{~d}, J=6.9 \mathrm{~Hz}, 3 \mathrm{H}), 1.06(\mathrm{t}, J=7.4 \mathrm{~Hz}, 3 \mathrm{H}), 0.86$ $(\mathrm{t}, J=8.0 \mathrm{~Hz}, 3 \mathrm{H})$.

${ }^{13} \mathrm{C}$-NMR $\left(75 \mathrm{MHz}, \mathrm{CDCl}_{3}\right): \delta=159.6\left(\mathrm{C}_{\mathrm{q}}\right), 157.7\left(\mathrm{C}_{\mathrm{q}}\right) 150.0\left(\mathrm{C}_{\mathrm{q}}\right), 149.5(\mathrm{CH}), 140.5\left(\mathrm{C}_{\mathrm{q}}\right), 136.6(\mathrm{CH})$, $122.0(\mathrm{CH}), 120.7(\mathrm{CH}), 118.3(\mathrm{CH}), 114.4(\mathrm{CH}), 109.8(\mathrm{CH}), 69.5\left(\mathrm{CH}_{2}\right), 40.2(\mathrm{CH}), 38.0\left(\mathrm{CH}_{2}\right), 30.0$ $\left(\mathrm{CH}_{2}\right), 22.8\left(\mathrm{CH}_{2}\right), 22.7\left(\mathrm{CH}_{2}\right), 22.3\left(\mathrm{CH}_{3}\right), 14.0\left(\mathrm{CH}_{3}\right), 10.6\left(\mathrm{CH}_{3}\right)$.

IR (ATR): $\tilde{v}=2958,2926,2872,1584,1566,1440,1330,1214,1170,1057,993,865,782 \mathrm{~cm}^{-1}$. MS (EI) m/z (relative intensity): 297 (38) [M+], 254 (20), 241 (100), 198 (38), 183 (26).

HR-MS (EI) $m / z$ calculated for $\mathrm{C}_{20} \mathrm{H}_{27} \mathrm{NO}^{+}:$297.2093; found: 297.2094.

\section{Synthesis of 2-[3-(Hexan-2-yl)-5-iso-propoxyphenyl]pyridine (147ti)}

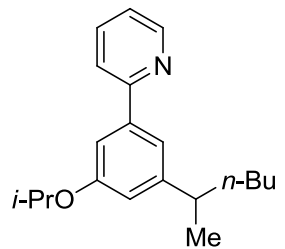

The general procedure $\mathbf{E}$ was followed, using $\left[\mathrm{RuCl}_{2}(p \text {-cymene })\right]_{2}(7.90 \mathrm{mg}, 0.013 \mathrm{mmol}, 2.5 \mathrm{~mol} \%)$, $\left.\mathrm{MesCO}_{2} \mathrm{H} \mathrm{(13a)} \mathrm{(24} \mathrm{mg,} 0.15 \mathrm{mmol}, 28 \mathrm{~mol} \%\right)$, 6ta (114 mg, $0.53 \mathrm{mmol}$ ) and 2-bromohexane (42bi) $(276 \mathrm{mg}, 1.67 \mathrm{mmol})$. After $20 \mathrm{~h}$, purification by column chromatography ( -hexane/EtOAc 5:1) yielded 147ti (60 mg, 38\%) as a colorless oil. 
${ }^{1} \mathrm{H}-\mathrm{NMR}\left(300 \mathrm{MHz}, \mathrm{CDCl}_{3}\right): \delta=8.73-8.60(\mathrm{~m}, 1 \mathrm{H}), 7.76-7.64(\mathrm{~m}, 2 \mathrm{H})$, 7.39-7.30 $(\mathrm{m}, 2 \mathrm{H})$, 7.22-7.13 (m, $1 \mathrm{H}), 6.77(\mathrm{dd}, J=2.4,1.6 \mathrm{~Hz}, 1 \mathrm{H}$ ), 4.66 (hept $J=6.0 \mathrm{~Hz}, 1 \mathrm{H}), 2.71$ (qt, $J=7.1 \mathrm{~Hz}, 1 \mathrm{H}), 1.67-1.49(\mathrm{~m}$, $2 \mathrm{H}), 1.35(\mathrm{~d}, J=6.1 \mathrm{~Hz}, 6 \mathrm{H}), 1.33-1.11(\mathrm{~m}, 7 \mathrm{H}), 0.83(\mathrm{t}, J=7.0 \mathrm{~Hz}, 3 \mathrm{H})$.

${ }^{13} \mathrm{C}$-NMR $\left(75 \mathrm{MHz}, \mathrm{CDCl}_{3}\right): \delta=158.3\left(\mathrm{C}_{\mathrm{q}}\right), 157.7\left(\mathrm{C}_{\mathrm{q}}\right), 150.1\left(\mathrm{C}_{\mathrm{q}}\right), 149.5(\mathrm{CH}), 140.5\left(\mathrm{C}_{\mathrm{q}}\right), 136.6(\mathrm{CH})$, 122.0 (CH), $120.7(\mathrm{CH}), 118.3(\mathrm{CH}), 115.7(\mathrm{CH}), 111.4(\mathrm{CH}), 69.8(\mathrm{CH}), 40.2(\mathrm{CH}), 38.1\left(\mathrm{CH}_{2}\right), 30.0\left(\mathrm{CH}_{2}\right)$, $22.8\left(\mathrm{CH}_{2}\right), 22.2\left(\mathrm{CH}_{3}\right), 22.1\left(2 \times \mathrm{CH}_{3}\right), 14.03\left(\mathrm{CH}_{3}\right)$.

IR (ATR): $\tilde{v}=2957,2926,2871,2857,1584,1566,1439,1325,1116,993,782 \mathrm{~cm}^{-1}$.

MS (El) m/z (relative intensity): 297 (29) [M+], 255 (15), 241 (21), 212 (21), 199 (100), 183 (29), 43 (19).

HR-MS (EI) $m / z$ calculated for $\mathrm{C}_{20} \mathrm{H}_{27} \mathrm{NO}^{+}:$297.2093; found: 297.2102 .

\section{Synthesis of 2-(3-Methoxy-5-pentan-2-ylphenyl)pyridine (147ui)}

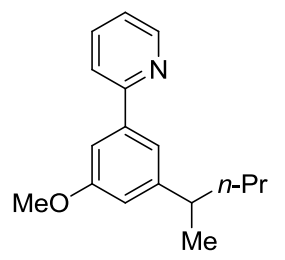

The general procedure $\mathbf{E}$ was followed, using $\left[\mathrm{RuCl}_{2}(p \text {-cymene })\right]_{2}(15 \mathrm{mg}, 0.025 \mathrm{mmol}, 5.0 \mathrm{~mol} \%)$, MesCO ${ }_{2} \mathrm{H}$ (13a) $(26 \mathrm{mg}, 0.15 \mathrm{mmol}, 32 \mathrm{~mol} \%)$, 6ua $(77.1 \mathrm{mg}, 0.42 \mathrm{mmol}$ ) and 2-bromopentane (42bi) (227 mg, $1.50 \mathrm{mmol}$ ). After $20 \mathrm{~h}$, purification by column chromatography ( $n$-hexane/EtOAc 9:1) yielded 147 ui ( $43 \mathrm{mg}, 40 \%)$ as a colorless oil.

${ }^{1} \mathrm{H}-\mathrm{NMR}\left(300 \mathrm{MHz}, \mathrm{CDCl}_{3}\right): \delta=8.69(\mathrm{~d}, J=4.8 \mathrm{~Hz}, 1 \mathrm{H}), 7.79-7.68(\mathrm{~m}, 2 \mathrm{H}), 7.39(\mathrm{dd}, J=3.4,1.9 \mathrm{~Hz}, 2 \mathrm{H})$, 7.23 (ddd, $J=6.8,4.9,2.3 \mathrm{~Hz}, 1 \mathrm{H}$ ), $6.81(\mathrm{~s}, 1 \mathrm{H}), 3.89(\mathrm{~s}, 3 \mathrm{H}), 2.77$ (qt, $J=7.1,6.9 \mathrm{~Hz}, 1 \mathrm{H}), 1.70-1.49(\mathrm{~m}$, $2 \mathrm{H}), 1.39-1.11(\mathrm{~m}, 2 \mathrm{H}), 1.27(\mathrm{~d}, J=6.9 \mathrm{~Hz}, 3 \mathrm{H}), 0.88(\mathrm{t}, J=7.3 \mathrm{~Hz}, 3 \mathrm{H})$.

${ }^{13} \mathrm{C}$-NMR $\left(75 \mathrm{MHz}, \mathrm{CDCl}_{3}\right): \delta=160.0\left(\mathrm{C}_{\mathrm{q}}\right), 157.5\left(\mathrm{C}_{\mathrm{q}}\right), 150.0\left(\mathrm{C}_{\mathrm{q}}\right), 149.3(\mathrm{CH}), 140.4\left(\mathrm{C}_{\mathrm{q}}\right), 136.6(\mathrm{CH})$, $122.0(\mathrm{CH}), 120.8(\mathrm{CH}), 118.4(\mathrm{CH}), 114.0(\mathrm{CH}), 109.1(\mathrm{CH}), 55.4(\mathrm{CH}), 40.6\left(\mathrm{CH}_{2}\right), 40.0\left(\mathrm{CH}_{3}\right), 22.3$ $\left(\mathrm{CH}_{3}\right), 20.9\left(\mathrm{CH}_{2}\right), 14.2\left(\mathrm{CH}_{3}\right)$.

IR (ATR): $\tilde{\boldsymbol{V}}=2956,2927,2870,1584,1566,1453,1417,1339,1217,1168,1056,864,781 \mathrm{~cm}^{-1}$.

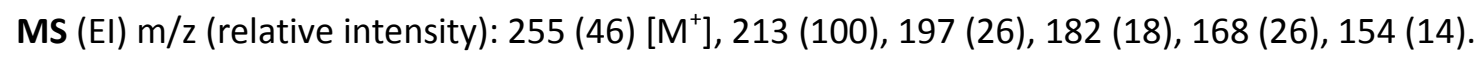

HRMS (EI) $\mathrm{m} / \mathrm{z}$ calculated for $\mathrm{C}_{17} \mathrm{H}_{21} \mathrm{NO}^{+}: 255.1623$; found: 255.1626 . 


\section{Synthesis of 2-[3-Methyl-5-(pentan-2-yl)phenyl]pyridine (147vi)}<smiles>CCCC(C)C(=O)c1cc(OC)cc(-c2ccccn2)c1</smiles>

The general procedure $\mathbf{E}$ was followed, using $\left[\mathrm{RuCl}_{2}(p \text {-cymene })\right]_{2}(16.0 \mathrm{mg}, 0.026 \mathrm{mmol}, 4.8 \mathrm{~mol} \%)$, $\mathrm{MesCO}_{2} \mathrm{H}$ (13a) (25 mg, $\left.0.15 \mathrm{mmol}, 28 \mathrm{~mol} \%\right), 6 \mathrm{va}(96.6 \mathrm{mg}, 0.57 \mathrm{mmol}$ ) and 2-bromopentane (42bi) (229 mg, $1.52 \mathrm{mmol}$ ). After $20 \mathrm{~h}$, purification by column chromatography ( $n$-hexane/EtOAc 9:1) yielded 147vi (52 $\mathrm{mg}, 38 \%$ ) as a colorless oil.

${ }^{1} \mathrm{H}-\mathrm{NMR}\left(300 \mathrm{MHz}, \mathrm{CDCl}_{3}\right): \delta=8.69$ (ddd, $\left.J=4.9,1.4,1.4 \mathrm{~Hz}, 1 \mathrm{H}\right)$ ) 7.79-7.66 (m, 2H), 7.65-7.55 (m, $2 \mathrm{H}), 7.25-7.16(\mathrm{~m}, 1 \mathrm{H}), 7.09-7.02(\mathrm{~m}, 1 \mathrm{H}), 2.76(\mathrm{qt}, J=7.0,6.9 \mathrm{~Hz}, 1 \mathrm{H}), 2.42(\mathrm{~s}, 3 \mathrm{H}), 1.71-1.48(\mathrm{~m}, 2 \mathrm{H})$, 1.41-1.13 (m, 2H), $1.26(\mathrm{~d}, J=6.9 \mathrm{~Hz}, 3 \mathrm{H}), 0.88(\mathrm{t}, J=7.3 \mathrm{~Hz}, 3 \mathrm{H})$.

${ }^{13} \mathrm{C}-\mathrm{NMR}\left(75 \mathrm{MHz}, \mathrm{CDCl}_{3}\right): \delta=158.1\left(\mathrm{C}_{\mathrm{q}}\right), 149.7(\mathrm{CH}), 148.6\left(\mathrm{C}_{\mathrm{q}}\right), 139.5\left(\mathrm{C}_{\mathrm{q}}\right), 138.4\left(\mathrm{C}_{\mathrm{q}}\right), 136.8(\mathrm{CH})$, $128.6(\mathrm{CH}), 125.4(\mathrm{CH}), 123.1(\mathrm{CH}), 122.0(\mathrm{CH}), 120.9(\mathrm{CH}), 40.8\left(\mathrm{CH}_{2}\right), 39.9\left(\mathrm{CH}_{3}\right), 22.4\left(\mathrm{CH}_{3}\right), 21.7$ (CH), $21.1\left(\mathrm{CH}_{2}\right), 14.3\left(\mathrm{CH}_{3}\right)$.

IR (ATR): $\tilde{v}=2956,2925,2869,1585,1566,1446,1377,991,781,742,704,671 \mathrm{~cm}^{-1}$.

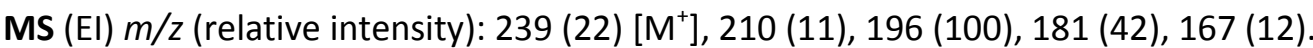
HR-MS (EI) $m / z$ calculated for $\mathrm{C}_{17} \mathrm{H}_{21} \mathrm{~N}^{+}$: 239.1674; found: 239.1672.

2-[2-Methoxy-3-(octan-2-yl)phenyl]pyridine (147wa') and 2-[2-Methoxy-5-(octan-2-yl)phenyl]pyridine (147wa)

The general procedure $\mathbf{E}$ was followed, using $\left[\mathrm{RuCl}_{2}(p \text {-cymene })\right]_{2}(8.00 \mathrm{mg}, 0.013 \mathrm{mmol}, 2.5 \mathrm{~mol} \%)$, $\mathrm{MesCO}_{2} \mathrm{H}$ (13a) $(25 \mathrm{mg}, 0.15 \mathrm{mmol}, 30 \mathrm{~mol} \%), 6 w a(90.3 \mathrm{mg}, 0.49 \mathrm{mmol}$ ) and $42 \mathrm{ba}(293 \mathrm{mg}$, $1.52 \mathrm{mmol}$ ). After $20 \mathrm{~h}$, purification by chromatography ( $n$-hexane/EtOAc 9:1) yielded a mixture of 147wa and 147wa' ( ${ }^{1} \mathrm{H}-\mathrm{NMR}$ ratio 147 wa: 147 wa' $\left.=1.0: 2.1 ; 62 \mathrm{mg}, 43 \%\right)$ as colorless oils. To get pure compounds some of the mixture was separated by HPLC ( $n$-hexane/EtOAc $=97: 3)$.

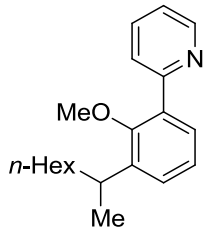




\section{2-[2-Methoxy-3-(octan-2-yl)phenyl]pyridine (147wa')}

${ }^{1} \mathrm{H}-\mathrm{NMR}\left(300 \mathrm{MHz}, \mathrm{CDCl}_{3}\right.$ ): $\delta=8.71$ (ddd, $J=4.8,1.8,1.0 \mathrm{~Hz}, 1 \mathrm{H}$ ), $7.84(\mathrm{dd}, J=8.0,1.2 \mathrm{~Hz}, 1 \mathrm{H}$ ), 7.72 (ddd, $J=7.4,1.8,1.0 \mathrm{~Hz}, 1 \mathrm{H}$ ), $7.50(\mathrm{dd}, J=7.4,2.0 \mathrm{~Hz}, 1 \mathrm{H}), 7.35-7.07(\mathrm{~m}, 3 \mathrm{H}), 3.41(\mathrm{~s}, 3 \mathrm{H}), 3.29-3.20$ $(\mathrm{m}, 1 \mathrm{H}), 1.69-1.50(\mathrm{~m}, 2 \mathrm{H}), 1.41-1.06(\mathrm{~m}, 8 \mathrm{H}), 1.24(\mathrm{~d}, J=6.9 \mathrm{~Hz}, 3 \mathrm{H}), 0.86(\mathrm{t}, J=6.6 \mathrm{~Hz}, 3 \mathrm{H})$.

${ }^{13} \mathrm{C}-N M R\left(75 \mathrm{MHz}, \mathrm{CDCl}_{3}\right): \delta=157.0\left(\mathrm{C}_{\mathrm{q}}\right), 155.5\left(\mathrm{C}_{\mathrm{q}}\right), 149.4(\mathrm{CH}), 141.3\left(\mathrm{C}_{\mathrm{q}}\right), 135.9(\mathrm{CH}), 133.3\left(\mathrm{C}_{\mathrm{q}}\right)$, $128.5(\mathrm{CH}), 127.5(\mathrm{CH}), 124.5(\mathrm{CH}), 124.4(\mathrm{CH}), 121.7(\mathrm{CH}), 61.6\left(\mathrm{CH}_{3}\right), 38.1\left(\mathrm{CH}_{2}\right), 31.9\left(\mathrm{CH}_{2}\right), 31.8$ (CH), $29.5\left(\mathrm{CH}_{2}\right), 28.0\left(\mathrm{CH}_{2}\right), 22.7\left(\mathrm{CH}_{2}\right), 22.3\left(\mathrm{CH}_{3}\right), 14.2\left(\mathrm{CH}_{3}\right)$.

IR (ATR): $\tilde{V}=2956,2925,2855,1586,1452,1430,1217,1008,775,746 \mathrm{~cm}^{-1}$.

MS (EI) m/z (relative intensity): 297 (29) [M+1, 282 (49), 226 (100), 212 (53), 196 (66), 184 (17), 167 (30).

HRMS (EI) $\mathrm{m} / \mathrm{z}$ calculated for $\mathrm{C}_{20} \mathrm{H}_{27} \mathrm{NO} \mathrm{H}^{+}$: 296.2014; found: 296.2026 .

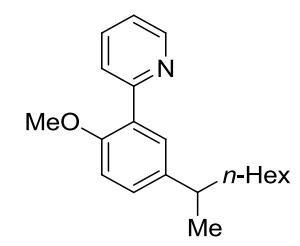

\section{2-[2-Methoxy-5-(octan-2-yl)phenyl]pyridine (147wa)}

${ }^{1} \mathrm{H}-\mathrm{NMR}\left(300 \mathrm{MHz}, \mathrm{CDCl}_{3}\right): \delta=8.69(\mathrm{dd}, J=4.8,1.9 \mathrm{~Hz}, 1 \mathrm{H}), 7.79(\mathrm{~d}, J=8.0 \mathrm{~Hz}, 1 \mathrm{H}), 7.73-7.61(\mathrm{~m}, 1 \mathrm{H})$, $7.55(\mathrm{~d}, J=2.4 \mathrm{~Hz}, 1 \mathrm{H}), 7.23-7.11(\mathrm{~m}, 2 \mathrm{H}), 6.92(\mathrm{~d}, J=8.5 \mathrm{~Hz}, 1 \mathrm{H}), 3.82(\mathrm{~s}, 3 \mathrm{H}), 2.69$ (qt, $J=7.1,6.8 \mathrm{~Hz}$, $1 \mathrm{H}), 1.64-1.48(\mathrm{~m}, 2 \mathrm{H}), 1.37-1.05(\mathrm{~m}, 8 \mathrm{H}), 1.22(\mathrm{~d}, J=6.8 \mathrm{~Hz}, 3 \mathrm{H}), 0.84(\mathrm{t}, J=6.9 \mathrm{~Hz}, 3 \mathrm{H})$.

${ }^{13} \mathrm{C}$-NMR $\left(75 \mathrm{MHz}, \mathrm{CDCl}_{3}\right): \delta=156.4\left(\mathrm{C}_{\mathrm{q}}\right), 155.0\left(\mathrm{C}_{\mathrm{q}}\right), 149.5\left(\mathrm{C}_{\mathrm{q}}\right), 149.3(\mathrm{CH}), 140.6\left(\mathrm{C}_{\mathrm{q}}\right), 135.6(\mathrm{CH})$, $129.8(\mathrm{CH}), 128.0(\mathrm{CH}), 125.2(\mathrm{CH}), 121.5(\mathrm{CH}), 111.4(\mathrm{CH}), 55.7\left(\mathrm{CH}_{3}\right), 39.2(\mathrm{CH}), 38.6\left(\mathrm{CH}_{2}\right), 31.8$ $\left(\mathrm{CH}_{2}\right), 29.4\left(\mathrm{CH}_{2}\right), 27.8\left(\mathrm{CH}_{2}\right), 22.7\left(\mathrm{CH}_{2}\right), 22.4\left(\mathrm{CH}_{3}\right), 14.1\left(\mathrm{CH}_{3}\right)$.

IR (ATR): $\tilde{V}=2955,2924,2854,1586,1500,1462,1238,1061,1027,812,746 \mathrm{~cm}^{-1}$.

MS (El) m/z (relative intensity): 297 (50) [M+], 226 (12), 212 (100), 197 (29), 183 (20), 167 (17), 80 (25).

HRMS (EI) m/z calculated for $\mathrm{C}_{20} \mathrm{H}_{27} \mathrm{NO}^{+} \mathrm{H}^{+}: 296.2014$; found: 296.2028.

2-[5-(Hexan-2-yl)-2-methylphenyl]pyridine (147xa) and 2-[3-(Hexan-2-yl)-2-methylphenyl]pyridine (147xa')

The general procedure $\mathbf{E}$ was followed, using $\left[\mathrm{RuCl}_{2}(p \text {-cymene })\right]_{2}(8.30 \mathrm{mg}, 0.013 \mathrm{mmol}, 2.7 \mathrm{~mol} \%)$, $\mathrm{MesCO}_{2} \mathrm{H}$ (13a) (24 mg, $\left.0.15 \mathrm{mmol}, 30 \mathrm{~mol} \%\right), 6 \times a(76.2 \mathrm{mg}, 0.45 \mathrm{mmol}$ ) and $42 \mathrm{ba}(242 \mathrm{mg}$, 
$1.47 \mathrm{mmol}$ ). After $20 \mathrm{~h}$, purification by chromatography ( $n$-hexane/EtOAc 9:1) yielded 147xa (18 mg, $16 \%$ ) and 147xa' (51 mg, 44\%) as colorless oils.<smiles>Cc1ccc(C(C)C)cc1-c1ccccn1</smiles>

\section{2-[5-(Hexan-2-yl)-2-methylphenyl]pyridine (147xa)}

${ }^{1} \mathrm{H}-\mathrm{NMR}\left(300 \mathrm{MHz}, \mathrm{CDCl}_{3}\right.$ ): $\delta=8.70$ (ddd, $J=4.9,1.8,0.9 \mathrm{~Hz}, 1 \mathrm{H}$ ), 7.74 (ddd, $J=7.7,1.9 \mathrm{~Hz}, 1 \mathrm{H}$ ), $7.42-$ $7.37(\mathrm{~m}, 1 \mathrm{H}), 7.24-7.17(\mathrm{~m}, 3 \mathrm{H}), 7.13(\mathrm{dd}, J=7.9,1.9 \mathrm{~Hz}, 1 \mathrm{H}), 2.69$ (qt, $J=7.0,7.0 \mathrm{~Hz}, 1 \mathrm{H}), 2.32(\mathrm{~s}, 3 \mathrm{H})$, 1.77-1.45 (m, 2H), 1.40-1.08 (m, 4H), $1.24(\mathrm{~d}, J=7.0 \mathrm{~Hz}, 3 \mathrm{H}), 0.85(\mathrm{t}, J=6.7 \mathrm{~Hz}, 3 \mathrm{H})$.

${ }^{13} \mathrm{C}-\mathrm{NMR}\left(75 \mathrm{MHz}, \mathrm{CDCl}_{3}\right): \delta=160.4\left(\mathrm{C}_{\mathrm{q}}\right), 149.1(\mathrm{CH}), 145.5\left(\mathrm{C}_{\mathrm{q}}\right), 140.2\left(\mathrm{C}_{\mathrm{q}}\right), 136.0\left(\mathrm{C}_{\mathrm{q}}\right), 132.9(\mathrm{CH})$, $130.6\left(\mathrm{C}_{\mathrm{q}}\right), 128.3(\mathrm{CH}), 126.8(\mathrm{CH}), 124.1(\mathrm{CH}), 121.5(\mathrm{CH}), 39.5(\mathrm{CH}), 38.1\left(\mathrm{CH}_{2}\right), 30.0\left(\mathrm{CH}_{2}\right), 22.8\left(\mathrm{CH}_{2}\right)$, $22.3\left(\mathrm{CH}_{3}\right), 19.8\left(\mathrm{CH}_{3}\right), 14.0\left(\mathrm{CH}_{3}\right)$.

IR (ATR): $\widetilde{v}=2955,2924,2857,1587,1563,1466,1426,894,823,792,748,639 \mathrm{~cm}^{-1}$. MS (EI) m/z (relative intensity): 252 (100) [M- $\left.\mathrm{H}^{+}\right], 196$ (98), 181 (61), 167 (27).

HRMS (EI) $\mathrm{m} / \mathrm{z}$ calculated for $\mathrm{C}_{18} \mathrm{H}_{23} \mathrm{~N}^{+}: 253.1830$, found: 253.1826 .<smiles>CC(C)c1cccc(-c2ccccn2)c1N(C)C(=O)O</smiles>

\section{2-[3-(Hexan-2-yl)-2-methylphenyl]pyridine (147xa')}

${ }^{1} \mathrm{H}-\mathrm{NMR}\left(300 \mathrm{MHz}, \mathrm{CDCl}_{3}\right): \delta=8.69$ (ddd, $\left.J=4.8,1.9,1.0 \mathrm{~Hz}, 1 \mathrm{H}\right), 7.72(\mathrm{td}, J=7.7,1.8 \mathrm{~Hz}, 1 \mathrm{H}$ ), 7.37 (dd, $J=7.9,1.1 \mathrm{~Hz}, 1 \mathrm{H}), 7.32-7.19(\mathrm{~m}, 3 \mathrm{H}), 7.16(\mathrm{dd}, J=6.7,2.3 \mathrm{~Hz}, 1 \mathrm{H}$ ), 3.08 (qt, $J=7.0,6.9 \mathrm{~Hz}, 1 \mathrm{H}$ ), $2.25(\mathrm{~s}, 3 \mathrm{H}), 1.78-1.50(\mathrm{~m}, 2 \mathrm{H}), 1.40-1.16(\mathrm{~m}, 4 \mathrm{H}), 1.23(\mathrm{~d}, J=6.9 \mathrm{~Hz}, 3 \mathrm{H}), 0.87(\mathrm{t}, J=6.7 \mathrm{~Hz}, 3 \mathrm{H})$.

${ }^{13} \mathrm{C}-\mathrm{NMR}\left(75 \mathrm{MHz}, \mathrm{CDCl}_{3}\right): \delta=161.2\left(\mathrm{C}_{\mathrm{q}}\right), 149.0(\mathrm{CH}), 146.8\left(\mathrm{C}_{\mathrm{q}}\right), 141.2\left(\mathrm{C}_{\mathrm{q}}\right), 135.9(\mathrm{CH}), 132.9\left(\mathrm{C}_{\mathrm{q}}\right)$, $126.9(\mathrm{CH}), 125.5(\mathrm{CH}), 125.3(\mathrm{CH}), 124.4(\mathrm{CH}), 121.3(\mathrm{CH}), 37.6\left(\mathrm{CH}_{2}\right), 34.4(\mathrm{CH}), 30.0\left(\mathrm{CH}_{2}\right), 22.9$ $\left(\mathrm{CH}_{2}\right), 21.7\left(\mathrm{CH}_{3}\right), 16.0\left(\mathrm{CH}_{3}\right), 14.0\left(\mathrm{CH}_{3}\right)$.

IR (ATR): $\tilde{\boldsymbol{V}}=2957,2926,2857,1580,1563,1458,1422,1377,1002,777,748,728 \mathrm{~cm}^{-1}$. MS (EI) m/z (relative intensity): 281 (50) [M+1, 266 (21), 224 (20), 210 (100), 196 (75), 181 (33), 167 (38), 84 (27), 41 (41).

HRMS (ESI) m/z calculated for $\mathrm{C}_{18} \mathrm{H}_{23} \mathrm{~N}+\mathrm{H}^{+}:$254.1909; found: 254.1911. 
2-[2-Fluoro-5-(octan-2-yl)phenyl]pyridine (147za) and 2-[2-Fluoro-3-(octan-2-yl)phenyl]pyridine (147za')

The general procedure $\mathbf{E}$ was followed, using $\left[\operatorname{RuCl}_{2}(p \text {-cymene })\right]_{2}(7.70 \mathrm{mg}, 0.013 \mathrm{mmol}, 2.5 \mathrm{~mol} \%)$, $\mathrm{MesCO}_{2} \mathrm{H}$ (13a) (25 mg, $\left.0.15 \mathrm{mmol}, 28 \mathrm{~mol} \%\right), 6 z a(93.5 \mathrm{mg}, 0.54 \mathrm{mmol}$ ) and 2-bromooctane (42ba) $(297 \mathrm{mg}, 1.54 \mathrm{mmol})$. After $20 \mathrm{~h}$, purification by column chromatography ( $n$-hexane/EtOAc 19:1) yielded $147 z a$ ( $4 \mathrm{mg}, 3 \%$ ) and 147za' (24 mg, 16\%) as colorless oils.

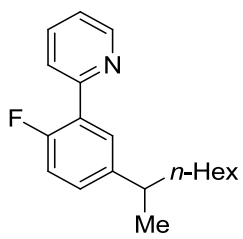

\section{2-[2-Fluoro-5-(octan-2-yl)phenyl]pyridine (147za)}

${ }^{1} \mathrm{H}-\mathrm{NMR}\left(300 \mathrm{MHz}, \mathrm{CDCl}_{3}\right): \delta=8.71$ (ddd, $\left.J=4.8,1.7,1.1 \mathrm{~Hz}, 1 \mathrm{H}\right), 7.83-7.65(\mathrm{~m}, 3 \mathrm{H}), 7.26-7.20(\mathrm{~m}$, 1H), 7.20-7.12 (m, 1H), $7.06(\mathrm{dd}, J=11.0,8.4 \mathrm{~Hz}, 1 \mathrm{H}), 2.73(\mathrm{qt}, J=7.1,7.0 \mathrm{~Hz}, 1 \mathrm{H}), 1.71-1.46(\mathrm{~m}, 2 \mathrm{H})$, $1.23(\mathrm{dd}, J=6.3,2.8 \mathrm{~Hz}, 8 \mathrm{H}), 1.26(\mathrm{~d}, J=7.0 \mathrm{~Hz}, 3 \mathrm{H}), 0.84(\mathrm{~d}, J=6.5 \mathrm{~Hz}, 3 \mathrm{H})$.

${ }^{13} \mathrm{C}-\mathrm{NMR}\left(75 \mathrm{MHz}, \mathrm{CDCl}_{3}\right): \delta=159.0\left(\mathrm{~d}, \mathrm{~J}_{\mathrm{C}-\mathrm{F}}=247 \mathrm{~Hz}, \mathrm{C}_{\mathrm{q}}\right), 154.1\left(\mathrm{~d}, \mathrm{~J}_{\mathrm{C}-\mathrm{F}}=2 \mathrm{~Hz}, \mathrm{C}_{\mathrm{q}}\right), 150.0(\mathrm{CH}), 144.5(\mathrm{~d}$, $\left.J_{C-F}=4 \mathrm{~Hz}, \mathrm{C}_{\mathrm{q}}\right), 136.6(\mathrm{CH}), 129.7\left(\mathrm{~d}, \mathrm{~J}_{\mathrm{C}-\mathrm{F}}=3 \mathrm{~Hz}, \mathrm{CH}\right), 128.9\left(\mathrm{~d}, J_{\mathrm{C}-\mathrm{F}}=8 \mathrm{~Hz}, \mathrm{CH}\right), 127.2\left(\mathrm{~d}, J_{\mathrm{C}-\mathrm{F}}=12 \mathrm{~Hz}, \mathrm{C}_{\mathrm{q}}\right)$, $125.0\left(\mathrm{~d}, \mathrm{~J}_{\mathrm{C}-\mathrm{F}}=9 \mathrm{~Hz}, \mathrm{CH}\right), 122.6(\mathrm{CH}), 116.3\left(\mathrm{~d}, \mathrm{~J}_{\mathrm{C}-\mathrm{F}}=23 \mathrm{~Hz}, \mathrm{CH}\right), 39.9(\mathrm{CH}), 39.0\left(\mathrm{CH}_{2}\right), 32.3\left(\mathrm{CH}_{2}\right), 29.9$ $\left(\mathrm{CH}_{2}\right), 28.2\left(\mathrm{CH}_{2}\right), 23.1\left(\mathrm{CH}_{2}\right), 22.8\left(\mathrm{CH}_{3}\right), 14.6\left(\mathrm{CH}_{3}\right)$.

${ }^{19}$ F-NMR $\left(282 \mathrm{MHz}, \mathrm{CDCl}_{3}\right): \delta=-111.79--137.55(\mathrm{~m})$. IR (ATR): $\tilde{v}=2956,2925,2855,1587,1568,1498,1462,1441,1252,1213,821,790,744 \mathrm{~cm}^{-1}$. MS (EI) m/z (relative intensity): 285 (12) [M+], 214 (15), 200 (100), 185 (26).

HR-MS (ESI) $m / z$ calculated for $\mathrm{C}_{19} \mathrm{H}_{24} \mathrm{FN}^{+}:$285.1893; found: 285.1892.<smiles>O=C(O)c1cccc(-c2ccccn2)c1F</smiles>

2-[2-Fluoro-3-(octan-2-yl)phenyl]pyridine (147za')

${ }^{1} \mathrm{H}-\mathrm{NMR}\left(300 \mathrm{MHz}, \mathrm{CDCl}_{3}\right): \delta=8.70$ (ddd, $\left.J=4.8,1.5,1.5 \mathrm{~Hz}, 1 \mathrm{H}\right), 7.79-7.64(\mathrm{~m}, 3 \mathrm{H}), 7.30-7.14(\mathrm{~m}$, $3 \mathrm{H}), 3.14$ (qt, $J=7.0,6.9 \mathrm{~Hz}, 1 \mathrm{H}), 1.69-1.50(\mathrm{~m}, 2 \mathrm{H}), 1.35-1.12(\mathrm{~m}, 8 \mathrm{H}), 1.27(\mathrm{~d}, J=6.9 \mathrm{~Hz}, 3 \mathrm{H}), 0.83(\mathrm{t}$, $J=6.5 \mathrm{~Hz}, 3 \mathrm{H})$. 
${ }^{13} \mathrm{C}-\mathrm{NMR}\left(75 \mathrm{MHz}, \mathrm{CDCl}_{3}\right): \delta=158.3\left(\mathrm{~d}, \mathrm{~J}_{\mathrm{C}-\mathrm{F}}=248 \mathrm{~Hz}, \mathrm{C}_{\mathrm{q}}\right), 154.2\left(\mathrm{~d}, \mathrm{~J}_{\mathrm{C}-\mathrm{F}}=2 \mathrm{~Hz}, \mathrm{C}_{\mathrm{q}}\right), 149.6(\mathrm{CH}), 136.1$ $(\mathrm{CH}), 135.0\left(\mathrm{~d}, J_{\mathrm{C}-\mathrm{F}}=16 \mathrm{~Hz}, \mathrm{C}_{\mathrm{q}}\right), 128.4\left(\mathrm{~d}, J_{\mathrm{C}-\mathrm{F}}=6 \mathrm{~Hz}, \mathrm{CH}\right), 128.3\left(\mathrm{~d}, \mathrm{~J}_{\mathrm{C}-\mathrm{F}}=3.2 \mathrm{~Hz}, \mathrm{C}_{\mathrm{q}}\right), 127.5\left(\mathrm{~d}, J_{\mathrm{C}-\mathrm{F}}=\right.$ $14 \mathrm{~Hz}, \mathrm{CH}$ ), 124.6 (d, $\left.J_{\mathrm{C}-\mathrm{F}}=8 \mathrm{~Hz}, \mathrm{CH}\right), 124.2\left(\mathrm{~d}, J_{\mathrm{C}-\mathrm{F}}=4 \mathrm{~Hz}, \mathrm{CH}\right), 122.1(\mathrm{CH}), 37.3\left(\mathrm{~d}, J_{\mathrm{C}-\mathrm{F}}=1 \mathrm{~Hz}, \mathrm{CH}_{2}\right), 32.4$ $\left(\mathrm{d}, \mathrm{J}_{\mathrm{C}-\mathrm{F}}=3 \mathrm{~Hz}, \mathrm{CH}\right), 31.8\left(\mathrm{CH}_{2}\right), 29.3\left(\mathrm{CH}_{2}\right), 27.6\left(\mathrm{CH}_{2}\right), 22.6\left(\mathrm{CH}_{2}\right), 21.1\left(\mathrm{~d}, \mathrm{~J}_{\mathrm{C}-\mathrm{F}}=1 \mathrm{~Hz}, \mathrm{CH}_{3}\right), 14.0\left(\mathrm{CH}_{3}\right)$.

${ }^{19}$ F-NMR $\left(283 \mathrm{MHz}, \mathrm{CDCl}_{3}\right): \delta=-124.49--124.61(\mathrm{~m})$.

IR (ATR): $\tilde{v}=2958,2926,2856,1587,1567,1443,1425,1198,1071,822,771,742 \mathrm{~cm}^{-1}$.

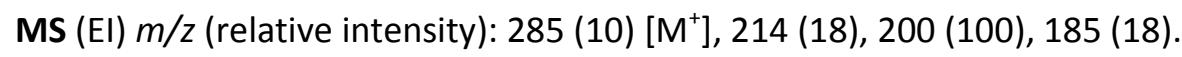

HR-MS (ESI) $m / z$ calculated for $\mathrm{C}_{19} \mathrm{H}_{24} \mathrm{FN}^{+}: 285.1893$; found: 285.1888 .

2-[5-(Octan-2-yl)-2-(n-octyl)phenyl]pyridine (150) and 2-[3-(Octan-2-yl)-2-(n-octanyl)phenyl]pyridine $\left(150^{\prime}\right)$

The general procedure $\mathbf{E}$ was followed, using $\left[\mathrm{RuCl}_{2}(p \text {-cymene })\right]_{2}(16.0 \mathrm{mg}, 0.027 \mathrm{mmol}, 5.0 \mathrm{~mol} \%)$, $\mathrm{MesCO}_{2} \mathrm{H}$ (13a) (25 mg, $\left.0.15 \mathrm{mmol}, 30 \mathrm{~mol} \%\right), 93 \mathrm{a}$ (138 mg, $0.52 \mathrm{mmol}$ ) and 2-bromooctane (42ba) (284 mg, $1.47 \mathrm{mmol}$ ). After $20 \mathrm{~h}$, purification by column chromatography ( $n$-hexane/EtOAc 19:1) yielded 150 (28 mg, 14\%) and 150' (36 mg, 18\%) as colorless oils.<smiles>O=Cc1ccc(-c2ccccn2)cc1C(=O)O</smiles>

\section{2-[5-(Octan-2-yl)-2-(n-octyl)phenyl]pyridine (150)}

${ }^{1} \mathrm{H}-\mathrm{NMR}\left(300 \mathrm{MHz}, \mathrm{CDCl}_{3}\right): \delta=8.68$ (ddd, $J=4.9,1.9,0.9 \mathrm{~Hz}, 1 \mathrm{H}$ ), 7.73 (ddd, $J=7.7,1.9,1.9 \mathrm{~Hz}, 1 \mathrm{H}$ ), 7.37 (ddd, $J=7.8,1.1,1.0 \mathrm{~Hz}, 1 \mathrm{H}$ ), 7.23 (dddd, $J=5.1,3.2,1.6,1.6 \mathrm{~Hz}, 2 \mathrm{H}$ ), 7.17-7.11 (m, 2H), 2.82$2.56(\mathrm{~m}, 3 \mathrm{H}), 1.68-1.37(\mathrm{~m}, 4 \mathrm{H}), 1.37-1.03(\mathrm{~m}, 21 \mathrm{H}), 0.91-0.76(\mathrm{~m}, 6 \mathrm{H})$.

${ }^{13} \mathrm{C}$-NMR $\left(75 \mathrm{MHz}, \mathrm{CDCl}_{3}\right): \delta=160.8\left(\mathrm{C}_{\mathrm{q}}\right), 149.2(\mathrm{CH}), 145.5\left(\mathrm{C}_{\mathrm{q}}\right), 140.2\left(\mathrm{C}_{\mathrm{q}}\right), 138.1\left(\mathrm{C}_{\mathrm{q}}\right), 136.1(\mathrm{CH})$, $129.7(\mathrm{CH}), 128.5(\mathrm{CH}), 126.9(\mathrm{CH}), 124.3(\mathrm{CH}), 121.6(\mathrm{CH}), 39.7(\mathrm{CH}), 38.6\left(\mathrm{CH}_{2}\right), 32.0\left(\mathrm{CH}_{2}\right), 31.9$ $\left(\mathrm{CH}_{2}\right), 31.8\left(\mathrm{CH}_{2}\right), 29.6\left(\mathrm{CH}_{2}\right), 29.6\left(\mathrm{CH}_{2}\right), 29.4\left(\mathrm{CH}_{2}\right), 29.4\left(\mathrm{CH}_{2}\right), 27.9\left(\mathrm{CH}_{2}\right), 22.8\left(\mathrm{CH}_{2}\right), 22.8\left(\mathrm{CH}_{2}\right), 22.2$ $\left(\mathrm{CH}_{2}\right), 22.2\left(\mathrm{CH}_{2}\right), 14.3\left(\mathrm{CH}_{3}\right), 14.2\left(\mathrm{CH}_{3}\right)$.

IR (ATR): $\tilde{\boldsymbol{v}}=2955,2923,2853,1587,1563,1466,1426,1271,829,793,747 \mathrm{~cm}^{-1}$.

MS (El) m/z (relative intensity): 379 (12) [M+], 294 (100), 208 (14), 194 (22).

HR-MS (EI) $m / z$ calculated for $\mathrm{C}_{27} \mathrm{H}_{41} \mathrm{~N}^{+}: 379.3239$; found: 379.3233. 
<smiles>CC(C)c1cccc(-c2ccccn2)c1OC(=O)O</smiles>

\section{2-[3-(Octan-2-yl)-2-(n-octanyl)phenyl]pyridine (150')}

${ }^{1} \mathrm{H}-\mathrm{NMR}\left(300 \mathrm{MHz}, \mathrm{CDCl}_{3}\right): \delta=8.72-8.62(\mathrm{~m}, 1 \mathrm{H}), 7.73(\mathrm{ddd}, J=7.7,1.8,1.8 \mathrm{~Hz}, 1 \mathrm{H}), 7.36(\mathrm{~d}, J=7.7$ $\mathrm{Hz}, 1 \mathrm{H}$ ), 7.24 (dd, $J=11.8,7.7 \mathrm{~Hz}, 3 \mathrm{H}$ ), 7.08 (dd, $J=7.1,1.8 \mathrm{~Hz}, 1 \mathrm{H}$ ), 3.03 (qt, $J=7.1,7.0 \mathrm{~Hz}, 1 \mathrm{H}$ ), 2.67$2.52(m, 2 H), 1.71-1.49(m, 2 H), 1.49-1.01(m, 23 H), 0.87(m, 6 H)$.

${ }^{13} \mathrm{C}$-NMR $\left(75 \mathrm{MHz}, \mathrm{CDCl}_{3}\right): \delta=162.2\left(\mathrm{C}_{\mathrm{q}}\right), 149.3(\mathrm{CH}), 147.2\left(\mathrm{C}_{\mathrm{q}}\right), 141.6\left(\mathrm{C}_{\mathrm{q}}\right), 138.6\left(\mathrm{C}_{\mathrm{q}}\right), 136.5(\mathrm{CH})$, $127.6(\mathrm{CH}), 126.4(\mathrm{CH}), 126.2(\mathrm{CH}), 124.8(\mathrm{CH}), 122.0(\mathrm{CH}), 39.1\left(\mathrm{CH}_{2}\right), 34.6(\mathrm{CH}), 32.4\left(\mathrm{CH}_{2}\right), 32.4$ $\left(\mathrm{CH}_{2}\right), 31.9\left(\mathrm{CH}_{2}\right), 30.4\left(\mathrm{CH}_{2}\right), 30.1\left(\mathrm{CH}_{2}\right), 29.6\left(\mathrm{CH}_{2}\right), 29.6\left(\mathrm{CH}_{2}\right), 29.5\left(\mathrm{CH}_{2}\right), 28.5\left(\mathrm{CH}_{2}\right), 23.3\left(\mathrm{CH}_{2}\right), 23.2$ $\left(\mathrm{CH}_{2}\right), 23.2\left(\mathrm{CH}_{3}\right), 14.7\left(\mathrm{CH}_{3}\right), 14.6\left(\mathrm{CH}_{3}\right)$.

IR (ATR): $\tilde{\boldsymbol{V}}=2956,2922,2853,1582,1563,1458,1420,779,747,723 \mathrm{~cm}^{-1}$.

MS (EI) m/z (relative intensity): 378 (100) [M-H'], 308 (78), 294 (41), 266 (21), 208 (48), 194 (50), 180 (30), $43(50)$.

HR-MS (ESI) $\mathrm{m} / \mathrm{z}$ calculated for $\mathrm{C}_{27} \mathrm{H}_{41} \mathrm{~N}+\mathrm{H}^{+}$: 380.3312; found: 380.3311.

2-[2-(n-Octyl)-5-(pentan-2-yl)phenyl]pyridine (151) and 2-[2-(n-Octyl)-3-(pentan-2-yl)phenyl]pyridine (151')

The general procedure $\mathbf{E}$ was followed, using $\left[\operatorname{RuCl}_{2}(p \text {-cymene })\right]_{2}(15.0 \mathrm{mg}, 0.025 \mathrm{mmol}, 5.0 \mathrm{~mol} \%)$, $\mathrm{MesCO}_{2} \mathrm{H}$ (13a) (25 mg, $0.15 \mathrm{mmol}, 29 \mathrm{~mol} \%$ ), 93a (138 mg, $0.52 \mathrm{mmol}$ ) and 2-bromopentane (42bi) $(236 \mathrm{mg}, 1.56 \mathrm{mmol})$. After $20 \mathrm{~h}$, purification by column chromatography ( $n$-hexane/EtOAc 30:1) yielded 151 (25 mg, 14\%) and 151' (30 mg, 17\%) as colorless oils.<smiles>O=C(O)c1cc(-c2ccccn2)ccc1[N+](=O)[O-]</smiles>

2-[2-(n-Octyl)-5-(pentan-2-yl)phenyl]pyridine (151)

${ }^{1} \mathrm{H}-\mathrm{NMR}\left(300 \mathrm{MHz}, \mathrm{CDCl}_{3}\right): \delta=8.73-8.63(\mathrm{~m}, 1 \mathrm{H}), 7.73$ (ddd, $\left.J=7.5,1.5,1.5 \mathrm{~Hz}, 1 \mathrm{H}\right), 7.37(\mathrm{~d}, J=7.8$ $H z, 1 H), 7.29-7.17(m, 2 H), 7.17-7.09(m, 2 H), 2.80-2.54(m, 3 H), 1.67-1.34(m, 4 H), 1.34-1.00(m$, $15 \mathrm{H}), 0.91-0.77(\mathrm{~m}, 6 \mathrm{H})$. 
${ }^{13} \mathrm{C}-\mathrm{NMR}\left(75 \mathrm{MHz}, \mathrm{CDCl}_{3}\right): \delta=160.7\left(\mathrm{C}_{\mathrm{q}}\right), 149.0(\mathrm{CH}), 145.2\left(\mathrm{C}_{\mathrm{q}}\right), 140.1\left(\mathrm{C}_{\mathrm{q}}\right), 138.0\left(\mathrm{C}_{\mathrm{q}}\right), 135.9(\mathrm{CH})$, $129.5(\mathrm{CH}), 128.4(\mathrm{CH}), 126.8(\mathrm{CH}), 124.1(\mathrm{CH}), 121.4(\mathrm{CH}), 40.7\left(\mathrm{CH}_{2}\right), 39.2(\mathrm{CH}), 32.6\left(\mathrm{CH}_{2}\right), 31.8$ $\left(\mathrm{CH}_{2}\right), 31.3\left(\mathrm{CH}_{2}\right), 29.5\left(\mathrm{CH}_{2}\right), 29.2\left(\mathrm{CH}_{2}\right), 29.1\left(\mathrm{CH}_{2}\right), 22.6\left(\mathrm{CH}_{2}\right), 22.2\left(\mathrm{CH}_{2}\right), 20.8\left(\mathrm{CH}_{2}\right), 14.1\left(\mathrm{CH}_{3}\right), 14.1$ $\left(\mathrm{CH}_{3}\right)$.

IR (ATR): $\tilde{v}=2955,2924,2853,1586,1563,1466,1425,1101,897,747 \mathrm{~cm}^{-1}$.

MS (EI) m/z (relative intensity): 337 (31) [M+], 252 (100), 238 (15), 208 (17), 194 (34), 167 (15), 43 (28).

HR-MS (EI) $m / z$ calculated for $\mathrm{C}_{24} \mathrm{H}_{35} \mathrm{~N}^{+}$: 337.2770; found: 337.2755 .<smiles>O=C(O)c1cccc(-c2ccccn2)c1C(=O)O</smiles>

\section{2-[2-(n-Octyl)-3-(pentan-2-yl)phenyl]pyridine (151')}

${ }^{1} \mathrm{H}-\mathrm{NMR}\left(300 \mathrm{MHz}, \mathrm{CDCl}_{3}\right): \delta=8.78-8.59(\mathrm{~m}, 1 \mathrm{H}), 7.72(\mathrm{td}, J=7.7,1.9 \mathrm{~Hz}, 1 \mathrm{H}), 7.35(\mathrm{dt}, J=7.8,1.2 \mathrm{~Hz}$, $1 \mathrm{H}), 7.31-7.17(\mathrm{~m}, 3 \mathrm{H}), 7.07(\mathrm{dd}, J=7.2,1.8 \mathrm{~Hz}, 1 \mathrm{H}), 3.05(\mathrm{~h}, J=7.0 \mathrm{~Hz}, 1 \mathrm{H}), 2.70-2.51(\mathrm{~m}, 2 \mathrm{H}), 1.66-$ $1.52(\mathrm{~m}, 2 \mathrm{H}), 1.49-1.00(\mathrm{~m}, 17 \mathrm{H}), 0.96-0.79(\mathrm{~m}, 6 \mathrm{H})$.

${ }^{13} \mathrm{C}-\mathrm{NMR}\left(75 \mathrm{MHz}, \mathrm{CDCl}_{3}\right): \delta=161.6\left(\mathrm{C}_{\mathrm{q}}\right), 148.8(\mathrm{CH}), 146.6\left(\mathrm{C}_{\mathrm{q}}\right), 141.0\left(\mathrm{C}_{\mathrm{q}}\right), 138.1\left(\mathrm{C}_{\mathrm{q}}\right), 135.9(\mathrm{CH})$, $127.0(\mathrm{CH}), 125.9(\mathrm{CH}), 125.6(\mathrm{CH}), 124.2(\mathrm{CH}), 121.4(\mathrm{CH}), 40.9\left(\mathrm{CH}_{2}\right), 33.8(\mathrm{CH}), 31.8\left(\mathrm{CH}_{2}\right), 31.7$ $\left(\mathrm{CH}_{2}\right), 31.3\left(\mathrm{CH}_{2}\right), 29.8\left(\mathrm{CH}_{2}\right), 29.1\left(\mathrm{CH}_{2}\right), 29.0\left(\mathrm{CH}_{2}\right), 28.9\left(\mathrm{CH}_{2}\right), 22.6\left(\mathrm{CH}_{3}\right), 21.0\left(\mathrm{CH}_{2}\right), 14.3\left(\mathrm{CH}_{3}\right), 14.1$ $\left(\mathrm{CH}_{3}\right)$.

IR (ATR): $\tilde{\boldsymbol{V}}=2956,2923,2853,1581,1563,1457,1421,779,747 \mathrm{~cm}^{-1}$.

MS (EI) m/z (relative intensity): 336 (100) [M-H'], 308 (71), 294 (29), 266 (23), 252 (98), 208 (44), 194 (54), 180 (30), 167 (33), 43 (31).

HR-MS (EI) $\mathrm{m} / \mathrm{z}$ calculated for $\mathrm{C}_{24} \mathrm{H}_{35} \mathrm{~N}^{+}$: 337.2770; found: 337.2766 .

Synthesis of 2-[3,5-Di(pentan-2-yl)phenyl]-3-methoxypyridine (152bi') and 3-Methoxy-2-[3(pentan-2-yl)phenyl]pyridine (152bi)

The general procedure $\mathbf{E}$ was followed, using $\left[\mathrm{RuCl}_{2}(p \text {-cymene })\right]_{2}(15.0 \mathrm{mg}, 0.025 \mathrm{mmol}, 4.0 \mathrm{~mol} \%)$, $\mathrm{MesCO}_{2} \mathrm{H}$ (13a) (26 mg, $\left.0.15 \mathrm{mmol}, 24 \mathrm{~mol} \%\right), 6 \mathrm{cb}$ (115 mg, $0.62 \mathrm{mmol}$ ) and 2-bromopentane (42bi) $(255 \mathrm{mg}, 1.69 \mathrm{mmol})$. After $20 \mathrm{~h}$, purification by column chromatography ( $n$-hexane/EtOAc 6:1) yielded 152bi' (23 mg, 11\%) and 152bi (65 mg, 41\%) as colorless oils. 


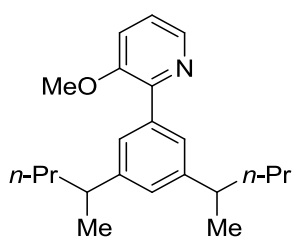

\section{(152bi')}

${ }^{1} \mathrm{H}-\mathrm{NMR}\left(300 \mathrm{MHz}, \mathrm{CDCl}_{3}\right): \delta=8.32(\mathrm{dd}, J=4.5,1.5 \mathrm{~Hz}, 1 \mathrm{H}), 7.51(\mathrm{~d}, J=1.7 \mathrm{~Hz}, 2 \mathrm{H}), 7.30-7.14(\mathrm{~m}, 2 \mathrm{H})$, 7.04-6.98 (m, 1H), $3.84(\mathrm{~s}, 3 \mathrm{H}), 2.75(\mathrm{qt}, J=7.0,6.9 \mathrm{~Hz}, 2 \mathrm{H}), 1.71-1.45(\mathrm{~m}, 4 \mathrm{H}), 1.38-1.14(\mathrm{~m}, 4 \mathrm{H}), 1.27$ $(\mathrm{d}, J=6.9 \mathrm{~Hz}, 6 \mathrm{H}), 0.87(\mathrm{t}, J=7.3 \mathrm{~Hz}, 6 \mathrm{H})$.

${ }^{13} \mathrm{C}$-NMR $\left(75 \mathrm{MHz}, \mathrm{CDCl}_{3}\right): \delta=153.7\left(\mathrm{C}_{\mathrm{q}}\right), 149.2\left(\mathrm{C}_{\mathrm{q}}\right), 147.4\left(\mathrm{C}_{\mathrm{q}}\right), 141.2(\mathrm{CH}), 128.4\left(\mathrm{C}_{\mathrm{q}}\right), 126.1(\mathrm{CH})$, 125.7 (CH), $122.7(\mathrm{CH}), 118.7(\mathrm{CH}), 55.6\left(\mathrm{CH}_{3}\right), 40.9(\mathrm{CH}), 39.8\left(\mathrm{CH}_{2}\right), 22.3\left(\mathrm{CH}_{2}\right), 21.0\left(\mathrm{CH}_{3}\right), 14.3\left(\mathrm{CH}_{3}\right)$. IR (ATR): $\tilde{v}=2956,2927,2871,1714,1580,1420,1359,1272,1218,1126,1018,768 \mathrm{~cm}^{-1}$. MS (El) m/z (relative intensity): 325 (28) [M+], 296 (15), 282 (100), 238 (16), 212 (20), 196 (10). HR-MS (EI) $m / z$ calculated for $\mathrm{C}_{22} \mathrm{H}_{31} \mathrm{NO}^{+}$: 325.2406 ; found: 325.2406 .<smiles>CCCCCCCNC(=O)c1cccc(-c2ncccc2OC)c1</smiles>

(152bi)

${ }^{1} \mathrm{H}-\mathrm{NMR}\left(300 \mathrm{MHz}, \mathrm{CDCl}_{3}\right): \delta=8.32(\mathrm{dd}, J=4.5,1.5 \mathrm{~Hz}, 1 \mathrm{H}), 7.81-7.65(\mathrm{~m}, 2 \mathrm{H}), 7.36(\mathrm{dd}, J=7.9$, $7.9 \mathrm{~Hz}, 1 \mathrm{H}), 7.32-7.13(\mathrm{~m}, 3 \mathrm{H}), 3.85(\mathrm{~s}, 3 \mathrm{H}), 2.78(\mathrm{qt}, J=7.1,6.9 \mathrm{~Hz}, 1 \mathrm{H}), 1.75-1.44(\mathrm{~m}, 2 \mathrm{H}), 1.44-1.12$ (m, 2H), $1.26(\mathrm{~d}, J=6.9 \mathrm{~Hz}, 3 \mathrm{H}), 0.88(\mathrm{t}, J=7.3 \mathrm{~Hz}, 3 \mathrm{H})$.

${ }^{13} \mathrm{C}$-NMR $\left(75 \mathrm{MHz}, \mathrm{CDCl}_{3}\right): \delta=153.5\left(\mathrm{C}_{\mathrm{q}}\right), 148.6\left(\mathrm{C}_{\mathrm{q}}\right), 147.4\left(\mathrm{C}_{\mathrm{q}}\right), 141.2(\mathrm{CH}), 137.4\left(\mathrm{C}_{\mathrm{q}}\right), 128.2(\mathrm{CH})$, $127.7(\mathrm{CH}), 126.9(\mathrm{CH}), 126.9(\mathrm{CH}), 122.7(\mathrm{CH}), 118.4(\mathrm{CH}), 55.4\left(\mathrm{CH}_{3}\right), 40.7\left(\mathrm{CH}_{2}\right), 39.7(\mathrm{CH}), 22.2$ $\left(\mathrm{CH}_{2}\right), 20.8\left(\mathrm{CH}_{3}\right), 14.1\left(\mathrm{CH}_{3}\right)$.

IR (ATR): $\tilde{\boldsymbol{V}}=3055,3007,2957,2937,2835,1578,1423,1267,1195,1125,1013,737,694 \mathrm{~cm}^{-1}$. MS (EI) m/z (relative intensity): 255 (34), 212 (100), 197 (56), 182 (37).

HR-MS (El) $\mathrm{m} / \mathrm{z}$ calculated for $\mathrm{C}_{17} \mathrm{H}_{21} \mathrm{NO}^{+}$: 255.1623; found: 255.1617.

\section{Synthesis of 3-Methyl-2-[3-(octan-2-yl)phenyl]pyridine (152da)}

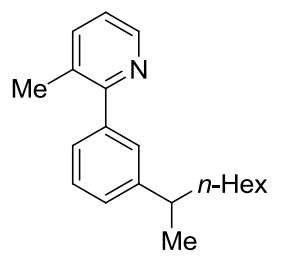


The general procedure $\mathbf{E}$ was followed, using $\left[\mathrm{RuCl}_{2}(p \text {-cymene })\right]_{2}(8.00 \mathrm{mg}, 0.013 \mathrm{mmol}, 2.4 \mathrm{~mol} \%)$, $\mathrm{MesCO}_{2} \mathrm{H}$ (13a) (25 mg, $\left.0.15 \mathrm{mmol}, 29 \mathrm{~mol} \%\right), 6 \mathrm{db}$ (90.2 mg, $0.53 \mathrm{mmol}$ ) and 2-bromooctane (42ba) (282 $\mathrm{mg}, 1.46 \mathrm{mmol}$ ). After $20 \mathrm{~h}$, purification by column chromatography ( $n$-hexane/EtOAc 4:1) yielded $152 \mathrm{da}$ ( $84 \mathrm{mg}, 56 \%$ ) as a colorless oil.

${ }^{1} \mathrm{H}-\mathrm{NMR}\left(300 \mathrm{MHz}, \mathrm{CDCl}_{3}\right): \delta=8.57-8.45(\mathrm{~m}, 1 \mathrm{H}), 7.57$ (ddd, $\left.J=7.7,1.7,0.8 \mathrm{~Hz}, 1 \mathrm{H}\right), 7.44-7.28(\mathrm{~m}$, $3 \mathrm{H}), 7.28-7.12(\mathrm{~m}, 2 \mathrm{H}), 2.73(\mathrm{qt}, J=7.0,6.9 \mathrm{~Hz}, 1 \mathrm{H}), 2.35(\mathrm{~s}, 3 \mathrm{H}), 1.70-1.49(\mathrm{~m}, 2 \mathrm{H}), 1.35-1.09(\mathrm{~m}, 8 \mathrm{H})$, $1.24(\mathrm{~d}, J=6.9 \mathrm{~Hz}, 3 \mathrm{H}), 0.92-0.77(\mathrm{t}, J=6.7 \mathrm{~Hz}, 3 \mathrm{H})$.

${ }^{13} \mathrm{C}$-NMR $\left(75 \mathrm{MHz}, \mathrm{CDCl}_{3}\right): \delta=159.4\left(\mathrm{C}_{\mathrm{q}}\right), 148.0\left(\mathrm{C}_{\mathrm{q}}\right), 147.2(\mathrm{CH}), 140.8\left(\mathrm{C}_{\mathrm{q}}\right), 138.7(\mathrm{CH}), 131.2\left(\mathrm{C}_{\mathrm{q}}\right)$, $128.4(\mathrm{CH}), 128.0(\mathrm{CH}), 126.9(\mathrm{CH}), 126.7(\mathrm{CH}), 122.3(\mathrm{CH}), 40.4\left(\mathrm{CH}_{3}\right), 38.9\left(\mathrm{CH}_{2}\right), 32.3\left(\mathrm{CH}_{2}\right), 29.9$ $\left(\mathrm{CH}_{2}\right), 28.2\left(\mathrm{CH}_{2}\right), 23.1\left(\mathrm{CH}_{2}\right), 22.8(\mathrm{CH}), 20.6\left(\mathrm{CH}_{3}\right), 14.6\left(\mathrm{CH}_{3}\right)$.

IR (ATR): $\tilde{v}=2956,2924,2854,1583,1566,1453,1417,1377,1118,786,766,708,626 \mathrm{~cm}^{-1}$. MS (EI): m/z (relative intensity): 281 (28) [M] ${ }^{+}, 210$ (51), 196 (100), 181 (40), 168 (21).

HRMS (EI) $\mathrm{m} / \mathrm{z}$ calculated for $\mathrm{C}_{20} \mathrm{H}_{27} \mathrm{~N}^{+}: 281.2143$, found: 281.2143 .

Synthesis of 2-[3,5-Di(pentan-2-yl)phenyl]-3-methoxypyridine (152ci') and 2-[3-(Pentan-2-yl)phenyl]-3-methoxypyridine (152ci)

The general procedure $\mathbf{E}$ was followed, using $\left[\mathrm{RuCl}_{2}(p \text {-cymene })\right]_{2}(8.00 \mathrm{mg}, 0.013 \mathrm{mmol}, 2.5 \mathrm{~mol} \%)$, $\mathrm{MesCO}_{2} \mathrm{H}$ (13a) (25 mg, $\left.0.15 \mathrm{mmol}, 30 \mathrm{~mol} \%\right), 6 \mathbf{c b}(92.1 \mathrm{mg}, 0.50 \mathrm{mmol}$ ) and 2-bromopentane (42bi) (250 mg, $1.51 \mathrm{mmol}$ ). After $20 \mathrm{~h}$, purification by column chromatography ( $n$-hexane/EtOAc 5:1) yielded 152 ci' $^{\prime}(8 \mathrm{mg}, 5 \%)$ and $152 \mathrm{ci}(62 \mathrm{mg}, 48 \%)$ as colorless oils.

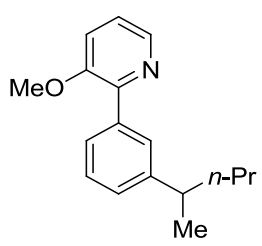

(152ci)

${ }^{1} \mathrm{H}-\mathrm{NMR}\left(300 \mathrm{MHz}, \mathrm{CDCl}_{3}\right): \delta=8.32(\mathrm{dd}, J=4.5,1.5 \mathrm{~Hz}, 1 \mathrm{H}), 7.75-7.67(\mathrm{~m}, 2 \mathrm{H}), 7.41-7.32(\mathrm{~m}, 1 \mathrm{H})$, 7.31-7.17 (m, 3H), $3.85(\mathrm{~s}, 3 \mathrm{H}), 2.76(\mathrm{qt}, J=7.0,6.9 \mathrm{~Hz}, 1 \mathrm{H}), 1.73-1.50(\mathrm{~m}, 2 \mathrm{H}), 1.37-1.10(\mathrm{~m}, 4 \mathrm{H}), 1.28$ (d, $J=7.0 \mathrm{~Hz}, 3 \mathrm{H}), 0.85(\mathrm{t}, J=6.8 \mathrm{~Hz}, 3 \mathrm{H})$.

${ }^{13} \mathrm{C}$-NMR $\left(75 \mathrm{MHz}, \mathrm{CDCl}_{3}\right): \delta=153.5\left(\mathrm{C}_{\mathrm{q}}\right), 148.6\left(\mathrm{C}_{\mathrm{q}}\right), 147.5\left(\mathrm{C}_{\mathrm{q}}\right), 141.3(\mathrm{CH}), 137.5\left(\mathrm{C}_{\mathrm{q}}\right), 128.1(\mathrm{CH})$, $127.7(\mathrm{CH}), 126.9(\mathrm{CH}), 126.8(\mathrm{CH}), 122.6(\mathrm{CH}), 118.4(\mathrm{CH}), 55.4\left(\mathrm{CH}_{3}\right), 40.0(\mathrm{CH}), 38.1\left(\mathrm{CH}_{2}\right), 29.9$ $\left(\mathrm{CH}_{2}\right), 22.8\left(\mathrm{CH}_{2}\right), 22.2\left(\mathrm{CH}_{3}\right), 14.1\left(\mathrm{CH}_{3}\right)$. 
IR (ATR): $\tilde{v}=3056,2956,2925,2870,2856,1579,1446,1417,1268,1125,1017,802,760,703 \mathrm{~cm}^{-1}$. MS (EI) m/z (relative intensity): 269 (44) [M+], 226 (34), 212 (100), 196 (35), 182 (24), 167 (13), 154 (11).

HRMS (EI) $\mathrm{m} / \mathrm{z}$ calculated for $\mathrm{C}_{18} \mathrm{H}_{23} \mathrm{NO}^{+}: 269.1780$; found: 269.1789 .<smiles>COc1cccnc1-c1cc(C(=O)P)cc(C(=O)N(C)c2ccccc2)c1</smiles>

(152ci')

${ }^{1} \mathrm{H}-\mathrm{NMR}\left(300 \mathrm{MHz}, \mathrm{CDCl}_{3}\right): \delta=8.31(\mathrm{dd}, J=4.6,1.5 \mathrm{~Hz}, 1 \mathrm{H}), 7.51(\mathrm{~d}, J=1.7 \mathrm{~Hz}, 2 \mathrm{H}), 7.31-7.14(\mathrm{~m}, 2 \mathrm{H})$, $7.01(\mathrm{dd}, J=1.8 \mathrm{~Hz}, 1 \mathrm{H}), 3.84(\mathrm{~s}, 3 \mathrm{H}), 2.72(\mathrm{qt}, J=7.0,6.9 \mathrm{~Hz}, 2 \mathrm{H}), 1.74-1.44(\mathrm{~m}, 4 \mathrm{H}), 1.44-1.10(\mathrm{~m}$, $8 \mathrm{H}), 1.27(\mathrm{~d}, J=6.9 \mathrm{~Hz}, 6 \mathrm{H}), 0.85(\mathrm{t}, J=6.9 \mathrm{~Hz}, 6 \mathrm{H})$.

${ }^{13} \mathrm{C}-\mathrm{NMR}\left(75 \mathrm{MHz}, \mathrm{CDCl}_{3}\right): \delta=153.5\left(\mathrm{C}_{\mathrm{q}}\right), 149.2\left(\mathrm{C}_{\mathrm{q}}\right), 147.2\left(\mathrm{C}_{\mathrm{q}}\right), 141.4(\mathrm{CH}), 137.7\left(\mathrm{C}_{\mathrm{q}}\right), 125.9(\mathrm{CH})$, 125.6 (CH), $122.5(\mathrm{CH}), 118.4(\mathrm{CH}), 55.5\left(\mathrm{CH}_{3}\right), 40.0(\mathrm{CH}), 38.2\left(\mathrm{CH}_{2}\right), 30.0\left(\mathrm{CH}_{2}\right), 22.8\left(\mathrm{CH}_{2}\right), 22.2\left(\mathrm{CH}_{3}\right)$, $14.1\left(\mathrm{CH}_{3}\right)$.

IR (ATR): $\tilde{\boldsymbol{V}}=2955,2925,2870,1580,1457,1420,1273,1181,1126,1018,797 \mathrm{~cm}^{-1}$.

MS (EI) m/z (relative intensity): $353(33)\left[\mathrm{M}^{+}\right], 310$ (23), 296 (100), 238 (11).

HR-MS (El) $\mathrm{m} / \mathrm{zc}$ calculated for $\mathrm{C}_{24} \mathrm{H}_{35} \mathrm{NO}^{+}: 353.2719$; found: 353.2720 .

Synthesis of 2-[3,5-Di(hexan-2-yl)phenyl]-3-methylpyridine (152dj') \& 2-[3-(Hexan-2-yl)phenyl]-3methylpyridine (152dj)

The general procedure $\mathbf{E}$ was followed, using $\left[\operatorname{RuCl}_{2}(p \text {-cymene })\right]_{2}(7.90 \mathrm{mg}, 0.013 \mathrm{mmol}, 2.5 \mathrm{~mol} \%)$, $\mathrm{MesCO}_{2} \mathrm{H}$ (13a) $(25 \mathrm{mg}, 0.15 \mathrm{mmol}, 30 \mathrm{~mol} \%), 6 \mathrm{db}(87.0 \mathrm{mg}, 0.51 \mathrm{mmol}$ ) and 2-bromohexane (42bj) $(255 \mathrm{mg}, 1.55 \mathrm{mmol})$. After $20 \mathrm{~h}$, purification by column chromatography ( $n$-hexane/EtOAc 9:1) yielded 152dj' (18 mg, 10\%) and 152dj (79 mg, 61\%) as colorless oils.

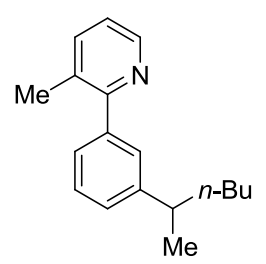

(152dj) 
${ }^{1} \mathrm{H}-\mathrm{NMR}\left(300 \mathrm{MHz}, \mathrm{CDCl}_{3}\right): \delta=8.54(\mathrm{dd}, J=4.8,1.8 \mathrm{~Hz}, 1 \mathrm{H}), 7.63-7.51(\mathrm{~m}, 1 \mathrm{H}), 7.43-7.25(\mathrm{~m}, 3 \mathrm{H})$, 7.25-7.09 (m, 2H), $2.75(\mathrm{qt}, J=7.1,6.9 \mathrm{~Hz}, 1 \mathrm{H}), 2.35(\mathrm{~s}, 3 \mathrm{H}), 1.73-1.48(\mathrm{~m}, 2 \mathrm{H}), 1.38-1.10(\mathrm{~m}, 4 \mathrm{H}), 1.27$ $(\mathrm{d}, J=6.9 \mathrm{~Hz}, 3 \mathrm{H}), 0.86(\mathrm{t}, J=6.7 \mathrm{~Hz}, 3 \mathrm{H})$.

${ }^{13} \mathrm{C}-\mathrm{NMR}\left(75 \mathrm{MHz}, \mathrm{CDCl}_{3}\right): \delta=159.1\left(\mathrm{C}_{\mathrm{q}}\right), 147.7\left(\mathrm{C}_{\mathrm{q}}\right), 146.9(\mathrm{CH}), 140.5\left(\mathrm{C}_{\mathrm{q}}\right), 138.3(\mathrm{CH}), 130.8\left(\mathrm{C}_{\mathrm{q}}\right)$, $128.0(\mathrm{CH}), 127.6(\mathrm{CH}), 126.5(\mathrm{CH}), 126.3(\mathrm{CH}), 121.9(\mathrm{CH}), 39.9\left(\mathrm{CH}_{3}\right), 38.1\left(\mathrm{CH}_{2}\right), 29.9\left(\mathrm{CH}_{2}\right), 22.7$ $\left(\mathrm{CH}_{2}\right), 22.3(\mathrm{CH}), 20.1\left(\mathrm{CH}_{3}\right), 14.0\left(\mathrm{CH}_{3}\right)$.

IR (ATR): $\tilde{\boldsymbol{v}}=3047,2956,2925,2857,1583,1565,1448,1417,1377,1118,900,786,765 \mathrm{~cm}^{-1}$. MS (EI) m/z (relative intensity): 253 (38) [M+], 210 (46), 196 (100), 181 (43), 168 (23).

HRMS (EI) m/z calculated for $\mathrm{C}_{18} \mathrm{H}_{23} \mathrm{~N}-\mathrm{H}^{+}$: 252.1752; found: 252.1751 .

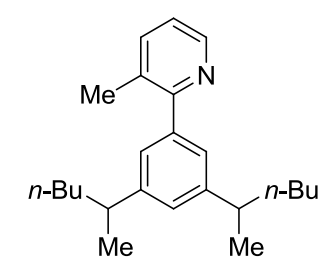

(152dj')

${ }^{1} \mathrm{H}-\mathrm{NMR}\left(300 \mathrm{MHz}, \mathrm{CDCl}_{3}\right): \delta=8.59-8.48(\mathrm{~m}, 1 \mathrm{H}), 7.57$ (ddd, $\left.J=7.7,1.8,0.9 \mathrm{~Hz}, 1 \mathrm{H}\right), 7.22-7.10(\mathrm{dd}, J=$ 7.7, $4.8 \mathrm{~Hz}, 2 \mathrm{H}$ ), 7.12 (d, $J=1.7 \mathrm{~Hz}, 1 \mathrm{H}$ ), 7.00 (t, $J=1.8 \mathrm{~Hz}, 1 \mathrm{H}$ ), 2.71 (qt, $J=7.0,6.9 \mathrm{~Hz}, 2 \mathrm{H}$ ), 2.33 (s, $3 \mathrm{H}), 1.68-1.47(\mathrm{~m}, 4 \mathrm{H}), 1.37-1.09(\mathrm{~m}, 8 \mathrm{H}), 1.26(\mathrm{~d}, J=6.9 \mathrm{~Hz}, 6 \mathrm{H}), 0.92-0.80(\mathrm{~m}, 6 \mathrm{H})$.

${ }^{13} \mathrm{C}$-NMR $\left(75 \mathrm{MHz}, \mathrm{CDCl}_{3}\right): \delta=159.7\left(\mathrm{C}_{\mathrm{q}}\right), 147.5\left(\mathrm{C}_{\mathrm{q}}\right), 146.8(\mathrm{CH}), 140.3\left(\mathrm{C}_{\mathrm{q}}\right), 138.3(\mathrm{CH}), 130.8\left(\mathrm{C}_{\mathrm{q}}\right)$, $125.5(\mathrm{CH}), 124.9(\mathrm{CH}), 121.7(\mathrm{CH}), 39.9\left(\mathrm{CH}_{3}\right), 38.2\left(\mathrm{CH}_{2}\right), 30.0\left(\mathrm{CH}_{2}\right), 22.7\left(\mathrm{CH}_{2}\right), 22.3(\mathrm{CH}), 20.1\left(\mathrm{CH}_{3}\right)$, $14.0\left(\mathrm{CH}_{3}\right)$.

IR (ATR): $\tilde{\boldsymbol{V}}=2955,2924,2857,1598,1583,1566,1421,1376,716 \mathrm{~cm}^{-1}$.

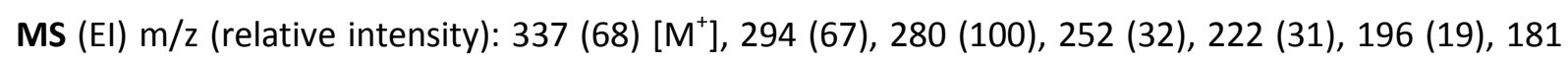
(11).

HRMS (EI) m/z calculated for $\mathrm{C}_{24} \mathrm{H}_{35} \mathrm{~N}-\mathrm{H}^{+}$: 336.2691; found: 336.2702 .

Synthesis of 2-[3-Isopropoxy-5-(pentan-2-yl)phenyl]-4-methylpyridine (152ei)<smiles>CCCC(=O)c1cc(OC(C)C)cc(-c2cc([N+](=O)[O-])ccn2)c1</smiles> 
The general procedure $\mathbf{E}$ was followed, using $\left[\mathrm{RuCl}_{2}(p \text {-cymene })\right]_{2}(15.2 \mathrm{mg}, 0.025 \mathrm{mmol}, 5.1 \mathrm{~mol} \%)$, MesCO ${ }_{2} \mathrm{H}$ (13a) (24 mg, $\left.0.15 \mathrm{mmol}, 31 \mathrm{~mol} \%\right)$, 6ec (109 mg, $0.48 \mathrm{mmol}$ ) and 2-bromopentane (42bi) (235 mg, $1.56 \mathrm{mmol}$ ). After $20 \mathrm{~h}$, purification by column chromatography ( $n$-hexane/EtOAc 19:1) yielded 152ei (47 mg, 33\%) as a colorless oil.

${ }^{1} \mathrm{H}-\mathrm{NMR}\left(300 \mathrm{MHz}, \mathrm{CDCl}_{3}\right): \delta=8.53(\mathrm{dd}, J=5.0,0.7 \mathrm{~Hz}, 1 \mathrm{H}$ ), 7.51 (ddd, $J=1.6,0.8,0.8 \mathrm{~Hz}, 1 \mathrm{H}$ ), 7.37$7.29(\mathrm{~m}, 2 \mathrm{H}), 7.04$ (ddd, $J=5.0,1.6,0.8 \mathrm{~Hz}, 1 \mathrm{H}), 6.78(\mathrm{dd}, J=1.9,1.9 \mathrm{~Hz}, 1 \mathrm{H}$ ), 4.68 (hept, $J=6.0 \mathrm{~Hz}$, $1 \mathrm{H}), 2.75$ (qt, $J=7.0,6.9 \mathrm{~Hz}, 1 \mathrm{H}), 2.41(\mathrm{~s}, 3 \mathrm{H}), 1.74-1.43(\mathrm{~m}, 2 \mathrm{H}), 1.37(\mathrm{~d}, J=6.1 \mathrm{~Hz}, 6 \mathrm{H}), 1.31-1.10(\mathrm{~m}$, $2 \mathrm{H}), 1.27(\mathrm{~d}, J=6.9 \mathrm{~Hz}, 3 \mathrm{H}), 0.87(\mathrm{t}, J=7.3 \mathrm{~Hz}, 3 \mathrm{H})$.

${ }^{13} \mathrm{C}$-NMR $\left(75 \mathrm{MHz}, \mathrm{CDCl}_{3}\right): \delta=158.2\left(\mathrm{C}_{\mathrm{q}}\right), 157.6\left(\mathrm{C}_{\mathrm{q}}\right), 150.0\left(\mathrm{C}_{\mathrm{q}}\right), 149.3(\mathrm{CH}), 147.6\left(\mathrm{C}_{\mathrm{q}}\right), 140.7\left(\mathrm{C}_{\mathrm{q}}\right)$, 123.0 (CH), $121.7(\mathrm{CH}), 118.4(\mathrm{CH}), 115.6(\mathrm{CH}), 111.4(\mathrm{CH}), 69.8(\mathrm{CH}), 40.6\left(\mathrm{CH}_{2}\right), 39.9(\mathrm{CH}), 22.2\left(\mathrm{CH}_{3}\right)$, $22.1\left(\mathrm{CH}_{3}\right), 21.2\left(\mathrm{CH}_{3}\right), 20.8\left(\mathrm{CH}_{2}\right), 14.1\left(\mathrm{CH}_{3}\right)$.

IR (ATR): $\tilde{v}=2957,2926,2871,2857,1584,1566,1439,1325,1116,993,782 \mathrm{~cm}^{-1}$.

MS (EI) m/z (relative intensity): 297 (20) [M+], 255 (32), 213 (100), 197 (21), 43 (47).

HR-MS (EI) $m / z$ calculated for $\mathrm{C}_{20} \mathrm{H}_{27} \mathrm{NO}^{+}$: 297.2093; found: 297.2086.

Synthesis of 2-(3,5-Dicyclopentylphenyl)-4-methylpyridine (152ek') \& 2-(3-Cyclopentylphenyl)-4methylpyridine (152ek)

The general procedure $\mathbf{E}$ was followed, using $\left[\mathrm{RuCl}_{2}(p \text {-cymene })\right]_{2}(16.3 \mathrm{mg}, 0.027 \mathrm{mmol}, 2.5 \mathrm{~mol} \%)$, MesCO ${ }_{2} \mathrm{H}$ (13a) $(52 \mathrm{mg}, 0.31 \mathrm{mmol}, 30 \mathrm{~mol} \%), 6 \mathrm{eb}(166 \mathrm{mg}, 0.98 \mathrm{mmol})$ and bromocyclopentane (42bk) $(449 \mathrm{mg}, 3.01 \mathrm{mmol}$ ). After $20 \mathrm{~h}$, purification by column chromatography ( $n$-hexane/EtOAc 19:1) yielded 152ek' (19 mg, 6\%) and 152ek ( $88 \mathrm{mg}, 38 \%$ ) as colorless oils.

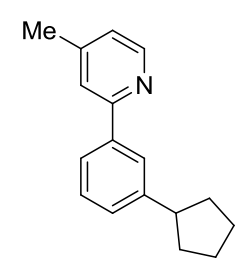

(152ek)

${ }^{1} \mathrm{H}-\mathrm{NMR}\left(300 \mathrm{MHz}, \mathrm{CDCl}_{3}\right): \delta=8.55(\mathrm{~d}, J=5.0 \mathrm{~Hz}, 1 \mathrm{H}), 7.88(\mathrm{~d}, J=2.0 \mathrm{~Hz}, 1 \mathrm{H}), 7.84-7.68(\mathrm{~m}, 1 \mathrm{H}), 7.62-$ $7.49(\mathrm{~m}, 1 \mathrm{H}), 7.38(\mathrm{dd}, J=7.6,7.5 \mathrm{~Hz}, 1 \mathrm{H}), 7.34-7.27(\mathrm{~m}, 1 \mathrm{H}), 7.15-6.97(\mathrm{~m}, 1 \mathrm{H}), 3.21-2.94(\mathrm{~m}, 1 \mathrm{H})$, $2.41(\mathrm{~s}, 3 \mathrm{H}), 2.23-2.04(\mathrm{~m}, 2 \mathrm{H}), 1.94-1.56(\mathrm{~m}, 6 \mathrm{H})$. 
${ }^{13} \mathrm{C}-\mathrm{NMR}\left(75 \mathrm{MHz}, \mathrm{CDCl}_{3}\right): \delta=157.7\left(\mathrm{C}_{\mathrm{q}}\right), 149.3(\mathrm{CH}), 147.6\left(\mathrm{C}_{\mathrm{q}}\right), 146.9\left(\mathrm{C}_{\mathrm{q}}\right), 139.4\left(\mathrm{C}_{\mathrm{q}}\right), 128.5(\mathrm{CH})$, $127.5(\mathrm{CH}), 125.8(\mathrm{CH}), 124.3(\mathrm{CH}), 122.9(\mathrm{CH}), 121.6(\mathrm{CH}), 46.1\left(\mathrm{CH}_{3}\right), 34.6\left(\mathrm{CH}_{2}\right), 25.5\left(\mathrm{CH}_{2}\right), 21.2$ $(\mathrm{CH})$.

IR (ATR): $\tilde{V}=3045,2949,2866,1599,1558,1449,825,793,698,455 \mathrm{~cm}^{-1}$.

MS (EI) m/z (relative intensity): 237 (29) [M+], 208 (48), 196 (100), 181 (14), 168 (22).

HR-MS (EI) $m / z$ calculated for $\mathrm{C}_{17} \mathrm{H}_{19} \mathrm{~N}-\mathrm{H}^{+}$: 236.1439; found: 236.1449.

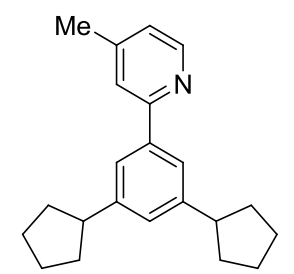

(152ek')

${ }^{1} \mathrm{H}-\mathrm{NMR}\left(300 \mathrm{MHz}, \mathrm{CDCl}_{3}\right): \delta=8.52(\mathrm{dd}, J=5.0,0.8 \mathrm{~Hz}, 1 \mathrm{H}), 7.63(\mathrm{~d}, J=1.7 \mathrm{~Hz}, 2 \mathrm{H}), 7.57-7.45(\mathrm{~m}, 1 \mathrm{H})$, 7.19-7.10 $(\mathrm{m}, 1 \mathrm{H}), 7.05-6.99(\mathrm{~m}, 1 \mathrm{H}), 3.04(\mathrm{dt}, J=9.7,7.3 \mathrm{~Hz}, 2 \mathrm{H}), 2.40(\mathrm{~s}, 3 \mathrm{H}), 2.14-2.03(\mathrm{~m}, 4 \mathrm{H})$, 1.88-1.55 (m, 12H).

${ }^{13} \mathrm{C}$-NMR $\left(75 \mathrm{MHz}, \mathrm{CDCl}_{3}\right): \delta=158.1\left(\mathrm{C}_{\mathrm{q}}\right), 149.3(\mathrm{CH}), 147.5\left(\mathrm{C}_{\mathrm{q}}\right), 146.8\left(\mathrm{C}_{\mathrm{q}}\right), 139.4\left(\mathrm{C}_{\mathrm{q}}\right), 126.6(\mathrm{CH})$, 123.3 (CH), $122.8(\mathrm{CH}), 121.7(\mathrm{CH}), 46.2\left(\mathrm{CH}_{3}\right), 34.7\left(\mathrm{CH}_{2}\right), 25.6\left(\mathrm{CH}_{2}\right), 21.2(\mathrm{CH})$.

IR (ATR): $\tilde{V}=2952,2865,1712,1595,1440,1360,1220,876,828,529 \mathrm{~cm}^{-1}$.

MS (EI) m/z (relative intensity): 305 (30) [M+], 277 (28), 264 (100), 208 (14), 43 (15).

HR-MS (EI) $\mathrm{m} / z$ calculated for $\mathrm{C}_{22} \mathrm{H}_{27} \mathrm{~N}^{+}: 305.2143$; found: 305.2128.

Synthesis of 5-Methyl-2-[3-(octan-2-yl)phenyl]pyridine (152fa)

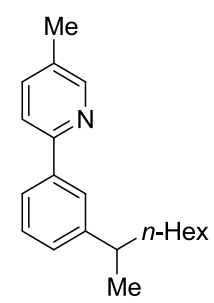

The general procedure $\mathbf{E}$ was followed, using $\left[\mathrm{RuCl}_{2}(p \text {-cymene })\right]_{2}(3.70 \mathrm{mg}, 0.006 \mathrm{mmol}, 2.5 \mathrm{~mol} \%)$, MesCO ${ }_{2} \mathrm{H}$ (13a) (13 mg, $\left.0.8 \mathrm{mmol}, 29 \mathrm{~mol} \%\right), 6 \mathrm{hb}(41.6 \mathrm{mg}, 0.25 \mathrm{mmol})$ and 2-bromooctane (42ba) (151 mg, $0.78 \mathrm{mmol}$ ). After $20 \mathrm{~h}$, purification by column chromatography ( $n$-hexane/EtOAc 9:1) yielded $152 \mathrm{ha} \mathrm{(30} \mathrm{mg}, 43 \%$ ) as a colorless oil. 
${ }^{1} \mathrm{H}-\mathrm{NMR}\left(300 \mathrm{MHz}, \mathrm{CDCl}_{3}\right): \delta=8.52(\mathrm{dd}, J=1.9,0.9 \mathrm{~Hz}, 1 \mathrm{H}), 7.80(\mathrm{~d}, J=1.8 \mathrm{~Hz}, 1 \mathrm{H}), 7.75(\mathrm{dd}, J=7.7$, $1.5 \mathrm{~Hz}, 1 \mathrm{H}), 7.63(\mathrm{dd}, J=8.1,0.8 \mathrm{~Hz}, 1 \mathrm{H}), 7.58-7.51(\mathrm{~m}, 1 \mathrm{H}), 7.38(\mathrm{~d}, J=7.6 \mathrm{~Hz}, 1 \mathrm{H}), 7.22$ (dd, $J=7.6$, $1.5 \mathrm{~Hz}, 1 \mathrm{H}), 2.77(\mathrm{qt}, J=7.1,6.9 \mathrm{~Hz}, 1 \mathrm{H}), 2.37(\mathrm{~s}, 3 \mathrm{H}), 1.73-1.51(\mathrm{~m}, 2 \mathrm{H}), 1.40-1.05(\mathrm{~m}, 8 \mathrm{H}), 1.29(\mathrm{~d}, J=$ $6.9 \mathrm{~Hz}, 3 \mathrm{H}), 0.86(\mathrm{t}, J=6.7 \mathrm{~Hz}, 3 \mathrm{H})$.

${ }^{13} \mathrm{C}$-NMR $\left(75 \mathrm{MHz}, \mathrm{CDCl}_{3}\right): \delta=155.1\left(\mathrm{C}_{\mathrm{q}}\right), 149.9(\mathrm{CH}) 148.5\left(\mathrm{C}_{\mathrm{q}}\right), 139.3(\mathrm{CH}), 137.2\left(\mathrm{C}_{\mathrm{q}}\right), 131.4(\mathrm{CH})$, $128.6(\mathrm{CH}), 127.2(\mathrm{CH}), 125.5(\mathrm{CH}), 124.2(\mathrm{CH}), 120.2(\mathrm{CH}), 40.1\left(\mathrm{CH}_{3}\right), 38.4\left(\mathrm{CH}_{2}\right), 31.8\left(\mathrm{CH}_{2}\right), 29.4$ $\left(\mathrm{CH}_{2}\right), 27.7\left(\mathrm{CH}_{2}\right), 22.6\left(\mathrm{CH}_{2}\right), 22.3(\mathrm{CH}), 18.1\left(\mathrm{CH}_{3}\right), 14.1\left(\mathrm{CH}_{3}\right)$.

IR (ATR): $\tilde{v}=3061,3032,3001,2922,2862,1475,1444,1378,1027,774,734,691 \mathrm{~cm}^{-1}$. MS (El) m/z (relative intensity): 281 (48) [M+], 210 (37), 196 (100), 181 (60).

HRMS (EI) $\mathrm{m} / \mathrm{z}$ calculated for $\mathrm{C}_{20} \mathrm{H}_{27} \mathrm{~N}^{+}: 281.2143$; found: 281.2140 .

\section{Synthesis of 5-Methyl-2-[3-(pentan-2-yl)phenyl]pyridine (152fi)}

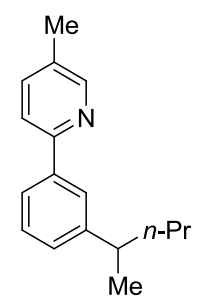

The general procedure $\mathbf{E}$ was followed, using $\left[\mathrm{RuCl}_{2}(p \text {-cymene })\right]_{2}(8.10 \mathrm{mg}, 0.013 \mathrm{mmol}, 2.5 \mathrm{~mol} \%)$, $\mathrm{MesCO}_{2} \mathrm{H}$ (13a) (23 mg, $\left.0.14 \mathrm{mmol}, 28 \mathrm{~mol} \%\right), 6 \mathrm{hb}(86.5 \mathrm{mg}, 0.51 \mathrm{mmol}$ ) and 2-bromopentane (42bi) (233 $\mathrm{mg}, 1.54 \mathrm{mmol}$ ). After $20 \mathrm{~h}$, purification by column chromatography ( $n$-hexane/EtOAc 9:1) yielded $152 \mathrm{hi} \mathrm{(68} \mathrm{mg,56 \% )} \mathrm{as} \mathrm{a} \mathrm{colorless} \mathrm{oil.}$

${ }^{1} \mathrm{H}-\mathrm{NMR}\left(300 \mathrm{MHz}, \mathrm{CDCl}_{3}\right): \delta=8.53(\mathrm{dd}, J=2.3,1.1 \mathrm{~Hz}, 1 \mathrm{H}), 7.81(\mathrm{t}, J=1.9 \mathrm{~Hz}, 1 \mathrm{H}), 7.75(\mathrm{dt}, J=7.7$, $1.5 \mathrm{~Hz}, 1 \mathrm{H}$ ), $7.63(\mathrm{dd}, J=8.1,0.9 \mathrm{~Hz}, 1 \mathrm{H}), 7.55(\mathrm{dd}, J=7.9,2.2 \mathrm{~Hz}, 1 \mathrm{H}$ ), $7.38(\mathrm{~d}, J=7.6 \mathrm{~Hz}, 1 \mathrm{H}$ ), 7.23 (dd, $J=7.5,1.5 \mathrm{~Hz}, 1 \mathrm{H}$ ), 2.80 (qt, $J=7.0,6.9 \mathrm{~Hz}, 1 \mathrm{H}$ ), $2.37(\mathrm{~s}, 3 \mathrm{H}), 1.74-1.48(\mathrm{~m}, 2 \mathrm{H}), 1.41-1.12(\mathrm{~m}$, $2 \mathrm{H}), 1.28(\mathrm{~d}, J=6.9 \mathrm{~Hz}, 3 \mathrm{H}), 0.88(\mathrm{t}, J=7.3 \mathrm{~Hz}, 3 \mathrm{H})$.

${ }^{13} \mathrm{C}$-NMR $\left(75 \mathrm{MHz}, \mathrm{CDCl}_{3}\right): \delta=155.1\left(\mathrm{C}_{\mathrm{q}}\right), 149.9(\mathrm{CH}), 148.4\left(\mathrm{C}_{\mathrm{q}}\right), 139.3\left(\mathrm{C}_{\mathrm{q}}\right), 137.2(\mathrm{CH}), 131.4\left(\mathrm{C}_{\mathrm{q}}\right)$, $128.6(\mathrm{CH}), 127.2(\mathrm{CH}), 125.5(\mathrm{CH}), 124.2(\mathrm{CH}), 120.1(\mathrm{CH}), 40.7\left(\mathrm{CH}_{2}\right), 39.8\left(\mathrm{CH}_{3}\right), 22.2\left(\mathrm{CH}_{2}\right), 20.8$ $(\mathrm{CH}), 18.1\left(\mathrm{CH}_{3}\right), 14.1\left(\mathrm{CH}_{3}\right)$.

IR (ATR): $\tilde{V}=2956,2925,2870,1600,1564,1470,1429,1377,794,701 \mathrm{~cm}^{-1}$.

MS (EI) m/z (relative intensity): 239 (41) [M+], 210 (14), 196 (100), 181 (59), 69 (10), 43 (24).

HRMS (EI) m/z calculated for $\mathrm{C}_{17} \mathrm{H}_{21} \mathrm{~N}^{+}: 239.1674$; found: 239.1672 . 
Synthesis of 2-[3,5-Dicyclopentylphenyl]-5-methylpyridine (152fk') \& 2-(3-Cyclopentylphenyl)-5methylpyridine (152fk)

The general procedure $\mathbf{E}$ was followed, using $\left[\operatorname{RuCl}_{2}(p \text {-cymene })\right]_{2}(14.2 \mathrm{mg}, 0.023 \mathrm{mmol}, 2.3 \mathrm{~mol} \%)$, $\mathrm{MesCO}_{2} \mathrm{H}$ (13a) (50 mg, $\left.0.29 \mathrm{mmol}, 29 \mathrm{~mol} \%\right), 6 \mathrm{fb}(176 \mathrm{mg}, 1.04 \mathrm{mmol})$ and bromocyclopentane (42bk) (453 mg, $3.03 \mathrm{mmol}$ ). After $20 \mathrm{~h}$, purification by column chromatography ( $n$-hexane/EtOAc 19:1) yielded 152fk' (12 mg, 4\%) and 152fk (96 mg, 39\%) as a colorless oils.

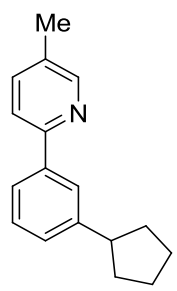

(152fk)

${ }^{1} \mathrm{H}-\mathrm{NMR}\left(300 \mathrm{MHz}, \mathrm{CDCl}_{3}\right): \delta=8.56-8.47(\mathrm{~m}, 1 \mathrm{H}), 7.88(\mathrm{dd}, J=1.9,1.9 \mathrm{~Hz}, 1 \mathrm{H}), 7.75$ (ddd, $J=7.6,1.6$, $1.5 \mathrm{~Hz}, 1 \mathrm{H}$ ), 7.62 (d, J = 7.9 Hz, 1H), 7.54 (dd, J = 8.0, 2.3 Hz, 1H), 7.39 (dd, J = 7.6, 7.6 Hz, 1H), 7.29 (ddd, $J=7.7,1.6,1.6 \mathrm{~Hz}, 1 \mathrm{H}$ ), $3.09(\mathrm{dt}, J=9.3,7.4 \mathrm{~Hz}, 1 \mathrm{H}), 2.37(\mathrm{~s}, 3 \mathrm{H}), 2.19-2.02(\mathrm{~m}, 2 \mathrm{H}), 1.94-1.57$ $(\mathrm{m}, 6 \mathrm{H})$.

${ }^{13} \mathrm{C}$-NMR $\left(75 \mathrm{MHz}, \mathrm{CDCl}_{3}\right): \delta=155.1\left(\mathrm{C}_{\mathrm{q}}\right), 149.9(\mathrm{CH}), 146.9\left(\mathrm{C}_{\mathrm{q}}\right), 139.3\left(\mathrm{C}_{\mathrm{q}}\right), 137.2(\mathrm{CH}), 131.3\left(\mathrm{C}_{\mathrm{q}}\right)$, $128.5(\mathrm{CH}), 127.3(\mathrm{CH}), 125.6(\mathrm{CH}), 124.1(\mathrm{CH}), 120.1(\mathrm{CH}), 46.0(\mathrm{CH}), 34.6\left(\mathrm{CH}_{2}\right), 25.5\left(\mathrm{CH}_{2}\right), 18.1$ $\left(\mathrm{CH}_{3}\right)$.

IR (ATR): $\tilde{v}=2950,2866,1600,1564,1470,1429,1377,1223,833,792,753,699 \mathrm{~cm}^{-1}$. MS (EI) m/z (relative intensity): 237 (42) [M+], 208 (56), 196 (100), 169 (17).

HR-MS (El) $\mathrm{m} / z$ calculated for $\mathrm{C}_{17} \mathrm{H}_{19} \mathrm{~N}^{+}: 237.1517$; found: 237.1507 .

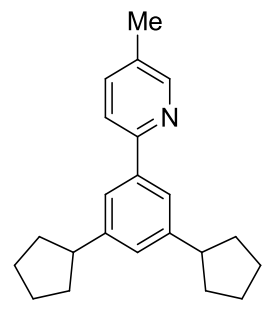

$\left(152 \mathrm{fk}^{\prime}\right)$

${ }^{1} \mathrm{H}-\mathrm{NMR}\left(300 \mathrm{MHz}, \mathrm{CDCl}_{3}\right): \delta=8.51(\mathrm{dd}, J=2.2,1.0 \mathrm{~Hz}, 1 \mathrm{H}), 7.67-7.57(\mathrm{~m}, 3 \mathrm{H}), 7.53(\mathrm{dd}, J=8.1$, $2.2 \mathrm{~Hz}, 1 \mathrm{H}), 7.16(\mathrm{dd}, J=1.7,1.7 \mathrm{~Hz}, 1 \mathrm{H}), 3.14-2.96(\mathrm{~m}, 2 \mathrm{H}), 2.36(\mathrm{~s}, 3 \mathrm{H}), 2.20-2.00(\mathrm{~m}, 4 \mathrm{H}), 1.93-1.51$ (m, 12H). 
${ }^{13} \mathrm{C}-\mathrm{NMR}\left(75 \mathrm{MHz}, \mathrm{CDCl}_{3}\right): \delta=155.5\left(\mathrm{C}_{\mathrm{q}}\right), 149.9(\mathrm{CH}), 146.8\left(\mathrm{C}_{\mathrm{q}}\right), 139.3(\mathrm{CH}), 137.1\left(\mathrm{C}_{\mathrm{q}}\right), 131.2(\mathrm{CH})$, $126.4(\mathrm{CH}), 123.1(\mathrm{CH}), 120.3\left(\mathrm{C}_{\mathrm{q}}\right), 46.2(\mathrm{CH}), 34.7\left(\mathrm{CH}_{2}\right), 25.6\left(\mathrm{CH}_{2}\right), 18.2\left(\mathrm{CH}_{3}\right)$.

IR (ATR): $\tilde{V}=2949,2867,1713,1685,1599,1565,1487,1449,1236,1035,831 \mathrm{~cm}^{-1}$.

MS (EI) m/z (relative intensity): 305 (34) [M+], 277 (25), 264 (100), 236 (13), 208 (14), 43 (18).

HR-MS (EI) $\mathrm{m} / \mathrm{z}$ calculated for $\mathrm{C}_{22} \mathrm{H}_{27} \mathrm{~N}^{+}: 305.2143$; found: 305.2136.

\section{Synthesis of 4-Methoxy-2-[3-(pentan-2-yl)phenyl]pyridine (152gi)}<smiles>COc1ccnc(-c2cccc(C(=O)N(C)C)c2)c1</smiles>

The general procedure $\mathbf{E}$ was followed, using $\left[\operatorname{RuCl}_{2}(p \text {-cymene })\right]_{2}(15.0 \mathrm{mg}, 0.025 \mathrm{mmol}, 5.0 \mathrm{~mol} \%)$, $\mathrm{MesCO}_{2} \mathrm{H}$ (13a) (25 mg, $\left.0.15 \mathrm{mmol}, 26 \mathrm{~mol} \%\right), 6 \mathrm{gb}$ (106 mg, $0.57 \mathrm{mmol}$ ) and 2-bromopentane (42bi) ( $225 \mathrm{mg}, 1.49 \mathrm{mmol}$ ). After $20 \mathrm{~h}$, purification by column chromatography ( $n$-hexane/EtOAc 18:1) yielded 152gi (48 $\mathrm{mg}, 33 \%)$ as a colorless oil.

${ }^{1} \mathrm{H}-\mathrm{NMR}\left(300 \mathrm{MHz}, \mathrm{CDCl}_{3}\right): \delta=8.53(\mathrm{~d}, J=5.7 \mathrm{~Hz}, 1 \mathrm{H}), 7.80(\mathrm{~d}, J=1.9 \mathrm{~Hz}, 1 \mathrm{H}), 7.77-7.68(\mathrm{~m}, 1 \mathrm{H}), 7.38$ $(\mathrm{t}, J=7.6 \mathrm{~Hz}, 1 \mathrm{H}), 7.29-7.17(\mathrm{~m}, 2 \mathrm{H}), 6.77(\mathrm{dd}, J=5.7,2.5 \mathrm{~Hz}, 1 \mathrm{H}), 3.91(\mathrm{~s}, 3 \mathrm{H}), 2.80$ (qt, $J=7.0,6.9 \mathrm{~Hz}$, $1 \mathrm{H}), 1.72-1.48(\mathrm{~m}, 2 \mathrm{H}), 1.37-1.11(\mathrm{~m}, 2 \mathrm{H}), 1.28(\mathrm{~d}, J=6.9 \mathrm{~Hz}, 3 \mathrm{H}), 0.87(\mathrm{t}, J=7.3 \mathrm{~Hz}, 3 \mathrm{H})$.

${ }^{13} \mathrm{C}$-NMR $\left(75 \mathrm{MHz}, \mathrm{CDCl}_{3}\right): \delta=166.3\left(\mathrm{C}_{\mathrm{q}}\right), 159.6\left(\mathrm{C}_{\mathrm{q}}\right), 150.8(\mathrm{CH}), 148.5\left(\mathrm{C}_{\mathrm{q}}\right), 139.3\left(\mathrm{C}_{\mathrm{q}}\right), 128.6(\mathrm{CH})$, $127.6(\mathrm{CH}), 125.8(\mathrm{CH}), 124.4(\mathrm{CH}), 107.9(\mathrm{CH}), 107.0(\mathrm{CH}), 55.1\left(\mathrm{CH}_{3}\right), 40.6\left(\mathrm{CH}_{2}\right), 39.8(\mathrm{CH}), 22.2$ $\left(\mathrm{CH}_{2}\right), 20.8\left(\mathrm{CH}_{3}\right), 14.1\left(\mathrm{CH}_{3}\right)$.

IR (ATR): $\tilde{V}=2956,2928,2870,1589,1562,1312,1219,1036,797,701 \mathrm{~cm}^{-1}$. MS (EI) m/z (relative intensity): 255 (15) [M+], 226 (14), 212 (100), 182 (17), 169 (14), 69 (16), 43 (28). HRMS (EI) m/z calculated for $\mathrm{C}_{17} \mathrm{H}_{21} \mathrm{NO}^{+}: 255.1623$; found: 255.1623 .

Synthesis of 2-[3,5-Di(pentan-2-yl)phenyl]pyrimidine (154') and 2-[3-(Pentan-2-yl)phenyl]pyrimidine (154)

The general procedure $\mathbf{E}$ was followed, using $\left[\mathrm{RuCl}_{2}(p \text {-cymene })\right]_{2}(15.2 \mathrm{mg}, 0.025 \mathrm{mmol}, 5.0 \mathrm{~mol} \%)$, $\mathrm{MesCO}_{2} \mathrm{H}$ (13a) $(25 \mathrm{mg}, 0.15 \mathrm{mmol}, 30 \mathrm{~mol} \%), 153$ (76.6 mg, $0.49 \mathrm{mmol}$ ) and 2-bromopentane (42bi) (229 mg, $1.52 \mathrm{mmol}$ ). After $20 \mathrm{~h}$, purification by column chromatography ( $n$-hexane/EtOAc 9:1) yielded 154' (17 mg, 12\%) and 154 (50 mg, 45\%) as a colorless oils. 


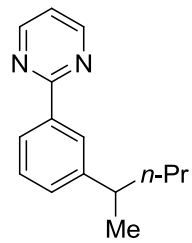

(154)

${ }^{1} \mathrm{H}-\mathrm{NMR}\left(300 \mathrm{MHz}, \mathrm{CDCl}_{3}\right): \delta=8.80(\mathrm{~d}, J=4.8 \mathrm{~Hz}, 2 \mathrm{H}), 8.28(\mathrm{~d}, J=1.6 \mathrm{~Hz}, 1 \mathrm{H}), 8.26(\mathrm{dd}, J=5.7,1.6 \mathrm{~Hz}$, 1H), 7.42 (dd, $J=7.7,7.7 \mathrm{~Hz}, 1 \mathrm{H}$ ), 7.32 (ddd, $J=7.6,1.5,1.4 \mathrm{~Hz}, 1 \mathrm{H}$ ), 7.16 (t, $J=4.8 \mathrm{~Hz}, 1 \mathrm{H}$ ), 2.82 (qt, $J$ $=7.0 \mathrm{~Hz}, 1 \mathrm{H}), 1.76-1.49(\mathrm{~m}, 2 \mathrm{H}), 1.42-1.07(\mathrm{~m}, 2 \mathrm{H}), 1.30(\mathrm{~d}, J=6.9 \mathrm{~Hz}, 3 \mathrm{H}), 0.88(\mathrm{t}, J=7.3 \mathrm{~Hz}, 3 \mathrm{H})$.

${ }^{13} \mathrm{C}-\mathrm{NMR}\left(75 \mathrm{MHz}, \mathrm{CDCl}_{3}\right): \delta=165.1\left(\mathrm{C}_{\mathrm{q}}\right), 157.3(\mathrm{CH}), 148.5\left(\mathrm{C}_{\mathrm{q}}\right), 137.6\left(\mathrm{C}_{\mathrm{q}}\right), 129.7(\mathrm{CH}), 128.7(\mathrm{CH})$, $126.9(\mathrm{CH}), 125.9(\mathrm{CH}), 119.1(\mathrm{CH}), 40.8\left(\mathrm{CH}_{2}\right), 39.9(\mathrm{CH}), 22.4\left(\mathrm{CH}_{2}\right), 21.0\left(\mathrm{CH}_{3}\right), 14.3\left(\mathrm{CH}_{3}\right)$.

IR (ATR): $\tilde{V}=2957,2926,2871,1567,1554,1453,1408,1377,785,699,635 \mathrm{~cm}^{-1}$.

MS (EI) m/z (relative intensity): 226 (20) [M+1, 183 (100), 168 (45), 103 (10), 58 (13), 43 (46).

HRMS (ESI) $\mathrm{m} / \mathrm{z}$ calculated for $\mathrm{C}_{15} \mathrm{H}_{18} \mathrm{~N}_{2}^{+}: 226.1470$; found: 226.1461 .<smiles>CCCC(=O)c1cc(C(=O)C(=O)O)cc(-c2ncccn2)c1</smiles>

$\left(154^{\prime}\right)$

${ }^{1} \mathrm{H}-\mathrm{NMR}\left(300 \mathrm{MHz}, \mathrm{CDCl}_{3}\right): \delta=8.82(\mathrm{~d}, J=4.7 \mathrm{~Hz}, 2 \mathrm{H}), 8.09(\mathrm{~d}, J=1.7 \mathrm{~Hz}, 2 \mathrm{H}), 7.16(\mathrm{t}, J=4.8 \mathrm{~Hz}, 1 \mathrm{H})$, $7.12(\mathrm{t}, J=1.7 \mathrm{~Hz}, 1 \mathrm{H}), 2.79(\mathrm{qt}, J=7.0,6.9 \mathrm{~Hz}, 2 \mathrm{H}), 1.74-1.48(\mathrm{~m}, 5 \mathrm{H}), 1.42-1.11(\mathrm{~m}, 4 \mathrm{H}), 1.29(\mathrm{~d}, J=$ $6.9 \mathrm{~Hz}, 6 \mathrm{H}), 0.87(\mathrm{t}, J=7.3 \mathrm{~Hz}, 6 \mathrm{H})$.

${ }^{13} \mathrm{C}-\mathrm{NMR}\left(75 \mathrm{MHz}, \mathrm{CDCl}_{3}\right): \delta=165.9\left(\mathrm{C}_{\mathrm{q}}\right), 157.7(\mathrm{CH}), 148.9\left(\mathrm{C}_{\mathrm{q}}\right), 137.9\left(\mathrm{C}_{\mathrm{q}}\right), 129.2(\mathrm{CH}), 124.9(\mathrm{CH})$, $119.4(\mathrm{CH}), 41.3\left(\mathrm{CH}_{2}\right), 40.4\left(\mathrm{CH}_{3}\right), 22.8(\mathrm{CH}), 21.4\left(\mathrm{CH}_{2}\right), 14.7\left(\mathrm{CH}_{3}\right)$.

IR (ATR): $\tilde{v}=2956,2926,2871,1568,1555,1455,1410,809,709 \mathrm{~cm}^{-1}$.

MS (EI) m/z (relative intensity): 296 (24) [ $\left.\mathrm{M}^{+}\right], 269$ (11), 253 (100), 211 (18), 183 (27), 168 (15).

HRMS (EI) m/z calculated for $\mathrm{C}_{20} \mathrm{H}_{28} \mathrm{~N}_{2}^{+}$: 296.2252; found: 296.2257 .

Synthesis of 2-[3-(Pentan-2-yl)phenyl]-1H-imidazole (155)

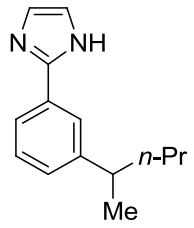


The general procedure $\mathbf{E}$ was followed, using $\left[\mathrm{RuCl}_{2}(p \text {-cymene })\right]_{2}(15.4 \mathrm{mg}, 0.025 \mathrm{mmol}, 4.9 \mathrm{~mol} \%)$, $\mathrm{MesCO}_{2} \mathrm{H}$ (13a) (24 mg, $\left.0.15 \mathrm{mmol}, 29 \mathrm{~mol} \%\right)$, 2-phenyl- $1 \mathrm{H}$-imidazole $(74.2 \mathrm{mg}, 0.52 \mathrm{mmol}$ ) and 2bromopentane (42bi) $(238 \mathrm{mg}, 1.57 \mathrm{mmol})$. After $20 \mathrm{~h}$, purification by column chromatography $(n-$ hexane/EtOAc 9:1) yielded 155 (49 mg, 44\%) as a colorless oil.

${ }^{1} \mathrm{H}-\mathrm{NMR}\left(300 \mathrm{MHz}, \mathrm{CDCl}_{3}\right): \delta=7.92(\mathrm{dd}, J=2.4,0.6 \mathrm{~Hz}, 1 \mathrm{H}), 7.73(\mathrm{dd}, J=1.7,0.6 \mathrm{~Hz}, 1 \mathrm{H}), 7.57(\mathrm{dd}, J=$ $1.9 \mathrm{~Hz}, 1 \mathrm{H}), 7.46(\mathrm{ddd}, J=8.0,2.2,1.1 \mathrm{~Hz}, 1 \mathrm{H}), 7.36(\mathrm{dd}, J=7.8 \mathrm{~Hz}, 1 \mathrm{H}), 7.12(\mathrm{~d}, J=7.6 \mathrm{~Hz}, 1 \mathrm{H}), 6.46$ $(\mathrm{dd}, J=2.5,1.8 \mathrm{~Hz}, 1 \mathrm{H}), 2.78(\mathrm{qt}, J=7.0 \mathrm{~Hz}, 1 \mathrm{H}), 1.72-1.44(\mathrm{~m}, 2 \mathrm{H}), 1.38-1.12(\mathrm{~m}, 2 \mathrm{H}), 1.28(\mathrm{~d}, J=$ $6.9 \mathrm{~Hz}, 3 \mathrm{H}), 0.88(\mathrm{t}, J=7.3 \mathrm{~Hz}, 3 \mathrm{H})$.

${ }^{13} \mathrm{C}$-NMR $\left(75 \mathrm{MHz}, \mathrm{CDCl}_{3}\right): \delta=149.9\left(\mathrm{C}_{\mathrm{q}}\right), 141.0(\mathrm{CH}), 140.3\left(\mathrm{C}_{\mathrm{q}}\right), 129.3(\mathrm{CH}), 127.0\left(\mathrm{C}_{\mathrm{q}}\right), 125.4(\mathrm{CH})$, $118.3(\mathrm{CH}), 116.8(\mathrm{CH}), 107.5(\mathrm{CH}), 40.7\left(\mathrm{CH}_{2}\right), 39.9(\mathrm{CH}), 22.3\left(\mathrm{CH}_{2}\right), 20.9\left(\mathrm{CH}_{2}\right), 14.2\left(\mathrm{CH}_{3}\right)$.

IR (ATR): $\tilde{\boldsymbol{V}}=2958,2927,2871,1609,1591,1519,1472,1451,1393,1042,787,731,698 \mathrm{~cm}^{-1}$.

MS (EI) m/z (relative intensity): 214 (34) [M+'], 171 (100), 157 (12), 144 (13), 103 (12), 77 (15).

HRMS (EI) $m / z$ calculated for $\mathrm{C}_{14} \mathrm{H}_{18} \mathrm{~N}_{2}{ }^{+}: 214.1470$; found: 214.1475 .

\section{Synthesis of 1-[3-(Pentan-2-yl)phenyl]-1H-pyrazole (156)}

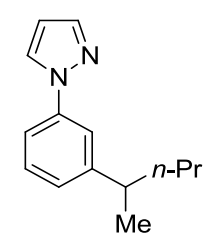

The general procedure $\mathbf{E}$ was followed, using $\left[\mathrm{RuCl}_{2}(p \text {-cymene })\right]_{2}(16.0 \mathrm{mg}, 0.026 \mathrm{mmol}, 4.8 \mathrm{~mol} \%)$, $\mathrm{MesCO}_{2} \mathrm{H}$ (13a) (25 mg, $\left.0.15 \mathrm{mmol}, 27 \mathrm{~mol} \%\right), 87 \mathrm{a}(83.8 \mathrm{mg}, 0.58 \mathrm{mmol}$ ) and 2-bromopentane (42bi) (219 mg, $1.45 \mathrm{mmol}$ ). After $20 \mathrm{~h}$, purification by column chromatography ( $n$-hexane/EtOAc 10:1 to $5: 1$ ) yielded 156 (54 mg, 43\%) as a colorless oil.

${ }^{1} \mathrm{H}-\mathrm{NMR}\left(300 \mathrm{MHz}, \mathrm{CDCl}_{3}\right): \delta=7.93(\mathrm{dd}, J=2.3,0.6 \mathrm{~Hz}, 2 \mathrm{H}), 7.73(\mathrm{~d}, J=1.9 \mathrm{~Hz}, 1 \mathrm{H}), 7.56(\mathrm{~s}, 1 \mathrm{H}), 7.46$ (ddd, $J=8.1,2.2,1.1 \mathrm{~Hz}, 1 \mathrm{H}$ ), $7.36(\mathrm{dd}, J=7.8,7.8 \mathrm{~Hz}, 1 \mathrm{H}), 7.12(\mathrm{~d}, J=7.6 \mathrm{~Hz}, 1 \mathrm{H}), 6.46(\mathrm{~d}, J=2.0 \mathrm{~Hz}$, $1 \mathrm{H}), 2.78(\mathrm{qt}, J=7.0,6.9 \mathrm{~Hz}, 1 \mathrm{H}), 1.74-1.46(\mathrm{~m}, 2 \mathrm{H}), 1.39-1.11(\mathrm{~m}, 2 \mathrm{H}), 1.27(\mathrm{~d}, J=6.9 \mathrm{~Hz}, 3 \mathrm{H}), 0.88(\mathrm{t}$, $J=7.4 \mathrm{~Hz}, 3 \mathrm{H})$.

${ }^{13} \mathrm{C}-\mathrm{NMR}\left(75 \mathrm{MHz}, \mathrm{CDCl}_{3}\right): \delta=149.8\left(\mathrm{C}_{\mathrm{q}}\right), 141.0(\mathrm{CH}), 140.3\left(\mathrm{C}_{\mathrm{q}}\right), 129.3(\mathrm{CH}), 126.9(\mathrm{CH}), 125.3(\mathrm{CH})$, $118.3(\mathrm{CH}), 116.7(\mathrm{CH}), 107.5(\mathrm{CH}), 40.7\left(\mathrm{CH}_{2}\right), 39.9\left(\mathrm{CH}_{3}\right), 22.3(\mathrm{CH}), 20.9\left(\mathrm{CH}_{2}\right), 14.2\left(\mathrm{CH}_{3}\right)$.

IR (ATR): $\tilde{V}=2957,2927,2871,1718,1609,1591,1392,1042,787,743 \mathrm{~cm}^{-1}$.

MS (El) m/z (relative intensity): 214 (59) [ $\left.\mathrm{M}^{+}\right], 171$ (100), 157 (13), 144 (14).

HRMS (EI) $\mathrm{m} / \mathrm{z}$ calculated for $\mathrm{C}_{14} \mathrm{H}_{18} \mathrm{~N}_{2}{ }^{+}: 214.1470$, found: 214.1468 . 
Synthesis of 1-Methyl-2-[3-(pentan-2-yl)phenyl]-1H-benzo[d]imidazole (157)

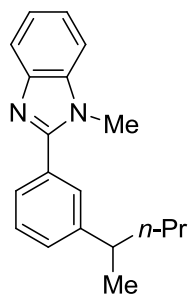

The general procedure $\mathbf{E}$ was followed, using $\left[\mathrm{RuCl}_{2}(p \text {-cymene })\right]_{2}(16.0 \mathrm{mg}, 0.026 \mathrm{mmol}, 5.3 \mathrm{~mol} \%)$, $\mathrm{MesCO}_{2} \mathrm{H}$ (13a) (25 mg, $\left.0.15 \mathrm{mmol}, 31 \mathrm{~mol} \%\right)$, 1-methyl-2-phenyl-1H-benzo[d]imidazole $(97.8 \mathrm{mg}$, $0.47 \mathrm{mmol}$ ) and 2-bromopentane (42bi) $(224 \mathrm{mg}, 1.48 \mathrm{mmol})$. After $20 \mathrm{~h}$, purification by column chromatography ( $n$-hexane/EtOAc 9:1 to 3:1) yielded 157 (71 mg, 54\%) as a colorless oil.

${ }^{1}$ H-NMR $\left(300 \mathrm{MHz}, \mathrm{CDCl}_{3}\right): \delta=7.85-7.80(\mathrm{~m}, 1 \mathrm{H}), 7.59(\mathrm{dd}, J=1.7,1.6 \mathrm{~Hz}, 1 \mathrm{H}), 7.52$ (ddd, $J=7.6$, 1.6 Hz, 1H), $7.42(\mathrm{dd}, J=7.8,7.3 \mathrm{~Hz}, 1 \mathrm{H}), 7.39-7.27(\mathrm{~m}, 4 \mathrm{H}), 3.83(\mathrm{~d}, J=1.3 \mathrm{~Hz}, 3 \mathrm{H}), 2.79(\mathrm{qt}, J=7.1$, $7.0 \mathrm{~Hz}, 1 \mathrm{H}), 1.73-1.41(\mathrm{~m}, 2 \mathrm{H}), 1.37-1.09(\mathrm{~m}, 2 \mathrm{H}), 1.27(\mathrm{~d}, J=7.0 \mathrm{~Hz}, 3 \mathrm{H}), 0.87(\mathrm{t}, J=7.3 \mathrm{~Hz}, 3 \mathrm{H})$.

${ }^{13} \mathrm{C}$-NMR $\left(75 \mathrm{MHz}, \mathrm{CDCl}_{3}\right): \delta=154.7\left(\mathrm{C}_{\mathrm{q}}\right), 149.1\left(\mathrm{C}_{\mathrm{q}}\right), 143.5\left(\mathrm{C}_{\mathrm{q}}\right), 137.1\left(\mathrm{C}_{\mathrm{q}}\right), 130.6\left(\mathrm{C}_{\mathrm{q}}\right), 129.0(\mathrm{CH})$, $129.0(\mathrm{CH}), 128.9(\mathrm{CH}), 127.3(\mathrm{CH}), 123.2(\mathrm{CH}), 122.9(\mathrm{CH}), 120.3(\mathrm{CH}), 110.1(\mathrm{CH}), 41.1\left(\mathrm{CH}_{2}\right), 40.2$ $\left(\mathrm{CH}_{3}\right), 32.2\left(\mathrm{CH}_{3}\right), 22.8(\mathrm{CH}), 21.4\left(\mathrm{CH}_{2}\right), 14.7\left(\mathrm{CH}_{3}\right)$.

IR (ATR): $\tilde{v}=3051,2956,2927,2870,1588,1457,1378,1324,1282,801,739,704 \mathrm{~cm}^{-1}$. MS (EI) m/z (relative intensity): 278 (75) [M+], 249 (31), 235 (100), 220 (23), 205 (20), 77 (25).

HRMS (EI) $\mathrm{m} / \mathrm{z}$ calculated for $\mathrm{C}_{19} \mathrm{H}_{22} \mathrm{~N}_{2}{ }^{+}$: 278.1783; found: 278.1786 .

\section{Synthesis of $N$-\{1-[4-Fluoro-3-(hexan-2-yl)phenyl]ethyl\}-4-methoxyaniline (158a)}

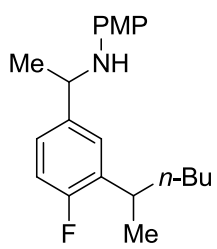

The general procedure $\mathbf{D}$ was followed, using $\left[\mathrm{RuCl}_{2}(p \text {-cymene })\right]_{2}(7.3 \mathrm{mg}, 0.012 \mathrm{mmol}, 2.4 \mathrm{~mol} \%)$, $\mathrm{MesCO}_{2} \mathrm{H}$ (13a) (25 mg, $\left.0.15 \mathrm{mmol}, 30 \mathrm{~mol} \%\right), 121 \mathrm{a}(123 \mathrm{mg}, 0.51 \mathrm{mmol}$ ) and 2-bromohexane (42ba) $(246 \mathrm{mg}, 1.49 \mathrm{mmol}$ ). After $20 \mathrm{~h}$, purification by column chromatography ( $n$-hexane/EtOAc 9:1) yielded 158a [32 mg, 19\%; isolated as a set of diastereomers (DS1 ans DS2) in a ratio of 1:1] as a brown oil. 
${ }^{1} \mathrm{H}-\mathrm{NMR}\left(300 \mathrm{MHz}, \mathrm{CDCl}_{3}\right): \delta=7.13-6.98(\mathrm{~m}, 3 \mathrm{H}), 6.84(\mathrm{dd}, J=10.1,8.3 \mathrm{~Hz}, 1 \mathrm{H}), 6.67-6.55(\mathrm{~m}, 2 \mathrm{H})$, 6.44-6.30 (m, 2H), $4.29(\mathrm{qd}, J=6.7,1.8 \mathrm{~Hz}, 1 \mathrm{H}), 3.62(\mathrm{~d}, J=0.9 \mathrm{~Hz}, 3 \mathrm{H}), 2.93(\mathrm{qt}, J=7.1,7.0 \mathrm{~Hz}, 1 \mathrm{H}$ ), 1.64-1.30 (m, 6H), 1.30-0.91 (m, 3H), 1.27 (d, $J=7.0 \mathrm{~Hz}, 3 \mathrm{H}), 0.86-0.63(\mathrm{~m}, 3 \mathrm{H})$.

${ }^{13} \mathrm{C}-\mathrm{NMR}\left(75 \mathrm{MHz}, \mathrm{CDCl}_{3}\right): \delta=159.9\left(\mathrm{~d}, \mathrm{~J}_{\mathrm{C}-\mathrm{F}}=243 \mathrm{~Hz}, \mathrm{C}_{\mathrm{q}}\right), 152.3\left(\mathrm{C}_{\mathrm{q}}\right), 141.6\left(\mathrm{C}_{\mathrm{q}}\right), 140.9\left(\mathrm{~d}, \mathrm{~J}_{\mathrm{C}-\mathrm{F}}=4 \mathrm{~Hz}\right.$, $\mathrm{C}_{\mathrm{q}}$ ), $134.4\left(\mathrm{dd}, \mathrm{J}_{\mathrm{C}-\mathrm{F}}=15,3 \mathrm{~Hz}, \mathrm{CH}\right.$ ), $125.8\left(\mathrm{dd}, \mathrm{J}_{\mathrm{C}-\mathrm{F}}=16,6 \mathrm{~Hz}, \mathrm{CH}\right.$ ), 124.4 (dd, $J_{\mathrm{C}-\mathrm{F}}=8,6 \mathrm{~Hz}, \mathrm{CH}$ ), 115.4 (dd, $\left.J_{C-F}=23,4 \mathrm{~Hz}, \mathrm{CH}\right), 115.0\left(\mathrm{~d}, J_{\mathrm{C}-\mathrm{F}}=3 \mathrm{~Hz}, \mathrm{CH}\right), 114.9(\mathrm{CH}), 55.9\left(\mathrm{CH}_{3}\right), 54.2$ (DS2, CH), 54.1 (DS1, $\mathrm{CH}), 36.9$ (DS2, CH $\mathrm{CH}_{2}$ ), 36.8 (DS1, $\mathrm{CH}_{2}$ ), 32.9 (DS2, CH), 32.7 (DS1, CH), 29.9 (DS2, CH $_{2}, 29.8$ (DS1, $\mathrm{CH}_{2}$ ), 25.1 (DS2, CH $\left.\mathrm{CH}_{3}\right), 25.0$ (DS1, $\mathrm{CH}_{3}$ ), 22.8 (DS2, $\left.\mathrm{CH}_{3}\right), 22.7$ (DS1, $\left.\mathrm{CH}_{3}\right), 21.2\left(\mathrm{DS} 2, \mathrm{CH}_{2}\right), 21.1$ (DS1, $\left.\mathrm{CH}_{2}\right)$, 14.3 (DS2, $\mathrm{CH}_{3}$ ), 14.2 (DS1, $\mathrm{CH}_{3}$ ).

${ }^{19}$ F-NMR $\left(282 \mathrm{MHz}, \mathrm{CDCl}_{3}\right): \delta=-121.10$ - - $123.33(\mathrm{~m}),-123.35$ - $125.15(\mathrm{~m})$.

IR (ATR): $\tilde{v}=2958,2928,2871,2859,1684,1509,1461,1233,1104,1035,817,517 \mathrm{~cm}^{-1}$.

MS (EI) $m / z$ (relative intensity): 329 (74) [ $\left.\mathrm{M}^{+}\right], 314$ (100), 270 (12), 254 (22), 148 (22), 77 (20).

HR-MS (El) $\mathrm{m} / \mathrm{z}$ calculated for $\mathrm{C}_{21} \mathrm{H}_{28} \mathrm{FNO}^{+}$: 329.2155 ; found: 329.2154 .

\section{Synthesis of $N$-[1-(3-Cycloheptyl-4-fluorophenyl)ethyl]-4-methoxyaniline (158c)}

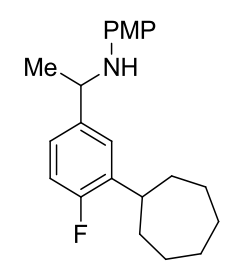

The general procedure $\mathbf{D}$ was followed, using $\left[\mathrm{RuCl}_{2}(p \text {-cymene })\right]_{2}(8.1 \mathrm{mg}, 0.013 \mathrm{mmol}, 2.4 \mathrm{~mol} \%)$, MesCO ${ }_{2} \mathrm{H}$ (13a) (25 mg, $0.15 \mathrm{mmol}, 29 \mathrm{~mol} \%$ ), 121a (129 mg, $0.53 \mathrm{mmol}$ ) and bromocycloheptane (42bc) $(268 \mathrm{mg}, 1.51 \mathrm{mmol})$. After $20 \mathrm{~h}$, purification by column chromatography ( $n$-hexane/EtOAc 9:1) yielded $158 \mathrm{c}(64 \mathrm{mg}, 35 \%)$ as a brown oil.

${ }^{1} \mathrm{H}-\mathrm{NMR}\left(300 \mathrm{MHz}, \mathrm{CDCl}_{3}\right): \delta=7.21(\mathrm{dd}, J=7.2,2.4 \mathrm{~Hz}, 1 \mathrm{H}), 7.12$ (ddd, $\left.J=8.4,5.0,2.3 \mathrm{~Hz}, 1 \mathrm{H}\right), 6.92$ $(\mathrm{dd}, J=10.2,8.3 \mathrm{~Hz}, 1 \mathrm{H}), 6.75-6.68(\mathrm{~m}, 2 \mathrm{H}), 6.52-6.45(\mathrm{~m}, 2 \mathrm{H}), 4.37(\mathrm{q}, J=6.7 \mathrm{~Hz}, 1 \mathrm{H}), 3.72(\mathrm{~s}, 3 \mathrm{H})$, $2.98(\mathrm{dt}, J=10.4,3.5 \mathrm{~Hz}, 1 \mathrm{H}), 2.02-1.51(\mathrm{~m}, 12 \mathrm{H}), 1.48(\mathrm{~d}, J=6.7 \mathrm{~Hz}, 3 \mathrm{H}) .(\mathrm{N}-\mathrm{H}$ was not detected)

${ }^{13} \mathrm{C}-\mathrm{NMR}\left(75 \mathrm{MHz}, \mathrm{CDCl}_{3}\right): \delta=158.9\left(\mathrm{~d}, \mathrm{~J}_{\mathrm{C}-\mathrm{F}}=243 \mathrm{~Hz}, \mathrm{C}_{\mathrm{q}}\right), 152.0\left(\mathrm{C}_{\mathrm{q}}\right), 141.6\left(\mathrm{C}_{\mathrm{q}}\right), 140.9\left(\mathrm{~d}, \mathrm{~J}_{\mathrm{C}-\mathrm{F}}=3 \mathrm{~Hz}\right.$, $\left.C_{q}\right), 136.3\left(d, J_{C-F}=15 \mathrm{~Hz}, C_{q}\right), 125.5\left(d, J_{C-F}=6 \mathrm{~Hz}, \mathrm{CH}\right), 124.0\left(\mathrm{~d}, J_{C-F}=8 \mathrm{~Hz}, \mathrm{CH}\right), 115.2\left(\mathrm{~d}, J_{\mathrm{C}-\mathrm{F}}=24 \mathrm{~Hz}\right.$, $\mathrm{CH}), 114.7(\mathrm{CH}), 114.7(\mathrm{CH}), 55.7\left(\mathrm{CH}_{3}\right), 54.0(\mathrm{CH}), 39.8(\mathrm{CH}), 39.7(\mathrm{CH}), 35.3\left(\mathrm{CH}_{2}\right), 27.8\left(\mathrm{CH}_{2}\right), 27.1$ $\left(\mathrm{CH}_{2}\right), 25.0\left(\mathrm{CH}_{3}\right)$.

${ }^{19} \mathrm{~F}-\mathrm{NMR}\left(282 \mathrm{MHz}, \mathrm{CDCl}_{3}\right): \delta=-121.55--123.63(\mathrm{~m})$.

IR (ATR): $\tilde{v}=3403,2960,2930,2871,2859,2244,1579,1512,1464,1238,1040,910,739 \mathrm{~cm}^{-1}$. 
MS (EI) m/z (relative intensity): 341 (89) [M+], 326 (100), 270 (10), 254 (11), 148 (17), 92 (18), 77 (25).

HR-MS (EI) $m / z$ calculated for $\mathrm{C}_{22} \mathrm{H}_{28} \mathrm{FNO}^{+}: 341.2155$; found: 341.2159 .

\section{Products of Direct Benzylation}

\section{Synthesis of 2-[4-Methoxy-3-(1-phenylpentyl)phenyl]pyridine (177b)}

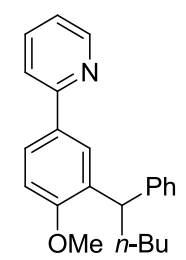

The general procedure $\mathbf{E}$ was followed, using $\left[\operatorname{RuCl}_{2}(p \text {-cymene })\right]_{2}(15.1 \mathrm{mg}, 0.025 \mathrm{mmol}, 4.5 \mathrm{~mol} \%)$, $\mathrm{MesCO}_{2} \mathrm{H} \quad$ (13a) $\quad(24 \mathrm{mg}, \quad 0.15 \mathrm{mmol}, \quad 27 \mathrm{~mol} \%), \quad 6$ ba $\quad(101 \mathrm{mg}, \quad 0.55 \mathrm{mmol})$ and (1bromopentyl)benzene (176) (344 mg, $1.51 \mathrm{mmol}$ ). After $20 \mathrm{~h}$, purification by column chromatography ( $n$-hexane/Et ${ }_{2} \mathrm{O} 19: 1$ to $9: 1$ ) yielded $177 \mathrm{~b}(29 \mathrm{mg}, 16 \%$ ) as a colorless oil.

${ }^{1} \mathrm{H}-\mathrm{NMR}\left(300 \mathrm{MHz}, \mathrm{CDCl}_{3}\right): \delta=8.67-8.65(\mathrm{~m}, 1 \mathrm{H}), 7.95-7.94(\mathrm{~m}, 1 \mathrm{H}), 7.83(\mathrm{dd}, J=8.5,2.3 \mathrm{~Hz}, 1 \mathrm{H})$, 7.70-7.60 (m, 2H), 7.35-7.23 (m, 4H), 7.17-7.11 (m, 2H), $6.91(\mathrm{t}, J=8.5 \mathrm{~Hz}, 1 \mathrm{H}), 4.43(\mathrm{t}, J=8.0 \mathrm{~Hz}, 1 \mathrm{H})$, $3.80(\mathrm{~s}, 3 \mathrm{H}), 2.19-2.05(\mathrm{~m}, 2 \mathrm{H}), 1.44-1.24(\mathrm{~m}, 4 \mathrm{H}), 0.89(\mathrm{t}, J=6.8 \mathrm{~Hz}, 3 \mathrm{H})$.

${ }^{13} \mathrm{C}-\mathrm{NMR}\left(75 \mathrm{MHz}, \mathrm{CDCl}_{3}\right): \delta=158.0\left(\mathrm{C}_{\mathrm{q}}\right), 157.4\left(\mathrm{C}_{\mathrm{q}}\right), 149.4(\mathrm{CH}), 145.1\left(\mathrm{C}_{\mathrm{q}}\right), 136.5(\mathrm{CH}), 134.0\left(\mathrm{C}_{\mathrm{q}}\right)$, $131.6\left(\mathrm{C}_{\mathrm{q}}\right), 128.1(\mathrm{CH}), 128.0(\mathrm{CH}), 126.2(\mathrm{CH}), 125.7(\mathrm{CH}), 125.6(\mathrm{CH}), 121.2(\mathrm{CH}), 119.9(\mathrm{CH}), 101.7$ (CH), $55.5\left(\mathrm{CH}_{3}\right), 43.4(\mathrm{CH}), 34.7\left(\mathrm{CH}_{2}\right), 30.2\left(\mathrm{CH}_{2}\right), 22.7\left(\mathrm{CH}_{2}\right), 14.0\left(\mathrm{CH}_{3}\right)$.

IR (ATR): $\tilde{v}=3051,2936,2915,1579,1513,1460,1431,775,736,717,556,485 \mathrm{~cm}^{-1}$. MS (EI) m/z (relative intensity): 331 (17) [M] ${ }^{+}, 274$ (100), 185 (12), 91 (74).

HR-MS (ESI) $\mathrm{m} / \mathrm{z}$ calculated for $\mathrm{C}_{23} \mathrm{H}_{25} \mathrm{NO}^{+}:$331.1936; found: 331.1937 .

\section{Synthesis of 2-[4-Fluoro-3-(1-phenylpentyl)phenyl]pyridine (177c)}

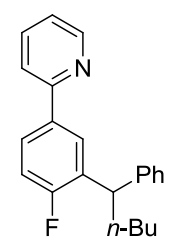

The general procedure $\mathbf{E}$ was followed, using $\left[\mathrm{RuCl}_{2}(p \text {-cymene })\right]_{2}(16 \mathrm{mg}, 0.026 \mathrm{mmol}, 5.3 \mathrm{~mol} \%)$, 1$\mathrm{AdCO}_{2} \mathrm{H}(13 \mathrm{c})(28 \mathrm{mg}, 0.16 \mathrm{mmol}, 33 \mathrm{~mol} \%), 6 \mathrm{ca}(85.1 \mathrm{mg}, 0.49 \mathrm{mmol})$ and (1-bromopentyl)-benzene 
(176) $\left(357 \mathrm{mg}, 1.57 \mathrm{mmol}\right.$ ). After $20 \mathrm{~h}$, purification by column chromatography ( $n$-hexane/Et ${ }_{2} \mathrm{O} 9: 1$ ) yielded $177 \mathrm{c}(18 \mathrm{mg}, 11 \%)$ as a colorless oil.

${ }^{1} \mathrm{H}-\mathrm{NMR}\left(300 \mathrm{MHz}, \mathrm{CDCl}_{3}\right): \delta=8.68(\mathrm{dd}, J=4.6,1.8 \mathrm{~Hz}, 1 \mathrm{H}), 8.03-8.83(\mathrm{~m}, 1 \mathrm{H}), 7.85-7.56(\mathrm{~m}, 3 \mathrm{H})$, 7.42-6.88 (m, 7H), 4.36-4.22 (m, 1H), 2.19-2.02 (m, 2H), 1.49-1.06 (m, 4H), $0.89(\mathrm{t}, J=7.5 \mathrm{~Hz}, 3 \mathrm{H})$.

${ }^{13} \mathrm{C}-\mathrm{NMR}\left(75 \mathrm{MHz}, \mathrm{CDCl}_{3}\right): \delta=161.6\left(\mathrm{~d}, \mathrm{~J}_{\mathrm{C}-\mathrm{F}}=248 \mathrm{~Hz}, \mathrm{C}_{\mathrm{q}}\right), 156.9\left(\mathrm{C}_{\mathrm{q}}\right), 149.7(\mathrm{CH}), 144.1\left(\mathrm{C}_{\mathrm{q}}\right), 136.6$ $(\mathrm{CH}), 35.6\left(\mathrm{~d}, J_{\mathrm{C}-\mathrm{F}}=4 \mathrm{~Hz}, \mathrm{C}_{\mathrm{q}}\right), 132.6\left(\mathrm{~d}, J_{\mathrm{C}-\mathrm{F}}=15 \mathrm{~Hz}, \mathrm{C}_{\mathrm{q}}\right), 128.4(\mathrm{CH}), 128.0(\mathrm{CH}), 127.5\left(\mathrm{~d}, J_{\mathrm{C}-\mathrm{F}}=5 \mathrm{~Hz}, \mathrm{CH}\right)$, $126.3\left(\mathrm{~d}, J_{\mathrm{C}-\mathrm{F}}=9 \mathrm{~Hz}, \mathrm{CH}\right), 126.2(\mathrm{CH}), 121.8(\mathrm{CH}), 120.2(\mathrm{CH}), 115.8\left(\mathrm{~d}, J_{\mathrm{C}-\mathrm{F}}=24 \mathrm{~Hz}, \mathrm{CH}\right), 44.1(\mathrm{CH}), 34.4$ $\left(\mathrm{CH}_{2}\right), 30.2\left(\mathrm{CH}_{2}\right), 22.6\left(\mathrm{CH}_{2}\right), 13.9\left(\mathrm{CH}_{3}\right)$.

${ }^{19}$ F-NMR $\left(282 \mathrm{MHz}, \mathrm{CDCl}_{3}\right) \delta=-117.4--117.5(\mathrm{~m})$.

IR (ATR): $\tilde{\boldsymbol{V}}=2955,2930,2859,1586,1566,1497,1464,1433,1257,1235,1152,780,742 \mathrm{~cm}^{-1}$. MS (EI) $m / z$ (relative intensity): 319 (36) [M+], 276 (15), 262 (100), 183 (14).

HR-MS (ESI) $m / z$ calculated for $\mathrm{C}_{22} \mathrm{H}_{22} \mathrm{FN}^{+}$: 319.1736; found: 319.1732 .

\section{Synthesis of 4-Methyl-2-[3-(1-phenylpentyl)phenyl]pyridine (177e)}

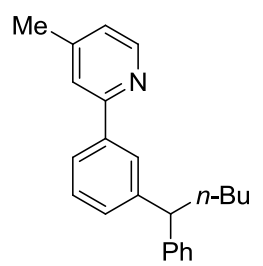

The general procedure $\mathbf{E}$ was followed, using $\left[\mathrm{RuCl}_{2}(p \text {-cymene })\right]_{2}(15.3 \mathrm{mg}, 0.025 \mathrm{mmol}, 4.8 \mathrm{~mol} \%)$, $\mathrm{MesCO}_{2} \mathrm{H} \quad$ (13a) $\quad(25 \mathrm{mg}, \quad 0.15 \mathrm{mmol}, \quad 25 \mathrm{~mol} \%), \quad 6 \mathrm{eb} \quad(104 \mathrm{mg}, \quad 0.61 \mathrm{mmol})$ and (1bromopentyl)benzene (176) (361 mg, $1.59 \mathrm{mmol}$ ). After $20 \mathrm{~h}$, purification by column chromatography ( $n$-hexane/Et $\left.\mathrm{Et}_{2} \mathrm{O} 19: 1\right)$ yielded $177 \mathrm{e}$ (58 $\mathrm{mg}, 30 \%$ ) as a colorless oil.

${ }^{1} \mathrm{H}-\mathrm{NMR}\left(300 \mathrm{MHz}, \mathrm{CDCl}_{3}\right): \delta=8.51(\mathrm{~d}, J=5.0 \mathrm{~Hz}, 1 \mathrm{H}), 7.87-7.86(\mathrm{~m}, 1 \mathrm{H}), 7.75-7.71(\mathrm{~m}, 1 \mathrm{H}), 7.48-7.46$ (m, $1 \mathrm{H}), 7.34(\mathrm{dd}, J=7.7,7.7 \mathrm{~Hz}, 1 \mathrm{H}), 7.17-7.09(\mathrm{~m}, 5 \mathrm{H}), 7.01-6.99(\mathrm{~m}, 1 \mathrm{H}), 3.97(\mathrm{t}, J=7.9 \mathrm{~Hz}, 1 \mathrm{H})$, $2.36(\mathrm{~s}, 3 \mathrm{H}), 2.16-2.01(\mathrm{~m}, 2 \mathrm{H}), 1.39-1.19(\mathrm{~m}, 4 \mathrm{H}), 0.84(\mathrm{t}, J=7.3 \mathrm{~Hz}, 3 \mathrm{H})$.

${ }^{13} \mathrm{C}$-NMR $\left(75 \mathrm{MHz}, \mathrm{CDCl}_{3}\right): \delta=157.6\left(\mathrm{C}_{\mathrm{q}}\right), 149.4(\mathrm{CH}), 147.7\left(\mathrm{C}_{\mathrm{q}}\right), 145.9\left(\mathrm{C}_{\mathrm{q}}\right), 145.3\left(\mathrm{C}_{\mathrm{q}}\right), 139.7\left(\mathrm{C}_{\mathrm{q}}\right)$, $128.8(\mathrm{CH}), 128.4(\mathrm{CH}), 128.3(\mathrm{CH}), 128.0(\mathrm{CH}), 126.8(\mathrm{CH}), 126.1(\mathrm{CH}), 124.8(\mathrm{CH}), 121.1(\mathrm{CH}), 121.7$ $(\mathrm{CH}), 51.7(\mathrm{CH}), 35.7\left(\mathrm{CH}_{2}\right), 30.5\left(\mathrm{CH}_{2}\right), 23.0\left(\mathrm{CH}_{2}\right), 21.5\left(\mathrm{CH}_{3}\right), 14.3\left(\mathrm{CH}_{3}\right)$. IR (ATR): $\tilde{v}=3025,2927,2858,1599,1493,1379,1032,835,699,589 \mathrm{~cm}^{-1}$. MS (EI) m/z (relative intensity): 315 (20) [M] ${ }^{+}, 258$ (100), 242 (5), 165 (10), 91 (8). HR-MS (ESI) $m / z$ calculated for $\mathrm{C}_{23} \mathrm{H}_{25} \mathrm{NO}+\mathrm{H}^{+}: 316.2065$; found: 316.2060 . 
Synthesis of 2-(4-Methoxy-3-(1-phenylpentyl)phenyl)-4-methylpyridine (177f)

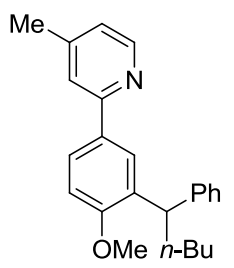

The general procedure $\mathbf{E}$ was followed, using $\left[\operatorname{RuCl}_{2}(p \text {-cymene })\right]_{2}(15.8 \mathrm{mg}, 0.026 \mathrm{mmol}, 4.6 \mathrm{~mol} \%)$, $\mathrm{MesCO}_{2} \mathrm{H}$ (13a) $(24 \mathrm{mg}, 0.15 \mathrm{mmol}, 27 \mathrm{~mol} \%), 6 f(111 \mathrm{mg}, 0.56 \mathrm{mmol})$ and (1-bromo-pentyl)benzene (176) $(360 \mathrm{mg}, 1.58 \mathrm{mmol})$. After $20 \mathrm{~h}$, purification by column chromatography ( $n$ hexane/Et ${ }_{2} \mathrm{O} 19: 1$ to $9: 1$ ) yielded $\mathbf{1 7 7 f}$ ( $38 \mathrm{mg}, 20 \%$ ) as a white solid.

M.r.: $109-110^{\circ} \mathrm{C}$.

${ }^{1} \mathrm{H}-\mathrm{NMR}\left(300 \mathrm{MHz}, \mathrm{CDCl}_{3}\right): \delta=8.52(\mathrm{~d}, J=5.0 \mathrm{~Hz}, 1 \mathrm{H}), 7.91-7.90(\mathrm{~m}, 1 \mathrm{H}), 7.80(\mathrm{dd}, J=8.5,2.3 \mathrm{~Hz}, 1 \mathrm{H})$, 7.46-7.42 (m, 1H), 7.33-7.22 (m, 4H), 7.16-7.11 (m, 1H), 7.00-6.99 (m, 1H), $6.90(\mathrm{~d}, J=8.6 \mathrm{~Hz}, 1 \mathrm{H})$, $4.40(\mathrm{t}, J=8.0 \mathrm{~Hz}, 1 \mathrm{H}), 3.81(\mathrm{~s}, 3 \mathrm{H}), 2.40(\mathrm{~s}, 3 \mathrm{H}), 2.14-2.07(\mathrm{~m}, 2 \mathrm{H}), 1.40-1.23(\mathrm{~m}, 4 \mathrm{H}), 0.87(\mathrm{t}$, $J=6.8 \mathrm{~Hz}, 3 \mathrm{H})$.

${ }^{13}$ C-NMR $\left(75 \mathrm{MHz}, \mathrm{CDCl}_{3}\right): \delta=157.9\left(\mathrm{C}_{\mathrm{q}}\right), 157.4\left(\mathrm{C}_{\mathrm{q}}\right), 149.2(\mathrm{CH}), 147.5\left(\mathrm{C}_{\mathrm{q}}\right), 145.2\left(\mathrm{C}_{\mathrm{q}}\right), 133.9\left(\mathrm{C}_{\mathrm{q}}\right)$, $131.8(\mathrm{CH}), 128.2(\mathrm{CH}), 128.0\left(\mathrm{C}_{\mathrm{q}}\right), 126.2(\mathrm{CH}), 125.7(\mathrm{CH}), 125.6(\mathrm{CH}), 122.3(\mathrm{CH}), 120.9(\mathrm{CH}), 110.8$ $(\mathrm{CH}), 55.6\left(\mathrm{CH}_{3}\right), 43.4(\mathrm{CH}), 34.7\left(\mathrm{CH}_{2}\right), 30.2\left(\mathrm{CH}_{2}\right), 22.7\left(\mathrm{CH}_{2}\right), 21.2\left(\mathrm{CH}_{3}\right), 14.0\left(\mathrm{CH}_{3}\right)$.

IR (ATR): $\tilde{v}=3082,3025,3000,2928,2858,1602,1557,1500,1278,1245,1202,1132,1028,812$, $698,413 \mathrm{~cm}^{-1}$.

MS (EI) $m / z$ (relative intensiy): 345 (29) [M] $]^{+}, 288$ (100), 272 (8), 91 (46).

HR-MS (ESI) $m / z$ calculated for $\mathrm{C}_{24} \mathrm{H}_{27} \mathrm{NO}+\mathrm{H}^{+}: 346.2171$; found: 346.2165 .

\section{Synthesis of 4-Methoxy-2-[3-(1-phenylpentyl)phenyl]pyridine (177g)}<smiles>CCCCC(c1ccccc1)c1cccc(-c2cc(OC)ccn2)c1</smiles>

The general procedure $\mathbf{E}$ was followed, using $\left[\mathrm{RuCl}_{2}(p \text {-cymene) }]_{2}(15.8 \mathrm{mg}, 0.026 \mathrm{mmol}, 5.1 \mathrm{~mol} \%)\right.$, $\mathrm{MesCO}_{2} \mathrm{H} \mathrm{(13a)}(24 \mathrm{mg}, 0.15 \mathrm{mmol}, 30 \mathrm{~mol} \%), 6 \mathrm{gb}(88.2 \mathrm{mg}, 0.48 \mathrm{mmol})$ and (1-bromopentyl)benzene (176) $(338 \mathrm{mg}, 1.49 \mathrm{mmol})$. After $20 \mathrm{~h}$, purification by column chromatography ( $n$ hexane/Et ${ }_{2} \mathrm{O} 9: 1$ ) yielded $\mathbf{1 7 7 g}$ (89 $\mathrm{mg}, 56 \%$ ) as a colorless oil. 
${ }^{1} \mathrm{H}-\mathrm{NMR}\left(300 \mathrm{MHz}, \mathrm{CDCl}_{3}\right): \delta=8.48(\mathrm{~d}, J=5.7 \mathrm{~Hz}, 1 \mathrm{H}), 7.86(\mathrm{dd}, J=1.7,1.6 \mathrm{~Hz}, 1 \mathrm{H}), 7.71$ (ddd, $J=7.6$, 1.6, $1.6 \mathrm{~Hz}, 1 \mathrm{H}), 7.37-7.07(\mathrm{~m}, 7 \mathrm{H}), 6.71(\mathrm{dd}, J=5.9,2.5 \mathrm{~Hz}, 1 \mathrm{H}), 4.13-4.05(\mathrm{~m}, 1 \mathrm{H}), 4.00-3.91(\mathrm{~m}, 1 \mathrm{H})$, $3.82(\mathrm{~s}, 3 \mathrm{H}), 2.12-1.99(\mathrm{~m}, 2 \mathrm{H}), 1.41-1.81(\mathrm{~m}, 4 \mathrm{H}), 0.84(\mathrm{t}, J=6.7 \mathrm{~Hz}, 3 \mathrm{H})$.

${ }^{13} \mathrm{C}$-NMR $\left(75 \mathrm{MHz}, \mathrm{CDCl}_{3}\right): \delta=166.3\left(\mathrm{C}_{\mathrm{q}}\right), 159.3\left(\mathrm{C}_{\mathrm{q}}\right), 150.8(\mathrm{CH}), 145.8\left(\mathrm{C}_{\mathrm{q}}\right), 145.1\left(\mathrm{C}_{\mathrm{q}}\right), 139.4\left(\mathrm{C}_{\mathrm{q}}\right)$, $128.7(\mathrm{CH}), 128.4(\mathrm{CH}), 128.3(\mathrm{CH}), 128.2(\mathrm{CH}), 127.9(\mathrm{CH}), 126.7(\mathrm{CH}), 126.0(\mathrm{CH}), 124.7(\mathrm{CH}), 107.9$ (CH), $107.3(\mathrm{CH}), 55.0\left(\mathrm{CH}_{3}\right), 51.4(\mathrm{CH}), 35.4\left(\mathrm{CH}_{2}\right), 30.2\left(\mathrm{CH}_{2}\right), 14.0\left(\mathrm{CH}_{3}\right)$.

IR (ATR): $\tilde{v}=3024,2998,2587,1590,1563,1451,1310,1219,1164,1035,989,796 \mathrm{~cm}^{-1}$.

MS (EI) $m / z$ (relative intensity): 331 (11) $\left[\mathrm{M}^{+}\right], 274$ (100), 230 (7).

HR-MS (ESI) $\mathrm{m} / \mathrm{z}$ calculated for $\mathrm{C}_{23} \mathrm{H}_{25} \mathrm{NO}^{+} \mathrm{H}^{+}$: 330.1858; found: 330.1873 .

\section{Synthesis of 2-[3-Methoxy-5-(1-phenylpentyl)phenyl]pyridine (177u)}<smiles>CCCCCC(c1ccccc1)c1cc(OC)cc(-c2ccccn2)c1</smiles>

The general procedure $\mathbf{E}$ was followed, using $\left[\mathrm{RuCl}_{2}(p \text {-cymene })\right]_{2}(14.9 \mathrm{mg}, 0.025 \mathrm{mmol}, 4.9 \mathrm{~mol} \%)$, $\mathrm{MesCO}_{2} \mathrm{H} \quad$ (13a) $\quad(25 \mathrm{mg}, \quad 0.15 \mathrm{mmol}, 26 \mathrm{~mol} \%)$ 6ua $\quad(107 \mathrm{mg}, 0.58 \mathrm{mmol})$ and (1bromopentyl)benzene (176) (339 mg, $1.49 \mathrm{mmol}$ ). After $20 \mathrm{~h}$, purification by column chromatography ( $n$-hexane/Et ${ }_{2} \mathrm{O} 9: 1$ ) yielded $177 \mathrm{u}(62 \mathrm{mg}, 32 \%$ ) as a colorless oil.

${ }^{1} \mathrm{H}-\mathrm{NMR}\left(300 \mathrm{MHz}, \mathrm{CDCl}_{3}\right): \delta=8.69-8.67(\mathrm{~m}, 1 \mathrm{H}), 7.76-7.66(\mathrm{~m}, 2 \mathrm{H}), 7.46-7.45(\mathrm{~m}, 1 \mathrm{H}), 7.38-7.37(\mathrm{~m}$, $1 \mathrm{H}), 7.29-7.26(\mathrm{~m}, 6 \mathrm{H}), 6.87-6.86(\mathrm{~m}, 1 \mathrm{H}), 3.95(\mathrm{t}, J=8.1 \mathrm{~Hz}, 1 \mathrm{H}), 3.86(\mathrm{~s}, 3 \mathrm{H}), 2.12-2.04(\mathrm{~m}, 2 \mathrm{H}), 1.43-$ $1.22(\mathrm{~m}, 4 \mathrm{H}), 0.87(\mathrm{t}, J=6.7 \mathrm{~Hz}, 3 \mathrm{H})$.

${ }^{13} \mathrm{C}-\mathrm{NMR}\left(75 \mathrm{MHz}, \mathrm{CDCl}_{3}\right): \delta=160.1\left(\mathrm{C}_{\mathrm{q}}\right), 157.4\left(\mathrm{C}_{\mathrm{q}}\right), 149.5(\mathrm{CH}), 147.3\left(\mathrm{C}_{\mathrm{q}}\right), 145.0\left(\mathrm{C}_{\mathrm{q}}\right), 140.7\left(\mathrm{C}_{\mathrm{q}}\right)$, $136.6(\mathrm{CH}), 128.3(\mathrm{CH}), 127.8(\mathrm{CH}), 126.0(\mathrm{CH}), 122.1(\mathrm{CH}), 120.7(\mathrm{CH}), 119.3(\mathrm{CH}), 115.0(\mathrm{CH}), 109.2$ (CH), $55.3\left(\mathrm{CH}_{3}\right), 51.4(\mathrm{CH}), 35.4\left(\mathrm{CH}_{2}\right), 30.2\left(\mathrm{CH}_{2}\right), 22.7\left(\mathrm{CH}_{2}\right), 14.0\left(\mathrm{CH}_{3}\right)$.

IR (ATR): $\tilde{v}=3059,3002,2954,1584,1451,1417,1149,867,782,703 \mathrm{~cm}^{-1}$.

MS (ESI) $m / z$ (relative intensity): 331 (31) [M $\left.{ }^{+}\right], 274$ (100), 259 (52), 230 (42), 91 (34).

HR-MS (ESI) $m / z$ calculated for $\mathrm{C}_{23} \mathrm{H}_{25} \mathrm{NO}^{+}$: 331.1936; found: 331.1927 . 
2-[2-Methoxy-5-(1-phenylpentyl)phenyl]pyridine (177w) and 2-[2-Methoxy-3-(1-phenylpentyl)phenyl]pyridine (177w')

The general procedure $\mathbf{E}$ was followed, using $\left[\mathrm{RuCl}_{2}(p \text {-cymene) }]_{2}(30 \mathrm{mg}, 0.025 \mathrm{mmol}, 2.5 \mathrm{~mol} \%)\right.$, $\mathrm{MesCO}_{2} \mathrm{H} \quad$ (13a) $\quad(49 \mathrm{mg}, \quad 0.30 \mathrm{mmol}, \quad 30 \mathrm{~mol} \%), \quad 6 \mathrm{wa} \quad(186 \mathrm{mg}, \quad 1.00 \mathrm{mmol})$ and (1bromopentyl)benzene (176) (676 mg, $2.98 \mathrm{mmol})$. After $20 \mathrm{~h}$, purification by column chromatography ( $n$-hexane/Et ${ }_{2} \mathrm{O}$ 19:1) yielded 177w (36 mg, 11\%) and 177w' (14 mg, 4\%) as colorless oils.<smiles>COc1ccc(C(c2ccccc2)c2ccccc2)cc1-c1ccccc1</smiles>

\section{2-[2-Methoxy-5-(1-phenylpentyl)phenyl]pyridine (177w)}

${ }^{1} \mathrm{H}-\mathrm{NMR}\left(300 \mathrm{MHz}, \mathrm{CDCl}_{3}\right): \delta=8.70(\mathrm{ddd}, J=4.9,1.9,1.0 \mathrm{~Hz}, 1 \mathrm{H}$ ), 7.77 (ddd, $J=8.0,1.2,1.2 \mathrm{~Hz}, 1 \mathrm{H}$ ), 7.71-7.63 (m, 2H), 7.33-7.10 (m, 7H), $6.92(\mathrm{~d}, J=8.5 \mathrm{~Hz}, 1 \mathrm{H}), 3.93(\mathrm{t}, J=7.8 \mathrm{~Hz}, 1 \mathrm{H}), 3.81(\mathrm{~d}, J=1.1 \mathrm{~Hz}$, $3 \mathrm{H}), 2.12-1.97(\mathrm{~m}, 2 \mathrm{H}), 1.43-1.16(\mathrm{~m}, 4 \mathrm{H}), 0.86(\mathrm{t}, J=7.4 \mathrm{~Hz}, 3 \mathrm{H})$.

${ }^{13} \mathrm{C}-\mathrm{NMR}\left(75 \mathrm{MHz}, \mathrm{CDCl}_{3}\right): \delta=156.5\left(\mathrm{C}_{\mathrm{q}}\right), 155.5\left(\mathrm{C}_{\mathrm{q}}\right), 149.6(\mathrm{CH}), 145.8\left(\mathrm{C}_{\mathrm{q}}\right), 138.2\left(\mathrm{C}_{\mathrm{q}}\right), 135.7(\mathrm{CH})$, $130.9(\mathrm{CH}), 129.1\left(\mathrm{C}_{\mathrm{q}}\right), 129.0(\mathrm{CH}), 128.6(\mathrm{CH}), 128.1(\mathrm{CH}), 126.1(\mathrm{CH}), 125.4(\mathrm{CH}), 121.8(\mathrm{CH}), 111.7$ (CH), $56.0\left(\mathrm{CH}_{3}\right), 50.9(\mathrm{CH}), 36.0\left(\mathrm{CH}_{2}\right), 30.8\left(\mathrm{CH}_{2}\right), 23.1\left(\mathrm{CH}_{2}\right), 14.4\left(\mathrm{CH}_{3}\right)$.

IR (ATR): $\tilde{v}=2956,2929,2859,1586,1566,1444,1433,1257,1235,1152,782,742,464 \mathrm{~cm}^{-1}$.

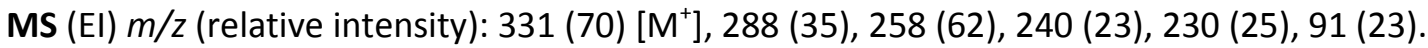
HR-MS (EI) $\mathrm{m} / \mathrm{z}$ calculated for $\mathrm{C}_{23} \mathrm{H}_{25} \mathrm{NO}-\mathrm{H}^{+}$: 330.1858; found: 330.1867 .

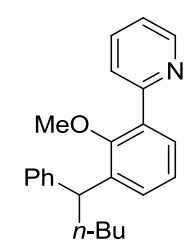

\section{2-[2-Methoxy-3-(1-phenylpentyl)phenyl]pyridine (177w')}

${ }^{1} \mathrm{H}-\mathrm{NMR}\left(300 \mathrm{MHz}, \mathrm{CDCl}_{3}\right.$ ): $\delta=8.68$ (ddd, $J=4.9,1.9,1.0 \mathrm{~Hz}, 1 \mathrm{H}$ ), 7.78 (ddd, $J=8.0,1.2,1.2 \mathrm{~Hz}, 1 \mathrm{H}$ ), 7.68 (ddd, $J=7.9,7.4,1.9 \mathrm{~Hz}, 1 \mathrm{H}$ ), 7.51 (dd, $J=7.6,1.8 \mathrm{~Hz}, 1 \mathrm{H}$ ), 7.37 (dd, $J=7.8,1.8 \mathrm{~Hz}, 1 \mathrm{H}$ ), 7.31 $7.09(\mathrm{~m}, 7 \mathrm{H}), 4.43(\mathrm{t}, J=7.8 \mathrm{~Hz}, 1 \mathrm{H}), 3.14(\mathrm{~s}, 3 \mathrm{H}), 2.02(\mathrm{td}, J=9.0,8.5,7.1 \mathrm{~Hz}, 2 \mathrm{H}), 1.43-1.18(\mathrm{~m}, 4 \mathrm{H})$, $0.86(\mathrm{t}, J=7.0 \mathrm{~Hz}, 3 \mathrm{H})$. 
${ }^{13} \mathrm{C}-\mathrm{NMR}\left(75 \mathrm{MHz}, \mathrm{CDCl}_{3}\right): \delta=157.1\left(\mathrm{C}_{\mathrm{q}}\right), 156.2\left(\mathrm{C}_{\mathrm{q}}\right), 149.7(\mathrm{CH}), 145.7\left(\mathrm{C}_{\mathrm{q}}\right), 138.7\left(\mathrm{C}_{\mathrm{q}}\right), 136.2(\mathrm{CH})$, $133.7\left(\mathrm{C}_{\mathrm{q}}\right), 129.4(\mathrm{CH}), 128.7(\mathrm{CH}), 128.4(\mathrm{CH}), 128.3(\mathrm{CH}), 126.0(\mathrm{CH}), 124.6(\mathrm{CH}), 124.4(\mathrm{CH}), 122.0$ $(\mathrm{CH}), 61.4\left(\mathrm{CH}_{3}\right), 43.8(\mathrm{CH}), 35.8\left(\mathrm{CH}_{2}\right), 30.5\left(\mathrm{CH}_{2}\right), 22.9\left(\mathrm{CH}_{2}\right), 14.2\left(\mathrm{CH}_{3}\right)$.

IR (ATR): $\tilde{v}=2954,2928,2857,1584,1498,1461,1249,1061,1025,745,697 \mathrm{~cm}^{-1}$.

MS (EI) $m / z$ (relative intensity): 331 (17) [M+], 316 (21), 28 (60), 274 (100), 240 (32), 165 (16), 91 (32).

HR-MS (EI) $m / z$ calculated for $\mathrm{C}_{23} \mathrm{H}_{25} \mathrm{NO}^{+}$: 331.1936; found: 331.1933 .

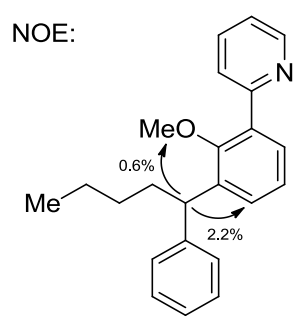

\section{Products of Direct Norbornylation}

Synthesis of 2-\{3-[(1RS,2RS,4SR)-Bicyclo[2.2.1]heptan-2-yl]-4-methoxyphenyl\}pyridine (exo-147bl) and 2-\{2-[(1RS,2RS,4SR)-Bicyclo[2.2.1]heptan-2-yl]-4-methoxyphenyl\}pyridine (exo-93bl)

The general procedure $\mathrm{E}-1$ was followed, using $\left[\mathrm{RuCl}_{2}(p \text {-cymene })\right]_{2}(8.3 \mathrm{mg}, 0.013 \mathrm{mmol}, 2.5 \mathrm{~mol} \%)$, $\mathrm{MesCO}_{2} \mathrm{H} \quad$ (13a) $\quad(24 \mathrm{mg}, \quad 0.15 \mathrm{mmol}, 27 \mathrm{~mol} \%), \quad 6$ ba $\quad(103 \mathrm{mg}, 0.56 \mathrm{mmol}$ ) and exo-2bromonorbornane (exo-42bl) $(265 \mathrm{mg}, 1.51 \mathrm{mmol})$. After $20 \mathrm{~h}$, purification by column chromatography ( $n$-hexane/EtOAc 9:1 to 4:1) yielded exo-147bl (51 mg, 33\%) and exo-93bl (53 mg, $34 \%)$ as colorless oils.

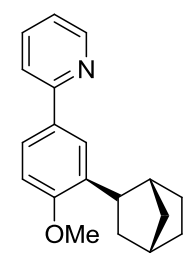

(exo-147bl)

${ }^{1} \mathrm{H}-\mathrm{NMR}\left(300 \mathrm{MHz}, \mathrm{CDCl}_{3}\right): \delta=8.66(\mathrm{ddd}, J=4.9,1.8,1.0 \mathrm{~Hz}, 1 \mathrm{H}$ ), $7.86(\mathrm{dd}, J=2.3,0.7 \mathrm{~Hz}, 1 \mathrm{H}), 7.79$ (dd, $J=8.4,2.3 \mathrm{~Hz}, 1 \mathrm{H}), 7.75-7.62(\mathrm{~m}, 2 \mathrm{H}), 7.15$ (ddd, $J=6.7,4.9,1.8 \mathrm{~Hz}, 1 \mathrm{H}), 6.92(\mathrm{~d}, J=8.5 \mathrm{~Hz}, 1 \mathrm{H}$ ), $3.88(\mathrm{~s}, 3 \mathrm{H}), 3.10-2.96(\mathrm{~m}, 1 \mathrm{H}), 2.45(\mathrm{~d}, J=3.5 \mathrm{~Hz}, 1 \mathrm{H}), 2.35(\mathrm{q}, J=3.9,3.0 \mathrm{~Hz}, 1 \mathrm{H}), 1.87-1.78(\mathrm{~m}, 1 \mathrm{H})$, 1.70-1.49 (m, 3H), 1.50-1.18 (m, 4H). 
${ }^{13} \mathrm{C}-\mathrm{NMR}\left(75 \mathrm{MHz}, \mathrm{CDCl}_{3}\right): \delta=158.8\left(\mathrm{C}_{\mathrm{q}}\right), 158.4\left(\mathrm{C}_{\mathrm{q}}\right), 150.1(\mathrm{CH}), 137.1(\mathrm{CH}), 136.7\left(\mathrm{C}_{\mathrm{q}}\right), 131.9\left(\mathrm{C}_{\mathrm{q}}\right)$, 125.6 (CH), $125.0(\mathrm{CH}), 121.7(\mathrm{CH}), 120.5(\mathrm{CH}), 110.8(\mathrm{CH}), 56.1\left(\mathrm{CH}_{3}\right), 41.7(\mathrm{CH}), 41.1(\mathrm{CH}), 39.2\left(\mathrm{CH}_{2}\right)$, $37.5(\mathrm{CH}), 37.0\left(\mathrm{CH}_{2}\right), 31.0\left(\mathrm{CH}_{2}\right), 29.6\left(\mathrm{CH}_{2}\right)$.

IR (ATR): $\tilde{v}=2947,2868,1715,1609,1586,1503,1462,1231,1144,790 \mathrm{~cm}^{-1}$.

MS (EI) m/z (relative intensity): 279 (56) [M+], 250 (100), 223 (57), 210 (28), 167 (20).

HR-MS (ESI) $m / z$ calculated for $\mathrm{C}_{19} \mathrm{H}_{21} \mathrm{NO}+\mathrm{H}^{+}: 280.1701$; found: 280.1700 .

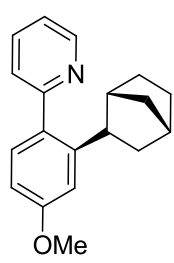

(exo-93bl)

${ }^{1} \mathrm{H}-\mathrm{NMR}\left(300 \mathrm{MHz}, \mathrm{CDCl}_{3}\right): \delta=8.67$ (ddd, $\left.J=4.9,1.9,0.9 \mathrm{~Hz}, 1 \mathrm{H}\right), 7.71$ (ddd, $J=7.7,1.9,1.9 \mathrm{~Hz}, 1 \mathrm{H}$ ), 7.32 (ddd, J = 7.9, 1.1, 1.0 Hz, 1H), 7.29-7.17 (m, 2H), 6.95 (d, J = 2.6 Hz, 1H), 6.77 (dd, J = 8.4, $2.6 \mathrm{~Hz}$, $1 \mathrm{H}), 3.84(\mathrm{~s}, 3 \mathrm{H}), 3.06-2.94(\mathrm{~m}, 1 \mathrm{H}), 2.42-2.32(\mathrm{~m}, 1 \mathrm{H}), 2.32-2.19(\mathrm{~m}, 1 \mathrm{H}), 1.70-1.60(\mathrm{~m}, 1 \mathrm{H}), 1.57-1.25$ $(\mathrm{m}, 4 \mathrm{H}), 1.25-1.13(\mathrm{~m}, 1 \mathrm{H}), 1.16-1.00(\mathrm{~m}, 2 \mathrm{H})$.

${ }^{13} \mathrm{C}$-NMR $\left(75 \mathrm{MHz}, \mathrm{CDCl}_{3}\right): \delta=160.7\left(\mathrm{C}_{\mathrm{q}}\right), 159.7\left(\mathrm{C}_{\mathrm{q}}\right), 149.1(\mathrm{CH}), 147.2\left(\mathrm{C}_{\mathrm{q}}\right), 136.1(\mathrm{CH}), 133.7\left(\mathrm{C}_{\mathrm{q}}\right)$, 131.1 (CH), $124.7(\mathrm{CH}), 121.4(\mathrm{CH}), 112.6(\mathrm{CH}), 109.7(\mathrm{CH}), 55.4\left(\mathrm{CH}_{3}\right), 43.4(\mathrm{CH}), 42.8(\mathrm{CH}), 40.2\left(\mathrm{CH}_{2}\right)$, $37.0(\mathrm{CH}), 36.7\left(\mathrm{CH}_{2}\right), 30.5\left(\mathrm{CH}_{2}\right), 28.7\left(\mathrm{CH}_{2}\right)$.

IR (ATR): $\tilde{v}=2948,2868,1605,1561,1462,1426,1279,1224,1166,1040,786,747 \mathrm{~cm}^{-1}$. MS (EI) m/z (relative intensity): 279 (100) [ $\left.\mathrm{M}^{+}\right], 248$ (33), 212 (61), 198 (35), 167 (44).

HR-MS (ESI) $m / z$ calculated for $\mathrm{C}_{19} \mathrm{H}_{21} \mathrm{NO}+\mathrm{H}^{+}: 280.1701$; found: 280.1697 .

Synthesis of 2-\{2-((1RS,2RS,4SR)-Bicyclo[2.2.1]heptan-2-yl)-4-fluorophenyl\}pyridine (exo-147cl) and 2-\{3-((1RS,2RS,4SR)-Bicyclo[2.2.1]heptan-2-yl)-4-fluorophenyl\}pyridine (exo-93cl)

The general procedure $\mathbf{E}$ was followed, using $\left[\mathrm{RuCl}_{2}(p \text {-cymene })\right]_{2}(8.3 \mathrm{mg}, 0.013 \mathrm{mmol}, 2.6 \mathrm{~mol} \%)$, $\mathrm{MesCO}_{2} \mathrm{H} \quad$ (13a) $\quad(25 \mathrm{mg}, \quad 0.15 \mathrm{mmol}, \quad 30 \mathrm{~mol} \%), \quad 6 \mathrm{ca} \quad(87.1 \mathrm{mg}, \quad 0.50 \mathrm{mmol})$ and exo-2bromonorbornane (exo-42bl) $(282 \mathrm{mg}, 1.61 \mathrm{mmol})$. After $20 \mathrm{~h}$, purification by column chromatography ( $n$-hexane/EtOAc 9:1) yielded exo-147cl (42 mg, 31\%) and exo-93cl (64 mg, 48\%) as colorless oils. 


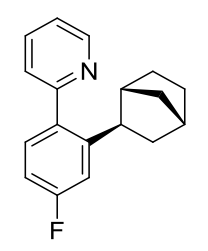

(exo-93cl)

${ }^{1} \mathrm{H}-\mathrm{NMR}\left(300 \mathrm{MHz}, \mathrm{CDCl}_{3}\right): \delta=8.69(\mathrm{~s}, 1 \mathrm{H}), 7.73(\mathrm{ddd}, J=7.7,1.9,1.9 \mathrm{~Hz}, 1 \mathrm{H}), 7.37-7.20(\mathrm{~m}, 3 \mathrm{H}), 7.10$ (dd, $J=11.1,2.6 \mathrm{~Hz}, 1 \mathrm{H}$ ), 6.92 (ddd, $J=8.3,2.6,2.6 \mathrm{~Hz}, 1 \mathrm{H}$ ), 2.95 (dd, $J=9.0,5.9 \mathrm{~Hz}, 1 \mathrm{H}$ ), 2.36-2.29 (m, $1 \mathrm{H}), 2.29-2.20(\mathrm{~m}, 1 \mathrm{H}), 1.59(\mathrm{dt}, J=9.9,2.0 \mathrm{~Hz}, 1 \mathrm{H}), 1.53-1.30(\mathrm{~m}, 4 \mathrm{H}), 1.20$ (ddd, $J=9.9,2.4$, $1.4 \mathrm{~Hz}, 1 \mathrm{H}), 1.14-0.99(\mathrm{~m}, 2 \mathrm{H})$.

${ }^{13} \mathrm{C}-\mathrm{NMR}\left(75 \mathrm{MHz}, \mathrm{CDCl}_{3}\right): \delta=162.9\left(\mathrm{~d}, \mathrm{~J}_{\mathrm{C}-\mathrm{F}}=246 \mathrm{~Hz}, \mathrm{C}_{\mathrm{q}}\right), 160.0\left(\mathrm{C}_{\mathrm{q}}\right), 149.3(\mathrm{CH}), 148.3\left(\mathrm{~d}, \mathrm{~J}_{\mathrm{C}-\mathrm{F}}=7 \mathrm{~Hz}\right.$, $\left.\mathrm{C}_{\mathrm{q}}\right), 136.8\left(\mathrm{~d}, J_{\mathrm{C}-\mathrm{F}}=3 \mathrm{~Hz}, \mathrm{C}_{\mathrm{q}}\right), 136.2(\mathrm{CH}), 131.5\left(\mathrm{~d}, J_{\mathrm{C}-\mathrm{F}}=8 \mathrm{~Hz}, \mathrm{CH}\right), 124.6(\mathrm{CH}), 121.8(\mathrm{CH}), 112.9\left(\mathrm{~d}, J_{\mathrm{C}-\mathrm{F}}\right.$ $=22 \mathrm{~Hz}, \mathrm{CH}), 112.1\left(\mathrm{~d}, \mathrm{~J}_{\mathrm{C}-\mathrm{F}}=21 \mathrm{~Hz}, \mathrm{CH}\right), 43.4\left(\mathrm{~d}, \mathrm{~J}_{\mathrm{C}-\mathrm{F}}=1 \mathrm{~Hz}, \mathrm{CH}\right), 42.8(\mathrm{CH}), 40.2\left(\mathrm{CH}_{2}\right), 36.9(\mathrm{CH}), 36.6$ $\left(\mathrm{CH}_{2}\right), 30.4\left(\mathrm{CH}_{2}\right), 28.6\left(\mathrm{CH}_{2}\right)$.

${ }^{19} \mathrm{~F}-\mathrm{NMR}\left(282 \mathrm{MHz}, \mathrm{CDCl}_{3}\right): \delta=-113.44--113.81(\mathrm{~m})$.

IR (ATR): $\tilde{v}=3051,2949,2869,1586,1462,1426,1274,1212,939,787,747,591 \mathrm{~cm}^{-1}$.

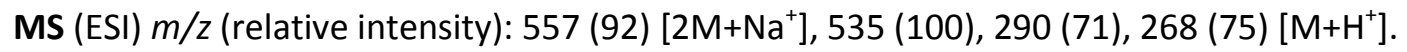

HR-MS (ESI) $m / z$ calculated for $\mathrm{C}_{18} \mathrm{H}_{18} \mathrm{FN}+\mathrm{H}^{+}: 268.1502$; found: 268.1499 .

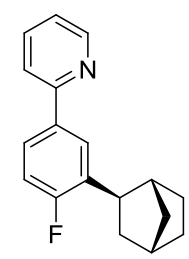

(exo-147cl)

${ }^{1} \mathrm{H}-\mathrm{NMR}\left(300 \mathrm{MHz}, \mathrm{CDCl}_{3}\right): \delta=8.32-8.05(\mathrm{~m}, 1 \mathrm{H}), 7.42(\mathrm{dd}, J=7.4,2.3 \mathrm{~Hz}, 1 \mathrm{H}), 7.34-7.12(\mathrm{~m}, 3 \mathrm{H})$, 6.85-6.69 (m, 1H), $6.62(\mathrm{dd}, J=10.0,8.4 \mathrm{~Hz}, 1 \mathrm{H}), 2.62-2.47(\mathrm{~m}, 1 \mathrm{H}), 2.00(\mathrm{~d}, J=3.6 \mathrm{~Hz}, 1 \mathrm{H}), 1.93(\mathrm{~d}, J=$ $3.9 \mathrm{~Hz}, 1 \mathrm{H}), 1.38(\mathrm{ddd}, J=11.7,8.9,2.2 \mathrm{~Hz}, 1 \mathrm{H}), 1.27-1.04(\mathrm{~m}, 4 \mathrm{H}), 1.03-0.90(\mathrm{~m}, 1 \mathrm{H}), 0.89-0.71(\mathrm{~m}$, $2 \mathrm{H})$.

${ }^{13} \mathrm{C}-\mathrm{NMR}\left(75 \mathrm{MHz}, \mathrm{CDCl}_{3}\right): \delta=161.8\left(\mathrm{~d}, \mathrm{~J}_{\mathrm{C}-\mathrm{F}}=247 \mathrm{~Hz}, \mathrm{C}_{\mathrm{q}}\right.$ ), $157.2\left(\mathrm{C}_{\mathrm{q}}\right), 149.7(\mathrm{CH}), 136.7(\mathrm{CH}), 135.2(\mathrm{~d}$, $\left.J_{C-F}=3 \mathrm{~Hz}, C_{q}\right), 134.6\left(d, J_{C-F}=15 \mathrm{~Hz}, C_{q}\right), 125.8\left(d, J_{C-F}=5 \mathrm{~Hz}, C H\right), 125.6\left(d, J_{C-F}=9 \mathrm{~Hz}, \mathrm{CH}\right), 121.9(\mathrm{CH})$, $120.4(\mathrm{CH}), 115.4\left(\mathrm{~d}, J_{\mathrm{C}-\mathrm{F}}=23 \mathrm{~Hz}, \mathrm{CH}\right), 41.8(\mathrm{CH}), 40.1\left(\mathrm{~d}, J_{\mathrm{C}-\mathrm{F}}=2 \mathrm{~Hz}, \mathrm{CH}\right), 38.4(\mathrm{CH}), 37.1\left(\mathrm{CH}_{2}\right), 36.6$ $\left(\mathrm{CH}_{2}\right), 30.6\left(\mathrm{CH}_{2}\right), 29.1\left(\mathrm{CH}_{2}\right)$.

${ }^{19} \mathrm{~F}-\mathrm{NMR}\left(282 \mathrm{MHz}, \mathrm{CDCl}_{3}\right): \delta=-116.21--116.64(\mathrm{~m})$.

IR (ATR): $\tilde{v}=2951,2871,1608,1575,1464,1427,1275,788 \mathrm{~cm}^{-1}$. 
MS (El) m/z (relative intensity): 267 (38), [M+'], 238 (100), 211 (76), 198 (64), 185 (62), 170 (24), 78 (26).

HR-MS (ESI) $\mathrm{m} / \mathrm{z}$ calculated for $\mathrm{C}_{18} \mathrm{H}_{18} \mathrm{FN}+\mathrm{Na}^{+}$: 290.1321; found: 290.1315 .

Synthesis of 1-\{2-[(1RS,2RS,4SR)-Bicyclo[2.2.1]heptan-2-yl]phenyl\}-1H-pyrazole (exo-118al)<smiles>C1=CC2CC1CC2c1ccccc1-n1cccn1</smiles>

The general procedure $\mathbf{E}$ was followed, using $\left[\operatorname{RuCl}_{2}(p \text {-cymene })\right]_{2}(7.80 \mathrm{mg}, 0.013 \mathrm{mmol}, 2.3 \mathrm{~mol} \%)$, MesCO $\mathrm{H}_{2} \mathrm{H}$ (13a) (24 mg, $\left.0.15 \mathrm{mmol}, 27 \mathrm{~mol} \%\right), 87 \mathrm{a}(81 \mathrm{mg}, 0.56 \mathrm{mmol}$ ) and exo-2-bromonorbornane (exo-42bl) (265 mg, $1.51 \mathrm{mmol}$ ). After $20 \mathrm{~h}$, purification by column chromatography ( $n$-hexane/EtOAc $9: 1)$ yielded exo-118al ( $87 \mathrm{mg}, 65 \%)$ as a colorless oil.

${ }^{1} \mathrm{H}-\mathrm{NMR}\left(300 \mathrm{MHz}, \mathrm{CDCl}_{3}\right): \delta=7.71(\mathrm{~d}, J=1.8 \mathrm{~Hz}, 1 \mathrm{H}), 7.54(\mathrm{~d}, J=2.3 \mathrm{~Hz}, 1 \mathrm{H}), 7.45-7.31(\mathrm{~m}, 2 \mathrm{H}), 7.28-$ $7.17(\mathrm{~m}, 2 \mathrm{H}), 6.41(\mathrm{dd}, J=2.1,2.1 \mathrm{~Hz}, 1 \mathrm{H}), 2.73-2.61(\mathrm{~m}, 1 \mathrm{H}), 2.31(\mathrm{dd}, J=3.4,1.6 \mathrm{~Hz}, 1 \mathrm{H}), 2.28-2.20$ $(\mathrm{m}, 1 \mathrm{H}), 1.61-1.30(\mathrm{~m}, 5 \mathrm{H}), 1.23-1.02(\mathrm{~m}, 3 \mathrm{H})$.

${ }^{13} \mathrm{C}-\mathrm{NMR}\left(75 \mathrm{MHz}, \mathrm{CDCl}_{3}\right): \delta=143.5\left(\mathrm{C}_{\mathrm{q}}\right), 139.8(\mathrm{CH}), 139.4\left(\mathrm{C}_{\mathrm{q}}\right), 130.8(\mathrm{CH}), 128.5(\mathrm{CH}), 126.9(\mathrm{CH})$, $126.3(\mathrm{CH}), 125.7(\mathrm{CH}), 105.7(\mathrm{CH}), 42.2(\mathrm{CH}), 41.3(\mathrm{CH}), 39.2\left(\mathrm{CH}_{2}\right), 36.5(\mathrm{CH}), 36.1\left(\mathrm{CH}_{2}\right), 30.1\left(\mathrm{CH}_{2}\right)$, $28.2\left(\mathrm{CH}_{2}\right)$.

IR (ATR): $\tilde{v}=2950,2869,1515,1493,1453,1393,1328,1042,938,745,728,623 \mathrm{~cm}^{-1}$.

MS (EI) $m / z$ (relative intensity): 238 (199) [M+], 209 (48), 197 (32), 182 (49), 144 (54), 115 (25), 77 (57), 51 (44).

HR-MS (ESI) $m / z$ calculated for $\mathrm{C}_{16} \mathrm{H}_{18} \mathrm{~N}_{2}+\mathrm{Na}^{+}: 261.1368$; found: 261.1366 . 


\section{Mechanistic Studies}

Intermolecular Competition Experiment between 2-Bromooctane (42ba) and 1-Bromohexane (42ab)

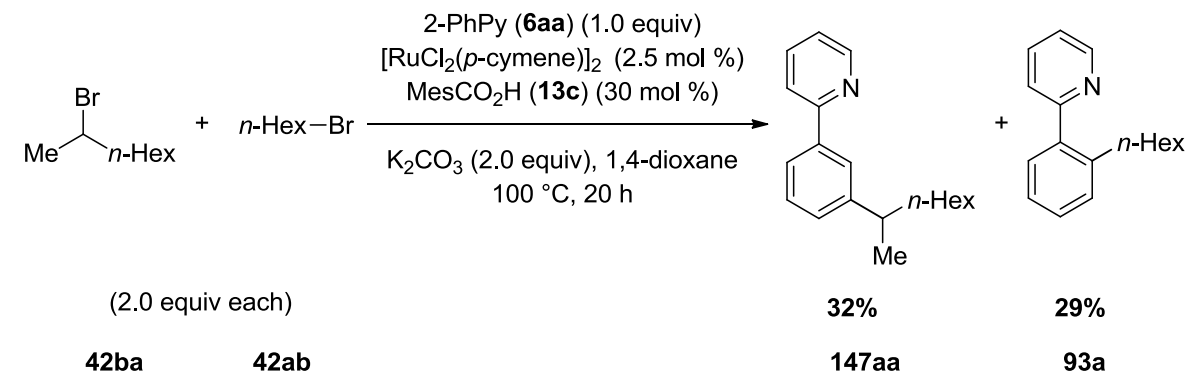

A suspension of $\left[\mathrm{RuCl}_{2}(p \text {-cymene })\right]_{2}(16.0 \mathrm{mg}, 0.026 \mathrm{mmol}, 2.6 \mathrm{~mol} \%), \mathrm{MesCO}_{2} \mathrm{H}$ (13a) (48.5 mg, $0.30 \mathrm{mmol}, 30 \mathrm{~mol} \%), \mathrm{K}_{2} \mathrm{CO}_{3}(277 \mathrm{mg}, 2.00 \mathrm{mmol}), 42 \mathrm{ba}(157 \mathrm{mg}, 1.02 \mathrm{mmol}), 42 \mathrm{ab}(375 \mathrm{mg}$, $1.94 \mathrm{mmol}$ ) and $6 \mathrm{aa}(328 \mathrm{mg}, 1.98 \mathrm{mmol})$ in dry 1,4-dioxane $(4.0 \mathrm{~mL})$ was stirred under $\mathrm{N}_{2}$ for $20 \mathrm{~h}$ at $100{ }^{\circ} \mathrm{C}$. EtOAc $(50 \mathrm{~mL})$ and $\mathrm{H}_{2} \mathrm{O}(50 \mathrm{~mL})$ were added to the reaction mixture at ambient temperature. The separated aqueous phase was extracted with EtOAc $(2 \times 50 \mathrm{~mL})$. The combined organic layers were washed with brine $(50 \mathrm{~mL})$, dried over $\mathrm{Na}_{2} \mathrm{SO}_{4}$ and concentrated in vacuo. The remaining residue was purified by column chromatography on silica gel ( $n$-hexane/EtOAc 19:1) to yield 147aa ( $88 \mathrm{mg}, 32 \%$ ) and $93 \mathrm{a}$ ( $80 \mathrm{mg}, 29 \%$ ) as colorless oils.

Intermolecular Competition Experiment between 2-(4-Methoxyphenyl)pyridine (6ba) \& 2-(4Fluorophenyl)pyridine (6ca)

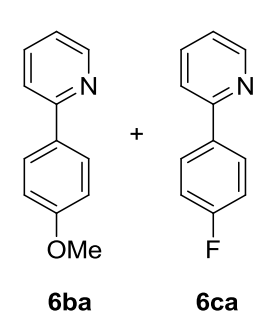

(each 2.0 equiv)

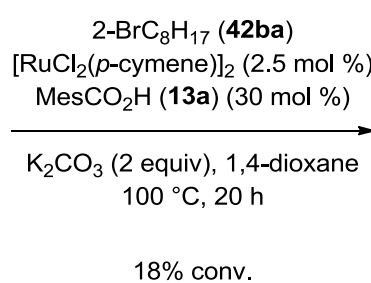

$147 \mathrm{ba}: 147 \mathrm{ca}=2.6: 1.0$ $\left({ }^{1} \mathrm{H}-\mathrm{NMR}\right)$

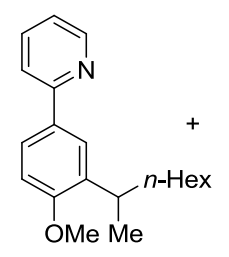

$147 \mathrm{ba}$

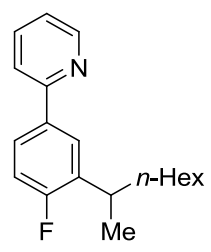

147ca

A suspension of $\left[\mathrm{RuCl}_{2}(p \text {-cymene })\right]_{2}(15.9 \mathrm{mg}, 0.026 \mathrm{mmol}, 2.6 \mathrm{~mol} \%), \mathrm{MesCO}_{2} \mathrm{H} \mathrm{(13a)}(50.1 \mathrm{mg}$, $0.30 \mathrm{mmol}, 30 \mathrm{~mol} \%), \mathrm{K}_{2} \mathrm{CO}_{3}(274 \mathrm{mg}, 2.00 \mathrm{mmol}), 6$ ba $(370 \mathrm{mg}, 2.00 \mathrm{mmol}), 6 \mathrm{ca}(347 \mathrm{mg}$, $2.00 \mathrm{mmol}$ ) and $42 \mathrm{ba}(200 \mathrm{mg}, 1.04 \mathrm{mmol})$ in dry 1,4-dioxane $(4.0 \mathrm{~mL})$ was stirred under $\mathrm{N}_{2}$ for $20 \mathrm{~h}$ at $100{ }^{\circ} \mathrm{C}$. EtOAc $(50 \mathrm{~mL})$ and $\mathrm{H}_{2} \mathrm{O}(50 \mathrm{~mL})$ were added to the reaction mixture at ambient temperature. The separated aqueous phase was extracted with EtOAc $(2 \times 50 \mathrm{~mL})$. The combined organic layers were washed with brine $(50 \mathrm{~mL})$, dried over $\mathrm{Na}_{2} \mathrm{SO}_{4}$ and concentrated in vacuo. The 
remaining residue was purified by column chromatography on silica gel ( $n$-hexane/EtOAc 19:1) to yield a mixture of $147 \mathrm{ba}$ and $147 \mathrm{ca}$ ( $18 \%$ conv.) in a ratio of $2.6: 1.0$ as determined by ${ }^{1} \mathrm{H}-\mathrm{NMR}$ spectroscopy.

Intermolecular Competition Experiment between 2-(4-Methylphenyl)pyridine (6oa) \& 2-(4Fluorophenyl)pyridine (6ca)
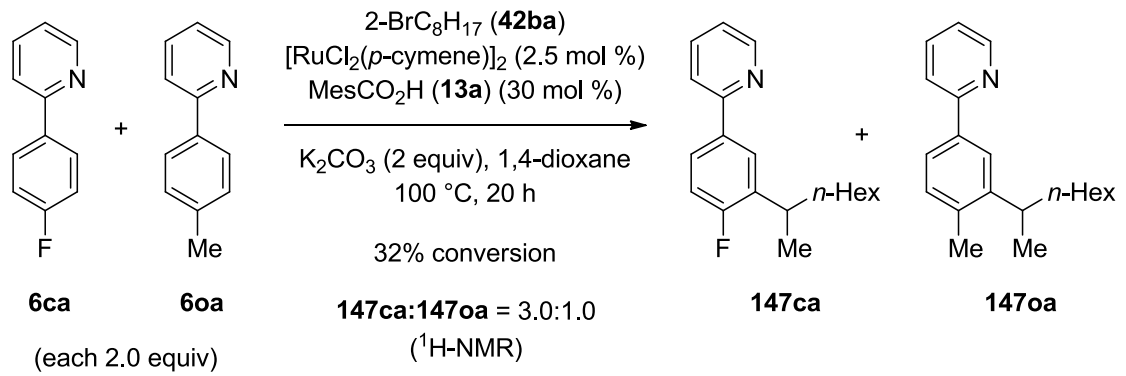

( $\left.{ }^{1} \mathrm{H}-\mathrm{NMR}\right)$

A suspension of $\left[\mathrm{RuCl}_{2}(p \text {-cymene })\right]_{2}(15.5 \mathrm{mg}, 0.025 \mathrm{mmol}, 2.0 \mathrm{~mol} \%)$, $\mathrm{MesCO}_{2} \mathrm{H} \quad(50.0 \mathrm{mg}$, $0.30 \mathrm{mmol}, 23.6 \mathrm{~mol} \%), \mathrm{K}_{2} \mathrm{CO}_{3}(280 \mathrm{mg}, 2.02 \mathrm{mmol}), 6 \mathrm{ca}(374 \mathrm{mg}, 2.02 \mathrm{mmol}), 60 a(333 \mathrm{mg}$, $1.97 \mathrm{mmol}$ ) and 42 ba $\left(245 \mathrm{mg}, 1.27 \mathrm{mmol}\right.$ ) in dry 1,4-dioxane $(4 \mathrm{~mL})$ was stirred under $\mathrm{N}_{2}$ for $20 \mathrm{~h}$ at $100{ }^{\circ} \mathrm{C}$. EtOAc $(50 \mathrm{~mL})$ and $\mathrm{H}_{2} \mathrm{O}(50 \mathrm{~mL})$ were added to the reaction mixture at ambient temperature. The separated aqueous phase was extracted with EtOAc $(2 \times 50 \mathrm{~mL})$. The combined organic layers were washed with brine $(50 \mathrm{~mL})$, dried over $\mathrm{Na}_{2} \mathrm{SO}_{4}$ and concentrated in vacuo. The remaining residue was purified by column chromatography on silica gel ( $n$-hexane/EtOAc 19:1). Careful ${ }^{1} \mathrm{H}-\mathrm{NMR}$ analysis gave a NMR-yield of $24 \%$ for $147 \mathrm{ca}$ and $8 \%$ for $1470 a$.

Intermolecular Competition Experiment between 2-(4-Methoxyphenyl)pyridine (6ba) \& 2-(4Methylphenyl)pyridine (6oa)

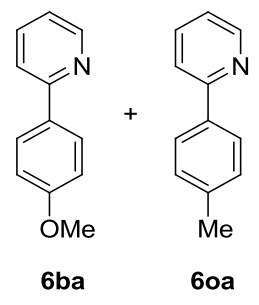

(each 2.0 equiv)

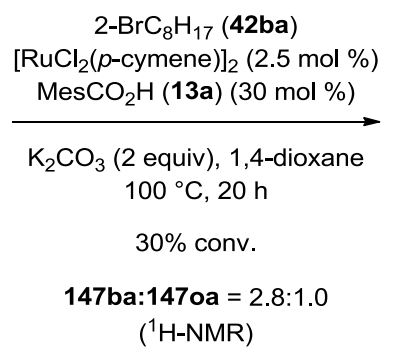

( $\left.{ }^{1} \mathrm{H}-\mathrm{NMR}\right)$

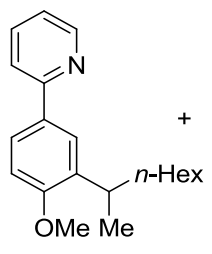

147ba

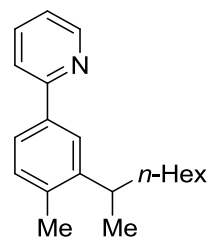

147 oa

A suspension of $\left[\mathrm{RuCl}_{2}(p \text {-cymene })\right]_{2}(15.8 \mathrm{mg}, 0.026 \mathrm{mmol}, 2.8 \mathrm{~mol} \%)$, $\mathrm{MesCO}_{2} \mathrm{H}(48.7 \mathrm{mg}$, $0.30 \mathrm{mmol}, 32 \mathrm{~mol} \%), \mathrm{K}_{2} \mathrm{CO}_{3}(277 \mathrm{mg}, 2.00 \mathrm{mmol}$ ), 6ba (343 mg, $2.03 \mathrm{mmol}$ ), 6oa (372 mg, $2.01 \mathrm{mmol}$ ) and $\mathbf{4 2} \mathrm{ba}(180 \mathrm{mg}, 0.93 \mathrm{mmol})$ in dry 1,4-dioxane $(4.0 \mathrm{~mL})$ was stirred under $\mathrm{N}_{2}$ for $20 \mathrm{~h}$ 
at $100{ }^{\circ} \mathrm{C}$. EtOAc $(50 \mathrm{~mL})$ and $\mathrm{H}_{2} \mathrm{O}(50 \mathrm{~mL})$ were added to the reaction mixture at ambient temperature. The separated aqueous phase was extracted with EtOAc $(2 \times 50 \mathrm{~mL})$. The combined organic layers were washed with brine $(50 \mathrm{~mL})$, dried over $\mathrm{Na}_{2} \mathrm{SO}_{4}$ and concentrated in vacuo. The remaining residue was purified by column chromatography on silica gel ( $n$-hexane/EtOAc 9:1) to yield a mixture of $147 \mathrm{ba}$ and $147 \mathrm{oa}$ ( $30 \%$ conv.) in a ratio of $2.8: 1.0$ as determined by ${ }^{1} \mathrm{H}$-NMR spectroscopy.

\section{Experiment with Deuterium-Labeled Phenylpyridine $\left[D_{5}\right]-6 a a$}<smiles>[2H]c1c([2H])c([2H])c(-c2ccccn2)c([2H])c1[2H]</smiles>

$\left[D_{5}\right]-6 \mathbf{a a}$
2- $\mathrm{BrC}_{8} \mathrm{H}_{17}$ (42ba) (1.5 equiv) $\left[\mathrm{RuCl}_{2}(p \text {-cymene })\right]_{2}(2.5 \mathrm{~mol} \%)$ $\mathrm{MesCO}_{2} \mathrm{H}$ (13a) (30 mol \%)

$\mathrm{K}_{2} \mathrm{CO}_{3}$ (2.0 equiv) 1,4-dioxane, $100^{\circ} \mathrm{C}, 20 \mathrm{~h}$

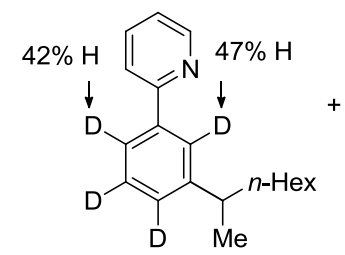

$\left[D_{n}\right]-147 a a$<smiles>[2H]c1c([2H])c([2H])c(-c2cccc[n+]2[2H])c([2H])c1[2H]</smiles>

$\left[D_{n}\right]-6 a a$

The general procedure $\mathbf{E}$ was followed, using $\left[\operatorname{RuCl}_{2}(p \text {-cymene })\right]_{2}(7.9 \mathrm{mg}, 0.013 \mathrm{mmol}, 2.5 \mathrm{~mol} \%)$, MesCO ${ }_{2} \mathrm{H}$ (13a) $(25 \mathrm{mg}, 0.15 \mathrm{mmol}, 23 \mathrm{~mol} \%),\left[\mathrm{D}_{5}\right]-6 a a(104 \mathrm{mg}, 0.65 \mathrm{mmol}$ ) and 2-bromooctane (42ba) $(288 \mathrm{mg}, 1.49 \mathrm{mmol}$ ). After $20 \mathrm{~h}$, purification by column chromatography ( $n$-hexane/EtOAc 19:1) yielded $\left[D_{n}\right]-147 a a(50 \mathrm{mg}, 29 \%)$ and reisolated $\left[D_{n}\right]-6 a a(55 \mathrm{mg}, 54 \%)$ as colorless oils.

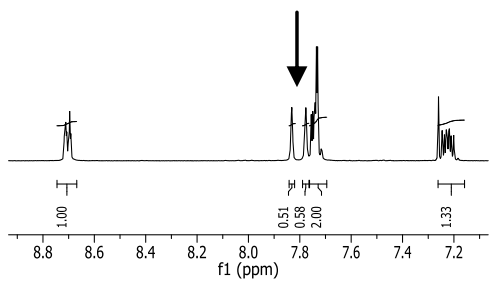

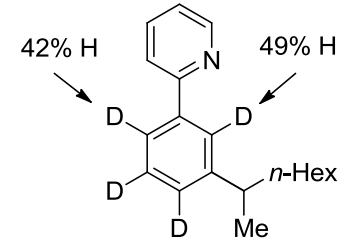

$\left[D_{n}\right]-147 a a$

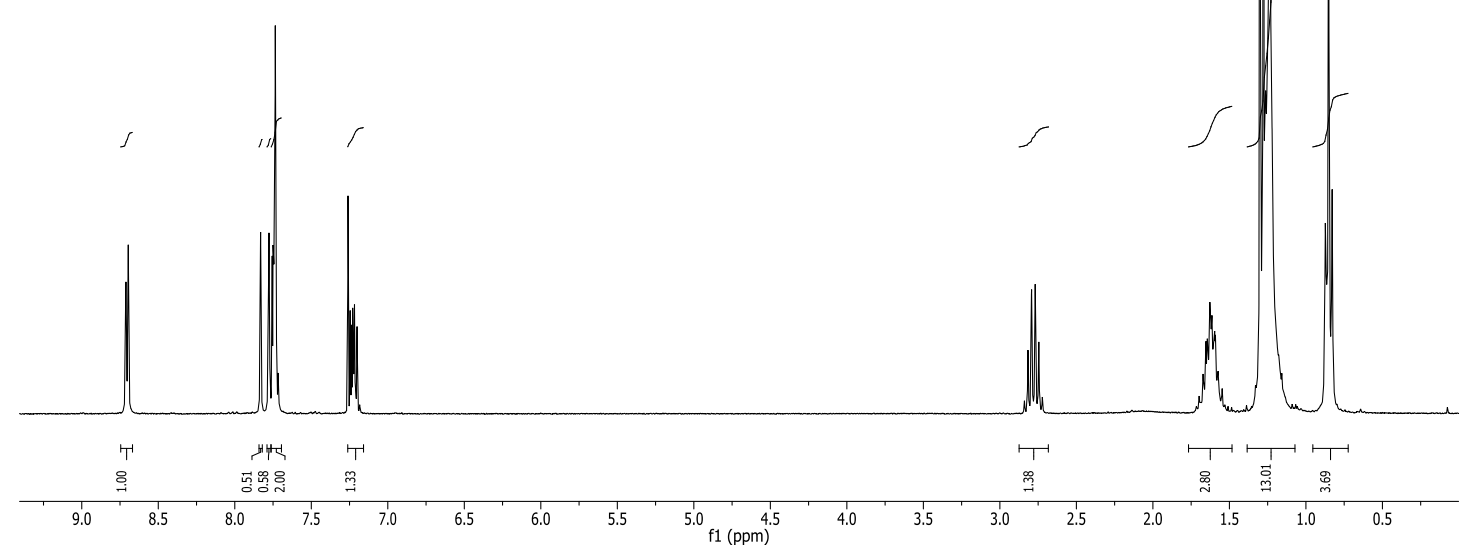




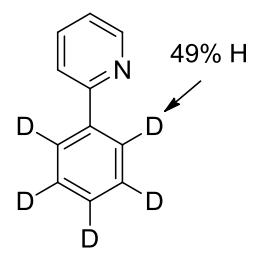

$\left[\mathrm{D}_{n}\right]-6 \mathrm{aa}$
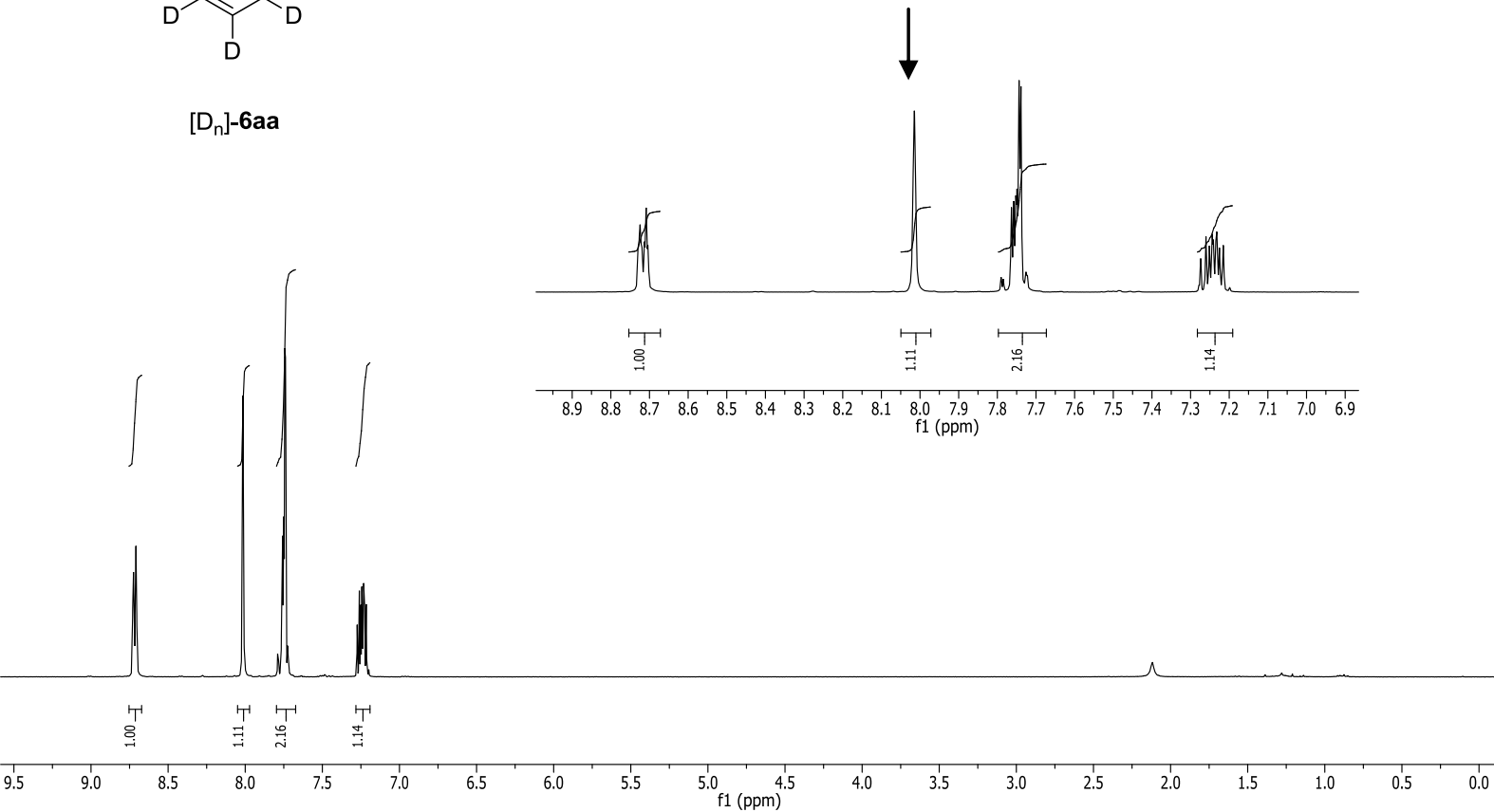

\section{Experiments with Deuterium-Labeled 2-(3,4,5-Trideuterophenyl)pyridine ([ $\left.\left.D_{3}\right]-6 a a\right)$}

\section{Synthesis of 2-(3,4,5-Trideuterophenyl)pyridine ([ $\left.\left.D_{3}\right]-6 a a\right)$}<smiles>[2H]c1c([2H])c([2H])c(-c2ccccn2)c([2H])c1[2H]</smiles>

$\left[\mathrm{D}_{5}\right]-6 \mathrm{aa}$

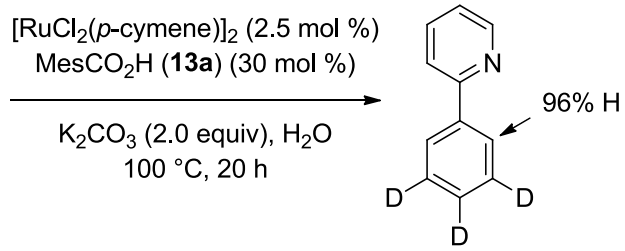

$\left[\mathrm{D}_{3}\right]-6 \mathrm{aa}$

A suspension of $\left[\mathrm{RuCl}_{2}(p \text {-cymene) }]_{2}(73.0 \mathrm{mg}, 0.119 \mathrm{mmol}, 2.5 \mathrm{~mol} \%), \mathrm{MesCO}_{2} \mathrm{H}\right.$ (13a) (244 mg, $1.49 \mathrm{mmol}, 31 \mathrm{~mol} \%), \mathrm{K}_{2} \mathrm{CO}_{3}(1.36 \mathrm{mg}, 9.86 \mathrm{mmol})$ and $\left[\mathrm{D}_{5}\right]-6 \mathrm{aa}(0.78 \mathrm{~g} 4.84 \mathrm{mmol})$ in degassed $\mathrm{H}_{2} \mathrm{O}$ $(20 \mathrm{~mL})$ was stirred under $\mathrm{N}_{2}$ for $20 \mathrm{~h}$ at $100{ }^{\circ} \mathrm{C}$. EtOAc $(50 \mathrm{~mL})$ and $\mathrm{H}_{2} \mathrm{O}(50 \mathrm{~mL})$ were added to the reaction mixture at ambient temperature. The separated aqueous phase was extracted with EtOAc $(2 \times 50 \mathrm{~mL})$. The combined organic layers were washed with brine $(50 \mathrm{~mL})$, dried over $\mathrm{Na}_{2} \mathrm{SO}_{4}$ and concentrated in vacuo. The remaining residue was purified by column chromatography on silica gel ( $n$-hexane/EtOAc 5:1) and Kugelrohr-distillation to yield [ $\left.\mathrm{D}_{3}\right]$-6aa $(0.56 \mathrm{~g}, 73 \%)$ as a colorless oil. 
${ }^{1} \mathrm{H}-\mathrm{NMR}\left(300 \mathrm{MHz}, \mathrm{CDCl}_{3}\right): \delta=8.74-8.65(\mathrm{~m}, 1 \mathrm{H}), 8.00(\mathrm{~s}, 2 \mathrm{H}), 7.82-7.69(\mathrm{~m}, 2 \mathrm{H}), 7.29-7.18(\mathrm{~m}, 1 \mathrm{H})$.

${ }^{13} \mathrm{C}-\mathrm{NMR}\left(75 \mathrm{MHz}, \mathrm{CDCl}_{3}\right): \delta=157.4\left(\mathrm{C}_{\mathrm{q}}\right), 149.6(\mathrm{CH}), 139.3\left(\mathrm{C}_{\mathrm{q}}\right), 136.7(\mathrm{CH}), 128.3\left(\mathrm{C}_{\mathrm{q}}\right), 128.0\left(\mathrm{C}_{\mathrm{q}}\right)$ $126.8(\mathrm{CH}), 122.1(\mathrm{CH}), 120.5(\mathrm{CH})$.

IR (ATR): $\tilde{v}=3053,3003,2272,2256,1582,1472,1420,783,741,610 \mathrm{~cm}^{-1}$.

MS (EI) m/z (relative intensity): 158 (100) [M+], 129 (12), 78 (14), 71 (12), 57 (29), 43 (60).

HR-MS (ESI) $m / z$ calculated for $\mathrm{C}_{11} \mathrm{H}_{6} \mathrm{D}_{3} \mathrm{~N}+\mathrm{H}^{+}: 159.1002$; found: 159.0995 .

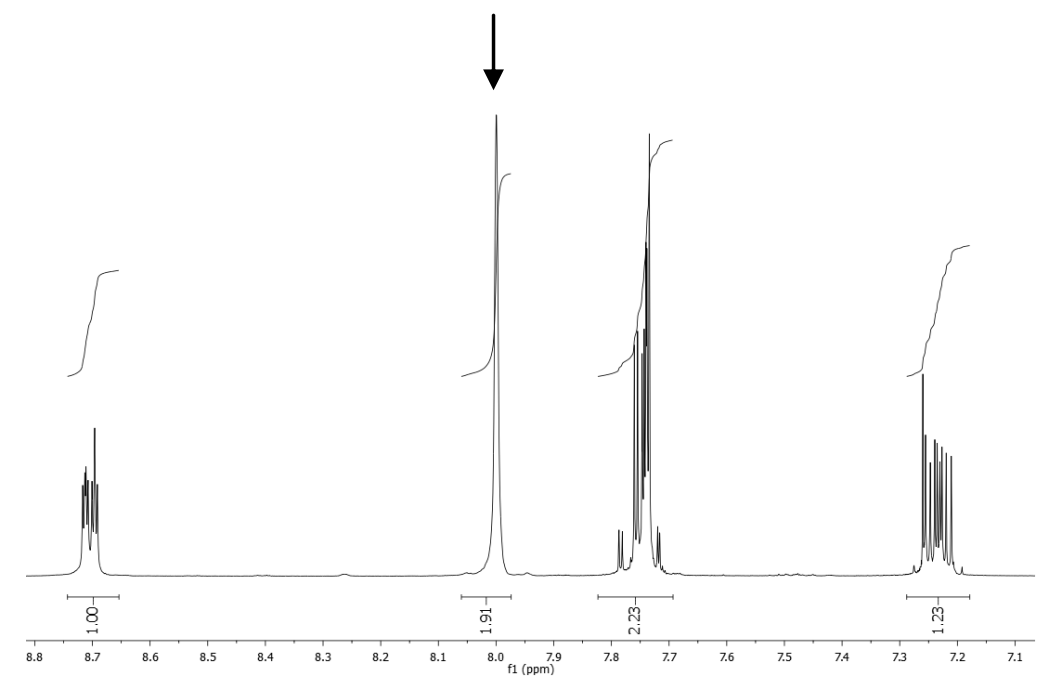

Synthesis of 2-[4,5-Dideutero-3-(pentan-2-yl)phenyl]pyridine ([D $]$-147ai)<smiles>[2H]c1cc(-c2ccccn2)cc([2H])c1[2H]</smiles>

$\left[\mathrm{D}_{3}\right]-6 \mathrm{aa}$<smiles>CCPC(C)Br</smiles>

42bi

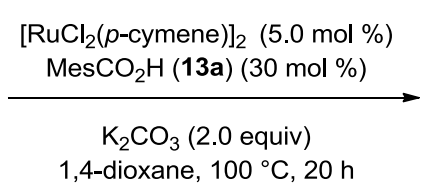

1,4-dioxane, $100{ }^{\circ} \mathrm{C}, 20 \mathrm{~h}$

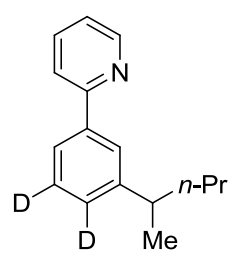

$\left[D_{2}\right]-147 a i$

The general procedure $\mathbf{E}$ was followed, using $\left[\mathrm{RuCl}_{2}(p \text {-cymene })\right]_{2}(16.3 \mathrm{mg}, 0.027 \mathrm{mmol}, 5.2 \mathrm{~mol} \%)$, MesCO ${ }_{2} \mathrm{H}$ (13a) (25 mg, $\left.0.15 \mathrm{mmol}, 29 \mathrm{~mol} \%\right),\left[\mathrm{D}_{3}\right]$-6aa $(82.4 \mathrm{mg}, 0.52 \mathrm{mmol}$ ) and 2-bromopentane (42bi) (219 mg, $1.45 \mathrm{mmol}$ ). After $20 \mathrm{~h}$, purification by column chromatography ( $n$-hexane/EtOAc 9:1) yielded $\left[D_{2}\right]$-147ai $(61 \mathrm{mg}, 52 \%$ ) as a colorless oil.

${ }^{1} \mathrm{H}-\mathrm{NMR}\left(300 \mathrm{MHz}, \mathrm{CDCl}_{3}\right): \delta=8.71(\mathrm{ddd}, J=4.8,1.4,1.4 \mathrm{~Hz}, 1 \mathrm{H}), 7.86(\mathrm{~d}, J=1.9 \mathrm{~Hz}, 1 \mathrm{H}), 7.79(\mathrm{~d}, J=$ $1.8 \mathrm{~Hz}, 1 \mathrm{H}), 7.76-7.67(\mathrm{~m}, 2 \mathrm{H}), 7.25-7.15(\mathrm{~m}, 1 \mathrm{H}), 2.82(\mathrm{qt}, J=7.0,6.9 \mathrm{~Hz}, 1 \mathrm{H}), 1.75-1.49(\mathrm{~m}, 2 \mathrm{H}), 1.41-$ $1.12(\mathrm{~m}, 2 \mathrm{H}), 1.26(\mathrm{~d}, J=6.9 \mathrm{~Hz}, 3 \mathrm{H}), 0.90(\mathrm{t}, J=7.2 \mathrm{~Hz}, 3 \mathrm{H})$. 
${ }^{13} \mathrm{C}-\mathrm{NMR}\left(126 \mathrm{MHz}, \mathrm{CDCl}_{3}\right): \delta=158.0\left(\mathrm{C}_{\mathrm{q}}\right), 149.7(\mathrm{CH}), 148.5\left(\mathrm{C}_{\mathrm{q}}\right), 139.5\left(\mathrm{C}_{\mathrm{q}}\right), 136.7(\mathrm{CH}), 128.4\left(\mathrm{t}, \mathrm{J}_{\mathrm{C}-\mathrm{D}}\right.$ $\left.=24 \mathrm{~Hz}, \mathrm{C}_{\mathrm{q}}\right), 127.3\left(\mathrm{t}, \mathrm{J}_{\mathrm{C}-\mathrm{D}}=24 \mathrm{~Hz}, \mathrm{C}_{\mathrm{q}}\right), 125.9(\mathrm{CH}), 124.4(\mathrm{CH}), 122.0(\mathrm{CH}), 120.8(\mathrm{CH}), 40.8\left(\mathrm{CH}_{2}\right), 39.9$ $(\mathrm{CH}), 22.4\left(\mathrm{CH}_{2}\right), 21.0\left(\mathrm{CH}_{3}\right), 14.3\left(\mathrm{CH}_{3}\right)$.

IR (ATR): $\tilde{v}=2957,2927,2871,1585,1560,1472,1426,907,782,732,587 \mathrm{~cm}^{-1}$.

MS (EI) m/z (relative intensity): 227 (37) [M+], 198 (11), 184 (100), 169 (54), 78 (11).

HR-MS (ESI) $m / z$ calculated for $\mathrm{C}_{16} \mathrm{H}_{17} \mathrm{D}_{2} \mathrm{~N}^{+}$: 227.1643; found: 227.1641 .
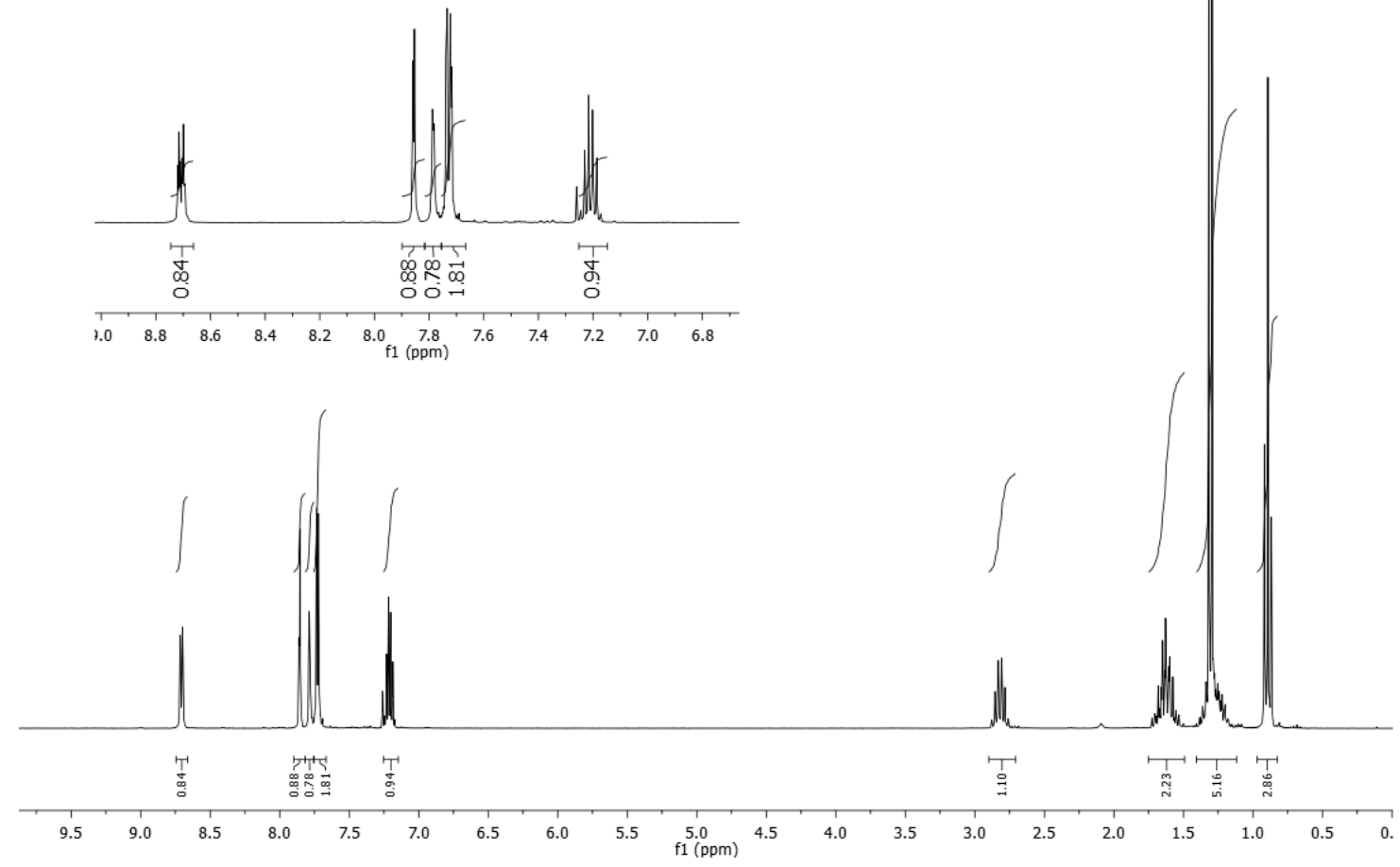

Intermolecular Competition Experiment between 2-(3,4,5-Trideuterophenyl)pyridine $\left(\left[\mathrm{D}_{3}\right]-6 \mathrm{aa}\right)$ and

\section{2-Phenylpyridine (6aa)}<smiles>c1ccc(-c2ccccn2)cc1</smiles><smiles>[2H]c1cc(-c2ccccn2)cc([2H])c1[2H]</smiles>

(2.0 equiv each)

6 aa

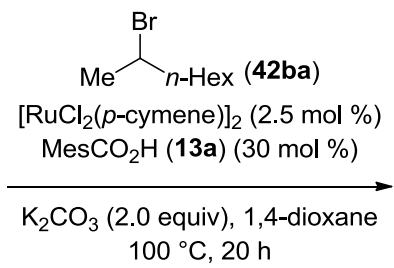
$100{ }^{\circ} \mathrm{C}, 20 \mathrm{~h}$

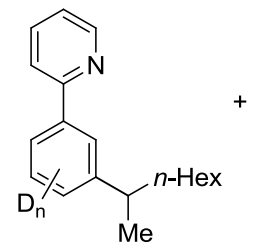

$26 \%$<smiles>c1ccc(-c2ccccn2)nc1</smiles>

$46 \%$

$\left[D_{0}\right]-147 a a:\left[D_{2}\right]-147$ aa $\quad\left[D_{0}\right]-6 a a:\left[D_{3}\right]-6 a a$ $=1: 1$

A suspension of $\left[\mathrm{RuCl}_{2}(p \text {-cymene })\right]_{2} \quad(7.90 \mathrm{mg}, 0.013 \mathrm{mmol}, 2.5 \mathrm{~mol} \%), \mathrm{MesCO}_{2} \mathrm{H} \quad(25.3 \mathrm{mg}$, $0.15 \mathrm{mmol}, 30 \mathrm{~mol} \%), \mathrm{K}_{2} \mathrm{CO}_{3}$ (139 mg, $1.01 \mathrm{mmol}, 2.0$ equiv), 6aa (162 mg, $1.05 \mathrm{mmol}$ ), [D $\mathrm{D}_{3}$-6aa (155 mg $0.93 \mathrm{mmol}$ ) and 42 ba (106 mg, $0.55 \mathrm{mmol}$ ) in 1,4-dioxane $\left(4.0 \mathrm{~mL}\right.$ ) was stirred under $\mathrm{N}_{2}$ for 
$20 \mathrm{~h}$ at $100{ }^{\circ} \mathrm{C}$. EtOAc $(50 \mathrm{~mL})$ and $\mathrm{H}_{2} \mathrm{O}(50 \mathrm{~mL})$ were added to the reaction mixture at ambient temperature. The separated aqueous phase was extracted with EtOAc $(2 \times 50 \mathrm{~mL})$. The combined organic layers were washed with brine $(50 \mathrm{~mL})$, dried over $\mathrm{Na}_{2} \mathrm{SO}_{4}$ and concentrated in vacuo. The remaining residue was purified by column chromatography on silica gel ( $n$-hexane/EtOAc 19:1) to yield a mixture of $\left[D_{0}\right]-147$ aa and $\left[D_{2}\right]-147$ aa $\left({ }^{1} \mathrm{H}-\mathrm{NMR}\right.$ ratio $\left.1: 1,38 \mathrm{mg}, 26 \%\right)$ and a mixture of reisolated $\left[\mathrm{D}_{0}\right]-6 \mathrm{aa}$ and $\left[\mathrm{D}_{3}\right]-6 \mathrm{aa}\left({ }^{1} \mathrm{H}-\mathrm{NMR}\right.$ ratio $\left.1: 1,47 \mathrm{mg}, 46 \%\right)$. 


\subsection{The Analytical Data for the Ruthenium-Catalyzed Oxidative Annulations}

Synthesis of 3,4-Bis(4-methoxyphenyl)-2-methylisoquinolin-1(2H)-one (180ab)<smiles>COc1ccc(-c2c(-c3ccc(OC)cc3)n(C)c(=O)c3ccccc23)cc1</smiles>

The general procedure $\mathbf{F}$ was followed using $\left[\operatorname{RuCl}_{2}(p \text {-cymene })\right]_{2}(15 \mathrm{mg}, 0.025 \mathrm{mmol}, 5.0 \mathrm{~mol} \%)$, $\mathrm{N}$-methylbenzamide (86a) $\quad(68.0 \mathrm{mg}, 0.50 \mathrm{mmol})$ and 1,2-bis(4-methoxyphenyl)ethyne (88b) (194.8 $\mathrm{mg}, 0.82 \mathrm{mmol}$ ). After $22 \mathrm{~h}$, purification by column chromatography ( $n$-hexane/EtOAc 3:1) gave 180ab (104 mg, 56\%) as an orange solid.

M.r.: $160-162^{\circ} \mathrm{C}$.

${ }^{1} \mathrm{H}-\mathrm{NMR}\left(300 \mathrm{MHz}, \mathrm{CDCl}_{3}\right): \delta=8.54(\mathrm{dd}, J=7.8,1.7 \mathrm{~Hz}, 1 \mathrm{H}), 7.59-7.41(\mathrm{~m}, 2 \mathrm{H}), 7.20-7.14(\mathrm{~m}, 1 \mathrm{H})$, 7.09-6.90 (m, 4H), 6.84-6.69 (m, 4H), $3.76(\mathrm{~s}, 6 \mathrm{H}), 3.35(\mathrm{~s}, 3 \mathrm{H})$.

${ }^{13} \mathrm{C}$-NMR $\left(75 \mathrm{MHz}, \mathrm{CDCl}_{3}\right): \delta=162.8\left(\mathrm{C}_{\mathrm{q}}\right), 159.1\left(\mathrm{C}_{\mathrm{q}}\right), 158.1\left(\mathrm{C}_{\mathrm{q}}\right), 141.3\left(\mathrm{C}_{\mathrm{q}}\right), 137.5\left(\mathrm{C}_{\mathrm{q}}\right), 132.5(\mathrm{CH})$, $131.9(\mathrm{CH}), 131.1(\mathrm{CH}), 128.9\left(\mathrm{C}_{\mathrm{q}}\right), 127.8(\mathrm{CH}), 127.6\left(\mathrm{C}_{\mathrm{q}}\right), 126.4(\mathrm{CH}), 125.3(\mathrm{CH}), 124.9\left(\mathrm{C}_{\mathrm{q}}\right), 118.7$ $\left(\mathrm{C}_{\mathrm{q}}\right), 113.6(\mathrm{CH}), 113.4(\mathrm{CH}), 55.1\left(\mathrm{CH}_{3}\right), 55.1\left(\mathrm{CH}_{3}\right), 34.3\left(\mathrm{CH}_{3}\right)$.

IR (ATR): $\tilde{v}=3002,2957,2925,2853,1788,1644,1506,1328,1291,1173,862,731 \mathrm{~cm}^{-1}$. MS (EI) $m / z$ (relative intensity): 371 (100) [M+], 355 (11), 267 (9), 239 (16), 165 (12), 135 (16). HR-MS (EI) $\mathrm{m} / \mathrm{z}$ calculated for $\mathrm{C}_{24} \mathrm{H}_{21} \mathrm{NO}_{3}{ }^{+}: 371.1521$; found: 371.1515 .

The spectral data were in accordance with those reported in the literature. ${ }^{212}$

Synthesis of 2-Methyl-3,4-di-p-tolylisoquinolin-1(2H)-one (180ac)<smiles>Cc1ccc(-c2c(-c3ccc(C)cc3)n(C)c(=O)c3ccccc23)cc1</smiles>

${ }^{212}$ Hyster, T. K.; Rovis, T. J. Am. Chem. Soc. 2010, 132, 10565-10569. 
The general procedure $\mathbf{F}$ was followed using $\left[\mathrm{RuCl}_{2}(p \text {-cymene })\right]_{2}(15 \mathrm{mg}, 0.025 \mathrm{mmol}, 5.0 \mathrm{~mol} \%), \mathrm{N}$ methylbenzamide $(86 \mathrm{a})(66.7 \mathrm{mg}, 0.49 \mathrm{mmol})$ and 1,2-di-p-tolylethyne $(88 \mathrm{c})(207.1 \mathrm{mg}, 1.00 \mathrm{mmol})$. After $22 \mathrm{~h}$, purification by column chromatography ( $n$-hexane/EtOAc 4:1) gave 180ac (118 mg, 71\%) as a white solid.

M.r.: $194-197^{\circ} \mathrm{C}$.

${ }^{1} \mathrm{H}-\mathrm{NMR}\left(300 \mathrm{MHz}, \mathrm{CDCl}_{3}\right): \delta=8.53(\mathrm{~d}, J=7.1 \mathrm{~Hz}, 1 \mathrm{H}), 7.54-7.39(\mathrm{~m}, 2 \mathrm{H}), 7.07-6.85(\mathrm{~m}, 9 \mathrm{H}), 3.30(\mathrm{~s}$, $3 \mathrm{H}), 2.26(\mathrm{~s}, 6 \mathrm{H})$.

${ }^{13} \mathrm{C}$-NMR $\left(75 \mathrm{MHz}, \mathrm{CDCl}_{3}\right): \delta=162.8\left(\mathrm{C}_{\mathrm{q}}\right), 141.3\left(\mathrm{C}_{\mathrm{q}}\right), 137.8\left(\mathrm{C}_{\mathrm{q}}\right), 137.4\left(\mathrm{C}_{\mathrm{q}}\right), 136.2\left(\mathrm{C}_{\mathrm{q}}\right), 133.5\left(\mathrm{C}_{\mathrm{q}}\right)$, $132.3\left(\mathrm{C}_{\mathrm{q}}\right), 131.9(\mathrm{CH}), 131.3(\mathrm{CH}), 129.7(\mathrm{CH}), 128.9(\mathrm{CH}), 128.6(\mathrm{CH}), 127.7(\mathrm{CH}), 126.4(\mathrm{CH}), 125.4$ $(\mathrm{CH}), 124.9\left(\mathrm{C}_{\mathrm{q}}\right), 118.7\left(\mathrm{C}_{\mathrm{q}}\right), 34.3\left(\mathrm{CH}_{3}\right), 21.2\left(\mathrm{CH}_{3}\right), 21.2\left(\mathrm{CH}_{3}\right)$.

IR (ATR): $\tilde{v}=3022,2947,2919,2863,1640,1480,1284,1022,996,817,705,690 \mathrm{~cm}^{-1}$. MS (EI) $m / z$ (relative intensity): 339 (100) [M+], 246 (8), 178 (12), 132 (17), 91 (13).

HR-MS (EI) $m / z$ calculated for $\mathrm{C}_{24} \mathrm{H}_{21} \mathrm{NO}^{+}$: 339.1623; found: 339.1617 .

\section{Synthesis of 3,4-Bis(4-fluorophenyl)-2-methylisoquinolin-1(2H)-one (180ad)}<smiles>Cn1c(-c2ccc(F)cc2)c(-c2ccc(F)cc2)c2ccccc2c1=O</smiles>

The general procedure $\mathbf{F}$ was followed using $\left[\mathrm{RuCl}_{2}(p \text {-cymene })\right]_{2}(15 \mathrm{mg}, 0.025 \mathrm{mmol}, 5.0 \mathrm{~mol} \%), \mathrm{N}$ methylbenzamide (86a) $(66.6 \mathrm{mg}, 0.49 \mathrm{mmol})$ and 1,2-bis(4-fluorophenyl)ethyne (88d) $(217.1 \mathrm{mg}$, $1.01 \mathrm{mmol}$ ). After $22 \mathrm{~h}$, purification by column chromato-graphy ( $n$-hexane/EtOAc 3:1) gave 180ad (107 $\mathrm{mg}, 61 \%)$ as a white solid.

M.r.: $172-173^{\circ} \mathrm{C}$.

${ }^{1} \mathrm{H}-\mathrm{NMR}\left(300 \mathrm{MHz}, \mathrm{CDCl}_{3}\right): \delta=8.54(\mathrm{~d}, J=7.2 \mathrm{~Hz}, 1 \mathrm{H}), 7.56-7.45(\mathrm{~m}, 2 \mathrm{H}), 6.99(\mathrm{~m}, 9 \mathrm{H}), 3.33(\mathrm{~s}, 3 \mathrm{H})$.

${ }^{13} \mathrm{C}-\mathrm{NMR}\left(75 \mathrm{MHz}, \mathrm{CDCl}_{3}\right): \delta=162.6\left(\mathrm{C}_{\mathrm{q}}\right), 162.2\left(\mathrm{~d}, \mathrm{~J}_{\mathrm{C}-\mathrm{F}}=248 \mathrm{~Hz}, \mathrm{C}_{\mathrm{q}}\right), 161.6\left(\mathrm{~d}, \mathrm{~J}_{\mathrm{C}-\mathrm{F}}=244 \mathrm{~Hz}, \mathrm{C}_{\mathrm{q}}\right), 140.5$ $\left(C_{q}\right), 136.93\left(C_{q}\right), 133.0\left(d, J_{C-F}=8 \mathrm{~Hz}, C H\right), 132.2\left(C_{q}\right), 131.7\left(d, J_{C-F}=9 \mathrm{~Hz}, C H\right), 131.0\left(d, J_{C-F}=3 \mathrm{~Hz}, C_{q}\right)$, $130.7(\mathrm{CH}), 127.9(\mathrm{CH}), 126.9(\mathrm{CH}), 125.1(\mathrm{CH}), 125.0\left(\mathrm{C}_{\mathrm{q}}\right), 118.2\left(\mathrm{C}_{\mathrm{q}}\right), 115.5\left(\mathrm{~d}, J_{\mathrm{C}-\mathrm{F}}=21 \mathrm{~Hz}, \mathrm{CH}\right), 115.2$ $\left(\mathrm{d}, J_{\mathrm{C}-\mathrm{F}}=20 \mathrm{~Hz}, \mathrm{CH}\right), 34.3\left(\mathrm{CH}_{3}\right)$.

${ }^{19}$ F-NMR $\left(283 \mathrm{MHz}, \mathrm{CDCl}_{3}\right): \delta=-112.0--112.2(\mathrm{~m}),-114.7--115.1(\mathrm{~m})$. 
IR (ATR): $\tilde{v}=3058,3040,2855,1639,1603,1224,1159,1054,866,771,728,701,688 \mathrm{~cm}^{-1}$. MS (EI) m/z (relative intensity): 346 (100) [M- $\left.\mathrm{H}^{+}\right], 303$ (8), 250 (10), 183 (14), 136 (12), 95 (13). HR-MS (EI) $\mathrm{m} / \mathrm{z}$ calculated for $\mathrm{C}_{22} \mathrm{H}_{14} \mathrm{~F}_{2} \mathrm{NO}-\mathrm{H}^{+}$: 346.1043; found: 346.1043 .

Synthesis of 4-Ethyl-2-methyl-3-phenylisoquinolin-1(2H)-one (180ae) and 3-Ethyl-2-methyl-4phenylisoquinolin-1(2H)-one (180ae')

The general procedure $\mathbf{F}$ was followed using $\left[\mathrm{RuCl}_{2}(p \text {-cymene })\right]_{2}(15 \mathrm{mg}, 0.025 \mathrm{mmol}, 5.0 \mathrm{~mol} \%), N$ methylbenzamide (86a) $(68.1 \mathrm{mg}, 0.50 \mathrm{mmol})$ and but-1-yn-1-ylbenzene $(88 \mathrm{e})(140 \mathrm{mg}, 1.07 \mathrm{mmol})$. After $22 \mathrm{~h}$, purification by column chromatography ( $n$-hexane/EtOAc 9:1 to 4:1) yielded 180ae and 180ae' as a mixture (106 mg, 80\%, ratio $7.2: 1.0$ by ${ }^{1} \mathrm{H}-\mathrm{NMR}$ ) and was isolated as a grey solid. (NMR spectra were analyzed only for the major regioisomer 180ae').<smiles></smiles>

(180ae)<smiles>CCc1c(-c2ccccc2)c2ccccc2c(=O)n1C</smiles>

(180ae')

Major isomer:

noe:<smiles>CCCCc1ccccc1-c1c(CC)c2ccccc2c(=O)n1C</smiles>

\section{(180ae')}

${ }^{1} \mathrm{H}-\mathrm{NMR}\left(300 \mathrm{MHz}, \mathrm{CDCl}_{3}\right): \delta=8.52(\mathrm{ddd}, J=8.1,1.5,0.7 \mathrm{~Hz}, 1 \mathrm{H}), 7.76-7.58(\mathrm{~m}, 2 \mathrm{H}), 7.54-7.30(\mathrm{~m}$, $4 \mathrm{H}), 7.28-7.19(\mathrm{~m}, 2 \mathrm{H}), 3.19(\mathrm{~s}, 3 \mathrm{H}), 2.39(\mathrm{q}, J=7.5 \mathrm{~Hz}, 2 \mathrm{H}), 1.01(\mathrm{t}, J=7.4 \mathrm{~Hz}, 3 \mathrm{H})$.

${ }^{13} \mathrm{C}-\mathrm{NMR}\left(75 \mathrm{MHz}, \mathrm{CDCl}_{3}\right): \delta=162.3\left(\mathrm{C}_{\mathrm{q}}\right), 140.0\left(\mathrm{C}_{\mathrm{q}}\right), 135.9\left(\mathrm{C}_{\mathrm{q}}\right), 135.4\left(\mathrm{C}_{\mathrm{q}}\right), 131.9(\mathrm{CH}), 128.9(\mathrm{CH})$, $128.8(\mathrm{CH}), 128.6(\mathrm{CH}), 128.2(\mathrm{CH}), 126.1(\mathrm{CH}), 125.5\left(\mathrm{C}_{\mathrm{q}}\right), 123.0(\mathrm{CH}), 116.4\left(\mathrm{C}_{\mathrm{q}}\right), 33.9\left(\mathrm{CH}_{3}\right), 21.4$ $\left(\mathrm{CH}_{2}\right), 14.7\left(\mathrm{CH}_{3}\right)$.

IR (ATR): $\tilde{v}=2965,2929,2872,1643,1556,1328,761,700,656,534 \mathrm{~cm}^{-1}$. MS (EI) m/z (relative intensity): 263 (77) [ $\left.\mathrm{M}^{+}\right], 248$ (100), 233 (20), 178 (11), 77 (13).

HR-MS (EI) $m / z$ calculated for $\mathrm{C}_{18} \mathrm{H}_{17} \mathrm{NO}^{+}: 263.1310$; found: 263.1308 . 
Synthesis of 2-Methyl-3-phenyl-4-n-propylisoquinolin-1(2H)-one (180af') \& 2-Methyl-4-phenyl-3-npropylisoquinolin-1(2H)-one (180af)

The general procedure $\mathbf{F}$ was followed using $\left[\mathrm{RuCl}_{2}(p \text {-cymene })\right]_{2}(16 \mathrm{mg}, 0.026 \mathrm{mmol}, 5.1 \mathrm{~mol} \%)$, $\mathrm{N}$-methylbenzamide (86a) $(67.5 \mathrm{mg}, 0.50 \mathrm{mmol})$ and pent-1-yn-1-ylbenzene (88f) (155 mg, $1.07 \mathrm{mmol}$ ). After $22 \mathrm{~h}$, purification by column chromatography ( $n$-hexane/EtOAc 4:1) yielded 180af' and 180af as a mixture (128 mg, 92\%, ratio 9.7:1.0 by ${ }^{1} \mathrm{H}-\mathrm{NMR}$ ) as a white solid.( NMR spectra were analyzed only for the major regioisomer 180af'.)<smiles>CCCc1c(-c2ccccc2)n(C)c(=O)c2ccccc12</smiles>

(180af) (180af')

Major isomer:

nOe:

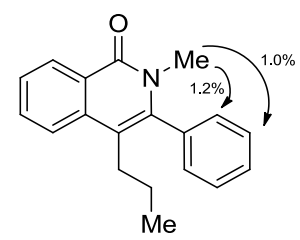

(180af')

${ }^{1} \mathrm{H}-\mathrm{NMR}\left(300 \mathrm{MHz}, \mathrm{CDCl}_{3}\right): \delta=8.50(\mathrm{dd}, J=7.8,1.0 \mathrm{~Hz}, 1 \mathrm{H}), 7.68-7.53(\mathrm{~m}, 2 \mathrm{H}), 7.49-7.32(\mathrm{~m}, 4 \mathrm{H}), 7.21$ $(\mathrm{dd}, J=7.5,2.0 \mathrm{~Hz}, 2 \mathrm{H}), 3.18(\mathrm{~s}, 3 \mathrm{H}), 2.37-2.23(\mathrm{~m}, 2 \mathrm{H}), 1.53-1.31(\mathrm{~m}, 2 \mathrm{H}), 0.74(\mathrm{t}, J=7.3 \mathrm{~Hz}, 3 \mathrm{H})$.

${ }^{13} \mathrm{C}-\mathrm{NMR}\left(75 \mathrm{MHz}, \mathrm{CDCl}_{3}\right): \delta=162.2\left(\mathrm{C}_{\mathrm{q}}\right), 140.2\left(\mathrm{C}_{\mathrm{q}}\right), 136.1\left(\mathrm{C}_{\mathrm{q}}\right), 135.4\left(\mathrm{C}_{\mathrm{q}}\right), 131.8(\mathrm{CH}), 129.0(\mathrm{CH})$, $128.7(\mathrm{CH}), 128.5(\mathrm{CH}), 128.1(\mathrm{CH}), 126.0(\mathrm{CH}), 125.4\left(\mathrm{C}_{\mathrm{q}}\right), 123.0(\mathrm{CH}), 115.1\left(\mathrm{C}_{\mathrm{q}}\right), 33.9\left(\mathrm{CH}_{3}\right), 30.4$ $\left(\mathrm{CH}_{2}\right), 23.5\left(\mathrm{CH}_{2}\right), 14.1\left(\mathrm{CH}_{3}\right)$.

IR (ATR): $\tilde{\boldsymbol{V}}=2953,2869,1640,1588,1486,1328,1072,1031,765,702,437 \mathrm{~cm}^{-1}$. MS (EI) m/z (relative intensity): 277 (43) [ $\left.\mathrm{M}^{+}\right], 248$ (100), 233 (15), 178 (9), 77 (9). HR-MS (EI): $m / z$ calculated for $\mathrm{C}_{19} \mathrm{H}_{19} \mathrm{NO}^{+}:$277.1467; found: 277.1466 .

Synthesis of 3-(4-Fluorophenyl)-4-n-hexyl-2-methylisoquinolin-1(2H)-one (180ag) and 4-(4-Fluorophenyl)-3-n-hexyl-2-methylisoquinolin-1(2H)-one (180ag')

The general procedure $\mathbf{F}$ was followed using $\left[\mathrm{RuCl}_{2}(p \text {-cymene })\right]_{2}(15 \mathrm{mg}, 0.025 \mathrm{mmol}, 5.0 \mathrm{~mol} \%), \mathrm{N}$ methylbenzamide (86a) $(68.1 \mathrm{mg}, 0.50 \mathrm{mmol}$ ) and 1-fluoro-4-(oct-1-ynyl)benzene $(\mathbf{8 8 g})(261 \mathrm{mg}$, 
$1.23 \mathrm{mmol}$ ). After $22 \mathrm{~h}$, purification by column chromatography ( $n$-hexane/EtOAc $5: 1$ to $3: 1$ ) yielded 180ag and 180ag' as a mixture (62 mg, 37\%, ratio $7.6: 1.0$ by ${ }^{1} \mathrm{H}-\mathrm{NMR}$ ) as a brown oil. (NMR spectra were analyzed only for the major regioisomer 180ag'.)

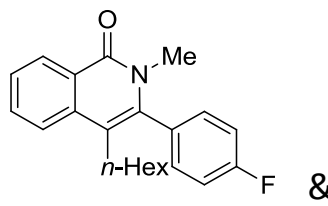

$(180 \mathrm{ag})$<smiles></smiles>

(180ag)

Major isomer:

noe:

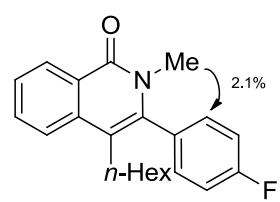

\section{(180ag')}

${ }^{1} \mathrm{H}-\mathrm{NMR}\left(300 \mathrm{MHz}, \mathrm{CDCl}_{3}\right): \delta=8.53(\mathrm{dd}, J=8.1,1.1 \mathrm{~Hz}, 1 \mathrm{H}), 7.72-7.65(\mathrm{~m}, 2 \mathrm{H}), 7.55-7.45(\mathrm{~m}, 1 \mathrm{H})$, 7.31-7.14 (m, 4H), $3.23(\mathrm{~s}, 3 \mathrm{H}), 2.41-2.30(\mathrm{~m}, 2 \mathrm{H}), 1.54-1.31(\mathrm{~m}, 2 \mathrm{H}), 1.31-1.02(\mathrm{~m}, 6 \mathrm{H}), 0.82(\mathrm{t}, J=$ $6.9 \mathrm{~Hz}, 3 \mathrm{H})$.

${ }^{13} \mathrm{C}-\mathrm{NMR}\left(75 \mathrm{MHz}, \mathrm{CDCl}_{3}\right): \delta=162.7\left(\mathrm{~d}, \mathrm{~J}_{\mathrm{C}-\mathrm{F}}=249 \mathrm{~Hz}, \mathrm{C}_{\mathrm{q}}\right), 162.4\left(\mathrm{C}_{\mathrm{q}}\right), 139.1\left(\mathrm{C}_{\mathrm{q}}\right), 136.1\left(\mathrm{C}_{\mathrm{q}}\right), 132.1(\mathrm{CH})$, $131.5\left(\mathrm{~d}, J_{\mathrm{C}-\mathrm{F}}=4 \mathrm{~Hz}, \mathrm{C}_{\mathrm{q}}\right), 131.1\left(\mathrm{~d}, \mathrm{~J}_{\mathrm{C}-\mathrm{F}}=8 \mathrm{~Hz}, \mathrm{CH}\right), 128.3(\mathrm{CH}), 126.4(\mathrm{CH}), 125.6\left(\mathrm{C}_{\mathrm{q}}\right), 123.2(\mathrm{CH}), 116.0$ (d, J $\left.J_{\text {-F }}=22 \mathrm{~Hz}, \mathrm{CH}\right), 116.0\left(\mathrm{C}_{q}\right), 34.0\left(\mathrm{CH}_{3}\right), 31.2\left(\mathrm{CH}_{2}\right), 30.2\left(\mathrm{CH}_{2}\right), 29.4\left(\mathrm{CH}_{2}\right), 28.4\left(\mathrm{CH}_{2}\right), 22.4\left(\mathrm{CH}_{2}\right)$, $13.9\left(\mathrm{CH}_{3}\right)$.

IR (ATR): $\widetilde{v}=2954,2927,2860,1641,1590,1330,1219,1160,858,776,708,542 \mathrm{~cm}^{-1}$. MS (El) m/z (relative intensity): 337 (53) [M+], 280 (15), 266 (100), 251 (22), 196 (10).

HR-MS (EI) $m / z$ calculated for $\mathrm{C}_{22} \mathrm{H}_{24} \mathrm{FNO}^{+}: 337.1842$; found: 337.1839 .

\section{Synthesis of 3-(4-Methoxyphenyl)-2,4-dimethylisoquinolin-1(2H)-one (180ah')}<smiles>COc1ccc(-c2c(C)c3ccccc3c(=O)n2C)cc1</smiles> 
The general procedure $\mathbf{F}$ was followed using $\left[\mathrm{RuCl}_{2}(p \text {-cymene })\right]_{2}(15 \mathrm{mg}, 0.025 \mathrm{mmol}, 4.8 \mathrm{~mol} \%)$, $\mathrm{N}$-methylbenzamide $(\mathbf{8 6 a})(70.0 \mathrm{mg}, 0.52 \mathrm{mmol})$ and 1-methoxy-4-(prop-1-ynyl)benzene (88h) ( $144.6 \mathrm{mg}, 0.99 \mathrm{mmol}$ ). After $22 \mathrm{~h}$, purification by column chromatography ( $n$-hexane/EtOAc 4:1 to 2:1) yielded 180ah' (96 mg, 66\%) as a yellow oil.

${ }^{1} \mathrm{H}-\mathrm{NMR}\left(300 \mathrm{MHz}, \mathrm{CDCl}_{3}\right): \delta=8.50(\mathrm{~d}, J=8.0 \mathrm{~Hz}, 1 \mathrm{H}), 7.72-7.58(\mathrm{~m}, 2 \mathrm{H}), 7.53-7.39(\mathrm{~m}, 1 \mathrm{H}), 7.21-$ $7.08(\mathrm{~m}, 2 \mathrm{H}), 7.06-6.92(\mathrm{~m}, 2 \mathrm{H}), 3.84(\mathrm{~s}, 3 \mathrm{H}), 3.25(\mathrm{~s}, 3 \mathrm{H}), 2.01(\mathrm{~s}, 3 \mathrm{H})$.

${ }^{13} \mathrm{C}$-NMR $\left(75 \mathrm{MHz}, \mathrm{CDCl}_{3}\right): \delta=162.5\left(\mathrm{C}_{\mathrm{q}}\right), 159.6\left(\mathrm{C}_{\mathrm{q}}\right), 140.0\left(\mathrm{C}_{\mathrm{q}}\right), 137.0\left(\mathrm{C}_{\mathrm{q}}\right), 131.9(\mathrm{CH}), 130.5(\mathrm{CH})$, $128.0(\mathrm{CH}), 128.0\left(\mathrm{C}_{\mathrm{q}}\right), 126.2(\mathrm{CH}), 125.2\left(\mathrm{C}_{\mathrm{q}}\right), 123.1(\mathrm{CH}), 114.2(\mathrm{CH}), 110.7\left(\mathrm{C}_{\mathrm{q}}\right), 55.2\left(\mathrm{CH}_{3}\right), 34.1$ $\left(\mathrm{CH}_{3}\right), 14.8\left(\mathrm{CH}_{3}\right)$.

IR (ATR): $\tilde{V}=3038,2985,2952,2935,1642,1449,1411,1342,1107,1029,693,639 \mathrm{~cm}^{-1}$.

MS (EI) m/z (relative intensity): 278 (100) [M-H'], 263 (53), 248 (20), 220 (11), 178 (10), 165 (11), 148 (19), 86 (15), 77 (16).

HR-MS (EI) $m / z$ calculated for $\mathrm{C}_{18} \mathrm{H}_{17} \mathrm{NO}_{2}^{+}: 279.1259$; found: 279.1263 .

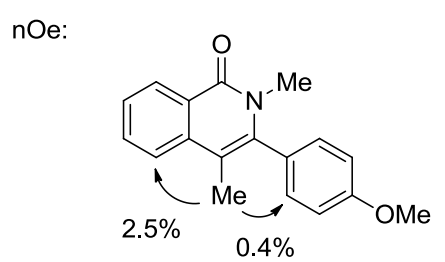

Synthesis of 2,4-Dimethyl-3-propylisoquinolin-1(2H)-one (180ai) and 2,3-Dimethyl-4-propylisoquinolin-1(2H)-one (180ai')

The general procedure $\mathbf{F}$ was followed using $\left[\mathrm{RuCl}_{2}(p \text {-cymene })\right]_{2}(15 \mathrm{mg}, 0.025 \mathrm{mmol}, 4.9 \mathrm{~mol} \%) \mathrm{N}$ methylbenzamide (86a) $(68.7 \mathrm{mg}, 0.51 \mathrm{mmol})$ and hex-2-yne (88i) $(89.3 \mathrm{mg}, 1.09 \mathrm{mmol})$. After $22 \mathrm{~h}$, purification by column chromatography ( $n$-hexane/EtOAc $4: 1$ ) yielded 180ai ( $26 \mathrm{mg}, 24 \%$ ) as a light brown oil and 180ai' (37 mg, 34\%) as a white solid.

nOe:

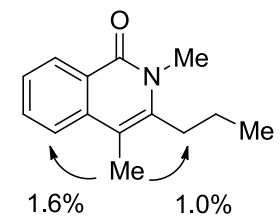

(180ai)

${ }^{1} \mathrm{H}-\mathrm{NMR}\left(300 \mathrm{MHz}, \mathrm{CDCl}_{3}\right): \delta=8.43(\mathrm{~d}, J=8.0 \mathrm{~Hz}, 1 \mathrm{H}), 7.62(\mathrm{~d}, J=3.4 \mathrm{~Hz}, 2 \mathrm{H}), 7.46-7.34(\mathrm{~m}, 1 \mathrm{H}), 3.65$ (s, 3H), 2.80-2.69 (m, 2H), $2.30(\mathrm{~s}, 3 \mathrm{H}), 1.68-1.51(\mathrm{~m}, 2 \mathrm{H}), 1.05(\mathrm{t}, J=7.3 \mathrm{~Hz}, 3 \mathrm{H})$. 
${ }^{13} \mathrm{C}-\mathrm{NMR}\left(75 \mathrm{MHz}, \mathrm{CDCl}_{3}\right): \delta=163.0\left(\mathrm{C}_{\mathrm{q}}\right), 139.7\left(\mathrm{C}_{\mathrm{q}}\right), 137.1\left(\mathrm{C}_{\mathrm{q}}\right), 131.9(\mathrm{CH}), 128.1(\mathrm{CH}), 125.7(\mathrm{CH})$, $124.5\left(\mathrm{C}_{\mathrm{q}}\right), 122.6(\mathrm{CH}), 108.9\left(\mathrm{C}_{\mathrm{q}}\right), 32.0\left(\mathrm{CH}_{2}\right), 31.3\left(\mathrm{CH}_{3}\right), 22.1\left(\mathrm{CH}_{2}\right), 14.0\left(\mathrm{CH}_{3}\right), 13.6\left(\mathrm{CH}_{3}\right)$.

IR (ATR): $\tilde{v}=3069,2961,2931,2872,1772,1642,1589,1486,1457,1413,1370,1323,1188,1075$, $1028,962,885,764,693,606,424 \mathrm{~cm}^{-1}$.

MS (EI) m/z (relative intensity): 215 (100) [M+], 200 (88), 11 (80), 172 (30), 156 (34), 147 (40), 129 (24), 115 (28), 102 (50), 77 (28).

HR-MS (EI) $m / z$ calculated for $\mathrm{C}_{14} \mathrm{H}_{17} \mathrm{NO}^{+}: 215.1310$; found: 215.1315 .

nOe:

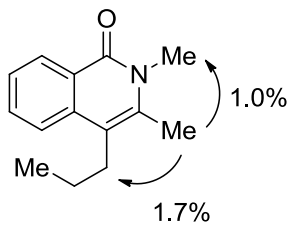

\section{(180ai')}

M.r.: $86-88^{\circ} \mathrm{C}$.

${ }^{1} \mathrm{H}-\mathrm{NMR}\left(300 \mathrm{MHz}, \mathrm{CDCl}_{3}\right): \delta=8.44(\mathrm{~d}, J=8.0 \mathrm{~Hz}, 1 \mathrm{H}), 7.69-7.52(\mathrm{~m}, 2 \mathrm{H}), 7.45-7.32(\mathrm{~m}, 1 \mathrm{H}), 3.62(\mathrm{~s}$, $3 \mathrm{H}), 2.80-2.59(\mathrm{~m}, 2 \mathrm{H}), 2.38(\mathrm{~s}, 3 \mathrm{H}), 1.69-1.42(\mathrm{~m}, 2 \mathrm{H}), 1.01(\mathrm{t}, J=7.3 \mathrm{~Hz}, 3 \mathrm{H})$.

${ }^{13} \mathrm{C}-\mathrm{NMR}\left(75 \mathrm{MHz}, \mathrm{CDCl}_{3}\right): \delta=162.7\left(\mathrm{C}_{\mathrm{q}}\right), 136.4\left(\mathrm{C}_{\mathrm{q}}\right), 135.9\left(\mathrm{C}_{\mathrm{q}}\right), 131.9(\mathrm{CH}), 128.3(\mathrm{CH}), 125.5(\mathrm{CH})$, $124.6\left(\mathrm{C}_{\mathrm{q}}\right), 122.4(\mathrm{CH}), 113.9\left(\mathrm{C}_{\mathrm{q}}\right), 31.6\left(\mathrm{CH}_{3}\right), 29.8\left(\mathrm{CH}_{2}\right), 23.1\left(\mathrm{CH}_{2}\right), 16.7\left(\mathrm{CH}_{3}\right), 14.1\left(\mathrm{CH}_{3}\right)$.

IR (ATR): $\tilde{V}=3070,2953,2934,2871,1724,1642,1555,1457,1412,1323,1029,699 \mathrm{~cm}^{-1}$.

MS (El: $m / z$ (relative intensity): 215 (36) [M+1, 187 (100), n158 (11), 115 (11), 56 (14).

HR-MS (El) $m / z$ calculated for $\mathrm{C}_{14} \mathrm{H}_{17} \mathrm{NO}^{+}: 215.1310$; found: 215.1307 .

Synthesis of 4-(Cyclohex-1-en-1-yl)-2-methyl-3-phenylisoquinolin-1(2H)-one (180aj) \& 3-(Cyclohex1-en-1-yl)-2-methyl-4-phenylisoquinolin-1(2H)-one (180aj')

The general procedure $\mathbf{F}$ was followed using $\left[\operatorname{RuCl}_{2}(p \text {-cymene })\right]_{2}(15 \mathrm{mg}, 0.025 \mathrm{mmol}, 5.1 \mathrm{~mol} \%), \mathrm{N}$ methylbenzamide (86a) $(68.8 \mathrm{mg}, 0.51 \mathrm{mmol})$ and cyclohex-1-en-1-ylethynylbenzene (88j) $(177 \mathrm{mg}$, $0.97 \mathrm{mmol}$ ). After $22 \mathrm{~h}$, purification by column chromatography ( $n$-hexane/EtOAc: 3:1 to 2:1) yielded 180aj and 180aj' as an inseperable mixture (42 mg, 26\%, ratio by $\left.{ }^{1} \mathrm{H}-\mathrm{NMR} 1.0: 1.3\right)$ as an orange oil.<smiles>Cn1c(C2=CCCCC2)c(-c2ccccc2)c2ccccc2c1=O</smiles>

(180aj)<smiles>Cn1c(-c2ccccc2)c(C2=CCCCC2)c2ccccc2c1=O</smiles>

(180aj') 
${ }^{1} \mathrm{H}-\mathrm{NMR}\left(300 \mathrm{MHz}, \mathrm{CDCl}_{3}\right): \delta=8.52-8.29(\mathrm{~m}, 2 \mathrm{H}), 7.65-6.91(\mathrm{~m}, 18 \mathrm{H})$, 5.61-5.51 (m, 1H), 5.52-5.41 (m, $1 \mathrm{H}), 3.52(\mathrm{~s}, 4 \mathrm{H}), 3.23(\mathrm{~s}, 3 \mathrm{H}), 2.15-1.86(\mathrm{~m}, 7 \mathrm{H}), 1.86-1.38(\mathrm{~m}, 7 \mathrm{H}), 1.38-1.03(\mathrm{~m}, 3 \mathrm{H})$.

Assignment of the resonances was not possible due to their overlapping.

${ }^{13} \mathrm{C}$-NMR $\left(75.5 \mathrm{MHz}, \mathrm{CDCl}_{3}\right): \delta=162.5\left(\mathrm{C}_{\mathrm{q}}\right), 162.3\left(\mathrm{C}_{\mathrm{q}}\right), 143.0\left(\mathrm{C}_{\mathrm{q}}\right), 139.5\left(\mathrm{C}_{\mathrm{q}}\right), 137.2\left(\mathrm{C}_{\mathrm{q}}\right), 136.8\left(\mathrm{C}_{\mathrm{q}}\right)$, $136.2\left(\mathrm{C}_{\mathrm{q}}\right), 135.0\left(\mathrm{C}_{\mathrm{q}}\right), 132.7\left(\mathrm{C}_{\mathrm{q}}\right), 132.4(\mathrm{CH}), 132.0\left(\mathrm{C}_{\mathrm{q}}\right), 132.0(\mathrm{CH}), 131.8(\mathrm{CH}), 131.6(\mathrm{CH}), 130.9$ $(\mathrm{CH}), 130.5(\mathrm{CH}), 130.0(\mathrm{CH}), 128.4(\mathrm{CH}), 128.1(\mathrm{CH}), 128.0(\mathrm{CH}), 127.9(\mathrm{CH}), 127.8(\mathrm{CH}), 127.6(\mathrm{CH})$, $127.6(\mathrm{CH}), 127.3(\mathrm{CH}), 126.8(\mathrm{CH}), 126.2(\mathrm{CH}), 125.9(\mathrm{CH}), 125.0(\mathrm{CH}), 124.8\left(\mathrm{C}_{q}\right), 124.5(\mathrm{CH}), 124.1$ $\left(\mathrm{C}_{\mathrm{q}}\right), 120.8\left(\mathrm{C}_{\mathrm{q}}\right), 117.2\left(\mathrm{C}_{\mathrm{q}}\right), 34.2\left(\mathrm{CH}_{3}\right), 32.9\left(\mathrm{CH}_{3}\right), 30.3\left(\mathrm{CH}_{2}\right), 29.4\left(\mathrm{CH}_{2}\right), 25.2\left(\mathrm{CH}_{2}\right), 24.8\left(\mathrm{CH}_{2}\right), 22.7$ $\left(\mathrm{CH}_{2}\right), 22.1\left(\mathrm{CH}_{2}\right), 21.7\left(\mathrm{CH}_{2}\right), 21.3\left(\mathrm{CH}_{2}\right)$.

IR (ATR): $\tilde{v}=2939,2860,1642,1606,1481,1327,1026,777,756,702 \mathrm{~cm}^{-1}$.

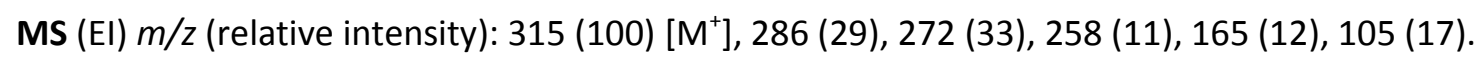

HR-MS (ESI) $\mathrm{m} / \mathrm{z}$ calculated for $\mathrm{C}_{22} \mathrm{H}_{21} \mathrm{NO}+\mathrm{H}^{+}: 316.1701$; found: 316.1696 .

Synthesis of 4-n-Butyl-3-(cyclohex-1-en-1-yl)-2-methylisoquinolin-1(2H)-one (180ak) \& 3-n-Butyl-4(cyclohex-1-en-1-yl)-2-methylisoquinolin-1(2H)-one (180ak')

The general procedure $\mathbf{F}$ was followed using $\left[\operatorname{RuCl}_{2}(p \text {-cymene })\right]_{2}(15 \mathrm{mg}, 0.025 \mathrm{mmol}, 5.0 \mathrm{~mol} \%), \mathrm{N}$ methylbenzamide (86a) $(68.8 \mathrm{mg}, 0.51 \mathrm{mmol}$ ) and 1-(hex-1-yn-1-yl)-cyclohex-1-ene (88k) (177 mg, $1.10 \mathrm{mmol}$ ). After $22 \mathrm{~h}$, purification by column chromatography ( $n$-hexane/EtOAc $5: 1$ ) yielded 180ak and 180ak' as an inseperable mixture (70 mg, 46\%, ratio det. by $\left.{ }^{1} \mathrm{H}-\mathrm{NMR} 10: 1.0\right)$ which was isolated as an orange oil. (NMR spectra were analyzed only for the major regioisomer 180ak.)<smiles>CCCCc1c(C2=CCCCC2)n(C)c(=O)c2ccccc12</smiles>

(180ak)<smiles>CCCCc1c(C2=CCCCC2)c2ccccc2c(=O)n1C</smiles>

(180ak')

Major regeoisomer:

nOe:<smiles>CCCCCc1c(C2=C(CCCC)C(CCCCC)CCC2)n(C)c(=O)c2ccccc12</smiles> 


\section{(180ak)}

${ }^{1} \mathrm{H}-\mathrm{NMR}\left(300 \mathrm{MHz}, \mathrm{CDCl}_{3}\right): \delta=8.47(\mathrm{dd}, J=8.0,1.1 \mathrm{~Hz}, 1 \mathrm{H}), 7.69-7.59(\mathrm{~m}, 2 \mathrm{H}), 7.43(\mathrm{ddd}, J=8.1,5.0$, $3.2 \mathrm{~Hz}, 1 \mathrm{H}), 5.81(\mathrm{dd}, J=3.7,2.0 \mathrm{~Hz}, 1 \mathrm{H}), 3.52(\mathrm{~s}, 3 \mathrm{H}), 2.81-2.61(\mathrm{~m}, 1 \mathrm{H}), 2.61-2.44(\mathrm{~m}, 1 \mathrm{H}), 2.33-2.04$ $(\mathrm{m}, 4 \mathrm{H}), 1.94-1.65(\mathrm{~m}, 4 \mathrm{H}), 1.52-1.33(\mathrm{~m}, 3 \mathrm{H}), 0.96(\mathrm{t}, J=7.0 \mathrm{~Hz}, 3 \mathrm{H})$.

${ }^{13} \mathrm{C}$-NMR $\left(75.5 \mathrm{MHz}, \mathrm{CDCl}_{3}\right): \delta=162.5\left(\mathrm{C}_{\mathrm{q}}\right), 142.0\left(\mathrm{C}_{\mathrm{q}}\right), 136.6\left(\mathrm{C}_{\mathrm{q}}\right), 132.9\left(\mathrm{C}_{\mathrm{q}}\right), 131.7(\mathrm{CH}), 130.5(\mathrm{CH})$, $128.0(\mathrm{CH}), 125.8(\mathrm{CH}), 124.9\left(\mathrm{C}_{\mathrm{q}}\right), 123.0(\mathrm{CH}), 114.0\left(\mathrm{C}_{\mathrm{q}}\right), 33.2\left(\mathrm{CH}_{3}\right), 32.6\left(\mathrm{CH}_{2}\right), 29.3\left(\mathrm{CH}_{2}\right), 28.0\left(\mathrm{CH}_{2}\right)$, $25.1\left(\mathrm{CH}_{2}\right), 23.0\left(\mathrm{CH}_{2}\right), 22.4\left(\mathrm{CH}_{2}\right), 21.6\left(\mathrm{CH}_{2}\right), 13.8\left(\mathrm{CH}_{3}\right)$.

IR (ATR): $\tilde{V}=3357,2829,2859,1643,1584,1555,1335,1070,770,701 \mathrm{~cm}^{-1}$.

MS (EI) m/z (relative intensity): 295 (53) [M+], 252 (100), 210 (26), 197 (10), 162 (10).

HR-MS (EI) $m / z$ calculated for $\mathrm{C}_{20} \mathrm{H}_{25} \mathrm{NO}^{+}$: 295.1936; found: 295.1942.

\section{Synthesis of 3-Cyclohexenyl-2,4-Dimethylisoquinolin-1(2H)-one (180al)}

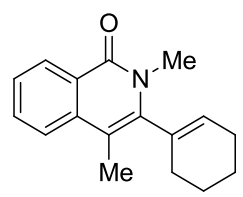

The general procedure $\mathbf{F}$ was followed using $\left[\operatorname{RuCl}_{2}(p \text {-cymene })\right]_{2}(31 \mathrm{mg}, 0.051 \mathrm{mmol}, 10 \mathrm{~mol} \%), \mathrm{N}$ methylbenzamide (86a) $(69.0 \mathrm{mg}, 0.51 \mathrm{mmol}$ ) and 1-(prop-1-ynyl)cyclohex-1-ene (88I) (126 mg, $1.05 \mathrm{mmol}$ ). After $22 \mathrm{~h}$, purification by column chroma-tography ( $n$-hexane/EtOAc: $2: 1$ ) yielded 180al (72 $\mathrm{mg}, 56 \%)$ as an orange oil.

${ }^{1} \mathrm{H}-\mathrm{NMR}\left(300 \mathrm{MHz}, \mathrm{CDCl}_{3}\right): \delta=8.47(\mathrm{~d}, J=8.3 \mathrm{~Hz}, 1 \mathrm{H}), 7.77-7.56(\mathrm{~m}, 2 \mathrm{H}), 7.55-7.36(\mathrm{~m}, 1 \mathrm{H})$, 5.86-5.71 $(m, 1 H), 3.52(s, 3 H), 2.31-2.18(m, 5 H), 2.17-2.05(m, 2 H), 1.76(s, 4 H)$.

${ }^{13} \mathrm{C}-\mathrm{NMR}\left(75.5 \mathrm{MHz}, \mathrm{CDCl}_{3}\right): \delta=162.7\left(\mathrm{C}_{\mathrm{q}}\right), 142.1\left(\mathrm{C}_{\mathrm{q}}\right), 137.3\left(\mathrm{C}_{\mathrm{q}}\right), 133.4\left(\mathrm{C}_{\mathrm{q}}\right), 131.8(\mathrm{CH}), 130.8(\mathrm{CH})$, $127.9(\mathrm{CH}), 125.9(\mathrm{CH}), 124.8\left(\mathrm{C}_{\mathrm{q}}\right), 123.0(\mathrm{CH}), 108.5\left(\mathrm{C}_{\mathrm{q}}\right), 32.7\left(\mathrm{CH}_{3}\right), 29.1\left(\mathrm{CH}_{2}\right), 25.2\left(\mathrm{CH}_{2}\right), 22.5\left(\mathrm{CH}_{2}\right)$, $21.7\left(\mathrm{CH}_{2}\right), 14.2(\mathrm{CH})$.

IR (ATR): $\tilde{V}=2925,2858,2836,1639,1588,1486,1414,1341,1323,1188,1030,919,765,728,694$, $644,564,424 \mathrm{~cm}^{-1}$.

MS (EI) m/z (relative intensity): 253 (100) $\left[\mathrm{M}^{+}\right], 238$ (22), 224 (38), 210 (59), 196 (27), 165 (10), 128 (8), 115 (10), 77 (16).

HR-MS (EI) $m / z$ calculated for $\mathrm{C}_{17} \mathrm{H}_{19} \mathrm{NO}^{+}: 253.1467$; found: 253.1458. 
Synthesis of 1,3-Dimethyl-5,6-diphenylpyridin-2(1H)-one (182aa)<smiles>Cc1cc(-c2ccccc2)c(-c2ccccc2)n(C)c1=O</smiles>

The general procedure $\mathbf{G}$ was followed using $\left[\operatorname{RuCl}_{2}(p \text {-cymene })\right]_{2}(15 \mathrm{mg}, 0.025 \mathrm{mmol}, 5.0 \mathrm{~mol} \%), \mathrm{N}$ methylmethacrylamide (181a) (111 mg, $1.12 \mathrm{mmol}$ ) and 1,2-diphenylethyne (88a) (89.0 mg, $0.50 \mathrm{mmol}$ ). Purification by column chromatography (EtOAc) yielded 182aa (126 mg, 92\%) as a white solid.

M.p.: $135^{\circ} \mathrm{C}$

${ }^{1} \mathrm{H}-\mathrm{NMR}\left(300 \mathrm{MHz}, \mathrm{CDCl}_{3}\right): \delta=7.32(\mathrm{~d}, J=1.0 \mathrm{~Hz}, 1 \mathrm{H}), 7.30-7.23(\mathrm{~m}, 3 \mathrm{H}), 7.12-7.03(\mathrm{~m}, 5 \mathrm{H}), 6.95-6.88$ $(\mathrm{m}, 2 \mathrm{H}), 3.32(\mathrm{~s}, 3 \mathrm{H}), 2.23(\mathrm{~d}, J=1.0 \mathrm{~Hz}, 3 \mathrm{H})$.

${ }^{13} \mathrm{C}-\mathrm{NMR}\left(75 \mathrm{MHz}, \mathrm{CDCl}_{3}\right): \delta=163.1\left(\mathrm{C}_{\mathrm{q}}\right), 144.0\left(\mathrm{C}_{\mathrm{q}}\right), 139.0(\mathrm{CH}), 138.7\left(\mathrm{C}_{\mathrm{q}}\right), 134.5\left(\mathrm{C}_{\mathrm{q}}\right), 133.9(\mathrm{CH})$, $131.2(\mathrm{CH}), 130.0(\mathrm{CH}), 129.5(\mathrm{CH}), 128.6(\mathrm{CH}), 127.8\left(\mathrm{C}_{\mathrm{q}}\right), 126.2(\mathrm{CH}), 119.9\left(\mathrm{C}_{\mathrm{q}}\right), 34.7\left(\mathrm{CH}_{3}\right), 17.3$ $\left(\mathrm{CH}_{3}\right)$.

IR (ATR): $\tilde{\boldsymbol{v}}=3057,2921,1646,1597,1490,1416,765,699 \mathrm{~cm}^{-1}$. MS (EI) $m / z$ (relative intensity): 274 (100) [M-H'] 246 (15), 118 (16), 77 (33), 43 (29).

HR-MS (EI) $m / z$ calculated for $\mathrm{C}_{19} \mathrm{H}_{16} \mathrm{NO}^{+}: 274.1232$, found 274.1238 .

\section{Synthesis of 5,6-Diethyl-3-methyl-1-phenylpyridine-2(1H)-one (182ap)}<smiles>CCc1c(C)cc(CC)n(-c2ccccc2)c1=O</smiles>

The general procedure $\mathbf{G}$ was followed using $\left[\operatorname{RuCl}_{2}(p \text {-cymene })\right]_{2}(16 \mathrm{mg}, 0.026 \mathrm{mmol}, 5.3 \mathrm{~mol} \%)$, $N$-phenylmethacrylamide (181a) (162 mg, $1.00 \mathrm{mmol}$ ) and hex-3-yne (88p) (40.0 mg, $0.49 \mathrm{mmol})$. Purification by column chromatography ( $n$-hexane/EtOAc 1:1) yielded 182ap (60 mg, 51\%) as a brown solid.

M.p.: $93^{\circ} \mathrm{C}$.

${ }^{1} \mathrm{H}-\mathrm{NMR}\left(300 \mathrm{MHz}, \mathrm{CDCl}_{3}\right): \delta=7.53-7.33(\mathrm{~m}, 3 \mathrm{H}), 7.21-7.08(\mathrm{~m}, 3 \mathrm{H}), 2.41(\mathrm{q}, J=7.5 \mathrm{~Hz}, 2 \mathrm{H}), 2.29$ (q, $J=7.5 \mathrm{~Hz}, 2 \mathrm{H}), 2.11(\mathrm{~d}, J=0.8 \mathrm{~Hz}, 3 \mathrm{H}), 1.18(\mathrm{t}, J=7.5 \mathrm{~Hz}, 3 \mathrm{H}), 0.87(\mathrm{t}, J=7.5 \mathrm{~Hz}, 3 \mathrm{H}$ ). 
${ }^{13} \mathrm{C}-\mathrm{NMR}\left(75 \mathrm{MHz}, \mathrm{CDCl}_{3}\right): \delta=163.5\left(\mathrm{C}_{\mathrm{q}}\right), 144.4\left(\mathrm{C}_{\mathrm{q}}\right), 139.6\left(\mathrm{C}_{\mathrm{q}}\right), 139.5(\mathrm{CH}), 129.3(\mathrm{CH}), 128.5(\mathrm{CH})$, $128.3(\mathrm{CH}), 127.1\left(\mathrm{C}_{\mathrm{q}}\right), 117.7\left(\mathrm{C}_{\mathrm{q}}\right), 23.9\left(\mathrm{CH}_{2}\right), 22.9\left(\mathrm{CH}_{2}\right), 16.9\left(\mathrm{CH}_{3}\right), 15.5\left(\mathrm{CH}_{3}\right), 13.8\left(\mathrm{CH}_{3}\right)$.

IR (ATR): $\tilde{V}=2968,2930,1646,1542,1315,773,695 \mathrm{~cm}^{-1}$.

MS (EI) m/z (relative intensity): 241 (100) [M+], 226 (96), 198 (83), 77 (47), 58 (21), 51 (24), 43 (93).

HR-MS (EI) $m / z$ calculated for $\mathrm{C}_{16} \mathrm{H}_{19} \mathrm{NO}^{+}$: 241.1467; found: 241.1461 .

\section{Synthesis of 3-Methyl-1-phenyl-5,6-di-n-propylpyridin-2(1H)-one (182aq)}

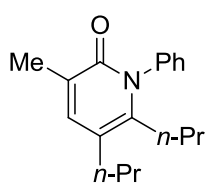

The general procedure $\mathbf{G}$ was followed using $\left[\mathrm{RuCl}_{2}(p \text {-cymene })\right]_{2}(15 \mathrm{mg}, 0.025 \mathrm{mmol}, 4.9 \mathrm{~mol} \%)$, $\mathrm{N}$-phenylmethacrylamide (181a) (161 mg, $1.00 \mathrm{mmol}$ ) and oct-4-yne (88q) $(54.0 \mathrm{mg}, 0.49 \mathrm{mmol})$. Purification by column chromatography ( $n$-hexane/EtOAc 1:1 to EtOAc) yielded 182aq ( $80 \mathrm{mg}, 61 \%$ ) as a grey solid.

M.p.: $99^{\circ} \mathrm{C}$.

${ }^{1} \mathrm{H}-\mathrm{NMR}\left(300 \mathrm{MHz}, \mathrm{CDCl}_{3}\right): \delta=7.53-7.36(\mathrm{~m}, 3 \mathrm{H}), 7.21-7.15(\mathrm{~m}, 2 \mathrm{H}), 7.13(\mathrm{~s}, 1 \mathrm{H}), 2.35(\mathrm{dd}, J=8.8$, $6.8 \mathrm{~Hz}, 2 \mathrm{H}), 2.26-2.15(\mathrm{~m}, 2 \mathrm{H}), 2.12(\mathrm{~d}, J=0.8 \mathrm{~Hz}, 3 \mathrm{H}), 1.66-1.48(\mathrm{~m}, 2 \mathrm{H}), 1.39-1.23(\mathrm{~m}, 2 \mathrm{H}), 0.98(\mathrm{t}, J=$ $7.3 \mathrm{~Hz}, 3 \mathrm{H}), 0.66(\mathrm{t}, J=7.3 \mathrm{~Hz}, 3 \mathrm{H})$.

${ }^{13} \mathrm{C}$-NMR $\left(75 \mathrm{MHz}, \mathrm{CDCl}_{3}\right): \delta=163.5\left(\mathrm{C}_{\mathrm{q}}\right), 143.4\left(\mathrm{C}_{\mathrm{q}}\right), 139.9(\mathrm{CH}), 139.6\left(\mathrm{C}_{\mathrm{q}}\right), 129.2(\mathrm{CH}), 128.4(\mathrm{CH})$, $128.2(\mathrm{CH}), 126.8\left(\mathrm{C}_{\mathrm{q}}\right), 116.5\left(\mathrm{C}_{\mathrm{q}}\right), 33.0\left(\mathrm{CH}_{2}\right), 31.8\left(\mathrm{CH}_{2}\right), 24.1\left(\mathrm{CH}_{2}\right), 22.6\left(\mathrm{CH}_{2}\right), 16.9\left(\mathrm{CH}_{3}\right), 14.0\left(\mathrm{CH}_{3}\right)$, $14.0\left(\mathrm{CH}_{3}\right)$.

IR (ATR): $\tilde{\boldsymbol{v}}=3295,3053,1646,1605,1541,696 \mathrm{~cm}^{-1}$.

MS (EI) m/z (relative intensity): 269 (47) [M+], 240 (100), 211 (25), 77 (32), 43 (20).

HR-MS (EI) $m / z$ calculated for $\mathrm{C}_{18} \mathrm{H}_{23} \mathrm{NO}^{+}: 269.1780$; found: 269.1782 .

Synthesis of 1,3,5-Trimethyl-6-phenylpyridin-2(1H)-one (182as) and 1,3,6-Trimethyl-5-phenylpyridin-2(1H)-one (182as')

The general procedure $\mathbf{G}$ was followed using $\left[\mathrm{RuCl}_{2}(p \text {-cymene })\right]_{2}(15 \mathrm{mg}, 0.025 \mathrm{mmol}, 5.0 \mathrm{~mol} \%)$, $\mathrm{N}$-methylmethacrylamide (181a) (101 mg, $1.02 \mathrm{mmol}$ ) and prop-1-yn-1-ylbenzene (88s) $(62.4 \mathrm{mg}$, $0.54 \mathrm{mmol}$ ). Purification by column chromatography ( $n$-hexane/EtOAc 1:1) yielded 182as (45 mg, $39 \%$ ) and 182as' (25 mg, 22\%) as white solids. 


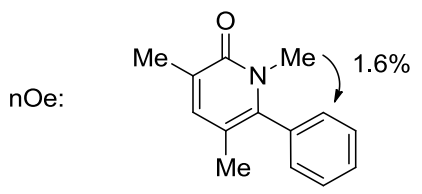

(182as)

M.p.: $104^{\circ} \mathrm{C}$.

${ }^{1} \mathrm{H}-\mathrm{NMR}\left(300 \mathrm{MHz}, \mathrm{CDCl}_{3}\right): \delta=7.55-7.37(\mathrm{~m}, 3 \mathrm{H}), 7.22-7.06(\mathrm{~m}, 3 \mathrm{H}), 3.22(\mathrm{~s}, 3 \mathrm{H}), 2.19(\mathrm{~s}, 3 \mathrm{H}), 1.76(\mathrm{~s}$, $3 \mathrm{H})$.

${ }^{13} \mathrm{C}-\mathrm{NMR}\left(75 \mathrm{MHz}, \mathrm{CDCl}_{3}\right): \delta=163.5\left(\mathrm{C}_{\mathrm{q}}\right), 144.2\left(\mathrm{C}_{\mathrm{q}}\right), 140.2(\mathrm{CH}), 135.8\left(\mathrm{C}_{\mathrm{q}}\right), 129.6(\mathrm{CH}), 129.5(\mathrm{CH})$, $129.3(\mathrm{CH}), 128.2\left(\mathrm{C}_{\mathrm{q}}\right), 113.5\left(\mathrm{C}_{\mathrm{q}}\right), 35.0\left(\mathrm{CH}_{3}\right), 18.3\left(\mathrm{CH}_{3}\right), 17.8\left(\mathrm{CH}_{3}\right)$.

IR (ATR): $\tilde{v}=2975,2944,1643,1591,1555,1254,1017,929,764,706,500 \mathrm{~cm}^{-1}$. MS (EI) m/z (relative intensity): 212 (100) [M-H $\left.\mathrm{H}^{+}\right], 197$ (12), 184 (35), 77 (17).

HR-MS (EI) $\mathrm{m} / \mathrm{z}$ calculated for $\mathrm{C}_{14} \mathrm{H}_{15} \mathrm{NO}^{+} \mathrm{H}^{+}$: 212.1075; found: 212.1073.

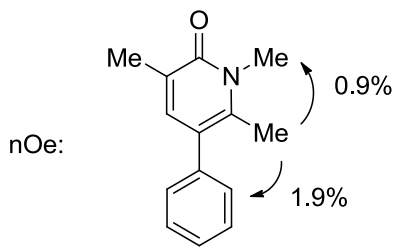

(182as')

M.r.: $77-79^{\circ} \mathrm{C}$.

${ }^{1} \mathrm{H}-\mathrm{NMR}\left(300 \mathrm{MHz}, \mathrm{CDCl}_{3}\right): \delta=7.45-7.28(\mathrm{~m}, 3 \mathrm{H}), 7.28-7.12(\mathrm{~m}, 3 \mathrm{H}), 3.64(\mathrm{~s}, 3 \mathrm{H}), 2.28(\mathrm{~s}, 3 \mathrm{H}), 2.17(\mathrm{~s}$, $3 \mathrm{H})$.

${ }^{13} \mathrm{C}-\mathrm{NMR}\left(75 \mathrm{MHz}, \mathrm{CDCl}_{3}\right): \delta=163.4\left(\mathrm{C}_{\mathrm{q}}\right), 140.2\left(\mathrm{C}_{\mathrm{q}}\right), 139.6\left(\mathrm{C}_{\mathrm{q}}\right), 138.7(\mathrm{CH}), 129.6(\mathrm{CH}), 128.4(\mathrm{CH})$, $127.0(\mathrm{CH}), 125.5\left(\mathrm{C}_{\mathrm{q}}\right), 119.7\left(\mathrm{C}_{\mathrm{q}}\right), 31.9\left(\mathrm{CH}_{3}\right), 18.2\left(\mathrm{CH}_{3}\right), 17.2\left(\mathrm{CH}_{3}\right)$.

IR (ATR): $\tilde{v}=2917,1639,1593,1549,1416,1286,1152,912,779,712,512 \mathrm{~cm}^{-1}$. MS (EI) m/z (relative intensity): 212 (100) [M-H $\left.\mathrm{H}^{+}\right], 184$ (44), 128 (17), 77 (10), 56 (20).

HR-MS (EI) $m / z$ calculated for $\mathrm{C}_{14} \mathrm{H}_{15} \mathrm{NO}-\mathrm{H}^{+}: 212.1075$; found: 212.1081 .

Synthesis of 5,6-Bis(4-methoxyphenyl)-3-methyl-1-phenylpyridin-2(1H)-one (182bb)

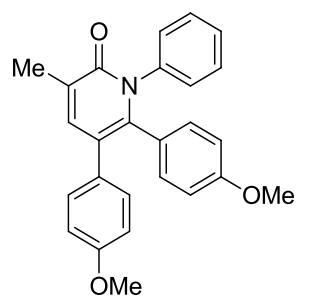


The general procedure $\mathbf{G}$ was followed using $\left[\operatorname{RuCl}_{2}(p \text {-cymene })\right]_{2}(15 \mathrm{mg}, 0.025 \mathrm{mmol}, 4.9 \mathrm{~mol} \%)$, $\mathrm{N}$-phenylmethacrylamide (181b) (161 mg, $1.00 \mathrm{mmol}$ ) and 1,2-bis(4-methoxyphenyl)-ethyne (88b) (121 mg, $0.51 \mathrm{mmol})$. Purification by column chromatography ( $n$-hexane/EtOAc 1:1 to EtOAc) yielded 182 bb (75 mg, 37\%) as a brown oil.

${ }^{1} \mathrm{H}-\mathrm{NMR}\left(300 \mathrm{MHz}, \mathrm{CDCl}_{3}\right): \delta=7.40(\mathrm{~s}, 1 \mathrm{H}), 7.27-7.07(\mathrm{~m}, 3 \mathrm{H}), 7.05-6.98(\mathrm{~m}, 2 \mathrm{H}), 6.90(\mathrm{~d}, J=8.3 \mathrm{~Hz}$, $2 \mathrm{H}), 6.72(\mathrm{~d}, J=8.8 \mathrm{~Hz}, 2 \mathrm{H}), 6.66(\mathrm{~d}, J=8.8 \mathrm{~Hz}, 2 \mathrm{H}), 6.46(\mathrm{~d}, J=9.2 \mathrm{~Hz}, 2 \mathrm{H}), 3.71(\mathrm{~s}, 3 \mathrm{H}), 3.62(\mathrm{~s}, 3 \mathrm{H})$, $2.24(\mathrm{~s}, 3 \mathrm{H})$.

${ }^{13} \mathrm{C}$-NMR $\left(75 \mathrm{MHz}, \mathrm{CDCl}_{3}\right): \delta=163.1\left(\mathrm{C}_{\mathrm{q}}\right), 158.5\left(\mathrm{C}_{\mathrm{q}}\right), 157.9\left(\mathrm{C}_{\mathrm{q}}\right), 143.3\left(\mathrm{C}_{\mathrm{q}}\right), 140.1(\mathrm{CH}), 139.6\left(\mathrm{C}_{\mathrm{q}}\right)$, $132.2(\mathrm{CH}), 131.2\left(\mathrm{C}_{\mathrm{q}}\right), 130.6(\mathrm{CH}), 129.1(\mathrm{CH}), 128.7(\mathrm{CH}), 128.5\left(\mathrm{C}_{\mathrm{q}}\right), 127.4(\mathrm{CH}), 126.7\left(\mathrm{C}_{\mathrm{q}}\right), 119.5$ $\left(\mathrm{C}_{\mathrm{q}}\right), 113.3(\mathrm{CH}), 112.9(\mathrm{CH}), 55.1\left(\mathrm{CH}_{3}\right), 54.9\left(\mathrm{CH}_{3}\right), 17.2\left(\mathrm{CH}_{3}\right)$.

IR (ATR): $\tilde{v}=2933,2836,1649,1609,1454,1288,1027,831 \mathrm{~cm}^{-1}$.

MS (EI) m/z (relative intensity): 397 (100) [M+], 369 (25), 354 (27), 210 (18), 77 (39).

HR-MS (EI) $m / z$ calculated for $\mathrm{C}_{26} \mathrm{H}_{23} \mathrm{NO}_{3}{ }^{+}: 397.1678$; found: 397.1671 .

\section{Synthesis of 3-Methyl-1-phenyl-5,6-di-p-tolylpyridin-2(1H)-one (182bc)}<smiles>Cc1ccc(-c2cc(C)c(=O)n(-c3ccccc3)c2-c2ccc([N+](=O)[O-])cc2)cc1</smiles>

The general procedure $\mathbf{G}$ was followed using $\left[\operatorname{RuCl}_{2}(p \text {-cymene })\right]_{2}(15 \mathrm{mg}, 0.025 \mathrm{mmol}, 5.0 \mathrm{~mol} \%)$, $N$-phenylmethacrylamide (181b) (164 mg, $1.02 \mathrm{mmol}$ ) and 1,2-di-p-tolylethyne (88c) (101 mg, $0.49 \mathrm{mmol}$ ). Purification by column chromatography ( $n$-hexane/EtOAc 1:1) yielded 182bc (174 mg, $97 \%)$ as a white solid.

M.p.: $168^{\circ} \mathrm{C}$.

${ }^{1} \mathrm{H}-\mathrm{NMR}\left(300 \mathrm{MHz}, \mathrm{CDCl}_{3}\right): \delta=7.44-7.39(\mathrm{~s}, 1 \mathrm{H}), 7.22-7.08(\mathrm{~m}, 3 \mathrm{H}), 7.04-6.98(\mathrm{~m}, 2 \mathrm{H}), 6.96-6.84(\mathrm{~m}$, $4 \mathrm{H}), 6.76-6.68(\mathrm{~m}, 4 \mathrm{H}), 2.25(\mathrm{~s}, 3 \mathrm{H}), 2.23(\mathrm{~s}, 3 \mathrm{H}), 2.11(\mathrm{~s}, 3 \mathrm{H})$.

${ }^{13} \mathrm{C}-\mathrm{NMR}\left(75 \mathrm{MHz}, \mathrm{CDCl}_{3}\right): \delta=163.0\left(\mathrm{C}_{\mathrm{q}}\right), 143.7\left(\mathrm{C}_{\mathrm{q}}\right), 140.2(\mathrm{CH}), 139.5\left(\mathrm{C}_{\mathrm{q}}\right), 137.2\left(\mathrm{C}_{\mathrm{q}}\right), 135.9\left(\mathrm{C}_{\mathrm{q}}\right)$, $135.8\left(\mathrm{C}_{\mathrm{q}}\right), 131.3\left(\mathrm{C}_{\mathrm{q}}\right), 130.8(\mathrm{CH}), 129.3(\mathrm{CH}), 129.1(\mathrm{CH}), 128.7\left(\mathrm{C}_{\mathrm{q}}\right), 128.6(\mathrm{CH}), 128.4(\mathrm{CH}), 128.1$ (CH), $127.4(\mathrm{CH}), 119.6\left(\mathrm{C}_{\mathrm{q}}\right), 21.1\left(\mathrm{CH}_{3}\right), 21.0\left(\mathrm{CH}_{3}\right), 17.2\left(\mathrm{CH}_{3}\right)$.

IR (ATR): $\tilde{v}=3032,2921,1652,1614,1503,1293,818,725 \mathrm{~cm}^{-1}$. MS (EI) m/z (relative intensity): 365 (100) [ $\left.\mathrm{M}^{+}\right], 337$ (29), 194 (19), 77 (37), 43 (23). 
HR-MS (EI) $\mathrm{m} / \mathrm{z}$ calculated for $\mathrm{C}_{26} \mathrm{H}_{23} \mathrm{NO}^{+}$: 365.1780 ; found: 365.1783 .

\section{Synthesis of 5,6-Bis(4-fluorophenyl)-3-methyl-1-phenylpyridin-2(1H)-one (182bd)}<smiles>Cc1cc(-c2ccc(F)cc2)c(-c2ccc(F)cc2)n(-c2ccccc2)c1=O</smiles>

The general procedure $\mathbf{G}$ was followed using $\left[\mathrm{RuCl}_{2}(p \text {-cymene })\right]_{2}(16 \mathrm{mg}, 0.026 \mathrm{mmol}, 5.0 \mathrm{~mol} \%), \mathrm{N}$ phenylmethacrylamide (181b) (160 mg, $0.99 \mathrm{mmol}$ ) and 1,2-bis(4-fluorophenyl)-ethyne (88d) (108 mg, $0.50 \mathrm{mmol}$ ). Purification by column chromatography ( $n$-hexane/EtOAc 1:1 to EtOAc) yielded 182bd (129 mg, 69\%) as an off-white solid.

M.p.: $188^{\circ} \mathrm{C}$.

${ }^{1} \mathrm{H}-\mathrm{NMR}\left(300 \mathrm{MHz}, \mathrm{CDCl}_{3}\right): \delta=7.41(\mathrm{t}, J=3.8 \mathrm{~Hz}, 1 \mathrm{H}), 7.30-7.09(\mathrm{~m}, 3 \mathrm{H}), 6.97(\mathrm{~m}, 4 \mathrm{H}), 6.89-6.75(\mathrm{~m}$, $4 \mathrm{H}), 6.75-6.59(\mathrm{~m}, 2 \mathrm{H}), 2.27(\mathrm{~s}, 3 \mathrm{H})$.

${ }^{13} \mathrm{C}-\mathrm{NMR}\left(75 \mathrm{MHz}, \mathrm{CDCl}_{3}\right): \delta=162.9\left(\mathrm{C}_{\mathrm{q}}\right), 161.8\left(\mathrm{~d}, \mathrm{~J}_{\mathrm{C}-\mathrm{F}}=248 \mathrm{~Hz}, \mathrm{C}_{\mathrm{q}}\right), 161.4\left(\mathrm{~d}, \mathrm{~J}_{\mathrm{C}-\mathrm{F}}=247 \mathrm{~Hz}, \mathrm{C}_{\mathrm{q}}\right), 142.7$ $\left(C_{q}\right), 139.6(C H), 139.2\left(C_{q}\right), 134.4\left(d, J_{C-F}=3 \mathrm{~Hz}, C_{q}\right), 132.8\left(d, J_{C-F}=8 \mathrm{~Hz}, 2 x C H\right), 131.1\left(d, J_{C-F}=8 \mathrm{~Hz}\right.$, 2xCH), $130.2\left(\mathrm{~d}, J_{\mathrm{C}-\mathrm{F}}=4 \mathrm{~Hz}, \mathrm{C}_{\mathrm{q}}\right.$ ), $129.6\left(\mathrm{C}_{\mathrm{q}}\right), 129.1(\mathrm{CH}), 128.7(\mathrm{CH}), 127.8(\mathrm{CH}), 119.0\left(\mathrm{C}_{\mathrm{q}}\right), 115.1\left(\mathrm{~d}, J_{\mathrm{C}-\mathrm{F}}\right.$ $=16 \mathrm{~Hz}, \mathrm{CH}), 114.8\left(\mathrm{~d}, \mathrm{~J}_{\mathrm{C}-\mathrm{F}}=17 \mathrm{~Hz}, \mathrm{CH}\right), 17.2\left(\mathrm{CH}_{3}\right)$.

${ }^{19}$ F-NMR $\left(283 \mathrm{MHz}, \mathrm{CDCl}_{3}\right): \delta=-112.4(\mathrm{~m}),-115.6(\mathrm{~m})$.

IR (ATR): $\tilde{v}=3056,2920,1647,1596,1544,1489,1207,765 \mathrm{~cm}^{-1}$.

MS (El) m/z (relative intensity): 373 (88) [M+], 345 (32), 198 (23), 146 (23), 77 (100), 51 (29).

HR-MS (EI) $m / z$ calculated for $\mathrm{C}_{24} \mathrm{H}_{17} \mathrm{~F}_{2} \mathrm{NO}^{+}$: 373.1278; found: 373.1279 .

Synthesis of the Mixture of 3-Methyl-1,6-diphenyl-5-propylpyridin-2(1H)-one (182bf') and 3Methyl-1,5-diphenyl-6-propylpyridin-2(1H)-one (182bf)

The general procedure $\mathbf{G}$ was followed using $\left[\mathrm{RuCl}_{2}(p \text {-cymene })\right]_{2}(16 \mathrm{mg}, 0.026 \mathrm{mmol}, 4.1 \mathrm{~mol} \%), \mathrm{N}$ phenylmethacrylamide (181b) (164 mg, $1.02 \mathrm{mmol}$ ) and pent-1-yn-1-ylbenzene (88f) (91.1 mg, $0.63 \mathrm{mmol}$ ). Purification by column chromatography ( $n$-hexane/EtOAc 1:1) yielded a mixture of 182bf and $\mathbf{1 8 2}$ bf' (48 mg, 25\%) as a slightly brown oil (ratio by ${ }^{1} \mathrm{H}-\mathrm{NMR}$ 4.7:1.0). 
<smiles>CCCc1cc(C)c(=O)n(-c2ccccc2)c1-c1ccccc1</smiles>

(182bf)<smiles></smiles>

(182bf')

${ }^{1} \mathrm{H}-\mathrm{NMR}\left(300 \mathrm{MHz}_{\mathrm{CDCl}}\right.$ ): $\delta=7.57-7.30(\mathrm{~m}, 2 \mathrm{H}), 7.32-7.22(\mathrm{~m}, 3 \mathrm{H}), 7.23-7.04(\mathrm{~m}, 9 \mathrm{H})$, 7.04-6.91 (m, $6 \mathrm{H}), 2.23(\mathrm{~d}, J=1.0 \mathrm{~Hz}, 5 \mathrm{H}), 2.16(\mathrm{~d}, J=1.0 \mathrm{~Hz}, 1 \mathrm{H}), 2.13-2.02(\mathrm{~m}, 4 \mathrm{H}), 1.51-1.35(\mathrm{~m}, 4 \mathrm{H}), 1.27-1.10$ (m, 1H), $0.79(\mathrm{t}, J=7.3 \mathrm{~Hz}, 4 \mathrm{H}), 0.43(\mathrm{t}, J=7.3 \mathrm{~Hz}, 1 \mathrm{H})$.

${ }^{13} \mathrm{C}-N M R\left(75 \mathrm{MHz}, \mathrm{CDCl}_{3}\right): \delta=163.6\left(\mathrm{C}_{\mathrm{q}}\right), 162.7\left(\mathrm{C}_{\mathrm{q}}\right), 144.4\left(\mathrm{C}_{\mathrm{q}}\right), 143.2\left(\mathrm{C}_{\mathrm{q}}\right), 139.9(\mathrm{CH}), 139.6\left(\mathrm{C}_{\mathrm{q}}\right)$, $139.3(\mathrm{CH}), 139.1\left(\mathrm{C}_{\mathrm{q}}\right), 134.2\left(\mathrm{C}_{\mathrm{q}}\right), 130.1(\mathrm{CH}), 129.4(\mathrm{CH}), 129.2(\mathrm{CH}), 129.0(\mathrm{CH}), 128.9\left(\mathrm{C}_{\mathrm{q}}\right), 128.5$ $(\mathrm{CH}), 128.4(\mathrm{CH}), 128.3(\mathrm{CH}), 127.7(\mathrm{CH}), 127.6(\mathrm{CH}), 127.3(\mathrm{CH}), 127.0(\mathrm{CH}), 126.6\left(\mathrm{C}_{q}\right), 119.5\left(\mathrm{C}_{q}\right)$, $117.6\left(\mathrm{C}_{\mathrm{q}}\right), 33.2\left(\mathrm{CH}_{2}\right), 32.6\left(\mathrm{CH}_{2}\right), 24.0\left(\mathrm{CH}_{2}\right), 22.6\left(\mathrm{CH}_{2}\right), 17.3\left(\mathrm{CH}_{2}\right), 16.9\left(\mathrm{CH}_{2}\right), 13.9\left(\mathrm{CH}_{3}\right)$.

NMR spectra for the mixture of regioisomers have been presented here (NMR-ratio is determined via comparison with comparable substituted pure products.)

IR (ATR): $\tilde{v}=2961,2928,2871,1710,1652,1609,1546,1361,1220,756,695,528 \mathrm{~cm}^{-1}$. MS (EI) m/z (relative intensity): 303 (66) $\left[\mathrm{M}^{+}\right], 274$ (100), 246 (19), 180 (17), 128 (12), 77 (45). HR-MS (ESI) $m / z$ calculated for $\mathrm{C}_{21} \mathrm{H}_{21} \mathrm{NO}+\mathrm{H}^{+}$: 304.1701; found: 304.1696 .

Synthesis of the Mixture of 6-(4-Methoxyphenyl)-3,5-dimethyl-1-phenylpyridin-2(1H)-one (182bh) and 5-(4-Methoxyphenyl)-3,6-dimethyl-1-phenylpyridin-2(1H)-one (182bh')

The general procedure $\mathbf{G}$ was followed using $\left[\mathrm{RuCl}_{2}(p \text {-cymene })\right]_{2}(15 \mathrm{mg}, 0.025 \mathrm{mmol}, 5.0 \mathrm{~mol} \%)$, N-phenylmethacrylamide (181b) $(162 \mathrm{mg}, 1.00 \mathrm{mmol})$ and 1-methoxy-4-(prop-1-yn-1-yl)-benzene (88h) (72.7 mg, $0.50 \mathrm{mmol})$. Purification by column chromatography ( $n$-hexane/EtOAc $1: 1)$ yielded a mixture of 182bh and 182bh' (64 mg, 42\%), which could not be separated any further and has been isolated as slightly yellow oil (ratio by ${ }^{1} \mathrm{H}-\mathrm{NMR}=1.0: 5.5$ ).<smiles>COc1ccc(-c2c(C)cc(C)c(=O)n2-c2ccccc2)cc1</smiles>

(182bh)<smiles>COc1ccc(-c2cc(C)c(=O)n(-c3ccccc3)c2C)cc1</smiles>

(182bh') 
${ }^{1} \mathrm{H}-\mathrm{NMR}\left(300 \mathrm{MHz}, \mathrm{CDCl}_{3}\right): \delta=7.57-7.39(\mathrm{~m}, 2 \mathrm{H}), 7.28-7.15(\mathrm{~m}, 8 \mathrm{H}), 7.12(\mathrm{~d}, J=7.2 \mathrm{~Hz}, 1 \mathrm{H}), 7.00-6.91$ $(\mathrm{m}, 3 \mathrm{H}), 6.88(\mathrm{~d}, J=8.7 \mathrm{~Hz}, 2 \mathrm{H}), 6.67(\mathrm{~d}, J=8.7 \mathrm{~Hz}, 3 \mathrm{H}), 3.84(\mathrm{~s}, 1 \mathrm{H}), 3.71(\mathrm{~s}, 5 \mathrm{H}), 2.21(\mathrm{~s}, 5 \mathrm{H}), 2.17(\mathrm{~s}$, $1 \mathrm{H}), 1.87(\mathrm{~s}, 1 \mathrm{H}), 1.86(\mathrm{~s}, 5 \mathrm{H})$.

${ }^{13} \mathrm{C}$-NMR $\left(75 \mathrm{MHz}, \mathrm{CDCl}_{3}\right): \delta=162.9\left(\mathrm{C}_{\mathrm{q}}\right), 161.7\left(\mathrm{C}_{\mathrm{q}}\right), 158.8\left(\mathrm{C}_{\mathrm{q}}\right), 158.6\left(\mathrm{C}_{\mathrm{q}}\right), 143.0\left(\mathrm{C}_{\mathrm{q}}\right), 140.4(\mathrm{CH})$, $139.9(\mathrm{CH}), 139.9\left(\mathrm{C}_{\mathrm{q}}\right), 139.9\left(\mathrm{C}_{\mathrm{q}}\right), 139.8\left(\mathrm{C}_{\mathrm{q}}\right), 131.5\left(\mathrm{C}_{\mathrm{q}}\right), 131.2(\mathrm{CH}), 130.6(\mathrm{CH}), 129.6(\mathrm{CH}), 129.0$ $(\mathrm{CH}), 128.7\left(\mathrm{C}_{\mathrm{q}}\right), 128.5(\mathrm{CH}), 128.4(\mathrm{CH}), 128.0(\mathrm{CH}), 127.4(\mathrm{CH}), 127.0\left(\mathrm{C}_{\mathrm{q}}\right), 126.7\left(\mathrm{C}_{\mathrm{q}}\right), 119.0\left(\mathrm{C}_{\mathrm{q}}\right)$, $113.8(\mathrm{CH}), 113.2(\mathrm{CH}), 113.1\left(\mathrm{C}_{\mathrm{q}}\right), 55.3\left(\mathrm{CH}_{3}\right), 55.0\left(\mathrm{CH}_{3}\right), 19.2\left(\mathrm{CH}_{3}\right), 17.8\left(\mathrm{CH}_{3}\right), 17.1\left(\mathrm{CH}_{3}\right), 16.8\left(\mathrm{CH}_{3}\right)$. NMR spectra for the mixture of regioisomers have been presented here (NMR-ratio is determined via comparison with comparable substituted pure products.)

IR (ATR): $\tilde{v}=2946,2917,2836,1649,1606,1504,1242,1030,841,694 \mathrm{~cm}^{-1}$.

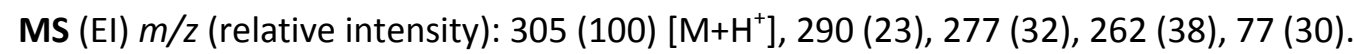

HR-MS (EI) $\mathrm{m} / z$ calculated for $\mathrm{C}_{20} \mathrm{H}_{19} \mathrm{NO}_{2}-\mathrm{H}^{+}$: 304.1338; found: 304.1337.

Synthesis of the mixture of 3,5-Dimethyl-1-phenyl-6-propylpyridin-2(1H)-one (182bi) and 3,6Dimethyl-1-phenyl-5-propylpyridin-2(1H)-one (182bi')

The general procedure $\mathbf{G}$ was followed using $\left[\mathrm{RuCl}_{2}(p \text {-cymene })\right]_{2}(15 \mathrm{mg}, 0.025 \mathrm{mmol}, 3.7 \mathrm{~mol} \%), \mathrm{N}$ phenylmethacrylamide (181b) (159 mg, $0.99 \mathrm{mmol}$ ) and hex-2-yne (88i) (56.1 mg, $0.68 \mathrm{mmol}$ ). Purification by column chromatography ( $n$-hexane/EtOAc 1:1) yielded a mixture of $\mathbf{1 8 2} \mathbf{b i}$ and $\mathbf{1 8 2} \mathbf{b i} \mathbf{i}^{\prime}$ (68 mg, 42\%) as slightly yellow oil (ratio by ${ }^{1} \mathrm{H}-\mathrm{NMR}=1.0: 2.3$ ).

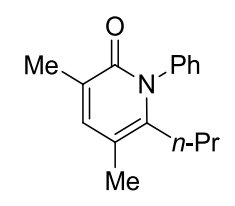

(182bi)

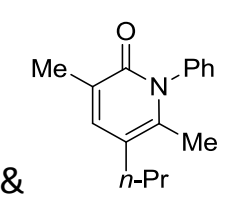

(182bi')

${ }^{1} \mathrm{H}-\mathrm{NMR}\left(300 \mathrm{MHz}, \mathrm{CDCl}_{3}\right): \delta=7.46(\mathrm{dtd}, J=15.0,7.4,1.7 \mathrm{~Hz}, 6 \mathrm{H}), 7.22-7.07(\mathrm{~m}, 6 \mathrm{H}), 2.44-2.31(\mathrm{~m}$, $2 \mathrm{H}), 2.25-2.15(\mathrm{~m}, 2 \mathrm{H}), 2.15-2.05(\mathrm{~m}, 9 \mathrm{H}), 1.87(\mathrm{~s}, 3 \mathrm{H}), 1.62-1.45(\mathrm{~m}, 2 \mathrm{H}), 1.41-1.23(\mathrm{~m}, 2 \mathrm{H}), 0.96(\mathrm{t}, J$ $=7.3 \mathrm{~Hz}, 3 \mathrm{H}), 0.69(\mathrm{t}, J=7.3 \mathrm{~Hz}, 3 \mathrm{H})$.

${ }^{13} \mathrm{C}-\mathrm{NMR}\left(75 \mathrm{MHz}, \mathrm{CDCl}_{3}\right): \delta=165.7\left(\mathrm{C}_{\mathrm{q}}\right), 163.5\left(\mathrm{C}_{\mathrm{q}}\right), 143.6\left(\mathrm{C}_{\mathrm{q}}\right), 141.0(\mathrm{CH}), 140.1(\mathrm{CH}), 140.1\left(\mathrm{C}_{\mathrm{q}}\right)$, $139.5\left(\mathrm{C}_{\mathrm{q}}\right), 139.1\left(\mathrm{C}_{\mathrm{q}}\right), 130.8(\mathrm{CH}), 129.5(\mathrm{CH}), 129.2(\mathrm{CH}), 128.4(\mathrm{CH}), 128.3(\mathrm{CH}), 128.2(\mathrm{CH}), 128.0$ $\left(\mathrm{C}_{\mathrm{q}}\right), 126.6\left(\mathrm{C}_{\mathrm{q}}\right), 116.8\left(\mathrm{C}_{\mathrm{q}}\right), 111.6\left(\mathrm{C}_{\mathrm{q}}\right), 33.8\left(\mathrm{CH}_{2}\right), 32.3\left(\mathrm{CH}_{2}\right), 23.7\left(\mathrm{CH}_{2}\right), 21.6\left(\mathrm{CH}_{2}\right), 17.3\left(\mathrm{CH}_{3}\right), 17.1$ $\left(\mathrm{CH}_{3}\right), 16.8\left(\mathrm{CH}_{3}\right), 16.8\left(\mathrm{CH}_{3}\right), 14.0\left(\mathrm{CH}_{3}\right), 13.8\left(\mathrm{CH}_{3}\right)$.

NMR spectra for the mixture of regioisomers have been presented here (NMR-ratio is determined via comparison with comparable substituted pure products.) 
IR (ATR): $\tilde{v}=2960,2929,2870,1647,1602,1547,1487,1293,1072,758,695 \mathrm{~cm}^{-1}$.

MS (EI) m/z (relative intensity): 241 (44), 212 (100), 184 (27), 118 (16), 77 (38), 43 (23).

HR-MS (EI) $\mathrm{m} / \mathrm{z}$ calculated for $\mathrm{C}_{16} \mathrm{H}_{19} \mathrm{NO}^{+}$: 241.1467; found: 241.1464 .

Synthesis of the Mixture of 6-(Cyclohex-1-en-1-yl)-3,5-dimethyl-1-phenylpyridin-2(1H)-one (182bl) and 5-(Cyclohex-1-en-1-yl)-3,6-dimethyl-1-phenylpyridin-2(1H)-one (182bl')

The general procedure $\mathbf{G}$ was followed using $\left[\mathrm{RuCl}_{2}(p \text {-cymene })\right]_{2}(17 \mathrm{mg}, 0.026 \mathrm{mmol}, 3.7 \mathrm{~mol} \%), \mathrm{N}$ phenylmethacrylamide (181b) (161 mg, $1.00 \mathrm{mmol}$ ) and 1-(prop-1-yn-1-yl)-cyclohex-1-ene (88I) $(84.1 \mathrm{mg}, 0.70 \mathrm{mmol})$. Purification by column chromatography ( $n$-hexane/EtOAc 1:1 to $100 \%$ EtOAc) yielded a mixture of $\mathbf{1 8 2} \mathbf{b l}$ and $\mathbf{1 8 2} \mathbf{b l}$ ' (73 $\mathrm{mg}, 40 \%$ ) which could not be further purified and was isolated as slightly yellow solid (ratio by ${ }^{1} \mathrm{H}-\mathrm{NMR}=1.0: 7.4$ ).<smiles>Cc1cc(C)c(=O)n(-c2ccccc2)c1C1=CCCCC1</smiles>

(182bl)<smiles>COc1cc(C2=CCCCC2)c(C)n(-c2ccccc2)c1=O</smiles>

$\left(182 b^{\prime}\right)$

${ }^{1} \mathrm{H}-\mathrm{NMR}\left(300 \mathrm{MHz}, \mathrm{CDCl}_{3}\right): \delta=7.40-7.30(\mathrm{~m}, 3 \mathrm{H}), 7.22-7.13(\mathrm{~m}, 2 \mathrm{H})$, 7.10-7.00 $(\mathrm{m}, 1 \mathrm{H})$, 5.56-5.51 $(\mathrm{m}$, $1 \mathrm{H}), 2.14(\mathrm{~s}, 3 \mathrm{H}), 2.00(\mathrm{~s}, 3 \mathrm{H}), 1.87-1.67(\mathrm{~m}, 1 \mathrm{H}), 1.66-1.51(\mathrm{~m}, 1 \mathrm{H}), 1.49-1.32(\mathrm{~m}, 2 \mathrm{H}), 1.28-1.12(\mathrm{~m}$, $2 \mathrm{H}), 1.11-0.97(\mathrm{~m}, 2 \mathrm{H})$.

${ }^{13} \mathrm{C}-\mathrm{NMR}\left(75 \mathrm{MHz}, \mathrm{CDCl}_{3}\right): \delta=163.0\left(\mathrm{C}_{\mathrm{q}}\right), 145.4\left(\mathrm{C}_{\mathrm{q}}\right), 140.7(\mathrm{CH}), 139.6\left(\mathrm{C}_{\mathrm{q}}\right), 132.5(\mathrm{CH}), 132.3\left(\mathrm{C}_{\mathrm{q}}\right)$, $130.1(\mathrm{CH}), 128.4(\mathrm{CH}), 128.3(\mathrm{CH}), 128.3(\mathrm{CH}), 127.7(\mathrm{CH}), 121.6\left(\mathrm{C}_{\mathrm{q}}\right), 111.1\left(\mathrm{C}_{\mathrm{q}}\right), 28.7\left(\mathrm{CH}_{2}\right), 24.9$ $\left(\mathrm{CH}_{2}\right), 22.1\left(\mathrm{CH}_{2}\right), 21.4\left(\mathrm{CH}_{2}\right), 17.2\left(\mathrm{CH}_{3}\right), 17.0\left(\mathrm{CH}_{3}\right)$.

NMR spectra for the mixture of regioisomers have been presented here (NMR-ratio is determined via comparison with comparable substituted pure products.)

IR (ATR): $\tilde{v}=2935,2916,2850,2648,1610,1546,1287,908,764,692,462 \mathrm{~cm}^{-1}$. MS (EI) m/z (relative intensity): 279 (100) [M+], 250 (53), 208 (17), 77 (45), 43 (29).

HR-MS (EI) $m / z$ calculated for $\mathrm{C}_{19} \mathrm{H}_{21} \mathrm{NO}^{+} \mathrm{H}^{+}: 278.1545$; found: 278.1549. 
Synthesis of 5,6-Bis(3,5-di-tert-butylphenyl)-3-methyl-1-phenylpyridin-2(1H)-one (182bm)<smiles>Cc1cc(-c2cc(Br)cc(Br)c2)c(-c2cc(Br)cc(Br)c2)n(-c2ccccc2)c1=O</smiles>

The general procedure $\mathbf{G}$ was followed using $\left[\mathrm{RuCl}_{2}(p \text {-cymene })\right]_{2}(16 \mathrm{mg}, 0.026 \mathrm{mmol}, 5.1 \mathrm{~mol} \%), \mathrm{N}$ phenylmethacrylamide (181b) (164 mg, $1.02 \mathrm{mmol}$ ) and 1,2-bis(3,5-di-tert-butyl-phenyl)ethyne $(88 \mathrm{~m})(201 \mathrm{mg}, 0.50 \mathrm{mmol})$. Purification by column chroma-tography ( $n$-hexane/EtOAc: 5/1 $\rightarrow 2 / 1$ ) yielded $\mathbf{1 8 2 b m}$ (173 $\mathrm{mg}, 62 \%)$ as an ivory solid.

M.p.: $215^{\circ} \mathrm{C}$.

${ }^{1} \mathrm{H}-\mathrm{NMR}\left(300 \mathrm{MHz}, \mathrm{CDCl}_{3}\right): \delta=7.51(\mathrm{~d}, J=1.1 \mathrm{~Hz}, 1 \mathrm{H}), 7.21-7.05(\mathrm{~m}, 4 \mathrm{H}), 7.05-6.99(\mathrm{~m}, 2 \mathrm{H}), 6.90(\mathrm{dd}$, $J=1.8,1.8 \mathrm{~Hz}, 1 \mathrm{H}), 6.81(\mathrm{~d}, J=1.8 \mathrm{~Hz}, 2 \mathrm{H}), 6.56(\mathrm{~d}, J=1.8 \mathrm{~Hz}, 2 \mathrm{H}), 2.28(\mathrm{~d}, J=1.0 \mathrm{~Hz}, 3 \mathrm{H}), 1.11(\mathrm{~s}$, $18 \mathrm{H}), 0.94(\mathrm{~s}, 18 \mathrm{H})$.

${ }^{13} \mathrm{C}$-NMR $\left(75 \mathrm{MHz}, \mathrm{CDCl}_{3}\right): \delta=163.1\left(\mathrm{C}_{\mathrm{q}}\right), 150.2\left(\mathrm{C}_{\mathrm{q}}\right), 149.7\left(\mathrm{C}_{\mathrm{q}}\right), 145.1\left(\mathrm{C}_{\mathrm{q}}\right), 139.9(\mathrm{CH}), 139.7\left(\mathrm{C}_{\mathrm{q}}\right)$, $138.2\left(\mathrm{C}_{\mathrm{q}}\right), 133.4\left(\mathrm{C}_{\mathrm{q}}\right), 129.1(\mathrm{CH}), 128.4(\mathrm{CH}), 128.4\left(\mathrm{C}_{\mathrm{q}}\right), 127.2(\mathrm{CH}), 125.9(\mathrm{CH}), 124.1(\mathrm{CH}), 120.7$ $\left(\mathrm{C}_{\mathrm{q}}\right), 120.5(\mathrm{CH}), 119.8(\mathrm{CH}), 34.6\left(\mathrm{C}_{\mathrm{q}}\right), 34.4\left(\mathrm{C}_{\mathrm{q}}\right), 31.4\left(\mathrm{CH}_{3}\right), 31.1\left(\mathrm{CH}_{3}\right), 17.2\left(\mathrm{CH}_{3}\right)$.

IR (ATR): $\tilde{v}=2962,1655,1594,1538,1362,875,719,699 \mathrm{~cm}^{-1}$.

MS (EI) m/z (relative intensity): 546 (80) [M-Me ], 504 (92), 474 (85), 276 (75), 57 (100).

HR-MS (El) $\mathrm{m} / \mathrm{z}$ calculated for $\mathrm{C}_{40} \mathrm{H}_{51} \mathrm{NO}+\mathrm{Na}^{+}: 584.3868$; found: 584.3863 .

\section{Synthesis of 3-Methyl-1-phenyl-5,6-bis\{4-(trifluoromethyl)phenyl\}pyridin-2(1H)-one (182bn)}<smiles>Cc1cc(-c2ccc(C(F)(F)F)cc2)n(-c2ccccc2)c(=O)c1</smiles>

The general procedure $\mathbf{G}$ was followed using $\left[\operatorname{RuCl}_{2}(p \text {-cymene })\right]_{2}(15 \mathrm{mg}, 0.025 \mathrm{mmol}, 4.8 \mathrm{~mol} \%)$, $\mathrm{N}$-phenylmethacrylamide (181b) (164 mg, $1.02 \mathrm{mmol}$ ) and 1,2-bis(4-trifluoromethylphenyl)ethyne (88n) (162 mg, $0.52 \mathrm{mmol}$ ). Purification by column chroma-tography ( $n$-hexane/EtOAc 1:1) yielded 188bn (175 mg, 71\%) as an off-white solid. 
M.p.: $158^{\circ} \mathrm{C}$.

${ }^{1} \mathrm{H}-\mathrm{NMR}\left(300 \mathrm{MHz}, \mathrm{CDCl}_{3}\right): \delta=7.41(\mathrm{~d}, J=1.1 \mathrm{~Hz}, 2 \mathrm{H}), 7.38(\mathrm{~s}, 1 \mathrm{H}), 7.28-7.12(\mathrm{~m}, 5 \mathrm{H}), 7.09(\mathrm{~d}, J=$ $8.7 \mathrm{~Hz}, 2 \mathrm{H}), 7.04-6.94(\mathrm{~m}, 4 \mathrm{H}), 2.27(\mathrm{~s}, 3 \mathrm{H})$.

${ }^{13} \mathrm{C}$-NMR $\left(75 \mathrm{MHz}, \mathrm{CDCl}_{3}\right): \delta=162.7\left(\mathrm{C}_{\mathrm{q}}\right), 142.5\left(\mathrm{C}_{\mathrm{q}}\right), 141.8\left(\mathrm{C}_{\mathrm{q}}\right), 139.1(\mathrm{CH}), 138.7\left(\mathrm{C}_{\mathrm{q}}\right), 137.4\left(\mathrm{C}_{\mathrm{q}}\right)$, $131.3(\mathrm{CH}), 130.5\left(\mathrm{C}_{\mathrm{q}}\right), 130.1\left(\mathrm{~d}, \mathrm{~J}_{\mathrm{C}-\mathrm{F}}=31 \mathrm{~Hz}, \mathrm{CH}\right), 130.0(\mathrm{CH}), 129.8(\mathrm{CH}), 129.0\left(\mathrm{~d}, J_{\mathrm{C}-\mathrm{F}}=31 \mathrm{~Hz}, \mathrm{CH}\right.$ ), $129.0(\mathrm{CH}), 128.8(\mathrm{CH}), 125.1\left(\mathrm{~d}, J_{\mathrm{C}-\mathrm{F}}=10 \mathrm{~Hz}, \mathrm{CH}\right), 124.8\left(\mathrm{q}, J_{\mathrm{C}-\mathrm{F}}=57 \mathrm{~Hz}, \mathrm{C}_{\mathrm{q}}\right), 124.7\left(\mathrm{~d}, J_{\mathrm{C}-\mathrm{F}}=11 \mathrm{~Hz}, \mathrm{CH}\right)$, $122.6\left(d, J_{C-F}=58 \mathrm{~Hz}, \mathrm{C}_{\mathrm{q}}\right), 118.6\left(\mathrm{C}_{\mathrm{q}}\right), 17.2\left(\mathrm{CH}_{3}\right)$.

${ }^{19} \mathrm{~F}-\mathrm{NMR}\left(283 \mathrm{MHz}, \mathrm{CDCl}_{3}\right): \delta=-62.6(\mathrm{~s}),-63.0(\mathrm{~s})$.

IR (ATR): $\tilde{v}=2922,1652,1545,1321,1082,1061,846 \mathrm{~cm}^{-1}$.

MS (El) $m / z$ (relative intensity): $473(100)\left[\mathrm{M}^{+}\right], 445$ (20), 77 (60), 43 (55).

HR-MS (EI) $m / z$ calculated for $\mathrm{C}_{26} \mathrm{H}_{17} \mathrm{~F}_{6} \mathrm{NO}^{+}: 473.1214$; found: 473.1217 .

\section{Synthesis of 5,6-Bis-(4-chlorophenyl)-3-methyl-1-phenylpyridin-2(1H)-one (182bo)}<smiles>COc1cc(-c2ccc(Cl)cc2)c(-c2ccc(Cl)cc2)n(-c2ccccc2)c1=O</smiles>

The general procedure $\mathbf{G}$ was followed using $\left[\mathrm{RuCl}_{2}(p \text {-cymene })\right]_{2}(15 \mathrm{mg}, 0.025 \mathrm{mmol}, 5.0 \mathrm{~mol} \%), \mathrm{N}$ phenylmethacrylamide (181b) (164 mg, $1.02 \mathrm{mmol}$ ) and 1,2-bis(4-chlorophenyl)ethyne (880) (124 mg, $0.50 \mathrm{mmol}$ ). Purification by column chromatography ( $n$-hexane/EtOAc 1:1) yielded $\mathbf{1 8 2}$ bo (121 mg, 59\%) as a white solid.

M.p.: $193^{\circ} \mathrm{C}$.

${ }^{1} \mathrm{H}-\mathrm{NMR}\left(300 \mathrm{MHz}, \mathrm{CDCl}_{3}\right): \delta=7.37(\mathrm{~d}, J=1.1 \mathrm{~Hz}, 1 \mathrm{H}), 7.27-7.07(\mathrm{~m}, 5 \mathrm{H})$, 7.03-6.85 $(\mathrm{m}, 6 \mathrm{H}), 6.75(\mathrm{~d}, J$ $=9.1 \mathrm{~Hz}, 2 \mathrm{H}), 2.24(\mathrm{~d}, J=1.1 \mathrm{~Hz}, 3 \mathrm{H})$.

${ }^{13} \mathrm{C}$-NMR $\left(75 \mathrm{MHz}, \mathrm{CDCl}_{3}\right): \delta=162.8\left(\mathrm{C}_{\mathrm{q}}\right), 142.5\left(\mathrm{C}_{\mathrm{q}}\right), 139.4(\mathrm{CH}), 138.9\left(\mathrm{C}_{\mathrm{q}}\right), 136.7\left(\mathrm{C}_{\mathrm{q}}\right), 133.9\left(\mathrm{C}_{\mathrm{q}}\right)$, $132.6\left(\mathrm{C}_{\mathrm{q}}\right), 132.4\left(\mathrm{C}_{\mathrm{q}}\right), 132.2(\mathrm{CH}), 130.8(\mathrm{CH}), 129.8\left(\mathrm{C}_{\mathrm{q}}\right), 129.0(\mathrm{CH}), 128.8(\mathrm{CH}), 128.3(\mathrm{CH}), 128.0$ (CH), $127.9(\mathrm{CH}), 118.7\left(\mathrm{C}_{\mathrm{q}}\right), 17.2\left(\mathrm{CH}_{3}\right)$.

IR (ATR): $\tilde{v}=3077,2915,1645,1487,1124,694 \mathrm{~cm}^{-1}$.

MS (EI) m/z (relative intensity): 405 (62) [M+], 377 (20), 214 (16), 127 (16), 77 (100), 51 (28).

HR-MS (EI) $\mathrm{m} / z$ calculated for $\mathrm{C}_{24} \mathrm{H}_{17} \mathrm{Cl}_{2} \mathrm{NO}^{+}: 405.0687$; found: 405.0690.

The spectral data were in accordance with those reported in the literature. 
Synthesis of 5-Ethyl-6-(2-methoxyethyl)-3-methyl-1-phenylpyridin-2(1H)-one (182bu') and 6-Ethyl5-(2-methoxyethyl)-3-methyl-1-phenylpyridin-2(1H)-one (182bu)

The general procedure $\mathbf{G}$ was followed using $\left[\operatorname{RuCl}_{2}(p \text {-cymene })\right]_{2}(16 \mathrm{mg}, 0.026 \mathrm{mmol}, 4.3 \mathrm{~mol} \%)$, $\mathrm{N}$-phenylmethacrylamide (181b) $(159 \mathrm{mg}, 0.99 \mathrm{mmol}$ ) and 1-methoxyhex-3-yne (88u) $(67.0 \mathrm{mg}$, $0.60 \mathrm{mmol}$ ). Purification by column chromatography ( $n$-hexane/EtOAc 1:1) yielded 182bu (42 mg, $26 \%$ ) as yellow oil and 182 bu' (43 $\mathrm{mg}, 27 \%$ ) as white solid.

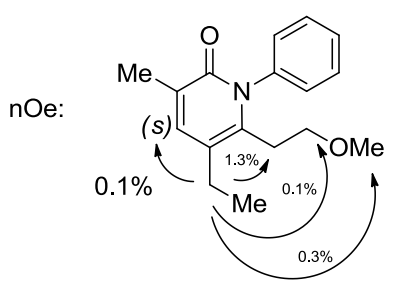

(182bu)

${ }^{1} \mathrm{H}-\mathrm{NMR}\left(300 \mathrm{MHz}, \mathrm{CDCl}_{3}\right): \delta=7.55-7.34(\mathrm{~m}, 3 \mathrm{H}), 7.24-7.09(\mathrm{~m}, 3 \mathrm{H}), 3.58-3.47(\mathrm{~m}, 2 \mathrm{H}), 3.37(\mathrm{~s}, 3 \mathrm{H})$, $2.67(\mathrm{t}, J=7.1 \mathrm{~Hz}, 2 \mathrm{H}), 2.33(\mathrm{q}, J=7.5 \mathrm{~Hz}, 2 \mathrm{H}), 2.11(\mathrm{~s}, 3 \mathrm{H}), 0.90(\mathrm{t}, J=7.5 \mathrm{~Hz}, 3 \mathrm{H})$.

${ }^{13} \mathrm{C}-\mathrm{NMR}\left(75 \mathrm{MHz}, \mathrm{CDCl}_{3}\right): \delta=163.7\left(\mathrm{C}_{\mathrm{q}}\right), 145.9\left(\mathrm{C}_{\mathrm{q}}\right), 140.1(\mathrm{CH}), 139.6\left(\mathrm{C}_{\mathrm{q}}\right), 129.5(\mathrm{CH}), 128.6(\mathrm{CH})$, 128.5 (CH), $127.2\left(\mathrm{C}_{\mathrm{q}}\right), 112.7\left(\mathrm{C}_{\mathrm{q}}\right), 73.0\left(\mathrm{CH}_{2}\right), 59.0\left(\mathrm{CH}_{3}\right), 31.3\left(\mathrm{CH}_{2}\right), 23.2\left(\mathrm{CH}_{2}\right), 17.0\left(\mathrm{CH}_{3}\right), 13.8\left(\mathrm{CH}_{3}\right)$. IR (ATR): $\tilde{v}=2965,2922,2876,2808,1649,1605,1550,1382,1195,1115,964,924,758,699 \mathrm{~cm}^{-1}$. MS (EI) m/z (relative intensity): 271 (69) [M+1, 256 (100), 240 (16), 226 (73), 198 (36), 77 (50). HR-MS (EI) $m / z$ calculated for $\mathrm{C}_{17} \mathrm{H}_{21} \mathrm{NO}_{2}^{+}: 271.1572$; found: 271.1577.

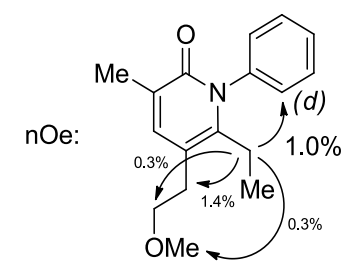

\section{(182bu')}

M.r.: $107^{\circ} \mathrm{C}$.

${ }^{1} \mathrm{H}-\mathrm{NMR}\left(300 \mathrm{MHz}, \mathrm{CDCl}_{3}\right): \delta=7.56-7.35(\mathrm{~m}, 3 \mathrm{H}), 7.22-7.12(\mathrm{~m}, 3 \mathrm{H}), 3.25(\mathrm{t}, J=7.4 \mathrm{~Hz}, 2 \mathrm{H}), 3.11(\mathrm{~s}$, $3 \mathrm{H}), 2.61(\mathrm{t}, J=7.9 \mathrm{~Hz}, 2 \mathrm{H}), 2.46(\mathrm{q}, J=7.5 \mathrm{~Hz}, 2 \mathrm{H}), 2.13(\mathrm{~s}, 3 \mathrm{H}), 1.18(\mathrm{t}, J=7.5 \mathrm{~Hz}, 3 \mathrm{H})$.

${ }^{13} \mathrm{C}-\mathrm{NMR}\left(75 \mathrm{MHz}, \mathrm{CDCl}_{3}\right): \delta=163.7\left(\mathrm{C}_{\mathrm{q}}\right), 139.6\left(\mathrm{C}_{\mathrm{q}}\right), 139.5(\mathrm{CH}), 138.8\left(\mathrm{C}_{\mathrm{q}}\right), 129.6(\mathrm{CH}), 128.7(\mathrm{CH})$, 128.7 (CH), $128.2\left(\mathrm{C}_{\mathrm{q}}\right), 119.6\left(\mathrm{C}_{\mathrm{q}}\right), 70.8\left(\mathrm{CH}_{2}\right), 58.5\left(\mathrm{CH}_{3}\right), 30.1\left(\mathrm{CH}_{2}\right), 24.3\left(\mathrm{CH}_{2}\right), 17.1\left(\mathrm{CH}_{3}\right), 15.5\left(\mathrm{CH}_{3}\right)$. IR (ATR): $\tilde{v}=3450,2977,2927,2876,1710,1651,1609,1544,1363,1111,759,699 \mathrm{~cm}^{-1}$. MS (EI) m/z (relative intensity): 271 (40) [M+], 226 (100), 211 (14), 132 (19), 77 (27), 45 (37). 
HR-MS (EI) $m / z$ calculated for $\mathrm{C}_{17} \mathrm{H}_{21} \mathrm{NO}_{2}^{+}: 271.1572$; found: 271.1573 .

\section{Synthesis of 5-Benzoyl-6-butyl-3-methyl-1-phenylpyridin-2(1H)-one (182bw)}<smiles>Cc1cc(C(=O)c2ccccc2)c(-c2ccccc2)n(-c2ccccc2)c1=O</smiles>

The general procedure $\mathbf{G}$ was followed using $\left[\operatorname{RuCl}_{2}(p \text {-cymene })\right]_{2}(15 \mathrm{mg}, 0.025 \mathrm{mmol}, 4.9 \mathrm{~mol} \%)$, $N$-phenylmethacrylamide (181b) (163 mg, $1.01 \mathrm{mmol}$ ) and 1-phenylhept-2-yn-1-one (88w) $(95 \mathrm{mg}$, $0.51 \mathrm{mmol}$ ). Purification by column chromatography ( $n$-hexane/EtOAc 2:1) yielded 182bw (27 mg, $15 \%)$ as slightly brown oil.

${ }^{1} \mathrm{H}-\mathrm{NMR}\left(300 \mathrm{MHz}, \mathrm{CDCl}_{3}\right): \delta=7.82-7.73(\mathrm{~m}, 2 \mathrm{H})$, 7.65-7.41 $(\mathrm{m}, 5 \mathrm{H})$, 7.32-7.19 $(\mathrm{m}, 4 \mathrm{H})$, 2.59-2.39 $(\mathrm{m}$, $2 \mathrm{H}), 2.09(\mathrm{~s}, 3 \mathrm{H}), 1.45-1.27(\mathrm{~m}, 2 \mathrm{H}), 0.98(\mathrm{~h}, J=7.3 \mathrm{~Hz}, 2 \mathrm{H}), 0.56(\mathrm{t}, J=7.3 \mathrm{~Hz}, 3 \mathrm{H})$.

${ }^{13} \mathrm{C}$-NMR $\left(75 \mathrm{MHz}, \mathrm{CDCl}_{3}\right): \delta=195.4\left(\mathrm{C}_{\mathrm{q}}\right), 163.9\left(\mathrm{C}_{\mathrm{q}}\right), 152.9\left(\mathrm{C}_{\mathrm{q}}\right), 138.5\left(\mathrm{C}_{\mathrm{q}}\right), 138.4\left(\mathrm{C}_{\mathrm{q}}\right), 137.9(\mathrm{CH})$, $133.0(\mathrm{CH}), 129.9(\mathrm{CH}), 129.7(\mathrm{CH}), 129.1(\mathrm{CH}), 128.7(\mathrm{CH}), 128.5(\mathrm{CH}), 125.7\left(\mathrm{C}_{\mathrm{q}}\right), 116.5\left(\mathrm{C}_{\mathrm{q}}\right), 31.9$ $\left(\mathrm{CH}_{2}\right), 30.5\left(\mathrm{CH}_{2}\right), 22.6\left(\mathrm{CH}_{2}\right), 17.0\left(\mathrm{CH}_{3}\right), 13.3\left(\mathrm{CH}_{3}\right)$.

IR (ATR): $\tilde{v}=3496,2959,2929,2874,1708,1638,1360,1220,910,759,697,529 \mathrm{~cm}^{-1}$. MS (EI) m/z (relative intensity): 345 (47) [M+1, 302 (64), 274 (23), 105 (100), 77 (77), 51 (17), 43 (62). HR-MS (EI) $m / z$ calculated for $\mathrm{C}_{23} \mathrm{H}_{23} \mathrm{NO}_{2}^{+}:$345.1729; found: 345.1725 .

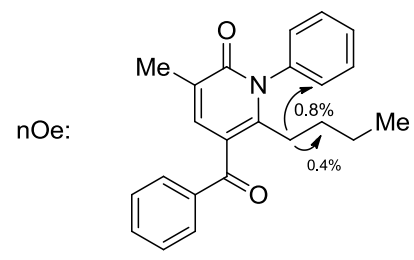

Synthesis of 1-Isopropyl-3-methyl-5,6-diphenylpyridin-2(1H)-one (182ca)<smiles></smiles> 
The general procedure $\mathbf{G}$ was followed using $\left[\operatorname{RuCl}_{2}(p \text {-cymene })\right]_{2}(15 \mathrm{mg}, 0.025 \mathrm{mmol}, 5.0 \mathrm{~mol} \%), \mathrm{N}$ isopropylmethacrylamide (181c) $(124 \mathrm{mg}, 0.98 \mathrm{mmol}$ ) and 1,2-diphenylethyne (88a) $(89.0 \mathrm{mg}$, $0.50 \mathrm{mmol}$ ). Purification by column chromatography ( $n$-hexane/EtOAc: 1:1 to EtOAc) yielded 182ca (105 $\mathrm{mg}, 69 \%)$ as a yellow solid.

M.p.: $171^{\circ} \mathrm{C}$.

${ }^{1} \mathrm{H}-\mathrm{NMR}\left(300 \mathrm{MHz}, \mathrm{CDCl}_{3}\right): \delta=7.32-7.22(\mathrm{~m}, 4 \mathrm{H})$, 7.15-7.01 $(\mathrm{m}, 5 \mathrm{H})$, 6.96-6.86 $(\mathrm{m}, 2 \mathrm{H})$, 4.22-4.06 $(\mathrm{m}$, $1 \mathrm{H}), 2.20(\mathrm{~d}, J=0.6 \mathrm{~Hz}, 3 \mathrm{H}), 1.54(\mathrm{~d}, J=6.8 \mathrm{~Hz}, 6 \mathrm{H})$.

${ }^{13} \mathrm{C}$-NMR $\left(75 \mathrm{MHz}, \mathrm{CDCl}_{3}\right): \delta=163.3\left(\mathrm{C}_{\mathrm{q}}\right), 144.2\left(\mathrm{C}_{\mathrm{q}}\right), 139.2\left(\mathrm{C}_{\mathrm{q}}\right), 138.5(\mathrm{CH}), 135.2\left(\mathrm{C}_{\mathrm{q}}\right), 129.8(\mathrm{CH})$, $129.5(\mathrm{CH}), 129.4\left(\mathrm{C}_{\mathrm{q}}\right), 128.4(\mathrm{CH}), 128.2(\mathrm{CH}), 127.6(\mathrm{CH}), 126.0(\mathrm{CH}), 120.1\left(\mathrm{C}_{\mathrm{q}}\right), 53.9\left(\mathrm{CH}_{3}\right), 19.3(\mathrm{CH})$, $17.0\left(\mathrm{CH}_{3}\right)$.

IR (ATR): $\tilde{v}=2968,1640,1608,1490,1372,763,704 \mathrm{~cm}^{-1}$.

MS (EI) $m / z$ (relative intensity): 302 (31) [M-H $\mathrm{H}^{+}, 261$ (100), 215 (20), 43 (17).

HR-MS (EI) $\mathrm{m} / \mathrm{z}$ calculated for $\mathrm{C}_{21} \mathrm{H}_{21} \mathrm{NO}-\mathrm{H}^{+}$: 302.1545; found: 302.1553 .

\section{Synthesis of 3-Methyl-1-(4-nitrophenyl)-5,6-dipropylpyridin-2(1H)-one (182dq)}<smiles>Cc1cc(C(C)C)c(C(C)C)n(-c2ccc([N+](=O)[O-])cc2)c1=O</smiles>

The general procedure $\mathbf{G}$ was followed using $\left[\operatorname{RuCl}_{2}(p \text {-cymene })\right]_{2}(10 \mathrm{mg}, 0.016 \mathrm{mmol}, 4.9 \mathrm{~mol} \%)$, $\mathrm{N}$-(4-nitrophenyl)-methacrylamide (181d) $(135 \mathrm{mg}, 0.65 \mathrm{mmol})$ and oct-4-yne (88q) (35.0 mg, $0.32 \mathrm{mmol}$ ). Purification by column chromatography ( $n$-hexane/EtOAc 1:1) yielded 182dq (92 mg, $91 \%)$ as a yellow solid.

M.p.: $105^{\circ} \mathrm{C}$.

${ }^{1} \mathrm{H}-\mathrm{NMR}\left(300 \mathrm{MHz}, \mathrm{CDCl}_{3}\right): \delta=8.35(\mathrm{~d}, J=9.0 \mathrm{~Hz}, 2 \mathrm{H}), 7.38(\mathrm{~d}, J=9.0 \mathrm{~Hz}, 2 \mathrm{H}), 7.15(\mathrm{~d}, J=1.1 \mathrm{~Hz}, 1 \mathrm{H})$, 2.41-2.26 (m, 2H), 2.23-2.14 (m, $2 \mathrm{H}), 2.10(\mathrm{~d}, J=1.0 \mathrm{~Hz}, 3 \mathrm{H}), 1.64-1.48(\mathrm{~m}, 2 \mathrm{H}), 1.36-1.20(\mathrm{~m}, 2 \mathrm{H})$, $0.98(\mathrm{t}, J=7.3 \mathrm{~Hz}, 3 \mathrm{H}), 0.68(\mathrm{t}, J=7.3 \mathrm{~Hz}, 3 \mathrm{H})$.

${ }^{13} \mathrm{C}$-NMR $\left(75 \mathrm{MHz}, \mathrm{CDCl}_{3}\right): \delta=163.2\left(\mathrm{C}_{\mathrm{q}}\right), 147.5\left(\mathrm{C}_{\mathrm{q}}\right), 145.5\left(\mathrm{C}_{\mathrm{q}}\right), 142.2\left(\mathrm{C}_{\mathrm{q}}\right), 140.6(\mathrm{CH}), 130.1(\mathrm{CH})$, 127.3 $\left(\mathrm{C}_{\mathrm{q}}\right), 124.7(\mathrm{CH}), 117.4\left(\mathrm{C}_{\mathrm{q}}\right), 32.9\left(\mathrm{CH}_{2}\right), 31.7\left(\mathrm{CH}_{2}\right), 24.1\left(\mathrm{CH}_{2}\right), 22.6\left(\mathrm{CH}_{2}\right), 16.8\left(\mathrm{CH}_{3}\right), 14.0\left(\mathrm{CH}_{3}\right)$, $14.0\left(\mathrm{CH}_{3}\right)$.

IR (ATR): $\tilde{\boldsymbol{v}}=3057,2921,1646,1597,1490,1416,765,699 \mathrm{~cm}^{-1}$.

MS (EI) m/z (relative intensity): 314 (48) [M+], 285 (100), 239 (16), 210 (20), 43 (18). 
HR-MS (EI) $m / z$ calculated for $\mathrm{C}_{18} \mathrm{H}_{22} \mathrm{~N}_{2} \mathrm{O}_{3}{ }^{+}$: 314.1630; found: 314.1641 .

\section{Synthesis of Ethyl 4-[3-Methyl-2-oxo-5,6-di-n-propylpyridin-1(2H)-yl]benzoate (182eq)}<smiles></smiles>

The general procedure $\mathbf{G}$ was followed using $\left[\operatorname{RuCl}_{2}(p \text {-cymene })\right]_{2}(15 \mathrm{mg}, 0.025 \mathrm{mmol}, 5.0 \mathrm{~mol} \%)$, ethyl 4-methacrylamidobenzoate (181e) $(239 \mathrm{mg}, 1.02 \mathrm{mmol}$ ) and oct-4-yne (88q) (55.0 mg, $0.50 \mathrm{mmol}$ ). Purification by column chromatography ( $n$-hexane/EtOAc 1:1) yielded 182eq (133 mg, $78 \%)$ as a yellow solid.

M.p.: $88^{\circ} \mathrm{C}$.

${ }^{1} \mathrm{H}-\mathrm{NMR}\left(300 \mathrm{MHz}, \mathrm{CDCl}_{3}\right): \delta=8.15(\mathrm{~d}, J=8.5 \mathrm{~Hz}, 2 \mathrm{H}), 7.25(\mathrm{~d}, J=8.5 \mathrm{~Hz}, 2 \mathrm{H}), 7.12(\mathrm{~d}, J=1.1 \mathrm{~Hz}, 1 \mathrm{H})$, $4.39(\mathrm{q}, J=7.1 \mathrm{~Hz}, 2 \mathrm{H}), 2.38-2.26(\mathrm{~m}, 2 \mathrm{H}), 2.23-2.12(\mathrm{~m}, 2 \mathrm{H}), 2.09(\mathrm{~d}, J=1.0 \mathrm{~Hz}, 3 \mathrm{H}), 1.63-1.44(\mathrm{~m}$, $2 \mathrm{H}), 1.39(\mathrm{t}, J=7.1 \mathrm{~Hz}, 3 \mathrm{H}), 1.34-1.17(\mathrm{~m}, 2 \mathrm{H}), 0.96(\mathrm{t}, J=7.3 \mathrm{~Hz}, 3 \mathrm{H}), 0.66(\mathrm{t}, J=7.2 \mathrm{~Hz}, 3 \mathrm{H})$.

${ }^{13} \mathrm{C}$-NMR $\left(75 \mathrm{MHz}, \mathrm{CDCl}_{3}\right): \delta=165.8\left(\mathrm{C}_{\mathrm{q}}\right), 163.3\left(\mathrm{C}_{\mathrm{q}}\right), 143.8\left(\mathrm{C}_{\mathrm{q}}\right), 142.8\left(\mathrm{C}_{\mathrm{q}}\right), 140.2(\mathrm{CH}), 130.6(\mathrm{CH})$, $130.5\left(\mathrm{C}_{\mathrm{q}}\right), 128.8(\mathrm{CH}), 127.0\left(\mathrm{C}_{\mathrm{q}}\right), 116.9\left(\mathrm{C}_{\mathrm{q}}\right), 61.2\left(\mathrm{CH}_{2}\right), 32.9\left(\mathrm{CH}_{2}\right), 31.7\left(\mathrm{CH}_{2}\right), 24.1\left(\mathrm{CH}_{2}\right), 22.7\left(\mathrm{CH}_{2}\right)$, $16.8\left(\mathrm{CH}_{3}\right), 14.3\left(\mathrm{CH}_{3}\right), 14.0\left(\mathrm{CH}_{3}\right), 14.0\left(\mathrm{CH}_{3}\right)$.

IR (ATR): $\tilde{v}=2959,2870,1713,1649,1543,1269,1100,768 \mathrm{~cm}^{-1}$.

MS (EI): $m / z$ (relative intensity) $341(40)\left[\mathrm{M}^{+}\right], 312$ (100), 285 (28), 210 (15).

HR-MS (EI) $m / z$ calculated for $\mathrm{C}_{21} \mathrm{H}_{27} \mathrm{NO}_{3}{ }^{+}: 341.1991$, found 341.1993 .

Synthesis of 1,3,4-Trimethyl-5,6-diphenylpyridin-2(1H)-one (182ia) and (2Z,4E)-N,2,3-Trimethyl-4,5diphenyl-penta-2,4-dienamide (182ia')

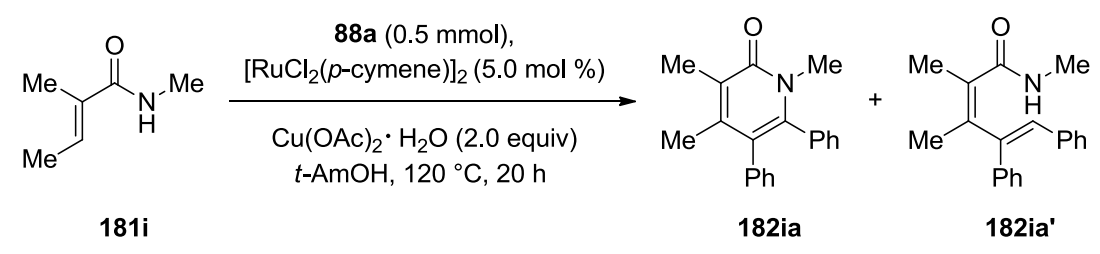

The general procedure $\mathbf{G}$ was followed using (E)-N,2-dimethylbut-2-enamide (181i) (125 mg, $1.11 \mathrm{mmol}), 1,2$-diphenylethyne (88a) $(89.0 \mathrm{mg}, 0.50 \mathrm{mmol})$, [RuCl${ }_{2}(p \text {-cymene) }]_{2}(16 \mathrm{mg}, 0.026 \mathrm{mmol}$, $5.0 \mathrm{~mol} \%)$ and $\mathrm{Cu}(\mathrm{OAc})_{2} \cdot \mathrm{H}_{2} \mathrm{O}(200 \mathrm{mg}, 1.00 \mathrm{mmol}, 2.0$ equiv) in $t-\mathrm{AmOH}(2.0 \mathrm{~mL})$. Purification by 
column chromatography ( $n$-hexane/EtOAc $4: 1$ ) yielded 182ia ( $82 \mathrm{mg}, 57 \%$ ) as a bright brown solid and 182ia' (23 mg, 16\%) as a colorless oil.<smiles></smiles>

\section{1,3,4-Trimethyl-5,6-diphenylpyridin-2(1H)-one (182ia)}

M.p.: $167^{\circ} \mathrm{C}$.

${ }^{1} \mathrm{H}-\mathrm{NMR}\left(300 \mathrm{MHz}, \mathrm{CDCl}_{3}\right): \delta=7.21-7.01(\mathrm{~m}, 6 \mathrm{H}), 7.01-6.94(\mathrm{~m}, 2 \mathrm{H}), 6.93-6.84(\mathrm{~m}, 2 \mathrm{H}), 3.25(\mathrm{~s}, 3 \mathrm{H})$, $2.22(\mathrm{~s}, 3 \mathrm{H}), 1.88(\mathrm{~s}, 3 \mathrm{H})$.

${ }^{13} \mathrm{C}$-NMR $\left(75 \mathrm{MHz}, \mathrm{CDCl}_{3}\right): \delta=162.6\left(\mathrm{C}_{\mathrm{q}}\right), 145.0\left(\mathrm{C}_{\mathrm{q}}\right), 143.3\left(\mathrm{C}_{\mathrm{q}}\right), 138.0\left(\mathrm{C}_{\mathrm{q}}\right), 134.9\left(\mathrm{C}_{\mathrm{q}}\right), 130.9(\mathrm{CH})$, $129.5(\mathrm{CH}), 128.1(\mathrm{CH}), 127.9(\mathrm{CH}), 127.7(\mathrm{CH}), 126.5(\mathrm{CH}), 124.7\left(\mathrm{C}_{\mathrm{q}}\right), 122.1\left(\mathrm{C}_{\mathrm{q}}\right), 34.7\left(\mathrm{CH}_{3}\right), 18.2$ $\left(\mathrm{CH}_{3}\right), 13.4\left(\mathrm{CH}_{3}\right)$.

IR (ATR): $\tilde{v}=3305,3052,2943,1634,1582,1441,763,703 \mathrm{~cm}^{-1}$. MS (EI) m/z (relative intensity): $288\left[\mathrm{M}-\mathrm{H}^{+}\right]$(100), 260 (18), 115 (12), 77 (24), 43 (44).

HR-MS (El) $m / z$ calculated for $\mathrm{C}_{20} \mathrm{H}_{19} \mathrm{NO}-\mathrm{H}^{+}$: 288.1388; found: 288.1398 .

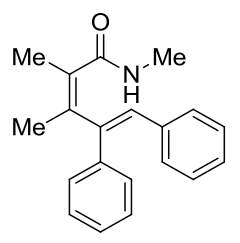

\section{(2Z,4E)-N,2,3-Trimethyl-4,5-diphenyl-penta-2,4-dienamide (182ia')}

${ }^{1} \mathrm{H}-\mathrm{NMR}\left(300 \mathrm{MHz}, \mathrm{CDCl}_{3}\right): \delta=7.28-7.20(\mathrm{~m}, 3 \mathrm{H}), 7.17-7.05(\mathrm{~m}, 5 \mathrm{H}), 7.01-6.93(\mathrm{~m}, 2 \mathrm{H}), 6.61(\mathrm{~s}, 1 \mathrm{H})$, $5.64(\mathrm{br} \mathrm{s}, 1 \mathrm{H}), 2.66(\mathrm{~d}, J=4.9 \mathrm{~Hz}, 3 \mathrm{H}), 1.98(\mathrm{~d}, J=1.0 \mathrm{~Hz}, 3 \mathrm{H}), 1.71(\mathrm{~d}, J=1.0 \mathrm{~Hz}, 3 \mathrm{H})$.

${ }^{13} \mathrm{C}-\mathrm{NMR}\left(75 \mathrm{MHz}, \mathrm{CDCl}_{3}\right): \delta=172.7\left(\mathrm{C}_{\mathrm{q}}\right), 143.0\left(\mathrm{C}_{\mathrm{q}}\right), 139.0\left(\mathrm{C}_{\mathrm{q}}\right), 138.2\left(\mathrm{C}_{\mathrm{q}}\right), 137.0\left(\mathrm{C}_{\mathrm{q}}\right), 132.0\left(\mathrm{C}_{\mathrm{q}}\right), 130.0$ $(\mathrm{CH}), 129.4(\mathrm{CH}), 128.7(\mathrm{CH}), 128.1(\mathrm{CH}), 128.0(\mathrm{CH}), 127.6(\mathrm{CH}), 126.9(\mathrm{CH}), 26.4\left(\mathrm{CH}_{3}\right), 18.4\left(\mathrm{CH}_{3}\right)$, $16.8\left(\mathrm{CH}_{3}\right)$.

IR (ATR): $\tilde{v}=3307,2960,1655,1448,1247,756,698 \mathrm{~cm}^{-1}$. MS (EI): m/z (relative intensity) $291\left[\mathrm{M}^{+}\right]$(100), 233 (84), 214 (96), 202 (44), 91 (33), 77 (50). HR-MS (EI) $\mathrm{m} / \mathrm{z}$ calculated for $\mathrm{C}_{20} \mathrm{H}_{21} \mathrm{NO}^{+}$: 291.1623; found: 291.1620 . 


\section{Synthesis of 3-Methyl-5,6-diphenyl-2H-pyran-2-one (184a)}<smiles>Cc1cc(-c2ccccc2)c(-c2ccccc2)oc1=O</smiles>

The general procedure $\mathbf{G}$ was followed using $\left[\operatorname{RuCl}_{2}(p \text {-cymene })\right]_{2}(15 \mathrm{mg}, 0.025 \mathrm{mmol}, 5.0 \mathrm{~mol} \%)$, methacrylic acid (183a) (148 mg, $1.72 \mathrm{mmol}, 3.44$ equiv) and 1,2-diphenylethyne (88a) (89.5 mg, $0.50 \mathrm{mmol}$ ). Purification by column chromatography ( $n$-hexane/EtOAc $3: 1$ ) yielded 184a (63 mg, 48\%) as slightly yellow oil.

${ }^{1} \mathrm{H}-\mathrm{NMR}(300 \mathrm{MHz}, \mathrm{CDCl}): \delta=7.34(\mathrm{t}, J=1.6 \mathrm{~Hz}, 1 \mathrm{H}), 7.32-7.27(\mathrm{~m}, 4 \mathrm{H}), 7.25$ (ddd, $J=5.0,2.1$, $1.0 \mathrm{~Hz}, 2 \mathrm{H}), 7.24-7.19(\mathrm{~m}, 2 \mathrm{H}), 7.18-7.14(\mathrm{~m}, 2 \mathrm{H}), 2.18(\mathrm{~d}, J=1.3 \mathrm{~Hz}, 3 \mathrm{H})$.

${ }^{13} \mathrm{C}-\mathrm{NMR}(75 \mathrm{MHz}, \mathrm{CDCl} 3): \delta=163.1\left(\mathrm{C}_{\mathrm{q}}\right), 155.4\left(\mathrm{C}_{\mathrm{q}}\right), 144.0(\mathrm{CH}), 136.6\left(\mathrm{C}_{\mathrm{q}}\right), 132.2\left(\mathrm{C}_{\mathrm{q}}\right), 129.5(\mathrm{CH})$, 129.2 (CH), $129.1(\mathrm{CH}), 128.9(\mathrm{CH}), 128.1(\mathrm{CH}), 127.7(\mathrm{CH}), 123.7\left(\mathrm{C}_{\mathrm{q}}\right), 128.0\left(\mathrm{C}_{\mathrm{q}}\right), 16.5\left(\mathrm{CH}_{3}\right)$.

IR (ATR): $\tilde{v}=1708,1550,1488,1443,1173,1050,949,764,693,574 \mathrm{~cm}^{-1}$.

MS (EI) m/z (relative intensity): 262 (100) [M+ $], 234$ (87), 191 (46), 129 (37), 105 (82), 77 (98), 51 (30).

HR-MS (EI) $m / z$ calculated for $\mathrm{C}_{18} \mathrm{H}_{14} \mathrm{O}_{2}^{+}: 262.0994$; found: 262.1000 .

The The analytical data were in accordance with those reported in the literature. ${ }^{213}$

\section{Intermolecular Competition Experiment between Alkynes 88a and 88p}

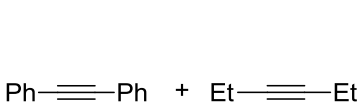

(2.0 equiv each)

$88 a$

$88 p$ benzamide $86 \mathrm{a}(0.5 \mathrm{mmol})$

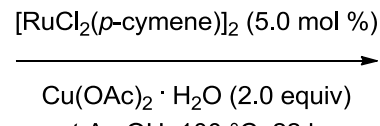

$t-\mathrm{AmOH}, 100^{\circ} \mathrm{C}, 22 \mathrm{~h}$

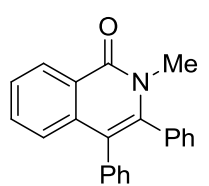

$49 \%$

180 ap

A mixture of $N$-methylbenzamide (86a) $(69.9 \mathrm{mg}, 0.52 \mathrm{mmol}), 88 \mathrm{a}(180 \mathrm{mg}, 1.01 \mathrm{mmol}), 88 \mathrm{p}$ (77.0 mg, $0.94 \mathrm{mmol}),\left[\mathrm{RuCl}_{2}(p \text {-cymene })\right]_{2}(16.0 \mathrm{mg}, 0.026 \mathrm{mmol}, 5.0 \mathrm{~mol} \%)$ and $\mathrm{Cu}(\mathrm{OAc}) \cdot \mathrm{H}_{2} \mathrm{O}$ (202 mg, $1.01 \mathrm{mmol})$ in $t-\mathrm{AmOH}(4.0 \mathrm{~mL})$ was stirred at $100^{\circ} \mathrm{C}$ for $22 \mathrm{~h}$. At ambient temperature, the reaction mixture was diluted with aq. $\mathrm{NH}_{4} \mathrm{Cl}(75 \mathrm{~mL})$ and extracted with EtOAc $(3 \times 75 \mathrm{~mL})$. After filtration and evaporation of the solvents in vacuo, the crude product was purified by column chromatography on silica gel ( $n$-hexane/EtOAc $3: 1$ ) to yield 180ap (79 mg, $49 \%$ ) as a colorless solid.

\footnotetext{
${ }^{213}$ Mochida, S.; Hirano, K.; Satoh, T.; Miura, M. J. Org. Chem. 2009, 74, 6295-6298.
} 


\section{(180ap)}

M.r.: $246-247^{\circ} \mathrm{C}$.

${ }^{1} \mathrm{H}-\mathrm{NMR}\left(300 \mathrm{MHz}, \mathrm{CDCl}_{3}\right): \delta=8.57(\mathrm{~d}, J=4.8 \mathrm{~Hz}, 1 \mathrm{H}), 7.52(\mathrm{~m}, 2 \mathrm{H}), 7.28-7.05(\mathrm{~m}, 11 \mathrm{H}), 3.36(\mathrm{~s}, 3 \mathrm{H})$.

${ }^{13} \mathrm{C}-\mathrm{NMR}\left(75 \mathrm{MHz}, \mathrm{CDCl}_{3}\right): \delta=162.7\left(\mathrm{C}_{\mathrm{q}}\right), 141.2\left(\mathrm{C}_{\mathrm{q}}\right), 137.2\left(\mathrm{C}_{\mathrm{q}}\right), 136.5\left(\mathrm{C}_{\mathrm{q}}\right), 135.1\left(\mathrm{C}_{\mathrm{q}}\right), 132.0(\mathrm{CH})$, $131.5(\mathrm{CH}), 129.9(\mathrm{CH}), 128.2(\mathrm{CH}), 128.2(\mathrm{CH}), 127.9(\mathrm{CH}), 127.8(\mathrm{CH}), 126.8(\mathrm{CH}), 126.6(\mathrm{CH}), 125.3$ $(\mathrm{CH}), 124.9\left(\mathrm{C}_{\mathrm{q}}\right), 118.8\left(\mathrm{C}_{\mathrm{q}}\right), 34.3\left(\mathrm{CH}_{3}\right)$.

IR (ATR): $\tilde{V}=1646,1604,1552,1489,1414,1176,1074,1025,924,781 \mathrm{~cm}^{-1}$.

MS (EI) $m / z$ (relative intensity): 311 (100) $\left[\mathrm{M}^{+}\right], 165$ (7), 77 (8).

HR-MS (EI) $m / z$ calculated for $\mathrm{C}_{22} \mathrm{H}_{17} \mathrm{NO}^{+}$: 311.1310; found: 311.1311 .

The The analytical data are in accordance with those reported in the literature. ${ }^{212}$

\section{Intermolecular Competition Experiment between Alkynes 88a and 88q}

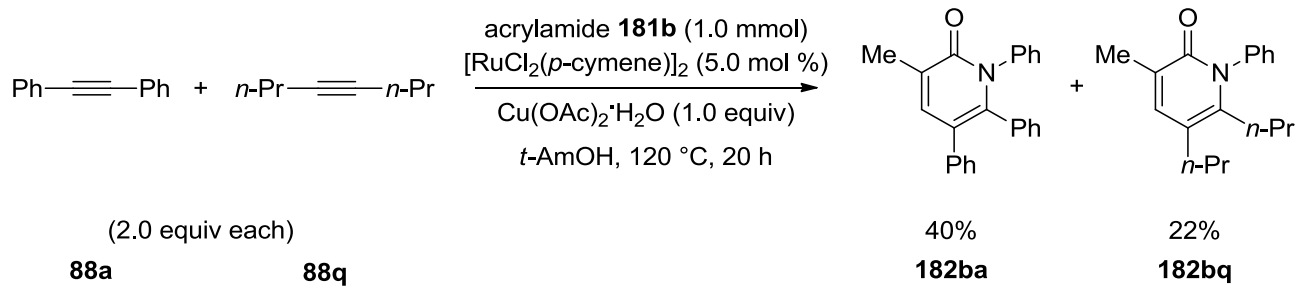

A mixture of $N$-phenylmethacrylamide (181b) $(81 \mathrm{mg}, 0.50 \mathrm{mmol}), \mathbf{8 8 a}(179 \mathrm{mg}, 1.00 \mathrm{mmol}), \mathbf{8 8 q}$ (114 mg, $1.01 \mathrm{mmol}),\left[\mathrm{RuCl}_{2}(p \text {-cymene })\right]_{2}(15.3 \mathrm{mg}, 5.0 \mathrm{~mol} \%)$ and $\mathrm{Cu}(\mathrm{OAc})_{2} \cdot \mathrm{H}_{2} \mathrm{O}(100 \mathrm{mg}, 0.50 \mathrm{mmol})$ in $t-\mathrm{AmOH}(4.0 \mathrm{~mL})$ was stirred at $120^{\circ} \mathrm{C}$ for $20 \mathrm{~h}$. At ambient temperature, the reaction mixture was diluted with aq. $\mathrm{NH}_{4} \mathrm{Cl}(75 \mathrm{~mL})$ and extracted with EtOAc $(3 \times 75 \mathrm{~mL})$. After filtration and evaporation of the solvents in vacuo, the crude product was purified by column chromatography on silica gel ( $n$ hexane/EtOAc 3:1 to EtOAc) to yield $182 \mathrm{ba}(67 \mathrm{mg}, 40 \%$ ) and $182 \mathrm{bg}$ ( $29 \mathrm{mg}, 22 \%$ ) as white solids.

Intermolecular Competition Experiment between Alkynes 88c and 88d
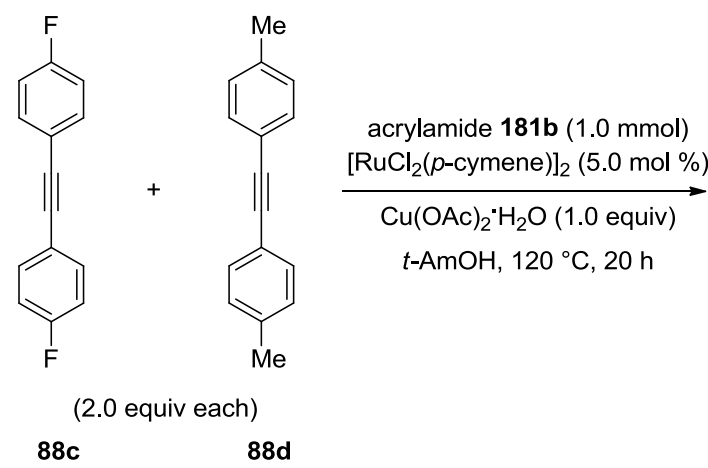<smiles>Cc1ccc(-c2cc(C)c(=O)n(-c3ccccc3)c2-c2ccc(C)cc2)cc1</smiles>

182bc: $41 \%$<smiles>COc1cc(-c2ccc(F)cc2)c(-c2ccc(F)cc2)n(-c2ccccc2)c1=O</smiles>

182bd: $30 \%$ 
A mixture of $\mathrm{N}$-phenylmethacrylamide $(\mathbf{1 8 1 b})(85.0 \mathrm{mg}, 0.53 \mathrm{mmol}), \mathbf{8 8 c}(214 \mathrm{mg}, 1.00 \mathrm{mmol}), \mathbf{8 8 d}$ (208 mg, $1.01 \mathrm{mmol}),\left[\mathrm{RuCl}_{2}(p \text {-cymene) }]_{2}(15.3 \mathrm{mg}, 5.0 \mathrm{~mol} \%)\right.$ and $\mathrm{Cu}(\mathrm{OAc})_{2} \cdot \mathrm{H}_{2} \mathrm{O}(100 \mathrm{mg}, 0.50 \mathrm{mmol})$ in $t-\mathrm{AmOH}(4.0 \mathrm{~mL})$ was stirred at $120^{\circ} \mathrm{C}$ for $20 \mathrm{~h}$. At ambient temperature, the reaction mixture was diluted with aq. $\mathrm{NH}_{4} \mathrm{Cl}(75 \mathrm{~mL})$ and extracted with EtOAc $(3 \times 75 \mathrm{~mL})$. After filtration and evaporation of the solvents in vacuo, the crude product was purified by column chromatography on silica gel ( $n$ hexane/EtOAc 1:1) to yield 182bd (59 mg, 30\%) and 182 bc (79 mg, 41\%) as white solids. 


\subsection{Crystallographic Details}

\section{Preparation of 2-Arylpyridinium Oxalates (129) and (149).}

To a stirred solution of (2-n-octylphenyl)pyridine (93aa) or 2-[3-(octan-2-yl)phenyl]pyridine (147aa) (1 equiv), in a mixture of DCM and one drop of $\mathrm{MeOH}$, a solution of anhydrous oxalic acid (1 equiv) in DCM was added in one portion at ambient temperature. After an additional stirring for $10 \mathrm{~min}$, the reaction mixture was concentrated under reduced pressure. The residue was dissolved with $\mathrm{DCM} / n$ octane mixture and filtered. Slow evaporation of this solution at ambient temperature afforded crystals suitable for X-ray diffractometry.

\section{2-(2-n-Octylphenyl)pyridinium Oxalate (129)}<smiles>O=C(O)C(=O)O</smiles>

M.r.: $82-84^{\circ} \mathrm{C}$.

${ }^{1} \mathrm{H}-\mathrm{NMR}\left(300 \mathrm{MHz}, \mathrm{CDCl}_{3}\right): \delta=11.10(\mathrm{~s}, 1 \mathrm{H}), 9.00(\mathrm{~s}, 1 \mathrm{H}), 8.29(\mathrm{t}, J=7.5 \mathrm{~Hz}, 1 \mathrm{H}), 7.74(\mathrm{~d}, J=7.9 \mathrm{~Hz}$, $1 \mathrm{H}), 7.56-7.42(\mathrm{~m}, 1 \mathrm{H}), 7.36(\mathrm{dd}, J=9.9,7.4 \mathrm{~Hz}, 3 \mathrm{H}), 2.71-2.50(\mathrm{~m}, 2 \mathrm{H}), 1.57-1.35(\mathrm{~m}, 2 \mathrm{H}), 1.21(\mathrm{~d}, J=$ $27.7 \mathrm{~Hz}, 12 \mathrm{H}), 0.85(\mathrm{t}, J=6.1 \mathrm{~Hz}, 3 \mathrm{H})$.

${ }^{13} \mathrm{C}-\mathrm{NMR}\left(126 \mathrm{MHz}, \mathrm{CDCl}_{3}\right): \delta=162.3\left(\mathrm{C}_{\mathrm{q}}\right), 158.1\left(\mathrm{C}_{\mathrm{q}}\right), 146.3(\mathrm{CH}), 141.2\left(\mathrm{C}_{\mathrm{q}}\right), 140.1(\mathrm{CH}), 130.2\left(\mathrm{C}_{\mathrm{q}}\right)$, $130.1(\mathrm{CH}), 130.1(\mathrm{CH}), 130.1(\mathrm{CH}), 126.3(\mathrm{CH}), 126.2(\mathrm{CH}), 123.2(\mathrm{CH}), 33.0\left(\mathrm{CH}_{2}\right), 31.9\left(\mathrm{CH}_{2}\right), 31.2$ $\left(\mathrm{CH}_{2}\right), 29.4\left(\mathrm{CH}_{2}\right), 29.3\left(\mathrm{CH}_{2}\right), 29.2\left(\mathrm{CH}_{2}\right), 22.7\left(\mathrm{CH}_{2}\right), 14.1\left(\mathrm{CH}_{3}\right)$.

HR-MS (ESI) $\mathrm{m} / \mathrm{z}$ calculated for $\mathrm{C}_{21} \mathrm{H}_{27} \mathrm{NO}_{4}-\mathrm{C}_{2} \mathrm{O}_{4} \mathrm{H}^{+}: 268.2065$; found: 268.2060 .

\section{2-[3-(Octan-2-yl)phenyl]pyridinium Oxalate (149)}

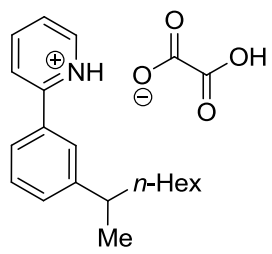

M.r.: $84-85^{\circ} \mathrm{C}$. 
${ }^{1} \mathrm{H}-\mathrm{NMR}\left(300 \mathrm{MHz}, \mathrm{CDCl}_{3}\right): \delta=8.89(\mathrm{~s}, 1 \mathrm{H}), 8.14(\mathrm{dd}, J=7.8,7.8 \mathrm{~Hz}, 1 \mathrm{H}), 7.93(\mathrm{~d}, J=8.0 \mathrm{~Hz}, 1 \mathrm{H}), 7.85-$ $7.71(\mathrm{~m}, 2 \mathrm{H}), 7.63-7.51(\mathrm{~m}, 1 \mathrm{H}), 7.48(\mathrm{dd}, J=7.6,7.6 \mathrm{~Hz}, 1 \mathrm{H}), 7.37(\mathrm{~d}, J=7.6 \mathrm{~Hz}, 1 \mathrm{H}), 2.79(\mathrm{qt}, J=7.1$, $7.0 \mathrm{~Hz}, 1 \mathrm{H}), 1.73-1.50(\mathrm{~m}, 2 \mathrm{H}), 1.42-1.11(\mathrm{~m}, 8 \mathrm{H}), 1.26(\mathrm{~d}, J=7.0 \mathrm{~Hz}, 3 \mathrm{H}), 0.85(\mathrm{t}, J=5.9 \mathrm{~Hz}, 3 \mathrm{H})$.

${ }^{13} \mathrm{C}$-NMR $\left(126 \mathrm{MHz}, \mathrm{CDCl}_{3}\right): \delta=162.7\left(\mathrm{C}_{\mathrm{q}}\right), 156.2\left(\mathrm{C}_{\mathrm{q}}\right), 150.0\left(\mathrm{C}_{\mathrm{q}}\right), 145.9(\mathrm{CH}), 142.0(\mathrm{CH}), 130.5(\mathrm{CH})$, $129.9(\mathrm{CH}), 127.0(\mathrm{CH}), 125.8(\mathrm{CH}), 123.6(\mathrm{CH}), 123.7(\mathrm{CH}), 40.4(\mathrm{CH}), 38.7\left(\mathrm{CH}_{2}\right), 32.1\left(\mathrm{CH}_{2}\right), 28.0$ $\left(\mathrm{CH}_{2}\right), 23.0\left(\mathrm{CH}_{2}\right), 22.6\left(\mathrm{CH}_{2}\right), 22.5\left(\mathrm{CH}_{3}\right), 14.4\left(\mathrm{CH}_{3}\right)$.

MS (EI) m/z (relative intensity): 267 (22) [M-Oxalat ${ }^{+}$], 196 (20), 182 (100), 167 (52), 43 (13).

HR-MS (EI) $\mathrm{m} / z$ calculated for $\mathrm{C}_{21} \mathrm{H}_{27} \mathrm{NO}_{4}-\mathrm{C}_{2} \mathrm{H}_{2} \mathrm{O}_{4}{ }^{+}: 267.1987$; found: 267.1996 .

\section{Preparation of 2-Arylpyridinium Chlorides (149) and ((R)-167).}

To a stirred solution of 2-[4-methoxy-3-(octan-2-yl)-phenyl]pyridine (147ba) or enantiomerically pure $(R)$-2-[3-(hexan-2-yl)-4-methoxyphenyl]pyridine [(R)-147bj], in a mixture of DCM and one drop of $\mathrm{MeOH}$, a concentrated aqueous solution of $\mathrm{HCl}$ (1 equiv) was added in one portion at ambient temperature. After an additional stirring for $10 \mathrm{~min}$, the reaction mixture was concentrated under reduced pressure. The residue was dissolved with $\mathrm{DCM} / n$-octane mixture and filtered. Slow evaporation of this solution at ambient temperature afforded crystals suitable for X-ray diffractometry.

\section{2-[4-Methoxy-3-(octan-2-yl)-phenyl]pyridinium Chloride (148)}

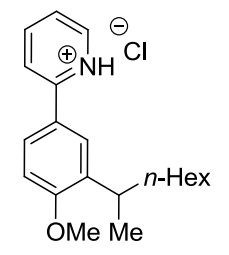

M.r.: $93-95^{\circ} \mathrm{C}$.

${ }^{1} \mathrm{H}-\mathrm{NMR}\left(300 \mathrm{MHz}, \mathrm{CDCl}_{3}\right): \delta=8.89(\mathrm{~d}, J=5.8 \mathrm{~Hz}, 1 \mathrm{H}), 8.37-8.20(\mathrm{~m}, 2 \mathrm{H}), 8.03(\mathrm{~d}, J=8.1 \mathrm{~Hz}, 1 \mathrm{H}), 7.88$ (d, $J=2.6 \mathrm{~Hz}, 1 \mathrm{H}$ ), 7.66 (ddd, $J=7.2,5.9,1.1 \mathrm{~Hz}, 1 \mathrm{H}$ ), 7.10 (d, $J=8.7 \mathrm{~Hz}, 1 \mathrm{H}$ ), $3.92(\mathrm{~s}, 3 \mathrm{H}), 3.24$ (qt, $J=$ 7.1, 7.0 Hz, 1H), 1.81-1.43 (m, 4H), 1.42-1.07 (m, 6H), $1.27(\mathrm{~d}, J=7.0 \mathrm{~Hz}, 3 \mathrm{H}), 0.85(\mathrm{t}, J=6.6 \mathrm{~Hz}, 3 \mathrm{H})$.

${ }^{13} \mathrm{C}-\mathrm{NMR}\left(126 \mathrm{MHz}, \mathrm{CDCl}_{3}\right): \delta=161.2\left(\mathrm{C}_{\mathrm{q}}\right), 153.1\left(\mathrm{C}_{\mathrm{q}}\right), 144.7(\mathrm{CH}), 141.8(\mathrm{CH}), 138.4\left(\mathrm{C}_{\mathrm{q}}\right), 128.1(\mathrm{CH})$, 127.0 (CH), $123.6(\mathrm{CH}), 122.7(\mathrm{CH}), 121.7\left(\mathrm{C}_{\mathrm{q}}\right), 111.8(\mathrm{CH}), 55.9\left(\mathrm{CH}_{3}\right), 37.2\left(\mathrm{CH}_{2}\right), 32.3(\mathrm{CH}), 32.1\left(\mathrm{CH}_{2}\right)$, $29.6\left(\mathrm{CH}_{2}\right), 27.8\left(\mathrm{CH}_{2}\right), 22.9\left(\mathrm{CH}_{2}\right), 21.0\left(\mathrm{CH}_{3}\right), 14.3\left(\mathrm{CH}_{3}\right)$.

MS (EI) m/z (relative intensity): 297 (41) [M-HCl ], 212 (100), 197 (17), 167 (30).

HR-MS (EI) $m / z$ calculated for $\mathrm{C}_{20} \mathrm{H}_{28} \mathrm{CINO}-\mathrm{HCl}^{+}: 297.2093$; found: 297.2088 . 
(R)-2-[3-(Hexan-2-yl)-4-methoxyphenyl]pyridinium chloride ((R)-167)

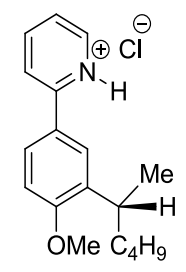

${ }^{1} \mathrm{H}-\mathrm{NMR}\left(300 \mathrm{MHz}, \mathrm{CDCl}_{3}\right): \delta=8.87(\mathrm{~d}, J=5.7 \mathrm{~Hz}, 1 \mathrm{H}), 8.37-8.20(\mathrm{~m}, 2 \mathrm{H}), 8.03(\mathrm{~d}, J=8.1 \mathrm{~Hz}, 1 \mathrm{H}), 7.88$ (d, $J=2.6 \mathrm{~Hz}, 1 \mathrm{H}$ ), 7.66 (ddd, $J=7.2,5.9,1.1 \mathrm{~Hz}, 1 \mathrm{H}$ ), 7.08 (d, $J=8.6 \mathrm{~Hz}, 1 \mathrm{H}$ ), $3.92(\mathrm{~s}, 3 \mathrm{H}), 3.24$ (qt, $J=$ 7.1, 7.0 Hz, 1H), 1.79-1.43 (m, 2H), 1.42-1.07 (m, 4H), $1.27(\mathrm{~d}, J=7.0 \mathrm{~Hz}, 3 \mathrm{H}), 0.85(\mathrm{t}, J=6.7 \mathrm{~Hz}, 3 \mathrm{H})$.

${ }^{13} \mathrm{C}$-NMR $\left(126 \mathrm{MHz}, \mathrm{CDCl}_{3}\right): \delta=161.2\left(\mathrm{C}_{\mathrm{q}}\right), 153.1\left(\mathrm{C}_{\mathrm{q}}\right), 144.7(\mathrm{CH}), 141.8(\mathrm{CH}), 138.4\left(\mathrm{C}_{\mathrm{q}}\right), 128.1(\mathrm{CH})$, 127.0 (CH), $123.6(\mathrm{CH}), 122.7(\mathrm{CH}), 121.7\left(\mathrm{C}_{\mathrm{q}}\right), 111.8(\mathrm{CH}), 55.9\left(\mathrm{CH}_{3}\right), 37.2\left(\mathrm{CH}_{2}\right), 32.3(\mathrm{CH}), 29.6\left(\mathrm{CH}_{2}\right)$, $22.9\left(\mathrm{CH}_{2}\right), 21.0\left(\mathrm{CH}_{3}\right), 14.3\left(\mathrm{CH}_{3}\right)$.

MS (El) $m / z$ (relative intensity): 269 (41) $\left[\mathrm{M}-\mathrm{HCl}^{+}\right], 184$ (100), 197 (22).

HR-MS (El) $m / z$ calculated for $\mathrm{C}_{18} \mathrm{H}_{24} \mathrm{ClNO}-\mathrm{HCl}^{+}$: 269.1780; found: 269.1783 .

Table S-1. Crystal and data collection parameters for compounds 129, 148, 149 and $(R)-167$

\begin{tabular}{|c|c|c|c|c|}
\hline Compound & 129 & 148 & 149 & (R)-167 \\
\hline $\begin{array}{l}\text { Empirical } \\
\text { formula }\end{array}$ & $\begin{array}{c}\mathrm{C}_{19} \mathrm{H}_{26} \mathrm{~N}^{+} \mathrm{x} \\
\mathrm{C}_{2} \mathrm{HO}_{4}^{-} \mathrm{x} \\
\mathrm{C}_{2} \mathrm{H}_{2} \mathrm{O}_{4}\end{array}$ & $\begin{array}{c}\mathrm{C}_{20} \mathrm{H}_{28} \mathrm{NO}^{+} \mathrm{x} \\
\mathrm{Cl}^{-} \mathrm{x} \\
\mathrm{H}_{2} \mathrm{O}\end{array}$ & $\begin{array}{c}{\left[\mathrm{C}_{19} \mathrm{H}_{26} \mathrm{~N}\right]^{+} \mathrm{x}} \\
{\left[\mathrm{C}_{2} \mathrm{O}_{4} \mathrm{H}\right]^{-} \mathrm{x}} \\
0.5\left[\mathrm{C}_{2} \mathrm{O}_{4} \mathrm{H}_{2}\right]\end{array}$ & $\begin{array}{c}\mathrm{C}_{18} \mathrm{H}_{24} \mathrm{ClNO} x \\
0.5 \mathrm{H}_{2} \mathrm{O}\end{array}$ \\
\hline $\begin{array}{c}\text { Molecular } \\
\text { mass [g/mol] }\end{array}$ & 447.47 & 351.90 & 402.45 & 314.84 \\
\hline $\begin{array}{c}\text { Temperature } \\
\qquad[\mathrm{K}]\end{array}$ & 120 & 120 & 120 & 100.0 \\
\hline $\begin{array}{l}\text { Crystal } \\
\text { system }\end{array}$ & monoclinic & triclinic & triclinic & monoclinic \\
\hline Space group & $C 2 / c$ & $P-1$ & $P-1$ & $C 2$ \\
\hline $\mathrm{a}[\AA ̊]$ & $32.502(5)$ & $4.9785(3)$ & $5.6937(7)$ & $34.0337(19)$ \\
\hline b [Å] & $14.839(2)$ & $8.7894(5)$ & $10.2647(12)$ & $5.5726(3)$ \\
\hline$c[\AA ̊]$ & $9.7776(14)$ & $22.6643(14)$ & $19.007(2)$ & $18.2007(11)$ \\
\hline$\alpha\left[{ }^{\circ}\right]$ & 90.00 & $87.606(2)$ & $95.608(4)$ & 90.00 \\
\hline$B\left[^{\circ}\right]$ & $106.084(4)$ & $86.998(2)$ & $97.574(4)$ & $90.524(2)$ \\
\hline
\end{tabular}




\begin{tabular}{|c|c|c|c|c|}
\hline Compound & 129 & 148 & 149 & $(R)-167$ \\
\hline$v\left[^{\circ}\right]$ & 90.00 & $77.422(2)$ & $97.614(4)$ & 90.00 \\
\hline Volume $\left[\AA^{3}\right]$ & $4531.2(11)$ & $966.15(10)$ & $1083.9(2)$ & $3451.7(3)$ \\
\hline$z$ & 8 & 2 & 2 & 8 \\
\hline $\begin{array}{c}D_{\text {calc }} \\
{\left[\mathrm{mg} / \mathrm{mm}^{3}\right]}\end{array}$ & 1.312 & 1.210 & 1.233 & 1.212 \\
\hline$\mu\left[\mathrm{mm}^{-1}\right]$ & 0.099 & 0.209 & 0.090 & 1.971 \\
\hline$F(000)$ & 1904.0 & 380.0 & 430.0 & 1352.0 \\
\hline $\begin{array}{l}\text { Crystal } \\
\text { size } / \mathrm{mm}^{3}\end{array}$ & $0.48 \times 0.12 \times 0.04$ & $0.42 \times 0.12 \times 0.09$ & $0.44 \times 0.06 \times 0.001$ & $0.38 \times 0.02 \times 0.01$ \\
\hline $\begin{array}{c}20 \text { range for } \\
\text { data } \\
\text { collection }\end{array}$ & 3.04 to $55^{\circ}$ & 3.6 to $58^{\circ}$ & 4.04 to $52^{\circ}$ & 4.86 to $120^{\circ}$ \\
\hline Index ranges & $\begin{array}{c}-42 \leq h \leq 42 \\
-19 \leq k \leq 19 \\
-12 \leq 1 \leq 12\end{array}$ & $\begin{array}{c}-6 \leq h \leq 6, \\
-11 \leq k \leq 11 \\
-30 \leq 1 \leq 30\end{array}$ & $\begin{array}{c}-7 \leq h \leq 7, \\
-11 \leq k \leq 12, \\
-23 \leq 1 \leq 23\end{array}$ & $\begin{array}{c}-35 \leq h \leq 38 \\
-6 \leq k \leq 5 \\
-19 \leq 1 \leq 19\end{array}$ \\
\hline $\begin{array}{l}\text { Reflections } \\
\text { collected }\end{array}$ & 22812 & 15955 & 8319 & 8125 \\
\hline $\begin{array}{l}\text { Independent } \\
\text { reflections }\end{array}$ & $\begin{array}{c}5206 \\
{[R(\mathrm{int})=0.2062]}\end{array}$ & $\begin{array}{c}5106 \\
{[R(\text { int })=0.0320]}\end{array}$ & $\begin{array}{c}4213 \\
{[R(\text { int })=0.0566]}\end{array}$ & $\begin{array}{c}4131 \\
{[R \text { (int) }=0.0503]}\end{array}$ \\
\hline $\begin{array}{c}\text { Data/ } \\
\text { restraints/ } \\
\text { parameters }\end{array}$ & $5206 / 0 / 406$ & $5106 / 0 / 337$ & $4213 / 0 / 306$ & $4131 / 1 / 588$ \\
\hline GoF & 0.972 & 1.013 & 0.983 & 1.022 \\
\hline $\begin{array}{c}\text { Final } R \\
\text { indexes } \\
{[1>2 \sigma(I)]}\end{array}$ & $\begin{array}{c}R_{1}=0.0727, \\
w R_{2}=0.1144\end{array}$ & $\begin{array}{c}R_{1}=0.0421, \\
\mathrm{w} R_{2}=0.1057\end{array}$ & $\begin{array}{l}R_{1}=0.0756 \\
w R_{2}=0.1886\end{array}$ & $\begin{array}{c}R_{1}=0.0523, \\
w R_{2}=0.1241\end{array}$ \\
\hline $\begin{array}{c}\text { Final R } \\
\text { indexes } \\
\text { [all data] }\end{array}$ & $\begin{array}{c}R_{1}=0.1694, \\
w R_{2}=0.1314\end{array}$ & $\begin{array}{c}R_{1}=0.0576, \\
w R_{2}=0.1164\end{array}$ & $\begin{array}{c}\mathrm{R}_{1}=0.1452, \\
w R_{2}=0.2204\end{array}$ & $\begin{array}{c}\mathrm{R}_{1}=0.0681, \\
\mathrm{wR}_{2}=0.1323\end{array}$ \\
\hline
\end{tabular}


More detailed illustrations of the different molecular structures of compounds $129,148,149$ and $(R)$ -

167 in the crystals including fragments of molecular packings and $\mathrm{H}$-bondings are presented below.
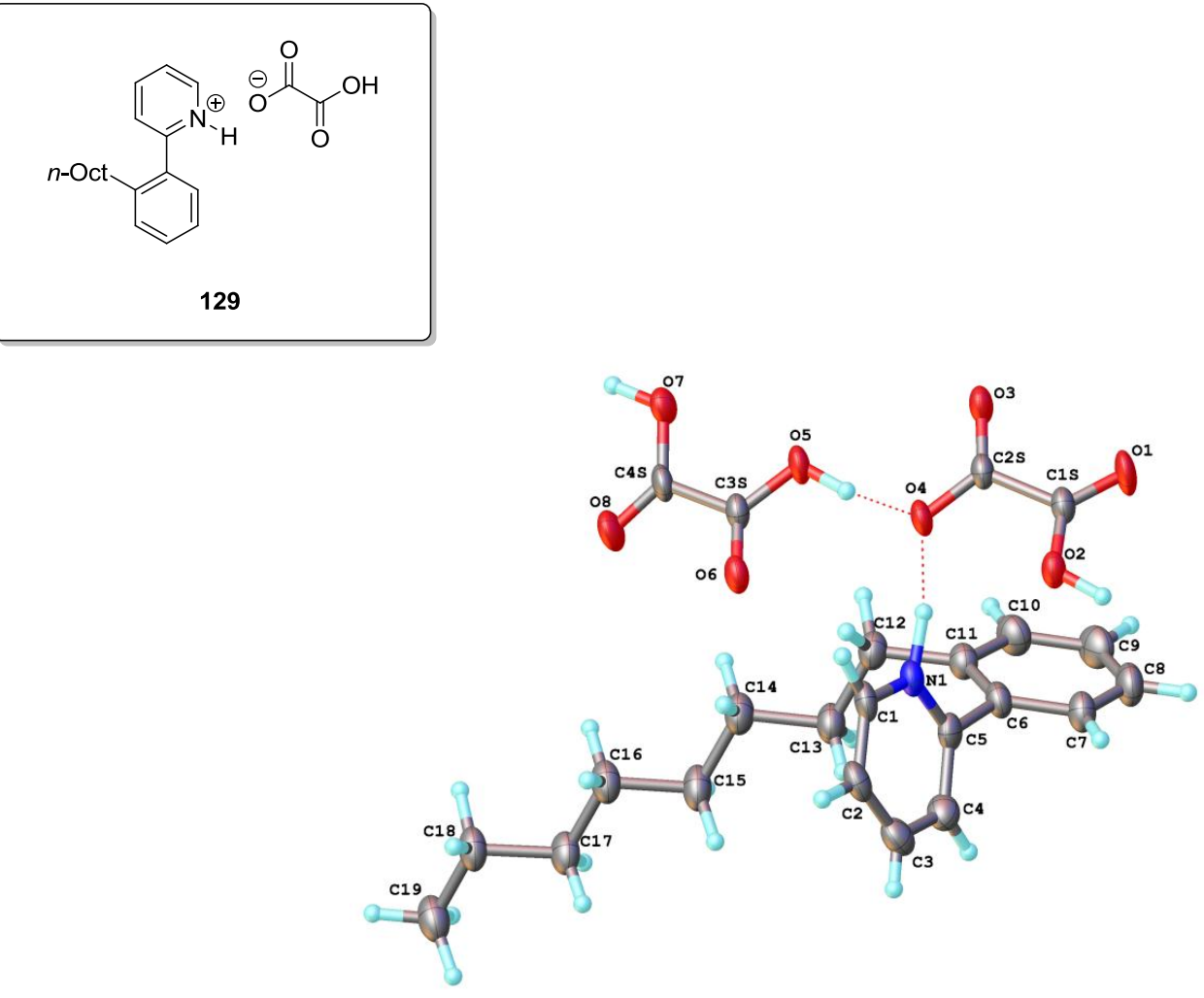

Figure 7.1: Molecular structure of $\mathbf{1 2 9}$ in the crystals. Thermal ellipsoids are shown at $50 \%$ probability.

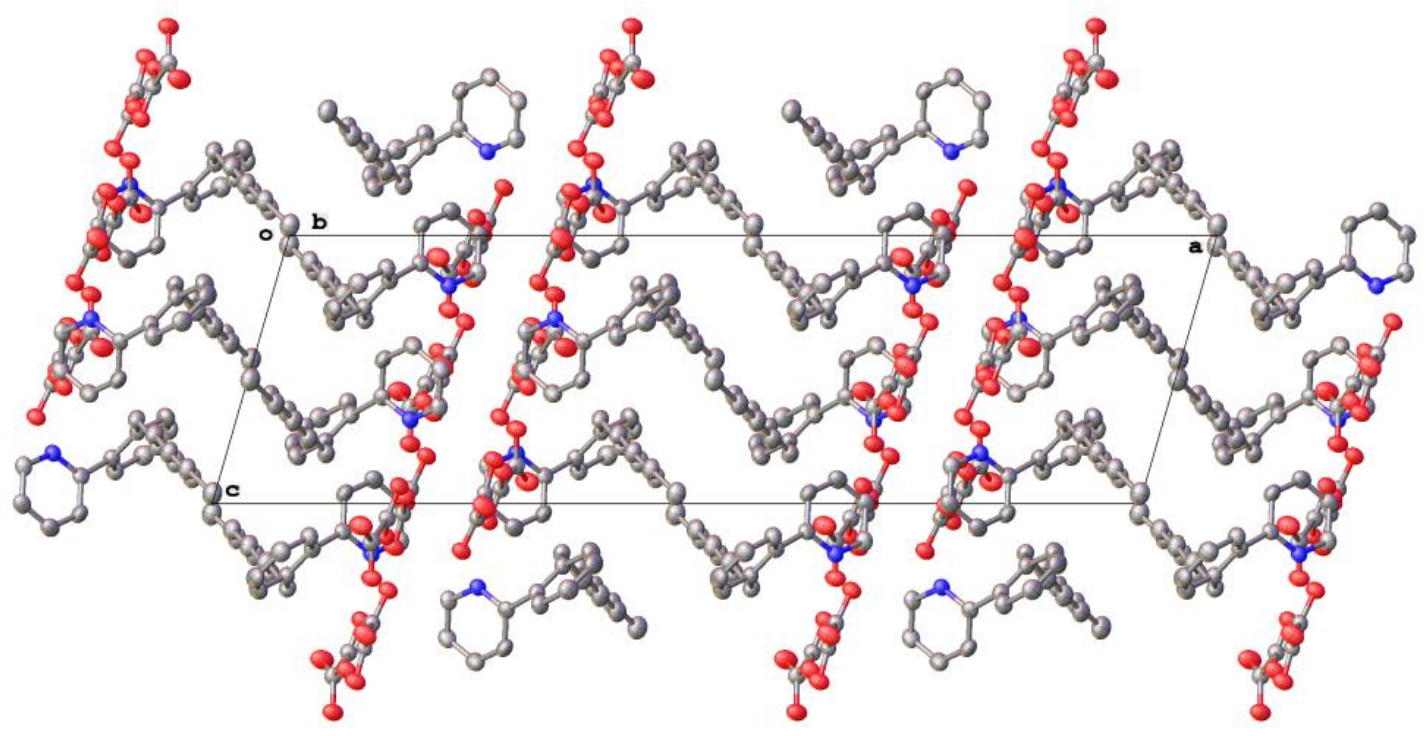

Figure 7.2: Fragment of the molecular packing in extended unit cell of 129; space group C2/c. 
Table S-2 Fractional Atomic Coordinates $\left(\times 10^{4}\right)$ and Equivalent Isotropic Displacement Parameters $\left(\AA^{2} \times 10^{3}\right)$ for $129 . U_{\text {eq }}$ is defined as $1 / 3$ of the trace of the orthogonalised $U_{\mathrm{IJ}}$ tensor.

\begin{tabular}{|c|c|c|c|c|}
\hline Atom & $x$ & $y$ & $z$ & $\mathrm{U}(\mathrm{eq})$ \\
\hline N1 & $6874.6(9)$ & $2772.9(14)$ & $1881(3)$ & $30.5(6)$ \\
\hline C1 & $7147.0(12)$ & $2258.1(17)$ & $1393(4)$ & $35.3(8)$ \\
\hline C2 & $7046.8(12)$ & $2026.8(19)$ & $-13(4)$ & $37.8(8)$ \\
\hline C3 & $6670.9(12)$ & $2331(2)$ & $-895(4)$ & $41.0(9)$ \\
\hline C4 & $6397.3(12)$ & $2842(2)$ & $-383(4)$ & $37.8(8)$ \\
\hline C5 & $6498.4(10)$ & $3056.0(17)$ & $1032(3)$ & $32.0(8)$ \\
\hline C6 & $6221.6(10)$ & $3614.4(18)$ & $1689(3)$ & $33.2(8)$ \\
\hline C7 & $6150.6(11)$ & $4510(2)$ & $1238(4)$ & $39.4(9)$ \\
\hline $\mathrm{C} 8$ & $5890.2(12)$ & $5045(2)$ & $1797(4)$ & $45.3(10)$ \\
\hline C9 & $5697.6(12)$ & $4713(2)$ & $2761(4)$ & $48.7(10)$ \\
\hline C10 & $5765.4(12)$ & $3825(2)$ & $3205(4)$ & $44.3(9)$ \\
\hline C11 & $6026.7(10)$ & $3259.3(18)$ & $2683(3)$ & $34.2(8)$ \\
\hline C12 & $6076.8(12)$ & 2277.6(19) & $3148(4)$ & $37.0(8)$ \\
\hline C13 & $5760.3(13)$ & $1652.0(19)$ & $2159(4)$ & $40.7(9)$ \\
\hline C14 & $5837.8(13)$ & $662(2)$ & $2591(4)$ & $41.8(9)$ \\
\hline C15 & $5526.5(13)$ & $33(2)$ & $1570(5)$ & $45(1)$ \\
\hline C16 & $5623.8(12)$ & $-958(2)$ & $1916(4)$ & $42.6(9)$ \\
\hline C17 & $5294.4(13)$ & $-1568(2)$ & $967(4)$ & $42.1(9)$ \\
\hline C18 & $5377.0(12)$ & $-2576(2)$ & $1292(4)$ & $41.9(9)$ \\
\hline C19 & $5027.9(14)$ & $-3167(2)$ & $373(5)$ & $50.6(10)$ \\
\hline 05 & $6964.9(7)$ & $1876.7(12)$ & $6205(2)$ & $35.9(6)$ \\
\hline 06 & $6965.8(7)$ & $1005.5(12)$ & $4349(2)$ & $35.1(5)$ \\
\hline 07 & $6951.5(7)$ & $463.2(13)$ & $7779(2)$ & $38.3(6)$ \\
\hline 08 & $6671.7(8)$ & $-355.3(12)$ & $5817(2)$ & $46.9(7)$ \\
\hline C3S & $6933.7(10)$ & $1112.4(17)$ & $5548(3)$ & $31.3(7)$ \\
\hline C4S & $6839.2(11)$ & $313.8(17)$ & $6421(4)$ & $32.8(8)$ \\
\hline 01 & $7055.5(8)$ & $5499.0(11)$ & $4891(2)$ & $45.9(6)$ \\
\hline 02 & $7164.9(7)$ & $4557.2(12)$ & $3227(2)$ & $34.8(6)$ \\
\hline 03 & 7096.7(7) & $4010.1(11)$ & $6622(2)$ & $37.8(6)$ \\
\hline 04 & $7060.6(7)$ & $3162.4(11)$ & $4720(2)$ & $33.8(5)$ \\
\hline C1S & $7098.5(10)$ & $4758.4(17)$ & $4458(3)$ & $31.2(7)$ \\
\hline $\mathrm{C} 2 \mathrm{~S}$ & $7089.4(10)$ & $3918.0(17)$ & $5374(3)$ & $29.5(7)$ \\
\hline
\end{tabular}

Table S-3 Anisotropic Displacement Parameters $\left(\AA^{2} \times 10^{3}\right)$ for 129. The Anisotropic displacement factor exponent takes the form: $-2 \pi^{2}\left[h^{2} a *^{2} U_{11}+\ldots+2 h k a \times b \times U_{12}\right]$

\begin{tabular}{|c|c|c|c|c|c|c|}
\hline Atom & $\mathrm{U}_{11}$ & $\mathrm{U}_{22}$ & $\mathrm{U}_{33}$ & $\mathbf{U}_{23}$ & $\mathbf{U}_{13}$ & $\mathrm{U}_{12}$ \\
\hline N1 & $37.8(17)$ & $16.7(11)$ & $38.7(16)$ & $1.2(11)$ & $13.1(14)$ & $1.9(12)$ \\
\hline C1 & $40(2)$ & $14.5(13)$ & $53(2)$ & $0.3(15)$ & $15.8(19)$ & $2.3(15)$ \\
\hline $\mathrm{C} 2$ & $47(2)$ & 19.1(15) & $51(2)$ & $-7.9(15)$ & $19(2)$ & $-5.2(15)$ \\
\hline C3 & $50(2)$ & 29.5(17) & $45(2)$ & $-8.4(17)$ & $16(2)$ & $-8.8(17)$ \\
\hline C4 & $33(2)$ & $31.8(17)$ & $43(2)$ & $-0.2(15)$ & $2.6(18)$ & $-0.8(16)$ \\
\hline C5 & $39(2)$ & $17.6(13)$ & $41(2)$ & $5.2(13)$ & $13.5(17)$ & $-2.0(13)$ \\
\hline C6 & $37(2)$ & $19.9(14)$ & $41.9(19)$ & $-3.5(13)$ & $10.5(16)$ & $-0.4(13)$ \\
\hline C7 & $43(2)$ & $23.9(16)$ & $52(2)$ & $2.4(15)$ & 15.1(19) & $4.0(15)$ \\
\hline C8 & $55(3)$ & $23.9(16)$ & $57(2)$ & $0.5(16)$ & $15(2)$ & $7.0(16)$ \\
\hline C9 & $46(2)$ & $40.5(19)$ & $59(3)$ & $-5.0(18)$ & $13(2)$ & $15.6(17)$ \\
\hline C10 & $50(2)$ & $35.3(18)$ & $51(2)$ & $-6.0(17)$ & $20(2)$ & $4.0(17)$ \\
\hline C11 & $36(2)$ & $24.1(15)$ & $42(2)$ & $-0.6(14)$ & $10.8(16)$ & $2.5(14)$ \\
\hline C12 & $39(2)$ & $25.6(15)$ & $46(2)$ & $5.2(15)$ & $10.0(18)$ & $0.8(15)$ \\
\hline C13 & $44(2)$ & $24.0(16)$ & $52(2)$ & $3.9(15)$ & $9(2)$ & $3.0(15)$ \\
\hline C14 & $44(2)$ & $26.4(16)$ & $53(2)$ & $5.4(15)$ & $10(2)$ & $0.4(16)$ \\
\hline C15 & $44(2)$ & $25.1(16)$ & $66(3)$ & $5.3(16)$ & $13(2)$ & $3.0(16)$ \\
\hline C16 & $39(2)$ & $26.2(16)$ & $59(3)$ & $-0.9(17)$ & $9(2)$ & $3.1(16)$ \\
\hline C17 & $42(2)$ & $26.0(17)$ & $58(3)$ & $3.1(16)$ & $14(2)$ & $6.5(15)$ \\
\hline C18 & $41(2)$ & $23.0(16)$ & $61(3)$ & $1.7(16)$ & $13(2)$ & $3.6(15)$ \\
\hline C19 & $50(3)$ & $28.2(18)$ & $72(3)$ & $-2.2(19)$ & $15(2)$ & $3.2(18)$ \\
\hline 05 & $54.3(15)$ & $12.5(9)$ & $43.7(13)$ & $-0.7(9)$ & $18.4(12)$ & $2.2(9)$ \\
\hline 06 & $49.1(15)$ & $16.9(10)$ & $41.8(13)$ & $-0.6(9)$ & $17.1(12)$ & $3.5(9)$ \\
\hline 07 & $57.6(16)$ & $19.1(10)$ & $38.9(15)$ & $-1.4(10)$ & $14.6(12)$ & $-6.3(10)$ \\
\hline 08 & $74.4(18)$ & $17.9(10)$ & $49.6(15)$ & $-3.5(10)$ & $19.2(13)$ & $-9.9(11)$ \\
\hline
\end{tabular}




\begin{tabular}{lcccccc}
\hline \hline C3S & $40(2)$ & $15.3(13)$ & $40(2)$ & $0.9(13)$ & $12.9(17)$ & $1.8(13)$ \\
C4S & $41(2)$ & $13.2(13)$ & $43(2)$ & $-1.7(14)$ & $10.1(16)$ & $2.6(13)$ \\
O1 & $76.5(18)$ & $11.9(10)$ & $56.5(15)$ & $-0.4(10)$ & $30.2(14)$ & $5.2(11)$ \\
O2 & $51.0(15)$ & $17.4(10)$ & $38.9(14)$ & $2.8(10)$ & $17.2(12)$ & $2.8(10)$ \\
O3 & $59.7(16)$ & $16.2(10)$ & $40.6(14)$ & $1.7(10)$ & $19.0(12)$ & $0.6(10)$ \\
O4 & $50.4(14)$ & $12.8(9)$ & $38.8(13)$ & $-3.0(9)$ & $13.3(11)$ & $0.4(9)$ \\
C1S & $35.2(19)$ & $18.1(14)$ & $41(2)$ & $0.8(13)$ & $12.0(16)$ & $1.0(13)$ \\
C2S & $35.5(18)$ & $15.6(14)$ & $39(2)$ & $1.1(13)$ & $12.7(16)$ & $2.1(13)$ \\
\hline \hline
\end{tabular}

Table S-4 Bond Lengths for 129.

\begin{tabular}{cccccc} 
Atom & Atom & Length/A & Atom & Atom & Length/Å \\
\hline \hline N1 & C1 & $1.352(4)$ & C14 & C15 & $1.527(5)$ \\
N1 & C5 & $1.341(4)$ & C15 & C16 & $1.522(4)$ \\
C1 & C2 & $1.366(5)$ & C16 & C17 & $1.508(5)$ \\
C2 & C3 & $1.363(5)$ & C17 & C18 & $1.538(4)$ \\
C3 & C4 & $1.365(5)$ & C18 & C19 & $1.516(5)$ \\
C4 & C5 & $1.368(5)$ & O5 & C3S & $1.293(3)$ \\
C5 & C6 & $1.493(4)$ & O6 & C3S & $1.216(3)$ \\
C6 & C7 & $1.398(4)$ & O7 & C4S & $1.295(4)$ \\
C6 & C11 & $1.402(4)$ & O8 & C4S & $1.205(3)$ \\
C7 & C8 & $1.379(5)$ & C3S & C4S & $1.540(4)$ \\
C8 & C9 & $1.359(5)$ & O1 & C1S & $1.200(3)$ \\
C9 & C10 & $1.386(4)$ & O2 & C1S & $1.314(4)$ \\
C10 & C11 & $1.388(4)$ & O3 & C2S & $1.222(3)$ \\
C11 & C12 & $1.521(4)$ & O4 & C2S & $1.281(3)$ \\
C12 & C13 & $1.518(5)$ & C1S & C2S & $1.540(4)$ \\
C13 & C14 & $1.531(4)$ & & & \\
\hline \hline
\end{tabular}

Table S-5 Bond Angles for 129.

\begin{tabular}{|c|c|c|c|c|c|c|c|}
\hline Atom & Atom & Atom & Angle/ ${ }^{\circ}$ & Atom & Atom & Atom & Angle $^{\circ}$ \\
\hline C5 & N1 & C1 & $122.2(3)$ & C12 & C13 & C14 & $112.4(3)$ \\
\hline N1 & C1 & C2 & $120.0(3)$ & C15 & C14 & C13 & $112.2(3)$ \\
\hline C3 & C2 & C1 & $118.4(3)$ & C16 & C15 & C14 & $112.7(3)$ \\
\hline C2 & C3 & C4 & $120.8(4)$ & C17 & C16 & C15 & $112.0(3)$ \\
\hline C3 & C4 & C5 & $120.1(3)$ & C16 & C17 & C18 & $113.8(3)$ \\
\hline N1 & C5 & C4 & $118.4(3)$ & C19 & C18 & C17 & $112.4(3)$ \\
\hline N1 & C5 & C6 & $117.6(3)$ & 05 & C3S & C4S & $113.6(3)$ \\
\hline C4 & C5 & C6 & $124.0(3)$ & 06 & C3S & 05 & $125.3(3)$ \\
\hline C7 & C6 & C5 & $117.3(3)$ & 06 & C3S & C4S & $121.2(2)$ \\
\hline C7 & C6 & C11 & $120.6(3)$ & 07 & C4S & C3S & $113.2(2)$ \\
\hline C11 & C6 & C5 & $122.1(2)$ & 08 & C4S & 07 & $127.1(3)$ \\
\hline C8 & C7 & C6 & $119.2(3)$ & 08 & C4S & C3S & $119.7(3)$ \\
\hline C9 & C8 & C7 & $121.2(3)$ & 01 & C1S & 02 & $126.6(3)$ \\
\hline C8 & C9 & C10 & $119.8(3)$ & 01 & C1S & C2S & $120.9(3)$ \\
\hline C9 & C10 & C11 & $121.3(4)$ & 02 & C1S & C2S & $112.5(2)$ \\
\hline C6 & C11 & C12 & $122.4(3)$ & 03 & $\mathrm{C} 2 \mathrm{~S}$ & 04 & $125.1(3)$ \\
\hline C10 & C11 & C6 & $117.9(3)$ & 03 & $\mathrm{C} 2 \mathrm{~S}$ & C1S & $119.5(2)$ \\
\hline C10 & C11 & C12 & $119.6(3)$ & 04 & $\mathrm{C} 2 \mathrm{~S}$ & C1S & $115.4(3)$ \\
\hline C13 & $\mathrm{C} 12$ & C11 & $113.4(3)$ & & & & \\
\hline
\end{tabular}

Table S-6 Hydrogen Bonds for 129.

\begin{tabular}{|c|c|c|c|c|c|c|}
\hline D & H & A & d(D-H)/Å & $d(H-A) / \AA ̊$ & $d(D-A) / \AA ̊$ & D-H-A $/^{\circ}$ \\
\hline N1 & H1 & 04 & $1.08(4)$ & $1.70(4)$ & $2.735(3)$ & $158(3)$ \\
\hline 07 & H7A & $06^{1}$ & $0.99(4)$ & $1.70(4)$ & $2.659(3)$ & $162(4)$ \\
\hline 02 & $\mathrm{H} 2 \mathrm{~A}$ & $03^{2}$ & $0.92(3)$ & $1.70(3)$ & $2.615(3)$ & $170(3)$ \\
\hline 05 & H5 & 04 & $0.99(5)$ & $1.48(5)$ & $2.469(3)$ & $174(5)$ \\
\hline
\end{tabular}


Table S-7 Torsion Angles for 129.

\begin{tabular}{ccccc} 
A & B & C & D & Angle/ $^{\circ}$ \\
\hline \hline N1 & C5 & C6 & C11 & $-67.9(4)$ \\
\hline \hline
\end{tabular}

Table S-8 Hydrogen Atom Coordinates $\left(\AA \times 10^{4}\right)$ and Isotropic Displacement Parameters $\left(\AA^{2} \times 10^{3}\right)$ for 129.

\begin{tabular}{ccccc} 
Atom & $\boldsymbol{X}$ & $\boldsymbol{y}$ & $\boldsymbol{Z}$ & $\boldsymbol{U}(\mathrm{eq})$ \\
\hline \hline H1A & $7422(9)$ & $2106(16)$ & $2110(30)$ & $21(7)$ \\
H1 & $7016(12)$ & $2990(20)$ & $2960(40)$ & $71(12)$ \\
H3 & $6602(13)$ & $2190(20)$ & $-1820(40)$ & $66(13)$ \\
H2 & $7250(10)$ & $1651(19)$ & $-400(30)$ & $44(9)$ \\
H4 & $6135(9)$ & $3010(15)$ & $-1010(30)$ & $14(7)$ \\
H7 & $6318(10)$ & $4693(18)$ & $560(30)$ & $37(9)$ \\
H8 & $5878(10)$ & $5650(20)$ & $1450(30)$ & $40(9)$ \\
H9 & $5477(12)$ & $5080(20)$ & $3210(40)$ & $71(11)$ \\
H10 & $5610(12)$ & $3600(20)$ & $3900(40)$ & $61(11)$ \\
H12A & $6053(10)$ & $2244(19)$ & $4250(40)$ & $48(9)$ \\
H12B & $6391(10)$ & $2057(17)$ & $3320(30)$ & $31(8)$ \\
H13A & $5449(12)$ & $1850(20)$ & $2000(40)$ & $60(11)$ \\
H13B & $5789(13)$ & $1700(20)$ & $1190(40)$ & $72(13)$ \\
H14A & $5812(10)$ & $572(17)$ & $3650(30)$ & $34(8)$ \\
H14B & $6120(11)$ & $550(20)$ & $2590(30)$ & $45(10)$ \\
H15A & $5257(12)$ & $110(20)$ & $1730(40)$ & $48(10)$ \\
H15B & $5565(11)$ & $160(20)$ & $450(40)$ & $59(10)$ \\
H16A & $5626(10)$ & $-1053(19)$ & $2990(40)$ & $49(10)$ \\
H16B & $5906(10)$ & $-1125(18)$ & $1810(30)$ & $34(8)$ \\
H17A & $4992(11)$ & $-1435(18)$ & $960(30)$ & $37(9)$ \\
H17B & $5313(11)$ & $-1460(20)$ & $-70(40)$ & $49(10)$ \\
H18A & $5391(11)$ & $-2650(20)$ & $2450(40)$ & $54(10)$ \\
H18B & $5655(10)$ & $-2743(17)$ & $1160(30)$ & $27(8)$ \\
H19A & $4995(10)$ & $-3050(19)$ & $-790(40)$ & $40(9)$ \\
H19B & $4775(12)$ & $-3000(20)$ & $600(30)$ & $46(10)$ \\
H19C & $5075(11)$ & $-3810(20)$ & $600(30)$ & $53(10)$ \\
H7A & $6900(13)$ & $-50(30)$ & $8360(40)$ & $58(13)$ \\
H2A & $7147(11)$ & $5020(20)$ & $2590(40)$ & $140(20)$ \\
H5 & $7008(17)$ & $2370(30)$ & $5570(60)$ & \\
\hline \hline
\end{tabular}

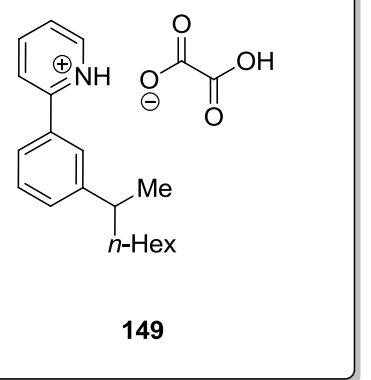

Beside an oxalate every cell includes another molecule of oxalic acid.

These molecules are bound to each other through $\mathrm{H}$-bonding on connect between two layers. Theses layers include the hydrophobic aliphatic chains. This compound could possibly be used as phase transfer catalyst, which should be further examined. The resolution of the structure is not perfect since the crystals have not been of higher quality. 


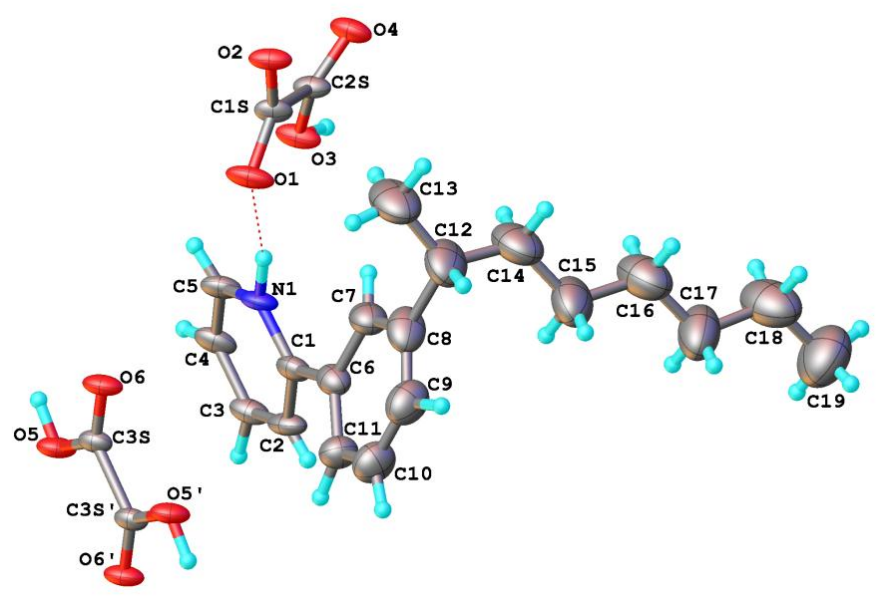

Figure 7.3 Molecular structure of $\mathbf{1 4 9}$ in the crystal. Thermal ellipsoids are shown at 50\% probability.

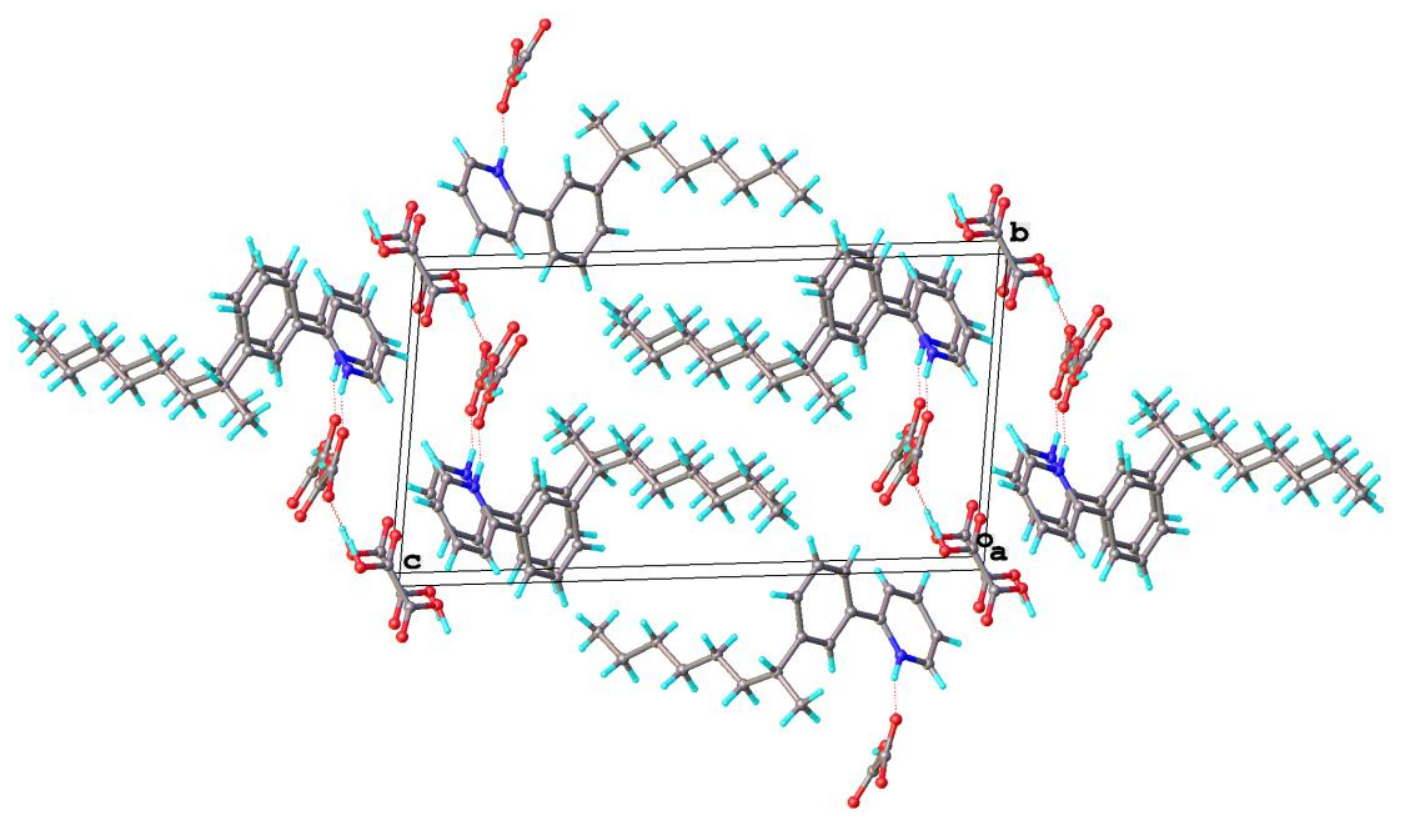

Figure 7.4: Fragment of the molecular packing in extended unit cell of 149; space group $P-1$.

Table S-9 Fractional Atomic Coordinates $\left(\times 10^{4}\right)$ and Equivalent Isotropic Displacement Parameters $\left(\AA^{2} \times 10^{3}\right)$ for $149 . U_{\text {eq }}$ is defined as $1 / 3$ of of the trace of the orthogonalised $U_{1 J}$ tensor.

\begin{tabular}{ccccc} 
Atom & $\boldsymbol{x}$ & $\boldsymbol{y}$ & $\boldsymbol{z}$ & U(eq) \\
\hline \hline N1 & $-790(5)$ & $6899(3)$ & $1146.3(17)$ & $30.7(7)$ \\
C1 & $-413(6)$ & $8087(3)$ & $1547(2)$ & $32.1(9)$ \\
C2 & $-2090(7)$ & $8923(4)$ & $1407(3)$ & $36.9(10)$ \\
C3 & $-4043(6)$ & $8556(4)$ & $898(2)$ & $35.2(9)$ \\
C4 & $-4365(7)$ & $7327(4)$ & $501(2)$ & $37.6(10)$ \\
C5 & $-2678(6)$ & $6526(4)$ & $638(2)$ & $34.4(9)$ \\
C6 & $1747(7)$ & $8437(4)$ & $2092(2)$ & $38.5(10)$ \\
C7 & $2780(8)$ & $7468(5)$ & $2440(2)$ & $46.9(11)$ \\
C8 & $4828(9)$ & $7806(6)$ & $2956(2)$ & $60.8(14)$ \\
C9 & $5873(10)$ & $9124(6)$ & $3104(3)$ & $62.9(14)$ \\
C10 & $4847(9)$ & $10067(5)$ & $2765(3)$ & $56.9(12)$ \\
C11 & $2792(8)$ & $9749(4)$ & $2274(2)$ & $44.1(10)$ \\
\hline \hline
\end{tabular}




\begin{tabular}{|c|c|c|c|c|}
\hline C12 & $5858(11)$ & $6745(6)$ & $3349(3)$ & $75.3(17)$ \\
\hline C13 & $6750(12)$ & $5750(6)$ & $2898(3)$ & $88(2)$ \\
\hline C14 & $4411(12)$ & $6331(6)$ & $3886(3)$ & $84.8(19)$ \\
\hline C15 & $3494(12)$ & $7261(6)$ & $4368(3)$ & $85.5(19)$ \\
\hline C16 & $2102(12)$ & $6758(6)$ & $4914(4)$ & $94(2)$ \\
\hline C17 & 1041(13) & $7634(7)$ & $5379(3)$ & $95(2)$ \\
\hline C18 & $-386(13)$ & 7049(7) & $5913(4)$ & $105(2)$ \\
\hline C19 & $-592(14)$ & $7878(8)$ & $6356(4)$ & 119(3) \\
\hline 01 & $2183(4)$ & 4992(2) & 1189.3(15) & $40.3(7)$ \\
\hline 02 & $3384(4)$ & $3061(2)$ & $1373.9(14)$ & $31.8(6)$ \\
\hline 03 & $-2299(4)$ & $3987(2)$ & $1261.3(15)$ & $35.4(7)$ \\
\hline 04 & $-1018(4)$ & $2271(2)$ & 1761.8(14) & $35.9(7)$ \\
\hline C1S & $1823(6)$ & $3834(3)$ & $1325(2)$ & $27.9(8)$ \\
\hline $\mathrm{C} 2 \mathrm{~S}$ & $-693(6)$ & $3259(3)$ & $1471(2)$ & $28.2(8)$ \\
\hline 05 & $-2164(4)$ & $9278(2)$ & $-715.6(14)$ & $32.7(6)$ \\
\hline 06 & $824(4)$ & $8427(2)$ & $-111.2(14)$ & $32.5(6)$ \\
\hline C3S & $-311(6)$ & $9311(3)$ & $-219.8(19)$ & $26.1(8)$ \\
\hline
\end{tabular}

Table S-10 Anisotropic Displacement Parameters $\left(\AA^{2} \times 10^{3}\right)$ for 149. The Anisotropic displacement factor exponent takes

\begin{tabular}{|c|c|c|c|c|c|c|}
\hline \multicolumn{7}{|c|}{ the form: $-2 \pi^{2}\left[h^{2} a *^{2} U_{11}+\ldots+2 h k a \times b \times U_{12}\right]$} \\
\hline Atom & $\mathrm{U}_{11}$ & $\mathrm{U}_{22}$ & $\mathrm{U}_{33}$ & $\mathrm{U}_{23}$ & $\mathrm{U}_{13}$ & $\mathrm{U}_{12}$ \\
\hline N1 & $30.0(17)$ & $14.9(15)$ & $50.8(19)$ & $11.0(14)$ & $9.8(15)$ & $6.7(12)$ \\
\hline C1 & $31.7(19)$ & 23.0(19) & $46(2)$ & $12.4(17)$ & 14.7(17) & $4.2(15)$ \\
\hline C2 & $38(2)$ & $19(2)$ & $59(3)$ & $9(2)$ & $21(2)$ & $8.3(17)$ \\
\hline C3 & $25.6(19)$ & $26(2)$ & 60(3) & $17.3(19)$ & $13.0(19)$ & $8.1(15)$ \\
\hline C4 & $27(2)$ & $24(2)$ & $63(3)$ & $17.4(19)$ & $8(2)$ & $-0.4(16)$ \\
\hline C5 & $28(2)$ & $17(2)$ & $58(3)$ & $8.5(19)$ & $7.9(19)$ & $0.7(15)$ \\
\hline C6 & $40(2)$ & $37(2)$ & $45(2)$ & $10.9(18)$ & $14.2(19)$ & $14.2(17)$ \\
\hline C7 & $56(3)$ & $40(3)$ & $51(3)$ & $10(2)$ & $11(2)$ & $19(2)$ \\
\hline C8 & $63(3)$ & $80(4)$ & $49(3)$ & $16(3)$ & $7(2)$ & $40(3)$ \\
\hline C9 & $61(3)$ & $70(4)$ & $54(3)$ & $-5(3)$ & $-3(3)$ & $19(3)$ \\
\hline C10 & $54(3)$ & $56(3)$ & $55(3)$ & $-4(3)$ & $-1(2)$ & $5(2)$ \\
\hline C11 & $46(2)$ & $36(2)$ & $49(3)$ & $1(2)$ & $4(2)$ & $4.8(19)$ \\
\hline C12 & $93(4)$ & $85(4)$ & $59(3)$ & $25(3)$ & $8(3)$ & $44(3)$ \\
\hline C13 & $104(5)$ & $78(4)$ & $105(4)$ & $40(4)$ & $37(4)$ & $53(4)$ \\
\hline C14 & $100(5)$ & $67(4)$ & $104(5)$ & 39(4) & $32(4)$ & $35(3)$ \\
\hline C15 & $114(5)$ & $95(5)$ & $63(3)$ & 29(3) & $23(3)$ & $48(4)$ \\
\hline C16 & $103(5)$ & $75(4)$ & $121(5)$ & 40(4) & $43(4)$ & $31(4)$ \\
\hline C17 & $123(5)$ & $116(6)$ & $63(4)$ & $18(4)$ & $27(4)$ & $62(5)$ \\
\hline C18 & $107(5)$ & $85(5)$ & $145(6)$ & $39(5)$ & $48(5)$ & $39(4)$ \\
\hline C19 & $131(7)$ & $135(7)$ & $99(5)$ & $-5(5)$ & $31(5)$ & $46(6)$ \\
\hline 01 & $24.2(13)$ & $17.7(13)$ & $81(2)$ & $15.9(13)$ & $10.6(13)$ & 1.4(10) \\
\hline 02 & $17.1(12)$ & $15.7(12)$ & $62.6(17)$ & $4.8(11)$ & $4.8(11)$ & $2.9(9)$ \\
\hline 03 & $16.4(12)$ & $21.4(13)$ & $71.9(19)$ & $15.7(12)$ & $10.7(12)$ & $3.8(9)$ \\
\hline 04 & $28.1(13)$ & $21.4(13)$ & $62.0(17)$ & $16.7(12)$ & $11.8(12)$ & $3.2(10)$ \\
\hline C1S & $16.4(16)$ & $17.2(17)$ & $48(2)$ & $3.5(15)$ & $2.1(15)$ & $-3.0(13)$ \\
\hline $\mathrm{C} 2 \mathrm{~S}$ & $19.1(17)$ & $17.3(17)$ & $49(2)$ & $4.9(16)$ & $6.6(15)$ & $4.2(13)$ \\
\hline 05 & $31.1(14)$ & $15.5(13)$ & $51.8(17)$ & $6.7(12)$ & $2.4(12)$ & $5.7(10)$ \\
\hline 06 & $27.8(13)$ & $15.8(12)$ & $56.0(16)$ & $9.1(11)$ & $8.1(11)$ & $5.9(10)$ \\
\hline C3S & $21.7(17)$ & $17.3(17)$ & $41(2)$ & 7.6(15) & $8.7(16)$ & $1.8(13)$ \\
\hline
\end{tabular}

Table S-11 Bond Lengths for 149.

\begin{tabular}{cccccc} 
Atom & Atom & Length/A & Atom & Atom & Length/Å \\
\hline \hline N1 & C1 & $1.348(5)$ & C12 & C14 & $1.454(8)$ \\
N1 & C5 & $1.334(5)$ & C14 & C15 & $1.453(8)$ \\
C1 & C2 & $1.384(5)$ & C15 & C16 & $1.478(8)$ \\
C1 & C6 & $1.480(6)$ & C16 & C17 & $1.445(8)$ \\
C2 & C3 & $1.359(6)$ & C17 & C18 & $1.503(8)$ \\
C3 & C4 & $1.383(6)$ & C18 & C19 & $1.439(9)$ \\
\hline \hline
\end{tabular}


Table S-11 Bond Lengths for 149.

\begin{tabular}{cccccc} 
Atom & Atom & Length/A & Atom & Atom & Length/Å \\
\hline \hline C4 & C5 & $1.361(5)$ & O1 & C1S & $1.238(4)$ \\
C6 & C7 & $1.398(5)$ & O2 & C1S & $1.267(4)$ \\
C6 & C11 & $1.389(6)$ & O3 & C2S & $1.302(4)$ \\
C7 & C8 & $1.402(7)$ & O4 & C2S & $1.206(4)$ \\
C8 & C9 & $1.390(7)$ & C1S & C2S & $1.546(4)$ \\
C8 & C12 & $1.516(6)$ & O5 & C3S & $1.313(4)$ \\
C9 & C10 & $1.366(7)$ & O6 & C3S & $1.200(4)$ \\
C10 & C11 & $1.378(6)$ & C3S & C3S $^{1}$ & $1.543(7)$ \\
C12 & C13 & $1.455(7)$ & & & \\
\hline \hline
\end{tabular}

Table S-12 Bond Angles for 149.

\begin{tabular}{cccccccc} 
Atom & Atom & Atom & Angle/ $^{\circ}$ & Atom & Atom & Atom & Angle $^{\circ}$ \\
\hline \hline C5 & N1 & C1 & $122.7(3)$ & C13 & C12 & C8 & $114.8(4)$ \\
N1 & C1 & C2 & $116.8(4)$ & C14 & C12 & C8 & $111.2(4)$ \\
N1 & C1 & C6 & $119.4(3)$ & C14 & C12 & C13 & $119.3(5)$ \\
C2 & C1 & C6 & $123.8(4)$ & C15 & C14 & C12 & $122.9(5)$ \\
C3 & C2 & C1 & $121.6(4)$ & C14 & C15 & C16 & $119.4(5)$ \\
C2 & C3 & C4 & $119.7(4)$ & C17 & C16 & C15 & $121.5(5)$ \\
C5 & C4 & C3 & $117.9(4)$ & C16 & C17 & C18 & $118.5(6)$ \\
N1 & C5 & C4 & $121.4(4)$ & C19 & C18 & C17 & $120.1(6)$ \\
C7 & C6 & C1 & $121.3(4)$ & O1 & C1S & O2 & $125.3(3)$ \\
C11 & C6 & C1 & $120.4(3)$ & O1 & C1S & C2S & $119.0(3)$ \\
C11 & C6 & C7 & $118.3(4)$ & O2 & C1S & C2S & $115.7(3)$ \\
C6 & C7 & C8 & $121.0(5)$ & O3 & C2S & C1S & $111.7(3)$ \\
C7 & C8 & C12 & $120.1(5)$ & O4 & C2S & O3 & $126.6(3)$ \\
C9 & C8 & C7 & $119.0(4)$ & O4 & C2S & C1S & $121.7(3)$ \\
C9 & C8 & C12 & $120.9(5)$ & O5 & C3S & C3S & $110.7(3)$ \\
C10 & C9 & C8 & $119.7(5)$ & O6 & C3S & O5 & $126.7(3)$ \\
C9 & C10 & C11 & $121.7(5)$ & O6 & C3S & C3S & $122.5(4)$ \\
C10 & C11 & C6 & $120.3(4)$ & & & & \\
\hline \hline
\end{tabular}

Table S-13 Hydrogen Bonds for 149.

\begin{tabular}{|c|c|c|c|c|c|c|}
\hline D & H & A & $d(D-H) / A ̊$ & $\mathrm{~d}(\mathrm{H}-\mathrm{A}) / \mathrm{A}$ & $d(D-A) / A ̊$ & D-H-A/ ${ }^{\circ}$ \\
\hline N1 & H1 & 01 & $1.03(4)$ & $1.75(4)$ & $2.753(4)$ & $165(3)$ \\
\hline 03 & HЗА & $02^{1}$ & 0.82 & 1.79 & $2.560(3)$ & 156.6 \\
\hline 05 & H5A & $02^{2}$ & $0.88(5)$ & $1.71(6)$ & $2.560(3)$ & $161(5)$ \\
\hline
\end{tabular}

${ }^{1}-1+X,+Y,+Z ;{ }^{2}-X, 1-Y,-Z$

Table S-14 Hydrogen Atom Coordinates $\left(\AA ̊ \times 10^{4}\right)$ and Isotropic Displacement Parameters $\left(\AA^{2} \times 10^{3}\right)$ for 149 .

\begin{tabular}{ccccc} 
Atom & $\boldsymbol{x}$ & $\boldsymbol{y}$ & $\boldsymbol{z}$ & U(eq) \\
\hline \hline H12 & 7324 & 7231 & 3636 & 90 \\
H13A & 5426 & 5204 & 2597 & 132 \\
\hline \hline H13B & 7612 & 5211 & 3193 & 132 \\
H13C & 7799 & 6178 & 2607 & 132 \\
H14A & 3035 & 5728 & 3634 & 102 \\
H14B & 5345 & 5812 & 4183 & 102 \\
H15A & 2493 & 7759 & 4077 & 103 \\
H15B & 4850 & 7884 & 4616 & 103 \\
H16A & 814 & 6092 & 4665 & 112 \\
H16B & 3145 & 6303 & 5218 & 112 \\
H17A & 3 & 8101 & 5080 & 114 \\
H17B & 2320 & 8290 & 5641 & 114 \\
H18A & -1588 & 6349 & 5653 & 126 \\
H18B & 688 & 6632 & 6229 & 126 \\
\hline \hline
\end{tabular}


Table S-14 Hydrogen Atom Coordinates $\left(\AA ̊ \times 10^{4}\right)$ and Isotropic Displacement Parameters $\left(\AA^{2} \times 10^{3}\right)$ for 149.

\begin{tabular}{ccccc} 
Atom & $\boldsymbol{x}$ & $\boldsymbol{y}$ & $\boldsymbol{z}$ & U(eq) \\
\hline \hline H19A & -2457 & 8422 & 6066 & 179 \\
H19B & -433 & 8430 & 6712 & 179 \\
H19C & -2689 & 7333 & 6586 & 179 \\
H1 & $420(70)$ & $6260(40)$ & $1250(20)$ & $44(11)$ \\
H2 & $-1940(50)$ & $9540(30)$ & $1634(16)$ & $6(9)$ \\
H3 & $-5200(60)$ & $9240(40)$ & $743(18)$ & $33(9)$ \\
H4 & $-5560(70)$ & $7030(40)$ & $112(19)$ & $30(10)$ \\
H5 & $-2650(60)$ & $5820(40)$ & $364(18)$ & $21(9)$ \\
H7 & $1980(60)$ & $6630(40)$ & $2344(18)$ & $26(10)$ \\
H9 & $7270(90)$ & $9290(50)$ & $3530(30)$ & $66(14)$ \\
H10 & $5660(90)$ & $10930(50)$ & $2950(30)$ & $67(15)$ \\
H11 & $2050(100)$ & $10460(60)$ & $2090(30)$ & $85(17)$ \\
H3A & -3543 & 3750 & 1417 & 53 \\
H5A & $-2240(90)$ & $8470(50)$ & $-920(30)$ & $75(17)$ \\
\hline \hline
\end{tabular}
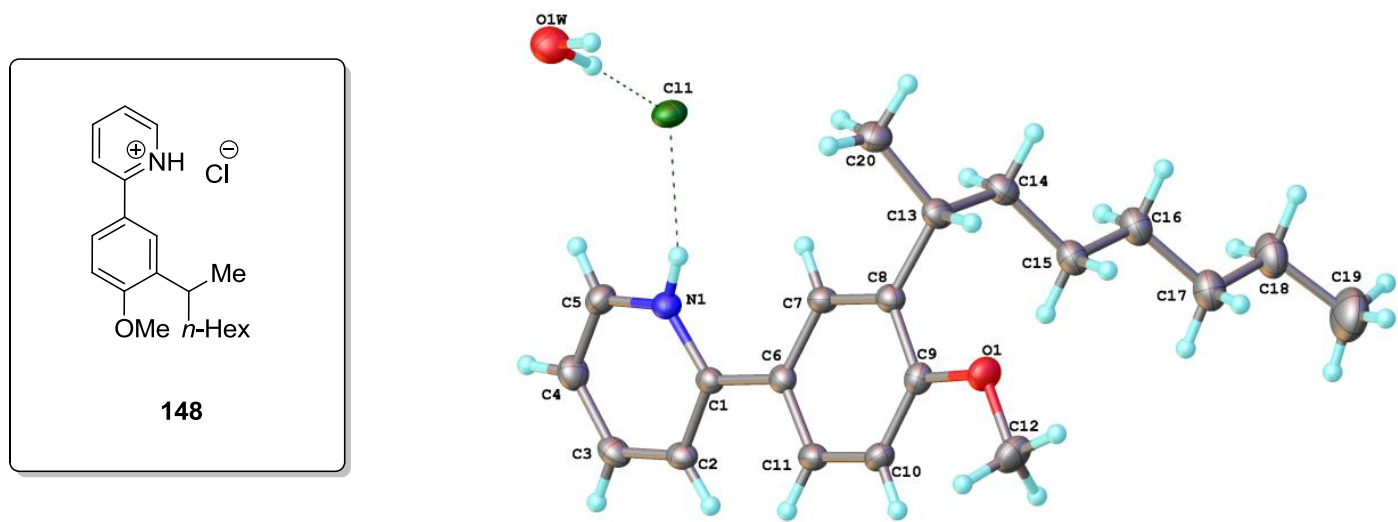

Figure 7.5: Molecular structure of $\mathbf{1 4 8}$ in the crystal. Thermal ellipsoids are shown at 50\% probability.

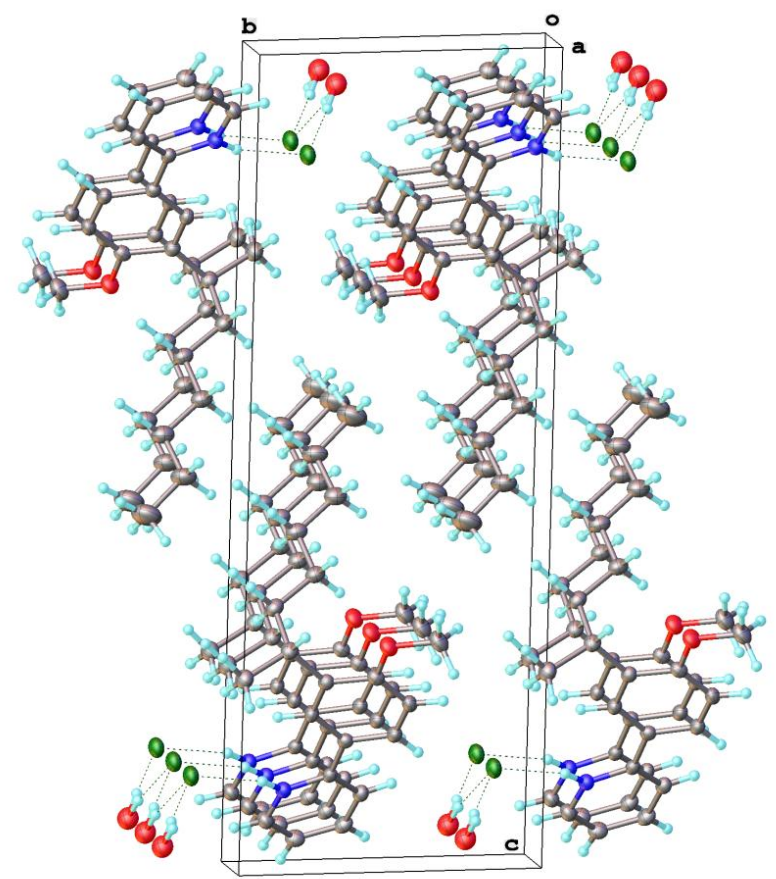

Figure 7.6: Fragment of the molecular packing in extended unit cell of 148; space group $P-1$. 
Table S-15 Fractional Atomic Coordinates $\left(\times 10^{4}\right)$ and Equivalent Isotropic Displacement Parameters $\left(\AA^{2} \times 10^{3}\right)$ for $148 . U_{\mathrm{eq}}$ is defined as $1 / 3$ of the trace of the orthogonalised $U_{11}$ tensor.

\begin{tabular}{ccccc} 
Atom & $\boldsymbol{x}$ & $\boldsymbol{y}$ & $\boldsymbol{z}$ & $\mathbf{U}(\mathrm{eq})$ \\
\hline \hline O1 & $10730(2)$ & $5862.1(12)$ & $7061.5(5)$ & $29.6(2)$ \\
N1 & $1109(2)$ & $8659.9(14)$ & $8949.3(5)$ & $21.7(2)$ \\
C1 & $1967(3)$ & $7185.7(15)$ & $8765.0(6)$ & $20.1(3)$ \\
C2 & $617(3)$ & $6070.0(17)$ & $9022.5(6)$ & $23.4(3)$ \\
C3 & $-1521(3)$ & $6493.0(18)$ & $9436.9(7)$ & $26.1(3)$ \\
C4 & $-2359(3)$ & $8031.4(19)$ & $9601.8(7)$ & $28.1(3)$ \\
C5 & $-983(3)$ & $9104.4(18)$ & $9349.1(7)$ & $25.9(3)$ \\
C6 & $4224(3)$ & $6837.1(16)$ & $8312.5(6)$ & $20.9(3)$ \\
C7 & $5078(3)$ & $8020.1(16)$ & $7962.7(6)$ & $21.9(3)$ \\
C8 & $7224(3)$ & $7692.9(16)$ & $7540.2(6)$ & $22.5(3)$ \\
C9 & $8595(3)$ & $6130.8(17)$ & $7474.3(6)$ & $23.2(3)$ \\
C10 & $7785(3)$ & $4948.9(17)$ & $7817.3(6)$ & $25.0(3)$ \\
C11 & $5599(3)$ & $5300.5(16)$ & $8226.3(6)$ & $24.1(3)$ \\
C12 & $12179(4)$ & $4285(2)$ & $6992.1(8)$ & $34.5(4)$ \\
C13 & $7958(3)$ & $8975.0(17)$ & $7133.7(6)$ & $25.1(3)$ \\
C14 & $5910(3)$ & $9389.2(18)$ & $6637.6(7)$ & $28.1(3)$ \\
C15 & $5667(3)$ & $8052.5(19)$ & $6251.4(7)$ & $29.5(3)$ \\
C16 & $3687(4)$ & $8592(2)$ & $5757.8(7)$ & $32.6(3)$ \\
C17 & $3431(4)$ & $7320(2)$ & $5342.1(7)$ & $36.0(4)$ \\
C18 & $1439(4)$ & $7925(3)$ & $4856.5(8)$ & $42.5(4)$ \\
C19 & $1290(6)$ & $6721(4)$ & $4404.6(11)$ & $62.4(6)$ \\
C20 & $8084(4)$ & $10447.8(19)$ & $7462.2(8)$ & $30.3(3)$ \\
O1W & $7014(3)$ & $12950.0(14)$ & $9496.5(6)$ & $37.1(3)$ \\
C11 & $2673.2(7)$ & $11819.5(4)$ & $8719.00(16)$ & $27.23(11)$ \\
\hline \hline
\end{tabular}

Table S-16 Anisotropic Displacement Parameters $\left(\AA^{2} \times 10^{3}\right)$ for 148 . The Anisotropic displacement factor exponent takes

\begin{tabular}{|c|c|c|c|c|c|c|}
\hline Atom & $\mathrm{U}_{11}$ & $\mathrm{U}_{22}$ & $\mathrm{U}_{33}$ & $U_{23}$ & $U_{13}$ & $\mathrm{U}_{12}$ \\
\hline 01 & $29.4(5)$ & $27.3(5)$ & $30.5(6)$ & $-4.9(4)$ & $5.6(4)$ & $-3.2(4)$ \\
\hline N1 & $24.5(6)$ & $19.4(6)$ & $22.6(6)$ & $-0.7(4)$ & $-0.8(4)$ & $-8.1(4)$ \\
\hline C1 & $23.2(6)$ & $18.7(6)$ & $19.2(6)$ & $1.0(5)$ & $-4.7(5)$ & $-5.7(5)$ \\
\hline C2 & $26.5(7)$ & $21.1(7)$ & $24.4(7)$ & $1.4(5)$ & $-4.3(5)$ & $-8.9(5)$ \\
\hline C3 & $27.4(7)$ & $27.8(7)$ & $25.7(7)$ & $5.3(6)$ & $-2.9(6)$ & $-12.2(6)$ \\
\hline C4 & $27.0(7)$ & $32.9(8)$ & $25.1(7)$ & $-0.9(6)$ & $2.0(6)$ & $-9.2(6)$ \\
\hline C5 & $29.2(7)$ & $22.5(7)$ & $26.4(7)$ & $-4.5(5)$ & $1.0(6)$ & $-6.5(6)$ \\
\hline C6 & $23.2(7)$ & $21.3(6)$ & $19.3(6)$ & $-0.5(5)$ & $-2.9(5)$ & $-6.9(5)$ \\
\hline C7 & $25.3(7)$ & $17.6(6)$ & $22.6(6)$ & $0.5(5)$ & $-2.3(5)$ & $-4.2(5)$ \\
\hline C8 & $24.5(7)$ & $21.5(6)$ & $22.2(6)$ & $0.3(5)$ & $-2.0(5)$ & $-6.6(5)$ \\
\hline $\mathrm{Cg}$ & 23.1(7) & $25.2(7)$ & $21.4(6)$ & $-3.8(5)$ & $-0.8(5)$ & $-5.2(5)$ \\
\hline C10 & $30.5(7)$ & $19.0(6)$ & $24.5(7)$ & $-2.5(5)$ & $-3.3(6)$ & $-2.6(5)$ \\
\hline C11 & $31.4(7)$ & $19.3(6)$ & $22.6(7)$ & $0.6(5)$ & $-3.8(6)$ & $-7.1(5)$ \\
\hline C12 & $33.2(8)$ & $30.0(8)$ & $38.9(9)$ & $-11.8(7)$ & $4.5(7)$ & $-3.2(7)$ \\
\hline C13 & $26.0(7)$ & $24.7(7)$ & $24.7(7)$ & $0.9(5)$ & $2.9(5)$ & $-6.8(5)$ \\
\hline C14 & $31.8(8)$ & $27.1(7)$ & $25.6(7)$ & $3.9(6)$ & $-0.5(6)$ & $-7.8(6)$ \\
\hline C15 & $32.0(8)$ & $32.7(8)$ & $23.8(7)$ & $1.8(6)$ & $-1.8(6)$ & $-7.4(6)$ \\
\hline C16 & $34.8(9)$ & $38.6(9)$ & $24.8(7)$ & $2.0(6)$ & $-2.0(6)$ & $-9.3(7)$ \\
\hline C17 & $38.5(9)$ & $42.9(10)$ & $26.8(8)$ & $-1.3(7)$ & $-1.6(7)$ & $-9.3(7)$ \\
\hline C18 & $50.1(11)$ & $55.0(12)$ & $26.0(8)$ & $-0.7(8)$ & $-6.3(8)$ & $-18.2(9)$ \\
\hline C19 & $76.7(18)$ & 76.0(17) & $39.5(12)$ & $-13.3(11)$ & $-11.4(12)$ & $-23.4(14)$ \\
\hline $\mathrm{C} 20$ & $34.7(8)$ & $26.7(7)$ & $31.2(8)$ & $0.9(6)$ & $0.6(7)$ & $-11.0(6)$ \\
\hline $01 \mathrm{~W}$ & $37.2(7)$ & $35.8(6)$ & $39.7(7)$ & $0.4(5)$ & $1.3(5)$ & $-11.7(5)$ \\
\hline $\mathrm{Cl} 1$ & $30.21(19)$ & $19.62(17)$ & $33.5(2)$ & $-2.79(13)$ & $2.47(14)$ & $-9.59(13)$ \\
\hline
\end{tabular}


Table S-17 Bond Lengths for 148.

\begin{tabular}{cccccc} 
Atom & Atom & Length/A & Atom & Atom & Length/Å \\
\hline \hline O1 & C9 & $1.3660(17)$ & C8 & C9 & $1.4041(19)$ \\
O1 & C12 & $1.4271(19)$ & C8 & C13 & $1.5196(19)$ \\
N1 & C1 & $1.3495(17)$ & C9 & C10 & $1.389(2)$ \\
N1 & C5 & $1.3461(19)$ & C10 & C11 & $1.382(2)$ \\
C1 & C2 & $1.3970(19)$ & C13 & C14 & $1.536(2)$ \\
C1 & C6 & $1.4712(19)$ & C13 & C20 & $1.534(2)$ \\
C2 & C3 & $1.381(2)$ & C14 & C15 & $1.523(2)$ \\
C3 & C4 & $1.386(2)$ & C15 & C16 & $1.522(2)$ \\
C4 & C5 & $1.372(2)$ & C16 & C17 & $1.522(2)$ \\
C6 & C7 & $1.4066(19)$ & C17 & C18 & $1.521(3)$ \\
C6 & C11 & $1.3916(19)$ & C18 & C19 & $1.519(3)$ \\
C7 & C8 & $1.387(2)$ & & & \\
\hline \hline
\end{tabular}

Table S-18 Bond Angles for 148 .

\begin{tabular}{cccccccc} 
Atom & Atom & Atom & Angle $^{\circ}$ & Atom & Atom & Atom & Angle $^{\circ}$ \\
\hline \hline C9 & O1 & C12 & $117.33(12)$ & C9 & C8 & C13 & $120.78(13)$ \\
C5 & N1 & C1 & $123.86(12)$ & O1 & C9 & C8 & $116.30(12)$ \\
N1 & C1 & C2 & $116.86(13)$ & O1 & C9 & C10 & $123.05(13)$ \\
N1 & C1 & C6 & $119.34(12)$ & C10 & C9 & C8 & $120.65(13)$ \\
C2 & C1 & C6 & $123.80(13)$ & C11 & C10 & C9 & $120.12(13)$ \\
C3 & C2 & C1 & $120.43(14)$ & C10 & C11 & C6 & $120.90(13)$ \\
C2 & C3 & C4 & $120.37(14)$ & C8 & C13 & C14 & $110.38(12)$ \\
C5 & C4 & C3 & $118.24(14)$ & C8 & C13 & C20 & $113.00(12)$ \\
N1 & C5 & C4 & $120.22(14)$ & C20 & C13 & C14 & $109.97(13)$ \\
C7 & C6 & C1 & $121.92(12)$ & C15 & C14 & C13 & $116.03(13)$ \\
C11 & C6 & C1 & $119.87(12)$ & C16 & C15 & C14 & $112.07(13)$ \\
C11 & C6 & C7 & $118.20(13)$ & C15 & C16 & C17 & $114.63(15)$ \\
C8 & C7 & C6 & $121.93(13)$ & C18 & C17 & C16 & $112.38(16)$ \\
C7 & C8 & C9 & $118.16(13)$ & C19 & C18 & C17 & $114.0(2)$ \\
C7 & C8 & C13 & $120.95(12)$ & & & & \\
\hline \hline
\end{tabular}

Table S-19 Hydrogen Bonds for 148 .

\begin{tabular}{|c|c|c|c|c|c|c|}
\hline D & H & A & $d(D-H) / \AA$ & $\mathrm{d}(\mathrm{H}-\mathrm{A}) / \AA$ & $d(D-A) / \AA ̊$ & D-H-A/ ${ }^{\circ}$ \\
\hline N1 & H1 & $\mathrm{Cl} 1$ & $0.87(2)$ & $2.23(2)$ & $3.0610(12)$ & $159.5(17)$ \\
\hline O1W & H1WA & $\mathrm{Cl}^{1}$ & $1.02(3)$ & $2.23(3)$ & $3.2309(14)$ & $168(2)$ \\
\hline $01 \mathrm{~W}$ & H1WB & $\mathrm{Cl} 1$ & $1.05(4)$ & $2.15(4)$ & $3.2004(14)$ & $175(3)$ \\
\hline
\end{tabular}

Table S-20 Hydrogen Atom Coordinates $\left(\AA \AA \times 10^{4}\right)$ and Isotropic Displacement Parameters $\left(\AA^{2} \times 10^{3}\right)$ for 148.

\begin{tabular}{ccccc} 
Atom & $\boldsymbol{x}$ & $\boldsymbol{y}$ & $\boldsymbol{z}$ & $\mathbf{U}(\mathrm{eq})$ \\
\hline H1 & $1880(40)$ & $9420(20)$ & $8822(9)$ & $36(5)$ \\
H2 & $1150(40)$ & $5050(20)$ & $8903(8)$ & $29(4)$ \\
H3 & $-2390(40)$ & $5740(20)$ & $9597(8)$ & $28(4)$ \\
H4 & $-3840(40)$ & $8400(20)$ & $9880(9)$ & $34(5)$ \\
H5 & $-1390(40)$ & $10120(20)$ & $9433(8)$ & $30(5)$ \\
H7 & $4130(40)$ & $9060(20)$ & $8003(8)$ & $27(4)$ \\
H10 & $8750(40)$ & $3910(20)$ & $7780(8)$ & $33(5)$ \\
H11 & $5110(40)$ & $4490(20)$ & $8454(8)$ & $29(4)$ \\
H12A & $13670(50)$ & $4390(30)$ & $6696(10)$ & $52(6)$ \\
H12B & $10920(40)$ & $3640(20)$ & $6859(8)$ & $32(5)$ \\
H12C & $13000(40)$ & $3840(20)$ & $7372(9)$ & $41(5)$ \\
H13 & $9810(40)$ & $8550(20)$ & $6950(8)$ & $31(5)$ \\
H14A & $6500(40)$ & $10240(20)$ & $6371(9)$ & $35(5)$ \\
H14B & $4030(40)$ & $9860(20)$ & $6826(8)$ & $32(5)$ \\
H15A & $7510(40)$ & $7560(20)$ & $6063(9)$ & $37(5)$ \\
H15B & $5080(40)$ & $7180(20)$ & $6494(8)$ & $34(5)$ \\
H16A & $4300(40)$ & $9470(20)$ & $5512(8)$ & $36(5)$ \\
H16B & $1780(40)$ & $9050(20)$ & $5938(8)$ & $32(5)$ \\
H17A & $2900(40)$ & $6420(20)$ & $5565(9)$ & $41(5)$ \\
\hline \hline
\end{tabular}


Table S-20 Hydrogen Atom Coordinates $\left(\AA \AA \times 10^{4}\right)$ and Isotropic Displacement Parameters $\left(\AA^{2} \times 10^{3}\right)$ for 148 .

\begin{tabular}{ccccc} 
Atom & $\boldsymbol{x}$ & $\boldsymbol{y}$ & $\boldsymbol{z}$ & $\boldsymbol{U}(\mathrm{eq})$ \\
\hline \hline H17B & $5220(50)$ & $6840(30)$ & $5174(10)$ & $50(6)$ \\
H18A & $2000(50)$ & $8860(30)$ & $4622(11)$ & $60(7)$ \\
H18B & $-500(50)$ & $8290(30)$ & $5053(10)$ & $57(7)$ \\
H19A & $-70(70)$ & $7190(40)$ & $4112(15)$ & $100(11)$ \\
H19B & $720(50)$ & $5810(30)$ & $4583(11)$ & $63(7)$ \\
H19C & $3290(60)$ & $6370(30)$ & $4195(13)$ & $86(9)$ \\
H20A & $6310(40)$ & $10970(20)$ & $7646(8)$ & $29(4)$ \\
H20B & $9210(40)$ & $10320(20)$ & $7793(9)$ & $34(5)$ \\
H20C & $8720(40)$ & $11210(30)$ & $7183(10)$ & $51(6)$ \\
H1WA & $8820(60)$ & $12750(30)$ & $9254(12)$ & $72(8)$ \\
H1WB & $5630(70)$ & $12620(40)$ & $9218(15)$ & $109(11)$ \\
\hline \hline
\end{tabular}
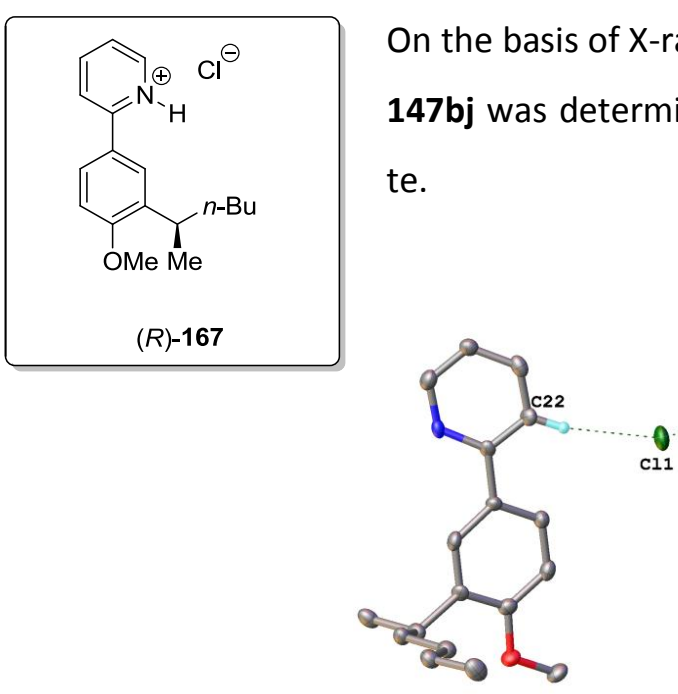
te.
On the basis of X-ray data, the absolute configuration of the compound $(R)$ 147bj was determined. Hydrochloride $(R)-167$ is arranged as a hemihydra-

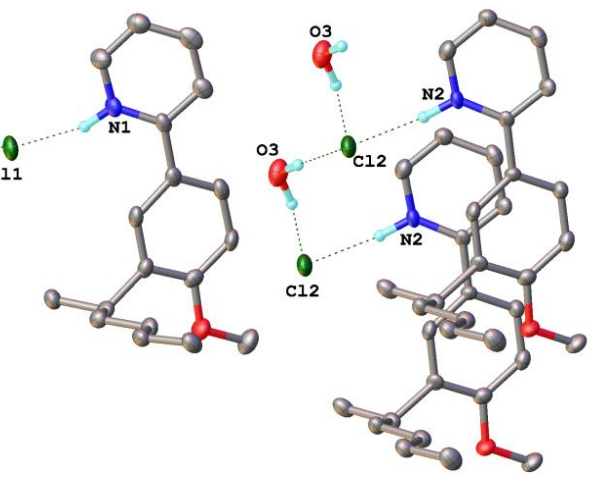

Figure 7.7: Molecular structure of $(R)-167$ in the crystal including the interesting $\mathrm{H}$-bonding. Thermal ellipsoids are shown at $50 \%$ probability.

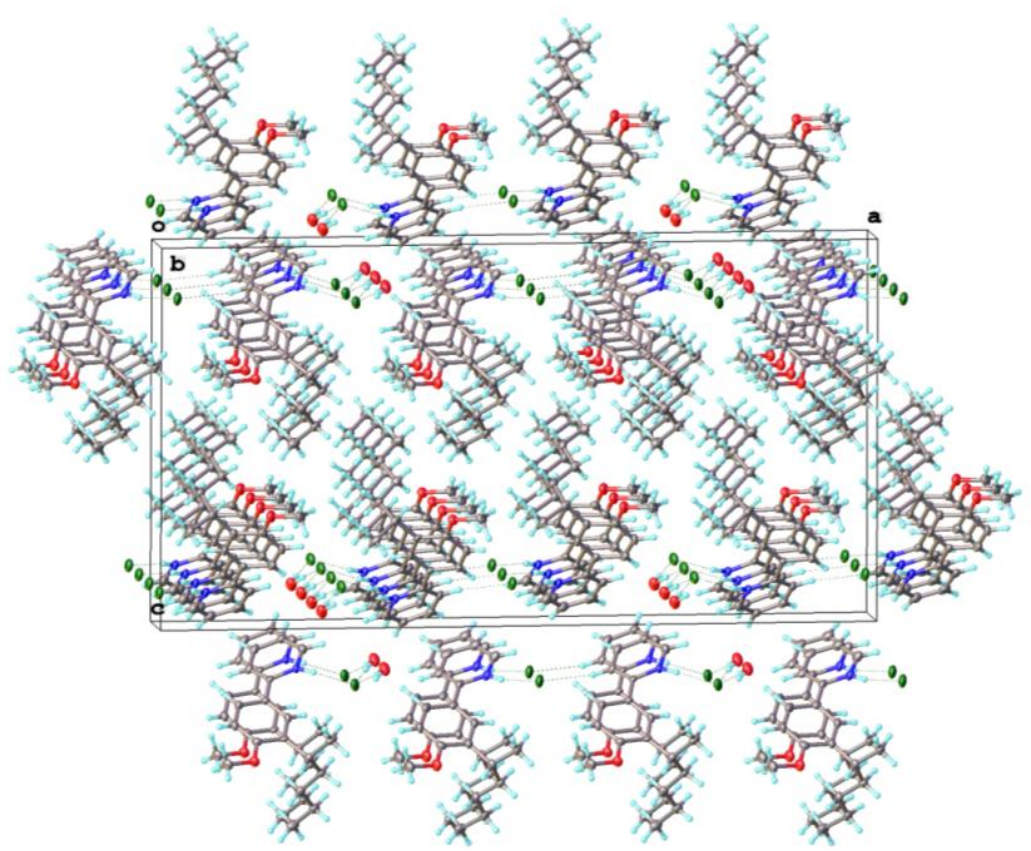

Figure 7.8: Fragment of the molecular packing in extended unit cell of $(R)-167$; space group $C 2$. 
Table S-21 Fractional Atomic Coordinates $\left(\times 10^{4}\right)$ and Equivalent Isotropic Displacement Parameters $\left(\AA^{2} \times 10^{3}\right)$ for $167 . U_{\text {eq }}$ is defined as $1 / 3$ of the trace of the orthogonalised $U_{1 J}$ tensor.

\begin{tabular}{|c|c|c|c|c|}
\hline Atom & $x$ & $y$ & $z$ & $\mathrm{U}(\mathrm{eq})$ \\
\hline $\mathrm{Cl} 1$ & $-192.4(3)$ & 1970(3) & $8719.5(7)$ & $33.1(4)$ \\
\hline $\mathrm{Cl} 2$ & $2366.8(3)$ & $644(2)$ & $8653.1(7)$ & $32.1(4)$ \\
\hline 01 & $1303.6(9)$ & $6279(6)$ & $6656.0(19)$ & $32.1(10)$ \\
\hline N1 & $497.5(11)$ & $-1276(8)$ & $8813(2)$ & $25.6(10)$ \\
\hline C1 & $875.6(13)$ & $-1136(9)$ & $8594(3)$ & $23.5(12)$ \\
\hline C2 & $1132.8(15)$ & $-2883(11)$ & $8847(3)$ & $28.0(12)$ \\
\hline C3 & $1005.8(16)$ & $-4671(11)$ & $9309(3)$ & $32.6(14)$ \\
\hline C4 & $612.4(16)$ & $-4791(11)$ & $9512(3)$ & $33.0(14)$ \\
\hline C5 & $365.3(15)$ & $-3057(12)$ & $9250(3)$ & $31.4(13)$ \\
\hline C6 & $989.4(13)$ & $814(10)$ & $8093(3)$ & $24.2(12)$ \\
\hline C7 & $714.9(14)$ & 1993(11) & $7640(3)$ & $26.2(12)$ \\
\hline C8 & $820.4(13)$ & $3775(10)$ & $7151(3)$ & $24.6(12)$ \\
\hline C9 & $1214.6(14)$ & $4441(10)$ & $7132(3)$ & $24.8(13)$ \\
\hline C10 & $1493.6(14)$ & $3349(10)$ & $7575(3)$ & $27.0(13)$ \\
\hline C11 & $1379.4(14)$ & $1525(11)$ & $8047(3)$ & $29.5(14)$ \\
\hline C12 & $1698.3(16)$ & $7167(14)$ & $6651(4)$ & $38.4(15)$ \\
\hline C13 & $513.0(14)$ & $4788(10)$ & $6627(3)$ & $25.7(13)$ \\
\hline C14 & $172.3(16)$ & $5997(12)$ & $7024(3)$ & $29.1(14)$ \\
\hline C15 & $366.3(14)$ & $2849(10)$ & $6089(3)$ & $25.8(13)$ \\
\hline C16 & $688.4(15)$ & $1472(11)$ & $5690(3)$ & $27.5(14)$ \\
\hline C17 & $533.0(15)$ & $-348(11)$ & $5159(3)$ & $30.2(14)$ \\
\hline $\mathrm{C} 18$ & $852.2(17)$ & $-1857(12)$ & $4793(4)$ & $33.4(14)$ \\
\hline 02 & 3846.1(9) & $6143(6)$ & $6809.9(17)$ & $25.2(9)$ \\
\hline N2 & $3151.4(10)$ & $-1597(8)$ & $9050(2)$ & $20(1)$ \\
\hline C21 & $3524.9(13)$ & $-1374(9)$ & $8784(2)$ & $19.1(11)$ \\
\hline C22 & $3797.8(14)$ & $-3046(10)$ & $9007(3)$ & $23.0(11)$ \\
\hline $\mathrm{C} 23$ & $3690.7(15)$ & $-4866(10)$ & $9480(3)$ & $26.5(13)$ \\
\hline $\mathrm{C24}$ & $3310.7(14)$ & $-5043(10)$ & $9735(3)$ & $24.7(12)$ \\
\hline $\mathrm{C} 25$ & $3045.0(15)$ & $-3338(11)$ & $9511(3)$ & $27.7(13)$ \\
\hline C26 & $3610.0(12)$ & $567(10)$ & $8260(2)$ & $18.6(11)$ \\
\hline C27 & $3317.6(13)$ & $1661(10)$ & $7835(3)$ & $22.6(12)$ \\
\hline $\mathrm{C} 28$ & $3394.4(12)$ & $3469(10)$ & $7335(2)$ & $20.6(11)$ \\
\hline C29 & $3785.1(13)$ & $4251(9)$ & $7283(3)$ & $23.5(12)$ \\
\hline C30 & 4079.7(15) & $3170(10)$ & $7693(3)$ & $25.0(13)$ \\
\hline C31 & $3997.9(13)$ & $1336(9)$ & $8174(3)$ & $22.5(13)$ \\
\hline C32 & $4233.3(16)$ & $7076(13)$ & $6769(3)$ & $30.1(13)$ \\
\hline C33 & $3064.0(13)$ & $4478(10)$ & $6860(3)$ & $23.8(12)$ \\
\hline C34 & $2767.9(16)$ & $5835(12)$ & $7336(3)$ & $28.9(12)$ \\
\hline C35 & 2859.0(14) & $2563(10)$ & $6399(3)$ & $24.4(13)$ \\
\hline C36 & $3128.3(16)$ & $1089(11)$ & $5904(3)$ & $26.1(13)$ \\
\hline C37 & 2912.7(16) & $-612(11)$ & $5400(3)$ & $28.6(13)$ \\
\hline C38 & $3188.5(18)$ & $-2128(12)$ & 4937(4) & $34.8(15)$ \\
\hline 03 & 2024.4(10) & $5626(9)$ & $9179(2)$ & $37(1)$ \\
\hline
\end{tabular}

Table S-22 Anisotropic Displacement Parameters $\left(\AA^{2} \times 10^{3}\right)$ for 167 . The Anisotropic displacement factor exponent takes

\begin{tabular}{|c|c|c|c|c|c|c|}
\hline Atom & $U_{11}$ & $\mathrm{U}_{22}$ & $U_{33}$ & $\mathrm{U}_{23}$ & $U_{13}$ & $U_{12}$ \\
\hline $\mathrm{Cl} 1$ & $16.8(6)$ & $39.4(8)$ & $43.1(8)$ & $-1.6(7)$ & $-3.5(5)$ & $4.3(6)$ \\
\hline $\mathrm{Cl} 2$ & $19.9(6)$ & $36.9(8)$ & $39.6(8)$ & $4.5(7)$ & $3.1(5)$ & $8.4(6)$ \\
\hline 01 & $23.3(18)$ & $37(3)$ & $36(2)$ & $1.1(18)$ & $0.8(15)$ & $-8.4(16)$ \\
\hline N1 & $18(2)$ & $31(3)$ & $28(3)$ & $-1(2)$ & $-6.3(19)$ & $-1(2)$ \\
\hline C1 & $21(3)$ & $31(3)$ & $19(3)$ & $-6(2)$ & $-5(2)$ & $6(2)$ \\
\hline C2 & $30(3)$ & $31(3)$ & $22(3)$ & $-7(3)$ & $-7(2)$ & $3(3)$ \\
\hline C3 & $42(3)$ & $31(4)$ & $24(3)$ & $-10(3)$ & $-12(3)$ & $3(3)$ \\
\hline C4 & $37(3)$ & $35(4)$ & $27(3)$ & $1(3)$ & $-7(3)$ & $-4(3)$ \\
\hline C5 & $28(3)$ & $34(3)$ & $32(3)$ & $3(3)$ & $-7(2)$ & $-6(3)$ \\
\hline C6 & $22(3)$ & $32(3)$ & $19(3)$ & $-5(3)$ & $0(2)$ & $5(2)$ \\
\hline C7 & $15(3)$ & 39(3) & $25(3)$ & $-5(3)$ & $-2(2)$ & $1(3)$ \\
\hline C8 & $18(2)$ & $33(3)$ & $23(3)$ & $-3(3)$ & $2(2)$ & $-1(2)$ \\
\hline C9 & $28(3)$ & $27(3)$ & $19(3)$ & $-4(2)$ & $5(2)$ & $-2(3)$ \\
\hline
\end{tabular}


Table S-22 Anisotropic Displacement Parameters $\left(\AA^{2} \times 10^{3}\right)$ for 167 . The Anisotropic displacement factor exponent takes the form: $-2 \pi^{2}\left[h^{2} a *^{2} U_{11}+\ldots+2 h k a \times b \times U_{12}\right]$

\begin{tabular}{|c|c|c|c|c|c|c|}
\hline C10 & $15(3)$ & $35(3)$ & $31(3)$ & $-3(3)$ & $4(2)$ & $1(3)$ \\
\hline C11 & $22(3)$ & $41(4)$ & $25(3)$ & $-4(3)$ & $-4(2)$ & $10(3)$ \\
\hline C12 & $27(3)$ & $49(4)$ & $39(4)$ & $-5(4)$ & $5(3)$ & $-11(3)$ \\
\hline C13 & $22(3)$ & $29(3)$ & $26(3)$ & $3(3)$ & $1(2)$ & $-7(2)$ \\
\hline C14 & $22(3)$ & $35(4)$ & $29(3)$ & $3(3)$ & $-3(3)$ & $5(3)$ \\
\hline C15 & $22(3)$ & $31(3)$ & $24(3)$ & $2(3)$ & $-2(2)$ & $-3(3)$ \\
\hline C16 & $19(3)$ & $31(4)$ & $32(3)$ & $1(3)$ & $-1(2)$ & $-4(3)$ \\
\hline C17 & $22(3)$ & $41(4)$ & $28(3)$ & $9(3)$ & $-4(3)$ & $2(3)$ \\
\hline C18 & $35(3)$ & $38(4)$ & $27(4)$ & $1(3)$ & $-2(3)$ & $14(3)$ \\
\hline 02 & $26.1(18)$ & $22(2)$ & $27(2)$ & $4.7(15)$ & $2.4(15)$ & $-4.9(15)$ \\
\hline N2 & $14(2)$ & $23(2)$ & $22(2)$ & $-3(2)$ & $-1.7(17)$ & $4(2)$ \\
\hline C21 & $18(2)$ & $27(3)$ & $12(3)$ & $-4(2)$ & $-3(2)$ & $1(2)$ \\
\hline C22 & $17(3)$ & $28(3)$ & $23(3)$ & $1(3)$ & $-5(2)$ & $-4(3)$ \\
\hline C23 & $23(3)$ & $27(4)$ & $29(3)$ & $-5(3)$ & $-8(2)$ & $4(3)$ \\
\hline C24 & $26(3)$ & $29(3)$ & $18(3)$ & $1(2)$ & $-2(2)$ & $2(2)$ \\
\hline $\mathrm{C} 25$ & $20(3)$ & $38(4)$ & $25(3)$ & $-1(3)$ & $2(2)$ & $-3(3)$ \\
\hline C26 & $20(2)$ & $23(3)$ & $14(3)$ & $2(2)$ & $-1.2(19)$ & $0(2)$ \\
\hline $\mathrm{C} 27$ & $14(3)$ & $30(3)$ & $24(3)$ & $-3(3)$ & $2(2)$ & $-2(3)$ \\
\hline C28 & $21(2)$ & $29(3)$ & $12(3)$ & $-2(2)$ & $-5(2)$ & $-1(2)$ \\
\hline C29 & $27(3)$ & $26(3)$ & $18(3)$ & $0(2)$ & $1(2)$ & $-2(3)$ \\
\hline C30 & $18(3)$ & $31(3)$ & $26(3)$ & $-4(3)$ & $3(2)$ & $-2(3)$ \\
\hline C31 & $18(2)$ & $28(4)$ & $22(3)$ & $1(2)$ & $-1(2)$ & $1(2)$ \\
\hline C32 & $28(3)$ & $32(4)$ & $30(4)$ & $4(3)$ & $5(3)$ & $-10(3)$ \\
\hline C33 & $22(3)$ & $26(3)$ & $23(3)$ & $2(2)$ & $-4(2)$ & $-4(2)$ \\
\hline C34 & $34(3)$ & $29(3)$ & $23(3)$ & $-1(3)$ & $-10(2)$ & $6(3)$ \\
\hline C35 & $21(3)$ & $33(4)$ & $19(3)$ & $1(2)$ & $-2(2)$ & $3(2)$ \\
\hline C36 & $26(3)$ & $27(4)$ & $26(3)$ & $4(3)$ & $-3(3)$ & $1(3)$ \\
\hline C37 & $29(3)$ & $29(3)$ & $27(3)$ & $2(3)$ & $-3(3)$ & $5(3)$ \\
\hline C38 & $40(3)$ & $37(4)$ & $26(4)$ & $-8(3)$ & $-4(3)$ & $10(3)$ \\
\hline 03 & $29(2)$ & $37(2)$ & $45(2)$ & $-14(2)$ & $5.7(17)$ & $0(2)$ \\
\hline
\end{tabular}

Table S-23 Bond Lengths for 167.

\begin{tabular}{|c|c|c|c|c|c|}
\hline Atom & Atom & Length/Å & Atom & Atom & Length/Å \\
\hline 01 & C9 & $1.377(6)$ & 02 & C29 & $1.378(6)$ \\
\hline 01 & C12 & $1.431(6)$ & 02 & C32 & $1.419(6)$ \\
\hline N1 & C1 & $1.353(6)$ & N2 & C21 & $1.370(6)$ \\
\hline N1 & C5 & $1.351(7)$ & N2 & C25 & $1.335(7)$ \\
\hline C1 & C2 & $1.385(7)$ & C21 & C22 & $1.374(7)$ \\
\hline C1 & C6 & $1.473(7)$ & C21 & C26 & $1.472(7)$ \\
\hline C2 & C3 & $1.376(8)$ & C22 & $\mathrm{C} 23$ & $1.381(7)$ \\
\hline C3 & C4 & $1.394(8)$ & C23 & C24 & $1.381(7)$ \\
\hline C4 & C5 & $1.364(8)$ & C24 & $\mathrm{C} 25$ & $1.371(8)$ \\
\hline C6 & C7 & $1.404(7)$ & C26 & $\mathrm{C} 27$ & $1.396(7)$ \\
\hline C6 & C11 & $1.389(7)$ & C26 & C31 & $1.398(6)$ \\
\hline C7 & C8 & $1.383(7)$ & C27 & $\mathrm{C} 28$ & $1.383(7)$ \\
\hline C8 & C9 & $1.392(6)$ & C28 & C29 & $1.404(6)$ \\
\hline $\mathrm{C} 8$ & C13 & $1.519(7)$ & C28 & C33 & $1.520(6)$ \\
\hline C9 & C10 & $1.380(7)$ & C29 & C30 & $1.383(7)$ \\
\hline $\mathrm{C} 10$ & C11 & $1.389(8)$ & C30 & C31 & $1.375(7)$ \\
\hline C13 & C14 & $1.529(7)$ & C33 & C34 & $1.534(7)$ \\
\hline C13 & C15 & $1.538(7)$ & C33 & C35 & $1.523(7)$ \\
\hline C15 & C16 & $1.527(7)$ & C35 & C36 & $1.531(7)$ \\
\hline C16 & C17 & $1.494(8)$ & C36 & C37 & $1.505(8)$ \\
\hline C17 & C18 & $1.531(7)$ & C37 & C38 & $1.522(8)$ \\
\hline
\end{tabular}

Table S-24 Bond Angles for 167.

\begin{tabular}{cccccccc} 
Atom & Atom & Atom & Angle/ $^{\circ}$ & Atom & Atom & Atom & Angle/ $^{\circ}$ \\
\hline \hline C9 & O1 & C12 & $118.2(4)$ & C29 & O2 & C32 & $117.3(4)$ \\
C5 & N1 & C1 & $122.6(5)$ & C25 & N2 & C21 & $123.1(4)$ \\
N1 & C1 & C2 & $117.5(5)$ & N2 & C21 & C22 & $117.5(5)$ \\
\hline \hline
\end{tabular}


Table S-24 Bond Angles for 167.

\begin{tabular}{cccccccc} 
Atom & Atom & Atom $^{\text {Angle/ }}$ & Atom & Atom & Atom & Angle/ $^{\circ}$ \\
\hline \hline N1 & C1 & C6 & $118.8(4)$ & N2 & C21 & C26 & $118.9(4)$ \\
C2 & C1 & C6 & $123.7(5)$ & C22 & C21 & C26 & $123.6(4)$ \\
C3 & C2 & C1 & $120.7(5)$ & C21 & C22 & C23 & $120.0(5)$ \\
C2 & C3 & C4 & $120.3(6)$ & C22 & C23 & C24 & $121.0(5)$ \\
C5 & C4 & C3 & $117.6(6)$ & C25 & C24 & C23 & $117.9(5)$ \\
N1 & C5 & C4 & $121.2(5)$ & N2 & C25 & C24 & $120.6(5)$ \\
C7 & C6 & C1 & $122.1(4)$ & C27 & C26 & C21 & $122.5(4)$ \\
C11 & C6 & C1 & $120.3(5)$ & C27 & C26 & C31 & $118.2(5)$ \\
C11 & C6 & C7 & $117.6(5)$ & C31 & C26 & C21 & $119.3(4)$ \\
C8 & C7 & C6 & $122.6(5)$ & C28 & C27 & C26 & $123.0(4)$ \\
C7 & C8 & C9 & $117.6(5)$ & C27 & C28 & C29 & $117.1(4)$ \\
C7 & C8 & C13 & $119.3(4)$ & C27 & C28 & C33 & $120.0(4)$ \\
C9 & C8 & C13 & $123.0(5)$ & C29 & C28 & C33 & $122.9(4)$ \\
01 & C9 & C8 & $115.5(4)$ & O2 & C29 & C28 & $115.4(4)$ \\
O1 & C9 & C10 & $122.7(4)$ & O2 & C29 & C30 & $123.9(4)$ \\
C10 & C9 & C8 & $121.8(5)$ & C30 & C29 & C28 & $120.7(5)$ \\
C9 & C10 & C11 & $119.2(5)$ & C31 & C30 & C29 & $121.1(5)$ \\
C6 & C11 & C10 & $121.2(5)$ & C30 & C31 & C26 & $119.8(5)$ \\
C8 & C13 & C14 & $112.8(4)$ & C28 & C33 & C34 & $110.4(4)$ \\
C8 & C13 & C15 & $110.9(4)$ & C28 & C33 & C35 & $112.8(4)$ \\
C14 & C13 & C15 & $111.6(4)$ & C35 & C33 & C34 & $110.9(4)$ \\
C16 & C15 & C13 & $115.2(4)$ & C33 & C35 & C36 & $115.3(4)$ \\
C17 & C16 & C15 & $113.4(4)$ & C37 & C36 & C35 & $113.9(4)$ \\
C16 & C17 & C18 & $113.9(5)$ & C36 & C37 & C38 & $112.8(5)$ \\
\hline \hline
\end{tabular}

Table S-25 Hydrogen Bonds for 167.

\begin{tabular}{|c|c|c|c|c|c|c|}
\hline D & H & A & $d(D-H) / \AA$ & $\mathrm{d}(\mathrm{H}-\mathrm{A}) / \AA$ & $d(D-A) / \AA ̊$ & D-H-A/ ${ }^{\circ}$ \\
\hline N1 & H1 & $\mathrm{Cl} 1$ & $0.97(6)$ & $2.03(6)$ & $2.968(4)$ & 161(5) \\
\hline N2 & $\mathrm{H} 2 \mathrm{~A}$ & $\mathrm{Cl} 2$ & $1.01(5)$ & $2.08(5)$ & $3.029(4)$ & $156(4)$ \\
\hline 03 & H3A & $\mathrm{Cl} 2$ & $0.97(5)$ & $2.20(5)$ & $3.162(5)$ & $175(4)$ \\
\hline 03 & H3B & $\mathrm{Cl} 2^{1}$ & $1.04(7)$ & $2.16(7)$ & $3.180(5)$ & $167(5)$ \\
\hline
\end{tabular}

Table S-26 Hydrogen Atom Coordinates $\left(\AA \times 10^{4}\right)$ and Isotropic Displacement Parameters $\left(\AA^{2} \times 10^{3}\right)$ for 167.

\begin{tabular}{|c|c|c|c|c|}
\hline Atom & $x$ & $y$ & $z$ & $\mathrm{U}(\mathrm{eq})$ \\
\hline H1 & $312(15)$ & $20(110)$ & $8730(30)$ & $45(17)$ \\
\hline H5 & $101(14)$ & $-2870(100)$ & $9360(20)$ & $35(15)$ \\
\hline $\mathrm{H} 2$ & $1392(14)$ & $-2800(100)$ & $8700(20)$ & $30(14)$ \\
\hline H3 & 1188(15) & $-6010(110)$ & $9460(30)$ & $45(17)$ \\
\hline H4 & 474(19) & $-5980(130)$ & $9790(40)$ & $70(20)$ \\
\hline H7 & $468(12)$ & $1550(80)$ & $7640(20)$ & 13(12) \\
\hline H10 & $1758(13)$ & $3900(80)$ & $7510(20)$ & 15(12) \\
\hline H11 & $1554(15)$ & $640(110)$ & $8300(30)$ & $38(16)$ \\
\hline H12A & $1688(14)$ & $8610(110)$ & $6310(30)$ & $41(16)$ \\
\hline H12B & $1769(12)$ & $7760(80)$ & $7110(30)$ & 16(14) \\
\hline $\mathrm{H} 12 \mathrm{C}$ & $1888(15)$ & $5820(120)$ & $6530(30)$ & $48(17)$ \\
\hline H13 & $639(12)$ & $5730(90)$ & $6310(20)$ & $12(12)$ \\
\hline H14A & $-14(14)$ & $6580(100)$ & $6660(30)$ & $33(14)$ \\
\hline H14B & $33(12)$ & $4900(90)$ & $7350(20)$ & $14(12)$ \\
\hline H14C & $257(17)$ & $7260(130)$ & $7330(30)$ & $60(20)$ \\
\hline H15A & 191(12) & $1650(90)$ & $6370(20)$ & 24(13) \\
\hline H15B & 179(16) & $3660(120)$ & $5770(30)$ & 54(18) \\
\hline H16A & $846(15)$ & 2690(110) & $5440(30)$ & $38(16)$ \\
\hline H16B & $835(17)$ & $650(130)$ & $5990(30)$ & $60(20)$ \\
\hline H17A & $382(14)$ & $420(110)$ & $4780(30)$ & $35(15)$ \\
\hline H17B & $332(13)$ & $-1360(90)$ & $5380(20)$ & 18(12) \\
\hline H18A & $723(13)$ & $-3170(100)$ & $4390(30)$ & $35(14)$ \\
\hline H18B & $987(13)$ & $-2510(90)$ & $5160(30)$ & 19(14) \\
\hline
\end{tabular}


Table S-26 Hydrogen Atom Coordinates $\left(\AA \AA \times 10^{4}\right)$ and Isotropic Displacement Parameters $\left(\AA^{2} \times 10^{3}\right)$ for 167.

\begin{tabular}{ccccc} 
Atom & $\boldsymbol{x}$ & $\boldsymbol{y}$ & $\boldsymbol{z}$ & $\boldsymbol{U}(\mathrm{eq})$ \\
\hline \hline H18C & $1030(20)$ & $-1050(170)$ & $4480(40)$ & $110(30)$ \\
H2A & $2929(13)$ & $-430(90)$ & $8970(20)$ & $29(14)$ \\
H27 & $3082(17)$ & $1160(120)$ & $7880(30)$ & $70(20)$ \\
H22 & $4063(14)$ & $-2920(100)$ & $8870(20)$ & $29(13)$ \\
H23 & $3853(13)$ & $-5940(90)$ & $9590(30)$ & $21(15)$ \\
H24 & $3229(12)$ & $-6410(100)$ & $10080(30)$ & $24(13)$ \\
H25 & $2769(14)$ & $-3150(90)$ & $9640(20)$ & $24(12)$ \\
H30 & $4299(13)$ & $3800(80)$ & $7670(20)$ & $11(13)$ \\
H31 & $4206(12)$ & $330(90)$ & $8470(20)$ & $17(11)$ \\
H32A & $4327(12)$ & $7660(90)$ & $7280(30)$ & $19(13)$ \\
H32B & $4238(14)$ & $8230(110)$ & $6430(30)$ & $33(16)$ \\
H32C & $4404(13)$ & $5940(90)$ & $6600(30)$ & $19(14)$ \\
H33 & $3187(13)$ & $5790(90)$ & $6520(20)$ & $23(12)$ \\
H34A & $2881(12)$ & $7210(90)$ & $7660(20)$ & $24(13)$ \\
H34B & $2637(15)$ & $4510(110)$ & $7650(30)$ & $49(17)$ \\
H34C & $2565(13)$ & $6540(90)$ & $6980(30)$ & $26(13)$ \\
H35A & $2703(13)$ & $1480(90)$ & $6720(30)$ & $27(14)$ \\
H35B & $2639(15)$ & $3370(110)$ & $6130(30)$ & $41(16)$ \\
H36A & $3280(16)$ & $1890(120)$ & $5600(30)$ & $48(18)$ \\
H36B & $3291(16)$ & $280(120)$ & $6170(30)$ & $50(19)$ \\
H37A & $2742(11)$ & $-1470(80)$ & $5710(20)$ & $6(11)$ \\
H37B & $2751(13)$ & $390(100)$ & $5150(30)$ & $21(13)$ \\
H38A & $3057(14)$ & $-3160(110)$ & $4590(30)$ & $36(15)$ \\
H38B & $3368(18)$ & $-1190(140)$ & $4580(40)$ & $80(20)$ \\
H38C & $3348(16)$ & $-3150(110)$ & $5250(30)$ & $47(17)$ \\
H3A & $2112(13)$ & $4070(100)$ & $9010(20)$ & $16(13)$ \\
H3B & $2167(17)$ & $7110(130)$ & $8970(30)$ & $60(20)$ \\
\hline \hline
\end{tabular}




\subsection{Selected HMBC-Spectra}

\section{$\mathrm{HMBC} 93 \mathrm{bb}$}<smiles>CCc1c(-c2ccccn2)cc2c(O[14CH])c1C[C@H](C)CCC[C@H](C)C2</smiles>
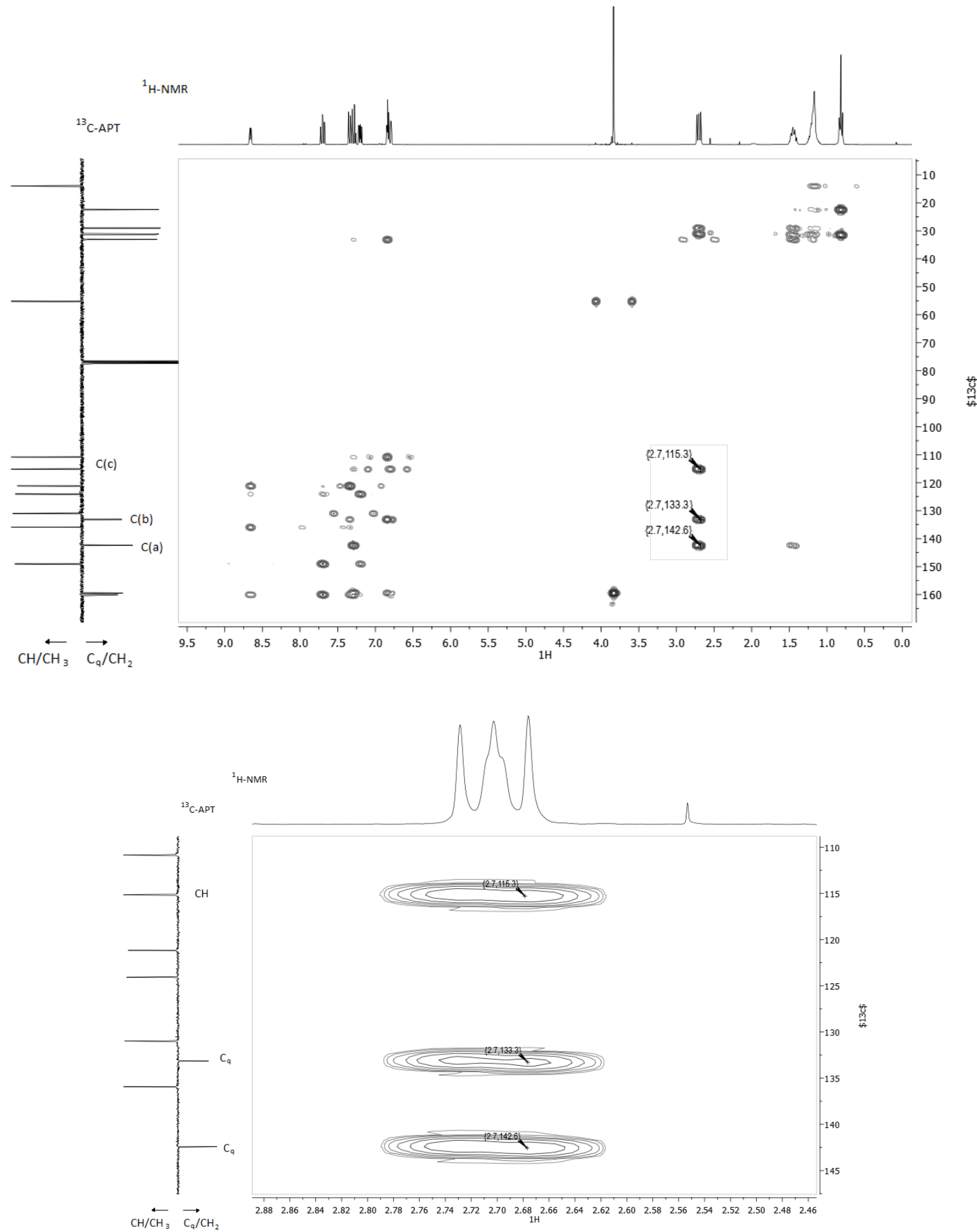
270

Experimental Procedures and Analytical Data

HMBC 93 bb'

nOe:
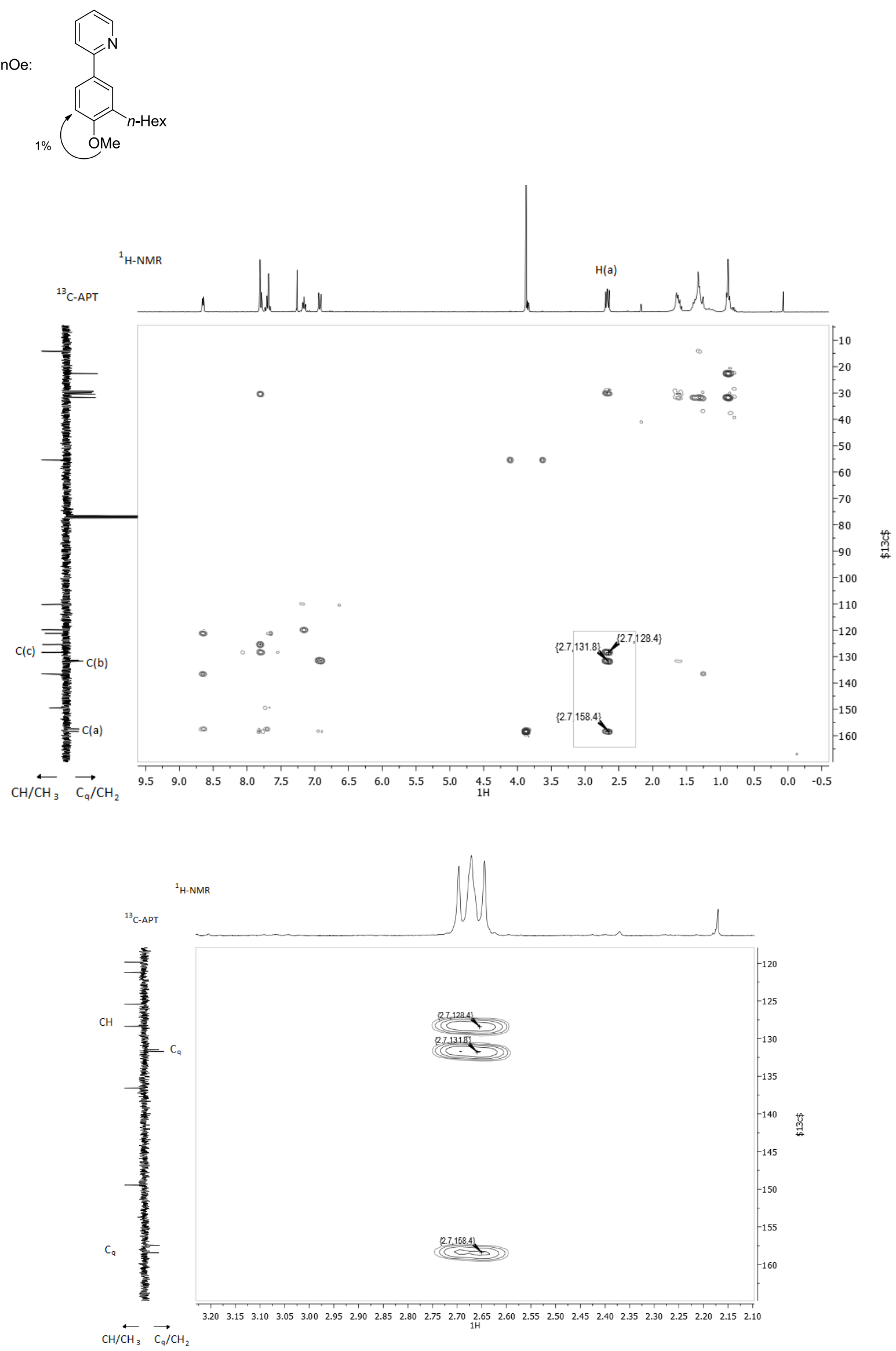
Experimental Procedures and Analytical Data

271

HMBC 122b
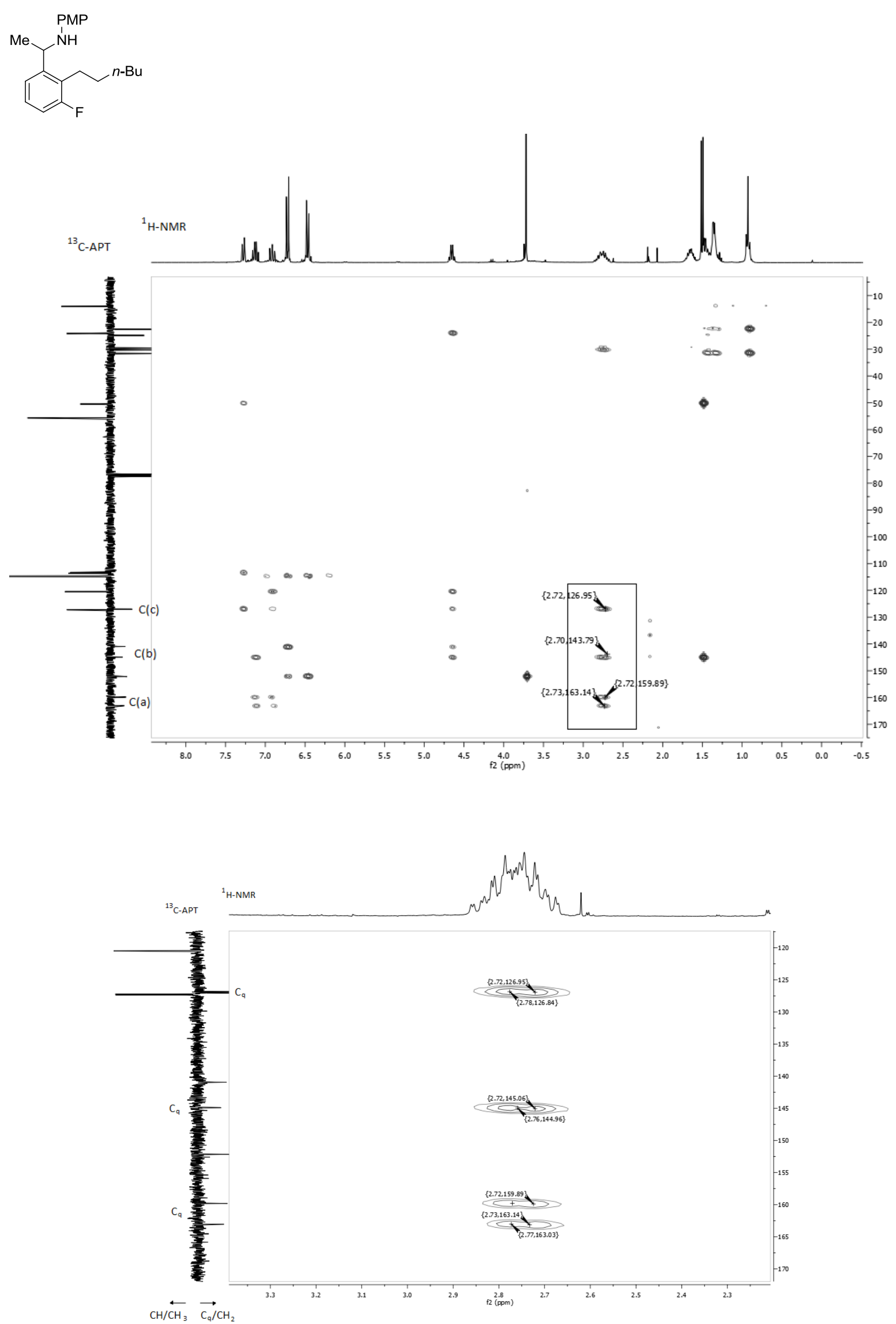
272

Experimental Procedures and Analytical Data

HMBC 122c
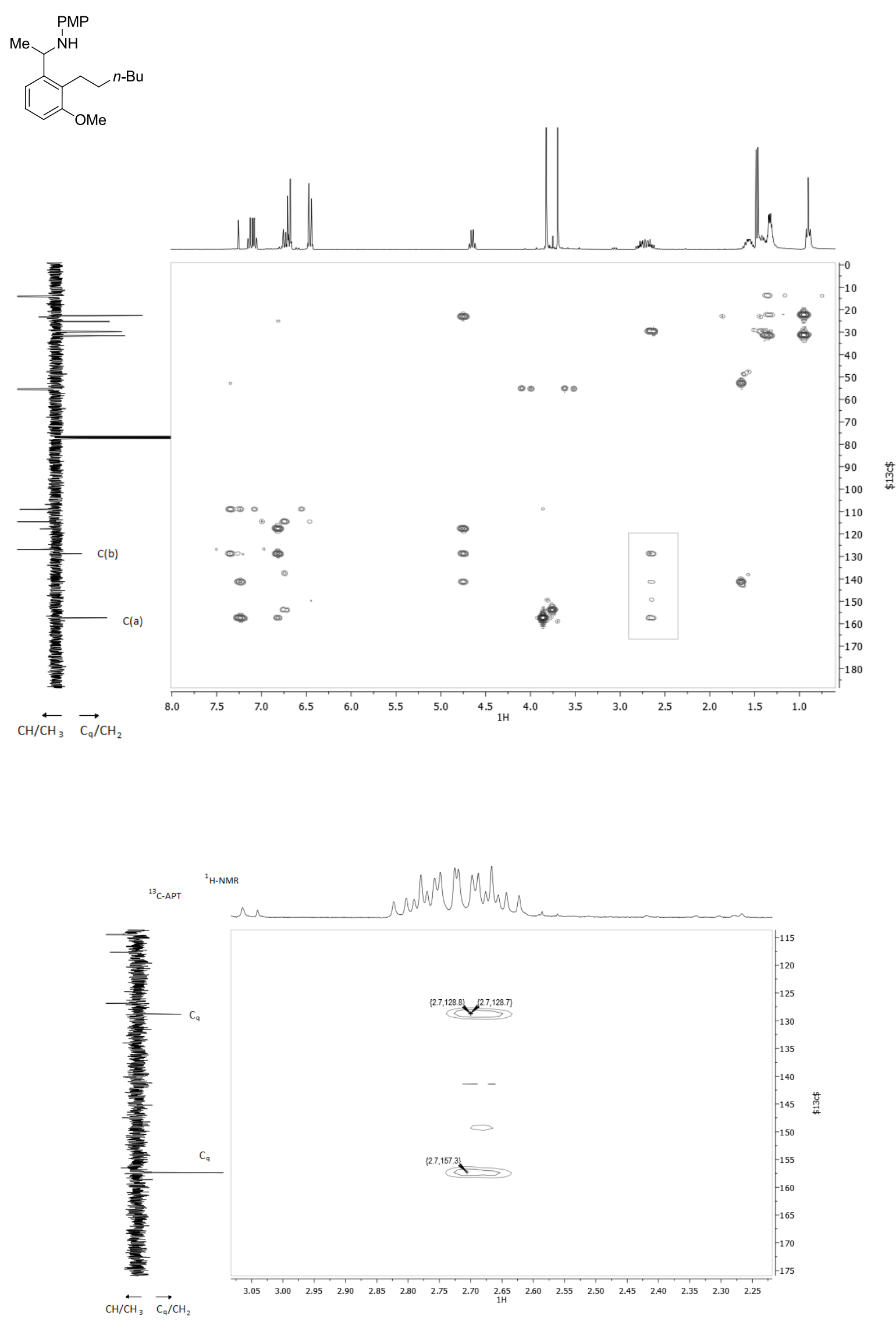
Experimental Procedures and Analytical Data

273

HMBC 122c'
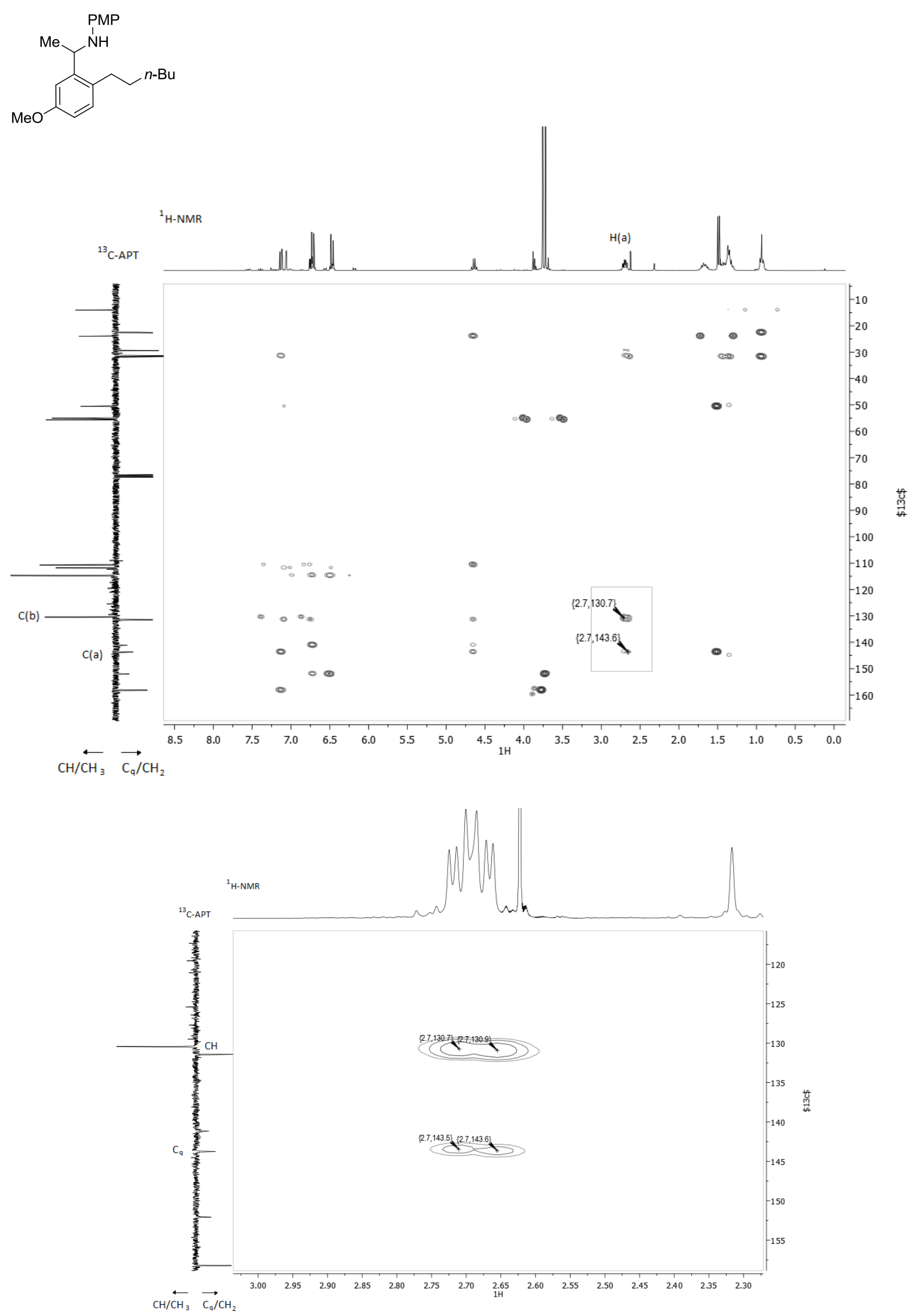


\section{HMBC 122d}

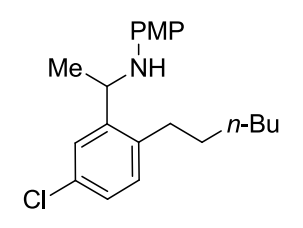
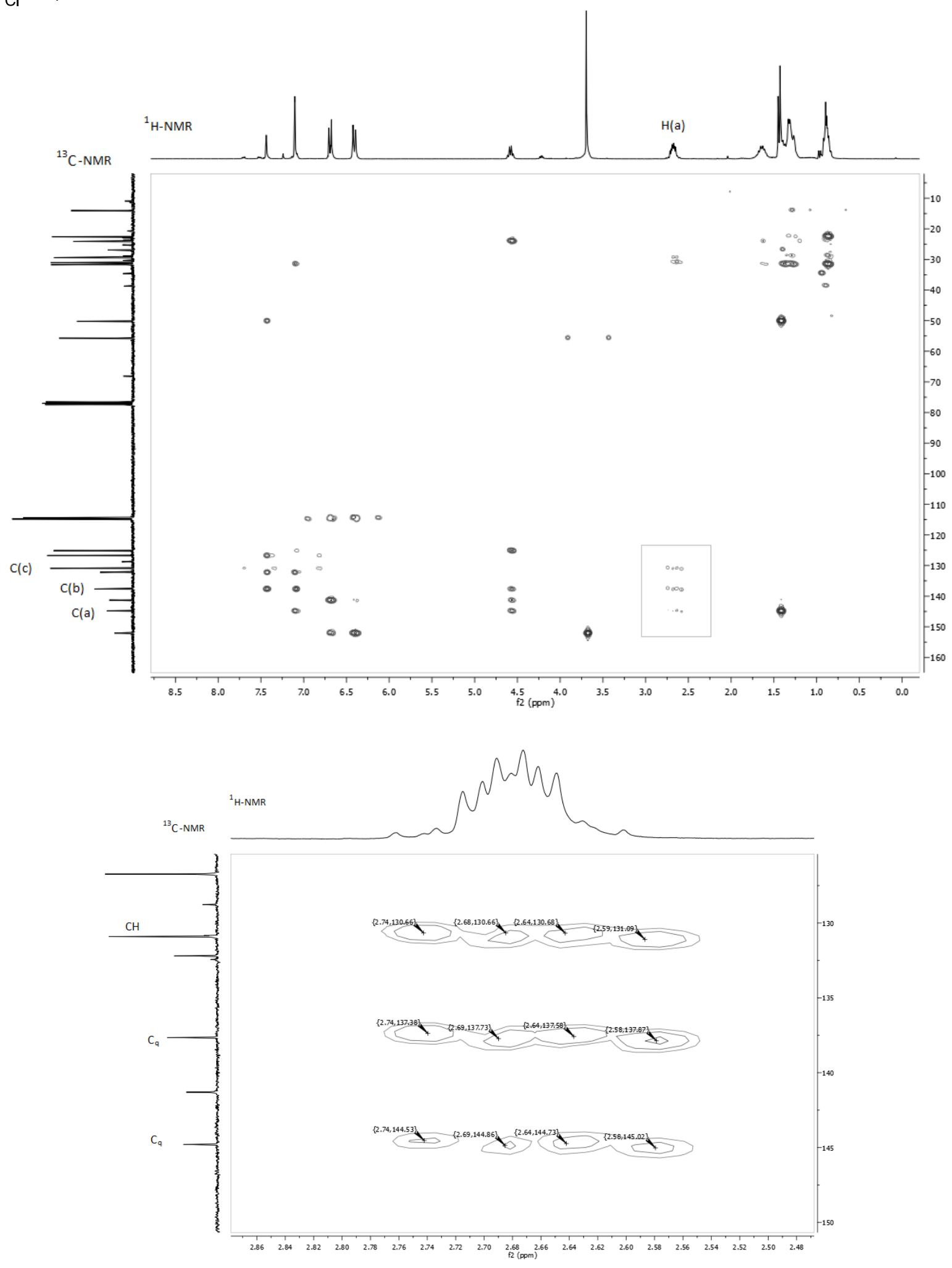


\section{HMBC 122e}<smiles>Cc1ccc(CCCC(C)(C)C)c(C(C)NP(=O)(O)OCc2ccccc2)c1</smiles>

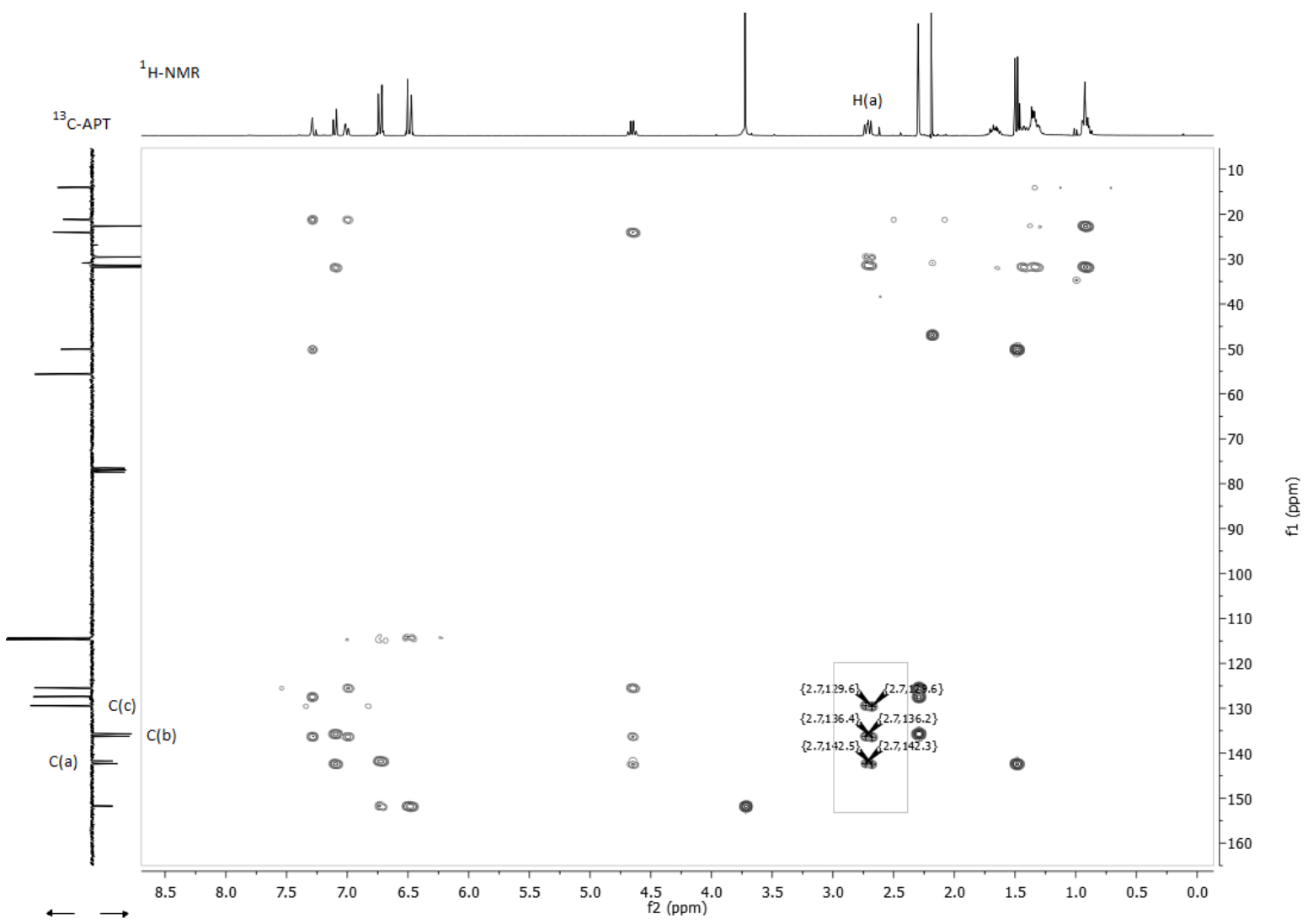

$\stackrel{\mathrm{CH} / \mathrm{CH}_{3}}{\longrightarrow} \underset{\mathrm{C}_{\mathrm{q}} / \mathrm{CH}_{2}}{\longrightarrow}$

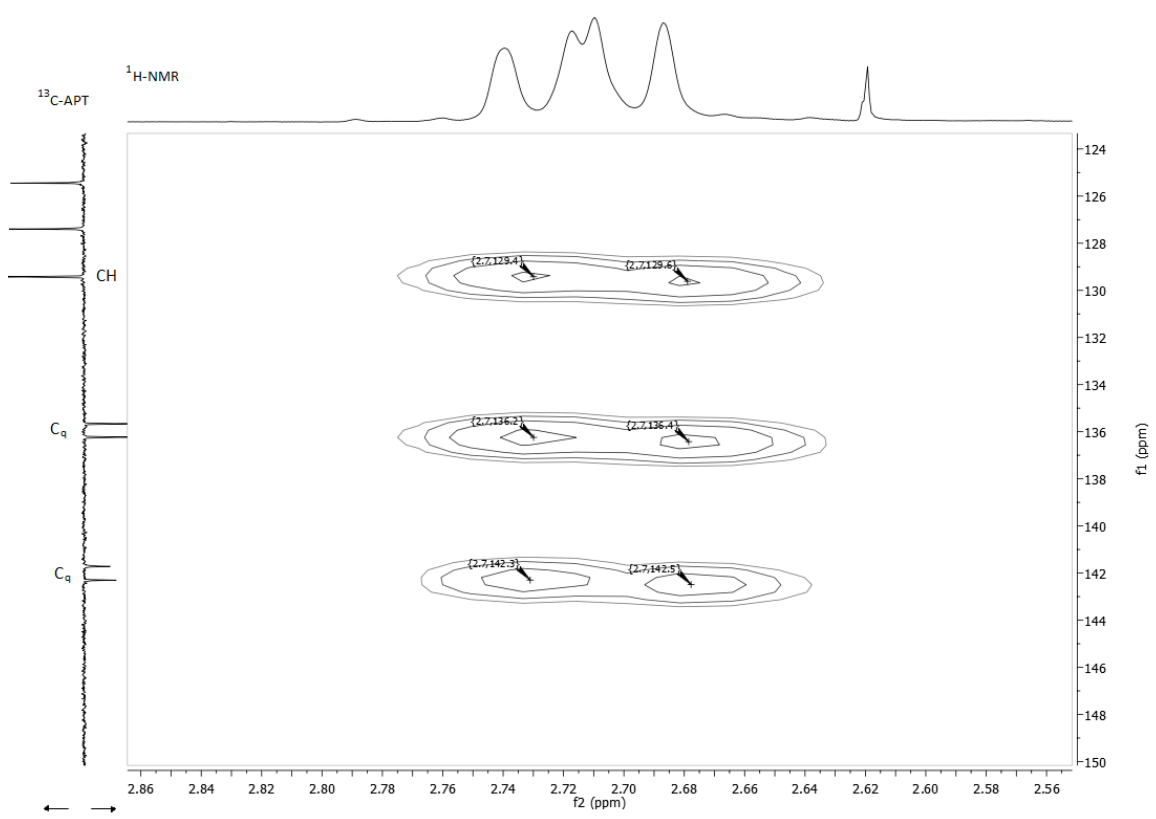
$\stackrel{\mathrm{CH} / \mathrm{CH}_{3}}{\leftarrow} \underset{\mathrm{C}_{9} / \mathrm{CH}_{2}}{\longrightarrow}$ 
276

Experimental Procedures and Analytical Data

HMBC 147aa

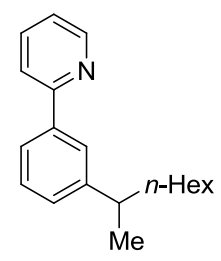
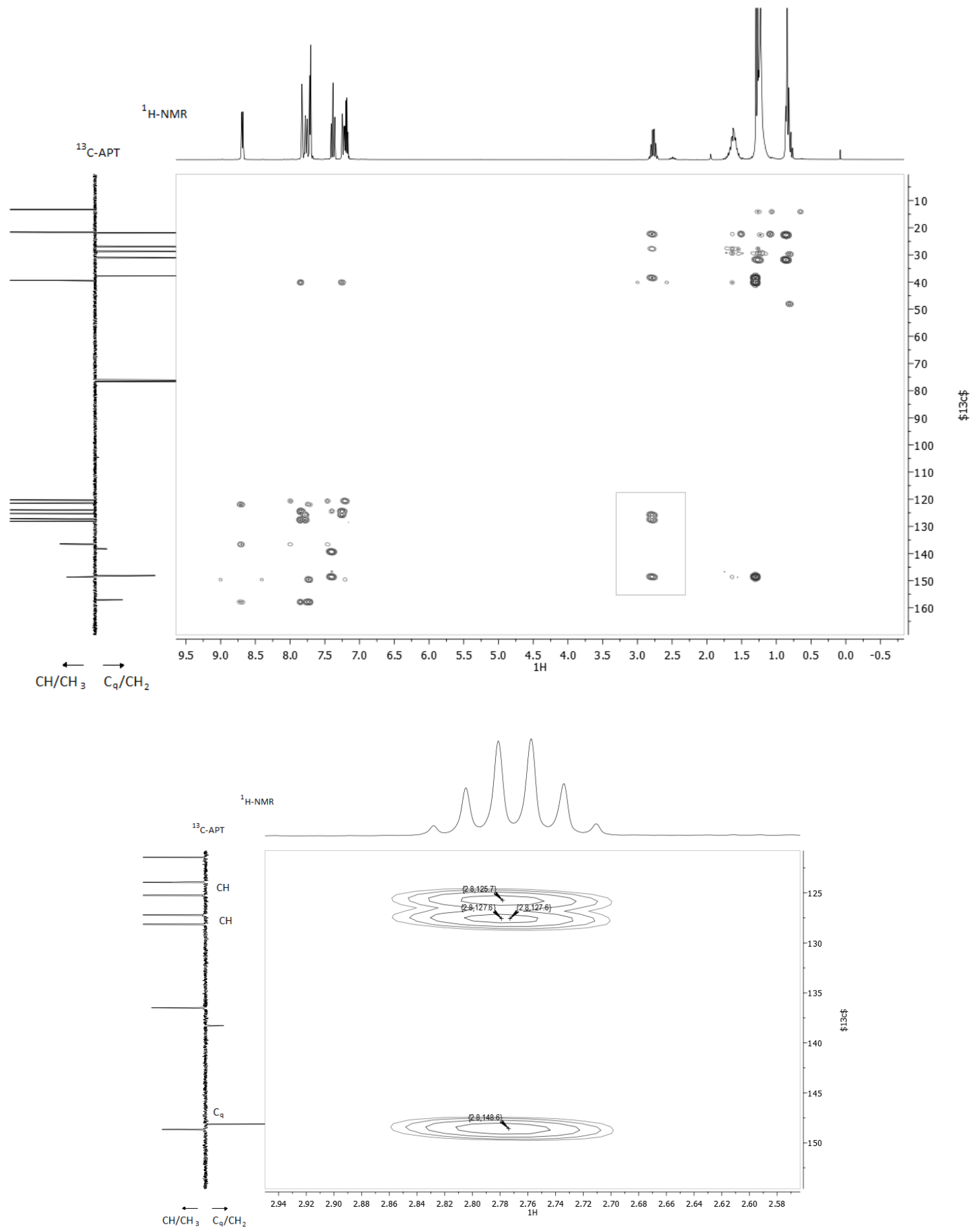


\section{HMBC 147ba}
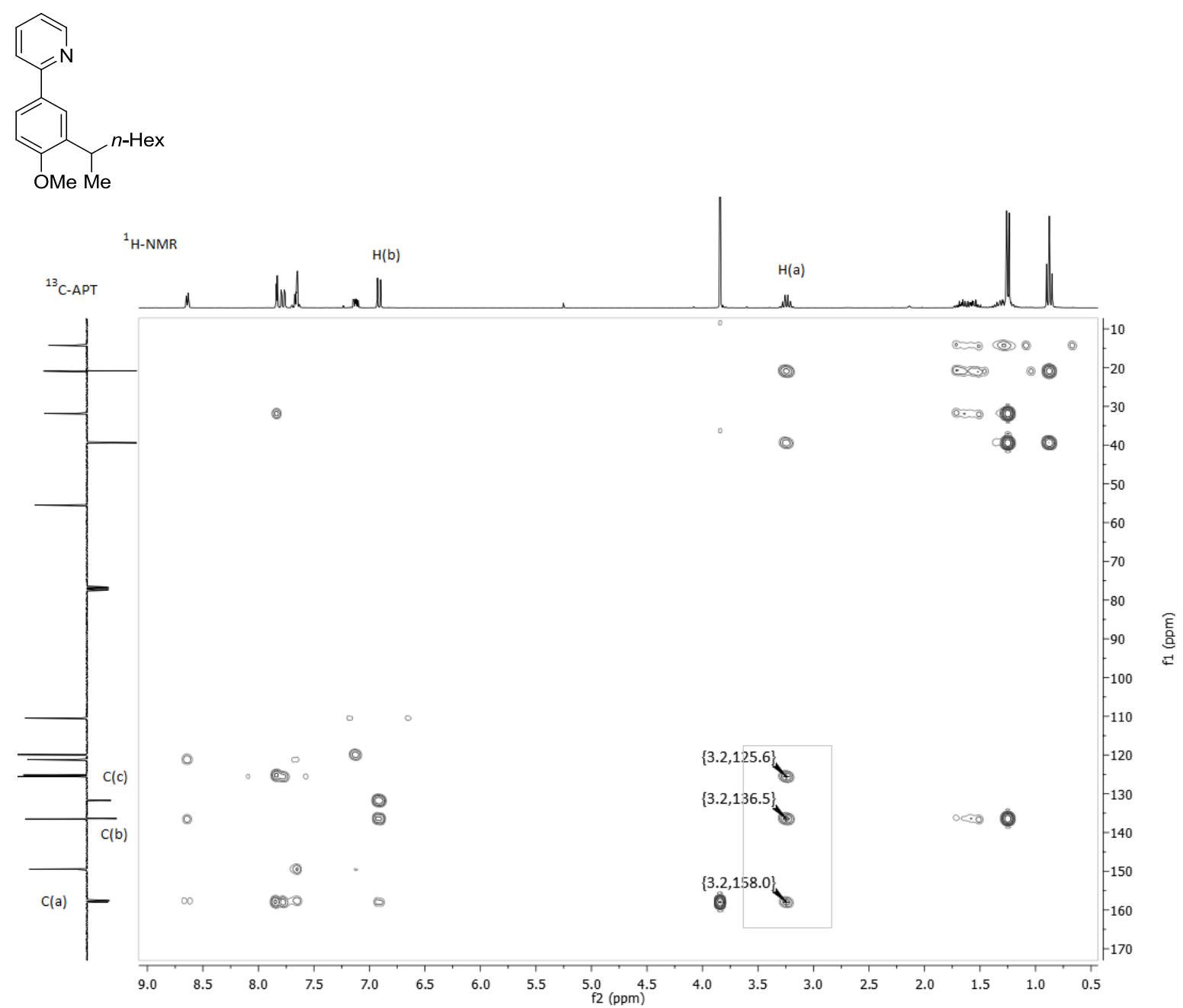

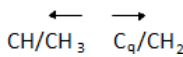

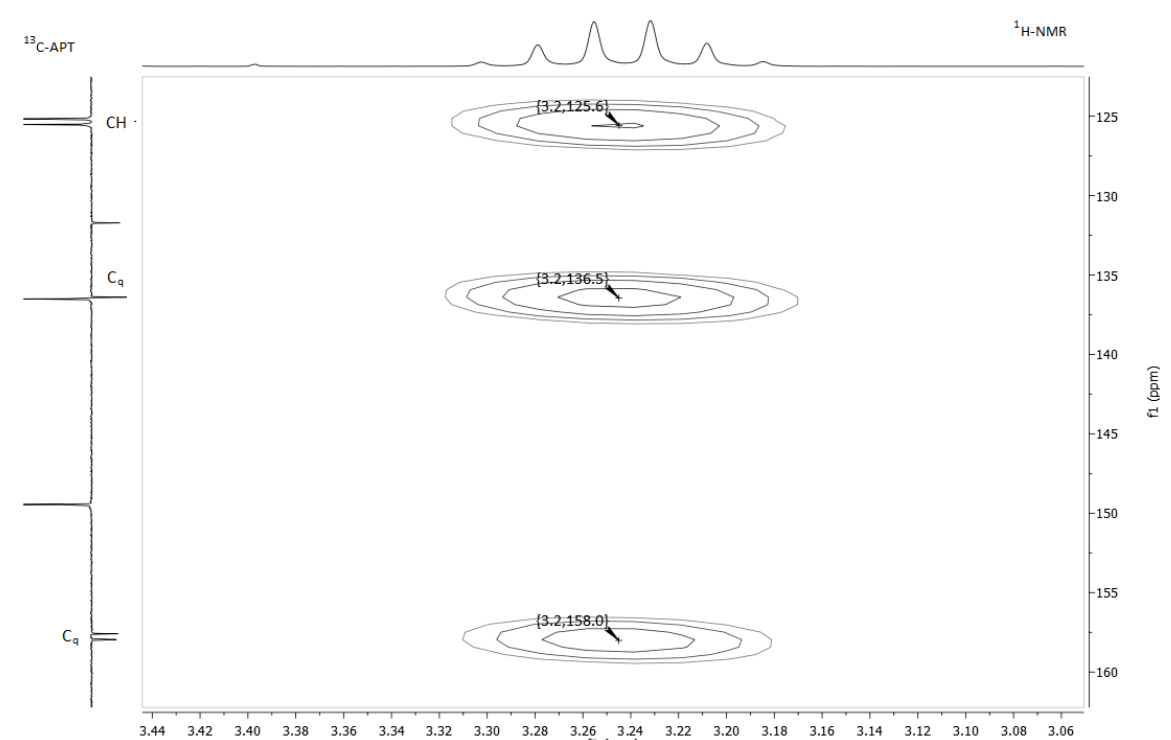

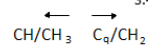




\section{HMBC 147bi}

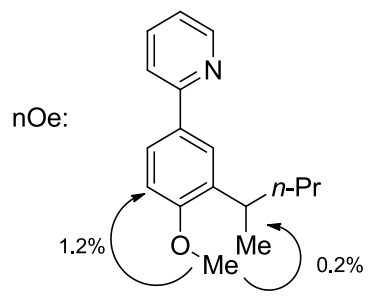

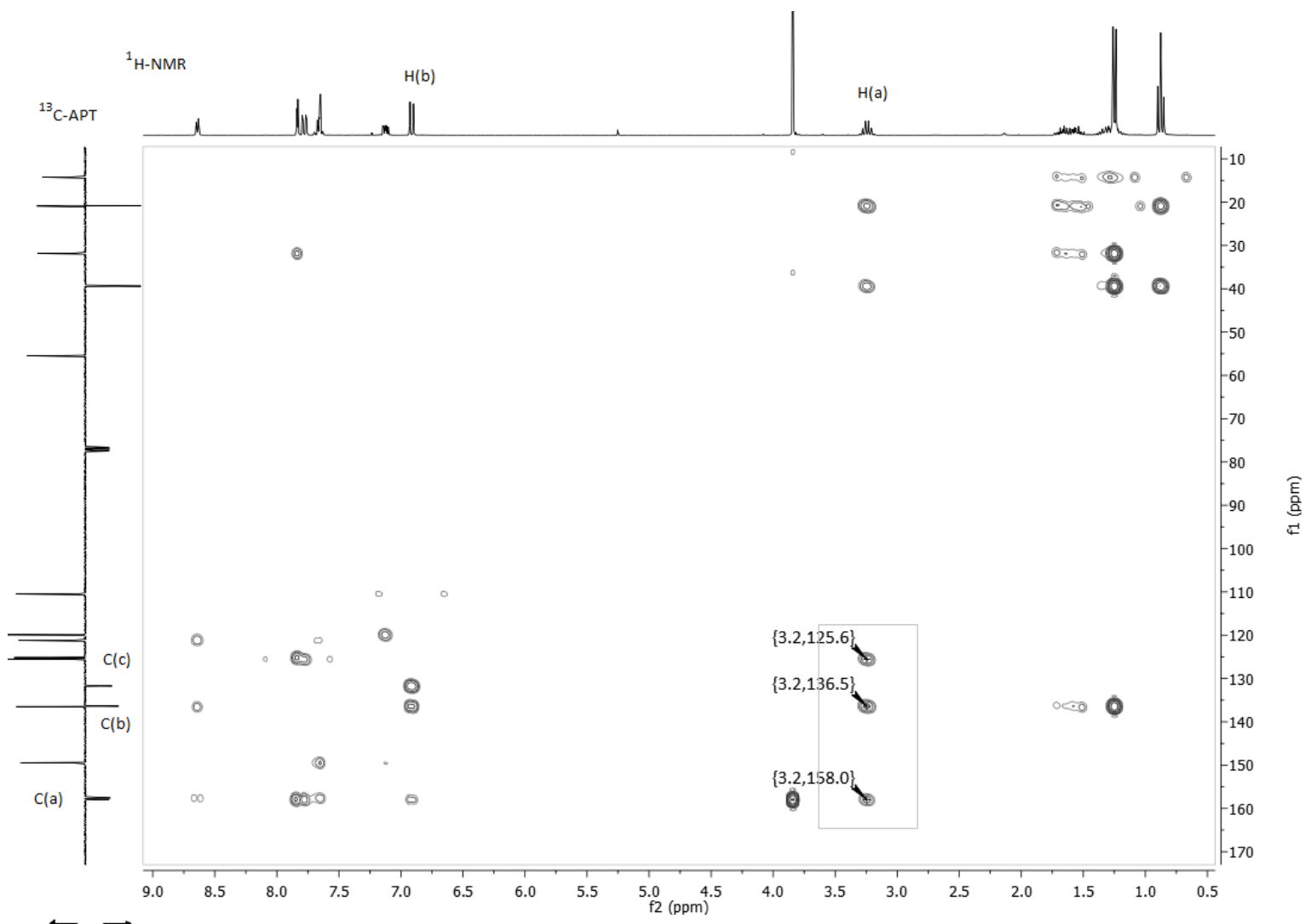

$\stackrel{\mathrm{CH} / \mathrm{CH}_{3}}{\leftarrow} \overrightarrow{\mathrm{C}_{9} / \mathrm{CH}_{2}}$

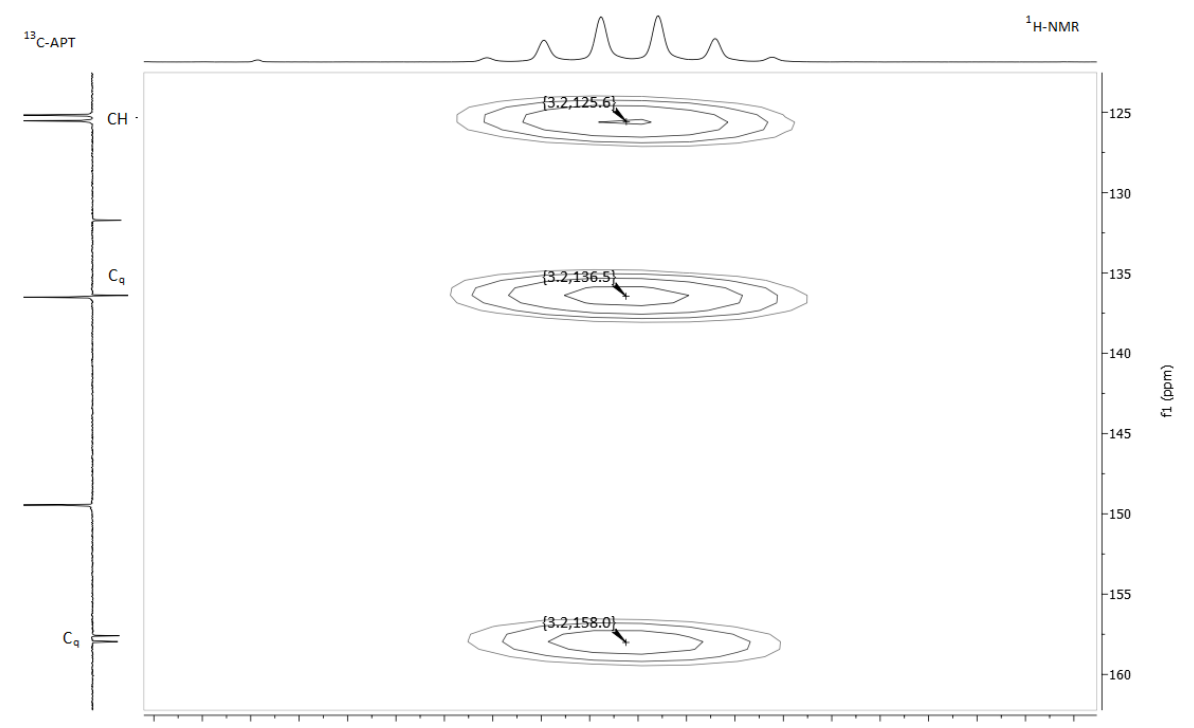

$\underset{\mathrm{CH} / \mathrm{CH}_{3}}{\leftarrow} \underset{\mathrm{C}_{9} / \mathrm{CH}_{2}}{\longrightarrow} \begin{array}{cccccccccccccccccccccc}3.44 & 3.42 & 3.40 & 3.38 & 3.36 & 3.34 & 3.32 & 3.30 & 3.28 & 3.26 & 3.24 & 3.22 & 3.20 & 3.18 & 3.16 & 3.14 & 3.12 & 3.10 & 3.08 & 3.06\end{array}$ 
Experimental Procedures and Analytical Data

279

HMBC 147ca<smiles>CC(C=[V])c1cc(-c2ccccn2)ccc1F</smiles>
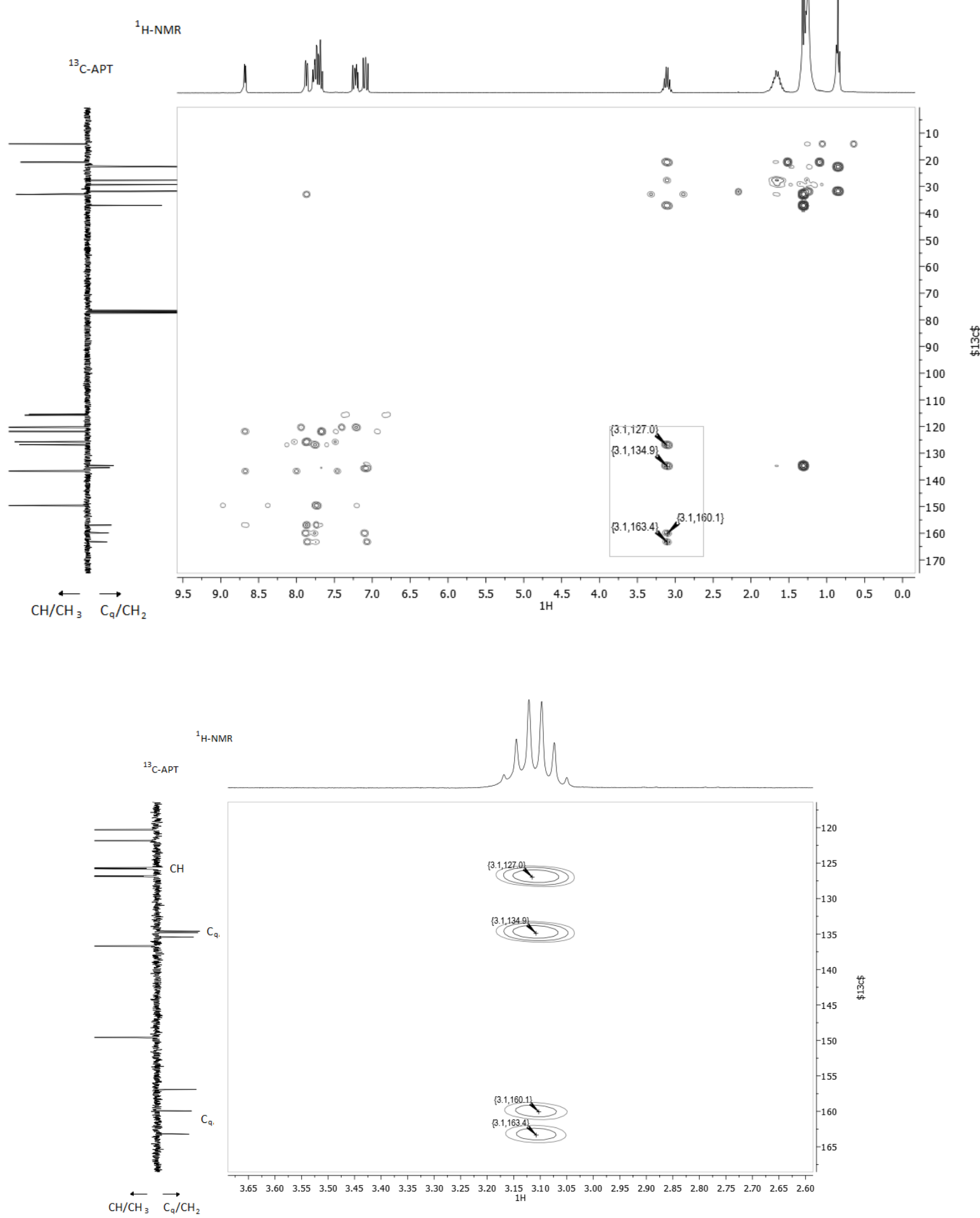


\section{HMBC 147ki}<smiles>CCCC(C)C(=O)c1cc(-c2ccccn2)ccc1C(=O)O</smiles>
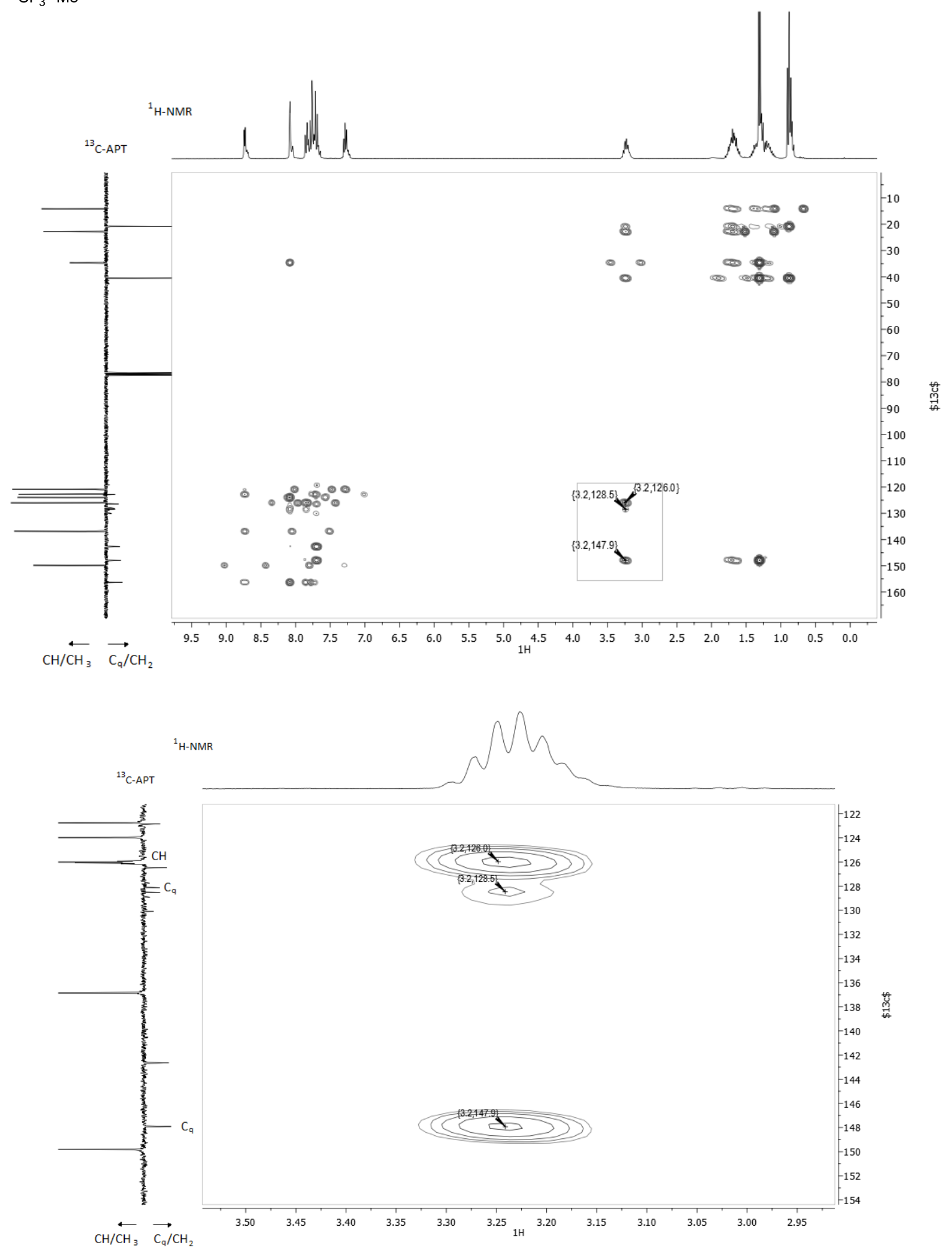


\section{HMBC 147oa}<smiles>Cc1ccc(-c2ccccn2)cc1C(C)CO</smiles>

Me Me

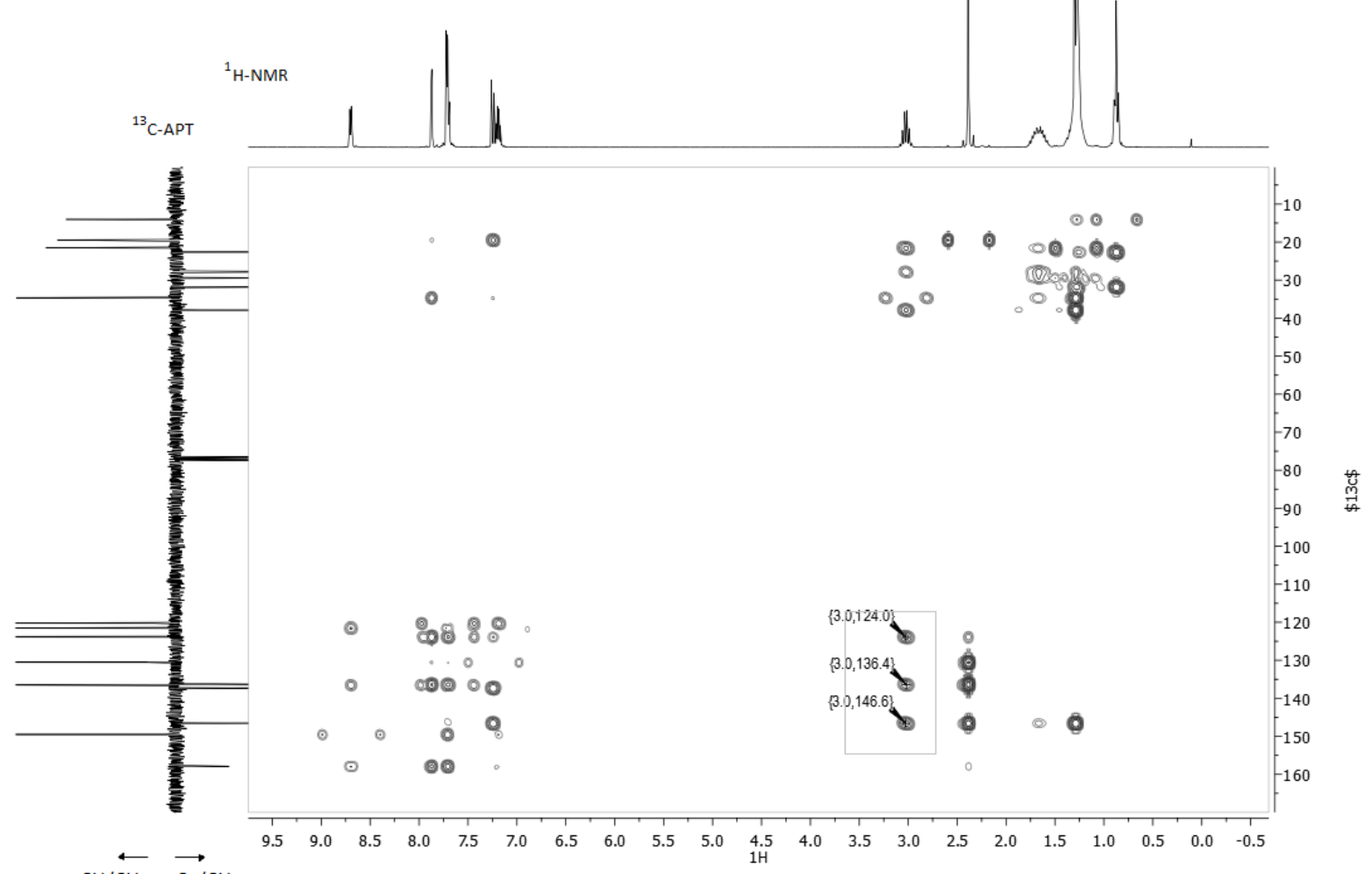

$\stackrel{\mathrm{CH} / \mathrm{CH}_{3}}{\stackrel{\mathrm{C}_{\mathrm{q}}}{\longrightarrow} / \mathrm{CH}_{2}}$

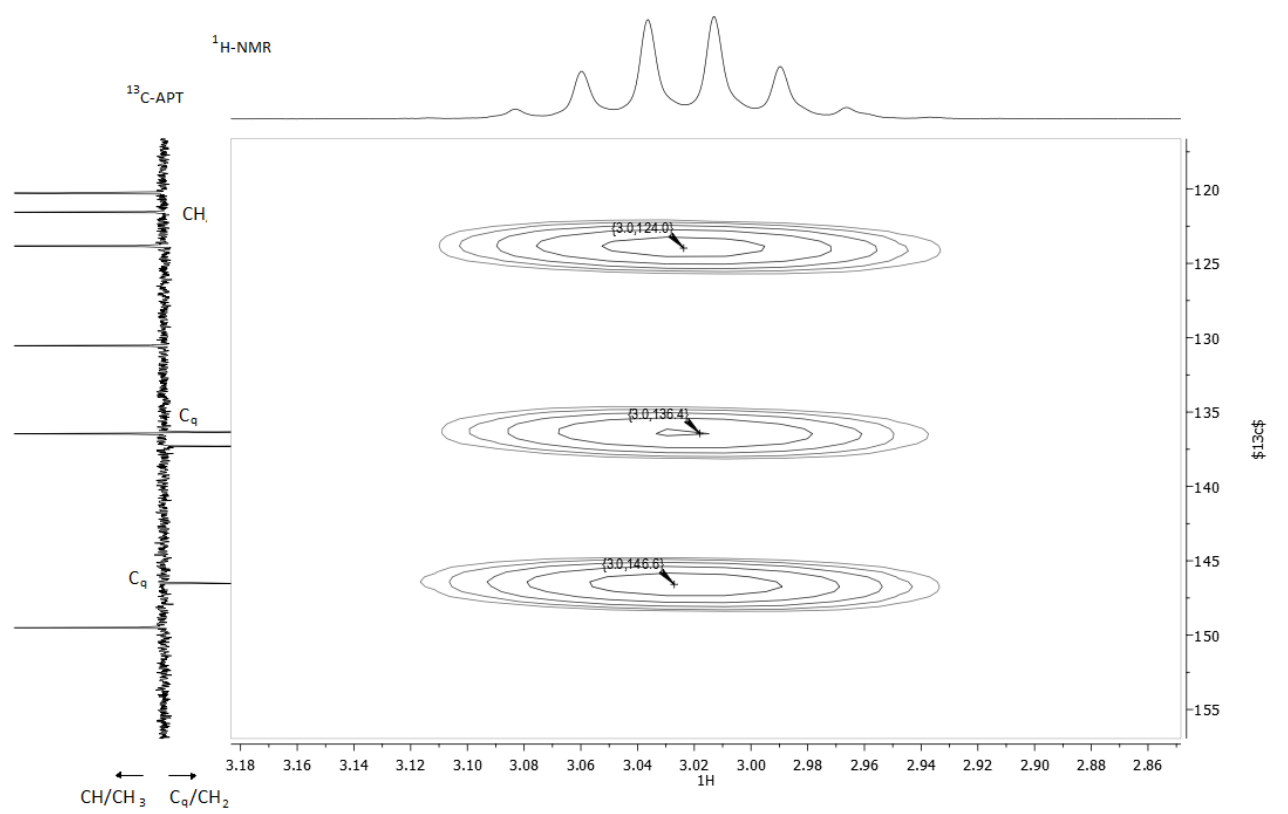


282

Experimental Procedures and Analytical Data

HMBC 147pi
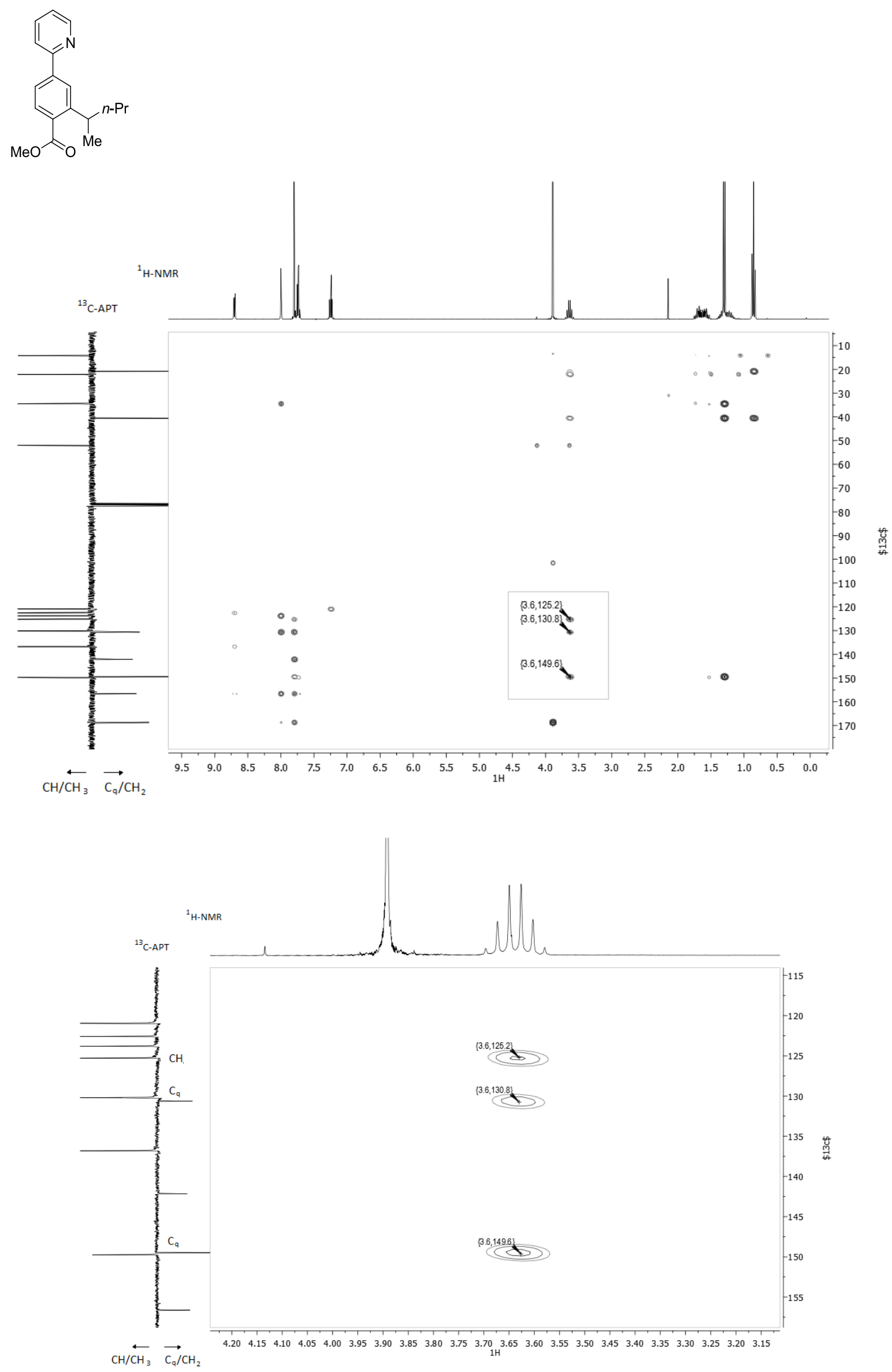
Experimental Procedures and Analytical Data

283

HMBC 147si
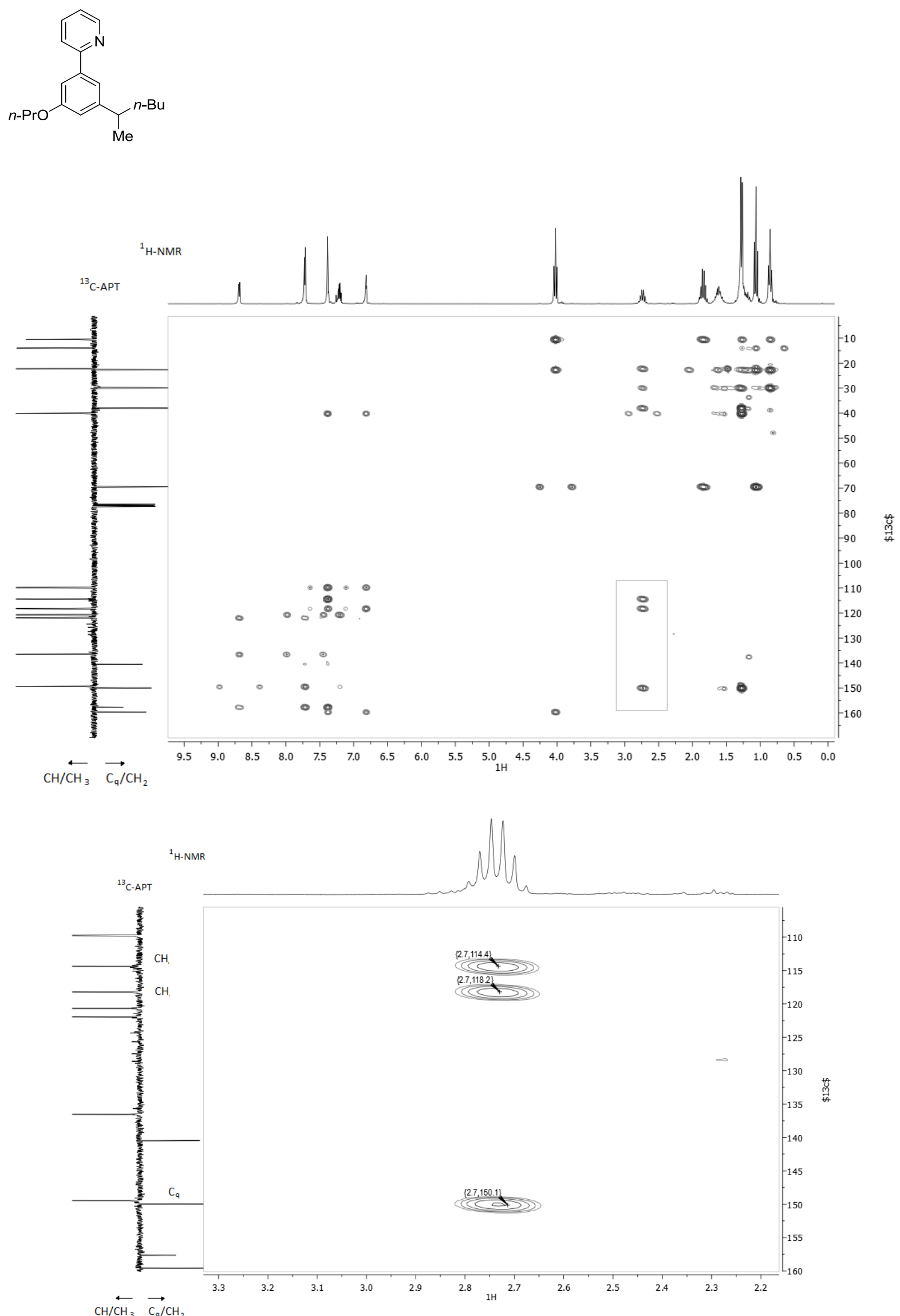

$\stackrel{\leftarrow H}{\longleftarrow} \stackrel{\mathrm{CH}_{3}}{\overrightarrow{\mathrm{C}_{9}} / \mathrm{CH}_{2}}$ 
284

Experimental Procedures and Analytical Data

HMBC 147ui
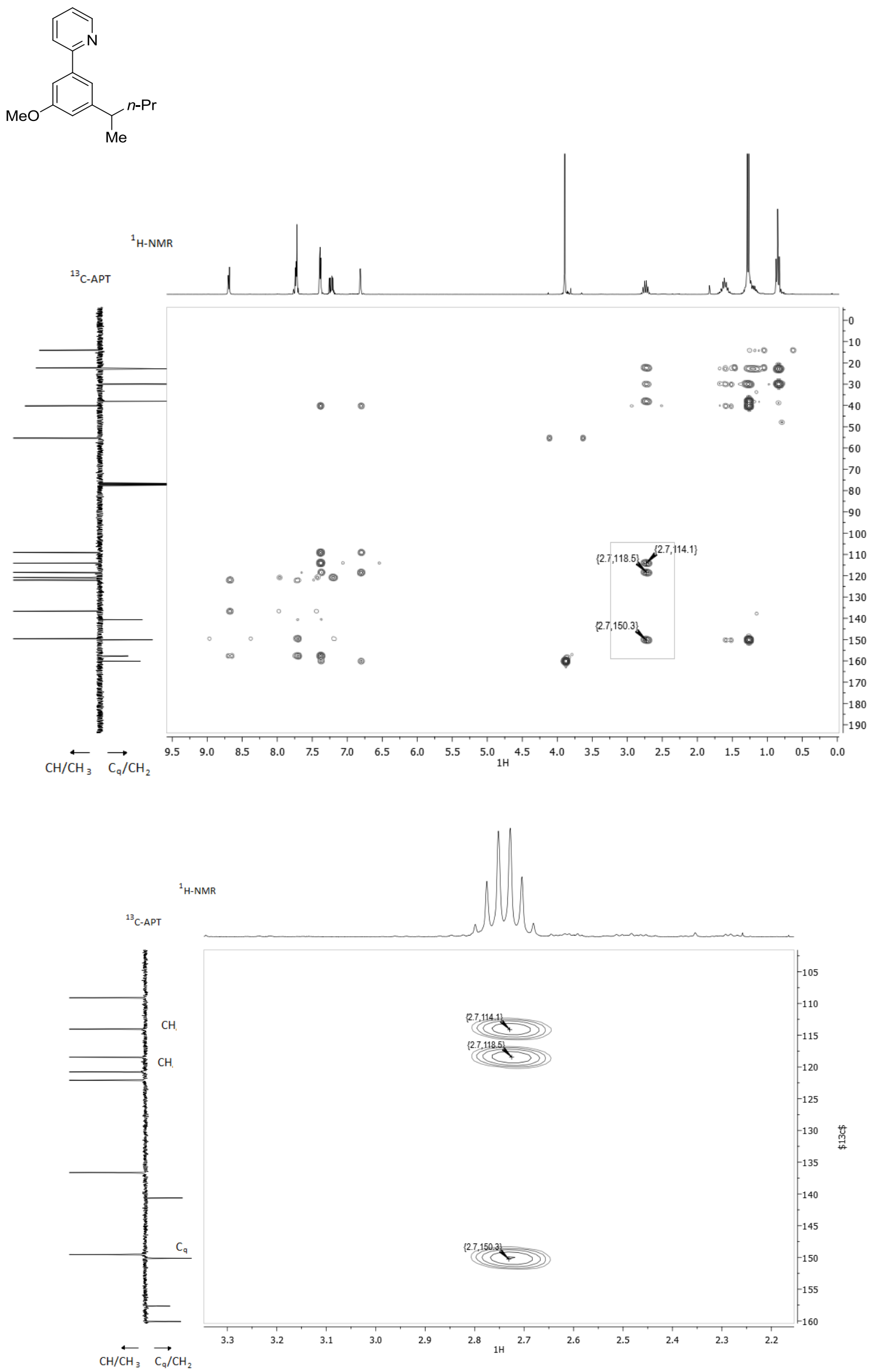
Experimental Procedures and Analytical Data

285

HMBC 147wa
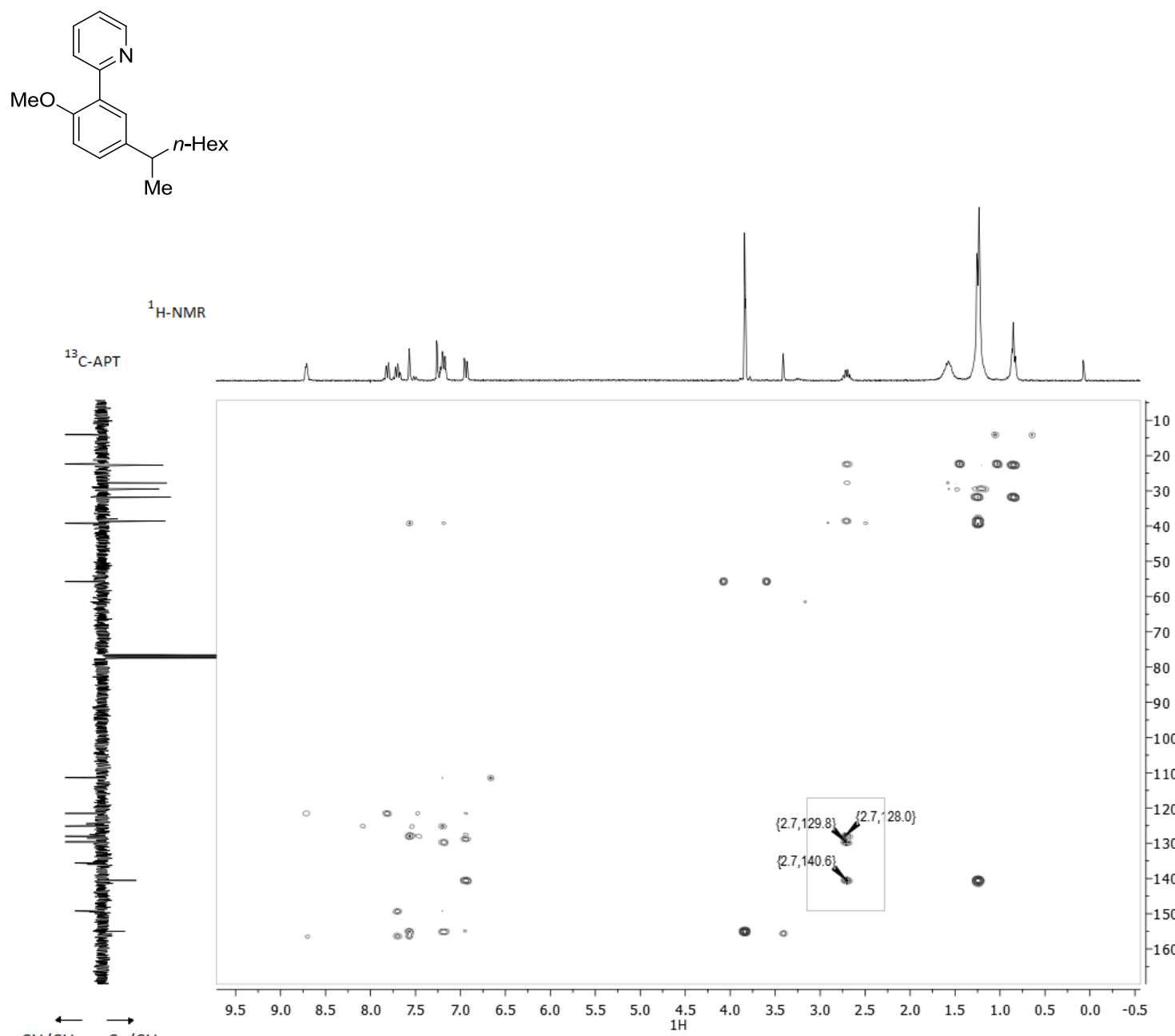

$\stackrel{\leftarrow H}{\longleftarrow} \underset{\mathrm{CH}_{3}}{\overrightarrow{\mathrm{C}_{9}} / \mathrm{CH}_{2}}$
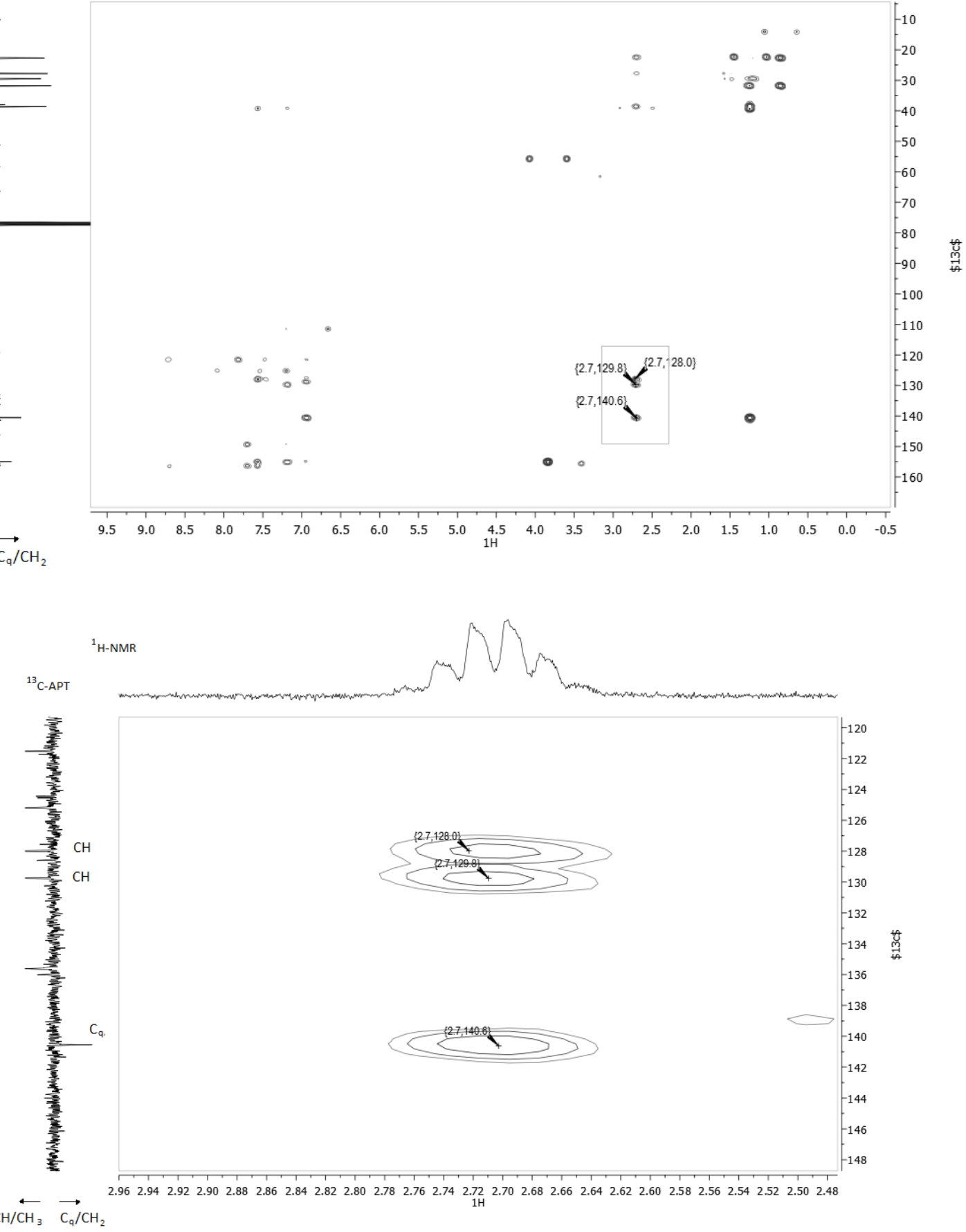


\section{HMBC 147wa“}<smiles>COc1c(-c2ccccn2)cccc1C(C)O</smiles>
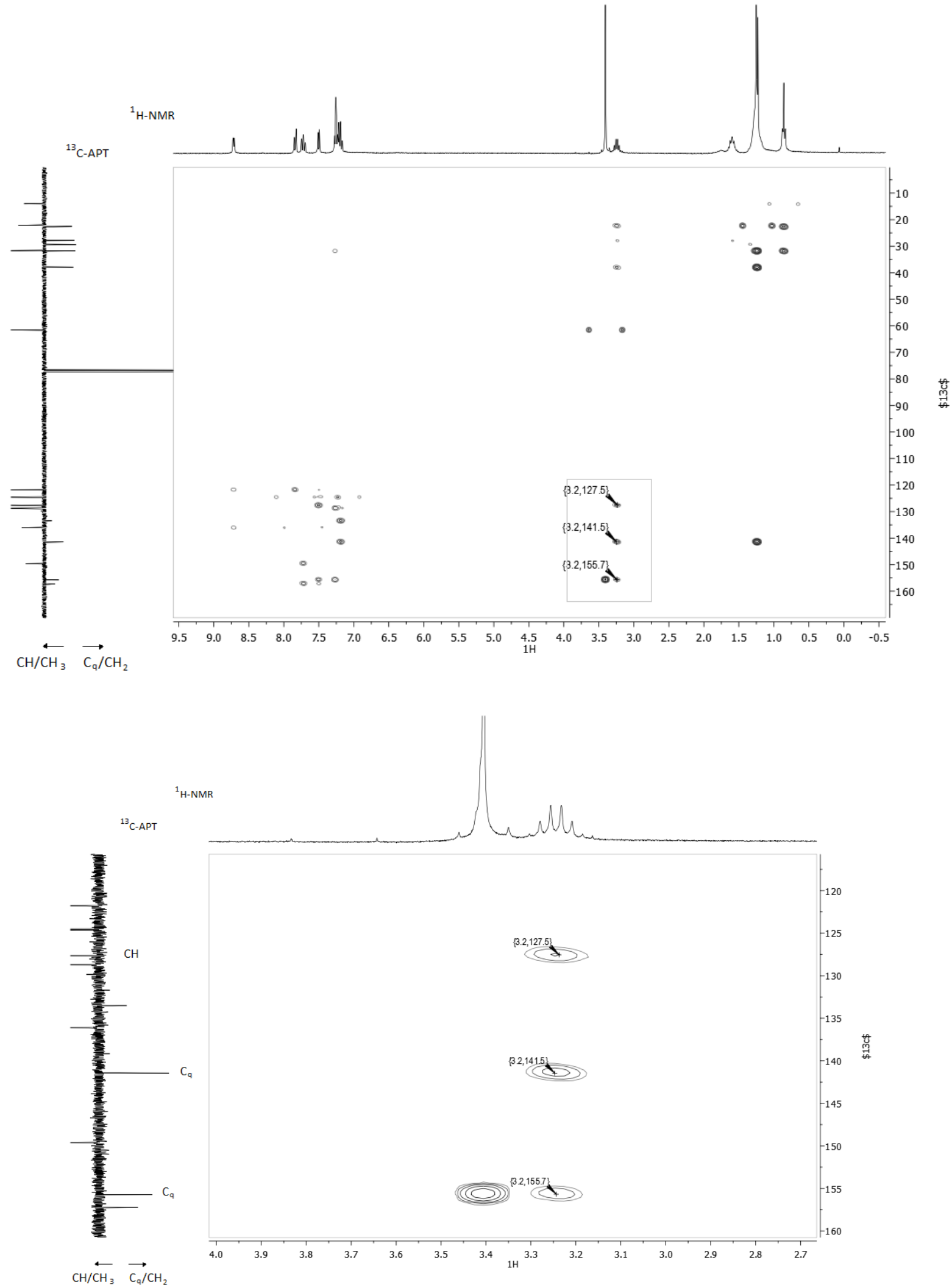


\section{HMBC 147xa}<smiles>Cc1ccc(C(C)C)cc1-c1ccccn1</smiles>
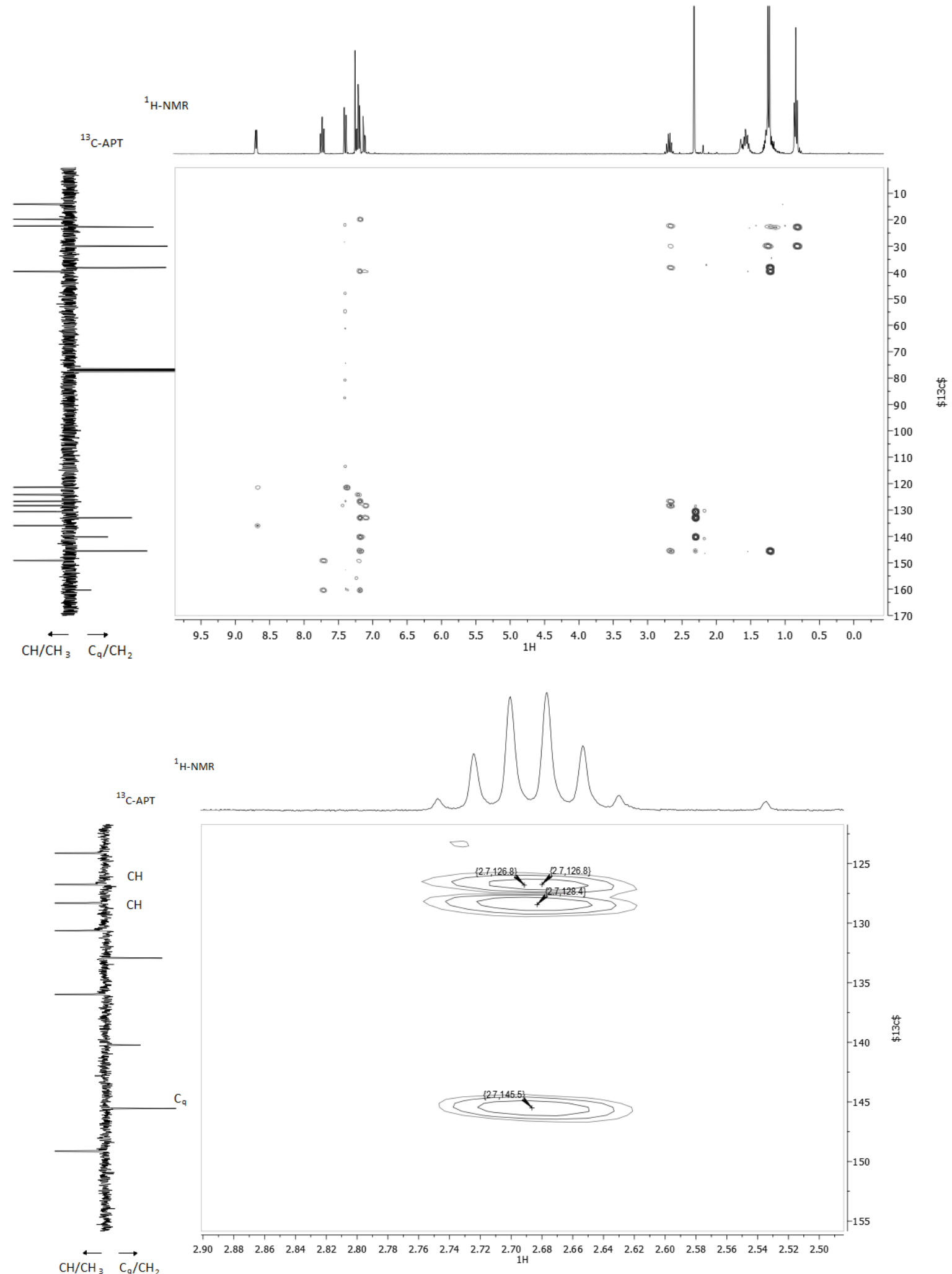
288

Experimental Procedures and Analytical Data

HMBC 147xa'
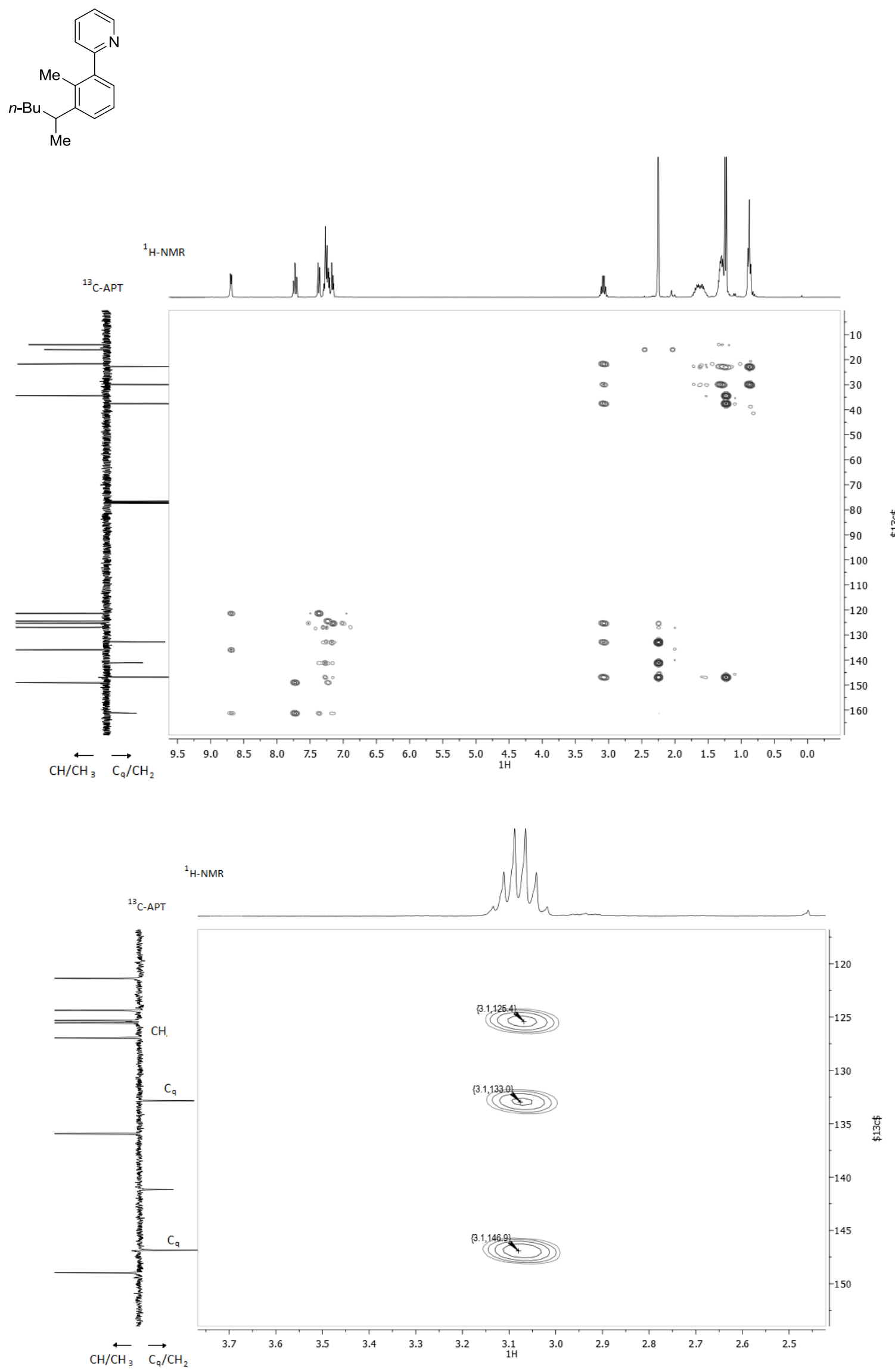
Experimental Procedures and Analytical Data

289

HMBC 152cj
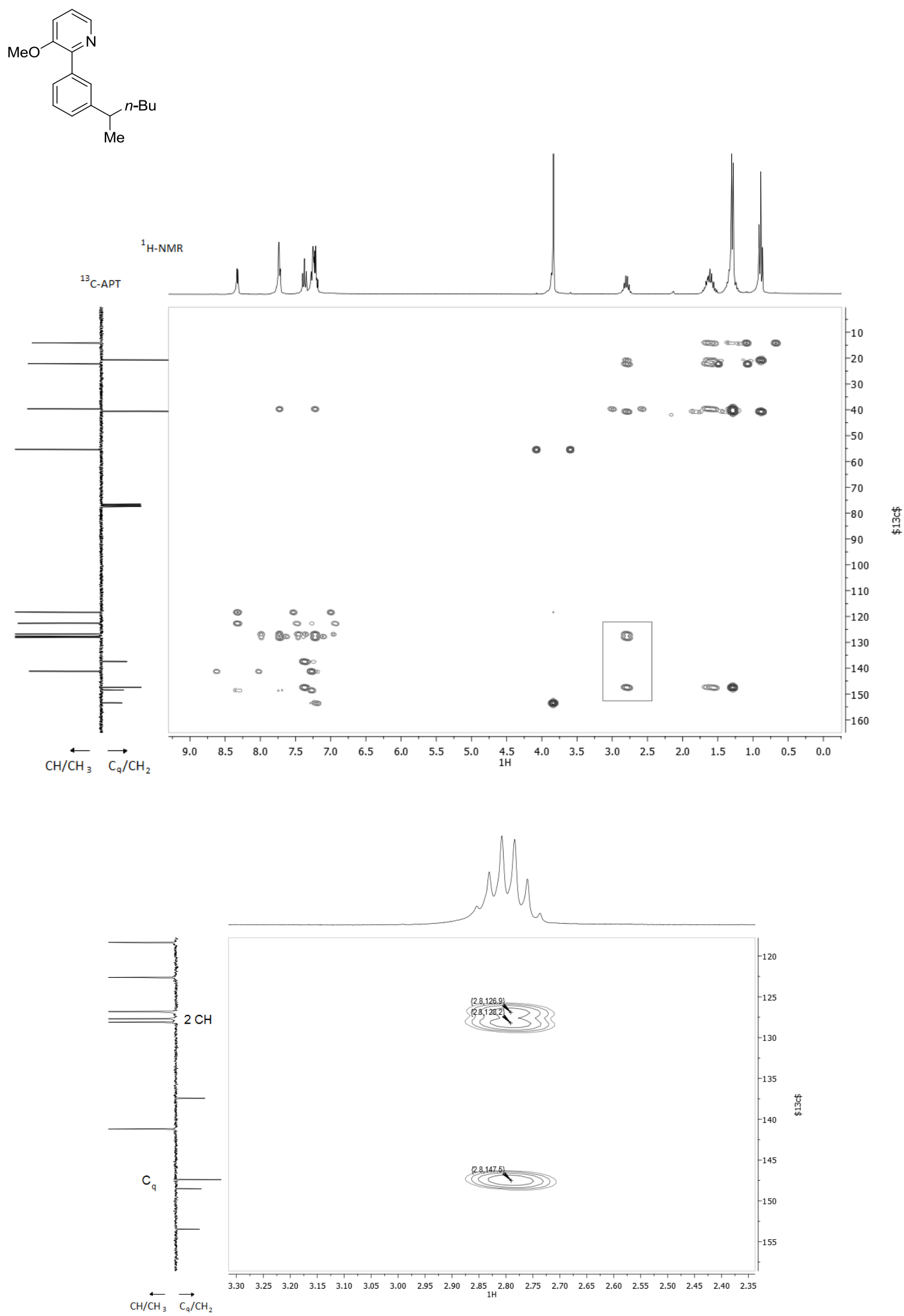
290

Experimental Procedures and Analytical Data

HMBC 152 dj<smiles>CCCCCC(C)c1cccc(-c2ncccc2C)c1</smiles>
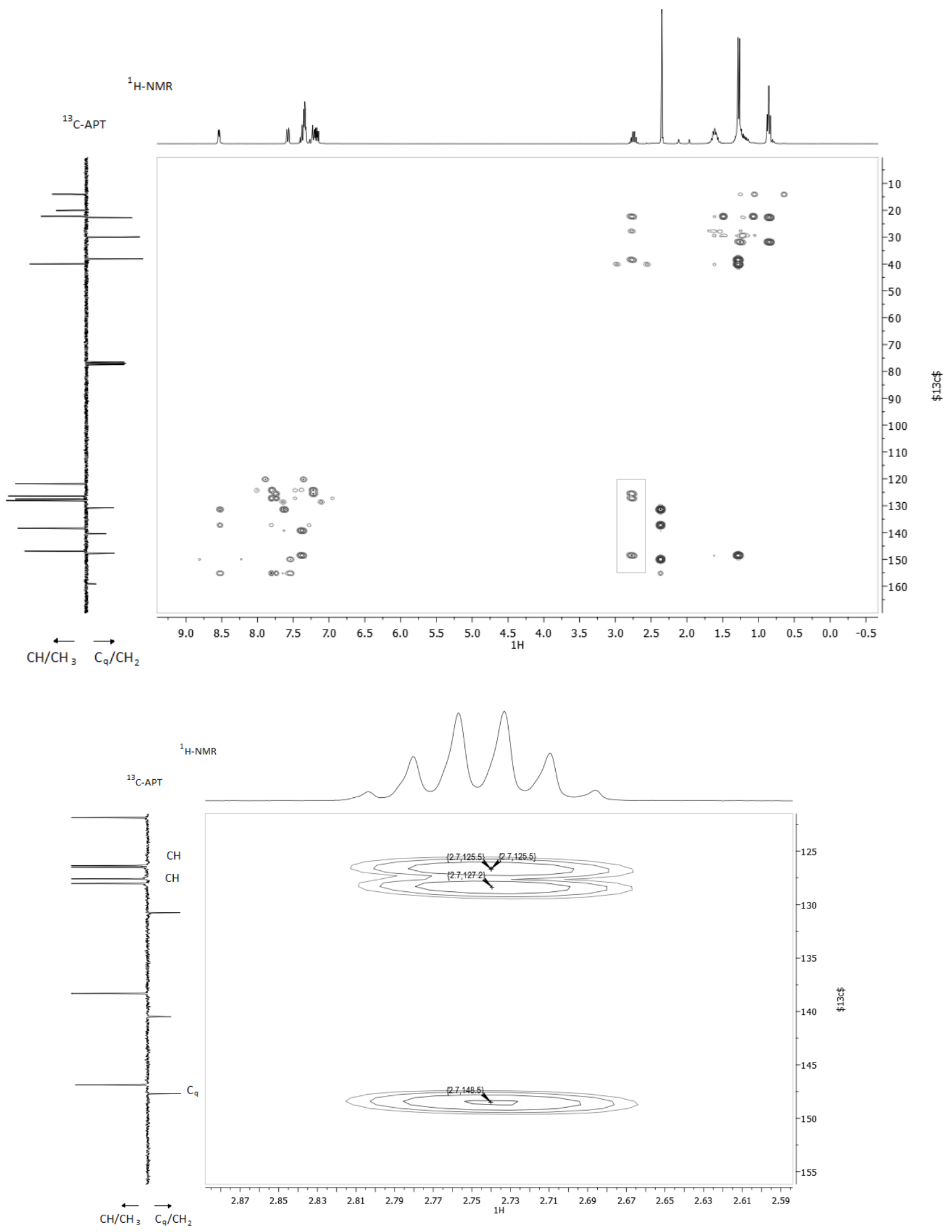


\section{HMBC 152gi}<smiles>CCCCC(=O)c1cccc(-c2cc(OC)ccn2)c1</smiles>
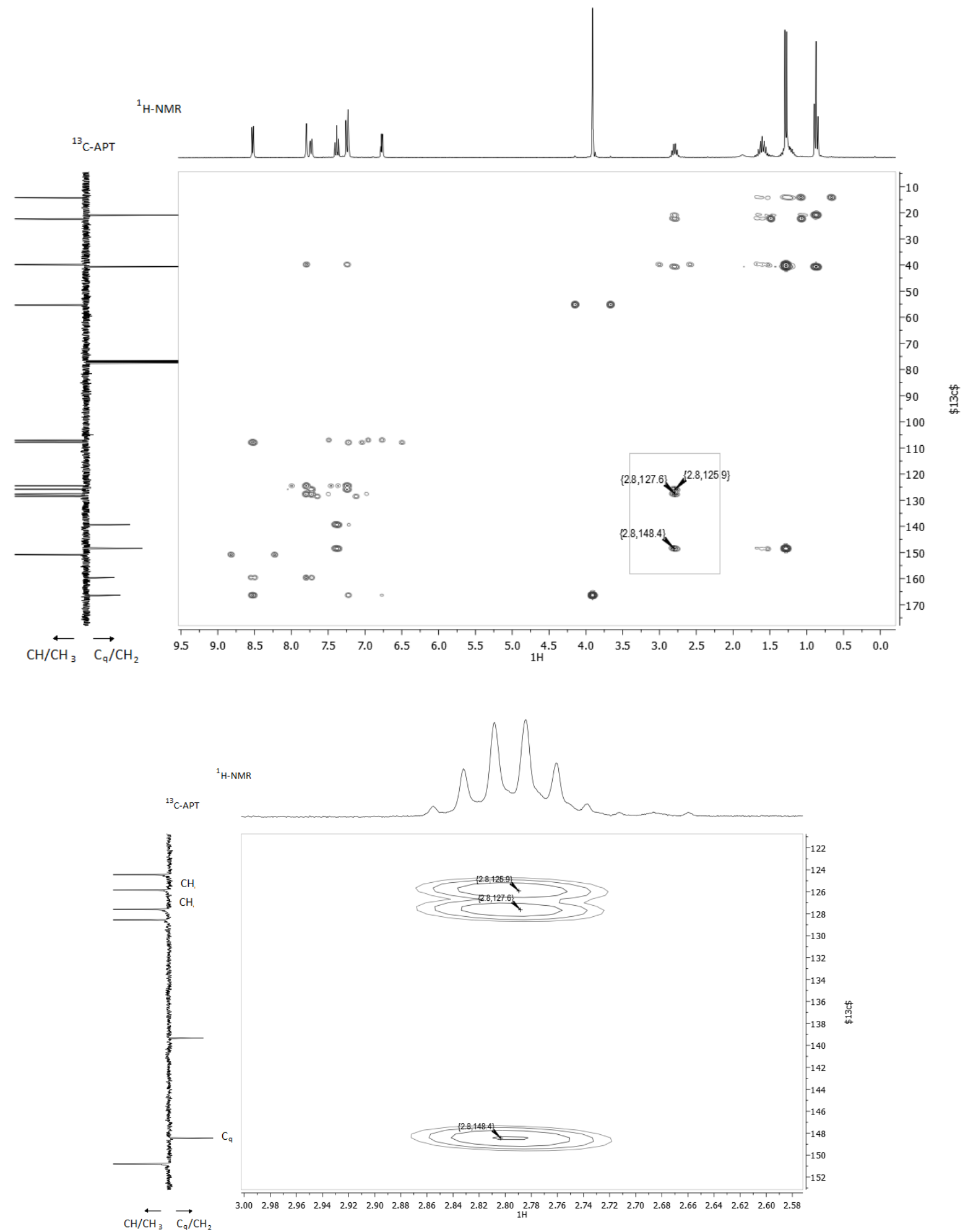


\section{HMBC 152fa}<smiles>CCCC(C)c1cccc(-c2ccc(C)cn2)c1</smiles>
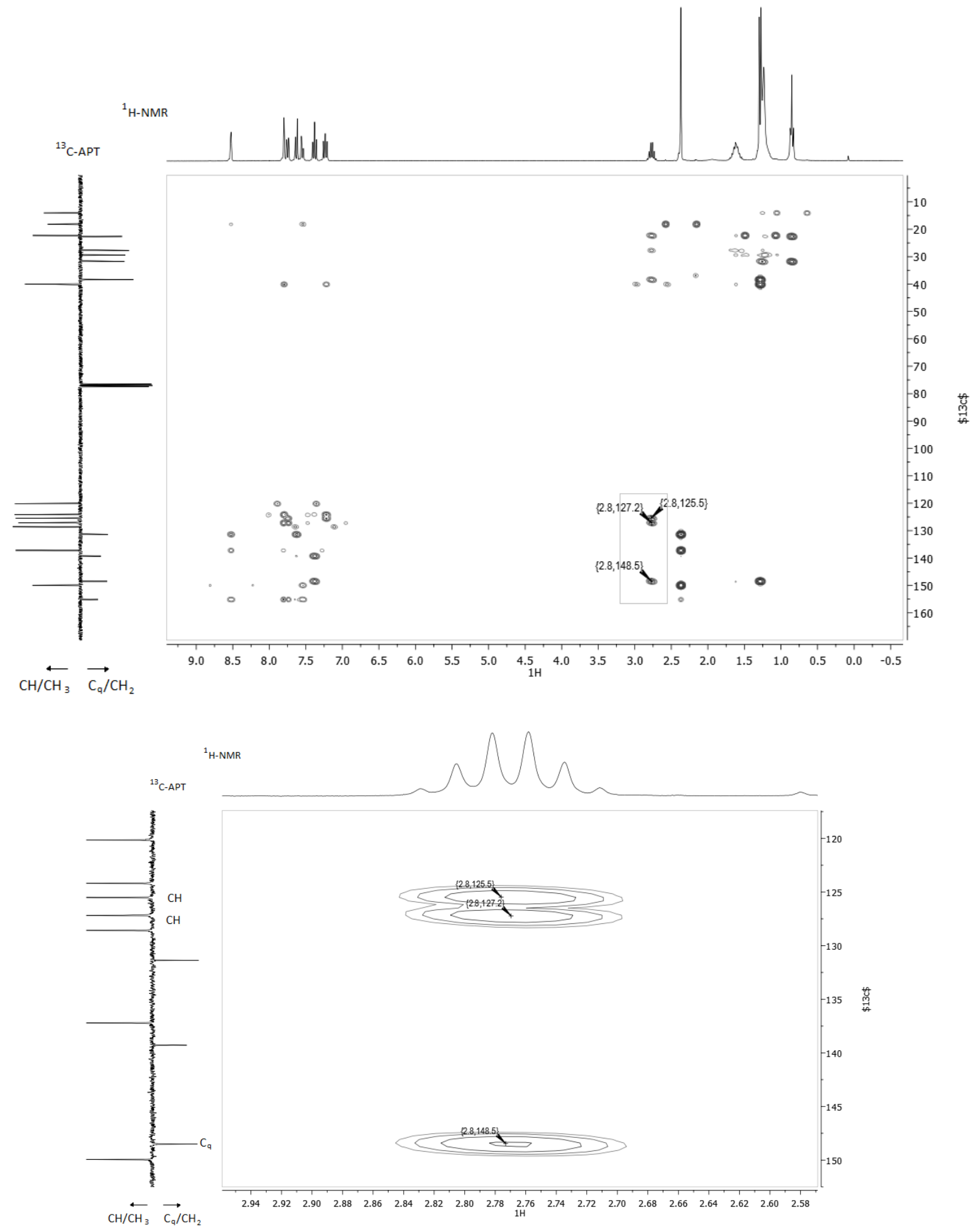


\section{HMBC 154}<smiles>O=[N+]([O-])c1cccc(-c2ncccn2)c1</smiles>

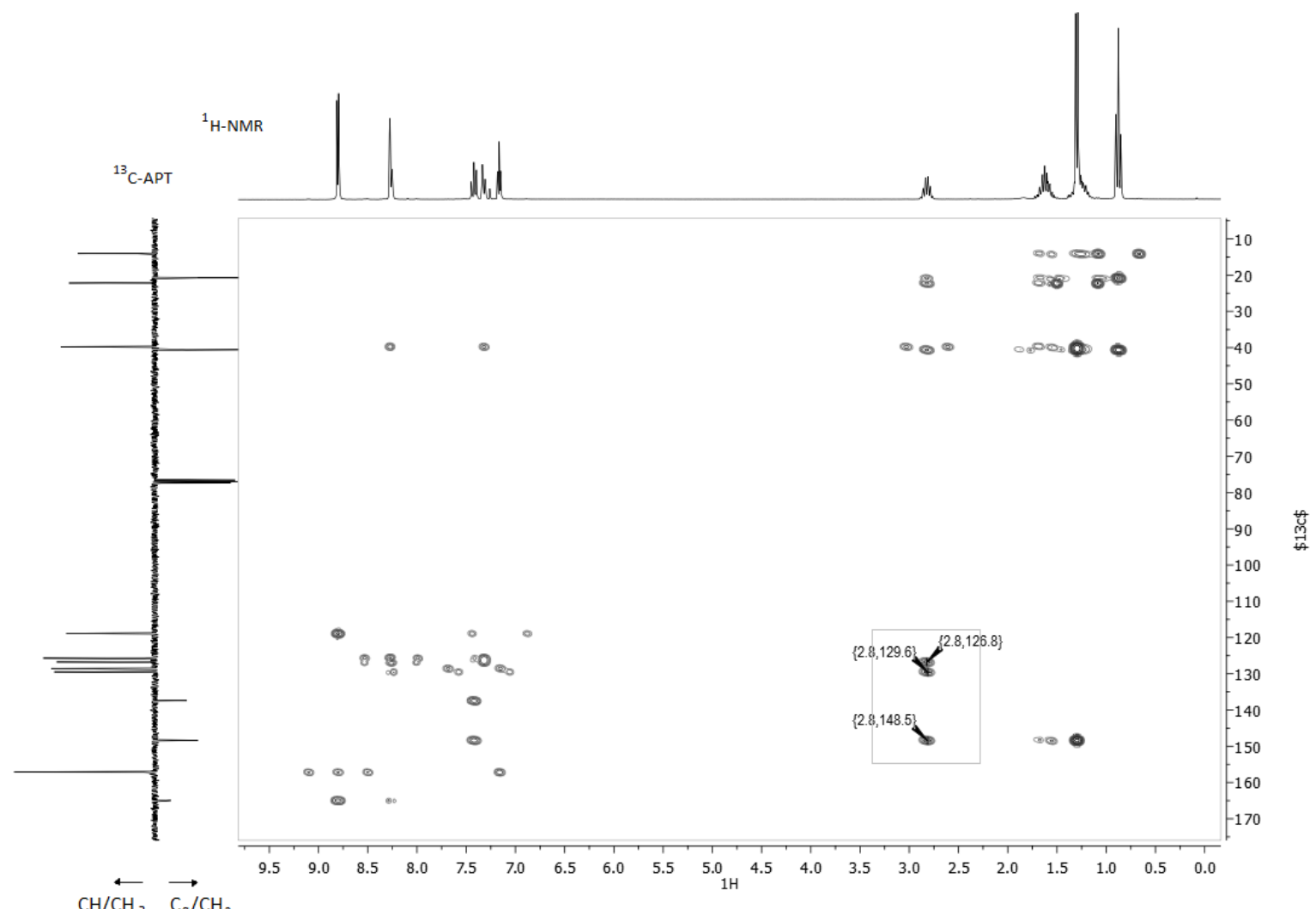
$\underset{\mathrm{CH} / \mathrm{CH}_{3}}{\leftarrow} \overrightarrow{\mathrm{C}_{9} / \mathrm{CH}_{2}}$

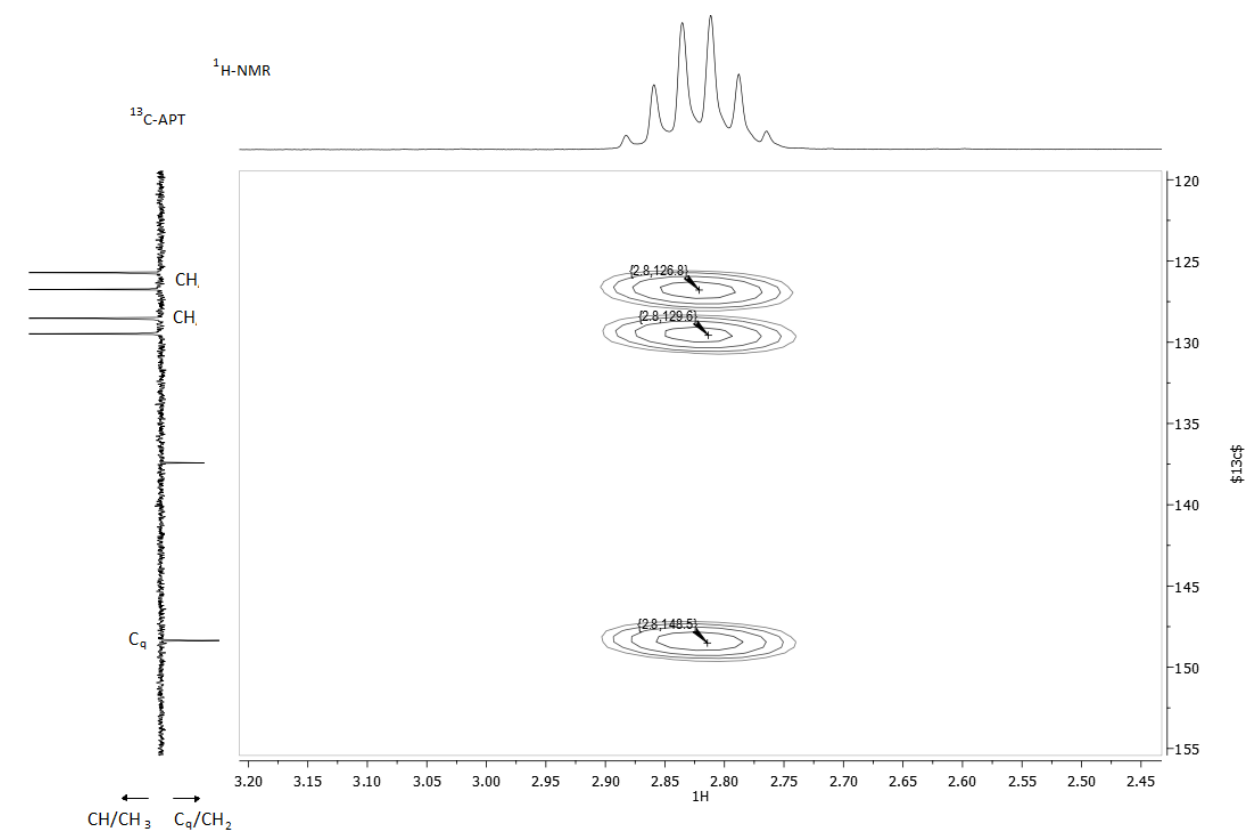




\section{HMBC 155}

$\underbrace{n-\mathrm{Pr}}_{\mathrm{Me}}$ -
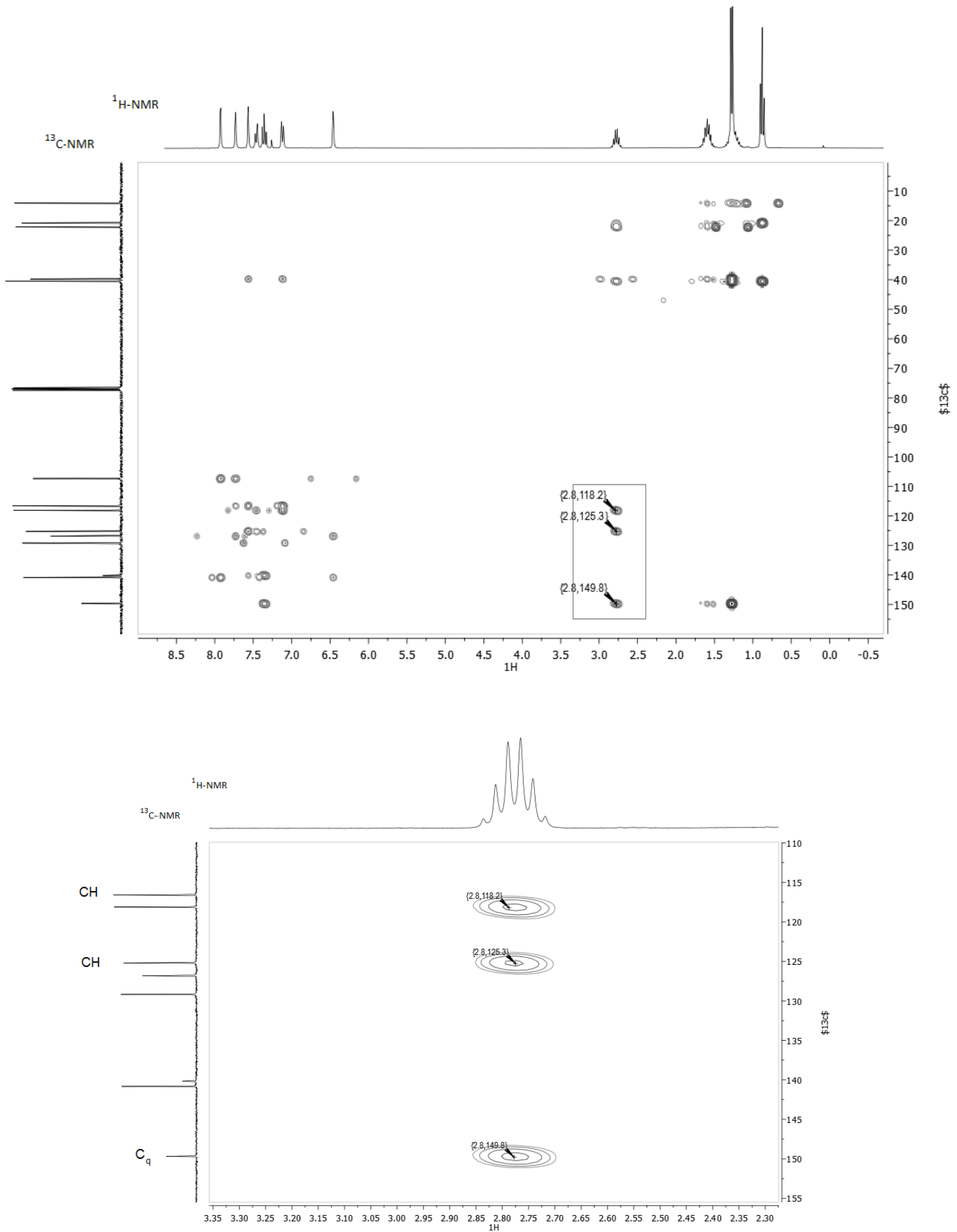


\section{HMBC 156}
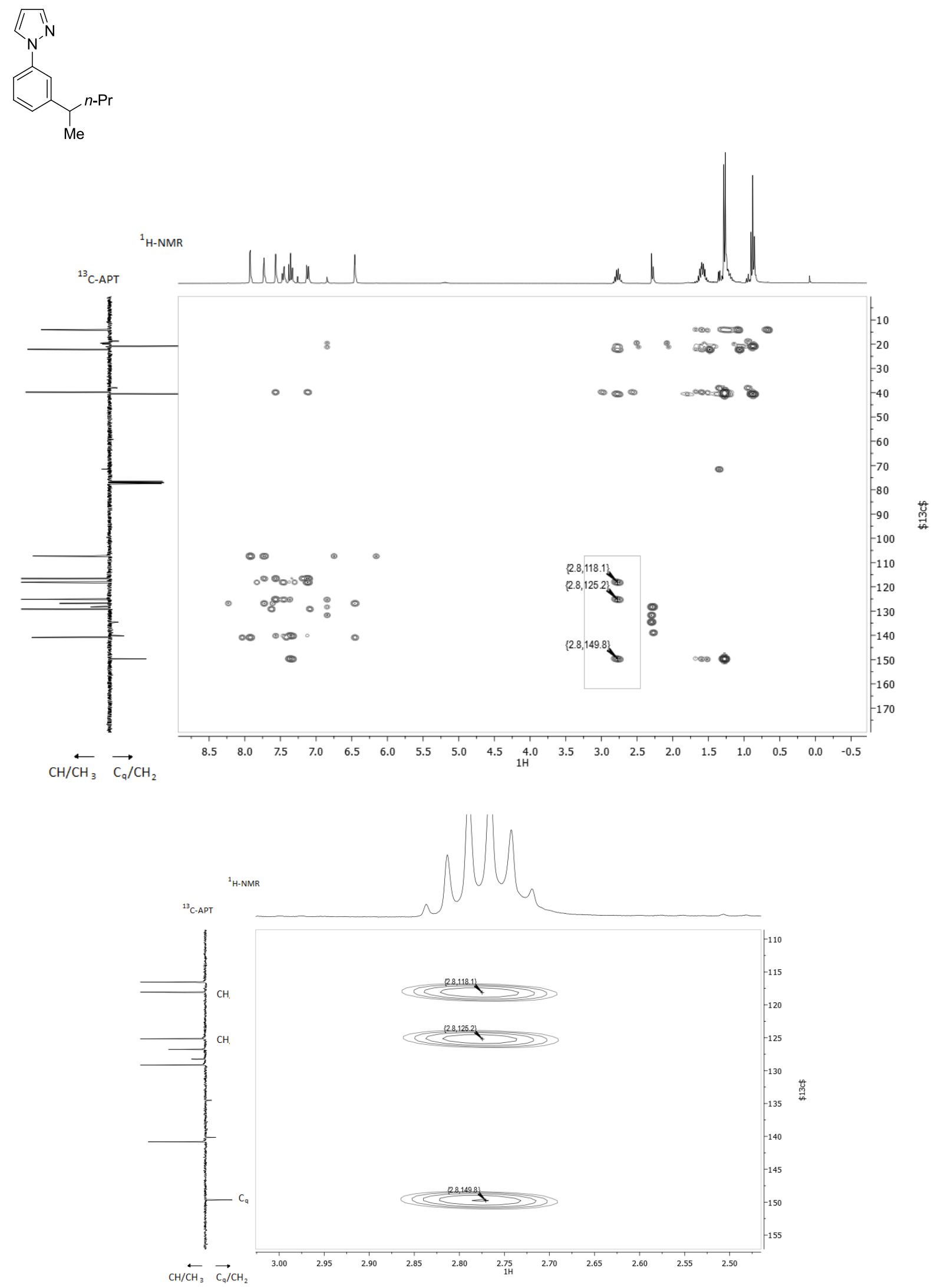
296

Experimental Procedures and Analytical Data

HMBC 157
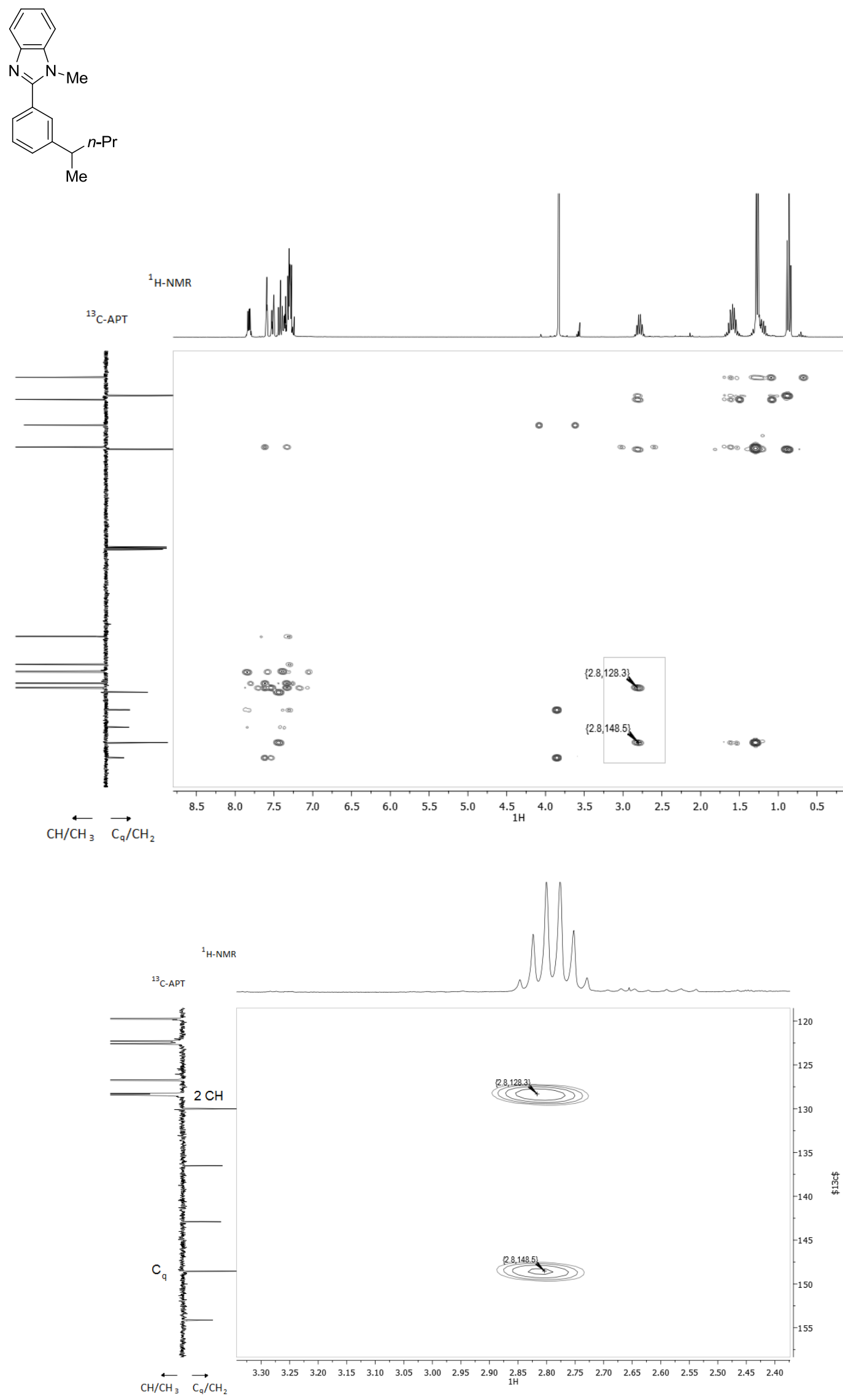
HMBC 93bl<smiles>COc1ccc(-c2ccccn2)c(C2CC3C=CC2C3)c1</smiles>
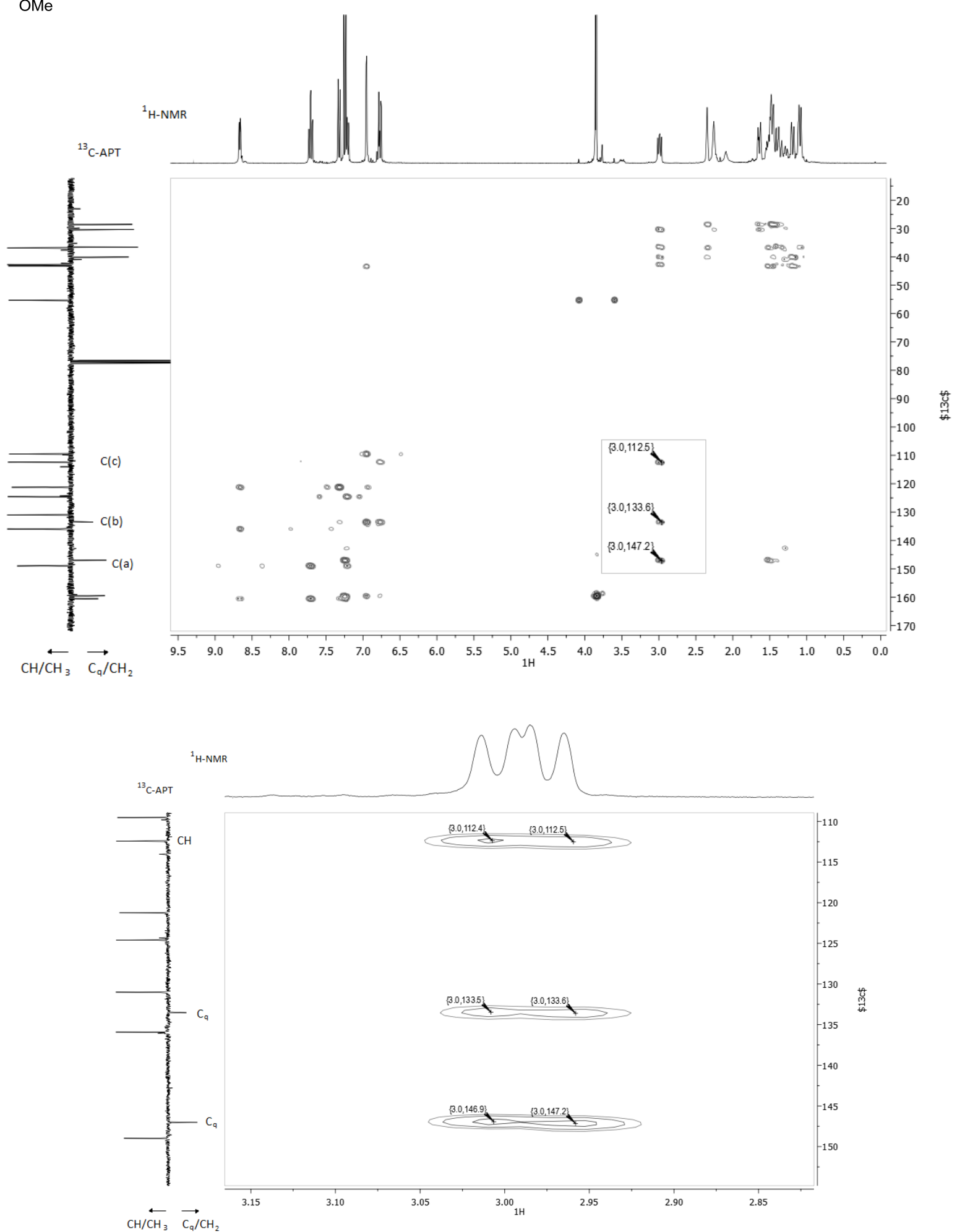

$\mathrm{CH} / \mathrm{CH}_{3} \quad \overrightarrow{\mathrm{C}_{4} / \mathrm{CH}_{2}}$ 


\section{HMBC 147bl}<smiles>COc1ccc(-c2ccccn2)cc1C1CCC2CCCC21</smiles>

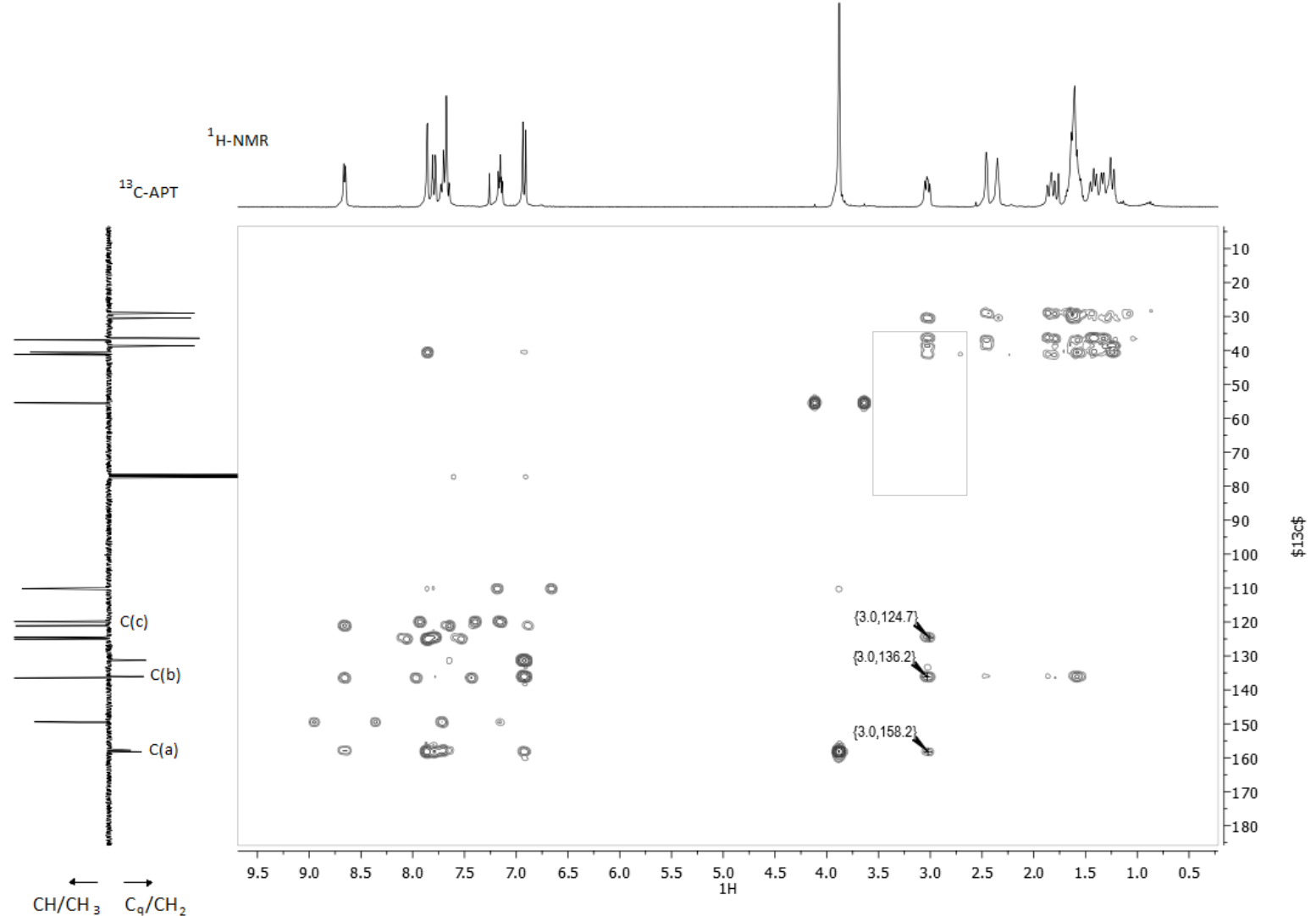
$\stackrel{\leftarrow \mathrm{CH} / \mathrm{CH}_{3}}{\leftarrow} \overrightarrow{\mathrm{C}_{9} / \mathrm{CH}_{2}}$

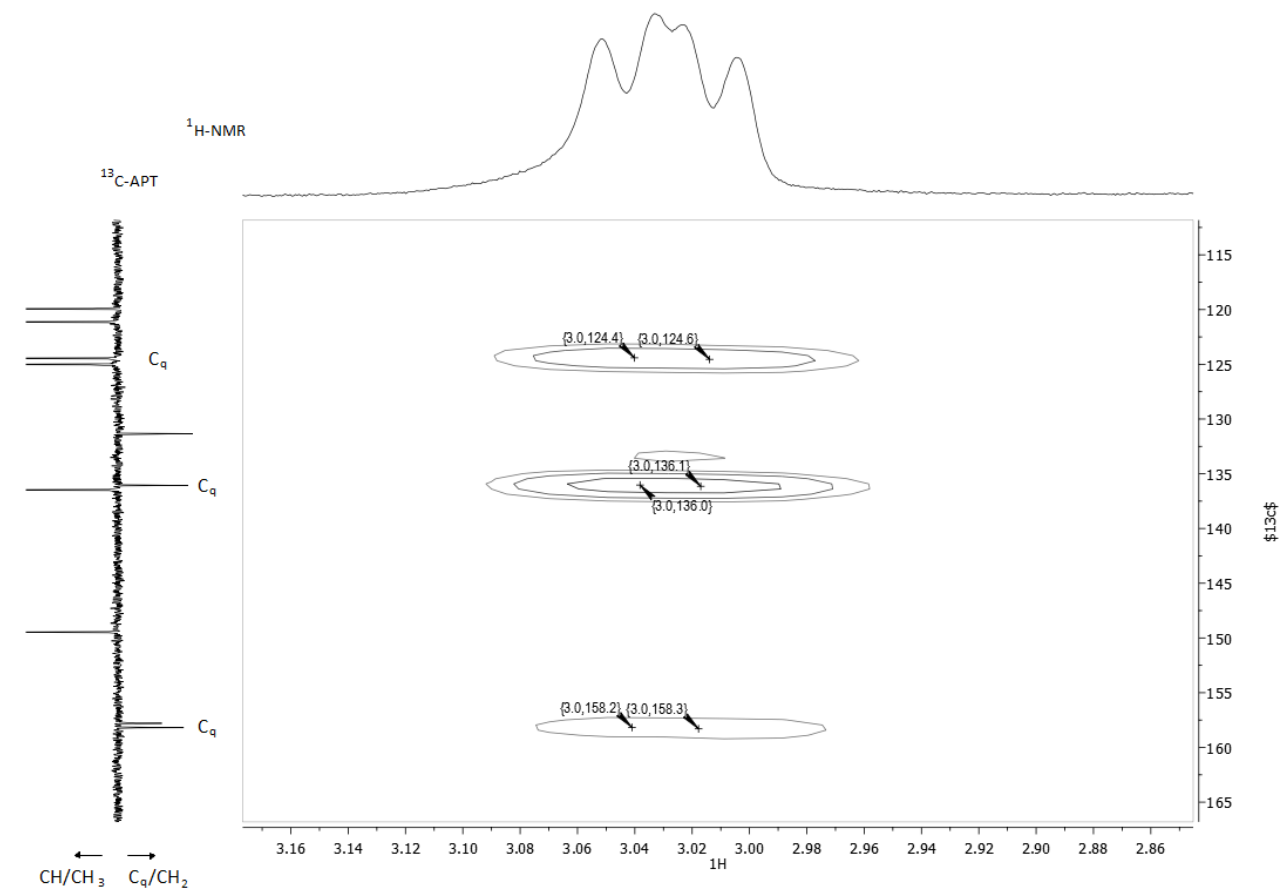


Experimental Procedures and Analytical Data

299

HMBC 118al
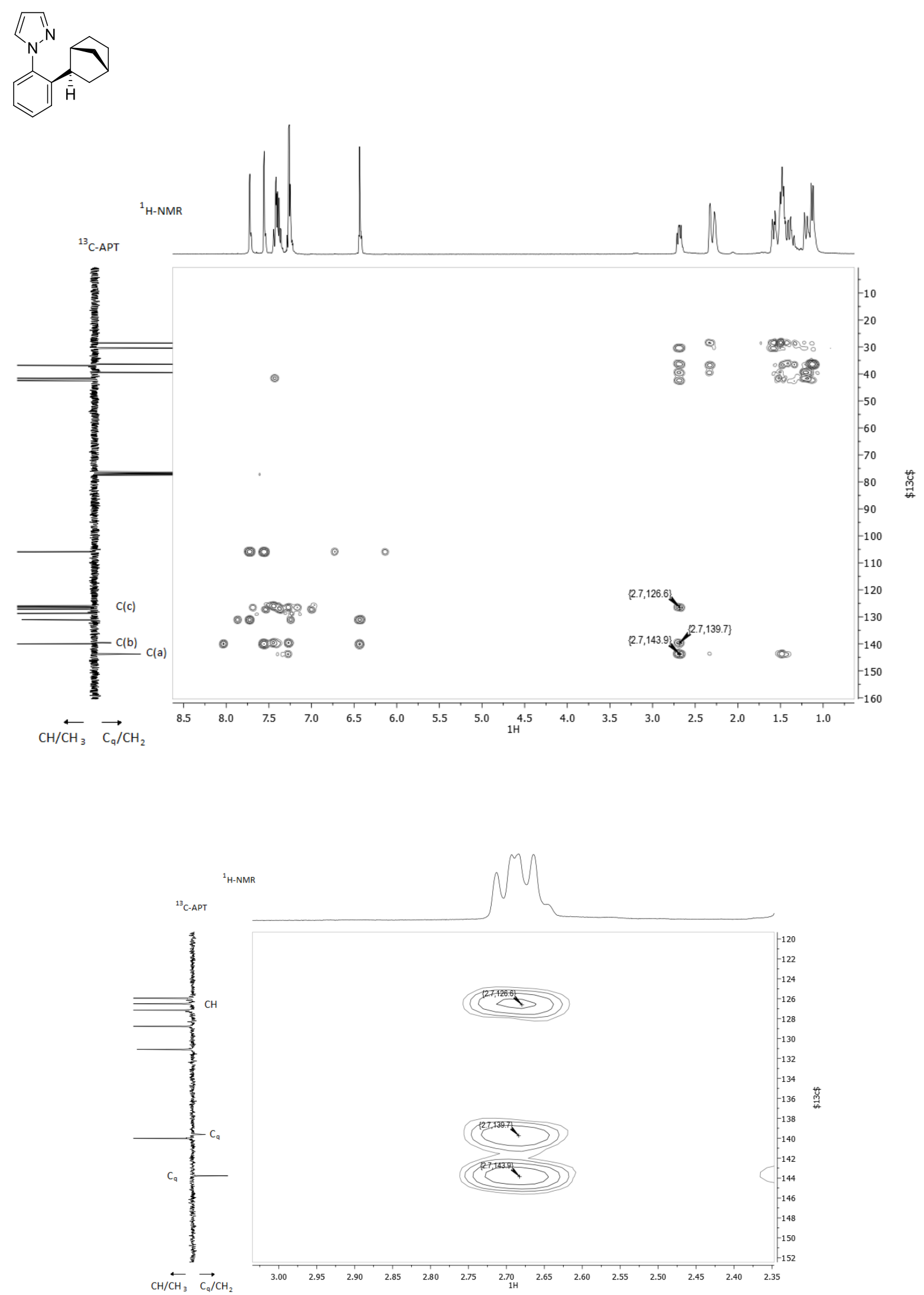


\section{List of Abbreviations}

\begin{tabular}{|c|c|c|c|}
\hline (HA)SPO & (heteroatom) substituted secondary & GC & gas chromatography \\
\hline (Het)Ar & (hetero)arene & Gly & glycine \\
\hline$[\mathrm{M}+]$ & molecular ion peak & GoF & goodness of fit \\
\hline 2D & two dimensional & $\mathrm{h}$ & hours \\
\hline 2-Py & 2-pyridyl & Hept & heptyl \\
\hline$\AA$ & Angström & Het & hetero \\
\hline acac & acetyl acetonate & Hex & hexyl \\
\hline Ad & adamantyl & HFIP & 1,1,1,3,3,3-hexafluoro-2-propanol \\
\hline Alk & alkyl & HMBC & heteronuclear multiple bond \\
\hline AMLA & ambiphilic metal-ligand activation & & correlation \\
\hline $\mathrm{AmOH}$ & amyl alcohol & $H R$ & high resolution \\
\hline APT & attached proton test & $\mathrm{Hz}$ & Hertz \\
\hline aq. & aqueous & 1 & intensity \\
\hline $\mathrm{Ar}$ & aryl & $i-$ & iso- \\
\hline $\mathrm{B}_{2} \mathrm{Pin}_{2}$ & bis(pinacolato)diboron & i.e. & id est \\
\hline BINOL & 1,1'-binaphthol & $\mathrm{IPr}$ & 1,3-bis(2,6-diisopropylphenyl) \\
\hline $\mathrm{Bn}$ & benzyl & IR & infrared spectroscopy \\
\hline$B Q$ & benzochinone & isol. & isolated \\
\hline $\mathrm{Bu}$ & butyl & IUPAC & International Union of Pure and Applied \\
\hline Boc & tert-butyloxycarbonyl & & Chemistry \\
\hline$c a$. & circa & $J$ & coupling constant \\
\hline calc. & calculated & K & Kelvin \\
\hline cat. & catalytic & KIE & kinetic isotope effect \\
\hline CCD & charge coupled device & $\mathrm{L}$ & ligand \\
\hline CDC & circular dichroism chromatography & M & metal \\
\hline CMD & concerted metalation deprotonation & M & molar \\
\hline $\operatorname{cod}$ & 1,5-cyclooctadien & $\mathrm{m}$ & multiplett \\
\hline $\mathrm{Cp}$ & cyclopentadienyl & M.p. & melting point \\
\hline$\delta$ & chemical shift & M.r. & melting range \\
\hline DCE & 1,2-dichloroethane & $m / z$ & mass-to-charge ratio \\
\hline DCM & dichloromethane & Me & methyl \\
\hline Dec & decyl & $\mathrm{MeCN}$ & acetonitrile \\
\hline DFT & density functional theory & Mes & mesityl \\
\hline DG & directing group & $\mathrm{mg}$ & milligram \\
\hline $\mathrm{D}_{\mathrm{H}}{ }^{289}$ & dissociation enthalphie at $289 \mathrm{~K}$ & $\mathrm{MHz}$ & megahertz \\
\hline diglyme & 1-methoxy-2-(2-methoxyethoxy)ethane & $\min$ & minute \\
\hline DMA & $\mathrm{N}, \mathrm{N}$-dimethylacetamid & $\mathrm{mL}$ & milliliter \\
\hline DMG & directed metalation group & $\mu \mathrm{m}$ & micrometer \\
\hline DMSO & dimethyl sulfoxide & TMP & 2,2,6,6-tetramethylpiperidine \\
\hline DoM & directed ortho metalation & tol & tolyl \\
\hline dppf & $1,1^{\prime}-\quad$ bis(diphenylphosphino)ferrocen & Ts & para-toluenesulfonyl \\
\hline$d r$ & diastereomeric ratio & TS & transition state \\
\hline dtbpy & 4,4'-di-tert-butyl bipyridine & Val & valine \\
\hline $\mathrm{E}^{+}$ & electrophile & wt\% & weight by volume \\
\hline Ed. & editor & $x$ & (pseudo)halide \\
\hline EDG & electron donating group & X-ray & roentgen-spectroscopy \\
\hline ee & enantiomeric excess & $\mathrm{mm}$ & millimeter \\
\hline EI & electron ionization & m- & meta- \\
\hline equiv & equivalent & $\mathrm{mmol}$ & millimol \\
\hline ESI & electronspray ionization & MPAA & monoprotected amino acid \\
\hline et al. & et alia & MPV & membrane pump vacuum \\
\hline Et & ethyl & MS & mass spectrometry \\
\hline $\mathrm{eV}$ & electron-Volt & MS & molecular sieves \\
\hline EWG & electron withdrawing group & $\mathrm{Mt} / \mathrm{a}$ & million tonnes per year \\
\hline FTICR & Fourier transform ion cyclotron resonance & MTBE & methyl tert-butyl ether \\
\hline g & gramm & $\mathrm{N}_{2}$ & nitrogen \\
\hline
\end{tabular}




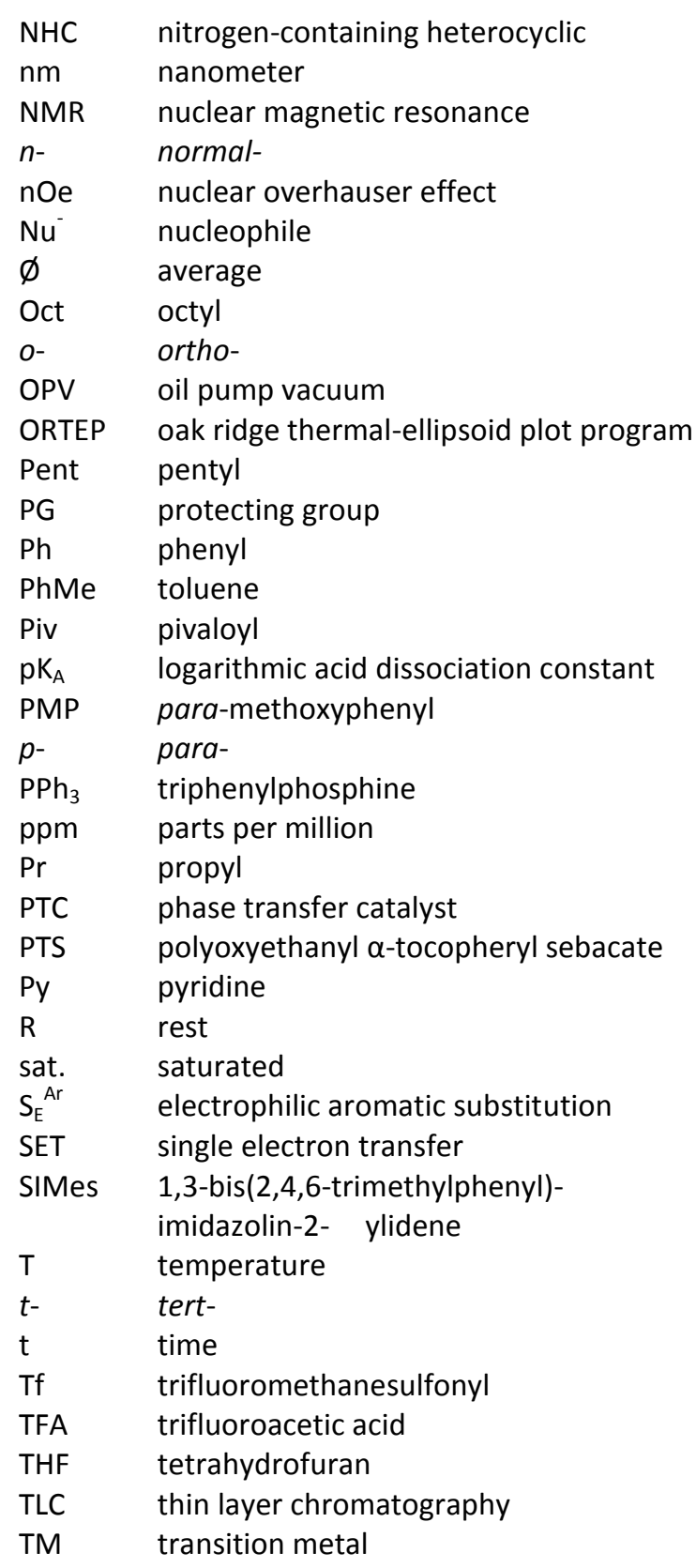




\section{Danksagung}

Zuerst und im Besonderen möchte ich mich bei Herrn Prof. Dr. Lutz Ackermann für die gute Betreuung während der Anfertigung meiner Dissertation, für die mir gegebene Möglichkeit, auf interessanten Themengebieten zu forschen, und für seine Unterstützung im Hinblick auf meinen weiteren Werdegang bedanken.

Mein Dank gilt natürlich auch Herrn Prof. Dr. Dietmar Stalke und Herrn Prof. Dr. Michael Buback für die freundliche Übernahme der Korreferate sowie den weiteren Mitgliedern der Prüfungskommission Herrn Prof. Dr. Ulf Diederichsen, Herrn Prof. Dr. Hartmut Laatsch und Frau Prof. Dr. Claudia Steinem dafür, dass sie mir die Chance geben, meine Forschungsergebnisse in einem angemessenen Rahmen zu präsentieren und zu verteidigen. Bei Herrn Prof. Dr. Franc Meyer und Herrn Prof. Dr. Dr. h.c. Lutz F. Tietze bedanke ich mich für das Verfassen von Gutachten im Rahmen von Bewerbungsverfahren.

Den Mitarbeitern der analytischen Abteilungen des IOBC danke ich für die zügige und gewissenhafte Bearbeitung meiner Aufträge. Besonders die unterhaltsamen und lehrreichen Gespräche zwischen Tür und Angel mit Herrn Machinek werden mir definitiv in Erinnerung bleiben. Desweiteren möchte ich Herrn Tucholla und Herrn Matthies ausdrücklich für die Hilfe bei der Lösung der vielen kleineren Probleme danken.

Herrn Dr. Dmitry S. Yufit von der Durham University gilt mein Dank für die unglaublich schnelle Messung der Kristallstrukturen und die hilfreichen zusätzlichen Hinweise in den Dokumenten.

An Herrn Dr. Sergei I. Kozhushkov geht ein ganz besonderes Dankeschön für die gewissenhafte Korrektur meiner Arbeit, für das Pfeifen auf den Fluren und die kleinen Anekdoten zwischendurch. Auch bei Carina, Karo und Darko möchte ich mich für das Korrekturlesen großer Abschnitte der Dissertation bedanken.

Ich sage auf diesem Wege auch allen Verantwortlichen des CaSuS Doktorandenprogramms für die Bereitstellung des Stipendiums, die vielen Einblicke in andere Forschungsgebiete und die Möglichkeit zur Teilnahme an diversen Konferenzen danke. Frau Dr. Hanna Steininger hat mir dankenswerter Weise organisatorische Hilfe und die Unterstützung beim Zulassungsverfahren gewährt.

Ich bin natürlich auch allen Arbeitskreismitgliedern, die mich in technischer, fachlicher oder freundschaftlicher Weise unterstützt haben, dankbar. Insbesondere Gabi rechne ich ihre organisatorische Hilfe und Stefan die Unterstützung beim Beheben der vielen kleinen und großen Computerprobleme und die Hilfe mit dem Mucke-Ordner hoch an. 
Marv möchte ich einfach für alles danken - Zusammenhalt, fachliche Diskussionen und technische Hilfe in allen Bereichen. Karo sage ich danke für ihre angenehm frische leicht verrückte Art, ihre fast permanent gute Laune und die erholsamen Balkon-Kaffeepausen

Den vielen Mitarbeitern und Mitstreitern, die mit mir das Labor geteilt haben, danke ich für das entspannte Arbeitsklima, das Ertragen meiner Musik und meiner Launen. Ganz besonderer Dank gilt hierbei Rubén und Alex, die mich an ihrem enormen Wissen haben teilhaben lassen und mit denen die Zusammenarbeit sehr viel Spaß gemacht hat. Zudem möchte ich natürlich meinen Bachelorstudenten für ihren Fleiß und ihr Engagement im Labor danken, besonders Sabine und Christian waren eine große Hilfe und die Zusammenarbeit hat mir viel Freude bereitet. Bei den zahlreichen Abteilungspraktikanten, besonders bei Michi, bedanke ich mich für die Unterstützung bei der Synthese einiger Startmaterialien und die Abwechslung, die Sie in meinen Laboralltag gebracht haben, auch wenn das ab und an etwas anstrengend war.

Mein aufrichtiger Dank gilt all den tollen Menschen, die ich in den fast 9 Jahren in Göttingen kennengelernt habe und nun zu meinen Freunden zählen darf. Die 'Reisegruppe' ist vom ersten Semester an dabei, und ich möchte euch allen für die lustige und aufregende Zeit in Göttingen danken. Besonders meinen Mädels Toni, Julia, Anke und Nora und natürlich auch Franz, mit seiner einmaligen Art, danke ich für ihre unvergleichbare Freundschaft, die Unterstützung, den Zusammenhalt, die wunderbaren Wein- und Schlemmerabende, die witzigen Partys und die Aufmunterung in schlechten Zeiten.

Kris gilt ein besonderer Dank, da er mir immer die positiven Seiten aufzeigt, an mich glaubt, meine Launen erträgt, mein Leben versüßt und mich sehr glücklich macht.

Der größte Dank geht an meine Familie. Meinen Eltern, die mich seit frühester Kindheit bei allen Vorhaben gefördert, mir meine Freiheiten gelassen, mir ihr Vertrauen geschenkt und mich auch in finanzieller Hinsicht unterstützt haben, danke ich von ganzem Herzen. Auch meiner Schwester Anja und meinen Großeltern gilt ein besonders herzlicher Dank für ihre Vorbildfunktion und ihren großartigen Rückhalt in der Familie. 


\section{Curriculum Vitae}

Date of birth: $\quad$ June $7^{\text {th }}, 1984$ (Berlin)

Nationality: German

\section{Further Education}

11/2009 - present

Studies for a doctorate under supervision of Prof. Dr. Lutz Ackermann, Institute of Organic and Biomolecular Chemistry; Georg-August University Göttingen: 'Carboxylate-Assisted Ruthenium-Catalyzed C-H Bond meta-Alkylations and Oxidative Annulations'

since $4 / 2010$ scholarship within the international Ph.D. program CaSuS (Catalysis for Sustainable Synthesis)

$09 / 2009$

Final examinations in chemistry ('Diplom', grade 'very good')

$01 / 2009-07 / 2009$

Diploma-thesis under supervision of Prof. Dr. Lutz Ackermann, Institute of Organic and Biomolecular Chemistry; Georg-August University Göttingen: 'Palladium-Catalyzed Intramolecular $\alpha$-Arylation and Ruthenium-Catalyzed Intermolecular Direct Alkylation.'

$04 / 2007-09 / 2007$ Erasmus exchange under supervision of Dr. Michael J. Hall, University of Newcastle upon Tyne (UK): 'Studies towards Encapsulated Fluorophores via Diels-Alder Reaction.'

10/2006-09/2009 Advanced studies in chemistry at the Georg-August University Göttingen $10 / 2006$ Intermediate examination in chemistry ('Vordiplom', grade 'Good')

$10 / 2004-09 / 2006$ Studies of Chemistry at the Georg-August University Göttingen

\section{Education}

$1997-2004$

Humboldt-Gymnasium Eichwalde

- Abitur with grade 1.7 (Major subjects: Chemistry and Mathematics)

- Participation at 'Jugend forscht' (Chemistry) in 2003

- Attendance at the 'Deutsche Schülerakademie' in 2002

- Participation at 'Mathematik- \& Chemieolympiade'

- Awarded with 'Humboldt-prize' in 2001

$1994-1997$

Primary school in Schulzendorf

$1991-1994$

Primary school in Berlin-Treptow 


\section{Methods Courses}

- Computer methods in catalysis research (Prof. M. Holthausen)

- Spectroscopic methods in catalysis research (Jun.-Prof. M. Bauer)

- Kinetic methods for elucidation of reaction mechanisms (Prof. M. Buback, Prof. P. Vana, Prof. M. Busch)

- Advanced High-Throughput Screening Techniques in Catalysis (Prof. O. Trapp)

- Intercultural competency (Prof. S. Klein-Franke)

- Varianten sprecherischer Performance (ZESS Göttingen)

- Process Engeneering (Dr. L. Rodefeld Bayer AG)

\section{Extra Curricular Roles}

- Student representative (2005 - 2008; elected member of the 'Fachschaftsrat Chemie', Vicepresident of the 'Fachschaftsräte-versammlung', member of the 'Studienkommission')

- CaSuS student representative (09/2010 - 2/2012)

- Member of the organization team of the Open Day at the IOBC (09/2011)

- Organisation of Bayer-Workshop Process Engeneering for PhD-students (07/2012)

\section{Teaching Experiences}

- Guidance of several Bachelor Theses, IOBC, Georg-August University of Göttingen.

- Preparation of weekly written exams in SoSe 2012 for course "Reaction Mechanisms in Organic Chemistry"

- Assistant for preparative practical "Advanced Organic Chemical Laboratory" in WiSe 11/12; "Basic Organic Chemical Practical Chemistry" in SoSe 2010 \& SoSe 2011

- Assistant for preparative practical and theoretics in WiSe 2009/2010 "Chemical Laboratory for Medical Students"

\section{Conferences}

07/2012 Poster presentation $15^{\text {th }}$ ICC (International Congress on Catalysis), Munich

09/2011 Poster presentation at the Summer School on Green Chemistry, Göttingen

07/2011 Attendance at the ICIQ Summer School 2011 (Institut Català d'Investigació Química) (holder of a scholarship), Tarragona

10/2010 Poster presentation $1^{\text {st }}$ NiKaS (Niedersächsisches Katalyse Symposium), Göttingen 09/2010 Poster presentation $17^{\text {th }}$ OrChem (Organisch-Chemische Tagung der GDCH), Weimar 


\section{Oral Presentations}

06/2011 $\quad 4^{\text {th }}$ Göttinger Chemie-Forum (GDCH/Jungchemikerforum), Göttingen

11/2010 ASMOS 6 (Advances in the Synthesis of Molecularly Ordered Structures), Dijon

06/2010 CaSuS Workshop, Mariaspring

\section{Publications}

\section{Dissertation}

[6] Hofmann, N.; Ackermann, L. J. Am. Chem. Soc. 2013, accepted for publication.

[5] Ackermann, L.; Lygin, A. V.; Hofmann, N. "Ruthenium-Catalyzed Oxidative Synthesis of 2Pyridones through $\mathrm{C}-\mathrm{H} / \mathrm{N}-\mathrm{H}$ Bond Functionalizations" Org. Lett. 2011, 13, 3278-3281. (highlighted in Synfacts)

[4] Ackermann, L.; Lygin, A. V.; Hofmann, N. "Ruthenium-Catalyzed Oxidative Annulation via $\mathrm{C}-\mathrm{H} / \mathrm{N}-\mathrm{H}$ Bond Cleavages" Angew. Chem. Int. Ed. 2011, 50, 6379-6382. (selected as hot paper)

[3] Ackermann, L.; Hofmann, N.; Vicente, R. "Carboxylate-Assisted Ruthenium-Catalyzed Direct Alkylations of Ketimines" Org. Lett. 2011, 13, 1875-1877.

\section{Diplomathesis}

[2] Ackermann, L.; Vicente, R.; Hofmann, N. "Air-Stable Secondary Phosphine Oxide as Preligand for Palladium-Catalyzed Intramolecular $\alpha$-Arylations with Chloroarenes" Org. Lett. 2009, 11, 4274-4276. (highlighted in Organic Chemistry Portal)

[1] Ackermann, L.; Novák, P.; Vicente, R.; Hofmann, N. "Ruthenium-Catalyzed Regioselective Direct Alkylation of Arenes with Unactivated Alkyl Halides through $\mathrm{C}-\mathrm{H}$ Bond Cleavage" Angew. Chem. Int. Ed. 2009, 48, 6045-6048. (selected as hot paper) 